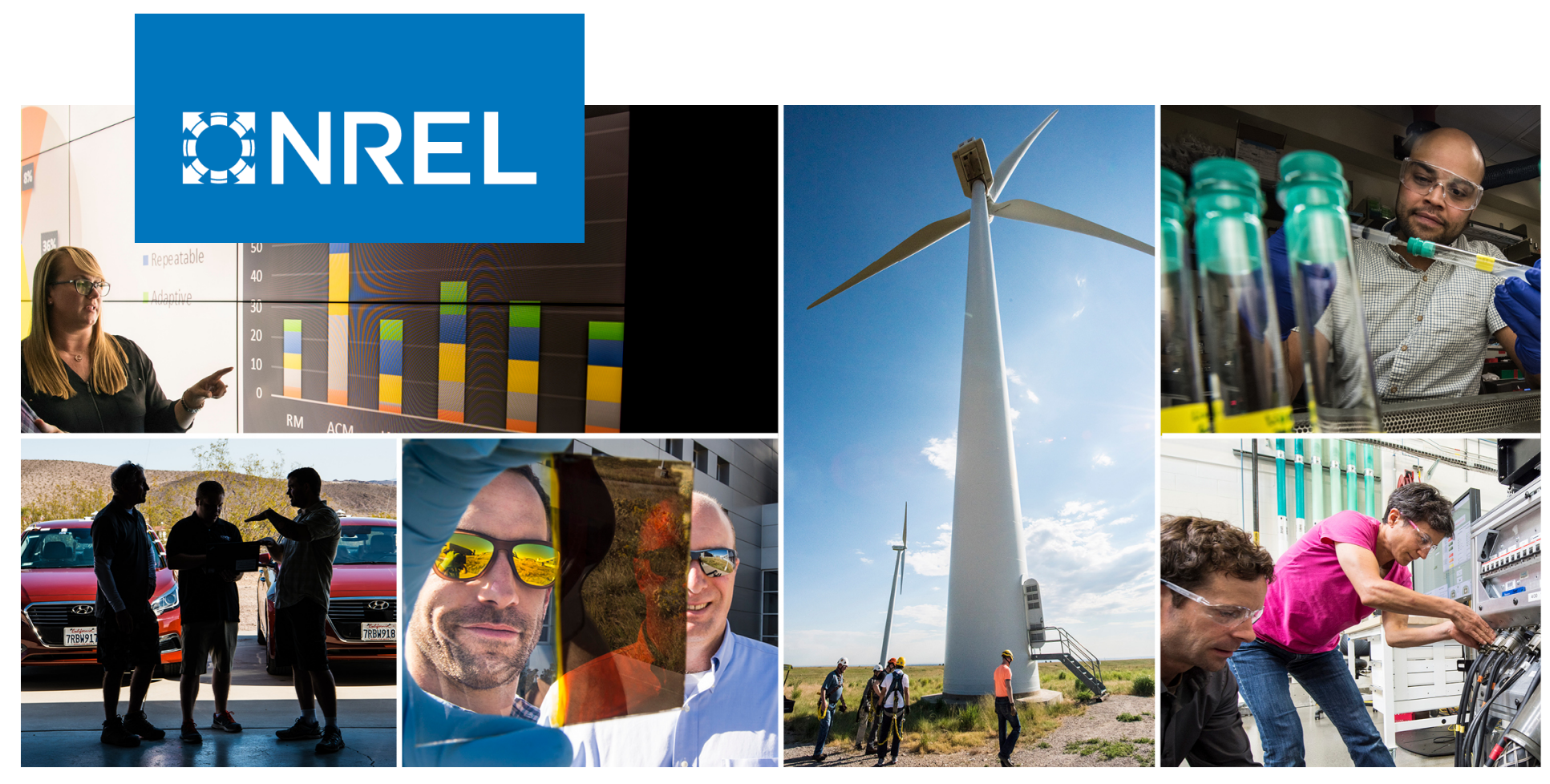

\title{
Adoption of Biofuels for the Marine Shipping Industry: A Long-Term Price and Scalability Assessment
}

Eric C. D. Tan, Kylee Harris, Stephen Tifft, Darlene Steward, and Chris Kinchin

National Renewable Energy Laboratory

NREL is a national laboratory of the U.S. Department of Energy Office of Energy Efficiency \& Renewable Energy

Operated by the Alliance for Sustainable Energy, LLC

This report is available at no cost from the National Renewable Energy Laboratory (NREL) at www.nrel.gov/publications.
Technical Report

NREL/TP-5100-78237

February 2021 


\title{
GHREL
}

\section{Adoption of Biofuels for the Marine Shipping Industry: A Long-Term Price and Scalability Assessment}

\author{
Eric C. D. Tan, Kylee Harris, Stephen Tifft, \\ Darlene Steward, and Chris Kinchin
}

National Renewable Energy Laboratory

\section{Suggested Citation}

Tan, Eric C. D., Kylee Harris, Stephen Tifft, Darlene Steward, and Chris Kinchin. 2021. Adoption of Biofuels for the Marine Shipping Industry: A Long-Term Price and Scalability Assessment. Golden, CO: National Renewable Energy Laboratory. NREL/TP-510078237. https://www.nrel.gov/docs/fy21osti/78237.pdf.

NREL is a national laboratory of the U.S. Department of Energy Office of Energy Efficiency \& Renewable Energy Operated by the Alliance for Sustainable Energy, LLC

This report is available at no cost from the National Renewable Energy Laboratory (NREL) at www.nrel.gov/publications.

Contract No. DE-AC36-08GO28308
Technical Report

NREL/TP-5100-78237

February 2021

National Renewable Energy Laboratory 15013 Denver West Parkway Golden, CO 80401 303-275-3000 • www.nrel.gov 


\section{NOTICE}

This work was authored by the National Renewable Energy Laboratory, operated by Alliance for Sustainable Energy, LLC, for the U.S. Department of Energy (DOE) under Contract No. DE-AC36-08GO28308. Funding provided by U.S. Department of Transportation Maritime Administration. The views expressed herein do not necessarily represent the views of the DOE or the U.S. Government.

This report is available at no cost from the National Renewable Energy Laboratory (NREL) at www.nrel.gov/publications.

U.S. Department of Energy (DOE) reports produced after 1991 and a growing number of pre-1991 documents are available free via www.OSTI.gov.

Cover Photos by Dennis Schroeder: (clockwise, left to right) NREL 51934, NREL 45897, NREL 42160, NREL 45891, NREL 48097, NREL 46526.

NREL prints on paper that contains recycled content. 


\section{Acknowledgments}

We thank the U.S. Department of Transportation's Maritime Administration (MARAD) for funding and supporting this work. The authors wish to thank Tom Thompson at MARAD for his support. We also thank Ryan Davis, Bruno Klein, and Avantika Singh for reviewing this report and providing valuable comments and acknowledge Michael Deneen and Kathy Cisar at the National Renewable Energy Laboratory Communications Office for their help in editing this report. 


\section{List of Acronyms}

$\begin{array}{ll}\text { ABE } & \text { acetone, n-butanol, and ethanol } \\ \text { BETO } & \text { Bioenergy Technologies Office } \\ \text { BT16 } & \text { 2016 Billion-Ton Report } \\ \text { Btu } & \text { British thermal unit } \\ \text { CHP } & \text { combined heat and power } \\ \text { CSTR } & \text { continuously stirred tank reactor } \\ \text { DCFROR } & \text { discounted cash flow rate of return } \\ \text { DDGS } & \text { distillers' dried grains with solubles } \\ \text { DME } & \text { dimethyl ether } \\ \text { DMT } & \text { dry metric ton } \\ \text { DOE } & \text { U.S. Department of Energy } \\ \text { EEZ } & \text { exclusive economic zone } \\ \text { EIA } & \text { U.S. Energy Information Administration } \\ \text { EJ } & \text { exajoule } \\ \text { FCI } & \text { fixed capital investment } \\ \text { FFA } & \text { free fatty acid } \\ \text { FT } & \text { Fischer-Tropsch } \\ \text { GGE } & \text { gasoline gallon equivalent } \\ \text { HEFA } & \text { hydroprocessed esters and fatty acids } \\ \text { HFO } & \text { heavy fuel oil } \\ \text { HFOGE } & \text { heavy fuel oil gallon equivalent } \\ \text { HTL } & \text { hydrothermal liquefaction } \\ \text { IRR } & \text { internal rate of return } \\ \text { LCFS } & \text { Low Carbon Fuel Standard (California) } \\ \text { MARAD } & \text { U.S. Maritime Administration } \\ \text { MFSP } & \text { minimum fuel selling price } \\ \text { MGO } & \text { marine gas oil } \\ \text { MSW } & \text { municipal solid waste } \\ \text { MT } & \text { metric ton } \\ \text { NREL } & \text { National Renewable Energy Laboratory } \\ \text { PNNL } & \text { Pacific Northwest National Laboratory } \\ \text { SAF } & \text { sustainable aviation fuel } \\ \text { TCI } & \text { total capital investment } \\ \text { TIC } & \text { TPEC }\end{array}$




\section{Executive Summary}

One of the biggest challenges in the 21 st century is transforming the transportation sector into a low-carbon-based sustainable industry, including maritime shipping. Bioenergy has an essential role in the transition to move maritime shipping toward carbon neutrality. Biomass-derived fuels can undoubtedly play a crucial role in the future of marine propulsion as renewable alternatives can offer potential synergistic benefits when blended with petroleum fuels. With inherently zeroor low-sulfur and renewable carbon sources, biofuels will help mitigate marine shipping sulfur emissions, improve overall emissions profiles, and enable the decarbonization transition.

As biofuel for marine propulsion is still at its nascent stage, knowledge gaps exist, including the life cycle environmental impacts, compatibility of biofuel blending with conventional marine fuels, scalability, and cost. This study assesses the biofuel availability and cost aspects for marine use and was supported by the U.S. Department of Transportation's Maritime Administration (MARAD) Office of Environment to project the long-term price and annual biofuel production capacity potential for marine propulsion in the United States. The study will shed light on the prospect of biofuel adoption for the maritime shipping industry.

For biofuels' benefits to be realized and impactful, a significant fraction of marine fuel volumes will need to be met with biofuel. This necessitates that biofuel production volume will be high enough to meet the demand. Furthermore, the potential of biofuel adoption also depends on future biofuel prices. Hence, marine biofuel's long-term price and availability are two critical factors for establishing the feasibility of marine biofuel adoption for operating vessels and set the stage for this analysis.

The basic assumptions for the biofuel and marine biofuel annual production and cost projections were predominantly based on feedstock availability and prices reported in the 2016 Billion-Ton Report and existing biomass-to-fuel conversion technologies in the public domain, including leveraging the portfolio of conversion pathways developed under the U.S. Department of Energy’s Bioenergy Technologies Office (BETO). A linear programming model was developed to assist the projections of production capacity and costs and provide insightful analyses. All projected available feedstocks in the United States were integrated with the selected promising conversion pathways.

For the scenario to maximize biofuel production, the projected long-term (2040) annual capacity of biofuels in the United States is 245 million metric tons (MT) or 65 billion gallons of heavy fuel oil gallon equivalent (HFOGE) when based on the median feedstock availability. The annual capacities are 162 and 391 million MT for the minimum and maximum feedstock availability, respectively. The projected annual capacity is 218 million MT (or 58 billion HFOGE) when based on the median feedstock availability for the scenario to minimize the biofuel price. The 2018 projected annual global marine fuel consumption is around 330 million MT (13.1 exajoules [EJ]). Additionally, between 2022 (near term) and 2040, the potential biofuel capacity increases by over $40 \%$, attributed to increased feedstock availability. Moreover, per our analysis, enough biomass could be utilized to cover the projected 2040 U.S. marine fuel sector demand completely, encompassing domestic (0.05 EJ), international shipping (0.90 EJ), and recreational boats $(0.26 \mathrm{EJ})$, or a total of $1.21 \mathrm{EJ}$ per year. 
Scaling up biofuel production will require more biomass feedstock. The greater feedstock demand will introduce new logistical challenges that need to be considered, including feedstock harvesting, delivery, and storage, resulting in higher feedstock cost (a key cost driver for biofuel production). Therefore, the biofuel price will be higher when more of it is produced at greater feedstock resource demands. However, over time, the overall feedstock cost will decrease, or more feedstock will be available at a similar price and drive down the biofuel production cost. For example, for the scenario to maximize biofuel production, the annual biofuel capacity increases by $42 \%$ between 2022 and 2040, whereas the biofuel price decreases by $36 \%$.

The current projected long-term (2040) biofuel prices are \$1,157/MT (in 2016 dollars) for the maximized total biofuel scenario and \$967/MT for the minimized price scenario. The average 2019 marine gas oil (MGO) price was \$700/MT, and at the time of this reporting, the MGO price is about $\$ 560 / \mathrm{MT}$. Between 2022 and 2040, the projected biofuel prices decrease by $36 \%$ and $43 \%$ for the maximized total biofuel production and minimized biofuel price scenarios, respectively.

These projected prices are weighted average prices from all evaluated technology groups. In order to utilize all available feedstocks in the United States for the biofuel production capacity projection, certain expensive feedstocks and pathways were included in the analysis, resulting in higher overall fuel prices reflecting their inclusion. Still, there are individual pathways and technology groups that produce biofuels at a price comparable with fossil fuels.

At a price range up to $\$ 500 / \mathrm{MT}$, biodiesel is the main product, and the capacity (12 million MT) is limited to feedstock availability constraints. Biodiesel and corn ethanol are the main biofuels at a price range up to $\$ 750 / \mathrm{MT}$. At a higher price point (above $\$ 750 / \mathrm{MT}$ ), the biofuel types and annual capacities increase substantially (218 million MT/year). Biofuels above this price include gasoline-, jet-, and diesel-range blendstocks, as well as bio-methanol, bio-propane, and biogas. Lowering the biofuel price to a more acceptable level holds the key for the maritime sector to tap into the projected biofuel capacity.

This study concludes that the U.S. domestic feedstock availability, coupled with advanced conversion technologies, can provide a large enough biofuel capacity to achieve a critical mass and be impactful as alternative marine fuels. Results from this study also highlight the need to reduce the biofuel price for marine shipping adoption. There are ample opportunities to enable lower-cost biofuels. Feedstock cost, a key cost contributor to biofuel production, can be lowered via the utilization of waste and low-quality feedstocks, adoption of integrated landscape management strategies, and feedstock logistic enhancements. Other strategies to achieve lower biofuel prices include co-processing biomass with fossil feedstock, developing atom-efficient biorefineries, intensifying process designs, utilizing existing infrastructure, and developing highvalue coproducts.

Additionally, although technical solutions and strategies will help lower future biofuel prices, policies and economic incentives would also be beneficial to facilitate maritime biofuel adoption. Initiative structures similar to those implemented in the Netherlands and other countries can provide temporary financial support to help accelerate the adoption of biofuels. 


\section{Table of Contents}

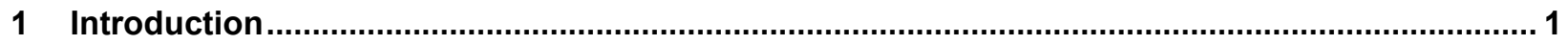

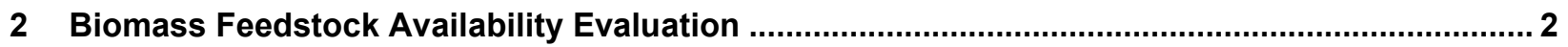

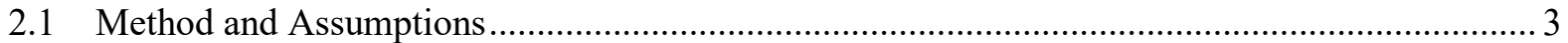

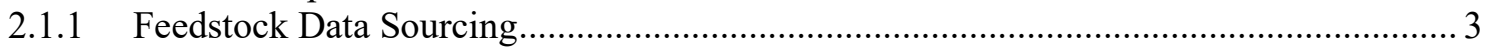

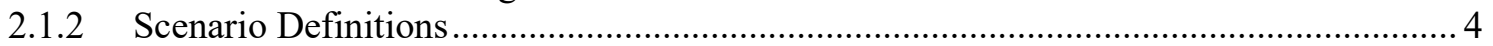

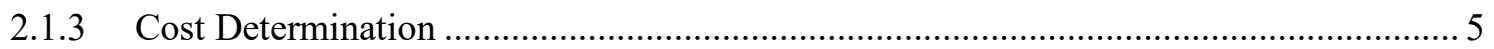

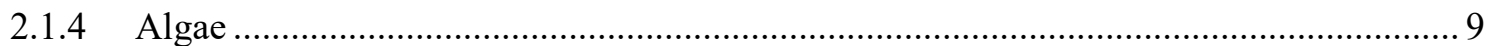

2.2 Total Feedstock Availability Results and Discussion ....................................................... 10

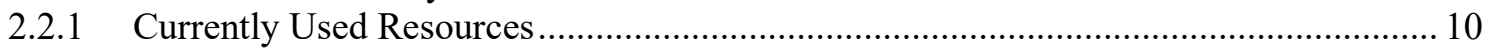

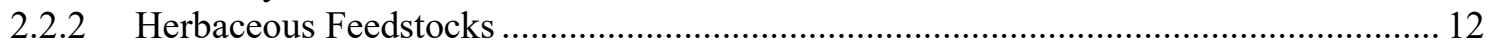

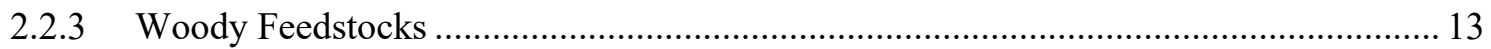

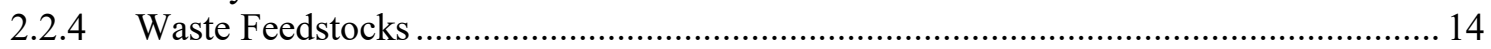

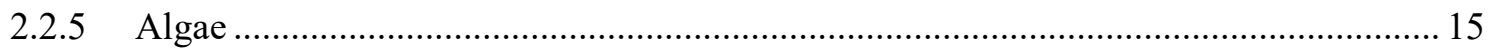

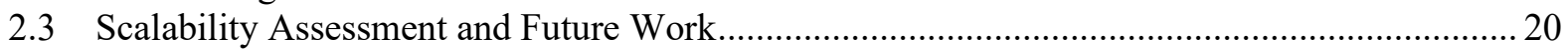

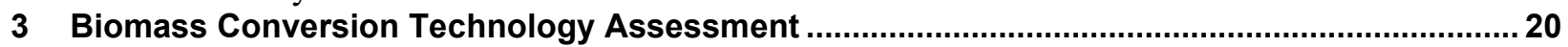

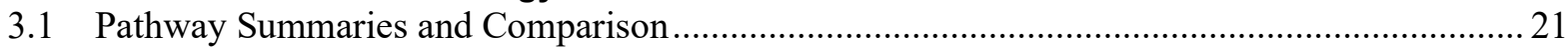

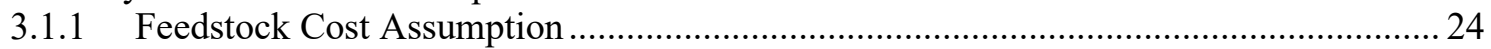

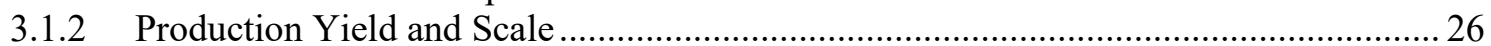

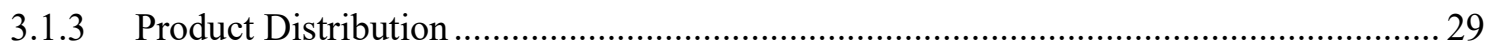

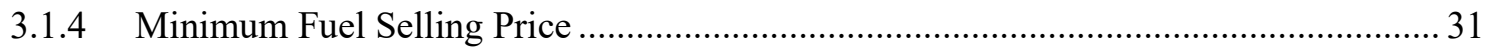

3.2 Conversion Pathway Screening Assessment Summary …...................................................... 34

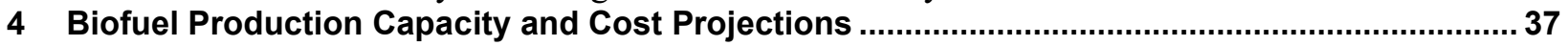

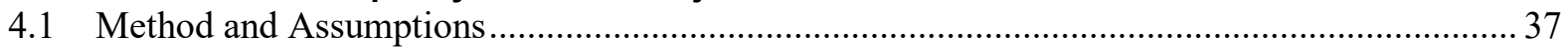

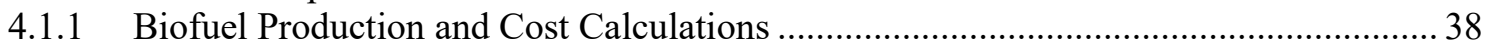

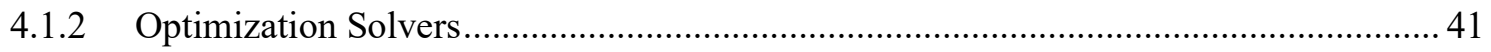

4.2 Annual Biofuel Production Capacity and Cost Projection ................................................. 42

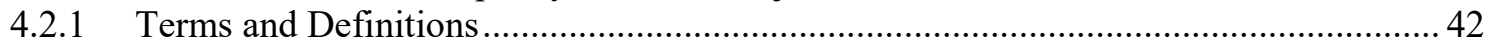

4.2.2 An Illustration of Linear Optimization Modeling Output ......................................... 42

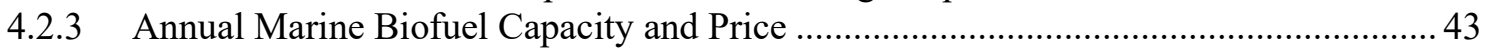

4.2.4 Breakdown of Fuel Contribution by Technology Group ........................................... 47

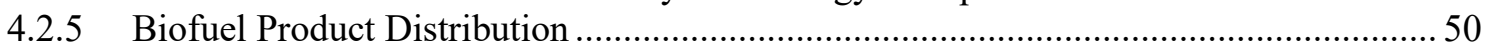

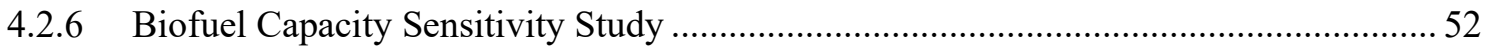

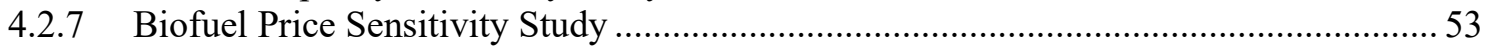

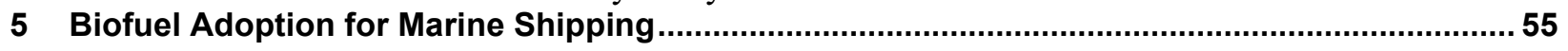

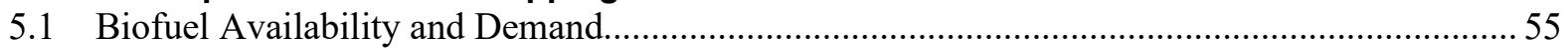

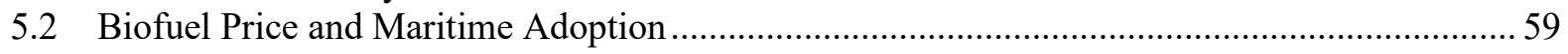

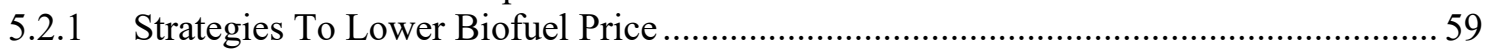

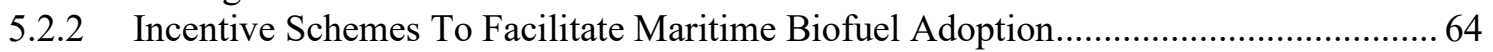

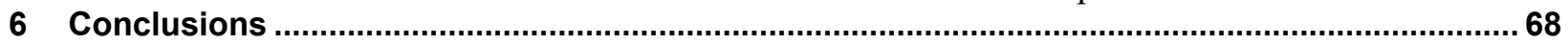

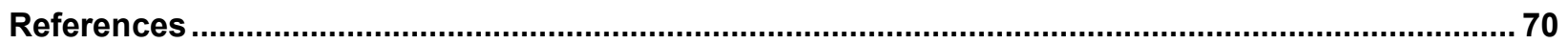

Appendix A. Biomass Feedstock Availability Supporting Information .............................................79

Appendix B. Biomass Conversion Technology Assessment Pathway Details ................................. 91

Appendix C. Annual Biofuel Production Capacity and Cost ........................................................... 177

Appendix D. Marine Biofuel Adoption Supporting Information .................................................... 197 


\section{List of Figures}

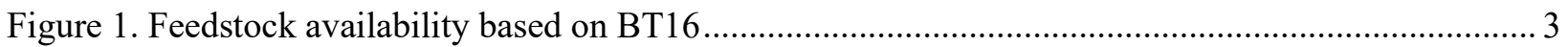

Figure 2. Feedstock analysis process summary based on BT16 ..................................................... 4

Figure 3. Feedstock availability scenarios for biofuel production capacity and cost projections................ 5

Figure 4. Total potential herbaceous feedstock availability by type and scenario ..................................... 13

Figure 5. Total potential woody feedstock availability by type and scenario .......................................... 14

Figure 6 . Total potential waste feedstock availability by type and scenario......................................... 15

Figure 7. Summary of total feedstock contributions by scenario...................................................... 17

Figure 8. Summary of near-term (2022) and long-term (2040) feedstock availability by feedstock type.. 18

Figure 9. Summary of near-term (2022) and long-term (2040) feedstock cost by feedstock type ............. 19

Figure 10. Feedstock cost assumptions used in the source material for each pathway.............................. 24

Figure 11. Production yield and production scale for screening conversion technologies ........................ 26

Figure 12. Product distribution for different conversion technologies used in this study, segmented by

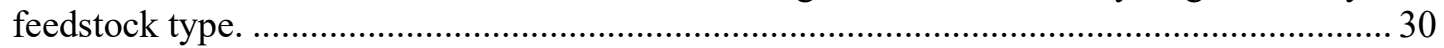

Figure 13. MFSP for the selected conversion technologies................................................................ 33

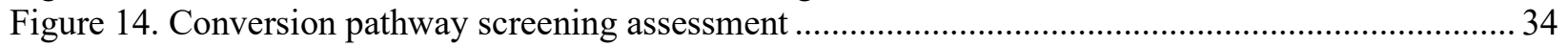

Figure 15. Marine biofuel production capacity and cost projections via bottom-up approach.................. 37

Figure 16. Schematic representation mapping feedstocks with conversion technologies for production

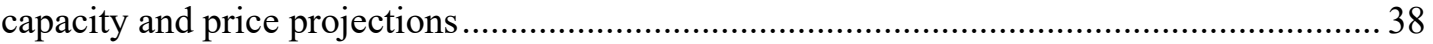

Figure 17. DCFROR output MFSP as a function of yield (Pathway 14) ................................................ 40

Figure 18. DCFROR inputs database and linear equation generator .................................................... 40

Figure 19. Illustration of linear optimization modeling output. (a) Harmonization and mapping of conversion technologies with corresponding technology groups. (b) Total biofuel production capacity for the near-term and long-term feedstock availability and the inclusion or exclusion of algae as a feedstock in the total production of biofuels.

Figure 20. (a) Projected biofuel capacity in million metric tons and (b) price in dollars per metric ton for maximum total biofuel and maximum marine biofuel scenarios ........................................ 44

Figure 21. (a) Projected biofuel capacity and (b) price on an HFOGE basis for maximum total biofuel and maximum marine biofuel scenarios

Figure 22. (a) Projected biofuel capacity and (b) price on a per-metric-ton basis for minimum cost scenario

Figure 23. (a) Projected biofuel capacity in billion HFOGE per year and (b) price in dollars per HFOGE basis for minimum cost scenario....

Figure 24. Projected annual biofuel capacity broken down by feedstock group contributions in per-metricton basis for maximum total biofuel and maximum marine biofuel scenarios ...................... 48

Figure 25. Technology group fuel contributions on a per-metric-ton basis for maximum total biofuel and maximum marine biofuel scenarios. Error bars indicate maximum and minimum feedstock availability for each group.

Figure 26. Price of produced biofuel per technology group on a per-ton basis for maximum total biofuel and maximum marine biofuel scenarios. Error bars indicate the maximum and minimum

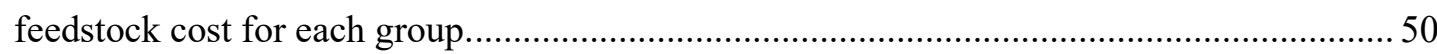

Figure 27. Biofuel product distribution for the minimum feedstock availability on a per-ton basis .......... 51

Figure 28. Biofuel product distribution for the median feedstock availability on a per-ton basis..............51

Figure 29. Biofuel product distribution for the maximum feedstock availability on a per-ton basis ......... 51

Figure 30. Sensitivity analysis for total biofuel production on a per-ton basis. Median (baseline case) for

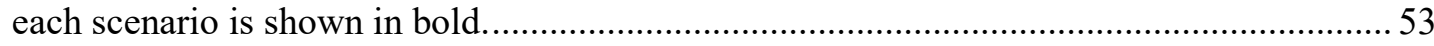

Figure 31. Sensitivity analysis for marine biofuel production on a per-ton basis. Median (baseline case) for each scenario is shown in bold..... 
Figure 32. Near-term (2022) “minimize \$/MT of produced fuel” scenario sensitivity analysis for price of total biofuel production including micro/macroalgae on a per-ton basis. Baseline:

$\$ 1,704 / \mathrm{MT}$

Figure 33. Near-term (2022) "minimize \$/MT of produced fuel" scenario sensitivity analysis for price of total biofuel production excluding micro/macroalgae on a per-ton basis. Baseline: \$758/MT.

Figure 34. Long-term (2040) "minimize \$/MT of produced fuel" scenario sensitivity analysis for price of total biofuel production including micro/macroalgae on a per-ton basis. Baseline: \$967/MT.

Figure 35. Long-term (2040) "minimize \$/MT of produced fuel" scenario sensitivity analysis for price of total biofuel production excluding micro/macroalgae on a per-ton basis. Baseline: \$816/MT.

Figure 36. Summary of the projected annual biofuel capacity in exajoules. Total annual biofuel production capacity is broken down into minimum, median, and maximum scenarios according to feedstock availability. A distinction is also made between total biofuel availability and marine biofuel availability. Further details are provided for each scenario in which relative contributions from each technology group are shown. Technology Group D contributed a significant percentage of each scenario and was therefore broken down even further into subgroups.

Figure 37. Total projected renewable energy consumption by sector, created with data obtained from EIA (U.S. EIA 2020a). Solid sections represent renewable energy consumed from biomass, and striped sections represent renewable energy from other technologies such as solar, wind,

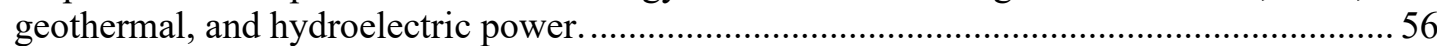

Figure 38. Biomass-based projected renewable energy consumption by sector in 2022 and 2040. Created

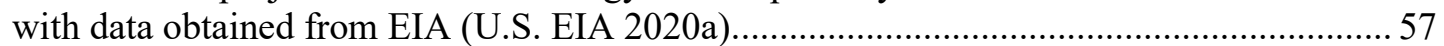

Figure 39. Total biofuel capacity projections versus demand projected by EIA .................................... 58

Figure 40. Total marine biofuel capacity projections versus demand projected by EIA .......................... 58

Figure 41. Transportation sector energy consumption projections in 2022 by EIA ............................... 59

Figure 42. Transportation sector energy consumption projections in 2040 by EIA ................................ 59

Figure 43. Projected biofuel prices and annual production capacities for the evaluated technology groups based on median feedstock availability. Note that for the price figure, fuel distribution is a

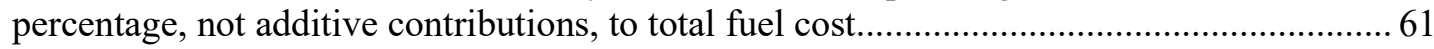

Figure 44. Summary of (a) feedstock availability and (b) feedstock prices derived from BT16. With the exception of microalgae, all feedstock availability was determined at fixed feedstock prices. Contrary to terrestrial feedstocks, as microalgae prices increase, availability decreases. ..... 62

Figure 45. Summary of near-term (2022) and long-term (2040) projected annual biofuel capacity (in million metric tons [MM MT]) and price (in \$/MT) based on the U.S. feedstock availability. Error bars are the range of annual capacities corresponding to minimum and maximum feedstock availability. Note: 1 gal HFO $=140,353$ Btu; 1 MT $=267$ gal HFO................... 63

Figure 46. Consolidated long-term projected biofuel capacity and product slate at various price ranges.. 64 Figure 47. Declining carbon intensity curve. Adapted from (California Air Resources Board 2020). ...... 67

Figure B1. Chemical Engineering Plant Cost Index data ................................................................ 92

Figure B2. Simplified bock flow diagram for biodiesel production from rapeseed oil via alkali catalysts 93

Figure B3. Simplified block flow diagram for hydroprocessed jet fuels ............................................... 95

Figure B4. Simplified block flow diagram for waste oil production of biodiesel via esterification........... 98

Figure B5. Simplified block flow diagram for yellow grease to jet via HEFA process ........................ 100

Figure B6. Simplified block flow diagram for corn ethanol via fermentation using dry grinding ........... 102

Figure B7. Simplified block flow diagram for corn stover to acetone, n-butanol, and ethanol via

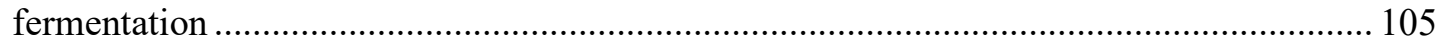

Figure B8. Process area contributions by percent for corn stover to ABE via fermentation ................... 107 
Figure B9. Simplified block flow diagram for lignocellulosic biomass to ethanol via dilute-acid pretreatment and enzymatic hydrolysis.

Figure B10. Simplified block flow diagram for corn stover to isobutanol via fermentation.....

Figure B11. Cost contribution by area shown in percentages for corn stover to isobutanol via fermentation

Figure B12. Simplified block flow diagram for woody biomass to liquid hydrocarbons via HTL .......... 114

Figure B13. Simplified block flow diagram for woody biomass fast pyrolysis to bio-oil with subsequent

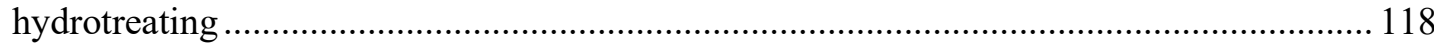

Figure B14. Simplified block flow diagram for woody biomass catalytic fast pyrolysis with in situ vapor upgrading

Figure B15. Simplified block flow diagram for woody biomass catalytic fast pyrolysis with ex situ vapor upgrading....

Figure B16. Simplified block flow diagram for high-octane gasoline via indirect gasification and methanol intermediate.

Figure B17. Simplified block flow diagram for gasification and Fischer-Tropsch synthesis of woody biomass.

Figure B18. Simplified block flow diagram for woody biomass to hydrocarbon fuels via gasification followed by Fischer-Tropsch synthesis...

Figure B19. Simplified block flow diagram for woody biomass via gasification to methanol upgraded to olefins and then to gasoline.....

Figure B20. Simplified block flow diagram for woody biomass to hydrocarbon fuels via gasification upgraded via alcohol condensation and oligomerization

Figure B21. Simplified block flow diagram for woody biomass to hydrocarbon fuels via gasification upgraded by syngas fermentation and alcohol condensation plus oligomerization

Figure B22. Simplified block flow diagram for woody biomass to hydrocarbon fuels via gasification upgraded via carbon coupling and oligomerization....

Figure B23. Simplified block flow diagram for woody biomass to hydrocarbon fuels via gasification upgraded via syngas fermentation and carbon coupling plus oligomerization.....

Figure B24. Simplified block flow diagram for woody biomass to hydrocarbon fuels via gasification and methanol-to-gasoline technologies...

Figure B25. Simplified block flow diagram for lignocellulosic biomass to ethanol via gasification and mixed-alcohol synthesis

Figure B26. Simplified block flow diagram for combined algal processing to renewable diesel blendstock

Figure B27. Simplified block flow diagram for diesel from wastewater sludge converted to bio-oil and

catalytically upgraded ......................................................................................... 160

Figure B28. Simplified block flow diagram for municipal solid waste upgraded to biogas via anaerobic

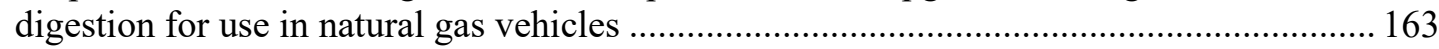

Figure B29. Simplified block flow diagram for ethanol production from fermentation of macroalgae... 165

Figure B30. Simplified block flow diagram for ethanol and electricity production from fermentation of macroalgae

Figure B31. Simplified block flow diagram for ethanol production from fermentation of seaweed........ 170

Figure B32. Simplified block flow diagram for macroalgae to biogas via anaerobic digestion............... 172

Figure B33. Simplified block flow diagram for macroalgae waste to ethanol via fermentation .............. 174

Figure C1. Optimization calculations ......................................................................................... 179

Figure C2. Projected annual biofuel and marine biofuel capacity by technology group in million metric

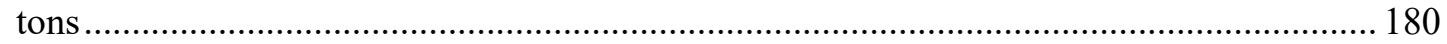

Figure C3. Projected annual biofuel and marine biofuel capacity by technology group in billion heavy fuel

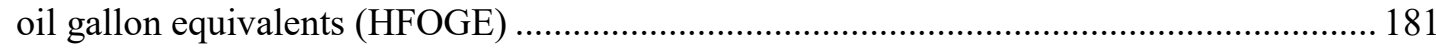

Figure C4. Projected biofuel capacity broken down by feedstock group contributions on an HFOGE basis for maximum total biofuel and maximum marine biofuel scenarios 
Figure C5. Feedstock group fuel contributions on an HFOGE basis for maximum total biofuel and maximum marine biofuel scenarios. Error bars indicate maximum and minimum feedstock

availability for each group.

Figure C6. Price of produced fuel per feedstock group on an HFOGE basis for maximum total biofuel and maximum marine biofuel scenarios. Error bars indicate maximum and minimum feedstock cost for each group.

\section{List of Tables}

Table 1. Chemical Cost Indices from SRI International (SRI Consulting 2011) ..................................... 5

Table 2. Cost Assumptions for Each Feedstock Type. Costs are presented in 2016 U.S. dollars. Bold values represent cost numbers, which were determined specifically for this analysis. Original values from BT16 in 2014 U.S. dollars are shown in Appendix A....................................... 6

Table 3. Contributing Factors to Logistics Costs by Feedstock Type and Year Scenario .......................... 7

Table 4. Feedstock Available at Marginal Roadside Cost and Delivered Cost of $\$ 83.34$ and $\$ 99.22$ per Ton in 2016 U.S. Dollars. Adapted from BT16. Costs from Table 2 rounded to the nearest dollar (e.g., \$99.22 becomes \$99) ..................................................................................... 8

Table 5. Near-Term Currently Utilized Feedstock Availability in 2016 U.S. Dollars. Adapted from BT16

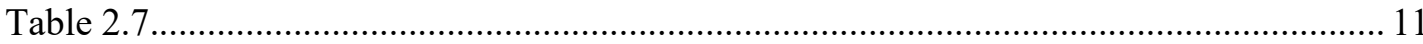

Table 6. Long-Term Currently Utilized Feedstock Availability in 2016 U.S. Dollars. Adapted from BT16

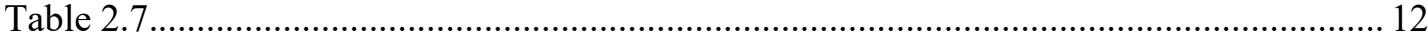

Table 7. Microalgae Availability for Present (Near-Term, 2022) and Future (Long-Term, 2040) Cases. Note that as opposed to terrestrial feedstocks, higher algae availability corresponds to lower

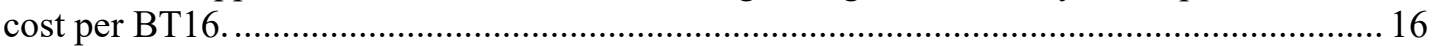

Table 8. A Portion of Exclusive Economic Zone Used for Macroalgae Production ................................. 16

Table 9. Macroalgae Cost and Availability Results for the Median Case .............................................. 16

Table 10. Pathway Conversion Technology Summary with Pathways Aligned by Feedstock and

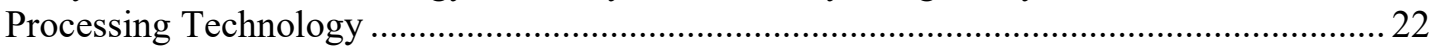

Table 11. Pathway Numbering with Associated Names and Source Material Reference ..........................22

Table 12. Relative Conversion Technology Assessment Metrics....................................................... 35

Table 13. Discounted Cash Flow Analysis Parameters .......................................................................... 38

Table 14. Examples of the Industry-Led Green Shipping Incentive Initiatives. Adapted from (Becqué,

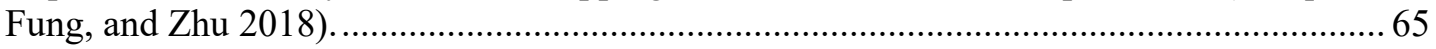

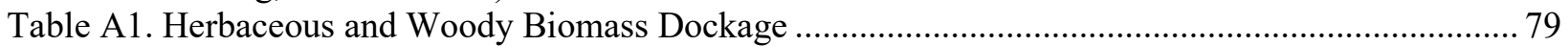

Table A2. Herbaceous Resource Availability Breakdown ............................................................... 80

Table A3. Million Tons of Unutilized Material in Each Case and Ratio of Utilized to Total Available

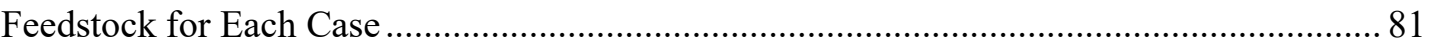

Table A4. Other Herbaceous Resource Availability Breakdown ........................................................... 81

Table A5. Breakdown of Unused Material for Each Herbaceous Case. High-Cost Case Recovers Material Recovered Due to Too Low Cost Assumptions ( $>\$ /$ ton notation) ......................................... 82

Table A6. Woody Feedstock Availability at a Given Cost, with Supply Chain Losses, Overcontracted

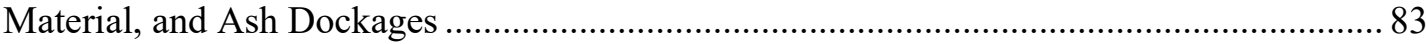

Table A7. Million Tons of Unutilized Material in Each Case and Ratio of Utilized to Total Available

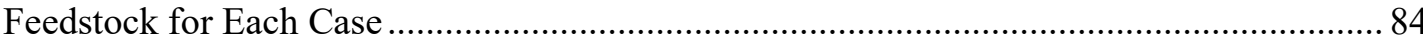

Table A8. Breakdown of Unused Material for Each Woody Case. High-Cost Case Recovers Material Recovered Due to Too Low Cost Assumptions ( $>\$$ /ton notation) .......................................... 84

Table A9. Waste Feedstock Availability at a Given Cost, with Supply Chain Losses, Overcontracted Material, and Ash Dockages ............................................................................................ 85

Table A10. Ratio of Utilized to Total Available Feedstock for Woody and Herbaceous Materials. These Assumptions Were Applied to Similar Materials in this Waste Feedstock Analysis.............. 85 
Table A11. Breakdown of Unused Material for Each Waste Case. High-Cost Case Recovers Material Recovered Due to Too Low Cost Assumptions ( $>\$$ ton notation).

Table A12. Adopted from BT16 Appendix D, Table D-12. Summary of Algae Productivities Used for

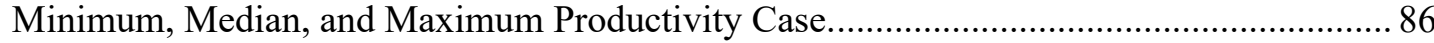

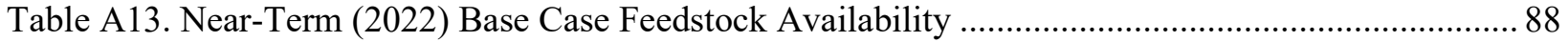

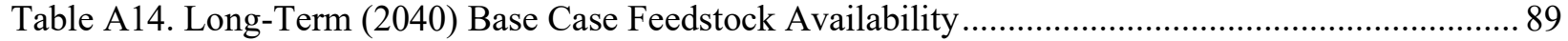

Table A15. Long-Term (2040) High-Yield Feedstock Availability ...................................................... 90

Table B1. Economic Assumptions for Biodiesel Production from Rapeseed Oil via Alkali Catalysts ...... 94

Table B2. Summary Results Table for Biodiesel Production from Rapeseed Oil via Alkali Catalysis...... 95

Table B3. Summary Results Table for Hydroprocessed Jet Fuels ......................................................... 97

Table B4. Equipment Costs for Waste Oil Production of Biodiesel via Esterification ............................ 99

Table B5. Summary Results Table for Waste Oil Production of Biodiesel via Esterification.................. 100

Table B6. Summary Results Table for Yellow Grease to Jet via HEFA Process ................................... 101

Table B7. Economic Assumptions for Corn Ethanol via Fermentation Using Dry Grinding................... 103

Table B8. Summary Results Table for Corn Ethanol via Fermentation Using Dry Grinding .................. 104

Table B9. Summary Results Table for Corn Stover to Acetone, n-Butanol, and Ethanol via Fermentation

108

Table B10. Summary Results Table for Lignocellulosic Biomass to Ethanol via Dilute-Acid Pretreatment

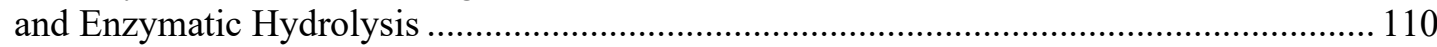

Table B11. Summary Results Table for Corn Stover to Isobutanol via Fermentation .......................... 113

Table B12. Economic Assumptions for Goal and State-of-Technology Case ........................................ 116

Table B13. Summary Results Table for Woody Biomass to Liquid Hydrocarbons via Hydrothermal Liquefaction.....

Table B14. Capital Equipment Costs by Conversion Plant Area for Woody Biomass Fast Pyrolysis to Bio-Oil with Subsequent Hydrotreating............................................................................. 119

Table B15. Summary Results Table for Woody Biomass Fast Pyrolysis to Bio-Oil with Subsequent

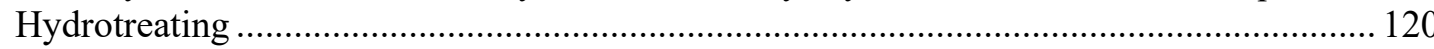

Table B16. Capital Expenses Broken Down by Processing Area for Woody Biomass Catalytic Fast Pyrolysis with In Situ Vapor Upgrading ........................................................................... 123

Table B17. Summary Results Table for Woody Biomass Catalytic Fast Pyrolysis with In Situ Vapor

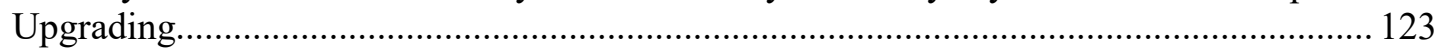

Table B18. Capital Expenses Broken Down by Processing Area for Woody Biomass Catalytic Fast Pyrolysis with Ex Situ Vapor Upgrading ........................................................................ 126

Table B19. Summary Results Table for Woody Biomass Catalytic Fast Pyrolysis with Ex Situ Vapor Upgrading.......................................................................................................... 126

Table B20. Summary Results Table for High-Octane Gasoline via Indirect Gasification and Methanol

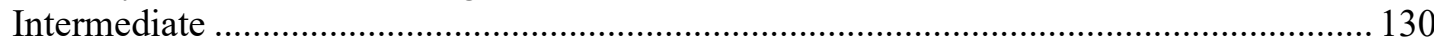

Table B21. Summary Results Table for Gasification Followed by Fischer-Tropsch Synthesis.............. 132

Table B22. Summary Results Table for Natural Gas to Enhance Biomass-to-Liquid Fuels .................... 133

Table B23. Capital Expenses Broken Down by Processing Area Woody Biomass to Hydrocarbon Fuels via Gasification Followed by Fischer-Tropsch Synthesis ................................................... 136

Table B24. Summary Results Table for Woody Biomass to Hydrocarbon Fuels via Gasification Followed by Fischer-Tropsch Synthesis ........................................................................................ 136

Table B25. Summary of Area Contributions to MFSP for Woody Biomass via Gasification to Methanol Upgraded to Olefins and then to Gasoline ....................................................................... 138

Table B26. Summary Results Table for Woody Biomass via Gasification to Methanol Upgraded to Olefins and then to Gasoline

Table B27. Capital Expenses Broken Down by Processing Area for Woody Biomass to Hydrocarbon Fuels via Gasification Upgraded via Alcohol Condensation and Oligomerization .............. 142

Table B28. Summary Results Table for Woody Biomass to Hydrocarbon Fuels via Gasification Upgraded via Alcohol Condensation and Oligomerization 142 
Table B29. Capital Expenses Broken Down by Processing Area Woody Biomass to Hydrocarbon Fuels via Gasification Upgraded by Syngas Fermentation and Alcohol Condensation Plus Oligomerization

Table B30. Summary Results Table for Woody Biomass to Hydrocarbon Fuels via Gasification Upgraded by Syngas Fermentation and Alcohol Condensation plus Oligomerization......................... 145

Table B31. Capital Expenses Broken Down by Processing Area for Woody Biomass to Hydrocarbon Fuels via Gasification Upgraded via Carbon Coupling and Oligomerization...................... 147

Table B32. Summary Results Table for Woody Biomass to Hydrocarbon Fuels via Gasification Upgraded via Carbon Coupling and Oligomerization ..................................................................... 148

Table B33. Capital Expenses Broken Down by Processing Area for Woody Biomass to Hydrocarbon Fuels via Gasification Upgraded via Syngas Fermentation and Carbon Coupling plus Oligomerization

Table B34. Summary Results Table for Woody Biomass to Hydrocarbon Fuels via Gasification Upgraded via Syngas Fermentation and Carbon Coupling plus Oligomerization............................... 150

Table B35. Summary Results Table for Woody Biomass to Hydrocarbon Fuels via Gasification and Methanol-to-Gasoline Technologies

Table B36. Summary of Capital Costs by Area for Lignocellulosic Biomass to Ethanol via Gasification and Mixed-Alcohol Synthesis.....

Table B37. Summary Results Table for Lignocellulosic Biomass to Ethanol via Gasification and MixedAlcohol Synthesis

Table B38. Summary Results Table for Combined Algal Processing...

Table B39. Summary Results Table for Diesel from Wastewater Sludge Converted to Bio-Oil and Catalytically Upgraded

Table B40. Summary of Resource Prices Assumed for Municipal Solid Waste Upgraded to Biogas via Anaerobic Digestion for Use in Natural Gas Vehicles

Table B41. Summary Results Table for Municipal Solid Waste Upgraded to Biogas via Anaerobic Digestion for Use in Natural Gas Vehicles

Table B42. Summary Results Table for Ethanol Production from Fermentation of Macroalgae.

Table B43. Summary Results Table for Ethanol and Electricity Production from Fermentation of Macroalgae.

Table B44. Summary Results Table for Ethanol Production from Fermentation of Seaweed ................. 171

Table B45. Biogas Composition by Weight and Volume for Major Components ................................. 172

Table B46. Summary Results Table for Macroalgae to Biogas via Anaerobic Digestion....................... 173

Table B47. Summary Results Table for Macroalgae Waste to Ethanol via Fermentation ...................... 176

Table C1. Detailed Description of Feedstock Group Used for Production Capacity and Cost Projection Modeling

Table C2. Solver Results (C2.1-C2.9) for Optimization Constraint: Minimize Biofuel Cost. All Results in \$/MT Biofuel.

Table C3. Solver Results (C3.10-C3.18) for Optimization Constraint: Maximize Total Biofuel. All Results in Million Metric Tons Biofuel.

Table C4. Solver Results (C4.19-C4.27) for Optimization Constraint: Maximize Total Marine Biofuel. All Results in Million Metric Tons Biofuel.

Table C5. Solver Results (C5.28-C5.36) for Optimization Constraint: Minimize Biofuel Cost. Data Are the Complementary Results to the Optimization Function (i.e., the Production Capacity Values at Optimized Cost). All Results in Million Metric Tons Biofuel.....

Table C6. Solver Results (C6.37-C6.45) for Optimization Constraint: Maximize Total Biofuel. Data Compiled are the Complementary Results to the Optimization Function (i.e., Biofuel Cost at the Optimized Production Capacity). All Results in \$/MT Biofuel.

Table C7. Solver Results (C7.46-C7.54) for Optimization Constraint: Maximize Total Marine Biofuel. Data are the Complementary Results to the Optimization Function (i.e., Biofuel Cost at the Optimized Production Capacity). All Results in \$/MT Biofuel. 
Table D1. Exajoule Unit Conversion Chart......

Table D2. Biofuel Availability by Technology Group in Exajoules.

Table D3. Data from U.S. Energy Information Administration's Annual Energy Outlook 2020 (Table 17 -

"Renewable Energy Consumption by Sector and Source") (U.S. EIA 2020a).

Table D4. Data from U.S. Energy Information Administration's Annual Energy Outlook 2020 (Table 7 "Transportation Sector Key Indicators and Delivered Energy Consumption") (U.S. EIA 2020a) 


\section{Introduction}

Marine shipping is the most energy-efficient form of freight transport and is the backbone of global trade, responsible for transporting $80 \%$ of the world's goods by volume and over $70 \%$ of global trade by value (Wan et al. 2018; UNCTAD 2018). The marine shipping sector heavily depends on liquid fuel and is one of the largest petroleum fuel consumers. Heavy fuel oil (HFO) is a residual of the refinery process that contains many undesirable impurities separated from other refinery products; the primary fuel used by the marine shipping sector is $\mathrm{HFO}-77 \%$ in 2013 (Tanzer et al. 2019). Other marine fuels include marine gas oil (MGO), marine diesel oil, intermediate fuel oil, and marine fuel oil, and are categorized based on their blending properties (Mohd Noor, Noor, and Mamat 2018). The annual global marine fuel consumption is around 330 million metric tons (MT) (87 billion gallons), which is higher than the world's yearly jet fuel consumption of 220 million MT (1.4 billion barrels) (Kass et al. 2018). The overall demand for marine fuels is expected to double by 2030 due to increased global trade (Squirrell 2017; Pearce 2009).

Moreover, ocean shipping is one of the most significant contributors to air emissions of sulfur oxides $\left(\mathrm{SO}_{\mathrm{x}}\right)$, nitrogen oxides $\left(\mathrm{NO}_{\mathrm{x}}\right)$, and particulate matter. Global shipping contributes $13 \%$ of human-caused emissions of $\mathrm{SO}_{\mathrm{x}}$ (Sofiev et al. 2018) and 2.6\% of anthropogenic carbon dioxide $\left(\mathrm{CO}_{2}\right)$ emissions (Olmer et al. 2017). As a major source of pollutant emissions, the marine industry is facing several challenges related to emissions regulations. The industry has started to meet the emissions targets set by the International Maritime Organization to reduce global marine fuel sulfur content from the current $3.5 \% \mathrm{~m} / \mathrm{m}$ (mass by mass) to $0.5 \% \mathrm{~m} / \mathrm{m}$ starting on January 1, 2020 (Birch et al. 2017). In addition, in the United States, the California Air Resources Board and other state agencies have established regulations limiting the sulfur content of fuel used in coastal regions to $0.1 \% \mathrm{~m} / \mathrm{m}$ (Kass et al. 2018; Chu Van et al. 2019). These regulations will require shipowners to find alternative fuel pathways. The options include lowsulfur HFO, low-sulfur MGO, installing sulfur scrubbers, or other alternative fuels and powertrains (Birch et al. 2017). In addition to sulfur emissions reduction targets, the International Maritime Organization has also established a framework for reducing the carbon intensity of shipping explicitly — a 40\% reduction relative to 2008 levels by 2030 and a $70 \%$ reduction by 2050 (Tanzer et al. 2019; Tan and Tao 2019).

Biomass-derived biofuels can undoubtedly play an essential role in the future marine fuel sector that is more renewable and offers potential synergistic benefits when blended with petroleum fuels by reducing the overall sulfur content, as well as improving overall emissions profiles and ultimately the environmental sustainability (including decarbonization). For example, biofuel oil derived from biomass such as forest residues is expected to reduce the well-to-propeller life cycle greenhouse gas emissions up to $90 \%$ versus fossil equivalents and virtually eliminate $\mathrm{SO}_{\mathrm{x}}$ emissions without any requirement for engine modifications (Kennedy 2019).

For biofuel's benefits to be realized and impactful, a significant fraction of marine fuel use will need to be met with biofuel. This necessitates that biofuel production volume be high enough to meet demand. Furthermore, the potential of biofuel adoption also depends on future biofuel prices. Hence, marine biofuel's long-term price and availability are two critical factors for establishing the feasibility of marine biofuel adoption for operating vessels. 
To meet both growing marine fuel demand and recently enacted aggressive air emissions targets, the U.S. Department of Transportation's Maritime Administration (MARAD) recently worked with the National Renewable Energy Laboratory (NREL) to carry out a preliminary technoeconomic analysis of marine biofuel production via various biomass conversion pathways (Tan and Tao 2019). In this project, MARAD continues to work with NREL to estimate the long-term price and production capacity of biofuel in the United States based on projected U.S. biomass resource availability and biofuel production technologies reported in the literature. The study aims to shed light on the prospect of biofuel adoption for maritime shipping.

\section{Biomass Feedstock Availability Evaluation}

Biomass feedstock availability is a critical factor that dictates the potential biofuel production capacity. This assessment aims to quantify the current and future biomass resource potential for marine biofuel utilization. Biomass feedstock cost and availability are matched to the corresponding conversion technology, described in later sections, to determine fuel yield and production costs. The long-term biofuel price and scalability assessment are based on the assessed feedstock cost and availability and the selected conversion pathways.

We assessed the biomass feedstock cost and availability using the latest available yield and cost data. The 2016 Billion-Ton Report (BT16) (Langholtz, Stokes, and Eaton 2016) served as the primary database for determining feedstock availability and cost for this analysis. In this study, guided by BT16, biomass is defined by a broad spectrum of organic materials including herbaceous materials (corn stover, soybean hulls, and switchgrass), woody materials (logging residues, whole tree biomass, and construction and demolition waste), waste materials (animal manure, municipal solid waste, and paper and paperboard), and algae (microalgae and macroalgae).

The geographical scope includes U.S. domestic resources without considering spatial distribution. This study's base case assumes all available feedstock contributes to the production of biofuels. This assumption does not consider market forces in which feedstocks will be used for other industries, such as power, biochemicals, and bioplastics, and all biomass availability would be used exclusively for marine fuels. Figure 1 summarizes feedstock availability as a function of yield assumption and time, showing the potential for greater than one billion tons of biomass by 2040 . 


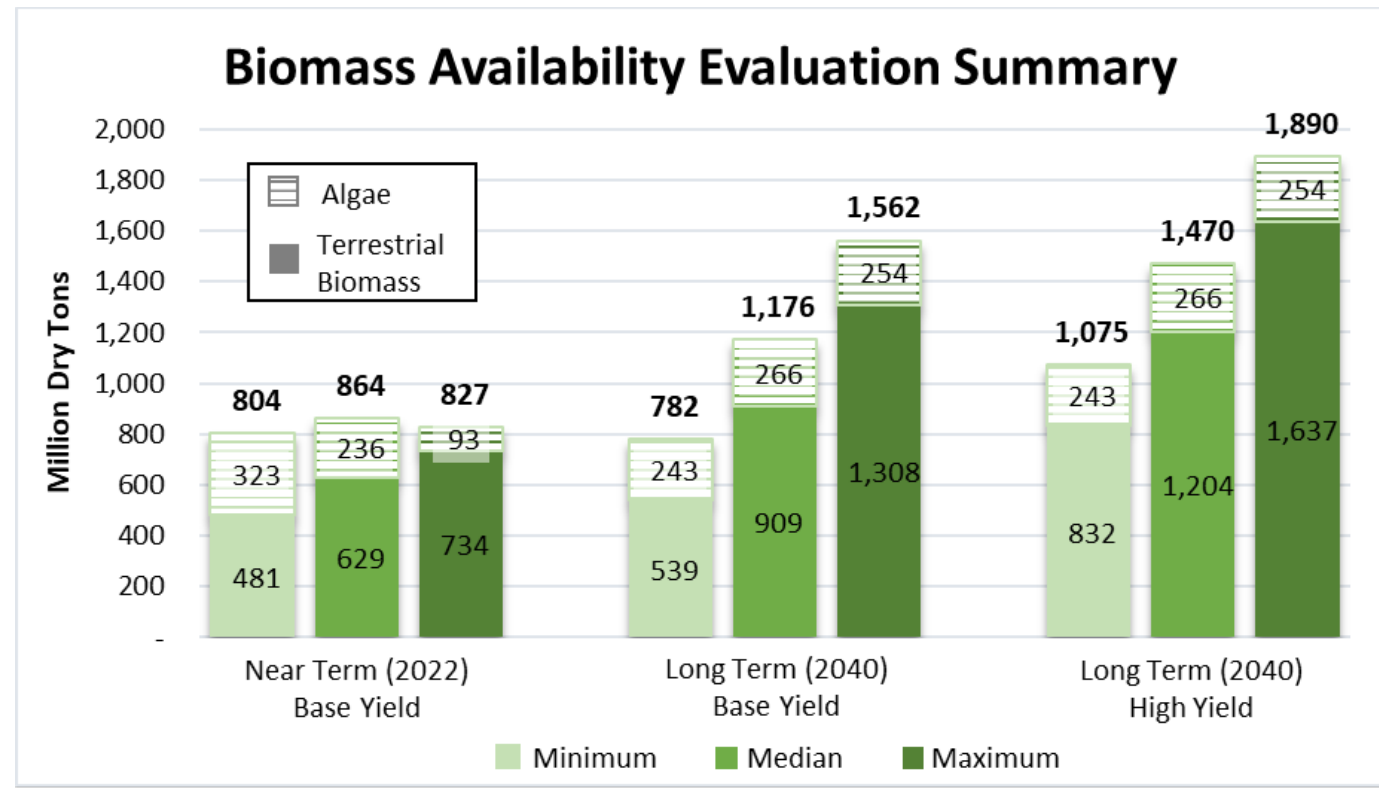

Figure 1. Feedstock availability based on BT16

\subsection{Method and Assumptions}

\subsubsection{Feedstock Data Sourcing}

Much of the feedstock availability analysis is derived from the data compiled in BT16. BT16 was created by Oak Ridge National Laboratory for the U.S. Department of Energy (DOE) to identify one billion tons per year of domestic biomass availability for bioenergy consumption. Production constraints such as economic incentives, land availability, and overall yield were applied to determine the total available biomass at the farmgate (agricultural resources), roadside (forestry resources), or sorting facility (waste resources). This analysis is applied to a range of biomass resources, including resources from agricultural lands, forest lands, wastes, and algae. Feedstocks were then broken down further into subcategories for a more granular look into feedstock availability. Another important designation within the feedstock analysis is "currently utilized resources" versus "potential resources." As the title implies, currently utilized resources are feedstocks that, as of 2014, are used to produce biofuels and bioenergy. Potential resources are the center of the analysis and are feedstocks that are not currently employed but are expected to be available for use to meet biofuel production targets. The overall structure of biomass classification and quantification methodology is summarized in Figure 2. The feedstock evaluation began with the selection of resource categories and applying a set of criteria to reach the final total availability of biomass in the United States. 


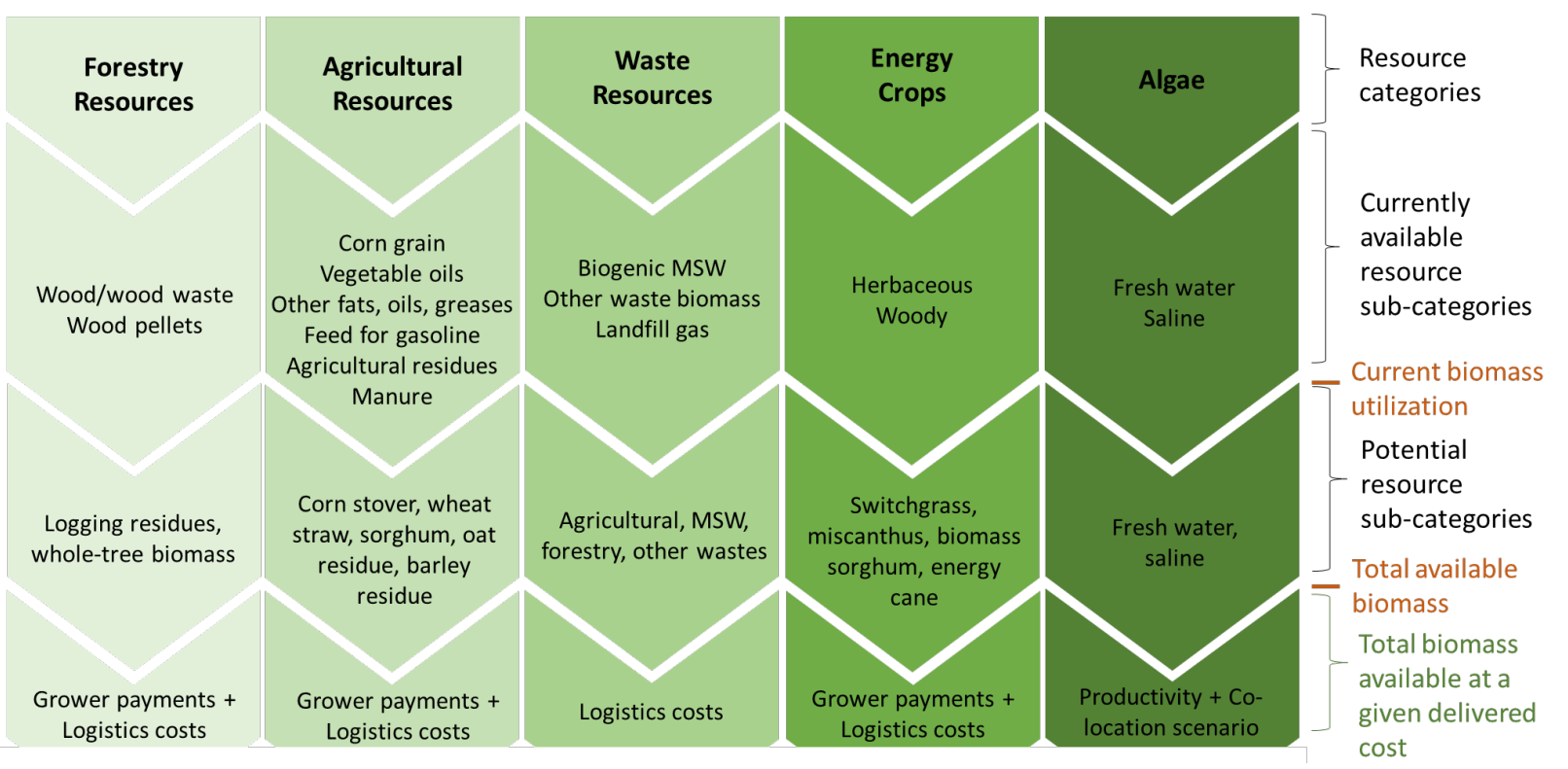

Figure 2. Feedstock analysis process summary based on BT16

\subsubsection{Scenario Definitions}

This study considered the feedstock outlook for a near-term scenario (2022) and a long-term scenario (2040). Additional constraints were applied to potential resources, including base case yield assumptions and high-yield assumptions. Base case and high-yield scenarios for agricultural feedstocks and energy crops were indicated by a $1 \%$ and $3 \%$ annual increase in yield, respectively. The base case for forestry resources is defined by a low rise in demand for biomass as a feedstock and a moderate increase in the demand for biomass for the housing and paper and paperboard industries. High yield for forestry resources denotes a high increase in biomass demand for both the biomass feedstock and housing industries and moderate growth for the paper and paperboard industry. The near-term scenario does not include a high-yield case due to the need for infrastructure development before achieving increased yields. The long-term case does include a high-yield scenario.

Additionally, each yield case has a low, median, and high cost and availability scenario. Both the base case yield and high-yield scenarios for the long-term scenario will be presented in this discussion. However, it is important to note that the long-term base case and high-yield case can be combined for the potential biofuel capacity and price projection, as shown in Figure 3. This is further elaborated in Section 4. In doing so, the base case assumptions were assumed for both the minimum and median availability cases, and the high-yield availabilities were assumed for the maximum availability case. Given that both the "lowest" case and the "highest" case will be analyzed, it is implied that the excluded cases will lie within the bounds of the calculated results. The overall scenario breakdown is depicted in Figure 3. 

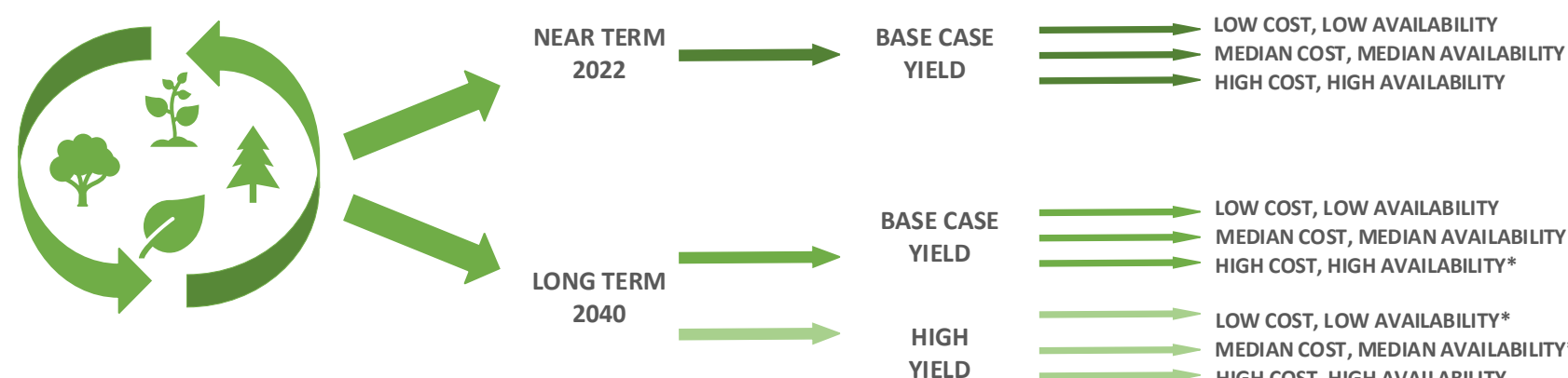

YIELD

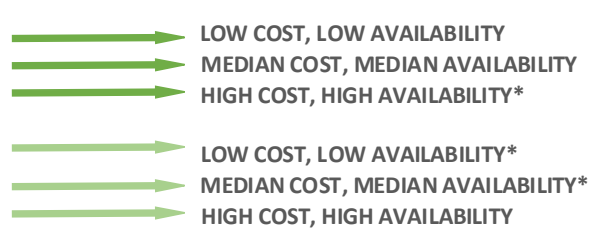

Figure 3. Feedstock availability scenarios for biofuel production capacity and cost projections

*Scenarios excluded from the linear programming model.

\subsubsection{Cost Determination}

Beyond the general mechanics applied for collecting the data, some underlying assumptions on feedstock cost were imposed on the available data to guide the extrapolation phases.

Extrapolation was required for feedstocks where logistical considerations were not already directly applied, or where maximum and minimum costs were not provided. Although some calculations in this analysis are based on new assumptions, BT16 data were used to the greatest extent possible to maintain consistency. This section highlights where assumptions were made in this study to BT16 information. An overview of the assumptions related to this analysis and the logical basis for their derivation are detailed here.

The cost year associated with feedstock prices in BT16 was in 2014 U.S. dollars. In the case of macroalgae, costs were provided in 1987 U.S. dollars. Using chemical cost indices, shown in Table 1 from SRI International's Chemical Economics Handbook (SRI Consulting 2011), the cost year was updated to 2016 U.S. dollars to maintain consistency between the feedstock analysis and conversion technology assessment.

Table 1. Chemical Cost Indices from SRI International (SRI Consulting 2011)

\begin{tabular}{ll}
\hline Cost Year & Index Used \\
\hline 1987 & 106.4 \\
2014 & 269.2 \\
2016 & 267.1 \\
\hline
\end{tabular}

We grouped the feedstocks into categories based on feedstock types determined by BT16. These new groups are identified as herbaceous feedstocks and woody feedstocks (in terms of logistics). Herbaceous feedstocks include resources that fall under the category of agricultural resources and some of the energy crops. Additionally, the total cost of a given feedstock was provided in two steps. First, the total feedstock availability at the roadside, farmgate, or sorting facility was determined at a fixed production cost. Next, transportation, preprocessing, and material loss costs were applied to generate a set of total delivered costs (i.e., the price paid by the biorefinery). A breakdown of these costs and logistical considerations is summarized at a high level in Table 2 and Table 3. Feedstock availability was determined as a function of cost; therefore, the cost determination steps were crucial for this assessment. 
Table 2. Cost Assumptions for Each Feedstock Type. Costs are presented in 2016 U.S. dollars. Bold values represent cost numbers, which were determined specifically for this analysis. Original values from BT16 in 2014 U.S. dollars are shown in Appendix A.

\begin{tabular}{llll}
\hline & \multicolumn{2}{l}{ Production/Procurement Costs $(\$ /$ ton) } \\
& Minimum & Median & Maximum \\
\hline Currently Utilized & - & $\$ 59.53$ & - \\
Herbaceous & $\$ 39.69$ & $\$ 59.53$ & $\$ 79.38$ \\
Woody & $\$ 39.69$ & $\$ 59.53$ & $\$ 79.38$ \\
Waste & $\$ 39.69$ & $\$ 49.61$ & $\$ 59.53$ \\
\hline & Delivered Costs (\$/ton) & & \\
& Minimum & Median & Maximum \\
\hline Currently Utilized & $\$ 47.63$ & $\$ 59.53$ & $\$ 71.44$ \\
Herbaceous & $\$ 83.34$ & $\$ 99.22$ & $\$ 119.06$ \\
Woody & $\$ 83.34$ & $\$ 99.22$ & $\$ 119.06$ \\
Waste & $\$ 69.45$ & $\$ 82.68$ & $\$ 99.22$ \\
\hline
\end{tabular}

BT16 reports feedstock availabilities for all feedstocks at the roadside, farmgate, or sorting facility at their respective costs shown in Table 2. BT16 provided minimum and median cost scenarios for both herbaceous and woody feedstocks, and the maximum cost scenario (\$119.06/ton) was assumed for this assessment. Additionally, all delivered cost assumptions for currently utilized feedstocks were determined to remain consistent with those in the herbaceous and woody feedstock categories. For currently utilized feedstocks, the median delivered price was assumed to be $\$ 59.53 /$ ton, which is consistent with the value provided in BT16. From the median cost, a factor of $84 \%$ was applied to derive a minimum cost, and a factor of $120 \%$ was applied to attain the maximum cost. This relationship is shown in Equations 1 and 2:

$$
\begin{aligned}
& \text { Minimum Delivered Cost Currently Utilized Resources }=\frac{\$ 59.53}{\text { Ton }} *\left(\frac{\$ 83.34}{\$ 99.22}\right) \\
& \text { Maximum Delivered Cost Currently Utilized Resources }=\frac{\$ 59.53}{\text { Ton }} *\left(\frac{\$ 119.06}{\$ 99.22}\right)
\end{aligned}
$$

For waste feedstocks, the median delivered cost is $\$ 49.61 /$ ton versus $\$ 59.53 /$ ton for herbaceous and woody feedstocks. To maintain a lower cost assumption or the waste category and still add on logistics and preprocessing costs, $\$ 49.61 /$ ton was used as the base production cost. New cost ratios based on the ratio of production cost and delivered cost for herbaceous and woody feedstocks were used to determine the waste material delivered cost. The calculations for waste delivered costs are shown in Equations 3-5:

$$
\begin{aligned}
& \text { Minimum Delivered Cost Waste Resources }=\frac{\$ 49.61}{\text { Ton }} *\left(\frac{\$ 83.34 \text { delivered }}{\$ 59.53 \text { production }}\right) \\
& \text { Median Delivered Cost Waste Resources }=\frac{\$ 49.61}{\text { Ton }} *\left(\frac{\$ 99.22 \text { delivered }}{\$ 59.53 \text { production }}\right)
\end{aligned}
$$




$$
\text { Maximum Delivered Cost Waste Resources }=\frac{\$ 49.61}{\text { Ton }} *\left(\frac{\$ 119.06 \text { delivered }}{\$ 59.53 \text { production }}\right)
$$

After determining delivered cost for each category, logistical factors listed in Table 3 were applied and availabilities were found based on the cost scenario.

Table 3. Contributing Factors to Logistics Costs by Feedstock Type and Year Scenario

\begin{tabular}{|c|c|c|}
\hline & Near Term & Long Term \\
\hline Herbaceous & $\begin{array}{l}\text { Storage costs } \\
\text { Loading/unloading truck } \\
\text { Storage at biorefinery } \\
\text { Grinding } \\
\text { Moisture dockage } \\
\text { Ash dockage } \\
\text { Time cost (transport to biorefinery) } \\
\text { Distance cost (transport to } \\
\text { biorefinery) }\end{array}$ & $\begin{array}{l}\text { Storage } \\
\text { Loading/unloading truck } \\
\text { Moisture dockage } \\
\text { Time cost (transport to preprocessing depot) } \\
\text { Distance cost (transport to preprocessing depot) } \\
\text { Grinding } \\
\text { Drying } \\
\text { Densifying } \\
\text { Handling } \\
\text { Storage at biorefinery } \\
\text { Time cost (transport to biorefinery) } \\
\text { Distance cost (transport to biorefinery) }\end{array}$ \\
\hline Woody & $\begin{array}{l}\text { Hammer mill (second-stage grind) } \\
\text { Handling } \\
\text { Chipper } \\
\text { Handling } \\
\text { Ash dockage } \\
\text { Time cost (transport to biorefinery) } \\
\text { Distance cost (transport to } \\
\text { biorefinery) }\end{array}$ & $\begin{array}{l}\text { Handling } \\
\text { Time cost (transport to preprocessing depot) } \\
\text { Distance cost (transport to preprocessing depot) } \\
\text { Hammer mill (second-stage grind) } \\
\text { Drying } \\
\text { Densifying } \\
\text { Handling } \\
\text { Storage at biorefinery } \\
\text { Time cost (transport to biorefinery) } \\
\text { Distance cost (transport to biorefinery) }\end{array}$ \\
\hline
\end{tabular}

The data showing the availability by feedstock type derived in BT16 is tabulated in Table 4. 
Table 4. Feedstock Available at Marginal Roadside Cost and Delivered Cost of $\$ 83.34$ and $\$ 99.22$ per Ton in 2016 U.S. Dollars. Adapted from BT16. Costs from Table 2 rounded to the nearest dollar (e.g., \$99.22 becomes \$99).

\begin{tabular}{|c|c|c|c|c|c|c|}
\hline & \multicolumn{2}{|c|}{ Herbaceous } & \multicolumn{2}{|l|}{ Woody } & \multicolumn{2}{|l|}{ Total } \\
\hline & Near Term & Long Term & Near Term & Long Term & Near Term & Long Term \\
\hline \multicolumn{7}{|c|}{ Base case yield scenario (million tons) } \\
\hline Roadside at $\leq \$ 60$ & 184 & 497 & 126 & 182 & 310 & 679 \\
\hline Delivered at $\leq \$ 83$ & 51 & 198 & 88 & 52 & 139 & 249 \\
\hline Delivered at $\leq \$ 99$ & 99 & 367 & 95 & 98 & 194 & 465 \\
\hline Unused & 85 & 130 & 31 & 84 & 116 & 214 \\
\hline \multicolumn{7}{|c|}{ High-yield scenario (million tons) } \\
\hline Roadside at $\leq \$ 60$ & & 754 & & 232 & & 985 \\
\hline Delivered at $\leq \$ 83$ & & 419 & & 109 & & 528 \\
\hline Delivered at $\leq \$ 99$ & & 588 & & 154 & & 742 \\
\hline Unused & & 166 & & 77 & & 243 \\
\hline
\end{tabular}

The data shown in Table 4 were only reported for corn stover, switchgrass, miscanthus, biomass sorghum (herbaceous) and whole-tree chips, logging residues, woody crops (coppice), and construction and demolition waste (woody). Therefore, the feedstock cost and availability data from Table 2, Table 3, and Table 4 were used in this analysis to derive minimum, median, and maximum biofuel production quantities for all feedstocks and project the corresponding costs. Feedstocks were grouped into either herbaceous, woody, or other/waste categories. Then, the feedstock utilization ratios were calculated for both herbaceous and woody feedstocks from the data shown in Table 4. This utilization ratio was used to calculate individual feedstock availability for the low (\$83/ton) and median (\$99/ton) cost scenarios. For example, according to BT16, the total amount of corn stover available at the farm gate for $\$ 60 /$ ton (rounded to the nearest dollar in 2016 dollars) in the near-term scenario is 106 million dry tons. These 106 million dry tons exclude logistics and any other associated losses with the feedstock and are a portion of the total 184 million dry tons of available herbaceous feedstock in the near-term scenario and at the roadside (or farmgate) cost of $\$ 60 /$ ton shown in Table 4 . After taking into account the logistics costs shown in Table 3 for near-term herbaceous feedstocks, it was determined that only 30 million dry tons of corn stover (out of 51 million tons in Table 4) would be available to the biorefinery for a delivered cost of $\$ 83 /$ ton for the base case near-term scenario. Likewise, 58.3 million dry tons of corn stover could be obtained for a delivered cost of $\$ 99 /$ ton for the base case near-term scenario out of a total of 99 million dry tons of herbaceous biomass available for $\$ 99 /$ ton.

More information was required to determine the amount of available feedstock for the highestcost scenario. The difference between the feedstock availability at the roadside, farmgate, or sorting facility and the biorefinery's total availability can be attributed to feedstock transportation and handling logistics and losses. This difference is referred to as the unused portion of the biomass. The unused portion has been further broken down into three categories: unused due to cost limitations, unused due to overcontracting, and unused due to supply-chain 
losses. Per BT16, a 10\% production buffer was applied to the near-term woody feedstock scenario to protect biorefinery production from variability in the supply chain.

Further analysis in the BT16 study assumes that advanced collection and distribution systems for future scenarios will eliminate the need for overcontracting. Similarly, an overcontracting buffer of $25 \%$ was applied to the near-term herbaceous scenario once again to protect biorefinery products from variability in the supply chain (e.g., fire, drought, pests) (Langholtz, Stokes, and Eaton 2016). It was assumed in this analysis that this amount of feedstock could not be recovered. The near-term scenario's supply-chain losses were assumed to equal the percent ash content for a given feedstock. An optimistic assumption was utilized for long-term scenarios in which the only limitations are feedstock cost and there are no supply-chain losses. Thus, given a high enough delivered cost to the biorefinery, it is assumed that all the potential biomass resources could be consumed.

For the near-term corn stover scenario described in the previous example, the high-cost total availability is equal to the total farmgate availability minus loses to ash (7\% of farmgate) and overcontracting ( $25 \%$ of farmgate), or about 73 million dry tons out of the total 106 million dry tons of corn stover. This same analysis method, derived from BT16 data for this analysis, was imposed on all other feedstocks in this study.

No logistical losses were assumed for waste feedstocks other than those that fell into the herbaceous or woody feedstock category. Overcontracting buffers and losses due to ash content were applied per the respective resource category for the scenarios termed other agricultural wastes, forestry residues, and other wood wastes per the nomenclature of BT16. The remainder of the detailed analysis data for every feedstock category can be found in Appendix A.6.

\subsubsection{Algae}

Due to algal biomass technologies' unique features, different projection methods were used to understand the potential of algae as a feedstock. Microalgae feedstock potential was sourced from BT16 (Table 7.7 and Table 7.8). Various scenarios were presented, including a variety of algal strain and carbon dioxide $\left(\mathrm{CO}_{2}\right)$ sources. The algal strains considered were a freshwater strain, Chlorella sorokiniana, and a saline strain, Nannochloropsis salina. The carbon feedstock (i.e., $\mathrm{CO}_{2}$ ) for algal biomass growth was assumed over various co-location scenarios, including $\mathrm{CO}_{2}$ from a coal electric generating unit, natural gas electric generating unit, and ethanol processing facility. The authors of BT16 also derived minimum, median, and maximum cost scenarios. A base case total available algal biomass value for each culture type and co-location scenario was provided and was assumed to be the median case. In Table D-12 of BT16, the productivities of the high-cost and low-cost scenarios were used to calculate the predicted total available biomass for the minimum and maximum availability scenarios. The total available microalgae feedstocks were assumed to be the sum of the availabilities for each algae culture type and each $\mathrm{CO}_{2}$ co-location scenario.

Macroalgae as a biofuel feedstock presents significant value in that seaweed cultivation can be relatively low maintenance. Moreover, seaweed can absorb ocean pollutants (NOAA Fisheries 2020), and there is less competition for space utilization in the ocean than on land (Food and Agriculture Organization of the United Nations 2014). This study's macroalgae analysis should be viewed as a preliminary assessment for a relatively untapped domestic market. However, 
other countries including Chile, China, and Norway have already begun extensive efforts to grow and cultivate macroalgae primarily for food and products (Ferdouse et al. 2018). In 2012, it was estimated by the Fishery and Aquaculture Organization that nearly 24 million MT of seaweed were farmed globally, and an estimated $38 \%$ of that was for human consumption (Food and Agriculture Organization of the United Nations 2014). In the United States, the Advanced Research Projects Agency - Energy released funding opportunities in a multimillion-dollar research effort toward Macroalgae Research Inspiring Novel Energy Resources (MARINER) (ARPA-E 2017). The results of these projects are expected to highlight the United States' potential for macroalgal biomass production in the coming years and will be key for future analyses of feedstock potential. Recently, seaweed farming operations in Alaska have begun to show promising growth in accessing the economic potential of the oceans (NOAA Fisheries 2020). For this analysis, we focus on projections based on potential yields and the reasonable growth projections provided by the Pacific Northwest National Laboratory (PNNL) (Roesijadi et al. 2010; Roesijadi et al. 2011).

Macroalgae availability values were sourced from reports by PNNL (Roesijadi et al. 2010). Potential seaweed yields and production costs, which included cultivation and harvesting, were provided based on previous data in terms of annual dry and ash free weight per hectare (Chynoweth 2002). In order to determine the potential biomass availability from yield information, it was necessary to estimate the area of the exclusive economic zone (EEZ) that could realistically be utilized for algal biomass in a near-term and long-term scenario. In a 2011 report, Roesijadi et al. (2011) list the United States EEZ as 468,000 $\mathrm{km}^{2}$ of usable area, and in a 2010 report (Roesijadi et al. 2010) suggest a reasonable utilization target would be $0.09 \%$ of the EEZ, or about 10,895 $\mathrm{km}^{2}$. However, they also note this target is a 10.7-fold increase from 2010 production levels (Roesijadi et al. 2010; Roesijadi et al. 2011). Given the uncertainty in time required to develop the market and infrastructure required for this biomass cultivation level, the $0.09 \%$ EEZ metric was set as the long-term target case (2040) to be conservative in this analysis. The near-term case (2022) was then estimated as 10.7 times less than the target case $\left(1,018 \mathrm{~km}^{2}\right.$, $0.008 \%$ of the EEZ); this assumes all productivity goes to biofuel production. These EEZ utilization areas were then multiplied by productivity values to yield predictions for the nearterm and long-term scenarios. Additionally, cost numbers from the original PNNL report were scaled from 1987 dollars to 2016 dollars. Due to uncertainty in data, a fixed factor of $\pm 20 \%$ was applied to both the cost and availability of each macroalgae type for the minimum and maximum cases.

\subsection{Total Feedstock Availability Results and Discussion}

The culmination of the aforementioned methods and assumptions provided the platform from which all feedstocks considered in this study were analyzed. The results are summarized in this section, and additional tables are provided in Appendix A.

\subsubsection{Currently Used Resources}

Currently used feedstocks primarily fall into the category of first-generation feedstocks. Firstgeneration feedstocks are mainly utilized for bioethanol, biodiesel, and bioenergy (heat and power). These feedstocks are also typically edible, like corn and vegetable oils, leading to market considerations with food availability (Lee and Lavoie 2013). According to the U.S. Energy Information Administration (EIA), over 15 million gallons of fuel ethanol (U.S. EIA 2021a) and 
1.5 million gallons of biodiesel (U.S. EIA 2021b) were produced in 2019 from first-generation feedstocks. Other currently used resources include wood waste and municipal solid waste (MSW), which are typically used for power generation. Table 5 and Table 6 summarize the presently used resources. It is important to note that neither near- versus long-term nor highversus low-yield variability was applied to the currently utilized resources. However, a factor was applied to give an upper and lower bound to both the cost and availability of those feedstocks. This factor was determined via the methods described in the previous section. The applied factor was a function of the data within the same year, so slightly different minimum and maximum values for the currently utilized resources are shown between the near-term and longterm scenarios. Additional data from the U.S. Department of Agriculture (USDA 2020) were utilized to break down the categories provided by BT16 for currently used resources into their constituent parts. This additional detail from the U.S. Department of Agriculture are shown in Table 5 and Table 6 as grey text.

Table 5. Near-Term Currently Utilized Feedstock Availability in 2016 U.S. Dollars. Adapted from BT16 Table 2.7.

\begin{tabular}{l|lll|lll|}
\hline \multirow{2}{*}{$\begin{array}{l}\text { Currently Used Feedstocks } \\
\text { Near Term (2022) }\end{array}$} & \multicolumn{3}{|c|}{ Total Annual Biomass (Million Dry Tons) } & \multicolumn{3}{l}{ Feedstock Cost $\$$ /Ton) } \\
& Minimum & Median & Maximum & Minimum & Median & Maximum \\
\hline Vegetable oils & 3.00 & 5.83 & 7.28 & $\$ 50.01$ & $\$ 59.53$ & $\$ 71.44$ \\
$\quad$ Soybean oil & 1.60 & 3.10 & 3.87 & $\$ 50.01$ & $\$ 59.53$ & $\$ 71.44$ \\
Corn oil & 0.39 & 0.76 & 0.95 & $\$ 50.01$ & $\$ 59.53$ & $\$ 71.44$ \\
Canola oil & 0.33 & 0.65 & 0.81 & $\$ 50.01$ & $\$ 59.53$ & $\$ 71.44$ \\
Other & 0.68 & 1.32 & 1.65 & $\$ 50.01$ & $\$ 59.53$ & $\$ 71.44$ \\
Other fats, oils, and greases & 0.97 & 1.89 & 2.36 & $\$ 50.01$ & $\$ 59.53$ & $\$ 71.44$ \\
$\quad$ Lard & 0.11 & 0.21 & 0.26 & $\$ 50.01$ & $\$ 59.53$ & $\$ 71.44$ \\
Edible tallow & 0.25 & 0.49 & 0.61 & $\$ 50.01$ & $\$ 59.53$ & $\$ 71.44$ \\
$\quad$ Other & 0.61 & 1.19 & 1.49 & $\$ 50.01$ & $\$ 59.53$ & $\$ 71.44$ \\
Corn grain & 64.48 & 125.17 & 156.26 & $\$ 50.01$ & $\$ 59.53$ & $\$ 71.44$ \\
Agricultural residues & 0.01 & 0.01 & 0.01 & $\$ 50.01$ & $\$ 59.53$ & $\$ 71.44$ \\
Wood/wood waste & 135.39 & 146.16 & 170.67 & $\$ 50.01$ & $\$ 59.53$ & $\$ 71.44$ \\
Wood pellets & 7.05 & 7.61 & 8.89 & $\$ 50.01$ & $\$ 59.53$ & $\$ 71.44$ \\
Feed for gasoline & 0.11 & 0.22 & 0.27 & $\$ 50.01$ & $\$ 59.53$ & $\$ 71.44$ \\
blendstock/naphtha & 18.87 & 18.87 & 18.87 & $\$ 50.01$ & $\$ 59.53$ & $\$ 71.44$ \\
Biogenic portion of MSW & 11.48 & 11.48 & 11.48 & $\$ 50.01$ & $\$ 59.53$ & $\$ 71.44$ \\
Other waste biomass & & & & &
\end{tabular}


Table 6. Long-Term Currently Utilized Feedstock Availability in 2016 U.S. Dollars. Adapted from BT16 Table 2.7.

\begin{tabular}{|c|c|c|c|c|c|c|}
\hline \multirow{2}{*}{$\begin{array}{l}\text { Currently Used Feedstocks } \\
\text { Long Term (2040) }\end{array}$} & \multicolumn{3}{|c|}{ Total Annual Biomass (Million Dry Tons) } & \multicolumn{3}{|c|}{$\begin{array}{l}\text { Feedstock Cost } \\
\text { (\$/Ton) }\end{array}$} \\
\hline & Minimum & Median & Maximum & Minimum & Median & Maximum \\
\hline Vegetable oils & 3.15 & 5.83 & 8.20 & $\$ 50.01$ & $\$ 59.53$ & $\$ 71.44$ \\
\hline Soybean oil & 1.67 & 3.10 & 4.36 & $\$ 50.01$ & $\$ 59.53$ & $\$ 71.44$ \\
\hline Corn oil & 0.41 & 0.76 & 1.07 & $\$ 50.01$ & $\$ 59.53$ & $\$ 71.44$ \\
\hline Canola oil & 0.35 & 0.65 & 0.91 & $\$ 50.01$ & $\$ 59.53$ & $\$ 71.44$ \\
\hline Other & 0.71 & 1.32 & 1.86 & $\$ 50.01$ & $\$ 59.53$ & $\$ 71.44$ \\
\hline Other fats, oils, and greases & 1.02 & 1.89 & 2.66 & $\$ 50.01$ & $\$ 59.53$ & $\$ 71.44$ \\
\hline Lard & 0.11 & 0.21 & 0.30 & $\$ 50.01$ & $\$ 59.53$ & $\$ 71.44$ \\
\hline Edible tallow & 0.26 & 0.49 & 0.68 & $\$ 50.01$ & $\$ 59.53$ & $\$ 71.44$ \\
\hline Other & 0.64 & 1.19 & 1.68 & $\$ 50.01$ & $\$ 59.53$ & $\$ 71.44$ \\
\hline Corn grain & 67.53 & 125.17 & 176.14 & $\$ 50.01$ & $\$ 59.53$ & $\$ 71.44$ \\
\hline Agricultural residues & 0.01 & 0.01 & 0.01 & $\$ 50.01$ & $\$ 59.53$ & $\$ 71.44$ \\
\hline Wood/wood waste & 77.55 & 146.16 & 262.06 & $\$ 50.01$ & $\$ 59.53$ & $\$ 71.44$ \\
\hline Wood pellets & 4.04 & 7.61 & 13.64 & $\$ 50.01$ & $\$ 59.53$ & $\$ 71.44$ \\
\hline $\begin{array}{l}\text { Feed for gasoline } \\
\text { blendstock/naphtha }\end{array}$ & 0.12 & 0.22 & 0.31 & $\$ 50.01$ & $\$ 59.53$ & $\$ 71.44$ \\
\hline Biogenic portion of MSW & 18.87 & 18.87 & 18.87 & $\$ 50.01$ & $\$ 59.53$ & $\$ 71.44$ \\
\hline Other waste biomass & 11.48 & 11.48 & 11.48 & $\$ 50.01$ & $\$ 59.53$ & $\$ 71.44$ \\
\hline
\end{tabular}

\subsubsection{Herbaceous Feedstocks}

Herbaceous feedstocks are composed of agricultural resources also known as second-generation biofuel feedstocks. Advances in collection technology can lead to the utilization of more crop residues, including corn stover, wheat straw, and sorghum, oat, and barley residues. Additional herbaceous feedstocks include energy crops. The current utilization of dedicated energy crops is minimal (Langholtz, Stokes, and Eaton 2016). The potential for incorporating energy crops into the biofuel economy poses significant advantages, as dedicated energy crops will not interfere with food, housing, or other markets. The results for the herbaceous feedstock analysis are shown in Figure 4. Herbaceous feedstocks contributed the largest percentage of material to the total available feedstocks in each scenario. In the near-term, low-cost scenario, the authors of BT16 calculate $72 \%$ of the total available biomass (or 141 million dry tons out of 197 million dry tons) is lost to reasons like cost (i.e., economic feasibility challenges), overcontracting (i.e., overproduction at the farm to account for pests and drought), or supply-chain losses (i.e., dry matter and ash loss). On the other hand, for the near-term, high-cost scenario, the amount calculated to be lost is only $31 \%$, corresponding to a total of 135 million dry tons of herbaceous feedstock potentially available in the near term. The total usable feedstock for the long-term, high-cost scenario is nearly six times greater than the near-term, high-cost scenario, at 795 million dry tons of herbaceous feedstock availability. The increase can be attributed to the high 
yield assumption, along with an optimistic assumption of no logistical or supply-chain losses. Additional feedstock information for herbaceous resources can be found in Appendix A.2.

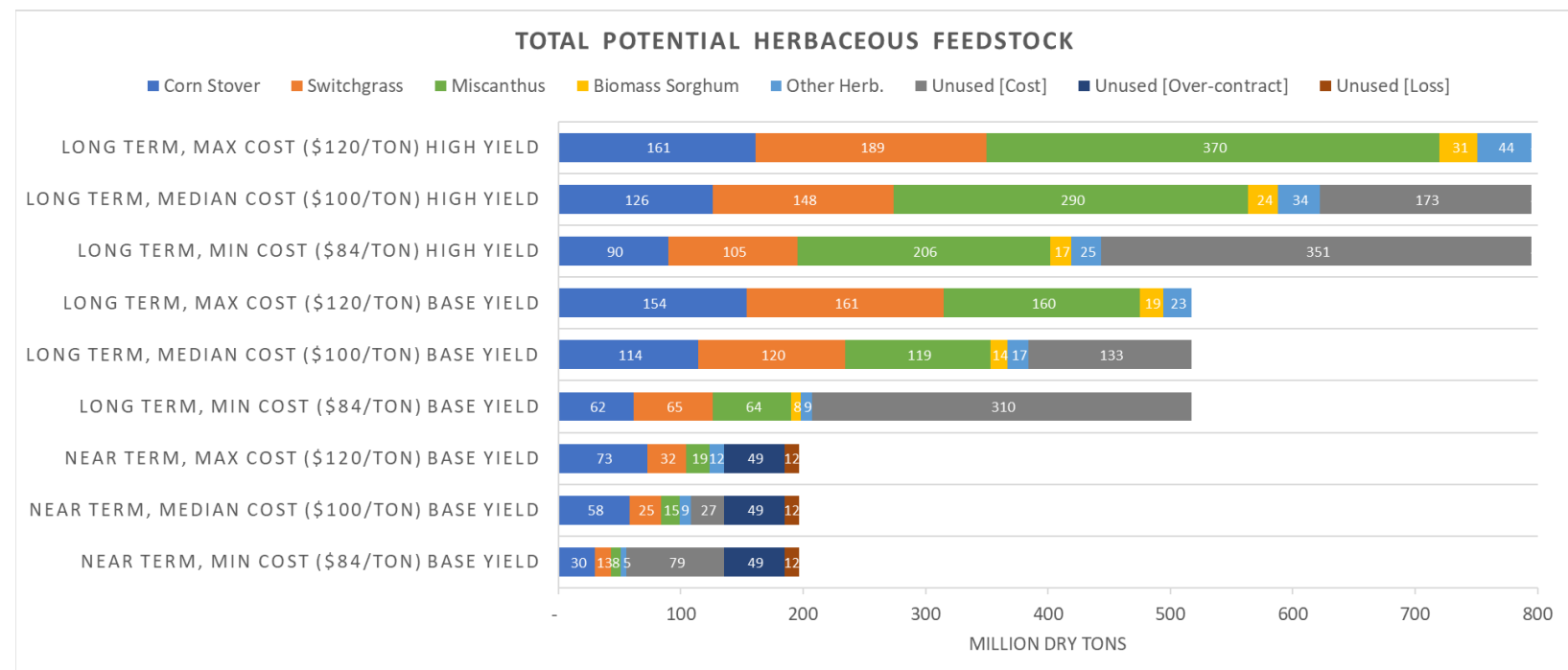

Figure 4. Total potential herbaceous feedstock availability by type and scenario

Nine total scenarios were analyzed for each feedstock grouping (i.e., herbaceous feedstocks), as shown in Figure 3. Availability of each feedstock grouping was derived from BT16, along with the three types of unused material (unused due to cost, overcontract, and loss in the supply chain). Our analysis assumed that losses due to cost could be recovered in the maximum cost scenario. As shown in the figure, the dark grey unused due to cost portion is completely utilized in each maximum cost scenario. However, it was assumed that unused feedstocks due to supplychain loss and overcontracting could not be recovered, as indicated by the dark blue and dark red bars in the nearterm scenario. These losses were not assumed in the long-term scenario.

\subsubsection{Woody Feedstocks}

Woody feedstocks contain mostly forestry resources, primarily second-generation lignocellulosic feedstocks. The current utilization of forestry resources is primarily for power generation. Despite this, woody lignocellulosic feedstocks are regarded as likely feedstocks for thermochemical conversion to fuels. Woody feedstocks exhibit fewer losses in each scenario than the herbaceous feedstocks, as seen in Figure 5. In the near-term, low-cost scenario, 30\% of the total available feedstock is lost to cost, overcontracting, and supply-chain losses. In the nearterm, high-cost scenario, only $12 \%$ of material is lost, resulting in 111 million dry tons of woody biomass available annually. In the long-term, high-cost scenario, no material is lost, and 234 million dry tons are assumed to be available. In the near-term scenarios, the largest contributor to woody biomass availability is whole-tree chips; however, woody energy crops are expected to provide more material in the long term. Between the near-term and the long-term cases, wholetree chips and logging residues decrease due to an assumed increase in demand for the housing and pulp and paperboard industries. Additional feedstock information for woody resources can be found in Appendix A.3. 


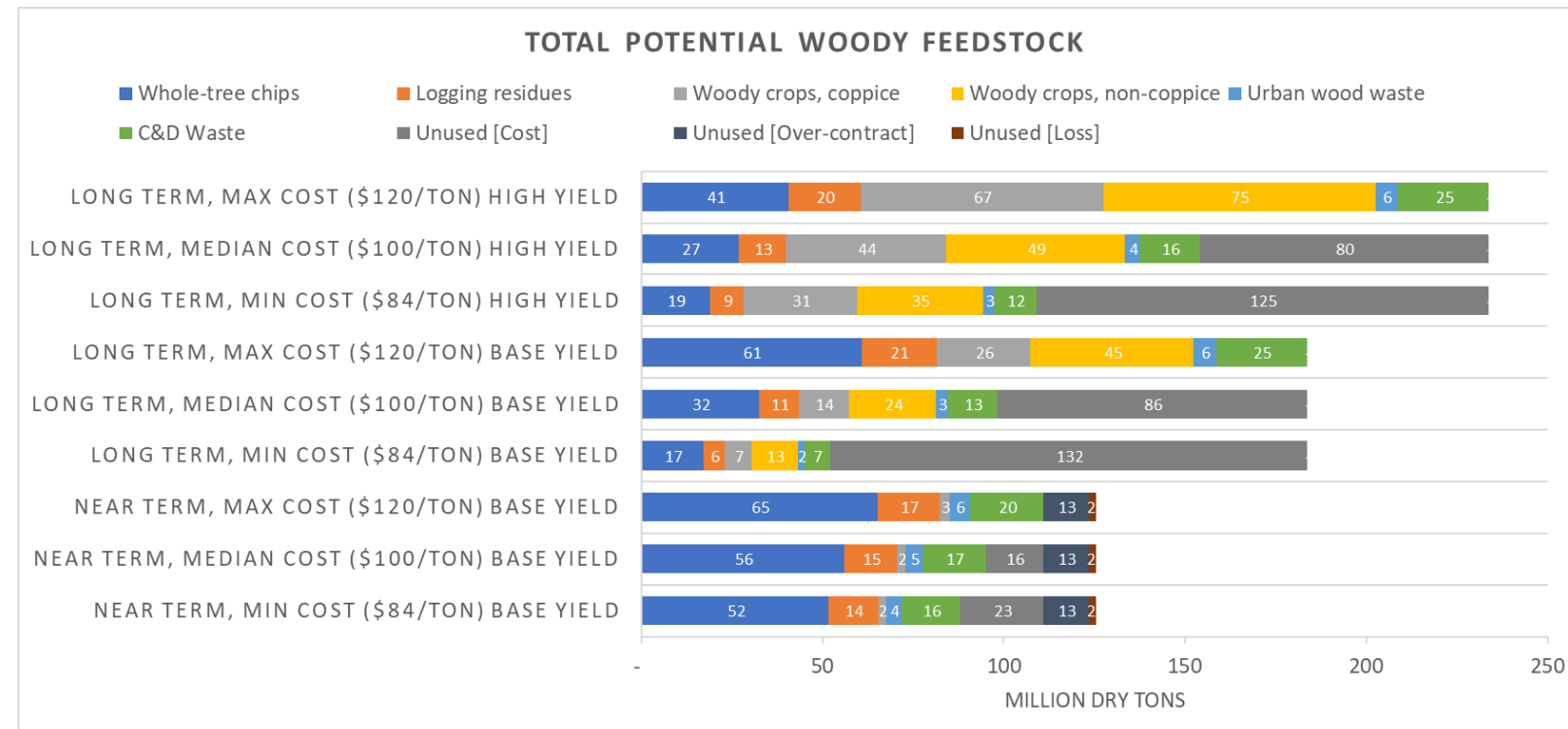

Figure 5. Total potential woody feedstock availability by type and scenario

Like herbaceous feedstocks, nine total scenarios were analyzed for woody feedstocks. Availability was derived from BT16 along with the three types of unused material (unused due to cost, overcontract, and loss in the supply chain). Our analysis assumed that losses due to cost could be recovered in the maximum cost scenario. As shown in the figure, the dark grey unused due to cost portion is completely utilized in each maximum cost scenario. Again, it was assumed that unused feedstocks due to supply-chain loss and overcontracting could not be recovered, as indicated by the dark blue and dark red bars in the near-term scenario. These losses were not assumed in the long-term scenario.

\subsubsection{Waste Feedstocks}

Minimal variation is expected in the waste feedstock availability scenarios. Therefore, a highyield versus base case yield comparison was not performed (consistent with BT16). Every waste scenario totals around 100 million dry tons of material available. In each scenario, just over $50 \%$ of the waste feedstock availability is expected to come from MSW, animal manures, and paper and paperboard. The other 50\% are compiled in Figure 6. Additional feedstock information for waste resources can be found in Appendix A.4. 


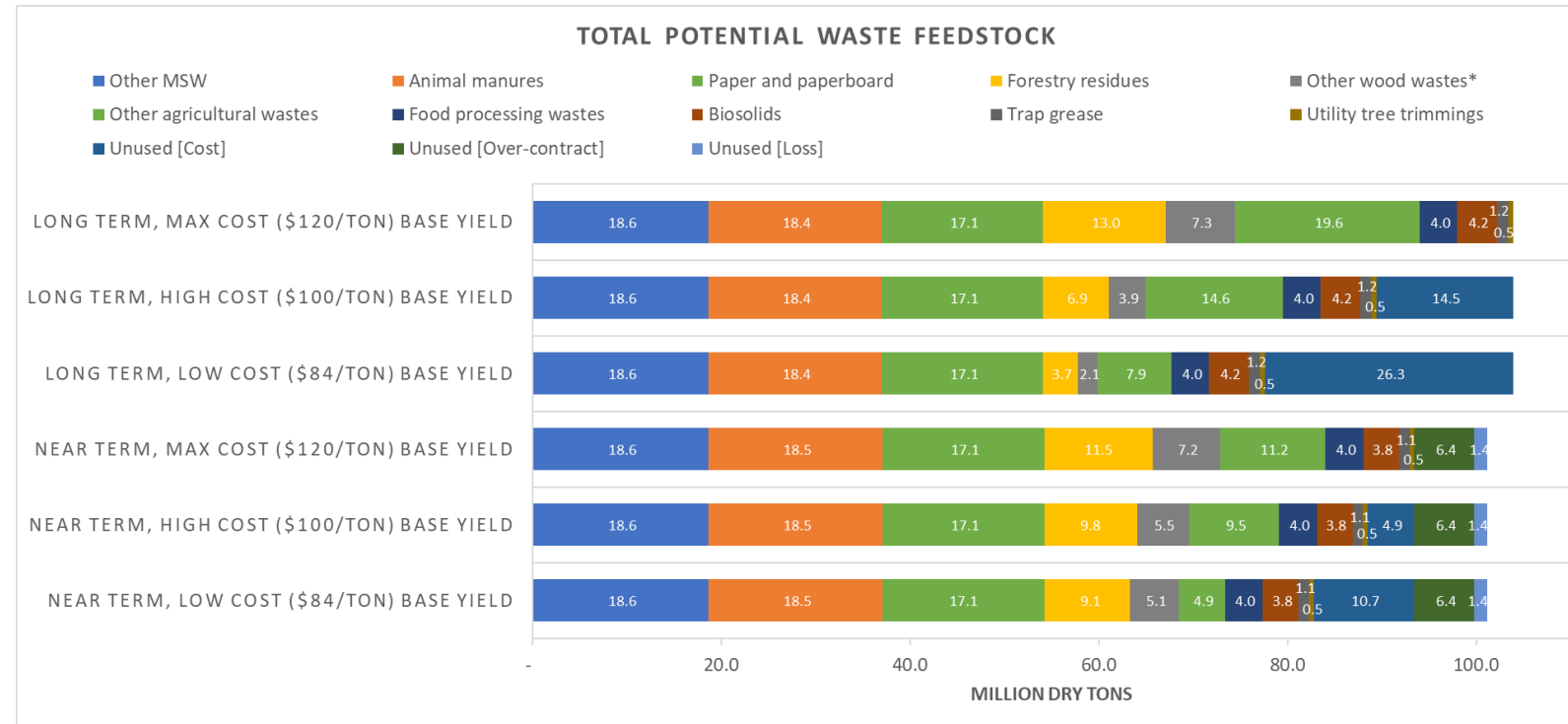

Figure 6. Total potential waste feedstock availability by type and scenario

Six scenarios were analyzed for waste feedstocks, as it was assumed in BT16 and this analysis that a high-yield scenario for waste feedstocks would not be relevant. Availability was derived from BT16, and the same three types of unused material (unused due to cost, overcontract, and loss in the supply chain) were applied. Unused feedstock due to cost could be recovered in the maximum cost scenario, but supply-chain loss and overcontracting (both only applied in the near-term scenario) could not be recovered.

\subsubsection{Algae}

Algae is considered the primary feedstock for third-generation biofuels (Lee and Lavoie 2013). Algal biofuels have received significant attention and research due to the high oil content of algal biomass and high yield potential. Still, algal technologies are currently limited significantly by cost (Adeniyi, Azimov, and Burluka 2018; Leite, Abdelaziz, and Hallenbeck 2013; Chowdhury et al. 2019). Two categories of algal biomass were considered for this assessment: microalgae and macroalgae. Microalgae feedstock production cost and annual production yield shown in Table 7 are adapted from BT16, which in turn were based largely on previous NREL reports. Algae feedstock availability was analyzed as a function of algae type, algal productivity, and cost and availability of $\mathrm{CO}_{2}$ for algae production. A differentiating trend between microalgae and the rest of the terrestrial feedstock analyzed in this study is that lower cost was associated with higher feedstock quantities. This is due to the assessment method. In this case, production metrics were fixed except for algae productivity, and thus when productivity increases, the cost decreases. The reverse is also true. Therefore, the minimum-minimum case nomenclature in this scenario presents more biomass at a low cost and less biomass availability at a high cost. The productivity values used for this calculation are included in Appendix A.5. 
Table 7. Microalgae Availability for Present (Near-Term, 2022) and Future (Long-Term, 2040) Cases. Note that as opposed to terrestrial feedstocks, higher algae availability corresponds to lower cost per BT16.

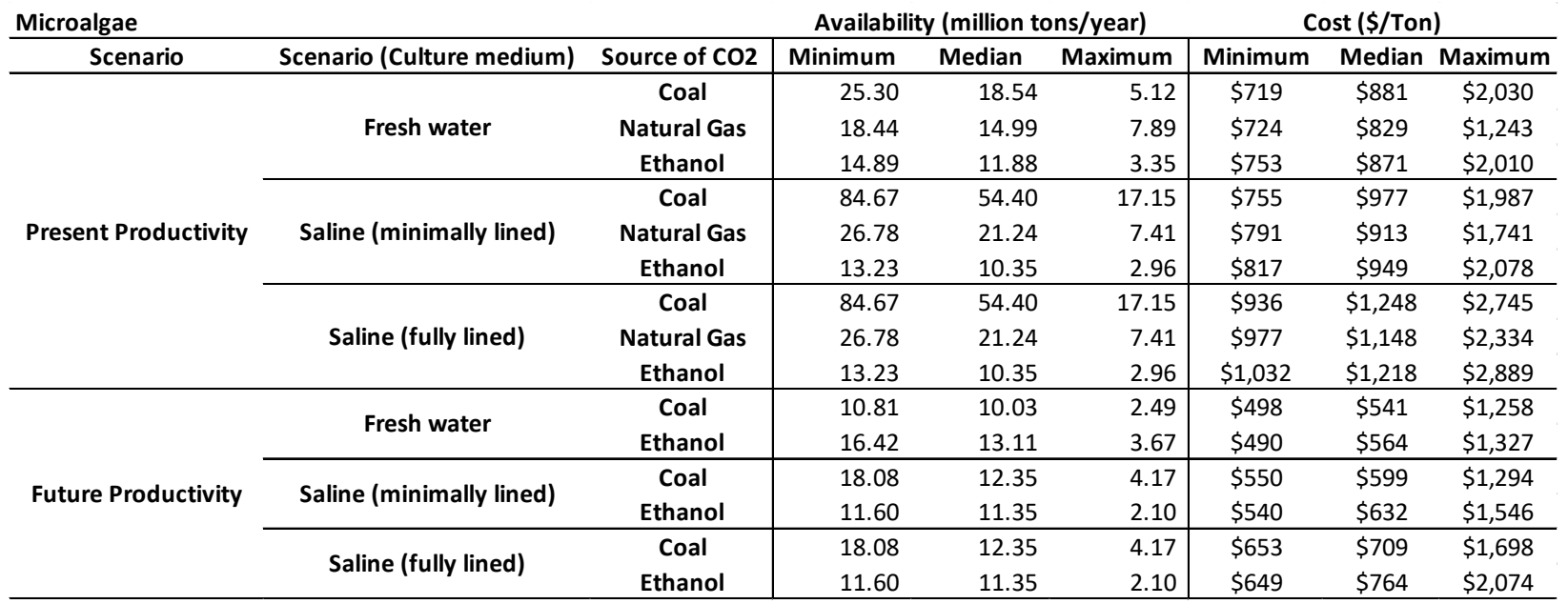

Macroalgae feedstock estimations were most accurate on best-available predictions for marine algae yields and approximate utilization of the United States EEZ. Results for macroalgae are tabulated in Table 8 and Table 9. Additional details for other scenarios can be found in Appendix A.6.

Table 8. A Portion of Exclusive Economic Zone Used for Macroalgae Production

\begin{tabular}{llll}
\hline Macroalgae & $\mathbf{k m}^{\mathbf{2}}$ & \% of EEZ & hectare \\
\hline 2022 Use of EEZ & 1,018 & $0.008 \%$ & 101,822 \\
2040 Use of EEZ & 10,895 & $0.09 \%$ & $1,089,500$ \\
\hline
\end{tabular}

Table 9. Macroalgae Cost and Availability Results for the Median Case

\begin{tabular}{lllllll}
\hline Cultivation System & Yield & & $\begin{array}{l}\text { Production } \\
\text { Cost }\end{array}$ & $\begin{array}{l}\text { Production } \\
\text { Cost }\end{array}$ & $\begin{array}{l}\text { Near Term } \\
\text { (2022) }\end{array}$ & $\begin{array}{l}\text { Future Projection } \\
\text { (2040) }\end{array}$ \\
\hline & free MT/ha/yr & $\begin{array}{l}\text { Dry } \\
\text { MT/ha/yr }\end{array}$ & $\begin{array}{l}\text { \$/dry wt MT } \\
\text { (1987 US\$) }\end{array}$ & $\begin{array}{l}\text { \$/dry wt MT } \\
\text { (2016 US\$) }\end{array}$ & $\begin{array}{l}\text { Million } \\
\text { Ton/yr }\end{array}$ & Million Ton/yr \\
\hline $\begin{array}{l}\text { Macrocystis, } \\
\text { nearshore }\end{array}$ & 50 & 83 & 25 & 63.25 & 5.61 & 60.05 \\
$\begin{array}{l}\text { Laminaria/Laminaria } \\
\text { rope farm (offshore) }\end{array}$ & 45 & 59 & 112 & 283.37 & 5.05 & 54.04 \\
$\begin{array}{l}\text { Ulva/Ulva, tidal flat } \\
\text { farm }\end{array}$ & 23 & 30 & 21 & 53.13 & 2.58 & 27.62 \\
$\begin{array}{l}\text { Sargassum, floating } \\
\text { cultivation }\end{array}$ & 45 & 47 & 25 & 63.25 & 5.05 & 54.04 \\
\hline
\end{tabular}

We have determined price and feedstock availability for the U.S. domestic resources in the near term and long term and considered base case and high-yield scenarios based on BT16. The total available biomass breakdown by resource category for the three median cases investigated is shown in Figure 7. Increases in herbaceous energy crops are expected to drive feedstock 
availability in long-term cases. Waste materials and currently utilized resources are not expected to significantly grow in availability over time. Therefore, their relative contributions over time are expected to decrease from $8 \%$ in the 2022 base case to $6 \%$ in the 2040 base case. Woody biomass is also expected to increase over time, but not to the same extent as herbaceous feedstocks. Finally, microalgae contributions are not projected to increase significantly over time. However, with significant infrastructure development and the pursuit of macroalgae technologies, it is predicted that macroalgae can become a significant contributor to feedstock availability in the long term.
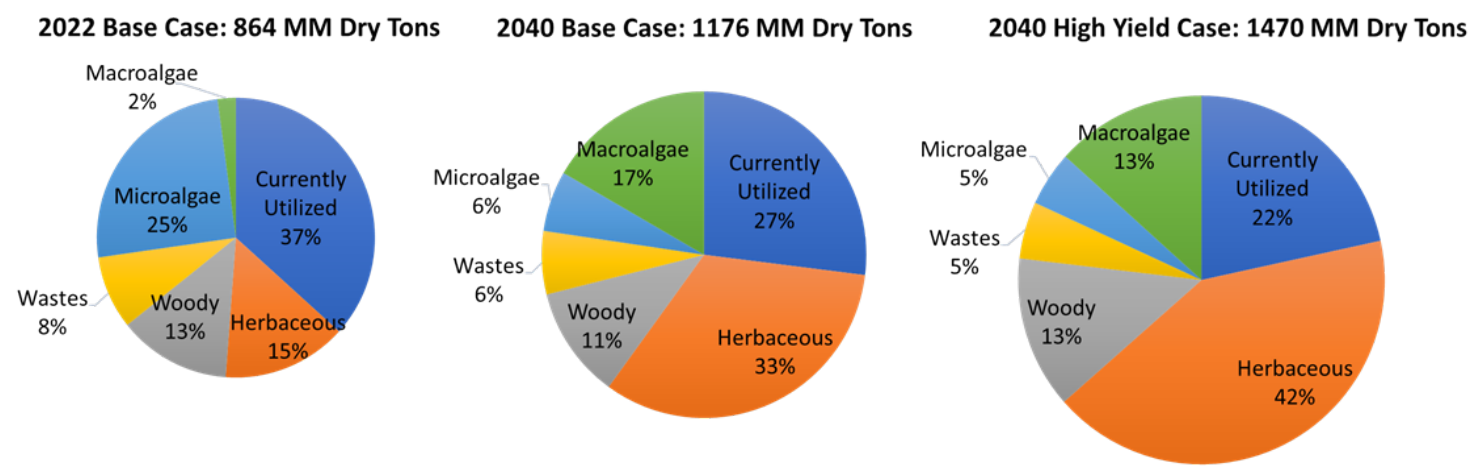

Figure 7. Summary of total feedstock contributions by scenario

All results presented for the median case

A summary of all feedstock availability over both the near-term (2022) and long-term (2040) scenarios is provided in Figure 8, highlighting that the largest projected increases in availability by individual feedstock type are for corn stover, switchgrass, miscanthus, and macroalgae. All data used to produce Figure 8 can be found in Appendix A.6. A similar summary of feedstock cost over the near-term and long-term scenarios is presented in Figure 9.

The feedstock cost evaluation strategy differs for non-algae and algae feedstocks. For non-algae feedstocks, the price was set at predetermined values as described in previous sections, regardless of the scenario. For example, the median price for corn stover was $\$ 99 /$ dry ton. BT16 determined that for $\$ 99 /$ dry ton in 2022, 58 million dry tons of corn stover is available. For the same cost of $\$ 99 /$ ton in 2040, 114 million dry tons of corn stover is available, with the long-term scenario availability typically greater than the near-term. However, for algae-specifically microalgae - the cost was not fixed at predetermined values. Instead, productivity projections were used for the near-term and long-term scenario, per the authors of BT16, to calculate algae availability and cost. For example, a 2022 algae cultivation productivity of $20 \mathrm{~g} / \mathrm{m}^{2} / \mathrm{d}$ may be assumed versus a 2040 projection of $40 \mathrm{~g} / \mathrm{m}^{2} / \mathrm{d}$, in either case assuming $\mathrm{CO}_{2}$ availability (as a feedstock for algal growth). Under that approach, algae availability and cost can then be derived. If, in this example, $\mathrm{CO}_{2}$ feedstock cost is equal for both cases, then more algae will be available at a lower cost in the longer-term scenario. For macroalgae, the cost is fixed like the terrestrial feedstocks, and availability changes over time. 


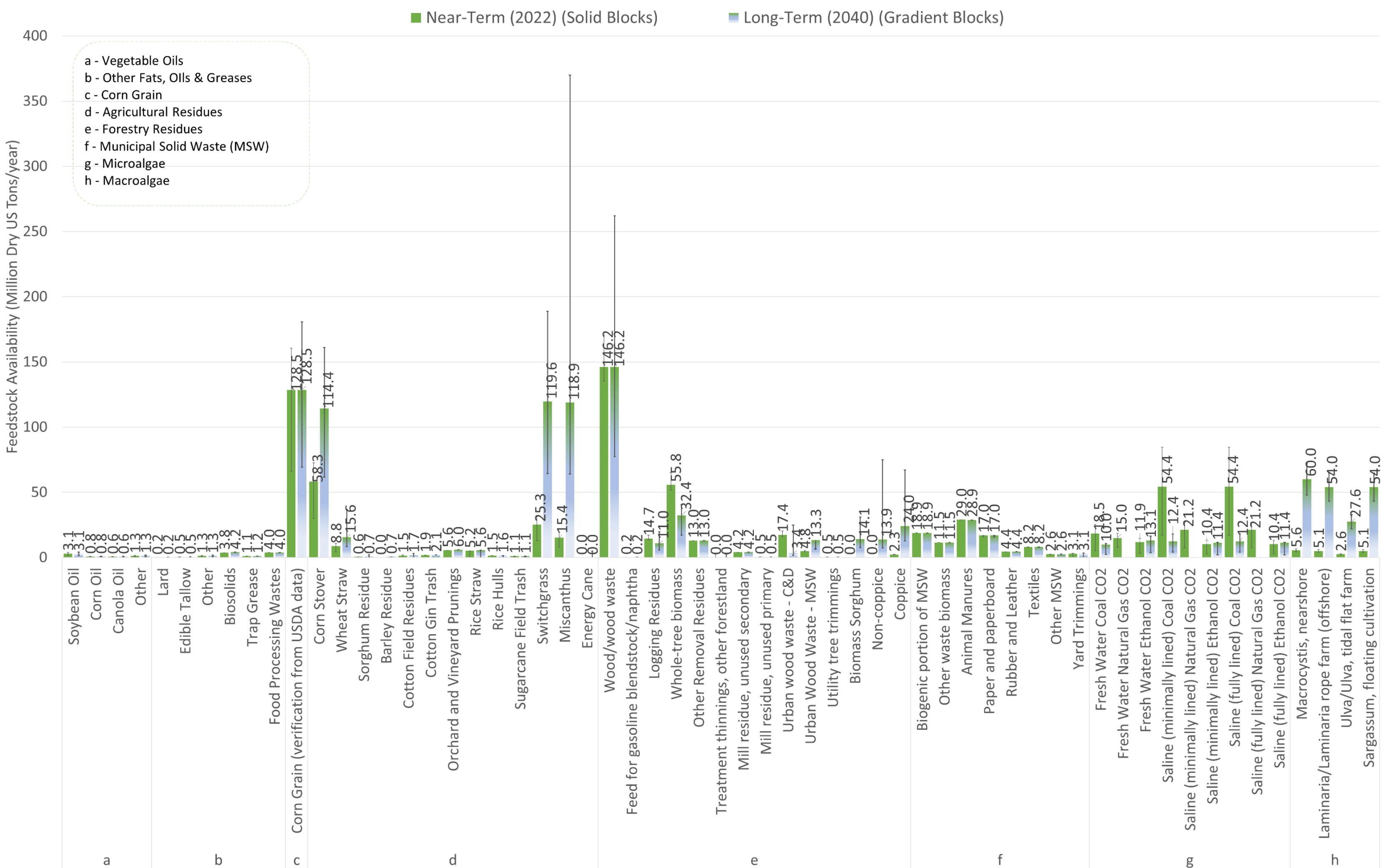

Figure 8. Summary of near-term (2022) and long-term (2040) feedstock availability by feedstock type

Solid bars show near-term availability and gradient bars show long-term feedstock availability. Error bars indicate the maximum and minimum feedstock availability for each feedstock. 


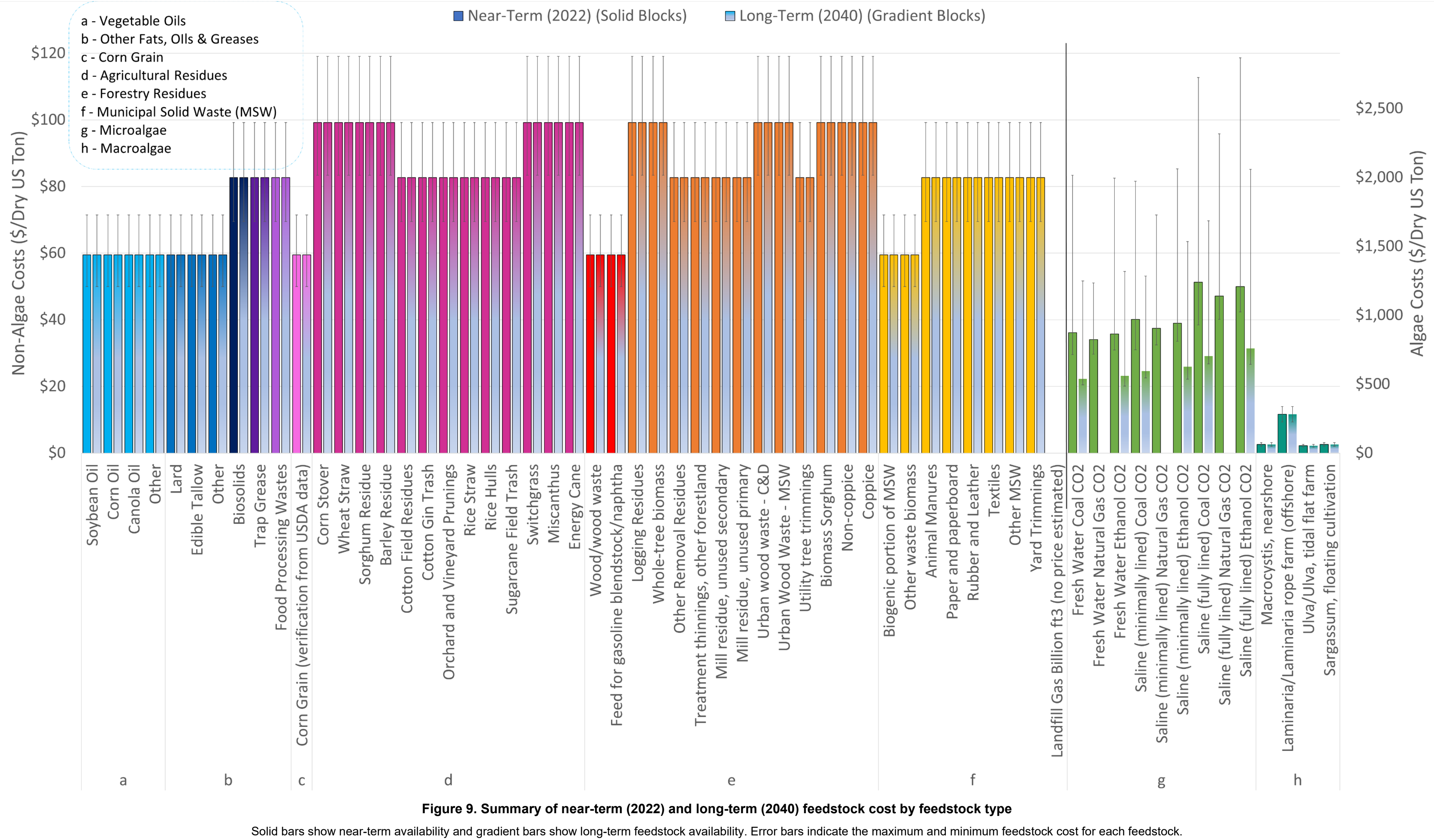




\subsection{Scalability Assessment and Future Work}

Domestic feedstock utilization for marine biofuel applications is highly dependent on feedstock availability. Other market forces could potentially compete for a share of the biomass feedstocks. Some of those markets include aviation fuels (Bell 2019; Tao, Milbrandt, et al. 2017), road vehicle fuels, and biobased plastics (Shen, Worrell, and Patel 2010). Feedstocks share with other biofuel markets will likely depend on biofuel cost and fuel type yield from each conversion technology (i.e., which fuel is most compatible with which market). Biobased plastics is a growing but relatively small market. Current data indicate about 2.1 million metric tons of global biobased plastic production in 2019, nearly a sixfold increase since 2007 ( 0.36 million metric tons globally in 2007) (Shen, Worrell, and Patel 2010; European Bioplastics 2020). Despite recent growth in the biobased plastic market, this sector's land use requirement was only about $1.6 \%$ of the biofuel's land use in 2019 (European Bioplastics 2020). With the continued increase in biomass availability through feedstock diversification and improved production and distribution methods projected by BT16 and outlined in this report, the coexistence of these two markets is likely feasible. The future pursuit of these works could include more detailed projections of competitive markets, coupled with modified biofuel production projections, to better understand how target biofuel and bioproduct production can be achieved across multiple sectors.

An additional consideration for large-scale utilization of domestic biomass is the co-development of conversion facilities. Domestic biomass potential may increase due to improved production, harvesting, and distribution technologies; consistent demand; and grower incentives from the biorefinery to the producer to maintain a supply. Additionally, large-scale deployment of these feedstocks and biorefineries needs to further consider the regional distribution of these products. Current biorefinery process designs are often limited in scale due to the regional availability of biomass to the biorefinery. Increasing daily throughput may be feasible if more feedstock can be delivered to a single biorefinery at lower economic and environmental burdens than is currently achieved. This increase could potentially lower fuel production costs due to the benefits of economies of scale; however, this would also introduce new logistical considerations at the biorefinery that would need to be considered, including feedstock delivery and storage (Argo et al. 2013; Muth et al. 2014; Lamers et al. 2015). Finally, future considerations may also include in-depth feedstock yield based on the carbon content of various feedstocks and feedstockspecific product slates to give a more detailed analysis of expected biofuel availability in the future.

\section{Biomass Conversion Technology Assessment}

This section reviews the existing biomass-to-fuel conversion technology analyses available in the public domain, largely leveraging the portfolio of conversion pathways developed under the U.S. Department of Energy's Bioenergy Technologies Office (BETO). BETO has focused on enabling the development of technologies to produce infrastructure-compatible, cost-competitive liquid hydrocarbon fuels from various feedstocks such as lignocellulosic biomass. The program portfolio is expanding to include research and development of advanced biofuels that will enable deploying a range of technologies to produce infrastructure-compatible hydrocarbon fuels. The crucial process performance metrics such as feedstock used, fuel yield, hydrocarbon product slate, carbon conversion efficiency, capital costs, and operating costs were gathered and used for 
the linear programing model for the biofuel production capacity and price projections in Section 4.

\subsection{Pathway Summaries and Comparison}

As not all reports used in this study were published in the same year, the costs were converted and normalized to the same cost year (2016), and performance metrics were normalized by equating fuel products to gasoline gallon equivalent (GGE). Once the data were compiled and harmonized, the economic and performance metrics were utilized in linear modeling, explained in detail in the next section. The biofuel production processes were segmented by their feedstock group into one of seven feedstock types for analysis in this section: (1) fats, oils, and greases; (2) corn grain; (3) lignocellulosic biomass; (4) microalgae; (5) wastewater sludge; (6) municipal solid waste; and (7) macroalgae.

The conversion pathways used in this study vary by feedstock type, conversion technologies, and product slates. The pathways also vary in market maturity. For example, sugar and starch crops treated by hydrolysis yielding sugars for fermentation to ethanol is a well-established industry with 17,378 million gallons of ethanol per year nameplate capacity in the United States as of January 2020 (U.S. EIA 2020b). On the other hand, there are technologies where limited commercialization has been attempted, or it is constrained to the bench scale because of the need for further technological advancement. Two of these technologies are hydrothermal liquefaction of wastewater sludge and fermentation of macroalgae.

Other pathways were explored but eliminated from this study early due to their final fuel not being usable for direct combustion (e.g., straight vegetable oil). According to DOE's Vehicle Technologies Office, using straight vegetable oil leads to reduced engine life because of the buildup of carbon deposits in the engine and the vegetable oil buildup in the engine lubricant. The selected biofuel production technologies used in this study are summarized in Table 10, including their feedstock types, conversion technologies, and final fuels. The corresponding pathways are summarized in Table 11. A detailed overview of the selected process design for each conversion technology with a summary of the feedstock, fuel distribution, assumed yields, and economic parameters are provided in Appendix B. 
Table 10. Pathway Conversion Technology Summary with Pathways Aligned by Feedstock and Processing Technology

\begin{tabular}{|c|c|c|c|c|c|}
\hline Feestock & Initial Processing & Fuel Precursor & Secondary Processing & Biofuel & Pathway \# \\
\hline \multirow{3}{*}{ Oil Crops } & \multirow{3}{*}{ Pressing/extraction } & \multirow{3}{*}{ Vegetable Oil } & Esterfication & Biodiesel (FAME) & 1 \\
\hline & & & $\begin{array}{l}\text { Hydroprocessed esters } \\
\text { and fatty acids (HEFA) }\end{array}$ & $\begin{array}{c}\text { Sustainable Aviation } \\
\text { Fuel (SAF) + Renewable } \\
\text { Diesel }\end{array}$ & $2,3,4,5$ \\
\hline & & & Direct & $\begin{array}{c}\text { Straight Vegetable Oil } \\
\text { (SVO) }\end{array}$ & N/A \\
\hline \multirow[b]{2}{*}{$\begin{array}{l}\text { Waste fat, oil, and grease } \\
\text { (FOG) }\end{array}$} & \multirow[b]{2}{*}{ Collection } & \multirow[b]{2}{*}{$\begin{array}{l}\text { Waste fat, oil, and } \\
\text { grease (FOG) }\end{array}$} & Esterfication & Biodiesel (FAME) & 6 \\
\hline & & & $\begin{array}{l}\text { Hydroprocessed esters } \\
\text { and fatty acids (HEFA) }\end{array}$ & $\begin{array}{c}\text { Sustainable Aviation } \\
\text { Fuel (SAF) + Renewable } \\
\text { Diesel }\end{array}$ & 7 \\
\hline Sugar/starch crops & Hydrolysis & Sugar & Fermentation & Ethanol, Butanol & 8 \\
\hline \multirow{18}{*}{ Lignocelluslosic Biomass } & \multirow{3}{*}{ Hydrolysis } & \multirow{3}{*}{ Sugar } & \multirow{3}{*}{ Fermentation } & Ethanol, n-Butanol & 9 \\
\hline & & & & Ethanol & 10 \\
\hline & & & & Isobutanol & 11 \\
\hline & Hydrothermal Liquefaction (HTL) & \multirow{4}{*}{ Bio-oil } & Catalytic refining & Renewable Diesel & 12 \\
\hline & Fast Pyrolysis & & Hydrotreating & Renewable Diesel & 13 \\
\hline & \multirow{2}{*}{ Catalytic Fast Pyrolysis CFP } & & $\begin{array}{c}\text { In Situ Catalytic } \\
\text { Upgrading }\end{array}$ & Renewable Gasoline & 14 \\
\hline & & & $\begin{array}{l}\text { Ex Situ Catalytic } \\
\text { Upgrading }\end{array}$ & Renewable Diesel & 15 \\
\hline & \multirow{11}{*}{ Gasification } & \multirow{11}{*}{ Syngas } & Catalytic Synthesis & $\begin{array}{c}\text { High-Octane Gasoline } \\
\text { (HOG) }\end{array}$ & 16 \\
\hline & & & Catalytic Synthesis & Methanol & 17 \\
\hline & & & Catalytic Synthesis & Methane, DME & 18 \\
\hline & & & Fischer-Tropsch (FT) & Renewable Diesel/SAF & $19,20,21$ \\
\hline & & & $\begin{array}{c}\text { Mobil olefines to } \\
\text { gasoline and distillates } \\
\text { (MOGD) }\end{array}$ & Renewable Gasoline & 22 \\
\hline & & & $\begin{array}{c}\mathrm{C} 2+\text { alcohols }+ \text { Guerbet } \\
\text { reaction }\end{array}$ & Renewable Diesel/SAF & 23 \\
\hline & & & $\begin{array}{c}\text { Syngas Fermentation + } \\
\text { Guerbet reaction }\end{array}$ & Renewable Diesel/SAF & 24 \\
\hline & & & $\begin{array}{c}\text { Oxygenates + Carbon } \\
\text { Coupling }\end{array}$ & $\begin{array}{l}\text { Sustainable Aviation } \\
\text { Fuel (SAF) }\end{array}$ & 25 \\
\hline & & & $\begin{array}{c}\mathrm{C} 2+\text { alcohols }+ \text { Carbon } \\
\text { Coupling }\end{array}$ & $\begin{array}{l}\text { Sustainable Aviation } \\
\text { Fuel (SAF) }\end{array}$ & 26 \\
\hline & & & $\begin{array}{c}\text { Catalytic Synthesis + } \\
\text { MtG }\end{array}$ & Gasoline & 27 \\
\hline & & & Mixed Alcohol Synthesis & Ethanol & 28 \\
\hline Micro Algae & Oil Extraction & Green Crude & Catalytic upgrading & Renewable Diesel & 29 \\
\hline \multirow{2}{*}{ Municipal Solid Waste (MSW) } & Hydrothermal Liquefaction (HTL) & Bio-crude & Catalytic refining & Upgraded Bio-oil & 30 \\
\hline & Anaerobic Digestion & Direct & $\mathrm{N} / \mathrm{A}$ & Methane & 31 \\
\hline \multirow{2}{*}{ Macro Algae } & Hydrolysis & Sugar & Fermentation & Ethanol, Butanol & $32,33,34,35$ \\
\hline & Anaerobic Digestion & Direct & N/A & Methane & 36 \\
\hline
\end{tabular}

Table 11. Pathway Numbering with Associated Names and Source Material Reference

\begin{tabular}{lll}
\hline $\begin{array}{l}\text { Pathway } \\
\#\end{array}$ & Pathway Name & Source Material \\
\hline 1 & $\begin{array}{l}\text { Biodiesel Production from Rapeseed Oil via Alkali } \\
\text { Catalysis }\end{array}$ & (Apostolakou et al. 2009) \\
\hline 2 & Jatropha Oil Crops to Jet via HEFA Process & (Tao, Milbrandt, et al. 2017) \\
\hline 3 & Camelina Oil Crops to Jet via HEFA Process & (Tao, Milbrandt, et al. 2017) \\
\hline 4 & Pennycress Oil Crops to Jet via HEFA Process & (Tao, Milbrandt, et al. 2017) \\
\hline 5 & Castor Bean Oil Crops to Jet via HEFA Process & (Tao, Milbrandt, et al. 2017) \\
\hline 6 & Waste Oil Production of Biodiesel via Esterification & (Marchetti, Miguel, and Errazu \\
\end{tabular}




\begin{tabular}{|c|c|c|}
\hline $\begin{array}{l}\text { Pathway } \\
\text { \# }\end{array}$ & Pathway Name & Source Material \\
\hline 7 & Yellow Grease to Jet via HEFA Process & (Tao, Milbrandt, et al. 2017) \\
\hline 8 & Corn Ethanol via Fermentation Using Dry Grinding & (Tao and Aden 2009) \\
\hline 9 & Corn Stover to Acetone-Butanol-Ethanol via Fermentation & (Tao, He, et al. 2014) \\
\hline 10 & $\begin{array}{l}\text { Lignocellulosic Biomass to Ethanol via Dilute-Acid } \\
\text { Pretreatment and Enzymatic Hydrolysis }\end{array}$ & (Humbird et al. 2011) \\
\hline 11 & Corn Stover to Isobutanol via Fermentation & (Tao, Tan, et al. 2014) \\
\hline 12 & $\begin{array}{l}\text { Woody Biomass to Liquid Hydrocarbons via Hydrothermal } \\
\text { Liquefaction }\end{array}$ & (Zhu et al. 2014) \\
\hline 13 & $\begin{array}{l}\text { Woody Biomass Fast Pyrolysis to Bio-Oil with Subsequent } \\
\text { Hydrotreating }\end{array}$ & (Jones et al. 2013) \\
\hline 14 & $\begin{array}{l}\text { Woody Biomass Catalytic Fast Pyrolysis with In Situ } \\
\text { Vapor Upgrading }\end{array}$ & (Dutta, Sahir, and Tan 2015) \\
\hline 15 & $\begin{array}{l}\text { Woody Biomass Catalytic Fast Pyrolysis with Ex Situ } \\
\text { Vapor Upgrading }\end{array}$ & (Dutta, Sahir, and Tan 2015) \\
\hline 16 & Woody Residue to High-Octane Gasoline via Gasification & (Tan et al. 2020) \\
\hline 17 & Woody Residue to $\mathrm{MeOH}$ via Gasification & This study \\
\hline 18 & Woody Residue to DME via Gasification & This study \\
\hline 19 & Woody Residue to Jet via Fischer-Tropsch Synthesis & (Tan and Tao 2019) \\
\hline 20 & Wood Chips to Jet via Gasification and Fischer-Tropsch & (Zhang et al. 2018) \\
\hline 21 & $\begin{array}{l}\text { Woody Biomass to Hydrocarbon Fuels via Gasification } \\
\text { followed by Fischer-Tropsch Synthesis }\end{array}$ & (Tan et al. 2017) \\
\hline 22 & $\begin{array}{l}\text { Woody Biomass via Gasification to Methanol Upgraded to } \\
\text { Olefins and then to Gasoline }\end{array}$ & $\begin{array}{l}\text { (Tan, Snowden-Swan, and } \\
\text { Talmadge 2015) }\end{array}$ \\
\hline 23 & $\begin{array}{l}\text { Woody Biomass to Hydrocarbon Fuels via Gasification } \\
\text { Upgraded via Alcohol Condensation and Oligomerization }\end{array}$ & (Tan et al. 2017) \\
\hline 24 & $\begin{array}{l}\text { Woody Biomass to Hydrocarbon Fuels via Gasification } \\
\text { Upgraded by Syngas Fermentation and Alcohol } \\
\text { Condensation plus Oligomerization }\end{array}$ & (Tan et al. 2017) \\
\hline 25 & $\begin{array}{l}\text { Woody Biomass to Hydrocarbon Fuels via Gasification } \\
\text { Upgraded via Carbon Coupling and Oligomerization }\end{array}$ & (Tan et al. 2017) \\
\hline 26 & $\begin{array}{l}\text { Woody Biomass to Hydrocarbon Fuels via Gasification } \\
\text { Upgraded via Syngas Fermentation and Carbon Coupling } \\
\text { plus Oligomerization }\end{array}$ & (Tan et al. 2017) \\
\hline 27 & $\begin{array}{l}\text { Woody Biomass to Hydrocarbon Fuels via Gasification } \\
\text { and Methanol-to-Gasoline Technologies }\end{array}$ & (Phillips et al. 2011) \\
\hline 28 & $\begin{array}{l}\text { Lignocellulosic Biomass to Ethanol via Gasification and } \\
\text { Mixed-Alcohol Synthesis }\end{array}$ & (Dutta et al. 2011) \\
\hline 29 & Algae and $\mathrm{CO}_{2}$ to Diesel via Combined Algal Processing & $\begin{array}{l}\text { (Davis et al. 2016; Davis et al. } \\
\text { 2014) }\end{array}$ \\
\hline 30 & $\begin{array}{l}\text { Diesel from Wastewater Sludge Converted to Bio-Oil and } \\
\text { Catalytically Upgraded }\end{array}$ & $\begin{array}{l}\text { (Seiple, Coleman, and Skaggs } \\
\text { 2017; Snowden-Swan et al. 2017) }\end{array}$ \\
\hline
\end{tabular}




\begin{tabular}{|c|c|c|}
\hline $\begin{array}{l}\text { Pathway } \\
\text { \# }\end{array}$ & Pathway Name & Source Material \\
\hline 31 & $\begin{array}{l}\text { Municipal Solid Waste Upgraded to Biogas via Anaerobic } \\
\text { Digestion for Use in Natural Gas Vehicles }\end{array}$ & (Rajendran et al. 2014) \\
\hline 32 & Ethanol Production from Fermentation of Macroalgae & (Konda et al. 2015) \\
\hline 33 & $\begin{array}{l}\text { Ethanol and Electricity Production from Fermentation of } \\
\text { Macroalgae }\end{array}$ & $\begin{array}{l}\text { (Soleymani and Rosentrater } \\
\text { 2017) }\end{array}$ \\
\hline 34 & Ethanol Production from Fermentation of Seaweed & (Roesijadi et al. 2010) \\
\hline 35 & Macroalgae to Biogas via Anaerobic Digestion & (Dave et al. 2013) \\
\hline 36 & Macroalgae Waste to Ethanol via Fermentation & (Chong et al. 2020) \\
\hline
\end{tabular}

\subsubsection{Feedstock Cost Assumption}

Each technology pathway used in this study has an assumed feedstock cost except Pathway 34, which fixed the minimum fuel selling price (MFSP) and varied the feedstock cost of brown seaweed. This was done to determine the minimum feedstock cost required for the technology to be profitable. Figure 10 shows the assumed feedstock cost for each conversion pathway, as originally reported in the source materials. Note that these are not the feedstock costs used in the linear modeling in Section 4. The linear modeling uses the feedstock costs obtained in Section 2.

Attributed to the category of fats, oils, and greases, Pathways 1-7 exhibit a much higher feedstock cost than the other pathways. The oils in the fats, oils, and greases feedstock category are more expensive than other feedstocks because they tend to be grown from oil crops, and the oil must be extracted after being grown (Evangelista, Isbell, and Cermak 2012). The oil extraction concentrates the oils and then allows for a high-conversion yield of the oils to fuel products, reflected in Figure 11.

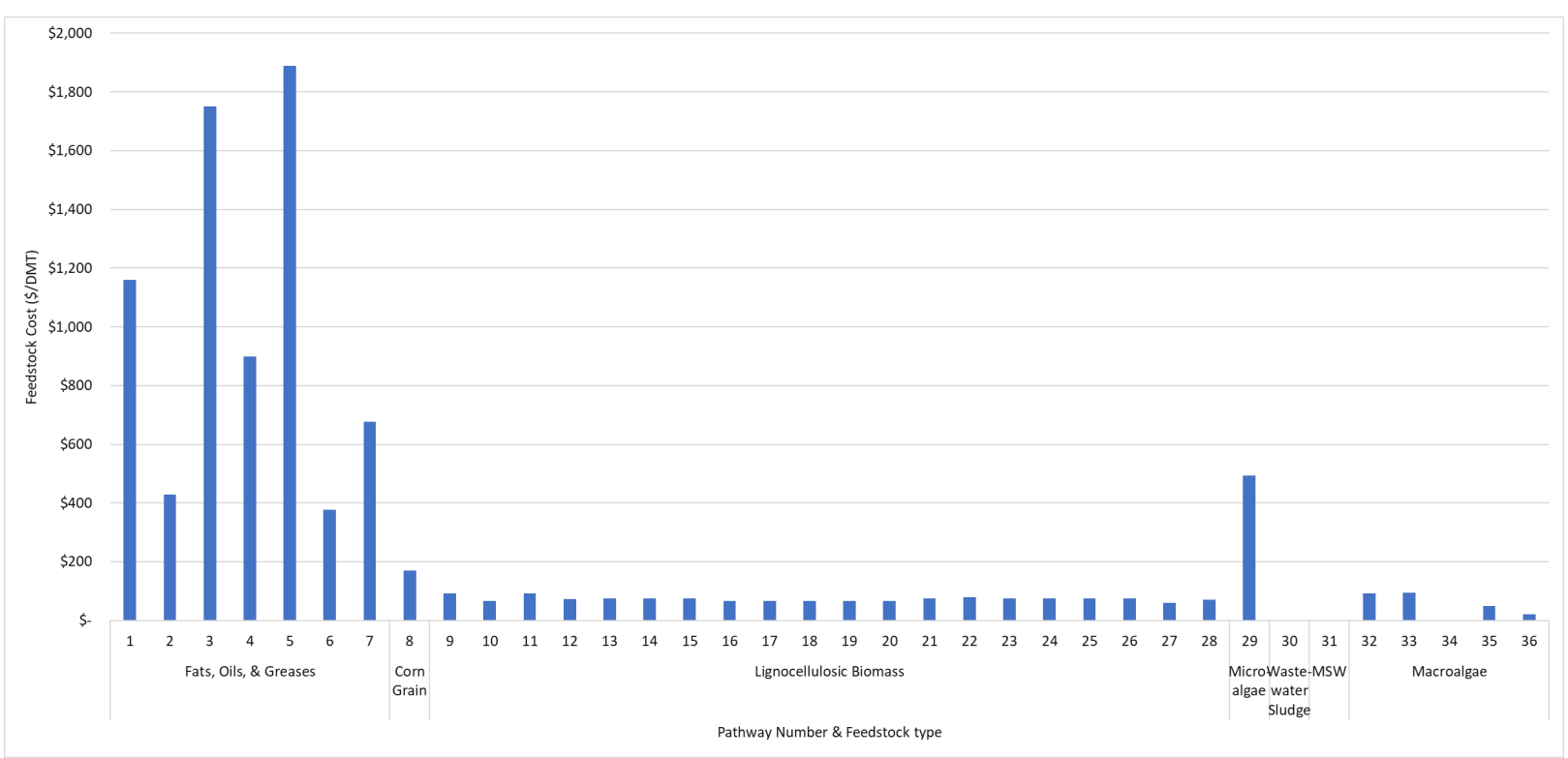

Figure 10. Feedstock cost assumptions used in the source material for each pathway 
Corn grain also has a higher relative feedstock cost and is more expensive because of high labor costs, large water requirements, and high herbicide and nitrogen requirements to grow and harvest the corn grain (Pimentel and Patzek 2005).

Microalgae rounds out the feedstocks with high costs. Microalgae is relatively more expensive because of the "farming" system requiring substantially higher costs to construct and operate cultivation ponds compared to terrestrial crop production on farmed land (Davis et al. 2016). The algae cultivation productivity rate has the most significant influence on the biomass cost, with small increases in productivity translating to potentially large reductions in feedstock cost. In turn, microalgae feedstock cost greatly impacts the resultant plant-gate price of biofuels (Davis et al. 2016).

All the terrestrial lignocellulosic biomass pathways fall within a narrower window of feedstock costs. The majority of the lignocellulosic biomass conversion pathways (Pathways 9-28) reflect BETO's portfolio using the feedstock costs determined by the program.

The other major feedstock groups associated with the conversion pathways are wastewater sludge, the organic fraction of MSW, and macroalgae. Pathway 30 utilizes wastewater sludge as the feedstock, with an assumed price of $\$ 0$ per dry metric ton (DMT). Currently, wastewater treatment facilities producing wastewater sludge incur an expense to dispose of it. The assumption is by reducing the expense to zero and utilizing the sludge for biofuel production is mutually beneficial. Therefore, biofuel production facilities would incur no cost for the sludge (Seiple, Coleman, and Skaggs 2017).

Pathway 31 utilizes the organic fraction of MSW as the feedstock, which has an assumed cost of \$0/DMT. About 2.5 billion tons per year of MSW is generated worldwide, with approximately $50 \%$ organic material. The MSW is placed in dumping areas or landfills that incur transportation costs, decrease the usable land, cause health implications, and loses the potential energy in the MSW (Rajendran et al. 2014). By avoiding the land displacement and health implications and utilizing the energy content, it is assumed that the organic fraction of the MSW could be obtained for \$0/DMT. Though there is still the cost incurred for transporting the MSW to the biorefinery, this is assumed to be paid for by the party needing to dispose of the waste, as opposed to the biorefinery. This was explored more as a sensitivity analysis, which will be discussed in Pathway 31's details in Appendix B.

Pathways 32-36 utilize macroalgae as the feedstock with varying assumptions for the cost. As noted previously, Pathway 34 assumed an MFSP and varied the feedstock cost. The resulting feedstock cost was determined to be \$0.08/DMT, which is deemed not practical (Roesijadi et al. 2010). This approach of back-calculating the feedstock cost was to understand what technology area(s) are most in need of improvement, namely feedstock production or conversion. This will be explored more in Pathway 34's details in Appendix B.

The price varied from \$20/DMT to \$90/DMT for the other macroalgae feedstocks. The low end is assumed for Pathway 36, which utilizes a macroalgae residue, a byproduct of the $\kappa-$ carrageenan production process. The food-grade $\kappa$-carrageenan is derived from red macroalgae. Because of the residue's avoided disposal cost, it is assumed that the feedstock can be obtained at a relatively low price (Chong et al. 2020). It should be noted that the food-grade $\kappa$-carrageenan 
market is limited in growth potential. Therefore, this process is not expected to have a large impact on future biofuel production but is included to demonstrate the possibility of using other industries' waste as a feedstock. The higher macroalgae feedstock costs (around \$90/DMT) were taken from the lignocellulosic biomass cultivation with the lack of an established brown macroalgae market and growth required for infrastructure in the areas of cleaning, drying, shredding, transportation, storage, and delivery

\subsubsection{Production Yield and Scale}

This section explores the process yields and production capacity of the conversion technologies used in this study. As with any conversion technology, the production yield varies by the state of technology, generally improving over time; the efficiency of the catalysts and enzymes; and optimization of process conditions. The process yield also depends on the conversion pathway's inherent limits.

As shown in Figure 11, the production yield and scale vary for all studies, with fats, oils, and greases (Pathways 1-7) having high production yields and relatively low capacities. In contrast, the remainder has a high production scale with a lower relative production yield. The scale refers to the plant size (i.e., the specified amount of feedstock being processed) and is expressed in dry metric tons per day.

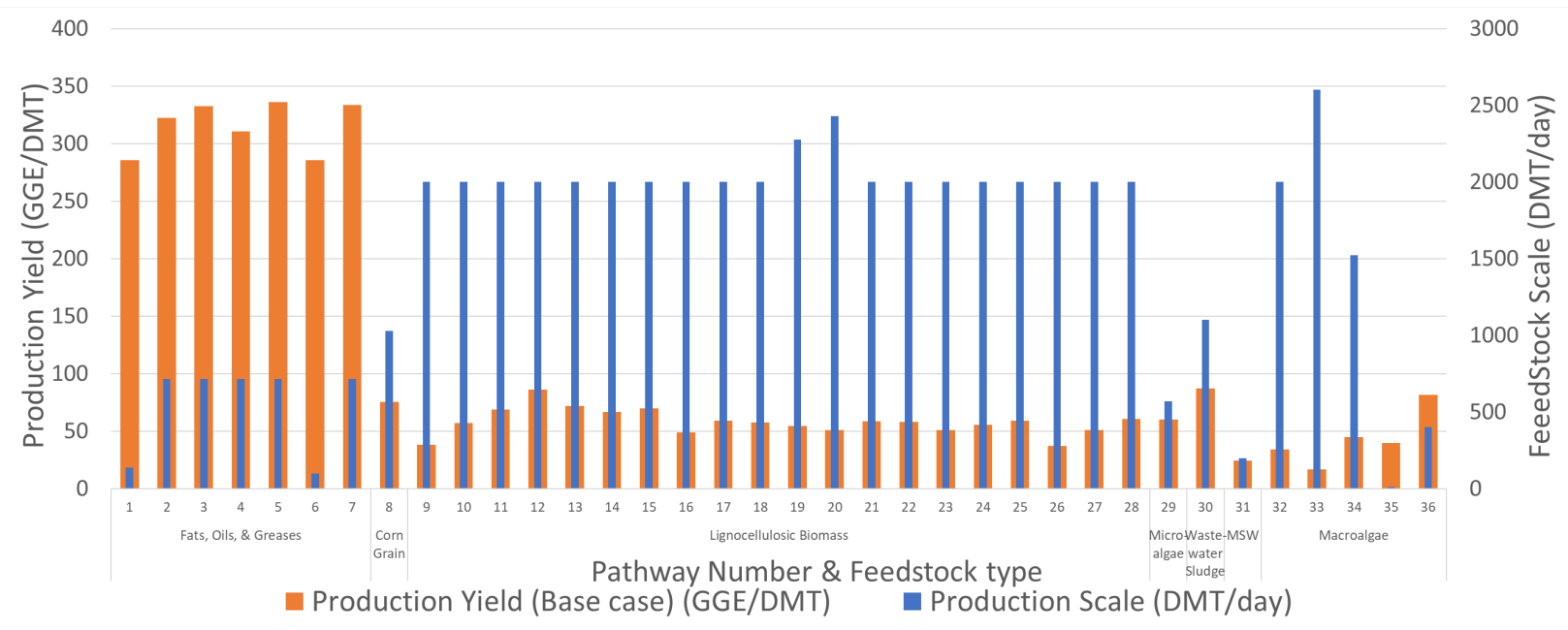

Figure 11. Production yield and production scale for screening conversion technologies

Fats, oils, and greases utilize a feedstock that is either waste or comes from oil crops and has the oil extracted before being processed in the facility. These feedstocks are very similar to fuels, consisting of oxygenated hydrocarbon chains that are liquids at room temperature and exhibit similar properties to higher-carbon-number and higher-boiling-point distillate fuels. This allows for easy conversion to distillate-range fuels (diesel, jet, and gasoline) through established technologies used in the petroleum industry like hydrogenation and hydrocracking, both of which are explained in Appendix B. These technologies allow for little waste from the process, converting over $90 \%$ of the incoming feedstock carbon into distillate-range fuels. The byproducts from these processes are often short-chained hydrocarbons like propane and butane that can be collected and burned on site for combined heat and power (CHP) generation, decreasing the energy required from local sources. The ability to convert that high percentage of 
incoming feedstock to distillate-range usable fuels gives these technologies their high production yield. These technologies' production scales were lower than the other technologies, likely due to feedstock availability constraints (see Figure 8). However, if feedstock availability is not a constraint, this technology (Pathways 1-7) has the potential to scale much higher than the lignocellulosic production scales studied here. For example, in August 2020, Phillips 66 announced they were in the process of reconfiguring a petroleum refinery to a biorefinery to convert used fats, oils, greases, and soybean oil to distillate-range fuels (Phillips 66 2020). When the plant is brought online in 2024, it is expected to produce up to 800 million GGE per year; assuming a similar production yield as Pathways 2-5 (which utilize oil crops and fats, oils, and greases as the feedstock), this is the equivalent of processing 2.7 million dry U.S. tons per year. As noted in the previous section, the United States' oil crops and fats, oils, and greases production is capped at about 7.2 million dry U.S. tons per year (median projection for 2022 in Section 2). This would mean that Phillips 66 would utilize just over one-third of all potentially available feedstock in the United States.

The conversion of corn grain used in this study (Pathway 8) was based on a dry milling technique used in over $80 \%$ of ethanol plants in the United States (Tao and Aden 2009). The production scale was assumed based on a production rate of 45 million gallons of ethanol per year, correlating to just over 1,000 DMT per day with a production yield of $75 \mathrm{GGE} / \mathrm{DMT}$. This production scale was chosen to represent a theoretical plant in the United States that falls within the range of corn grain ethanol facilities, producing between $0.75-313$ million gallons per year with an average of 77 million gallons per year as of June 2018, according to the Nebraska Department of Environment and Energy (2020).

The lignocellulosic biomass conversion technologies used in this study were mainly based on a scale of 2,000 DMT per day. This figure is the baseline assumption for BETO's conceptual lignocellulosic biomass conversion pathways considered under $\mathrm{n}^{\text {th }}$-plant techno-economic analyses. Oak Ridge National Laboratory and NREL jointly performed a rigorous study that took into account the increased feedstock transportation costs associated with a larger collection radius and the economy-of-scale advantages derived from increased plant capacity and determined that the optimal cellulosic ethanol plant size is 2,000 DMT/day (Tan et al. 2017). Additionally, recent studies on biochemical and thermochemical biorefinery capacity revealed cost advantages that support larger biorefineries up to 10,000 DMT/day when adopting advanced feedstock logistic supply systems that include depots and preprocessing operations (Argo et al. 2013; Muth et al. 2014). The studies demonstrated that the economies of scale enabled by advanced logistics offset much of the added logistics costs from additional depot processing and transportation; the ability to mitigate moisture and ash in the system will improve the storage and conversion processes. Additionally, utilizing feedstocks from further distances will alleviate the risk of biomass supply to the conversion facility. More in-depth consideration for biorefinery sizing is beyond the scope of this study.

The conversion yields for the lignocellulosic biomass feedstock cases varied from 37-86 GGE per DMT. The low-end conversion technology converted woody biomass to distillate-range fuels by syngas fermentation, carbon coupling, oligomerization, and hydrogenation (Pathway 26). The high-end conversion technology converted woody biomass to distillate-range fuels via hydrothermal liquefaction (Pathway 12). Details on these technologies' production yields are not 
discussed here, as the assumptions and metrics for conversion are discussed in each pathway's detailed description (Appendix B).

Microalgae conversion assumed a feedstock flow rate of 570 DMT per day (Pathway 29). This production scale was determined from source material analysis that found 5,000 wetted acres for microalgae production was optimal. This is smaller than previous studies of 10,000 wetted acres, as the larger scale was assumed to present too many logistical and siting challenges.

Additionally, a smaller production scale at 1,000 wetted acres was found to increase the feedstock (microalgae) cost by up to $\$ 100$ per U.S. ton; as mentioned in the previous section, microalgae is a relatively higher-cost feedstock than others in this study. The production yield for microalgae conversion was approximately 60 GGE per DMT. Alternative processing approaches have also been evaluated that could increase the fuel yield up to 90 GGE per DMT or higher. The current upgrading strategy (Pathway 29) separates lipids, carbohydrates, and proteins for separate upgrading, whereas a more recent conceptual strategy may allow for co-upgrading proteins and carbohydrates (Davis et al. 2020). This theoretical study was published after the start of this study and was therefore not used in the modeling.

Wastewater sludge assumed a production scale of 1,100 DMT per day and a yield of $87 \mathrm{GGE}$ per DMT. Because of the distributed nature and high moisture content of wastewater sludge, its shipping costs can be high. To avoid the high shipping costs for the wastewater sludge, the proposed technology used 10 separate wastewater treatment plants operating at $110 \mathrm{DMT} /$ day to convert wastewater sludge to biocrude, sourcing their wastewater from local areas generally serving about 1.3 million people (Pathway 30 ). The biocrude was subsequently shipped to a central processing plant for upgrading to distillate-range fuels. All the wastewater treatment plants were assumed to be within a 100-mile radius of the biocrude upgrading plant. An economic sensitivity analysis determined this to be the most reasonable configuration for several of the most densely populated regions of the United States; however, it was noted that for the largest plants in the United States, it could be feasible to have one or two plants feeding biocrude to the upgrading facility. The yield of 87 GGE per DMT was based on laboratory experiments performed at PNNL (Snowden-Swan et al. 2017).

Additionally, the pathway model represented a target case for the technology with slightly higher yields than currently proven, but which are expected to be achieved by 2022. Because this technology was based on laboratory yields and not a pilot or commercial scale, the technology maturity of converting wastewater sludge via hydrothermal liquefaction (HTL) scored low, as shown in Figure 11. Comparatively, this HTL pathway has a higher conversion to fuel because of lower $\mathrm{CO}_{2}$ carbon losses from the technology and slightly higher carbon content in the feedstock than lignocellulosic biomass.

In this study, the MSW conversion using anaerobic digestion of the organic fraction (Pathway 31) was assumed to be slightly less than 200 DMT per day feed and a conversion yield of 25 GGE per DMT. The study looked to understand the MFSP of the biogas for a city of just over 100,000 people who would use the biogas both to power vehicles within the city and in marine applications. It was assumed that the city produced $55,000 \mathrm{~m}^{3}$ of organic MSW and an assumed density of $1,200 \mathrm{~kg} / \mathrm{m}^{3}$, resulting in just under 200 DMT per day. The conversion yield to biogas was calculated to be about 25 GGE per DMT. This was based on $9,600-\mathrm{m}^{3} /$ day biogas produced, and an assumed biogas energy density of 65 British thermal units (Btu) per U.S. gallon. The 
relatively low yield compared to other technologies is largely attributed to the fact that during anaerobic digestion, only about $70 \%$ of the incoming carbon goes to methane, while the remainder goes to carbon dioxide. Additionally, the low energy density of methane compared to distillate-range fuels contributes to this lower conversion yield.

Macroalgae processes' scales and yields varied considerably across the explored conversion technologies considered in this study (Pathway 32-36). On the low end, production scale and yield were at 9 DMT per day and 16 GGE per DMT, respectively. On the high end, the scale and yield were at 2,600 DMT per day and 82 GGE per DMT, respectively. The conversion technology for macroalgae generally fell into fermentation, anaerobic digestion, or a combination of the two. The fermentation processes were largely based on the corn stover fermentation to ethanol design report represented by Pathway 10, substituting macroalgae for corn stover. Using the lignocellulosic biomass fermentation pathway (Pathway 10) as the design basis, the scale and conversion yield for the fermentation of macroalgae for Pathways 32, 34, and 36 are similar, with slight variances due to ash and moisture content. The anaerobic digestiononly route (Pathway 35) sources its conversion yield from literature at 40 GGE per DMT. Pathway 25 had a much lower production scale than other macroalgae pathways due to the higher assumed water content upon entering the biorefinery $(90 \%$ moisture, versus $10 \%$ moisture after drying assumed in other pathways) and because the location of macroalgae cultivation was in the North Atlantic, which limited the cultivation season due to temperature variations. The combined fermentation and anaerobic digestion pathway (Pathway 33) had a conversion yield of 16.44 GGE per DMT, much lower than other pathways. The lower conversion yield is because the biogas produced in this study was used for on-site CHP, and the calorific production was not disclosed. Due to this, only ethanol yield was used in the calculation for production yield.

Overall, various conversion technologies allow for different feedstock types, giving rise to different yields and scales. The scale can depend on many factors such as feedstock availability and growth constraints, feedstock collection constraints, proven scalability of the technology, and desired energy production for the end user. Conversion yields also vary greatly depending on feedstock types, technology classes, biological agent conversion efficiencies, catalyst efficiencies, and other factors.

\subsubsection{Product Distribution}

The selected conversion technologies produce a range of different fuels. The majority of the evaluated pathways produce gasoline and distillate-range fuels (jet and diesel fuel). Other biofuels considered include methanol, ethanol, butanol, and dimethyl ether (DME). Furthermore, there are pathways that produce fuels that need to be used in specific engines designed for them, like propane or biogas; biogas can also be upgraded to enrich the methane content and compressed to renewable natural gas. In this study, both jet- and diesel-range biofuels are collectively referred to as marine biofuels and all biofuels have the potential to be used for marine shipping.

The fuel produced depends on multiple factors, including feedstock type, process operation, operating conditions, and upgrading strategies used. For example, the hydroprocessed esters and fatty acids (HEFA) conversion route primarily for the fats, oils, and greases feedstock group produces gasoline, jet, and diesel fuel. The HEFA pathway can be tailored to produce more diesel fuel or more jet fuel depending on operating conditions. 
Figure 12 shows the product distribution for the different conversion technologies segmented by various feedstock groups. As mentioned, the fats, oils, and greases feedstock produce mainly gasoline-, jet-, and diesel-range fuels. One key conversion technology used for these feedstocks is the HEFA pathway, allowing hydrocracking of the larger fatty acids and esters followed by hydrogenation, producing fuels in the jet range with a byproduct being gasoline. The exceptions in this feedstock group are Pathway 1 and Pathway 6, which convert the fats, oils, or greases into biodiesel, defined as monoalkyl esters of long-chained fatty acids. Biodiesel differs from traditional petroleum diesel or renewable diesel in that it contains oxygen in the fuel molecules instead of just hydrogen and carbon. Although this limits the biodiesel produced from this pathway from being directly hydrocracked into the jet fuel range without other process steps, it is suitable for marine shipping.

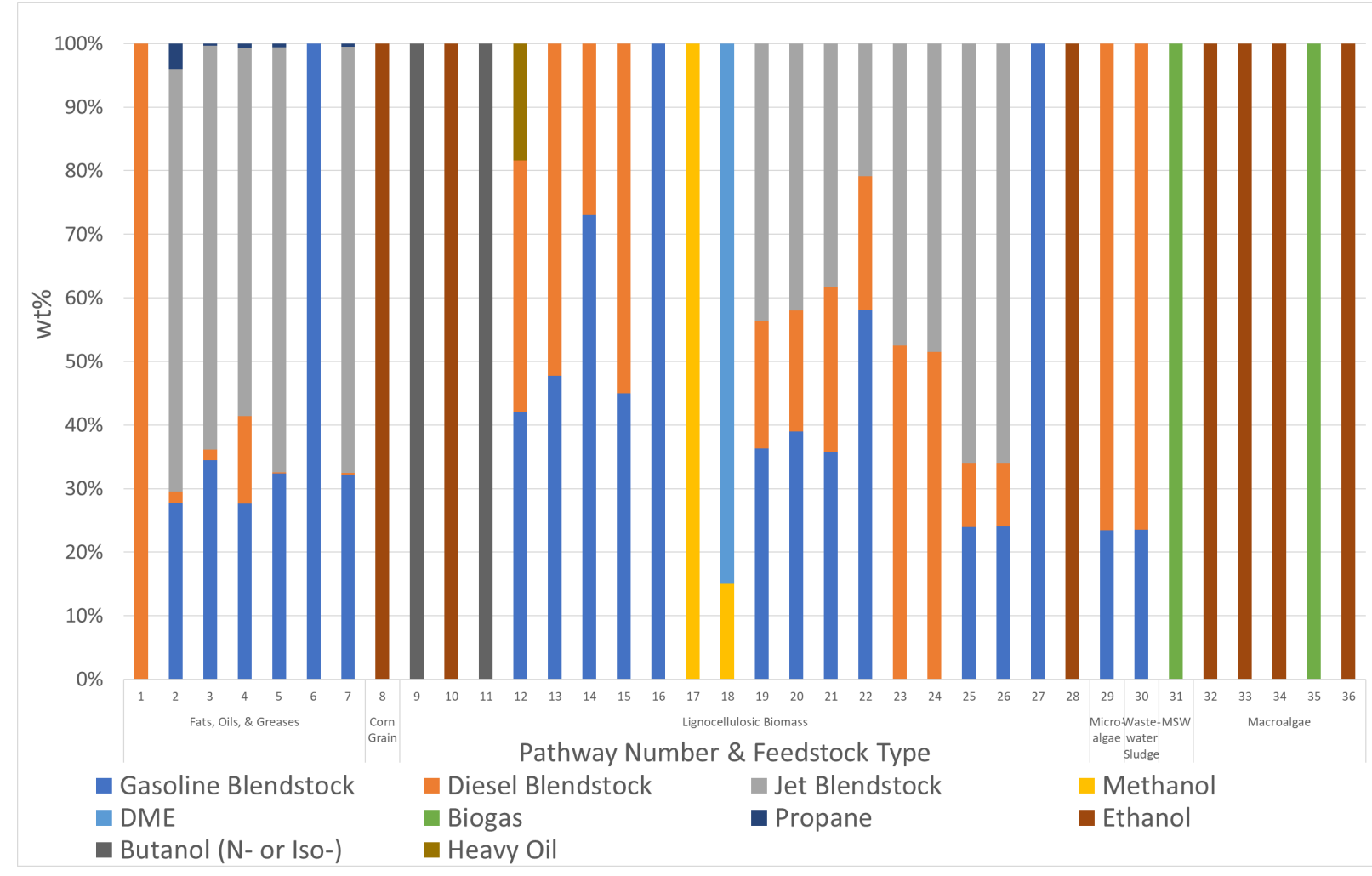

Figure 12. Product distribution for different conversion technologies used in this study, segmented by feedstock type.

Corn grain conversion (Pathway 8) produces 100\% ethanol as its fuel, as seen in Figure 12. The conversion of corn grain to ethanol utilizes yeast (strain depending on specific biorefinery) in the fermentation process. Corn grain ethanol production in the United States is currently used for blending applications into gasoline fuels and is approximately a 14-billion-gallon market as of 2019 (U.S. EIA 2021a).

Lignocellulosic biomass conversion routes produce a variety of fuels, including gasoline, butanol, diesel, and heavy oil. Pathways 9, 10, and 11 produce butanol and ethanol through fermentation using different microorganism strains and subsequent purification. Both ethanol and butanol are used as blends in petroleum gasoline in the United States. They are approved for blends up to $10 \%$ and $12.5 \%$ by volume, respectively, with ethanol approved for gasoline blends 
up to $15 \%$ by volume for use in cars model year 2001 and newer. Pathways $12-15$ produce varying amounts of gasoline and diesel fuels, with Pathway 12 producing a small amount of heavy oil. These pathways utilize HTL, fast pyrolysis, and catalytic fast pyrolysis as their conversion routes, producing either biocrude, bio-oil, or pyrolysis-oil intermediates that are then upgraded to distillate fuels using a combination of deoxygenation and hydrogenation upgrading techniques. Note that pyrolysis bio-oils and HTL biocrude derived from various feedstocks and without upgrading can be blended with HFO for marine shipping (Kass et al. 2020). The upgraded diesel-range renewable diesel can be used as marine diesel. Pathways 16-18 use the same conversion technology. Pathway 16 converts the biomass all the way to gasoline (highoctane gasoline). Methanol and DME can be produced via Pathway 17 and Pathway 18, respectively. In addition to DME, Pathway 18 also produces methanol as a coproduct. The highoctane gasoline contains similar hydrocarbons to petroleum gasoline and can be blended with gasoline for use in spark-ignition engines. However, because the process has not been scaled up, this has not been used in the market. In the past, DME has been used in blends with diesel fuel, and methanol has been used in blends with petro-gasoline for use in spark-ignition engines (ASTM International 2018). Pathways 19-27 produce varying amounts of gasoline, jet, and diesel fuel by producing syngas intermediate and using different upgrading technologies. The technologies are described in detail in Appendix B. Pathway 28 produces ethanol and higher alcohols suitable for gasoline blending or further upgrading to jet- and diesel-range fuels.

The microalgae pathway (Pathway 29) uses fermentation to make succinic acid (sold as a coproduct). The remaining stillage consisting of the lipids is converted to a raw oil for deoxygenation and hydrogenation upgrading. The distribution of gasoline to diesel is dependent on the operating conditions used for the oil upgrading, and therefore could be altered by exchanging catalysts or running at different temperatures or pressures; the study chose operating conditions to maximize GGE yield from the feedstock.

Wastewater sludge was converted using HTL, like Pathway 12, producing a bio-oil intermediate for deoxygenation and hydrogenation upgrading to distillate-range products. The upgrading process conditions can be altered to change the fuel distribution; however, this study used a distribution similar to those expected from hydrotreating petroleum.

MSW and macroalgae utilize either fermentation or anaerobic digestion, as mentioned in the previous section. Like corn grain fermentation, ethanol is the main target product of macroalgae's fermentation process (Pathways 32, 33, and 36). It should be noted that there are technologies to convert ethanol up to distillate-range fuels and are presented in this study in Pathways 23-26, as well as in other work (Tao, Markham, et al. 2017; Geleynse et al. 2018; Yao et al. 2017). Anaerobic digestion (Pathway 35) creates a mixture of methane and carbon dioxide, also known as biogas. Biogas can be further upgraded by removing the carbon dioxide to produce renewable natural gas for use in natural gas vehicles.

\subsubsection{Minimum Fuel Selling Price}

All conversion pathway metrics discussed thus far-feedstock cost, production scale and yield, and product distribution - affect the MFSP, which is the price required to obtain a zero net present value with a finite internal rate of return (IRR), as described in Section 4. MFSP can be used to assess the cost-competitiveness and market penetration potential of biofuels compared to benchmark fuel products. The MFSP presented here does not consider any policy factors such as 
carbon credits or premium values of certain biofuels that may be attributed to premium fuel properties. As each biofuel has different energy density, the MFSP is normalized and based on GGE. Note that 1 GGE is equal to 116,090 Btu/gal (Argonne National Laboratory 2016). Additionally, all costs are in 2016 U.S. dollars.

Figure 13 shows the MFSP for all the pathways. The cost contribution to MFSP includes feedstock, operating expenses, coproduct credits, capital expenses, and taxes. For conversion technologies utilizing fats, oils, and greases, the MFSP varies from $\$ 2.30 / \mathrm{GGE}$ to $\$ 10.32 / \mathrm{GGE}$. The extensive range of MFSPs is due to the varying feedstock contributions. For instance, Pathway 3 using camelina oil has a high feedstock cost, contributing $\$ 9.01 / \mathrm{GGE}(87 \%)$ to the overall cost. Camelina oil is more expensive than other oils because it is high in omega-3 fatty acids, which have perceived health benefits, causing competition for the oil from the food sector. However, Pathway 6 has a low feedstock contribution, at only $\$ 1.35 /$ GGE $(59 \%)$ of the overall MFSP. Pathway 6 utilizes waste oils, which within this study were shown to cost less than oil from oil crops. All the fat, oil, and grease technologies had comparable cost contributions from the operating, capital, and tax expenses. All had minimal coproduct credit contributions except for Pathway 6, which sells glycerol as a coproduct for a credit of \$2.5 million per year. Glycerol is a byproduct of the biodiesel production process, which within this feedstock group is only produced in Pathway 1. Glycerol was not sold as a coproduct for credits due to its low value at the time of the study. Overall, the high feedstock cost of the fats, oils, and greases group contributes to their higher overall MFSP compared to the lignocellulosic biomass group.

Corn grain conversion (Pathway 8) to ethanol's MFSP also has a high contribution from feedstock prices, accounting for $\$ 1.91 / \mathrm{GGE}(79 \%)$ of the $\$ 2.41 / \mathrm{GGE}$ MFSP. This is slightly offset by the sale of distillers dried grains sold as a fertilizer for $\$ 15.5$ million per year, or $\$ 0.50 /$ GGE. Historically, capital costs for corn grain conversion increased between 2002 and 2006 due to the sharp increase in steel costs, which would have affected all capital-intensive conversion technologies as opposed to technologies that do not rely heavily on capital equipment.

The lignocellulosic biomass feedstock group has less variance in MFSP, ranging from $\$ 1.43 / \mathrm{GGE}$ to $\$ 4.66 / \mathrm{GGE}$. This is attributed to relatively inexpensive feedstock compared to other biomass groups and high production scale contributing to economies of scale. Pathway 9 is the outlier in this group, with higher feedstock, capital, and operating costs. This is offset due to the sale of acetone, electricity, and ethanol (sold as a non-fuel commodity in the study), reducing the MFSP by $\$ 2.75 / \mathrm{GGE}$. Without the coproduct credits, the MFSP would be $\$ 6.47 / \mathrm{GGE}$. Pathways 19, 20, and 28 all have coproducts that make a considerable impact on the MFSP with $\$ 0.45 / \mathrm{GGE}, \$ 0.62 / \mathrm{GGE}$, and $\$ 0.37 / \mathrm{GGE}$ reductions, respectively. More analysis and explanation of the types of coproducts are explored in the pathway details in Appendix B.

The microalgae conversion case explored in this study (Pathway 29) exhibits a higher feedstock cost contribution $(\$ 6.65 / \mathrm{GGE})$, operating cost contribution $(\$ 3.82 / \mathrm{GGE})$, and capital cost contribution $(\$ 2.87 / \mathrm{GGE})$ when compared to other conversion technologies. The overall high cost is offset by a large coproduct credit from succinic acid used in polyester polyols, coatings, and plasticizers. It is assumed to be sold at \$2.10/kg (Nghiem, Kleff, and Schwegmann 2017). Succinic acid is produced as a coproduct during the fermentation of the sugars, whereas the distillate-range fuels (gasoline and diesel) are produced from the extracted lipids. This means 
that there is a large amount of succinic acid produced, approximately 7,600 $\mathrm{kg}$ per hour, generating coproduct credits to offset the feedstock, capital, and operating expenses. Annually, just under 60,000 MT of succinic acid would be produced, and estimates anticipate the market to be 768 million MT by 2025, showing a demand for renewable production as traditional production comes from fermentation or fossil-based chemicals (Nghiem, Kleff, and Schwegmann 2017).

As mentioned previously, wastewater sludge and MSW are assumed as \$0/DMT feedstocks, allowing for no contribution from feedstock to MFSP and leaving the capital and operating expenses to make up the majority of the MFSP. The conversion of MSW to biogas (Pathway 31) had a large contribution from taxes because of the high tax rate assumed in the study. The high cost for converting MSW at $\$ 16.20 / \mathrm{GGE}$ is attributed to the low production scale and the lower specific energy of biogas. The smaller and less energy-dense fuel produced needs to compensate for the large capital costs and operating costs associated with the plant by increasing the MFSP. If the process were scaled up, there would be a reduction in MFSP due to increased economy of scale.

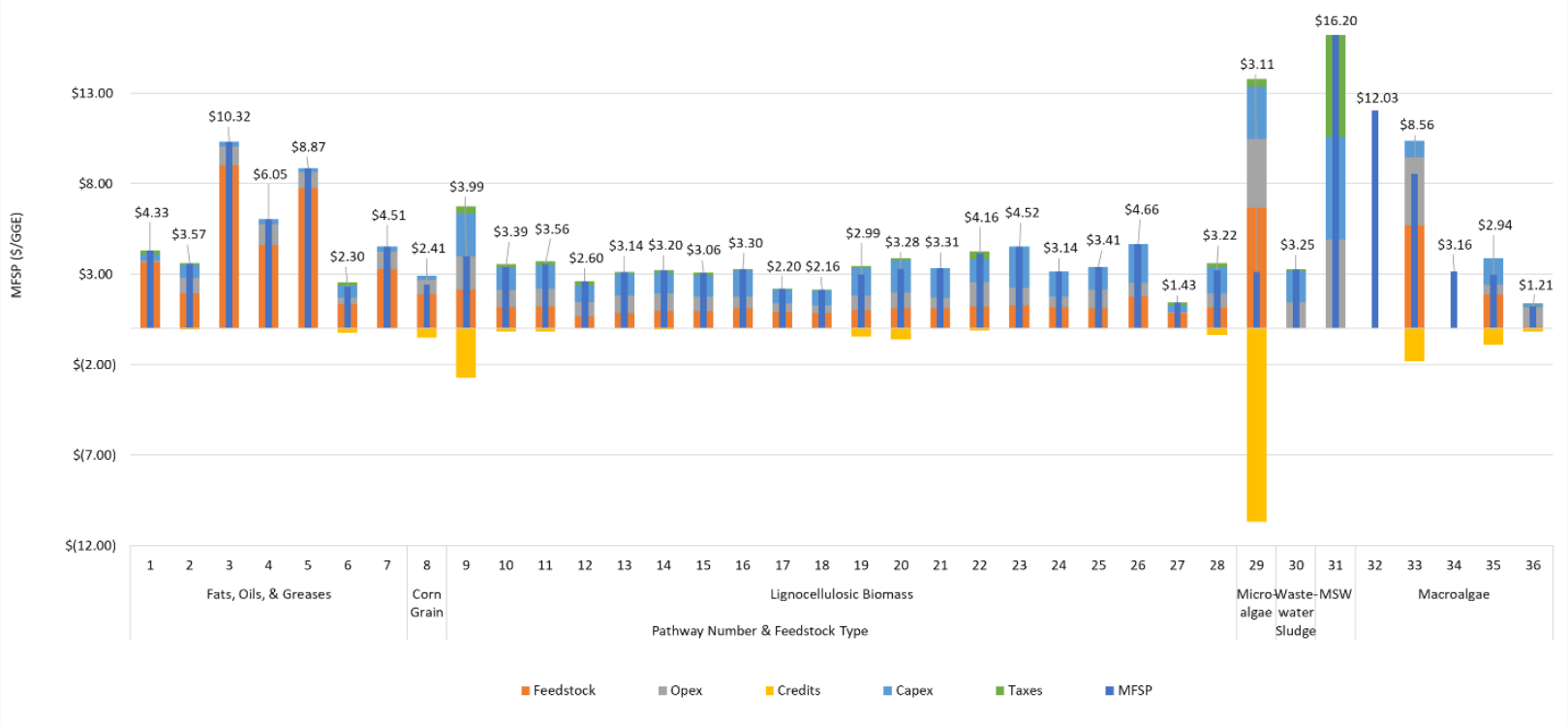

Figure 13. MFSP for the selected conversion technologies

Note: MFSP presented in \$/GGE and in 2016 dollars. All MFSPs are based on data sources' data without harmonizing the financial parameters used for their calculation.

The technologies reported here for macroalgae conversion did not always specify their cost breakdown by area, only reporting the MFSP. Generally, for macroalgae, the MFSP is influenced mostly by feedstock cost and secondly by capital or operating expenses, consistent with other conversion technologies. The exception to this in the macroalgae feedstock group is Pathway 36, which has a lower feedstock cost because it utilizes macroalgae residue from another industry, decreasing the feedstock cost, as explained in Section 3.1.1. Further information on the coproduct credits for the macroalgae feedstock group is given in the pathway details section in Appendix B. 


\subsection{Conversion Pathway Screening Assessment Summary}

Figure 14 summarizes the details described in the previous subsections, containing the screening results for potential marine biofuel production pathways. Eight metrics were developed for each evaluated pathway. The pathway metrics were compiled, harmonized, and then compared for their technical and economic viability (Table 12). The metrics include: (1) feedstock agnostic, which is the variability of feedstock the conversion technology can handle; (2) feedstock scalability, which takes into account total feedstock available and feedstock expected growth on the long-term horizon; (3) feedstock production and logistics, which accounts for cultivation, collection, and transportation of feedstock from its origin to the biorefinery; (4) technology maturity, which encompasses the technology readiness level that accounts for the proven scale of the technology including pilot plants, commercial demonstration, and market penetration; (5) carbon conversion efficiency, which is the carbon content from the biomass that makes it into the final fuel(s); (6) yield, which is the energy produced per dry metric ton and is related to carbon conversion efficiency but also can include the electricity and heat produced on site from the biomass that is not part of the carbon conversion efficiency (i.e., hydrocarbon blendstocks); (7) feedstock cost, which is the feedstock cost assumed in the technology reports that the information was taken from; and (8) MFSP, which is the minimum price to sell the main fuel product for as calculated in the technology reports that the information was taken from. The pathways were given relative qualitative scores based on various metrics. Each technology pathway was assessed and determined to be favorable, neutral, or unfavorable with respect to each metric. Note that these metrics are directly related to the marine biofuel production capacity and price. Environmental and fuel properties are excluded, as they are outside the scope of this study.

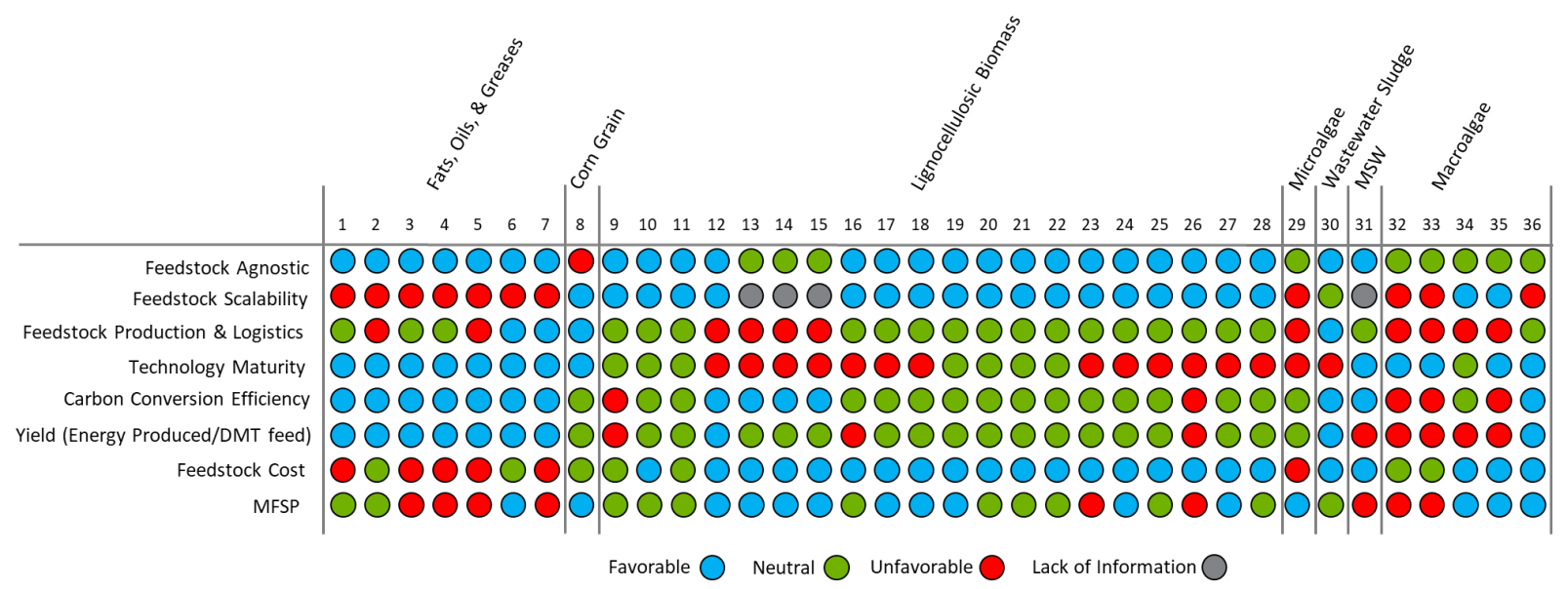

Figure 14. Conversion pathway screening assessment

These relative comparison metrics were determined based on the compiled database described at the beginning of this section. The database was further visualized and analyzed in the previous subsections based on assumed feedstock costs, production scale and yield, product distribution, and MFSP. It is evident from Figure 14 that the majority of the metrics are either favorable or neutral for most pathways. However, metrics related to feedstock scalability and technology maturity are in need of improvement. The feedstock availability for fats, oils, and greases poses a challenge for Pathways 1-7. Technology maturity associated with Pathways 12-18 and 23-30 is not favorable for the near term. The default description for technologies is their state of 
technology, unless specified in Appendix B. It is a target case expected to be achieved within five years. For the technology maturity metric, all cases were compared based on their state of technology. Macroalgae pathways exhibit the most unfavorable metrics.

Table 12. Relative Conversion Technology Assessment Metrics

\begin{tabular}{llllll}
\hline Metric & Definition & Unfavorable & Neutral & Favorable & Approach \\
\hline Feedstock & The ability for & If the & Can & Can & Evaluate \\
Agnostic & the technology & feedstock can & accommodate & accommodate & literature, DOE \\
& to & only utilize & more than & multiple & states of \\
& accommodate & one feedstock & one feedstock & feedstock & technology, \\
& various & type or & type or does & types and & and source \\
& feedstock & requires & not require & requires little to & material to \\
& types or & significant & extensive & no feedstock & determine \\
& compositions & feedstock & feedstock & cleaning/ & feedstock \\
& & cleaning/ & cleaning/ & preprocessing & variability and \\
& & preprocessing & preprocessing & & cleaning \\
Feedstock & Total & Significant & Some to no & Little to no & Use literature, \\
fealability & feedstock & feedstock is & feedstock & feedstock & Section 1 \\
& available & already & currently & currently & feedstock \\
& currently and & currently & utilized or & utilized or & availability \\
& expected & utilized or & some growth & considerable & data, and \\
& growth for the & feedstock & expected in & growth & feedstock \\
& long-term & growth is zero & long-term & expected in & requirement \\
& horizon & or negative in & feedstock & long-term & form source \\
& long-term & forecasting & feedstock & material to \\
& & & & forecasting & project \\
& & & & & technology \\
& & & & & scalability
\end{tabular}




\begin{tabular}{|c|c|c|c|c|c|}
\hline Metric & Definition & Unfavorable & Neutral & Favorable & Approach \\
\hline $\begin{array}{l}\text { Technology } \\
\text { Maturity }\end{array}$ & $\begin{array}{l}\text { Encompasses } \\
\text { technology } \\
\text { readiness } \\
\text { level and the } \\
\text { proven scale } \\
\text { of the } \\
\text { technology, } \\
\text { including pilot } \\
\text { plants, } \\
\text { commercial } \\
\text { demonstration, } \\
\text { and market } \\
\text { penetration }\end{array}$ & $\begin{array}{l}\text { Bench-scale } \\
\text { tests } \\
\text { completed } \\
\text { and } \\
\text { technology } \\
\text { advancements } \\
\text { required } \\
\text { before pilot } \\
\text { plant } \\
\text { demonstration } \\
\text { is attempted }\end{array}$ & $\begin{array}{l}\text { Bench-scale } \\
\text { tests confirm } \\
\text { technology } \\
\text { and some } \\
\text { attempt, } \\
\text { planning, or } \\
\text { pilot plant } \\
\text { demonstration } \\
\text { completed }\end{array}$ & $\begin{array}{l}\text { Commercially } \\
\text { proven with } \\
\text { multiple } \\
\text { biorefineries } \\
\text { operating, } \\
\text { selling fuel, } \\
\text { and long up- } \\
\text { time production }\end{array}$ & $\begin{array}{l}\text { Investigate } \\
\text { technology } \\
\text { readiness } \\
\text { level, where } \\
\text { available, or } \\
\text { estimate } \\
\text { technology } \\
\text { maturity from } \\
\text { literature and } \\
\text { government } \\
\text { databases }\end{array}$ \\
\hline $\begin{array}{l}\text { Carbon } \\
\text { Conversion } \\
\text { Efficiency }\end{array}$ & $\begin{array}{l}\text { Carbon } \\
\text { content from } \\
\text { the biomass } \\
\text { that makes it } \\
\text { into the final } \\
\text { fuels } \\
\text { (excluding } \\
\text { carbon used } \\
\text { for on-site } \\
\text { CHP) }\end{array}$ & $\begin{array}{l}\text { Less than } \\
26 \% \text { of } \\
\text { feedstock } \\
\text { carbon ending } \\
\text { up in final fuel }\end{array}$ & $\begin{array}{l}\text { Between } 26 \% \\
\text { and } 40 \% \text { of } \\
\text { feedstock } \\
\text { carbon ending } \\
\text { up in final fuel }\end{array}$ & $\begin{array}{l}\text { Over } 40 \% \text { of } \\
\text { feedstock } \\
\text { carbon ending } \\
\text { up in final fuel }\end{array}$ & $\begin{array}{l}\text { Divide carbon } \\
\text { content in fuel } \\
\text { products by } \\
\text { the carbon } \\
\text { content in the } \\
\text { feedstock }\end{array}$ \\
\hline $\begin{array}{l}\text { Yield (Energy } \\
\text { Produced/DMT } \\
\text { Feed) }\end{array}$ & $\begin{array}{l}\text { Energy } \\
\text { produced in } \\
\text { fuel and for } \\
\text { CHP given the } \\
\text { incoming } \\
\text { feedstock }\end{array}$ & $\begin{array}{l}\text { Less than } 50 \\
\text { GGE/DMT } \\
\text { produced } \\
\text { between fuel } \\
\text { and CHP }\end{array}$ & $\begin{array}{l}\text { Between } 50 \\
\text { and } 80 \\
\text { GGE/DMT } \\
\text { produced } \\
\text { between fuel } \\
\text { and CHP }\end{array}$ & $\begin{array}{l}\text { Over } 80 \\
\text { GGE/DMT } \\
\text { produced } \\
\text { between fuel } \\
\text { and CHP }\end{array}$ & $\begin{array}{l}\text { Divide energy } \\
\text { produced in } \\
\text { fuel and CHP } \\
\text { by energy } \\
\text { content in the } \\
\text { feedstock }\end{array}$ \\
\hline Feedstock Cost & $\begin{array}{l}\text { Feedstock } \\
\text { cost assumed } \\
\text { in the } \\
\text { technical } \\
\text { reports that } \\
\text { the information } \\
\text { was sourced } \\
\text { from }\end{array}$ & $\begin{array}{l}\text { Over } \\
\text { \$400/DMT }\end{array}$ & $\begin{array}{l}\text { Between } \\
\text { \$80/DMT and } \\
\text { \$400/DMT }\end{array}$ & $\begin{array}{l}\text { Below } \\
\text { \$80/DMT }\end{array}$ & $\begin{array}{l}\text { Evaluate } \\
\text { feedstock cost } \\
\text { in the source } \\
\text { material }\end{array}$ \\
\hline MFSP & $\begin{array}{l}\text { Minimum price } \\
\text { to sell the } \\
\text { main fuel } \\
\text { product as } \\
\text { calculated in } \\
\text { the technical } \\
\text { reports that } \\
\text { the information } \\
\text { was sourced } \\
\text { from }\end{array}$ & $\begin{array}{l}\text { MFSP above } \\
\$ 4.50 / G G E\end{array}$ & $\begin{array}{l}\text { MFSP } \\
\text { between } \\
\$ 3.20 / G G E \\
\text { and } \\
\$ 4.50 / G G E\end{array}$ & $\begin{array}{l}\text { MFSP below } \\
\$ 3.20 / G G E\end{array}$ & $\begin{array}{l}\text { Evaluate } \\
\text { MFSP } \\
\text { reported in the } \\
\text { source } \\
\text { material }\end{array}$ \\
\hline
\end{tabular}




\section{Biofuel Production Capacity and Cost Projections}

The basic assumptions for the biofuel and marine biofuel annual production and cost projections were predominantly based on (1) feedstock availability and prices reported in BT16 (see Section 2) and (2) existing biomass-to-fuel conversion technology analyses in the public domain, including leveraging the portfolio of conversion pathways developed under BETO (see Section 3). A high-level linear programming model was developed to assess production capacity and costs and provide insightful analyses. All projected available feedstocks in the United States were integrated with the selected promising and top-performance conversion pathways (i.e., based on yields and production costs), as depicted in Figure 15.

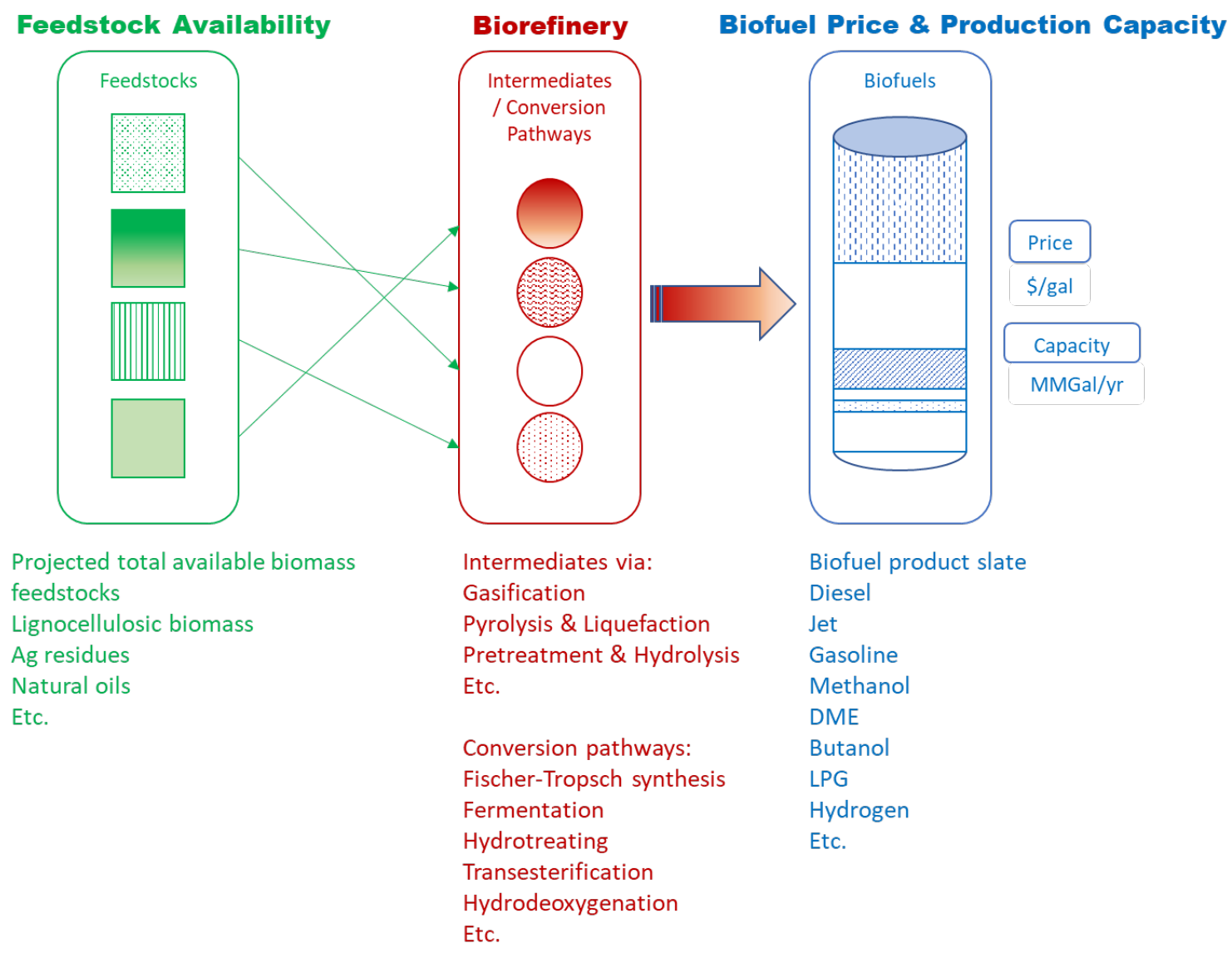

Figure 15. Marine biofuel production capacity and cost projections via bottom-up approach

\subsection{Method and Assumptions}

A linear optimization model was developed for the biofuel production capacity and cost projection. The model consists of two sub-models: (1) a database of biomass conversion pathway techno-economic cost inputs and a discounted cash flow rate of return (DCFROR) solver that calculates MFSP for the fuel output for each pathway and (2) an optimization solver that varies the amount of biomass routed to each pathway and calculates the biofuel output and plant-gate cost for each biomass conversion pathway and biomass feedstock combination, as depicted in Figure 16, with the detailed list of feedstock and pathway technology summarized in Table C1 and Table 11, respectively. 


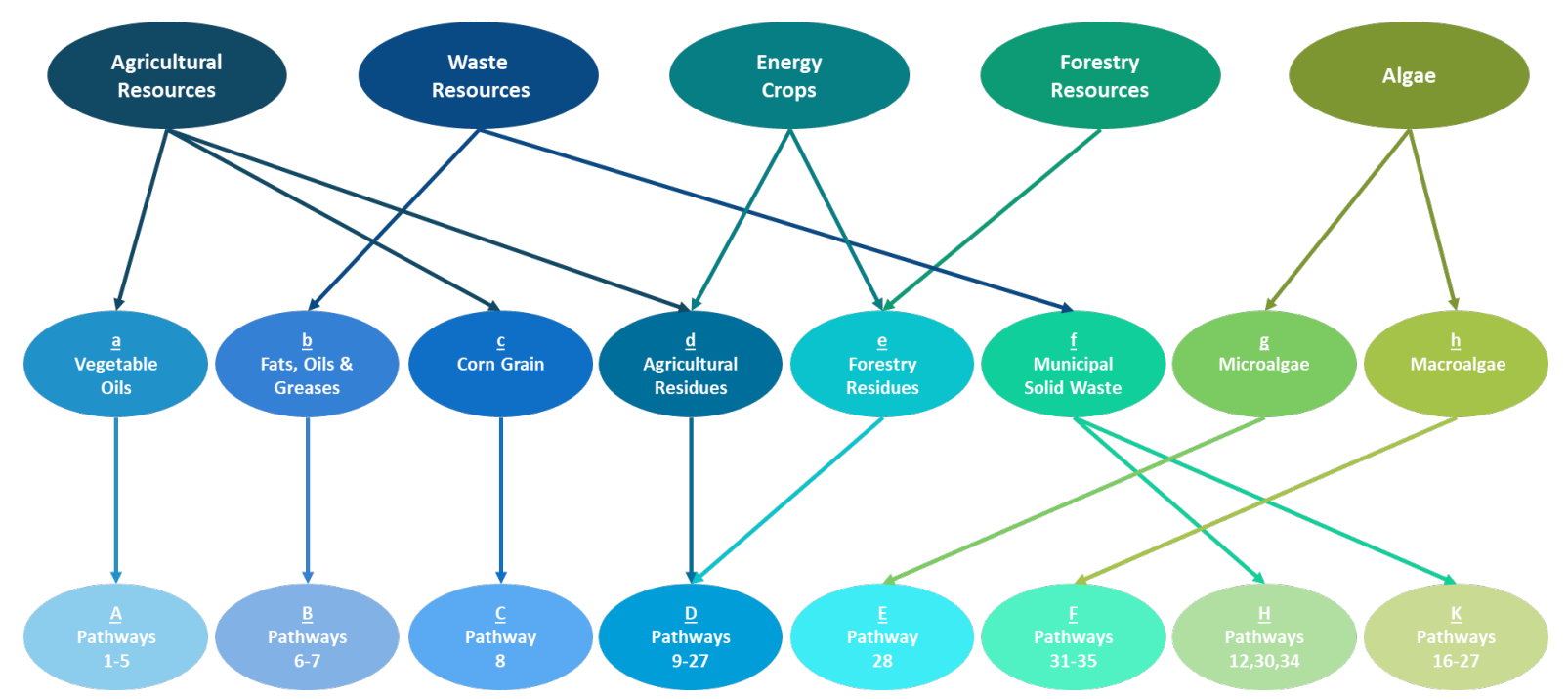

Figure 16. Schematic representation mapping feedstocks with conversion technologies for production capacity and price projections

The calculated fuel production costs and annual fuel production rates are optimized for three strategies: (1) maximize the total biofuel produced, (2) maximize the amount of combined diesel and jet fuel produced, and (3) minimize the cost of produced biofuel. Note that a majority of evaluated pathways produce both jet- and diesel-range hydrocarbon blendstocks (see Figure 12). These processes were modeled with the focus on producing jet fuel that meets the jet fuel specifications (e.g., high flash point and good cold flow properties), and these are accomplished with the hydrocracking and isomerization steps. These processes can be further optimized for marine fuel-range hydrocarbon production with properties that resemble those of marine diesel oil. Hence, in this study, both jet- and diesel-range biofuels are collectively referred to as marine biofuels.

\subsubsection{Biofuel Production and Cost Calculations}

A DCFROR calculation approach (Tan et al. 2017) was incorporated into the pathways database and used to develop sets of linear equations to calculate the plant-gate price or MFSP (\$/GGE) for each pathway. With feedstock cost, operating costs, and total capital investment, a DCFROR was performed to determine the MFSP required to obtain a zero net present value with a finite IRR. The MFSP is the plant-gate price that represents the minimum selling price of biofuel that meets the specified economic parameters (see Table 13). All pathways were normalized to a consistent cost year (2016 U.S. dollars).

Table 13. Discounted Cash Flow Analysis Parameters

\begin{tabular}{ll}
\hline Description of Assumption & Assumed Value \\
\hline Cost year & 2016 U.S. dollars \\
\hline IRR on equity & $10 \%$ \\
\hline Plant financing by equity/debt & $40 \% / 60 \%$ of total capital investment \\
\hline Plant life & 30 years \\
\hline Income tax rate & $21 \%$ \\
\hline
\end{tabular}




\begin{tabular}{ll}
\hline Description of Assumption & Assumed Value \\
\hline Interest rate for debt financing & $8.0 \%$ annually \\
\hline Term for debt financing & 10 years \\
\hline Working capital cost & $\begin{array}{l}5.0 \% \text { of fixed capital investment } \\
\text { (excluding land purchase cost) }\end{array}$ \\
\hline Depreciation schedule & 7 -year MACRS schedulea \\
\hline Construction period (spending schedule) & 3 years ( $8 \%$ Y1, 60\% Y2, 32\% Y3) \\
\hline Plant salvage value & No value \\
\hline Startup time & 6 months \\
\hline Revenue and costs during startup & $\begin{array}{l}\text { Revenue }=50 \% \text { of normal } \\
\text { Variable costs }=75 \% \text { of normal }\end{array}$ \\
& Fixed costs = 100\% of normal \\
\hline $\begin{array}{l}\text { On-stream percentage after startup } \\
\text { a Capital depreciation is computed according to the United States Internal Revenue Service modified }\end{array}$ \\
$\begin{array}{l}\text { accelerated cost recovery system (MACRS). Because the plant described here is not a net exporter of } \\
\text { electricity, the steam plant and power generation equipment are not depreciated over a 20-year period }\end{array}$
\end{tabular}

The optimization model was run for the baseline case for each technology pathway and feedstock set as well as for sensitivity cases. A set of 14 variables can be included in sensitivity analyses, but four variables-feedstock cost, capital cost, operating cost (excluding feedstock costs), and yield - were chosen as the primary sensitivity variables for the production cost. Linear equation parameters were developed for each of the sensitivity variables to be used in the optimization study. The range applied for the single-point sensitivity cases are yield $( \pm 20 \%)$, biomass feedstock price $( \pm 20 \%)$, capital cost $( \pm 30 \%)$, and plant operating cost $( \pm 20 \%)$ excluding feedstock cost. Additionally, feedstock availability $(\mathrm{max} / \mathrm{min})$ and yield $( \pm 20 \%)$ are the two sensitivity variables pertinent to the biofuel production capacity.

The model output biofuel production (in GGE) and MFSP (in $\$ / G G E$ ) values are not a linear function of the yield (as illustrated in Figure 17). Therefore, a single linear equation for calculating the output MFSP cannot be developed with parameters for all four of the sensitivity variables (feedstock cost, capital cost, operating cost, and yield). However, for a given yield, the output MFSP can be calculated as a linear function of the other three sensitivity variables. Therefore, a separate set of linear equation parameters were calculated for the other three variables for each pathway for various feedstock availability scenarios, namely the low-, median(baseline), and high-yield cases (i.e., three linear equations were developed for each pathway). A snapshot of the DCFROR inputs database and linear equation generator is depicted in Figure 18. The linear equation generator uses a combination of Excel's MINVERSE and MMULT functions to solve for the coefficients for the general equation:

$$
\operatorname{MFSP}(\$ / G G E)=A *[\text { feedstock cost }]+\mathrm{B} *[\text { capital cost }]+\mathrm{C} *[\text { operating cost }]+\mathrm{D}
$$

The MINVERSE function returns the inverse matrix of an array; in this case, a $4 \times 4$ array of values for the three sensitivity variables and the constant (set to 1). The MMULT function returns the matrix product of two arrays: the output matrix from the MINVERSE function and the array of costs calculated using the DCFROR solver corresponding to the array of variable 
values. The output of the MMULT function is the parameters of the linear equation: $\mathrm{A}, \mathrm{B}, \mathrm{C}$, and D. A simple Excel macro is used to generate values of the variables, solve for the output cost (\$/GGE), and copy the resulting linear equation parameters to a summary datasheet.

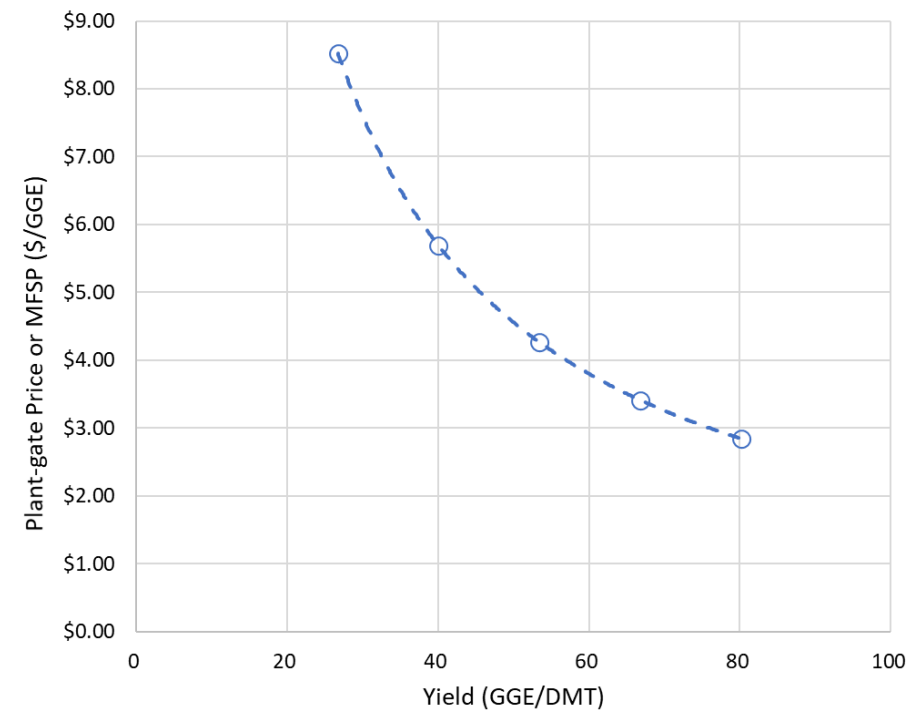

Figure 17. DCFROR output MFSP as a function of yield (Pathway 14)

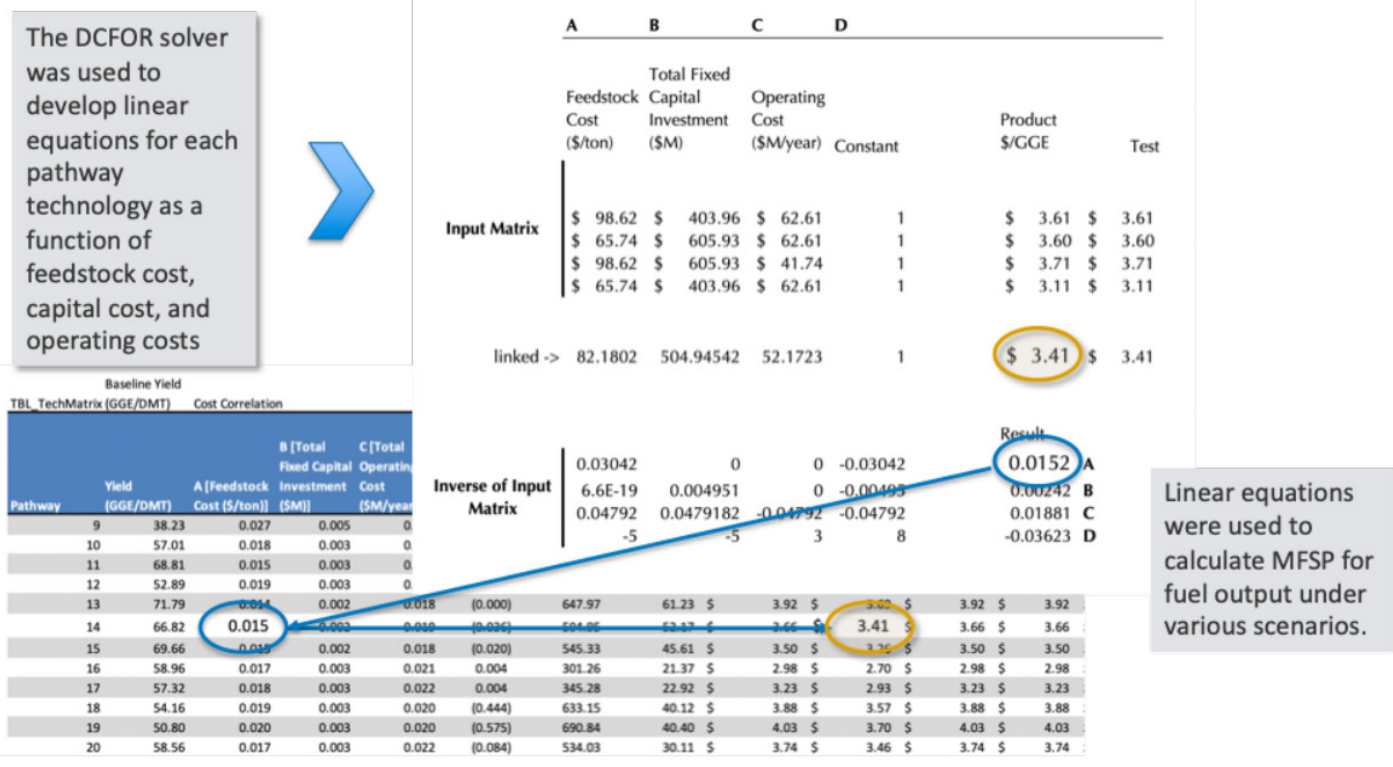

Figure 18. DCFROR inputs database and linear equation generator

The baseline case for each pathway was used as the basis for developing the yield cases. The yield and annual energy production rate (in GGE of fuel produced) were included in each pathway's baseline data. The baseline biomass feed rate was calculated from the energy production rate and the yield. The biomass feed rate, which determines the yearly cost of input biomass, and energy production rate are used in the DCFROR solver to calculate the plant-gate price ( $\$ / G G E)$ for the plant output products. The low- and high-yield cases were constructed by 
assuming a constant feed rate (and thus feed cost) and varying the yield to give each yield case a different energy production rate. New linear equations were generated for each yield case.

\subsubsection{Optimization Solvers}

The optimization model calculates fuel production costs and fuel production rates under three optimization strategies - minimize the cost (\$/GGE) of produced fuel, maximize the GGE of the total fuel produced, and maximize the amount of diesel and jet fuel (or marine biofuel) produced (GGE). The maximum GGE and maximum diesel and jet fuel (marine biofuel) calculations are straightforward linear relationships and are easily solved using a fast linear solver. However, the weighted average plant-gate price calculation is more complex, and a nonlinear solver is required. The systemwide (i.e., the combination of all feedstocks and all pathways) MFSP value is a weighted average of the costs for each biomass feedstock and conversion pathway combination according to the equation:

$$
\text { Weighted Average MFSP }\left(\frac{\$}{G G E}\right)=\sum_{d_{b=1}}^{B} \sum_{p=1}^{P}\left(C_{b p} \times D T_{b} \text { yield }_{p}\right) \div \sum_{p=1}^{P}\left(\text { DT }_{b} \text { yield }_{p}\right)
$$

Where:

$$
\begin{aligned}
& B=\text { feedstocks } \\
& P=\text { conversion technology pathways } \\
& C_{b p}=\text { cost }(\$ / G G E) \text { for output fuel from each biomass/pathway combination } \\
& D T_{b}=\text { mass of biomass feedstock routed to each pathway } \\
& \text { Yield }_{p}=\text { pathway yield (GGE/DMT) }
\end{aligned}
$$

Because the weighted average cost is a function of both the cost for each individual pathway and the amount of fuel produced by each pathway, the relationship between the amount of feedstock routed to a pathway and the resulting weighted average cost is not linear.

Microsoft Excel's solver function was used for the optimizations, and a set of visual basic macros was used to set up the solver problem and loop through the sensitivity cases. The model simplifies user input and allows the user to control the key variables (e.g., the \pm percentages used in sensitivity cases). Excel's GRG nonlinear solver engine was used to calculate the minimum cost, and the Simplex LP linear engine was used to calculate the maximum GGE and maximum GGE of marine biofuel blendstocks. Moreover, two constraints were used for all cases: all of the available biomass feedstock must be used, and all values must be positive. The optimization model was run for the baseline case for each technology pathway and feedstock combination set, as well as sensitivity cases for yield, biomass feedstock price, capital cost, and plant operating cost (\$/year) excluding feedstock cost.

When running the optimization model, the cost of output fuel (\$/GGE) is calculated using the appropriate set of linear equations, and the fuel production rate is calculated using the corresponding yield value. The linear equation parameters were incorporated into the optimization model to calculate the cost of output fuel (\$/GGE) for each conversion pathwayfeedstock combination. With the cost calculation functionality, the optimization model is capable 
of evaluating the sensitivity of the technology-biomass feedstock optimization to uncertain variables.

The model is set up by first selecting the biomass feedstocks, the feedstock supply curve (minimum, median, or maximum availability), and the analysis timeframe, either near term (2022) or long term (2040). These values determine the total availability (in million dry U.S. tons per year) and the price (in \$/dry U.S. ton) for each selected biomass feedstock. The pathways that will be evaluated in the optimization are selected in another database. This database serves as a lookup table for the yield values, baseline capital and operating costs, and the linear equation parameters needed to calculate the cost of fuel output for each conversion pathway-biomass feedstock combination. Once the feedstocks and pathways have been specified, the user then sets the sensitivity multipliers for capital cost, feedstock cost, and operating costs. The yield sensitivity values are set by selecting the yield case, which in turn determines which set of linear equations will be used to calculate the plant-gate price $(\$ / G G E)$ for each pathway as well as the corresponding yield value for the pathway (see Appendix C).

\subsection{Annual Biofuel Production Capacity and Cost Projection}

\subsubsection{Terms and Definitions}

The followings are key terms used in this section.

Feedstock availability: Refers to Section 2 feedstock assessment results. Minimum, median, and maximum feedstock availability represent the three sub-scenarios evaluated in Section 2. Further indications may include "near-term" or "long-term" availability referring to feedstock projections for 2022 or 2040 , respectively.

Feedstock cost: Refers to Section 2 feedstock cost assessment results. For example, "feedstock availability;" minimum, median, and maximum feedstock cost; and "near-term" or "long-term" feedstock cost are in reference to those in Section 2.

Feedstock group: Refers to those designated in Section 2. Feedstock groups such as forestry residues, waste resources, or algae refer to the categories outlined in Figure 2.

Conversion technology/pathway: Refers to the conversion pathways in Section 3. Conversion technologies and pathways are described in detail in Section 3 and Appendix B.

Technology group: Determined by coupling the efforts from feedstock availability and cost (Section 2) and conversion pathways (Section 3) for marine biofuel capacity and cost projection in this section. Technology groups indicate feedstocks, which can all be converted to biofuel via the same conversion technology.

\subsubsection{An Illustration of Linear Optimization Modeling Output}

Figure 19 exhibits the linear optimization modeling analysis of biofuel capacity projection. The model harmonizes and maps the conversion technologies with corresponding technology groups (Figure 19a). Technologies shaded with a color represent those selected by the solver for the given optimization constraint. In some scenarios, only one pathway was selected for a given technology group (like Group A), as indicated by shading the selected pathway in green. In other 
cases, multiple pathways were selected depending on the optimization constraint. The compilation of the results depicted in Figure 19a yields the total biofuel production data as a function of multiple variables. Variables presented in Figure 19b include the near-term and longterm feedstock availability and the inclusion or exclusion of algae as a feedstock in the total production of biofuels.

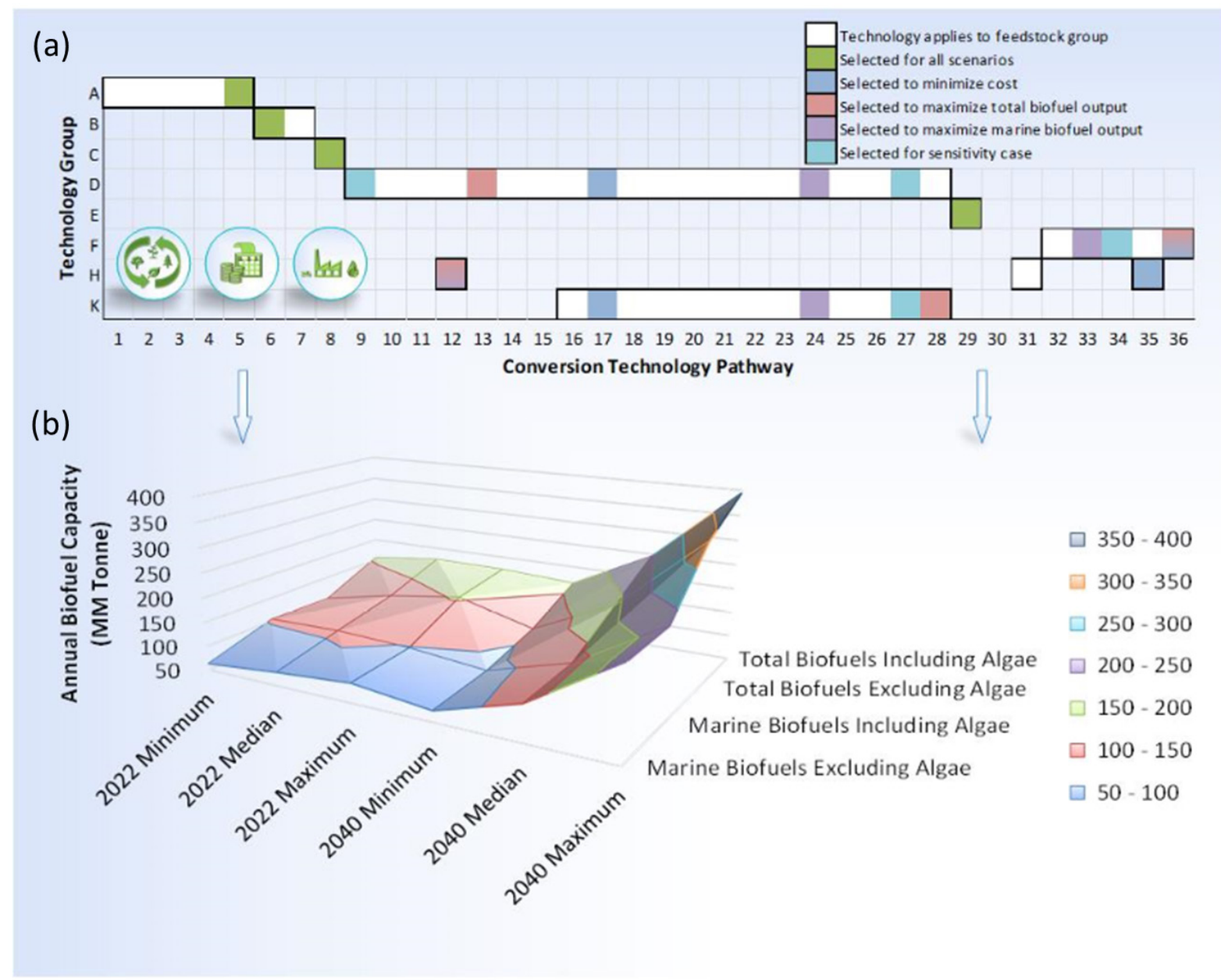

Figure 19. Illustration of linear optimization modeling output. (a) Harmonization and mapping of conversion technologies with corresponding technology groups. (b) Total biofuel production capacity for the near-term and long-term feedstock availability and the inclusion or exclusion of algae as a feedstock in the total production of biofuels.

\subsubsection{Annual Marine Biofuel Capacity and Price}

The projected annual overall biofuel capacity presented in Figure 20a results from two optimization cases: (1) maximize total biofuel and (2) maximize total marine biofuel (jet- and diesel-range hydrocarbon blendstocks). The maximization of the total biofuel produced results in greater quantities of biofuel produced in each corresponding marine biofuel scenario. The error bars indicate biofuel capacity at the maximum and minimum feedstock availability, respectively, and the median case serves as the baseline. Each scenario was also assessed to either include or exclude the contributions of microalgae and macroalgae. Similarly, Figure 20b shows the projected biofuel cost at the projected biofuel capacity. Biofuel cost was determined as a 
weighted average of the individual technology group cost, and availabilities are discussed further in later sections.

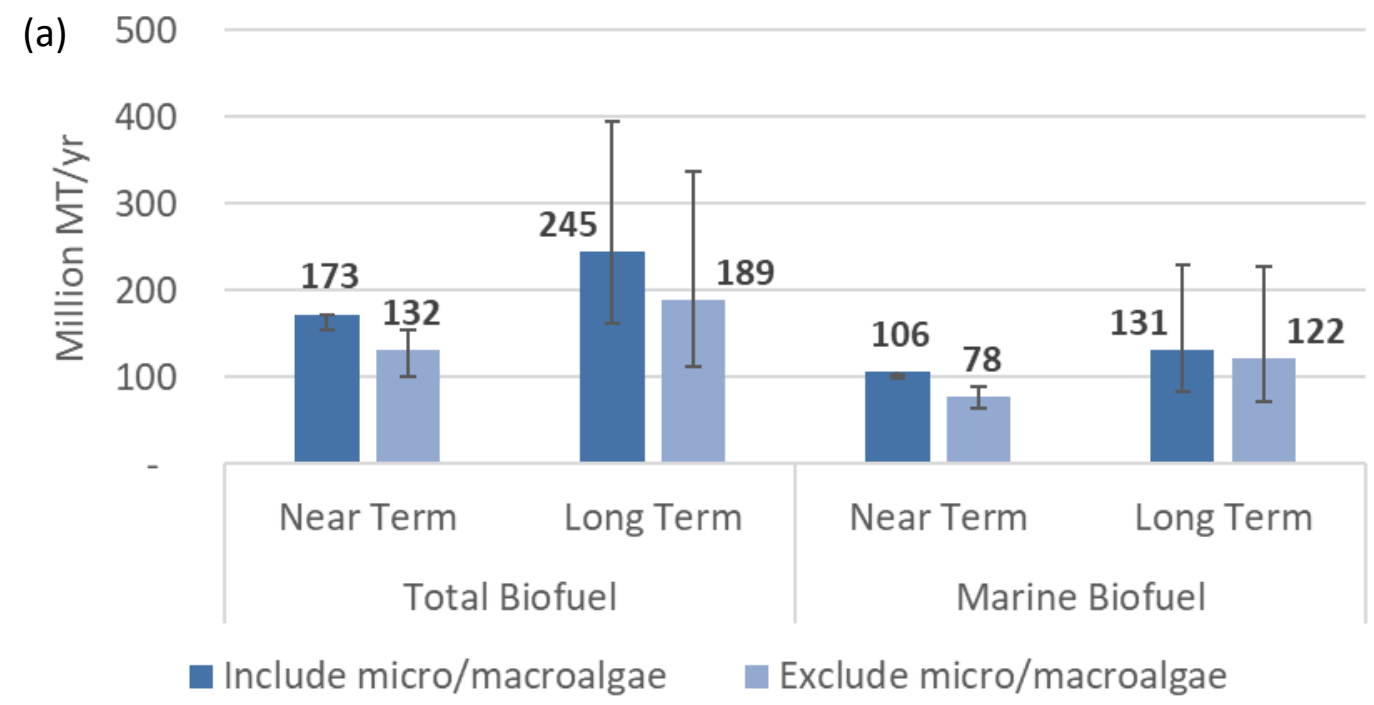

(b) 2,500

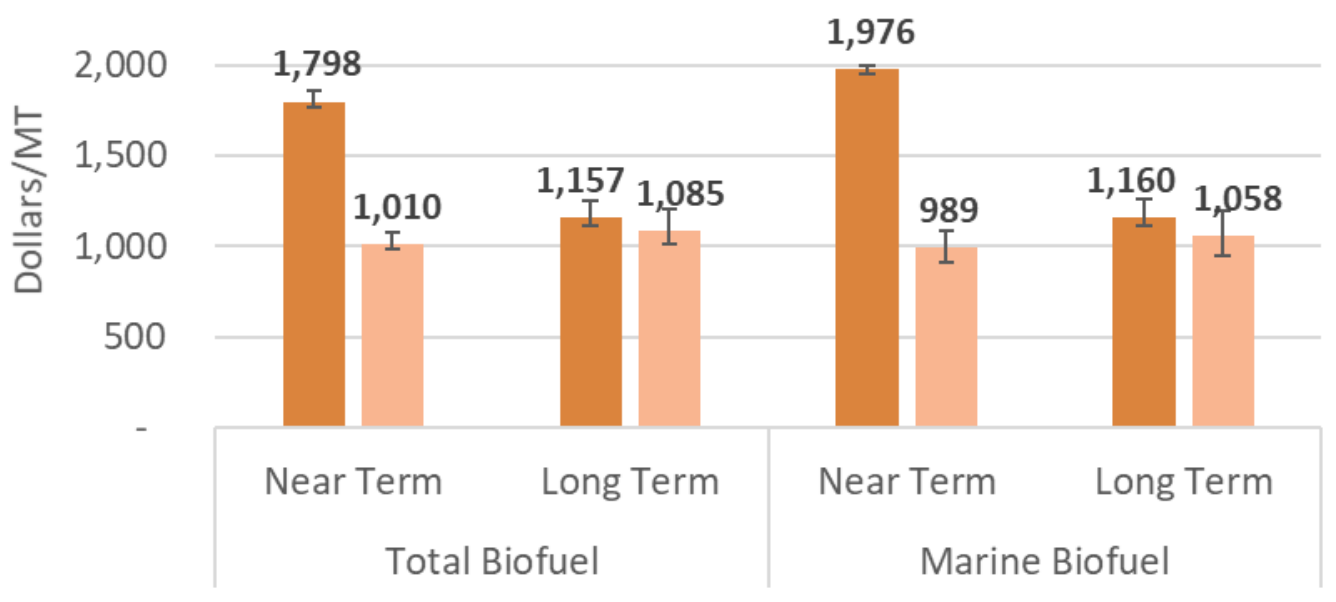

Include micro/macroalgae \# Exclude micro/macroalgae

Figure 20. (a) Projected biofuel capacity in million metric tons and (b) price in dollars per metric ton for maximum total biofuel and maximum marine biofuel scenarios

Figure 21 shows the same results as those in Figure 20 but on a heavy fuel oil gallon equivalent (HFOGE) basis instead of a per-ton basis. The conversion factors used for this study are that 1 HFOGE is equal to $140,353 \mathrm{Btu}$ and 1 metric ton of heavy fuel oil is equal to $267 \mathrm{HFOGE}$ (Argonne National Laboratory 2016). 
(a) 120

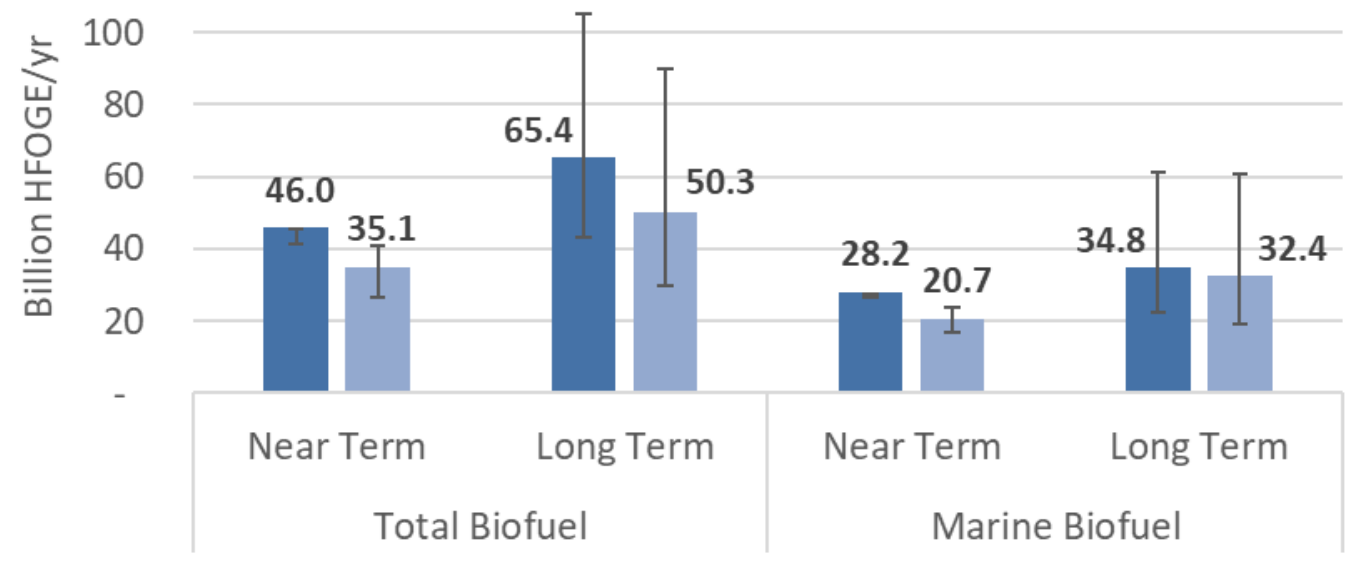

Include micro/macroalgae Exclude micro/macroalgae

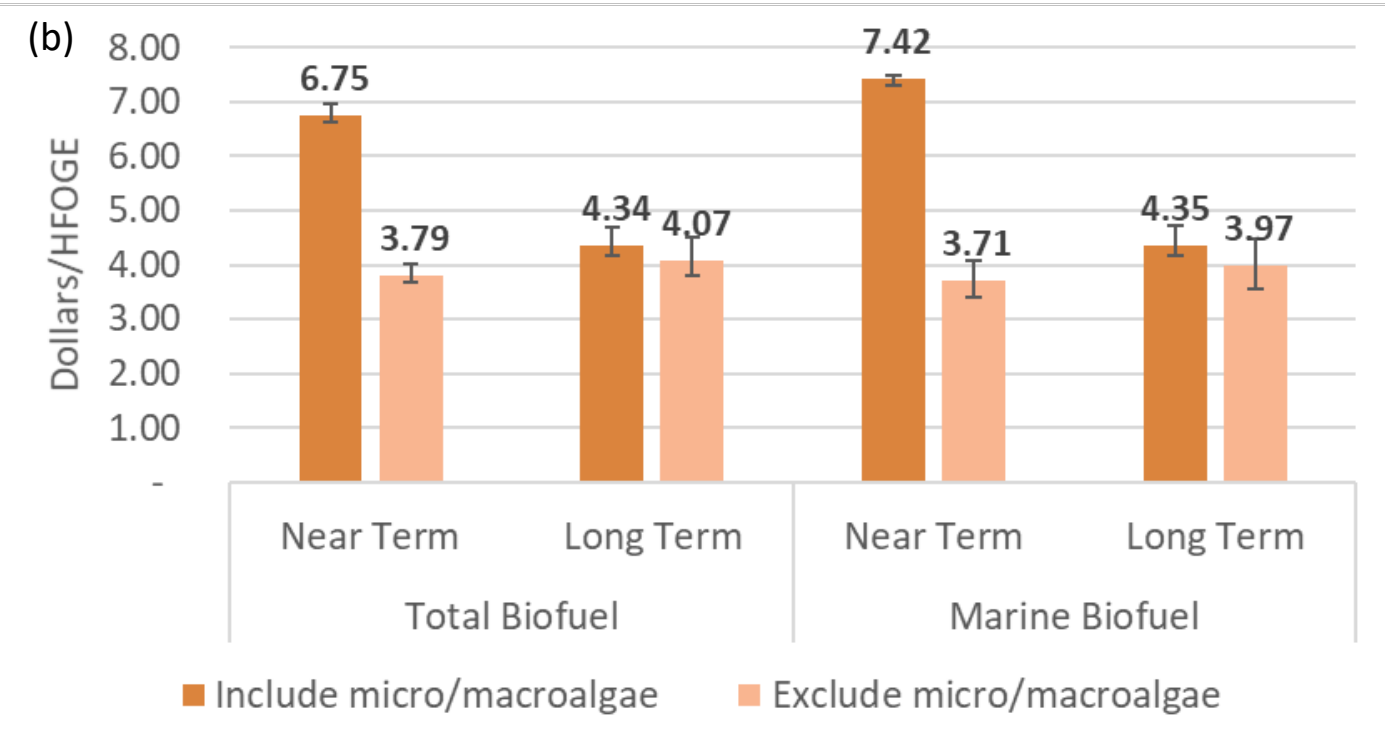

Figure 21. (a) Projected biofuel capacity and (b) price on an HFOGE basis for maximum total biofuel and maximum marine biofuel scenarios

A third optimization scenario was also carried out in which the cost of biofuel was minimized. The summarized results of this scenario are presented in Figure 22. Similarly, the error bars indicate the maximum and minimum feedstock availability compared to the median availability baseline. However, in this scenario, there is only one capacity value for each near-term and longterm case (versus a total biofuel and marine biofuel case). This results from the cost optimization objective function; to optimize cost, constraints were not put on the product distribution. From the optimized cost results, the projected annual biofuel capacity could also be determined. The same summarized results of the cost optimization scenario are also presented in Figure 23 on an HFOGE basis. 


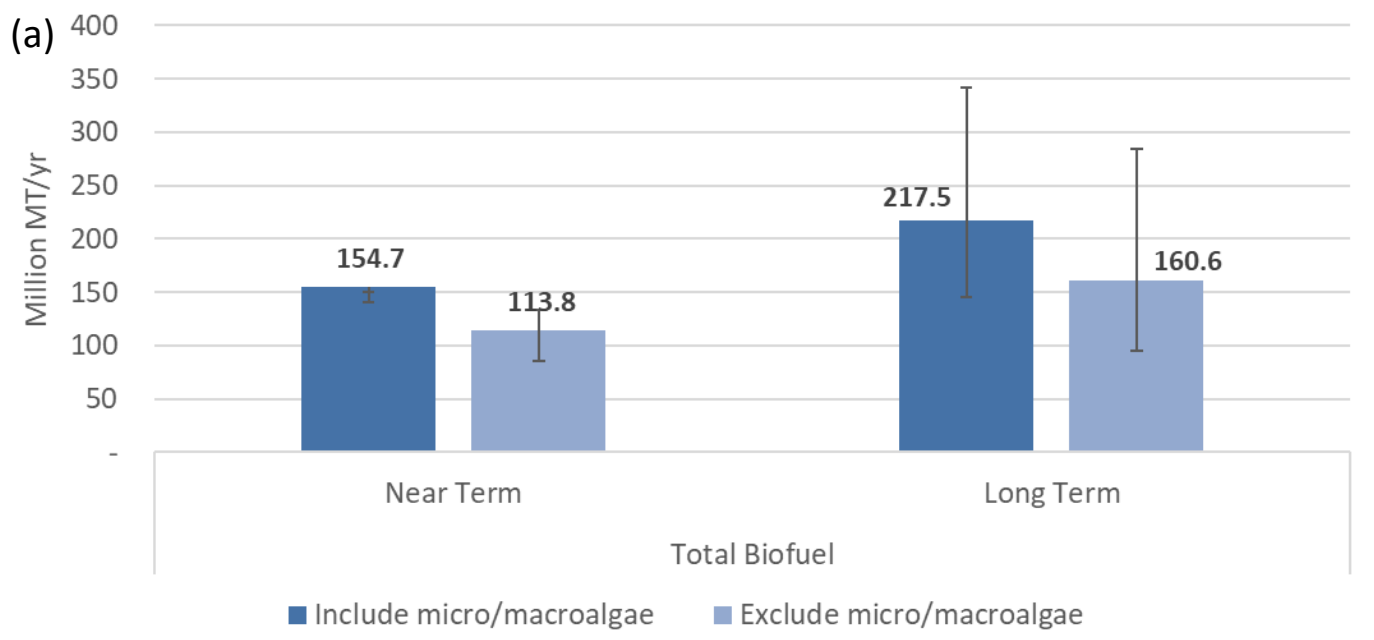

(b) 2,000

1,800

1,600

1,400

这 1,200

嘀 1,000

产 800

600

400

200

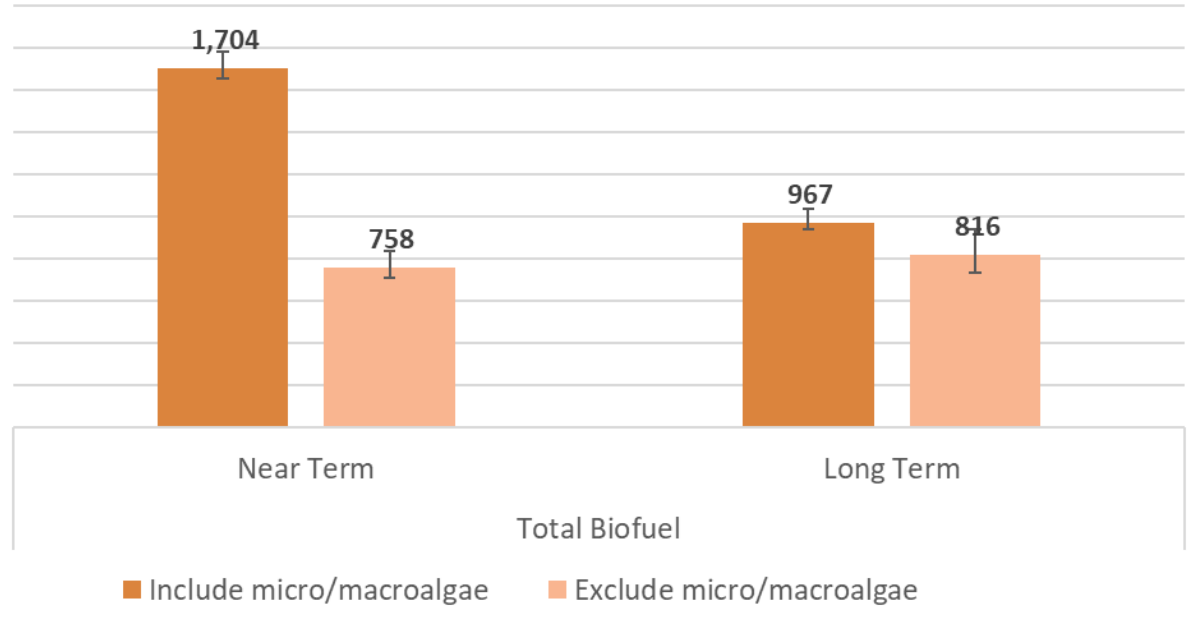

Figure 22. (a) Projected biofuel capacity and (b) price on a per-metric-ton basis for minimum cost scenario 

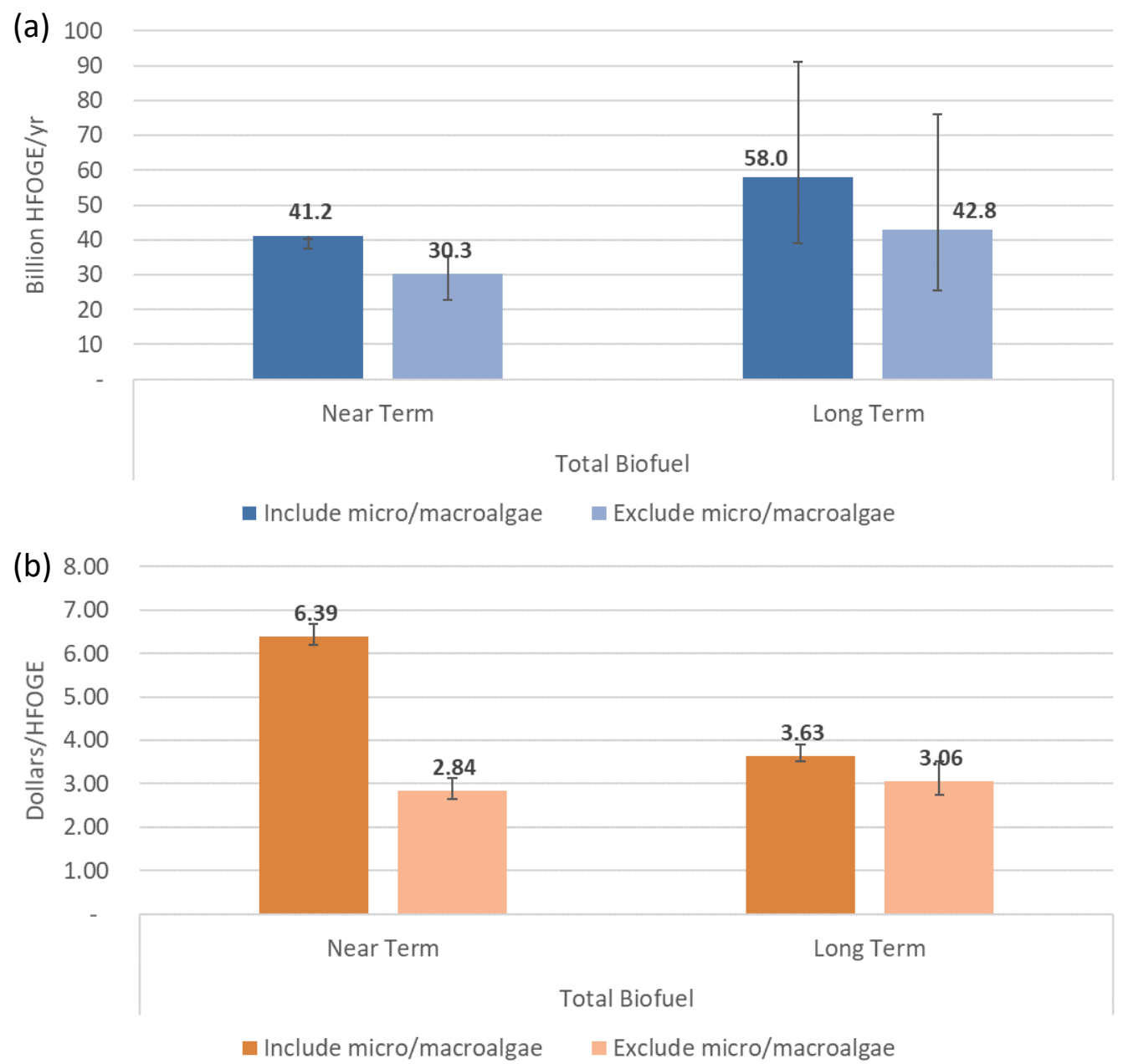

Figure 23. (a) Projected biofuel capacity in billion HFOGE per year and (b) price in dollars per HFOGE basis for minimum cost scenario

\subsubsection{Breakdown of Fuel Contribution by Technology Group}

Technology groups were determined by matching feedstock categories from Section 2 with conversion technologies from Section 3, as depicted in Figure 16 (as well as in Table C1 and Table 11). Each technology group was analyzed independently to determine the pathway that optimized either total biofuel produced, cost, or total marine biofuel produced. The quantity of biofuel produced is dependent on feedstock availability and yield of the selected conversion technology. A high-level summary of maximum biofuel yield and maximum marine biofuel yield for the near-term and long-term scenarios is broken down by technology group contributions in Figure 24. The summary shown in Figure 24 is for the median feedstock availability scenario for both 2022 and 2040. Results in the main text from Figure 24 forward will be presented on a per-metric-ton basis only; however, additional figures and tables are provided in Appendix C on the HFOGE basis. 


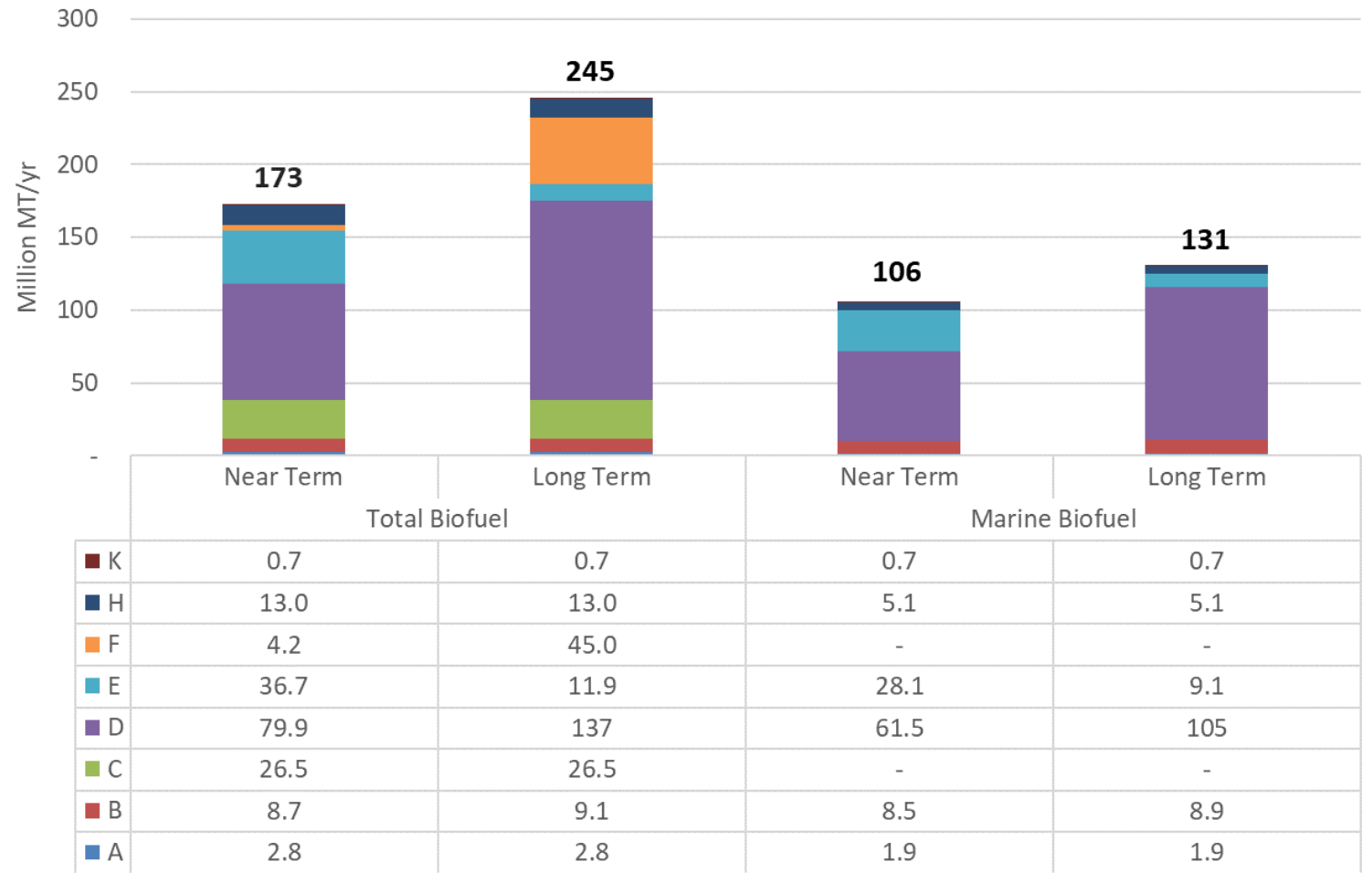

Figure 24. Projected annual biofuel capacity broken down by feedstock group contributions in per-metric-ton basis for maximum total biofuel and maximum marine biofuel scenarios

A more detailed breakdown of biofuel capacity contributions is provided in Figure 25 . The error bars indicate the minimum and maximum feedstock availability scenarios for each technology group. Technology Group D contributes greater than $50 \%$ of the biofuel production capacity in all scenarios. 


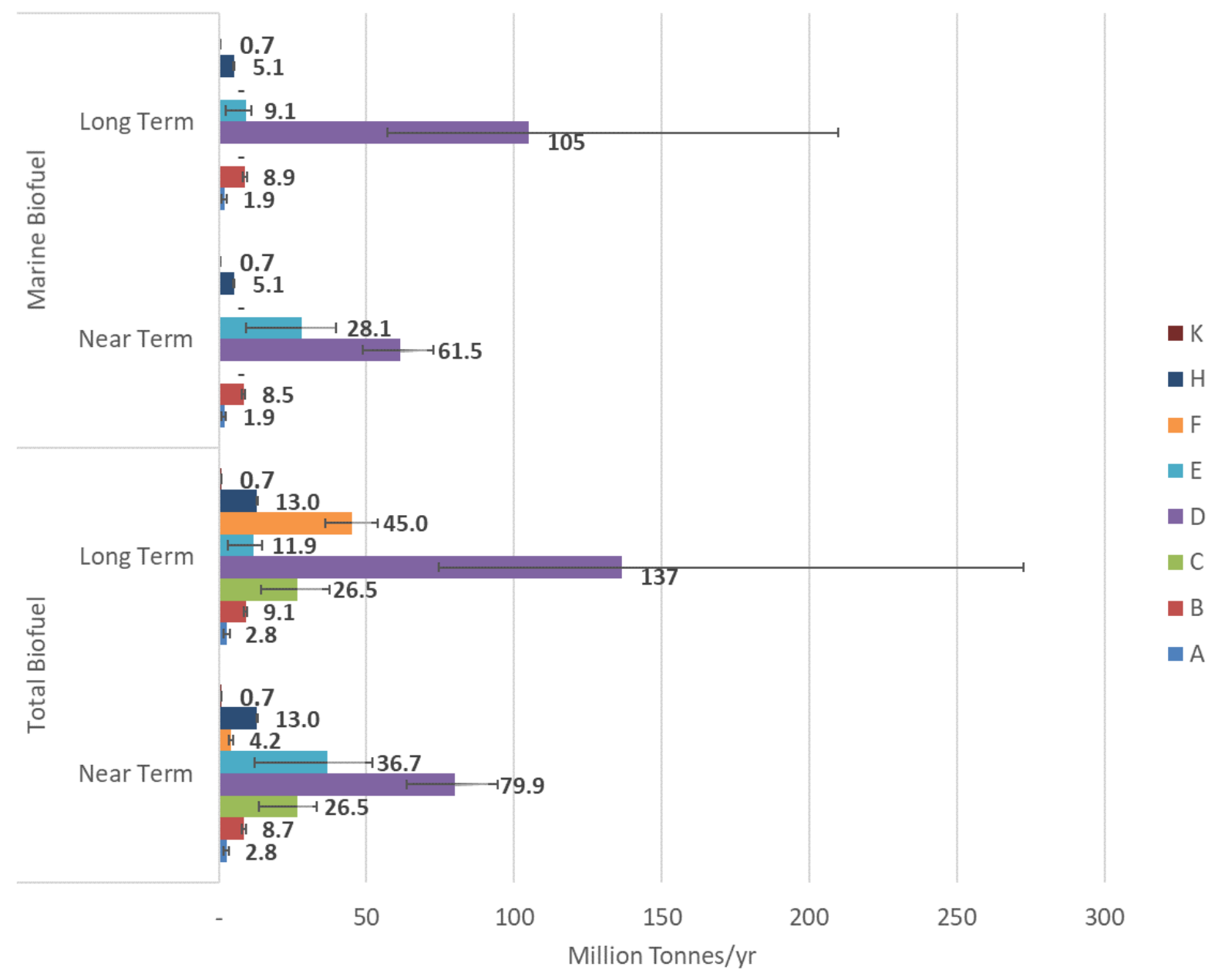

Figure 25. Technology group fuel contributions on a per-metric-ton basis for maximum total biofuel and maximum marine biofuel scenarios. Error bars indicate maximum and minimum feedstock availability for each group.

In this analysis, biofuel cost depended on feedstock cost and conversion cost, specific to the selected pathway. Per the feedstock availability analysis in Section 2, the majority of the feedstock analysis, excluding algae, was determined at a fixed feedstock cost with a range applied to give a minimum and maximum cost and availability scenario. In the optimization scenarios maximizing either total biofuel production or marine biofuel production, conversion cost was not used as a criterion for the solver in selecting the optimal pathway. The resulting cost at the annual biofuel capacity for each technology group was then calculated after the pathway was selected. The results of this calculation are presented in Figure 26. Conversion of microalgae to biofuels (Group E) consistently resulted in the highest fuel price due to high feedstock and conversion costs, whereas conversion of fats, oils, and greases (Group B) was consistently the lowest due to lower feedstock cost and more mature technologies. 


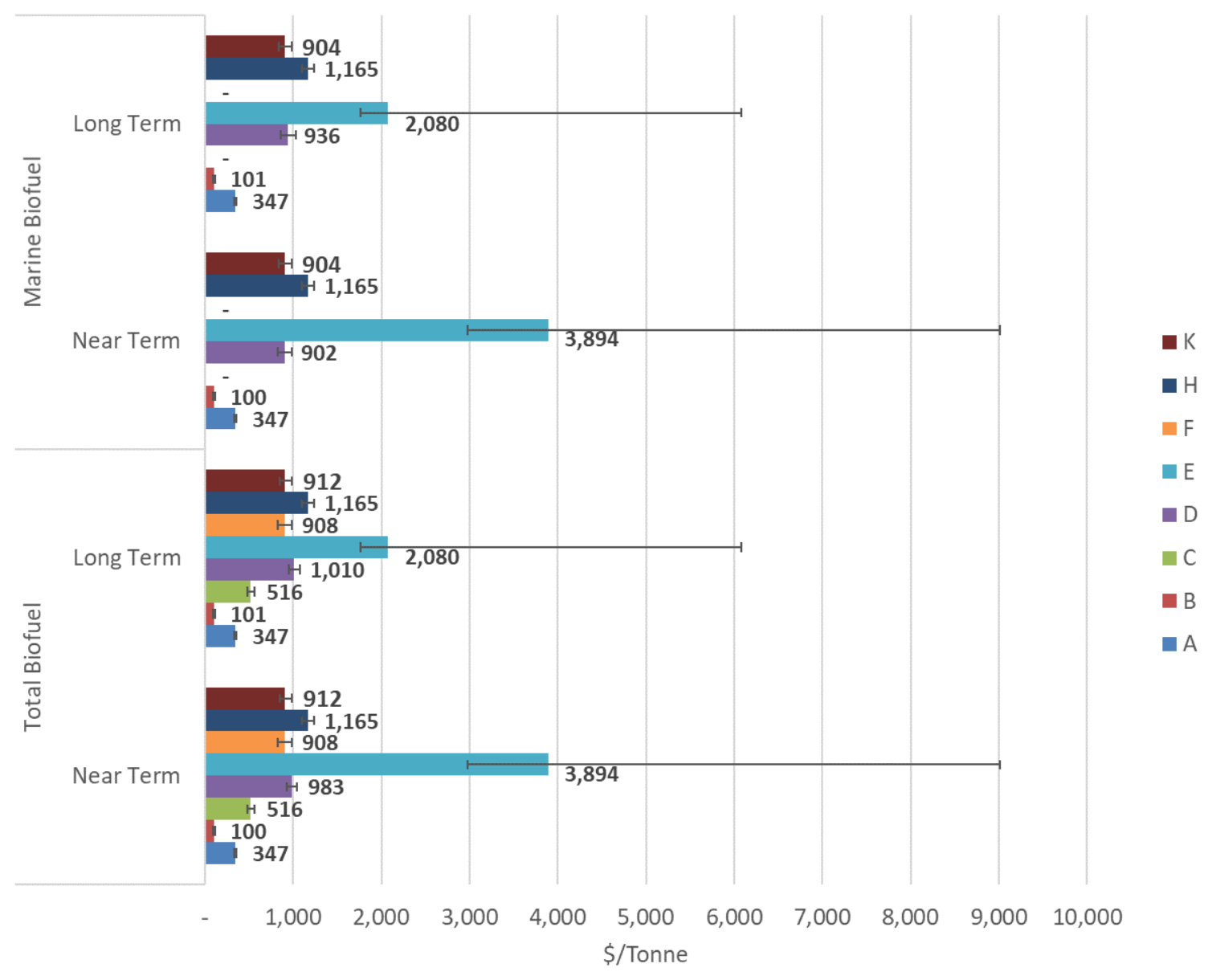

Figure 26. Price of produced biofuel per technology group on a per-ton basis for maximum total biofuel and maximum marine biofuel scenarios. Error bars indicate the maximum and minimum feedstock cost for each group.

\subsubsection{Biofuel Product Distribution}

Another critical aspect of the biofuel production analysis is the type of biofuel produced by a selected conversion pathway. Figure 27, Figure 28, and Figure 29 display the resulting product slate for each optimization scenario for the minimum, median, and maximum feedstock availability scenarios, respectively. 


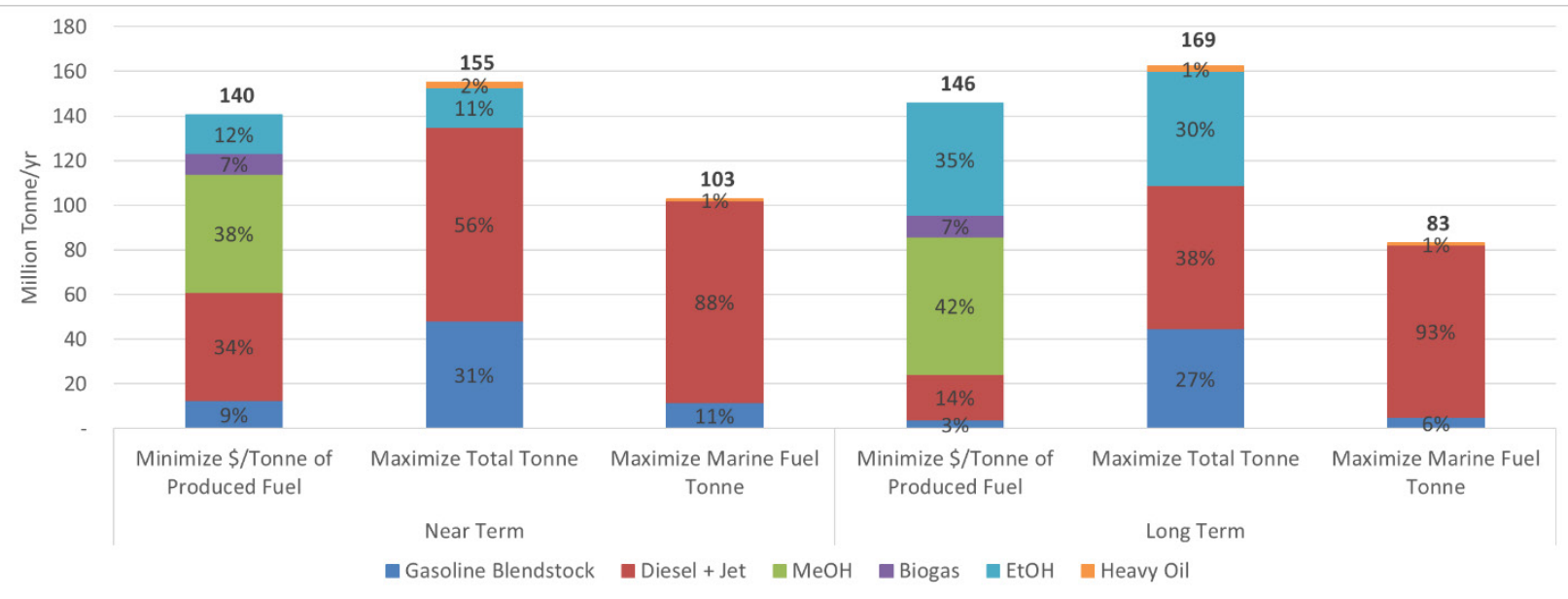

Figure 27. Biofuel product distribution for the minimum feedstock availability on a per-ton basis

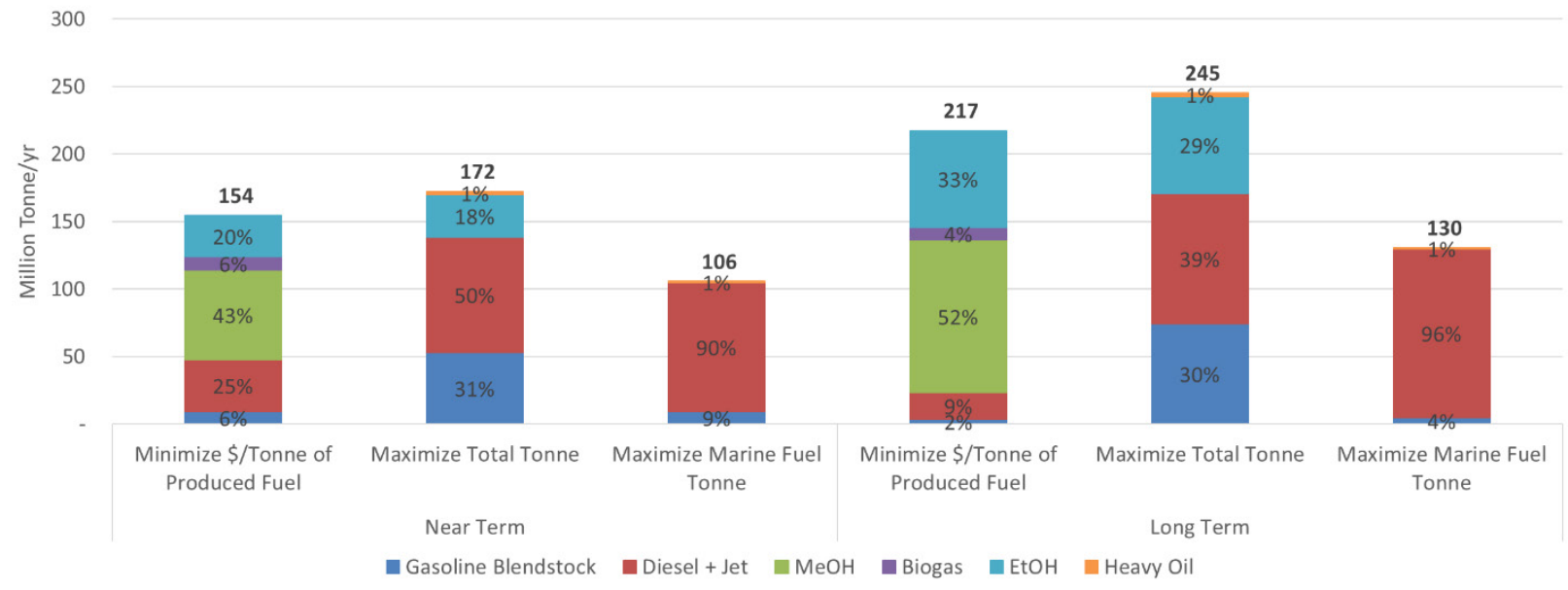

Figure 28. Biofuel product distribution for the median feedstock availability on a per-ton basis

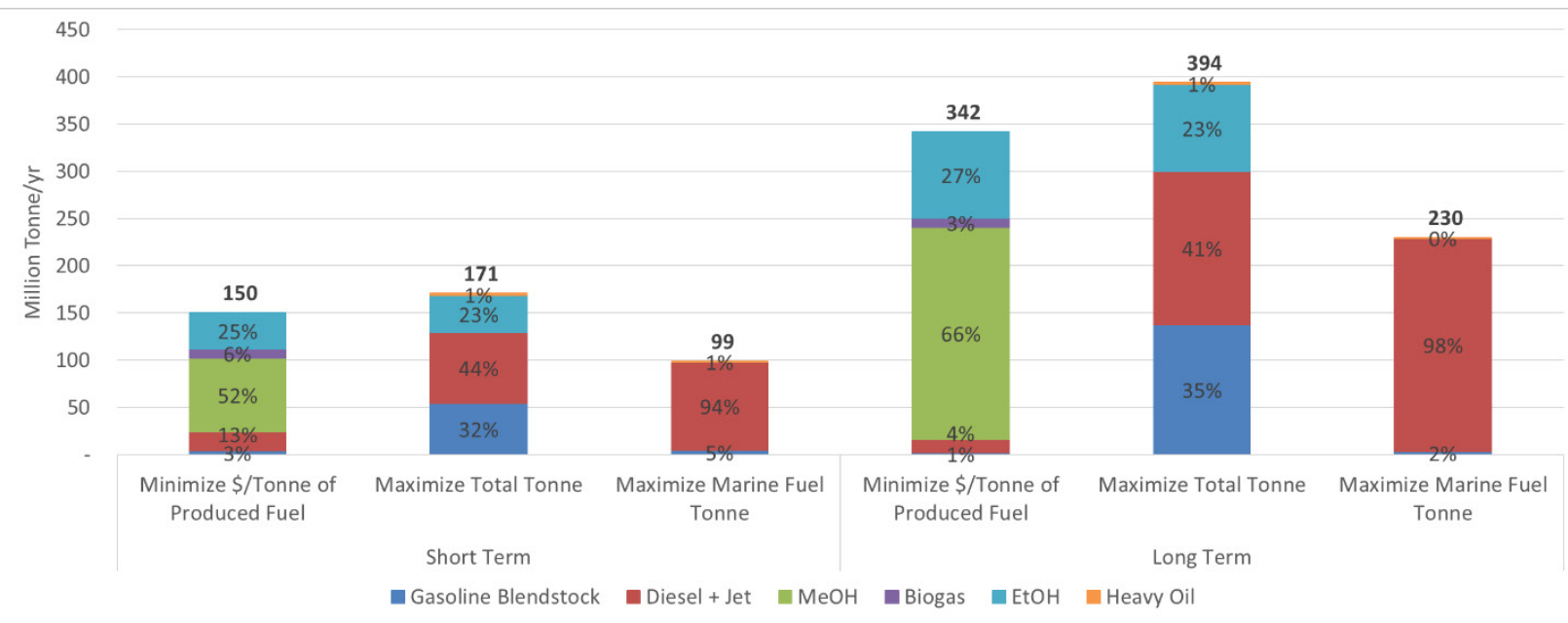

Figure 29. Biofuel product distribution for the maximum feedstock availability on a per-ton basis

For each feedstock availability scenario, the minimum cost objective function produces more methanol, ethanol, and biogas than the optimized production cases. Therefore, although the lowcost scenarios produce comparable amounts of fuel (Figure 20a and Figure 22a), the trade-off is 
in product distribution. The maximum total biofuel optimization case primarily produces gasoline, diesel, and ethanol. The marine biofuel scenario produces less fuel than the other two optimization scenarios due to the exclusion of pathways producing ethanol (such as Group C corn grain) or preferentially selecting pathways that produce greater proportions of diesel and jet, even at the expense of lower overall yield.

\subsubsection{Biofuel Capacity Sensitivity Study}

Sensitivity cases were conducted to provide insight into areas of uncertainty and identify the key factors impacting projected biofuel production capacity and cost. The sensitivity cases for biofuel production were conducted as follows:

- Yield: A factor of $\pm 20 \%$ was applied to the overall yield of the conversion pathways

- Feedstock availability: Refers to definitions of minimum, median, and maximum feedstock availability in Section 2.

This section summarizes the biofuel production sensitivity analysis conducted for both total biofuel production (Figure 30) and marine biofuel production (Figure 31). Results are shown for the near-term and long-term scenarios and are also broken up to either include or exclude algal biofuel contributions. In each case, the median (baseline) scenario is indicated by bold text.

In this analysis, the conversion pathway yield scales linearly with biofuel production. Therefore, a $\pm 20 \%$ factor applied to yield resulted in $\pm 20 \%$ in overall biofuel production. Feedstock availability also scales linearly with production. However, feedstock availability depends on both the minimum, median, and maximum designation, as well as near-term versus long-term factors. An interesting phenomenon occurs in the near-term scenario including algae. In this case, the median scenario is projected to have produced the most biofuel for both the total and marine biofuel cases. This is due to the inverse accounting scheme utilized for algae compared to terrestrial biomass (more algae is available at a lower cost). In reference to Figure 1, the increase in terrestrial biomass availability between the median and maximum case in 2022 (near term) is smaller in magnitude than the decrease in availability of algae between the same median and maximum case. Compounded with the respective yields of each pathway, this results in the perceived pattern. 

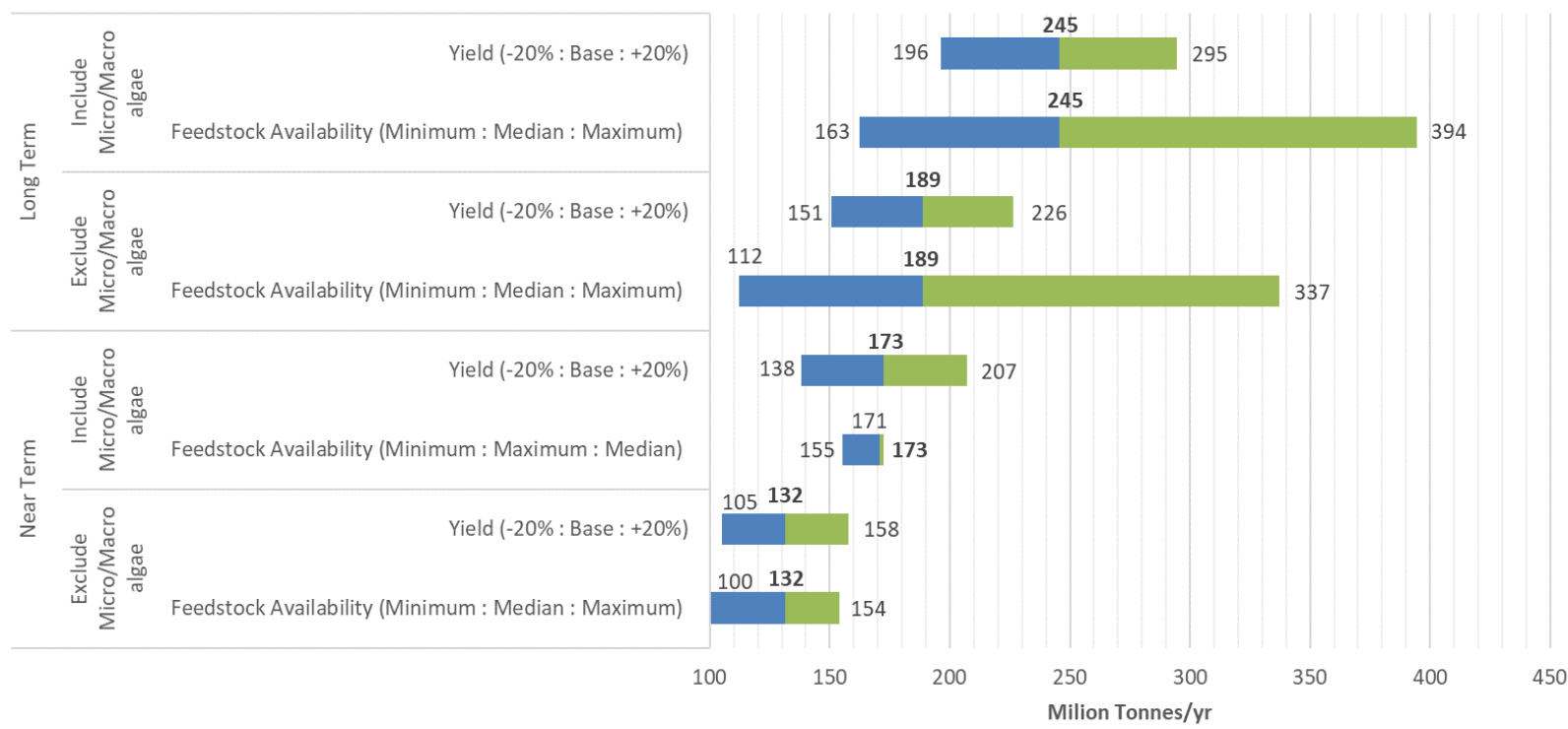

Figure 30. Sensitivity analysis for total biofuel production on a per-ton basis. Median (baseline case) for each scenario is shown in bold.
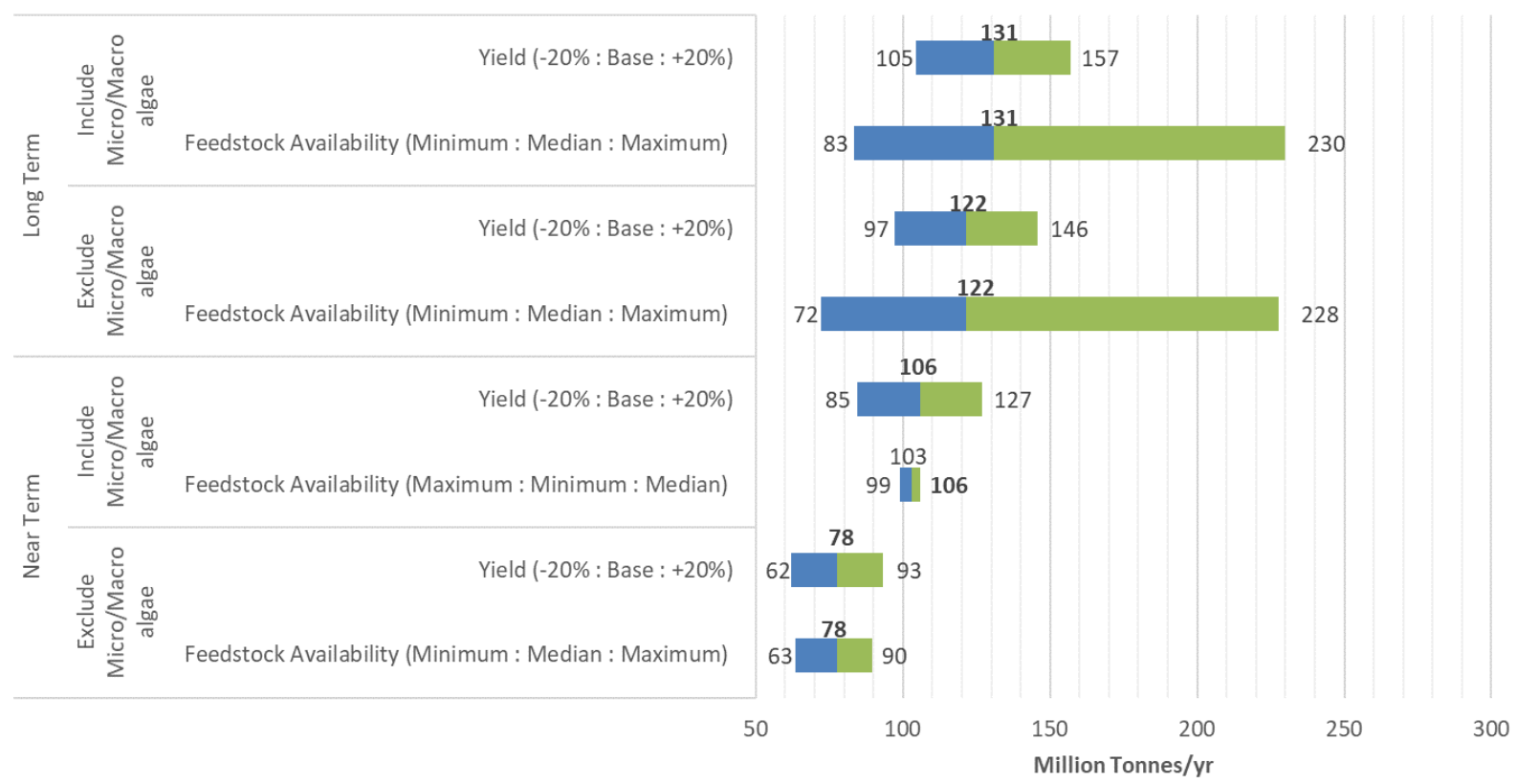

Figure 31. Sensitivity analysis for marine biofuel production on a per-ton basis. Median (baseline case) for each scenario is shown in bold.

\subsubsection{Biofuel Price Sensitivity Study}

Cost sensitivity scenarios were completed to analyze the biofuel production cost as a function of yield, feedstock cost (in the conversion pathway), capital expenses, operating expenses, and feedstock availability and cost (Section 2). This analysis was conducted for the near-term and long-term scenarios, including and excluding contributions from algae. 
In the near-term scenario including algae (Figure 32), the baseline weighted average biofuel cost was $\$ 1,704 / \mathrm{MT}$. The largest cost driver was yield, resulting in a cost increase of $25 \%$ when the yield was decreased by $20 \%$ and a cost decrease of $17 \%$ when the yield is increased by $20 \%$. The yield was followed by feedstock cost (from the conversion pathway).

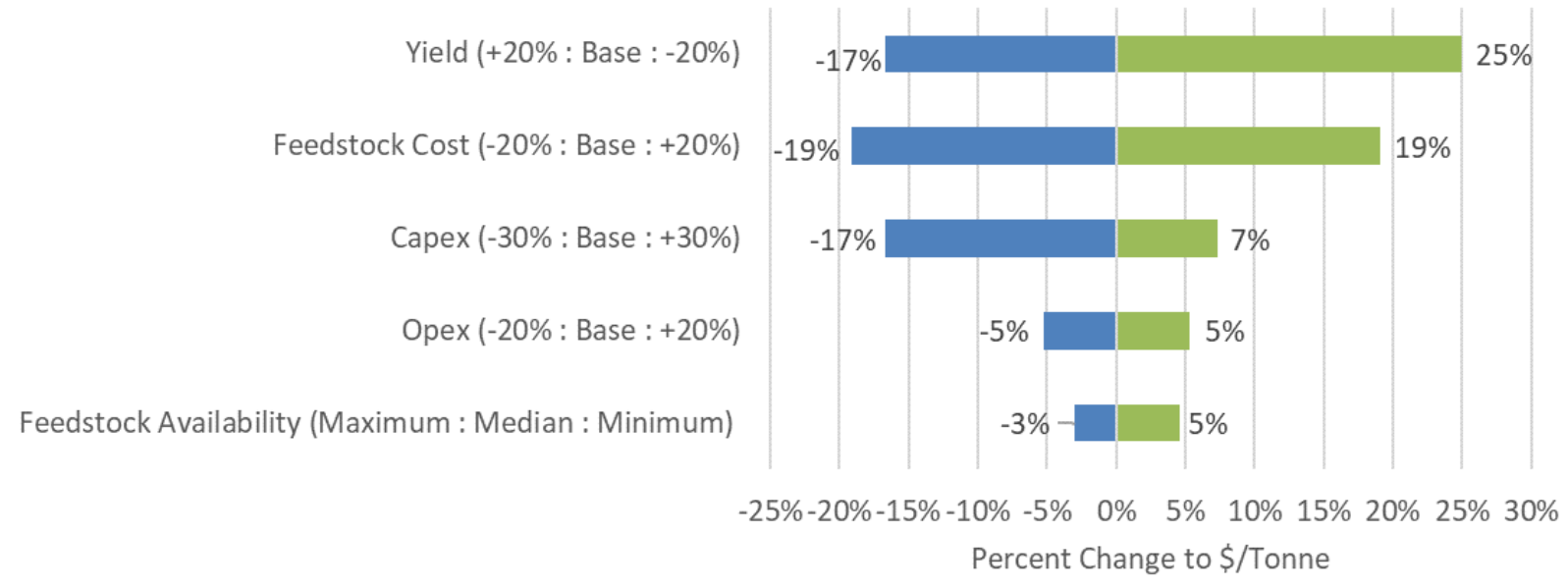

Figure 32. Near-term (2022) "minimize \$/MT of produced fuel" scenario sensitivity analysis for price of total biofuel production including micro/macroalgae on a per-ton basis. Baseline: $\$ 1,704 / \mathrm{MT}$.

Capex $=$ capital expenses; Opex $=$ operating expenses

In the near-term case excluding algae (Figure 33), the baseline weighted average biofuel cost is significantly lower $\$ 758 / \mathrm{MT}$ (a 56\% reduction from the case including algae). In this scenario, yield also had the largest impact on cost variability. However, capital expenses is the secondlargest driver versus feedstock cost.
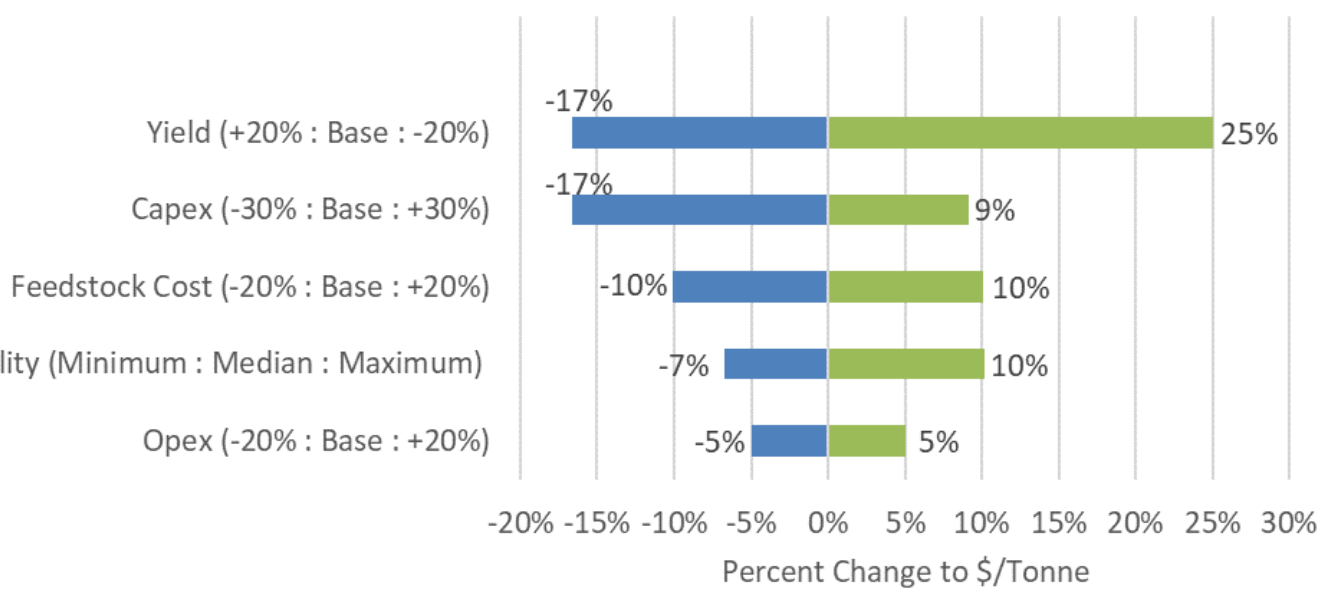

Feedstock Availability (Minimum : Median : Maximum)

Opex (-20\% : Base : +20\%)

Percent Change to $\$ / T o n n e$

Figure 33. Near-term (2022) "minimize \$/MT of produced fuel" scenario sensitivity analysis for price of total biofuel production excluding micro/macroalgae on a per-ton basis. Baseline: \$758/MT.

The baseline cost for the long-term scenario including algae (Figure 34) is $\$ 967 / \mathrm{MT}$. The sensitivity variables in this scenario follow the same trend as that displayed in the near-term case 
including algae. The long-term case excluding algae displays moderate reductions in cost at \$816/MT biofuel (Figure 35).

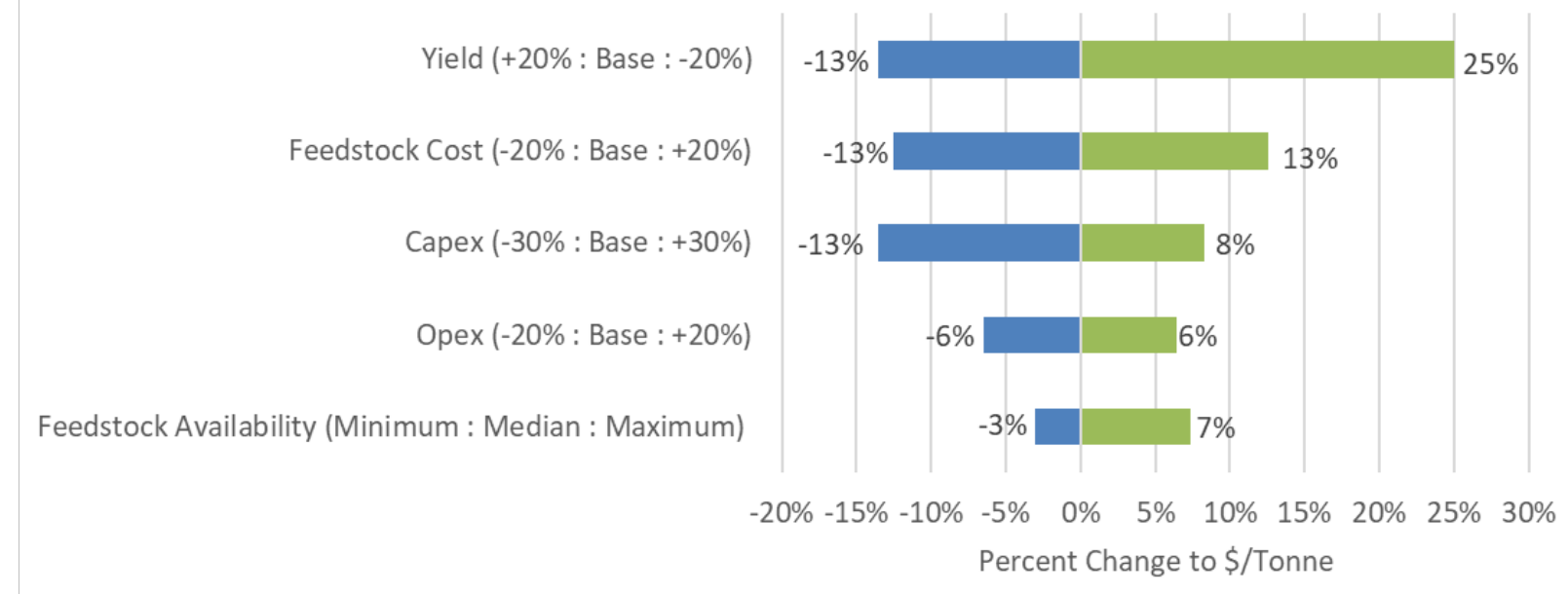

Figure 34. Long-term (2040) "minimize \$/MT of produced fuel” scenario sensitivity analysis for price of total biofuel production including micro/macroalgae on a per-ton basis. Baseline: \$967/MT.

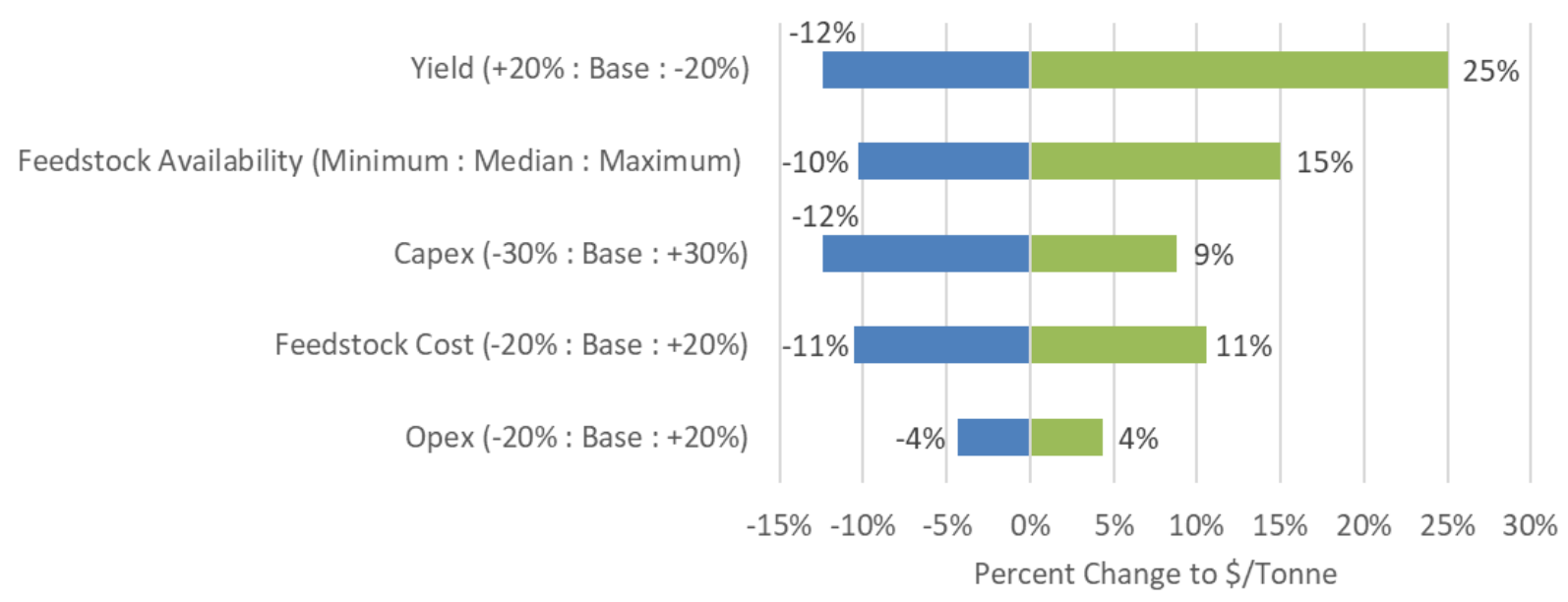

Figure 35. Long-term (2040) "minimize \$/MT of produced fuel" scenario sensitivity analysis for price of total biofuel production excluding micro/macroalgae on a per-ton basis. Baseline: $\$ 816 / \mathrm{MT}$.

\section{Biofuel Adoption for Marine Shipping}

\subsection{Biofuel Availability and Demand}

A high-level summary of the projected biofuel availability is provided in Figure 36 . To provide context, data for current and projected renewable energy consumption in the United States were collected from the EIA database (U.S. EIA 2020a). Figure 37 presents the total renewable energy usage by sector in the United States projected for 2022 (14.0 exajoules [EJ]) and 2040 (18.3 EJ). The total renewable energy includes renewable energy consumed from biomass and other renewable sources (i.e., solar, wind, geothermal, hydroelectric). Biomass utilization, shown in 
Figure 37 as the solid shaded portions, is projected to contribute $41 \%$ of the total renewable energy consumption in 2022 and 34\% in 2040.

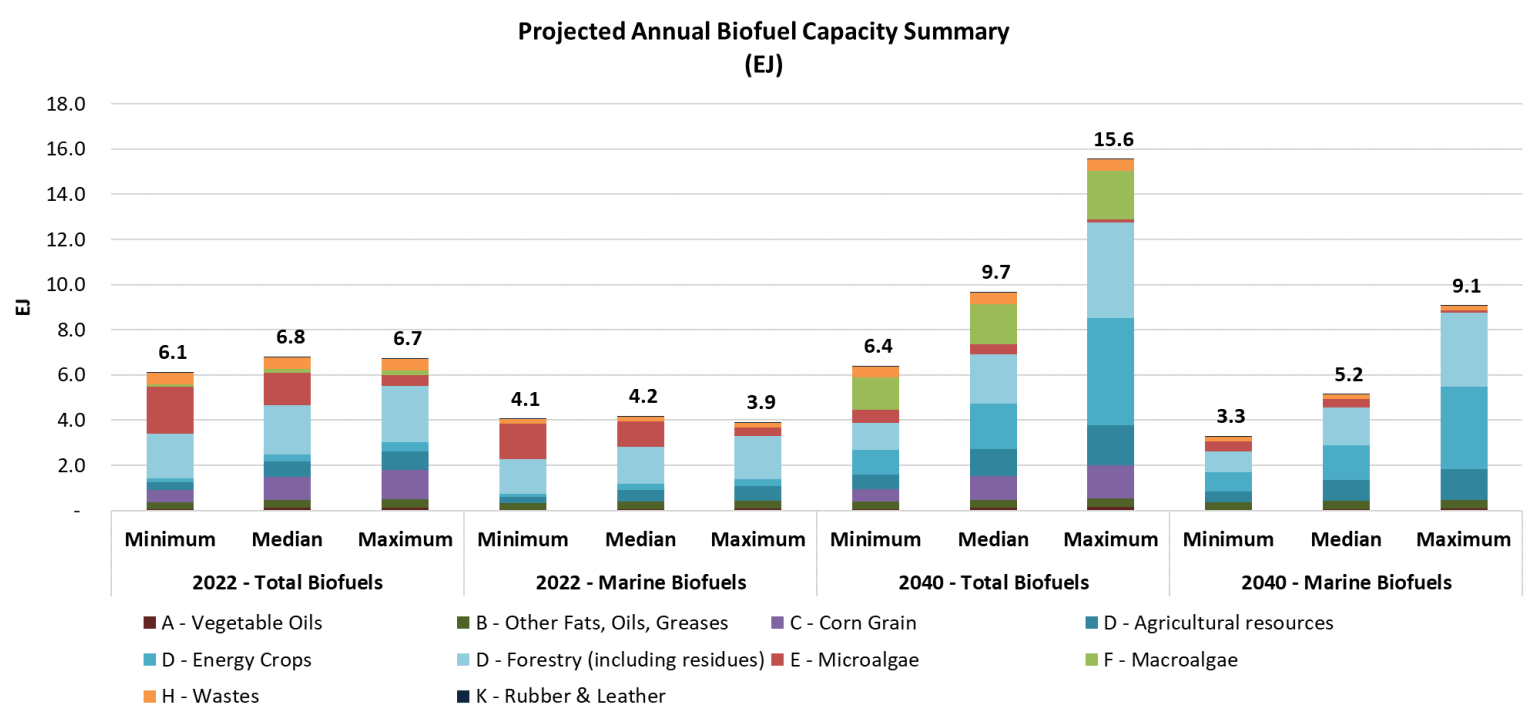

Figure 36. Summary of the projected annual biofuel capacity in exajoules. Total annual biofuel production capacity is broken down into minimum, median, and maximum scenarios according to feedstock availability. A distinction is also made between total biofuel availability and marine biofuel availability. Further details are provided for each scenario in which relative contributions from each technology group are shown. Technology Group D contributed a significant percentage of each scenario and was therefore broken down even further into subgroups.

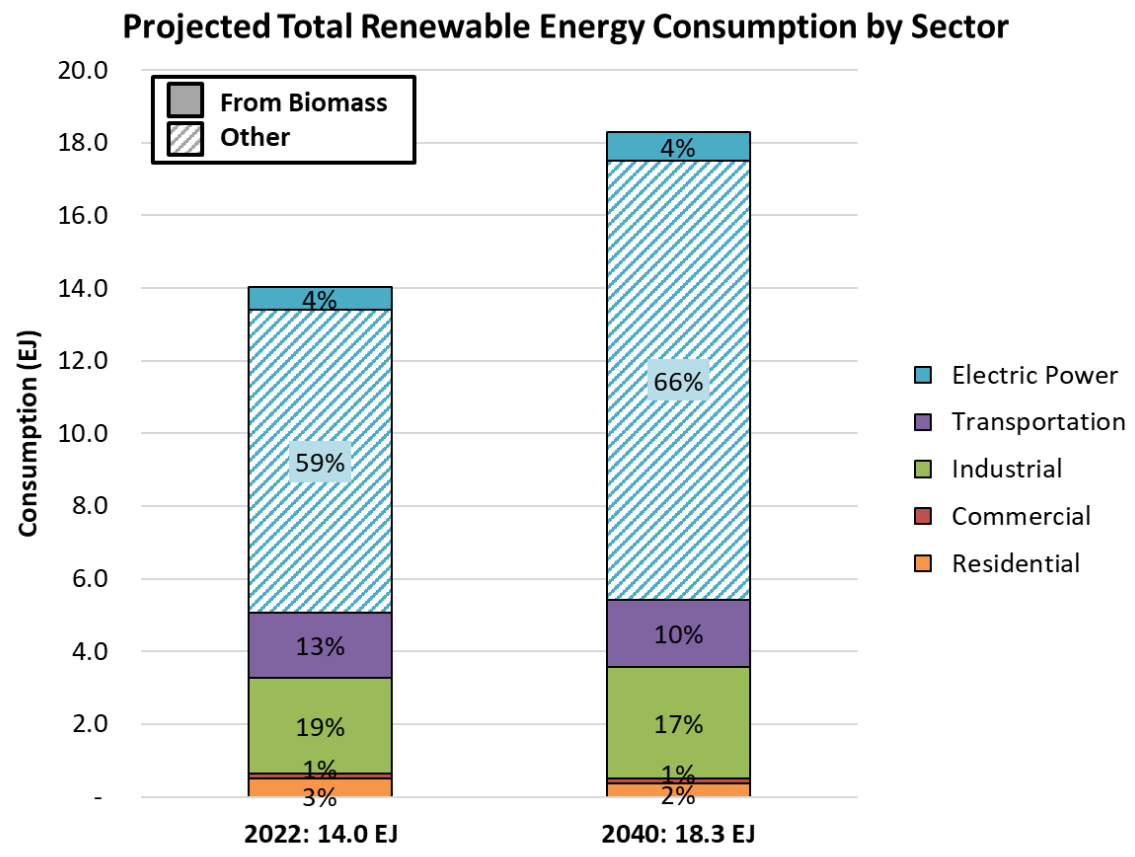

Figure 37. Total projected renewable energy consumption by sector, created with data obtained from EIA (U.S. EIA 2020a). Solid sections represent renewable energy consumed from biomass, and striped sections represent renewable energy from other technologies such as solar, wind, geothermal, and hydroelectric power. 
Further consolidation of the data to include only biomass-based energy (as heat, power, or liquid fuels) is represented in Figure 38 (the shaded portions in Figure 37). EIA projects 5.7 EJ of biomass-based energy consumption in 2022 and $6.2 \mathrm{EJ}$ in 2040. Of this projected amount, the transportation sector is expected to consume 32\% (1.7 EJ) in 2022 and 30\% (1.8 EJ) in 2040. It is important to note that this excludes the energy demand for electric vehicles, which would contribute to the increased consumption of electric power shown in Figure 37.

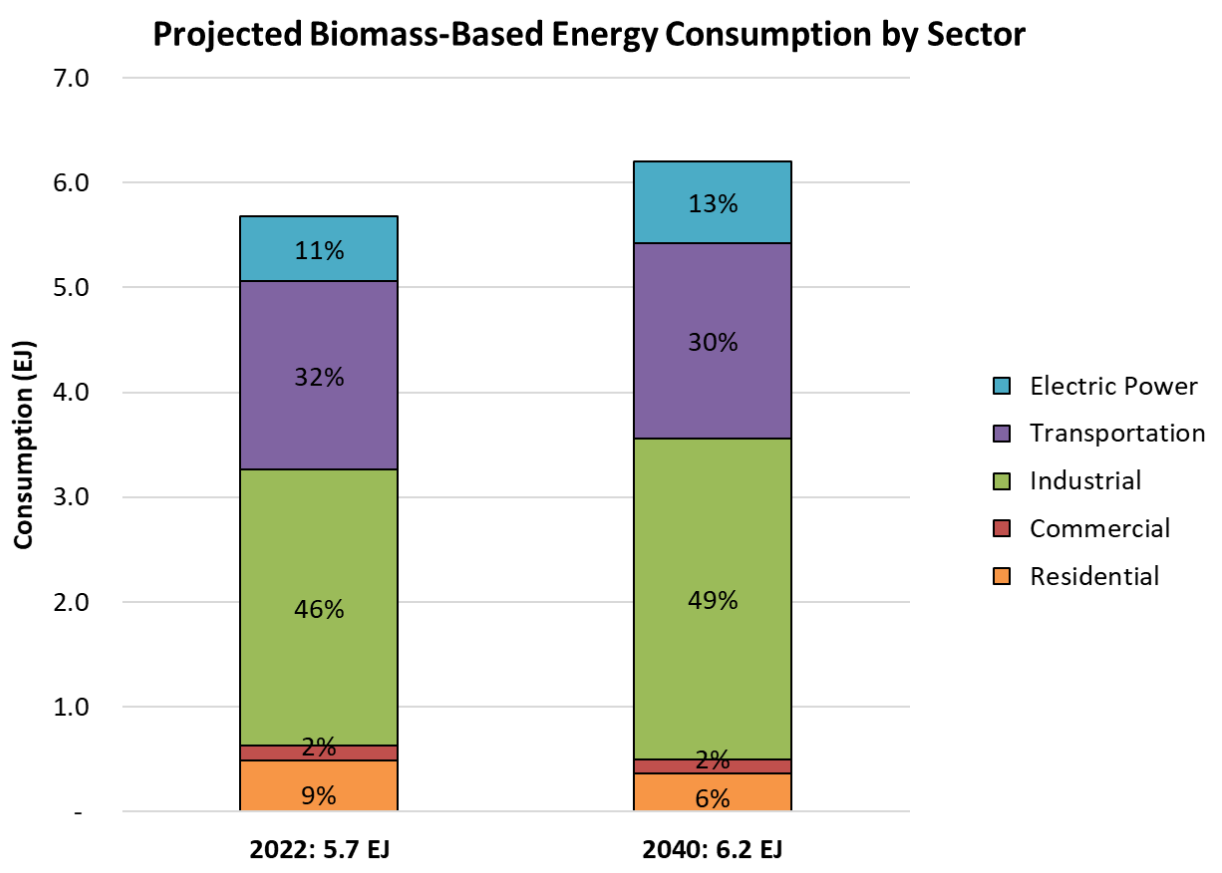

Figure 38. Biomass-based projected renewable energy consumption by sector in 2022 and 2040 . Created with data obtained from EIA (U.S. EIA 2020a).

Overlaying EIA's projected domestic biofuel demand with the projected biofuel availability calculated in this report (Figure 39) shows excess biofuel availability (based on demand) in both the near-term and long-term scenarios, indicating the potential for growth. Even the minimum biofuel availability scenarios could also meet the projected demand. It is also important to note that the projected biofuel consumption by EIA included energy consumed for heat and power versus conversion to liquid fuels in this report. Additionally, liquid transportation fuel demand also includes consumption for marine shipping. 


\section{Projected Total Biofuel Availability and Projected Demand (Energy Basis)}

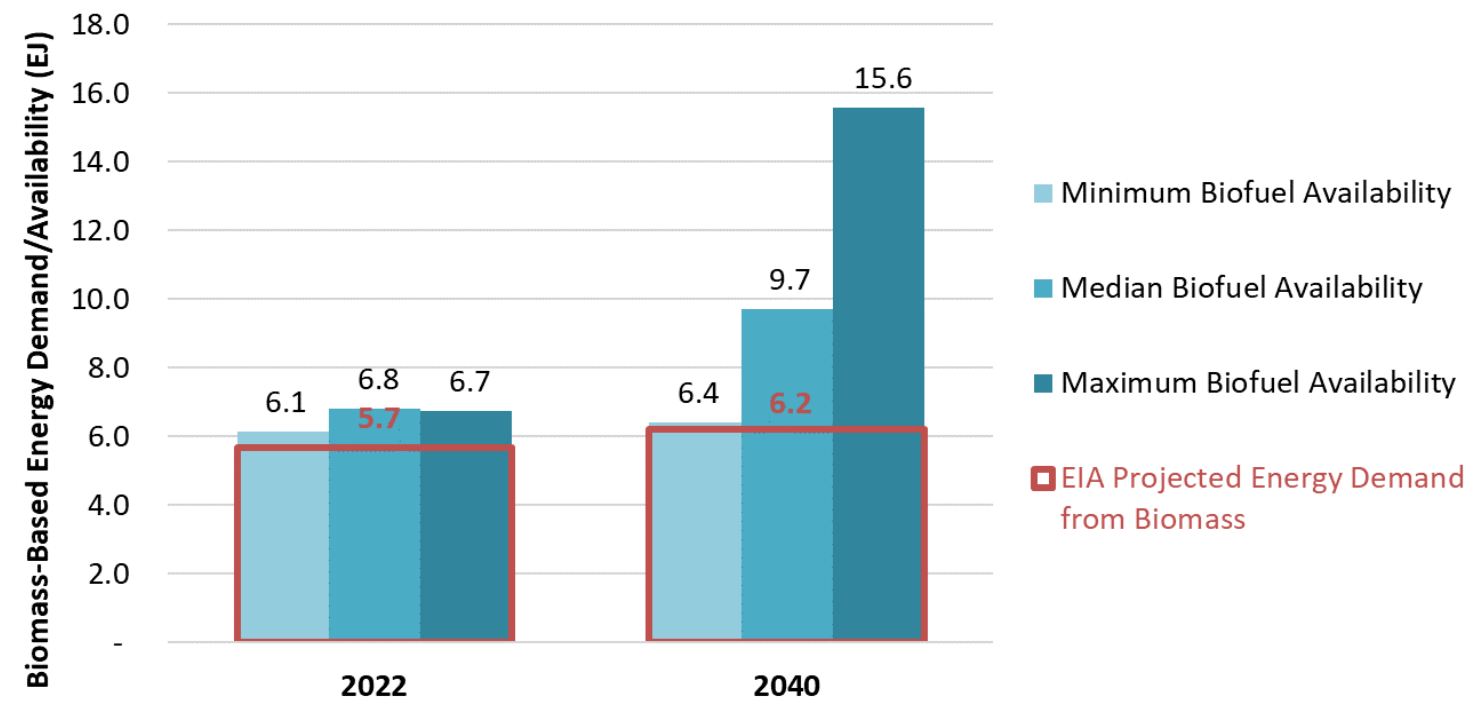

Figure 39. Total biofuel capacity projections versus demand projected by EIA

Although total biofuel capacity is projected to meet this demand, including only marine biofuels is not sufficient to meet the total projected demand in any scenario except for the long-term maximum feedstock availability scenario, as shown in Figure 40.

\section{Projected Marine Biofuel Availability and Projected Demand (Energy Basis)}

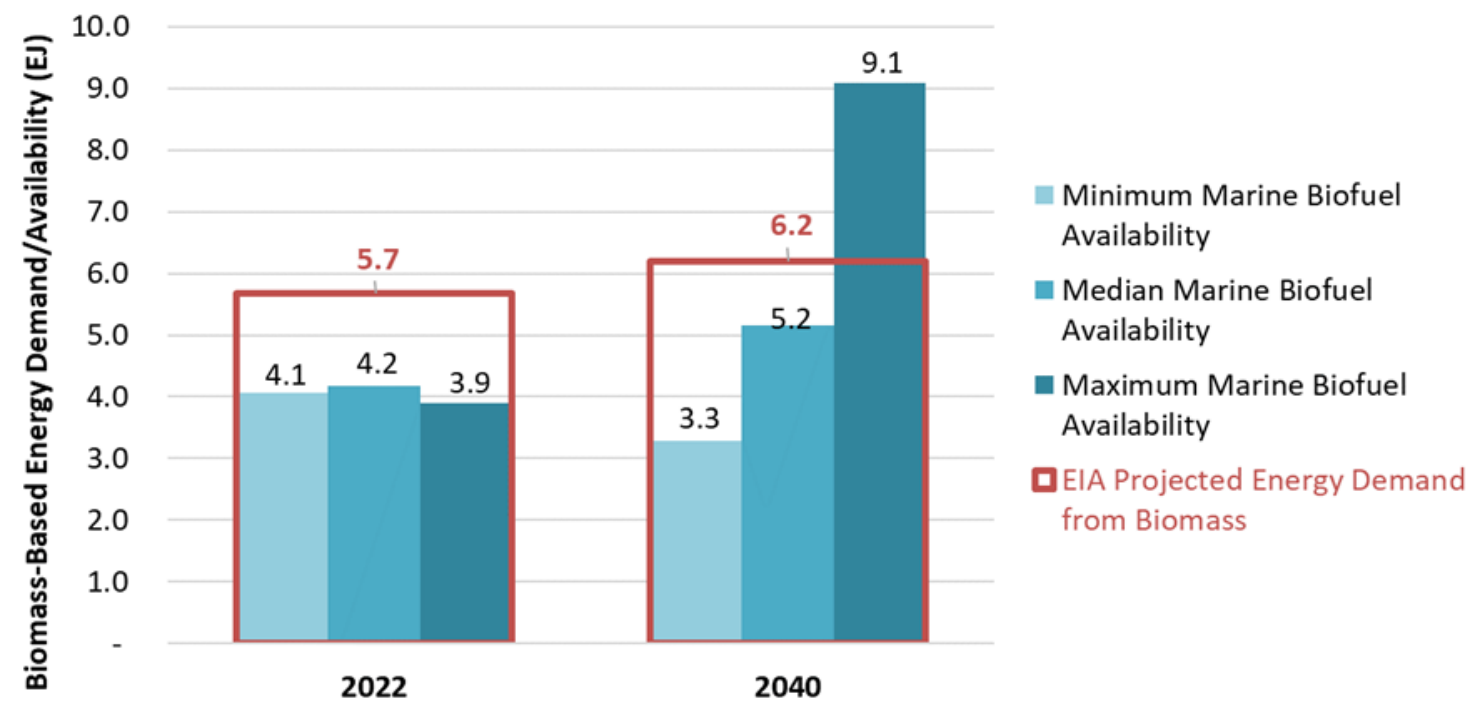

Figure 40. Total marine biofuel capacity projections versus demand projected by EIA

Despite the promising results represented by the projected biofuel availability versus demand, the total biofuel production projections are still a fraction of the total energy consumption of the transportation sector alone. In 2022, the total consumption of the transportation sector is 
projected to be 29.2 EJ, and 26.41 EJ in 2040. Reduced consumption between 2022 and 2040 is a function of increased end-use efficiency and reduced use for some subsectors.

Figure 41 and Figure 42 indicate the breakdown of projected demand by transportation subsections (e.g., ground transportation, air, marine). Marine fuels are projected to contribute only $4 \%$ (about $1.23 \mathrm{EJ}$ ) of the total consumption in 2022 and 5\% (about $1.21 \mathrm{EJ}$ ) in 2040. Per our analysis, enough biomass could be utilized to cover the marine fuel sector completely. However, actual biofuel usage and availability will depend on competition from other sectors.

\section{Total Transportation Energy Consumption: 29.17 EJ}

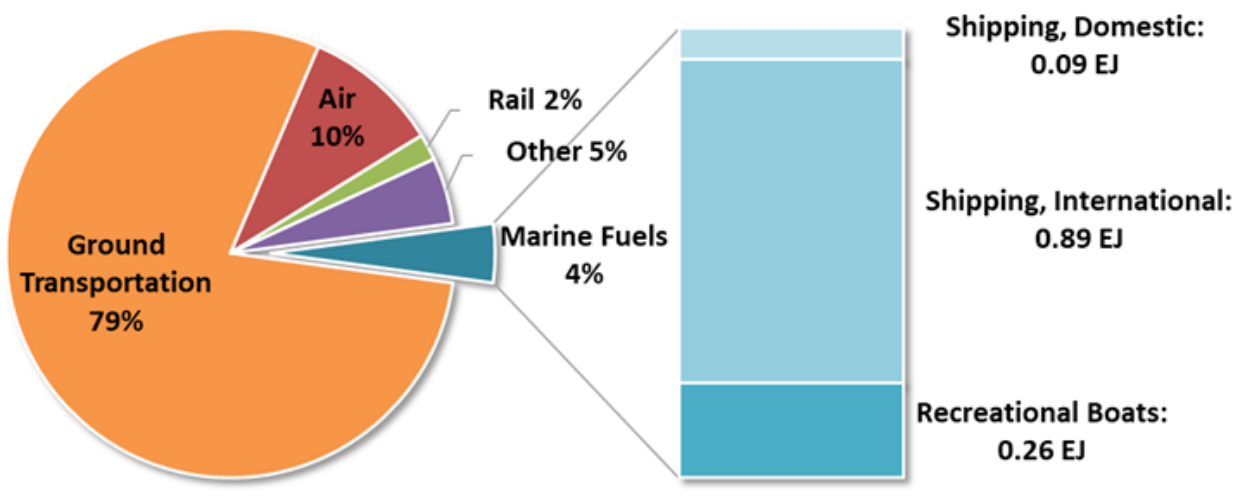

Figure 41. Transportation sector energy consumption projections in 2022 by EIA 2040 Total Transportation Energy Consumption: 26.41 EJ

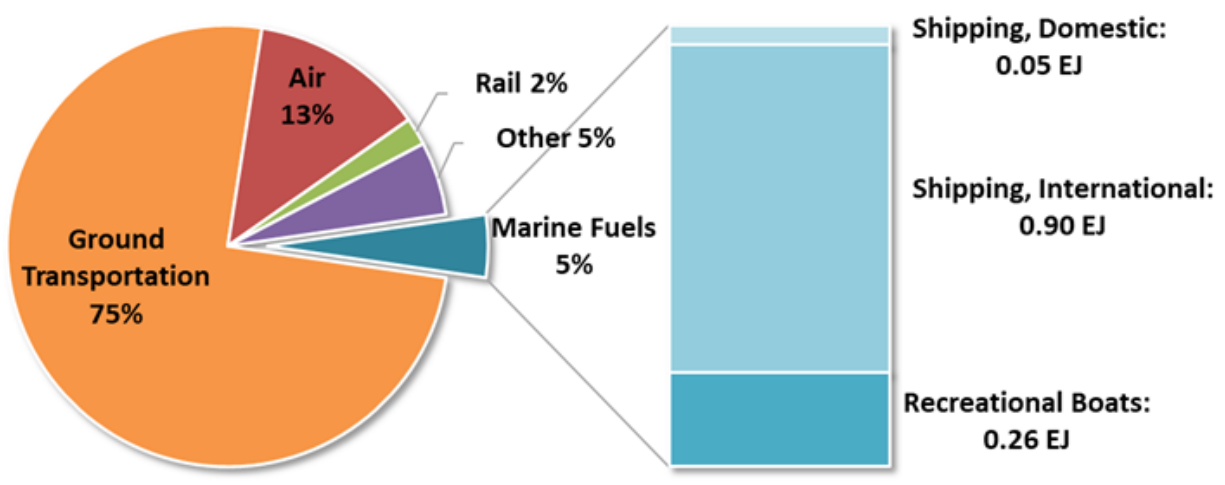

Figure 42. Transportation sector energy consumption projections in 2040 by EIA

\subsection{Biofuel Price and Maritime Adoption}

\subsubsection{Strategies To Lower Biofuel Price}

The choice of biofuel adoption to enable the shipping industry to comply with low-sulfur regulations and achieve long-term decarbonization is primarily dependent on the vessel owner's financial decisions. Fuel costs represent more than 50\% of total operating expenses, making it challenging for shippers to absorb additional operating expenses and stay operational (IHS Markit 2019). 
Projected biofuel prices are higher than current marine fossil fuel prices. The projected long-term biofuel prices average $\$ 1,157 / \mathrm{MT}$ for the maximized total biofuel scenario (Figure 20b) and $\$ 967 / \mathrm{MT}$ for the minimized price scenario (Figure 22b). To put this into perspective, the average 2019 MGO price was $\$ 700 / \mathrm{MT}$, and at the time of this report writing, the MGO price was about \$560/MT (Ship \& Bunker 2020). However, these projected prices are weighted averages from all evaluated technology groups (i.e., culminating from various feedstock and production pathway combinations). Note that in order to consider all potentially available feedstocks in the United States for the total biofuel capacity projection, it is inevitable that certain expensive feedstocks and pathways, such as algal pathways, are also included in the analysis, resulting in the overall high fuel price. Still, there are pathways and technology groups that produce biofuels that are price competitive with fossil fuels. For example, technology Groups A, B, and C in Figure 26 and Figure 43 exhibit biofuel prices similar to or even better than fossil fuels (less than $\$ 500 / \mathrm{MT})$. Moreover, when higher-cost algae pathways are excluded, the weighted biofuel price can be around \$730/MT (Figure 22), which is very close to the 2019 MGO price (pre-COVID-19 pandemic).

Scaling up biofuel production at a given time point (i.e., near-term [2022] or long-term [2040] scenario) appears to have an inverse relationship to price. That is, the more biofuel produced, the higher the biofuel price. As scaling up will require more biomass feedstock, the higher feedstock demand will introduce new logistical challenges (Langholtz, Stokes, and Eaton 2016) that would need to be considered, including feedstock harvesting, delivery, and storage. Thus, feedstock availability and cost are largely dictated by the feedstock handling technologies that handle the logistical constraints within a given time point. As higher feedstock availability is associated with higher feedstock cost (Figure 44), scaling up (utilizing more feedstocks) will lead to higher biofuel production costs. However, when the perspective shifts from scaling up within a given time point to scaling up over time (between 2022 and 2040), logistical limitations are overcome with improved technologies; it is plausible to achieve much larger capacities of biofuel production at similar or potentially lower costs. For example, Figure 45 shows that for the maximum total biofuel production scenario, the potential biofuel capacity increases by over $40 \%$ between 2022 and 2040, attributing to increased feedstock availability. During the same period, the projected biofuel price decreases by $36 \%$. Although both the short-term and long-term feedstock prices for terrestrial biomass remain constant in each feedstock availability scenario (i.e., minimum, median, maximum) within a given feedstock group, microalgae prices are projected to reduce over time. Thus, including microalgae as a feedstock can also decrease the overall biofuel price in the long run. 


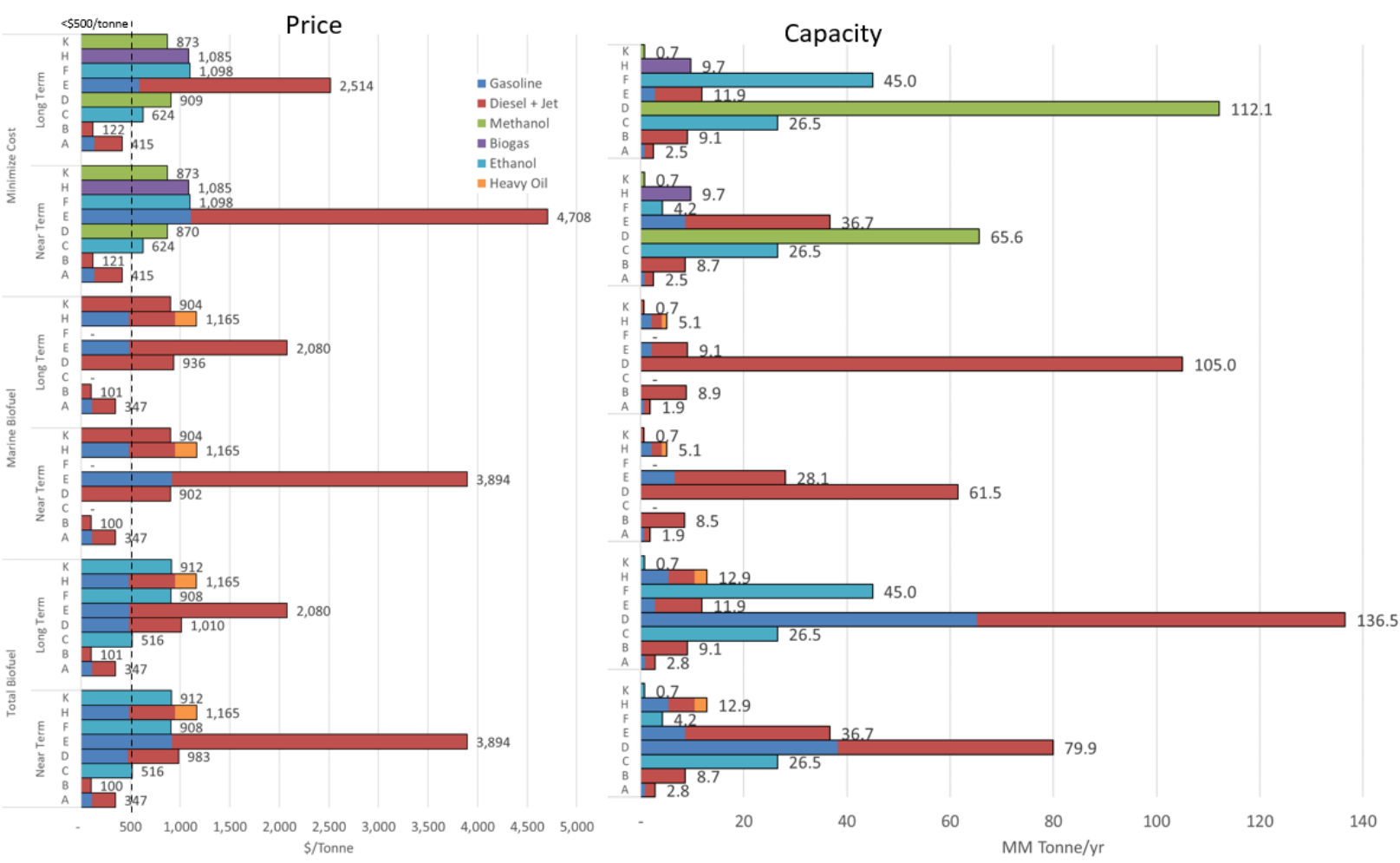

Figure 43. Projected biofuel prices and annual production capacities for the evaluated technology groups based on median feedstock availability. Note that for the price figure, fuel distribution is a percentage, not additive contributions, to total fuel cost. 


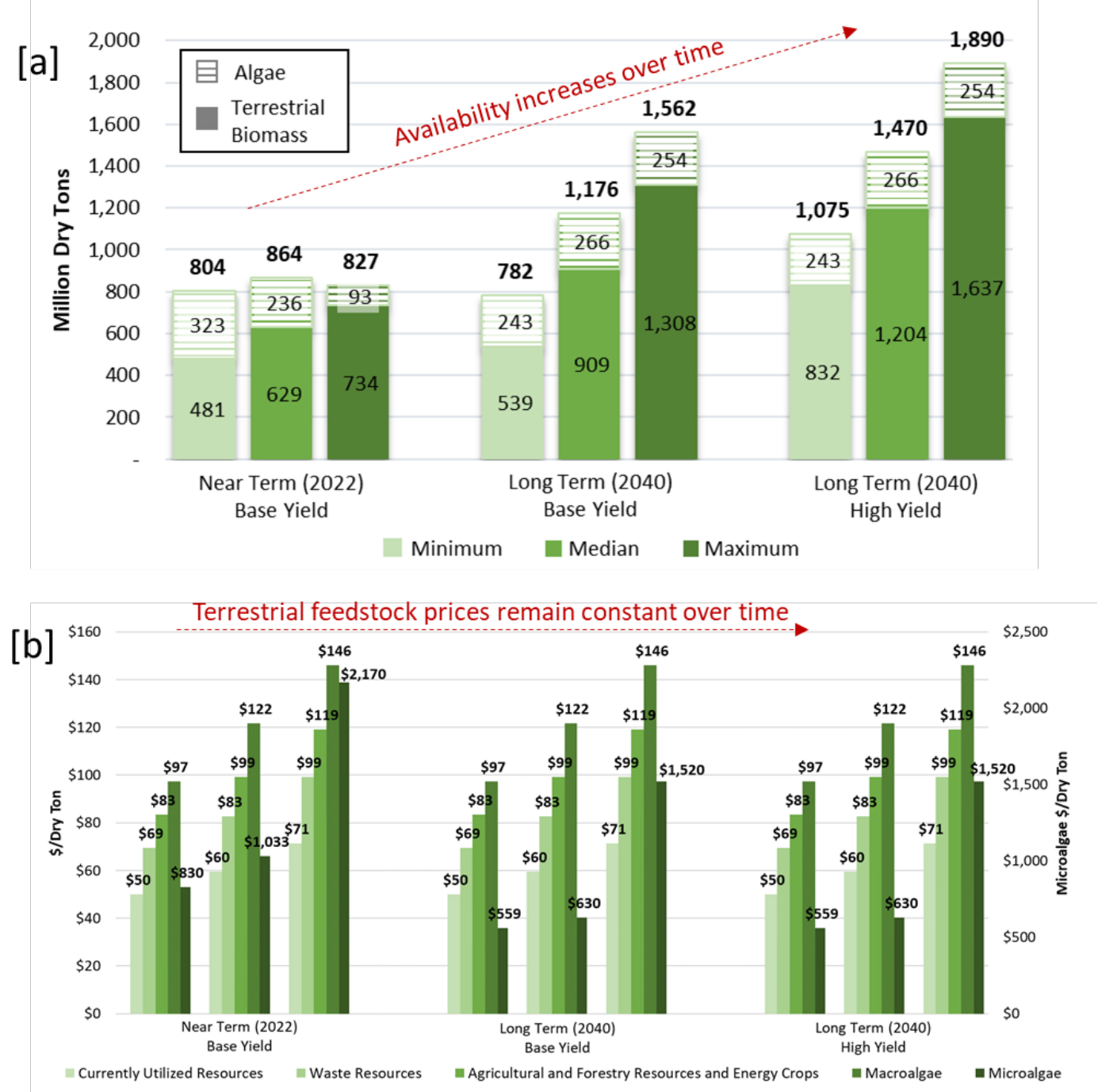

Figure 44. Summary of (a) feedstock availability and (b) feedstock prices derived from BT16. With the exception of microalgae, all feedstock availability was determined at fixed feedstock prices. Contrary to terrestrial feedstocks, as microalgae prices increase, availability decreases. 


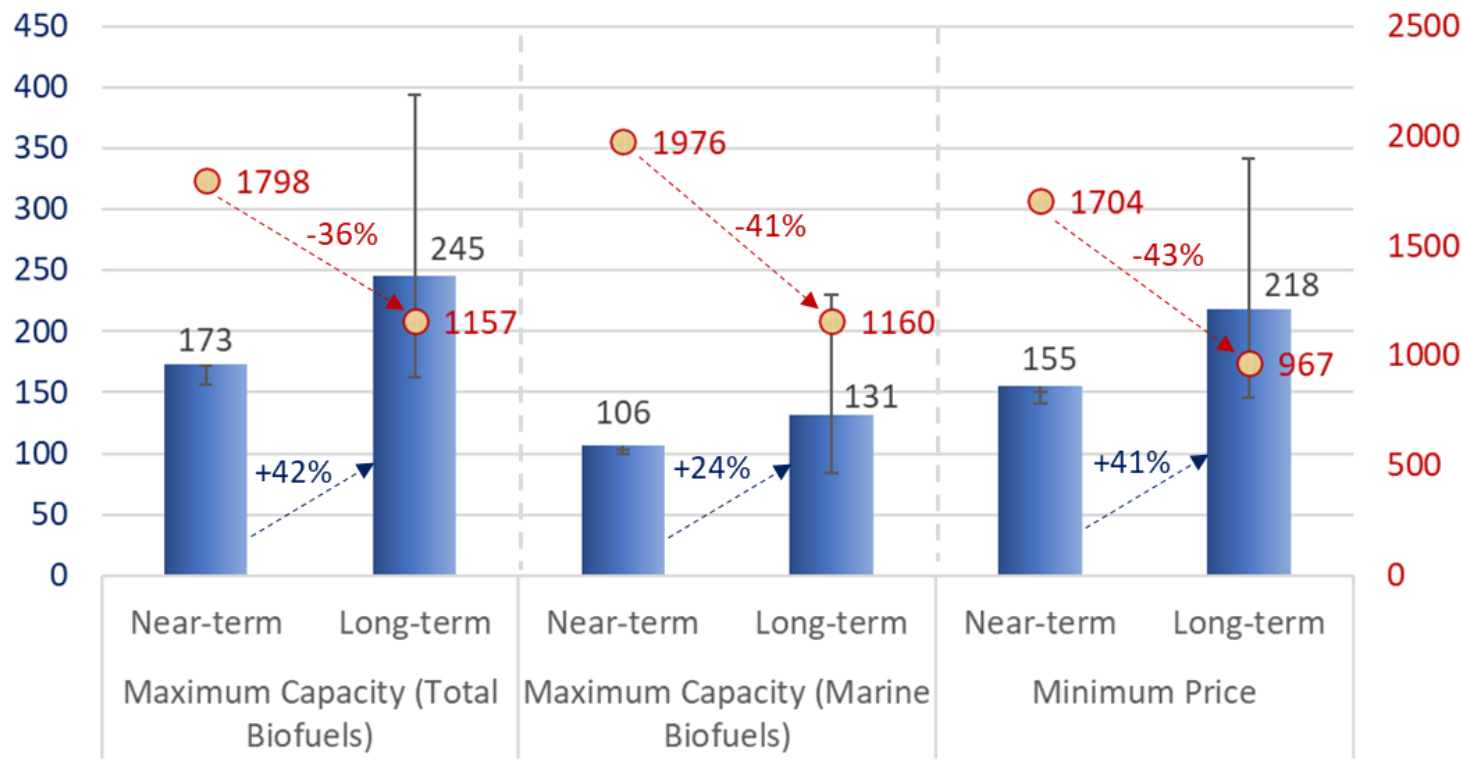

Figure 45. Summary of near-term (2022) and long-term (2040) projected annual biofuel capacity (in million metric tons [MM MT]) and price (in \$/MT) based on the U.S. feedstock availability. Error bars are the range of annual capacities corresponding to minimum and maximum feedstock availability. Note: 1 gal HFO = 140,353 Btu; 1 MT = 267 gal HFO.

Additionally, the biofuel product slate is related to biofuel prices. There is a trade-off between price and product distribution (Figure 27, Figure 28, and Figure 29). For each feedstock availability scenario, the minimized cost scenario produces more methanol, ethanol, and biogas than the cases that are optimized for biofuel production. The maximum total biofuel optimization case primarily produces gasoline, diesel, and ethanol. The marine biofuel scenario produces less fuel than the other two optimization scenarios due to the exclusion of pathways producing ethanol or due to preferentially selecting pathways that produce greater proportions of diesel and jet, even at the expense of lower overall yield.

Figure 43 shows that technology Groups A and B can produce low-price biofuels (up to about \$500/MT), predominantly dominated by biodiesel from vegetable oils and fats, oils, and greases. Due to low feedstock availability, the projected annual capacity for biodiesel is a mere 12 million MT. When the price point increases to $\$ 750 / \mathrm{MT}$, the capacity increases to 29 million MT, of which about 17 million MT is attributed to corn ethanol. Incidentally, the corn ethanol price was around $\$ 1.52 / \mathrm{gal}$ (or \$746/MT HFO equivalent) at the beginning of 2021. At a higher price point, both the biofuel types and annual capacity increase substantially (218 million MT/year), as depicted in Figure 46. Essentially, all the second- and third-generation biofuels are greater than $\$ 750 /$ MT. Consequently, lowering the biofuel price to a more acceptable level holds the key for the maritime sector to tap into the projected biofuel capacity.

Biofuel production cost correlates strongly with feedstock cost and conversion cost (depending on the selected pathway). Feedstock cost is the key cost contributor to biofuel production (Figure 13). The strategies to reduce feedstock costs include the utilization of waste and low-quality 
feedstocks, the adoption of integrated landscape management strategies, and feedstock logistic enhancement. Improving material conversion and utilization efficiency and energy sustainability via process intensification can improve the biorefinery economy (Tan 2019). Additionally, coprocessing biomass with fossil feedstock such as natural gas has shown to be an effective synergistic approach to improve liquid fuel yields and lower production cost (Tan and Tao 2019). Furthermore, to enable biofuels to be economically viable, BETO has recently identified five integrated strategies needed to achieve lower biofuel production costs in an integrated biorefinery: developing atom-efficient biorefineries, intensifying process designs, utilizing existing infrastructure, reducing feedstock costs, and developing high-value products (BETO 2020).

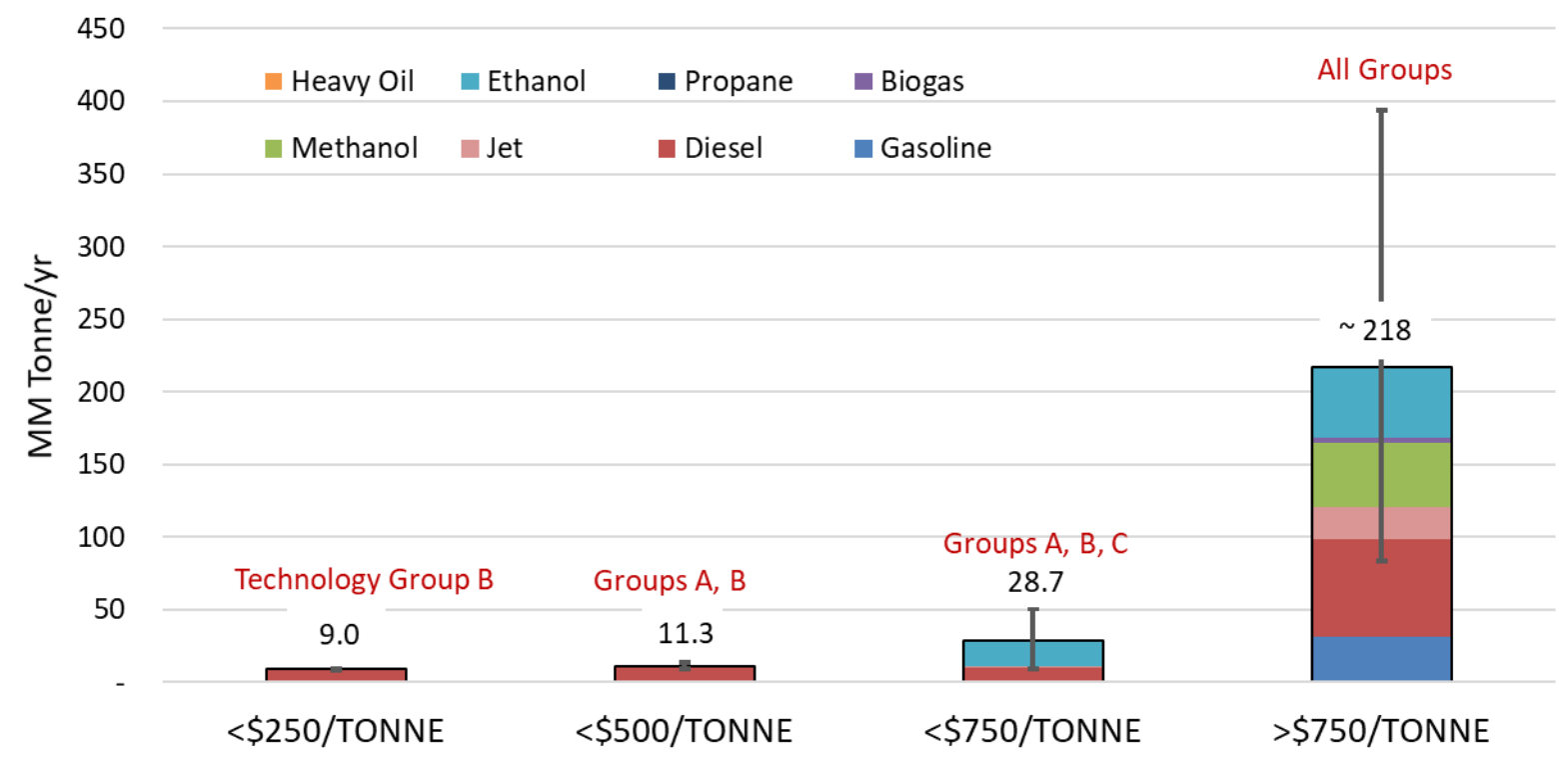

Figure 46. Consolidated long-term projected biofuel capacity and product slate at various price ranges

\subsubsection{Incentive Schemes To Facilitate Maritime Biofuel Adoption}

In addition to the aforementioned technical solutions and strategies to lower biofuel production costs, policies and economic incentives would also help facilitate maritime biofuel adoption, as some form of economic support mechanism would help facilitate biofuel development during the nascent stages of marine biofuel adoption. The potential for an additional price reduction coupled with incentives and policies would further enable biofuel adoption for maritime (in terms of pricing).

There are a number of examples of policies geared directly toward the marine sector. A clear example is the "Clean Inland Shipping and Sustainable Logistics in Rotterdam," a temporary financial support incentive scheme supported by EICB (Expertise and Innovation Centre Inland Shipping) in cooperation with the Port of Rotterdam. The incentive scheme has accelerated the adoption of biofuels, as illustrated by the successful demonstration of the first inland vessel running on $100 \%$ drop-in replacement biofuel produced by GoodFuels for Heineken to transport its beers from its brewer in Zoeterwoude to the Port of Rotterdam (GoodFuels 2019). A similar approach for ocean freight is underway, led by GoodFuels in collaboration with IKEA, the 
shipping company CMA CGM, and the GoodShipping Program (Supply Chain Movement 2019).

Other existing financial incentive schemes that help accelerate the adoption of clean fuel and technologies for maritime shipping include the Environmental Ship Index, Clean Shipping Index, GHG Emissions Rating, and Green Award, as illustrated in Figure 47 (Becqué, Fung, and Zhu 2018; Meister and Wagner 2018). Collaborating among multiple ports on major shipping routes and ship owners, these incentive programs encourage shipowners and operators to reduce air pollution from their ships by adopting green shipping practices, of which marine biofuel can play an important role. Qualified ships will receive incentives from all participating ports and other incentive providers participating in these programs. For example, qualified ships will be rewarded with decreased port dues that can offset the (bio)fuel costs. The U.S. government, ports, and industry could benefit from participating in or adopting similar industry-initiated incentive programs. The ports of Los Angeles, New York, and New Jersey have already joined the Environmental Ship Index program (Becqué, Fung, and Zhu 2018).

There are also incentive programs within the United States that the marine sector could utilize. Other transportation sectors have considered policy strategies that could be altered for use in the marine sector. California's Low Carbon Fuel Standard (LCFS) was approved in 2009 and was intended to decrease the carbon intensity of fuels used in California by $10 \%$ by 2020 and $20 \%$ by 2030 from a 2010 baseline (California Air Resources Board 2020). The program set a baseline benchmark for the carbon intensity of gasoline, diesel, and fuels that replace them using life cycle analyses (in grams of $\mathrm{CO}_{2}$ equivalent per megajoule). The program then set a trend curve representing the decline in overall carbon intensity over time and gave credits to fuels that achieve the reduction target (below the curve) and deficits to fuels above the curve; those further below the curve tended to receive more credits (Figure 47). Over 900 fuel production pathways currently have carbon intensity scores in the LCFS database, with over 180 of them producing either biodiesel or renewable diesel, both of which could be used in the marine sector (California Air Resources Board 2021). As of September 2020, California, Oregon, and British Columbia have implemented this program with plans for Washington State, other regions of Canada, and Brazil to implement similar programs. Although LCFS regulation currently does not apply to fuels used in oceangoing vessels, this is one opportunity for the marine sector to utilize a credit system already in place.

Table 14. Examples of the Industry-Led Green Shipping Incentive Initiatives. Adapted from (Becqué, Fung, and Zhu 2018).

\begin{tabular}{|c|c|c|c|c|}
\hline & $\begin{array}{l}\text { Environmental } \\
\text { Ship Index } \\
\text { (ESI) }\end{array}$ & Clean Shipping Index (CSI) & GHG Emissions Rating & Green Award \\
\hline Purpose & $\begin{array}{l}\text { Reducing port } \\
\text { dues for } \\
\text { registered } \\
\text { vessels with } \\
\text { good } \mathrm{NOx}, \mathrm{SOx} \\
\text { and/or } \mathrm{CO}_{2} \\
\text { performance }\end{array}$ & $\begin{array}{l}\text { Rating and benchmarking of } \\
\text { environmental performance } \\
\text { on ship-to-ship + aggregated } \\
\text { carrier basis - can be used } \\
\text { by shippers for shipping } \\
\text { service procurement, vetting } \\
\text { or risk mitigation as well as } \\
\text { by ports to attract green }\end{array}$ & $\begin{array}{l}\text { Rating and benchmarking } \\
\text { of } \mathrm{CO}_{2} \text { performance on the } \\
\text { vessel basis - can be } \\
\text { used by } \\
\text { shippers for shipping } \\
\text { service procurement, } \\
\text { vetting or risk mitigation as } \\
\text { well as by ports to attract }\end{array}$ & $\begin{array}{l}\text { Certifying vessels to } \\
\text { incentivize } \\
\text { improvements in } \\
\text { safety of shipping } \\
\text { and environmental } \\
\text { protection } \\
\text { - can be used by } \\
\text { incentive providers, } \\
\text { including ports, to }\end{array}$ \\
\hline
\end{tabular}




\begin{tabular}{|c|c|c|c|c|}
\hline & $\begin{array}{l}\text { Environmental } \\
\text { Ship Index } \\
\text { (ESI) }\end{array}$ & Clean Shipping Index (CSI) & GHG Emissions Rating & Green Award \\
\hline & & $\begin{array}{l}\text { ships by offering port due } \\
\text { discounts }\end{array}$ & $\begin{array}{l}\text { green ships by offering } \\
\text { port due discounts }\end{array}$ & $\begin{array}{l}\text { provide financial or } \\
\text { non- financial } \\
\text { benefits }\end{array}$ \\
\hline Primary users & Ports, carriers & $\begin{array}{l}\text { Carriers, shippers, and to a } \\
\text { lesser extent, ports including } \\
\text { the Swedish Maritime } \\
\text { Administration }\end{array}$ & $\begin{array}{l}\text { Carriers (mainly bulk } \\
\text { carriers and tankers), } \\
\text { shippers, and to a lesser } \\
\text { extent, banks and ports }\end{array}$ & $\begin{array}{l}\text { Carriers, shippers, } \\
\text { ports, and to a lesser } \\
\text { extent, maritime } \\
\text { service providers and } \\
\text { banks }\end{array}$ \\
\hline $\begin{array}{l}\text { Ease of entry } \\
\text { for owners of } \\
\text { OGVs }\end{array}$ & $\begin{array}{l}\text { Easy - self- } \\
\text { registration with } \\
\text { small chance of } \\
\text { being audited }\end{array}$ & $\begin{array}{l}\text { Moderate - more effort } \\
\text { needed and verification } \\
\text { required for highest score }\end{array}$ & $\begin{array}{l}\text { None - nearly all OGVs in } \\
\text { the world are already } \\
\text { captured and scored in } \\
\text { database; companies can } \\
\text { submit edits if they do not } \\
\text { agree with score }\end{array}$ & $\begin{array}{l}\text { Difficult - scheme } \\
\text { aims to attract } \\
\text { frontrunners. } \\
\text { All registered OGVs } \\
\text { go through rigorous } \\
\text { audits and } \\
\text { verification. }\end{array}$ \\
\hline
\end{tabular}

\section{Late 2017:}

Late 2017: $\quad>2,250$ ships with CSI score

$\sim 7,130$ ships $\quad 30$ members (cargo owners, with valid ESI forwarders, ports, score

Popularity of the scheme
47 participating ports 6 non-port incentive providers shipowners, clean tech providers)

74 affiliated shipping companies (reporting shipowners)

6 ports

1 national authority (Sweden)
All types of OGVs
Late 2017:

54 affiliated charterers

24 shipowners/managers (although 76,000 vessels listed)

3 private terminals

2 participating ports

4 participating finance or insurance providers

All OGVs, but key focus on bulk carriers and tankers
Late 2017:

45 ship companies

257 ships (sea) 630 ships (inland) 60 participating ports, of which 33 are seaports

\section{Several types of OGVs + inland vessels}

Actual; office audit and ship survey; for OGVs, annual checks once certified, for inland vessels, survey conducted once

every three years; certification is renewed every 3 years
N.A. - design efficiency (approximation based on a global database) some ports are

allowed to

conduct audits
Actual; self-registration + requirement to have at least 2 vessels of the fleet verified by audit 


\begin{tabular}{|c|c|c|c|c|}
\hline & $\begin{array}{l}\text { Environmental } \\
\text { Ship Index } \\
\text { (ESI) }\end{array}$ & Clean Shipping Index (CSI) & GHG Emissions Rating & Green Award \\
\hline $\begin{array}{l}\text { How is the } \\
\text { scheme paid } \\
\text { for? }\end{array}$ & $\begin{array}{l}\text { ESI incentive } \\
\text { providers } \\
\text { contribute to } \\
\text { the costs for } \\
\text { maintaining the } \\
\text { ESI website, } \\
\text { with } \\
\text { contributions } \\
\text { based on the } \\
\text { port's "tonnage } \\
\text { handled". } \\
\text { Shipowners } \\
\text { pay no fee. }\end{array}$ & $\begin{array}{l}\text { CSI network members } \\
\text { (shipping companies, cargo } \\
\text { owners and forwarders) are } \\
\text { charged } € 2,800 \text { a year for } \\
\text { administration and further } \\
\text { development. }\end{array}$ & $\begin{array}{l}\text { Carbon War Room pays } \\
\text { for creating and } \\
\text { maintaining the Shipping } \\
\text { Efficiency website, through } \\
\text { which companies can } \\
\text { have free access to design } \\
\text { efficiency information of } \\
\text { listed ships. Companies } \\
\text { can pay a fee to RightShip } \\
\text { if they want to obtain full } \\
\text { access to data. }\end{array}$ & $\begin{array}{l}\text { Incentive providers } \\
\text { pay no fee. } \\
\text { Shipowners pay a fee } \\
\text { for application, audits } \\
\text { and surveys; once } \\
\text { certified, } \\
\text { shipowners pay an } \\
\text { annual fee. }\end{array}$ \\
\hline
\end{tabular}

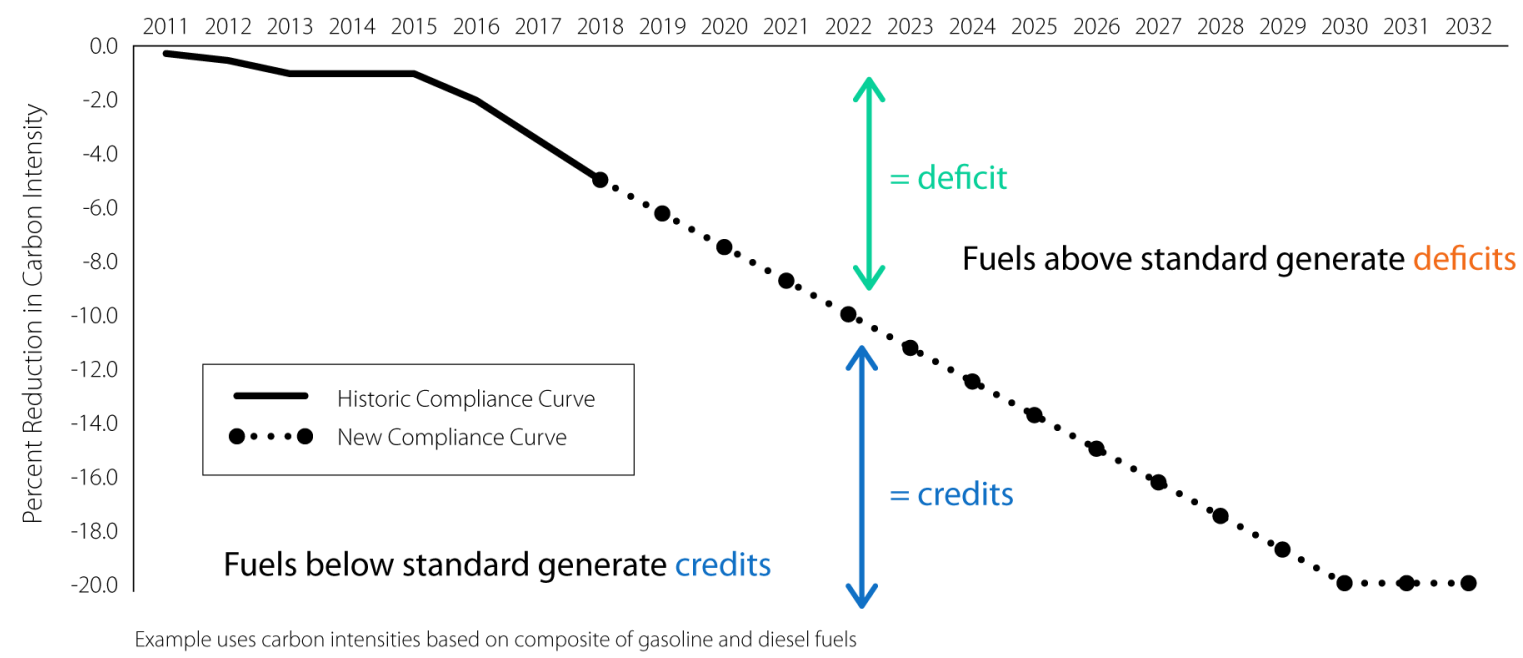

Figure 47. Declining carbon intensity curve. Adapted from (California Air Resources Board 2020).

The aviation industry has also investigated policy ideas that could target their sector, which the marine industry could emulate for their needs. Sustainable aviation fuel (SAF) has a higher carbon intensity than renewable diesel as scored by the LCFS, incentivizing the production of renewable diesel over SAF, even while ground diesel use has easier pathways to decarbonizing than the aviation industry does (California Air Resources Board 2021). Some ideas to work around this roadblock for SAF deployment have been (Ydersbond, Kristensen, and ThuneLarsen 2020): (1) blending mandates requiring a certain volume of SAF to be used in comparison to all jet fuel, (2) setting life cycle greenhouse gas emissions reduction requirements, (3) providing an SAF fund that would reduce the prices of SAF funded by taxes or by government budgets, (4) imposing a fuel tax based on $\mathrm{CO}_{2}$ emitted per megajoule fuel, or (5) passing the extra cost of SAF to passengers (passenger taxes) based on distance traveled. The marine sector could follow one of these policy ideas; however, further exploration into the pros and cons for the maritime industry is warranted. 


\section{Conclusions}

Biofuels play an important role in accelerating the energy transition and enabling the marine shipping industry to achieve decarbonization and low-sulfur targets. This study projected the potential long-term biofuel price and annual production capacity in the United States. The study's approach combined literature review, economic and linear program model development, and meta-analysis. The basic assumptions of the study were predominantly based on (1) the feedstock availability and prices reported in BETO's 2016 Billion-Ton Report and (2) existing biomass-to-fuel conversion technology in the public domain, including leveraging the portfolio of conversion pathways developed under BETO. The study did not take market forces into consideration, and all available feedstocks were assumed to be utilized for biofuel production for marine shipping.

The three scenarios evaluated in this study are: (1) maximize the overall biofuel production capacity, (2) maximize marine biofuels (i.e., capitalizing on total potential afforded by jet- and diesel-range blendstocks as may be suitable for use in marine engines), and (3) minimize overall biofuel price. The projected biofuel capacity and biofuel product slate are aggregated results, and the projected biofuel prices are weighted averages.

Based on the median feedstock availability, for the scenario to maximize total biofuel production, the projected short-term (2022) and long-term (2040) annual U.S. biofuel capacities are estimated at 173 and 245 million MT, respectively (a 42\% increase). Similarly, for the scenario to minimize the biofuel price, the projected annual capacity increases by $41 \%$, from 155 million MT for the short-term to 218 million MT for the long-term. As a reference, the recent global marine fuel consumption was around 330 million MT (or 13.1 EJ). Additionally, the liquid transportation fuel demand per EIA also includes consumption for maritime shipping-in other words, about $5 \%$ of 2040 total transportation energy consumption (26.4 EJ), encompassing domestic $(0.05 \mathrm{EJ})$, international shipping $(0.90 \mathrm{EJ})$, and recreational boats $(0.26 \mathrm{EJ})$, or a total of 1.21 EJ per year. Per our analysis, enough biomass could be utilized to completely meet the needs for the U.S. marine fuel sector, although this is "best-case" scenario that does not consider competition with other biofuel sectors such as that from aviation.

The projected aggregated biofuel prices are in a range higher than current marine fuels. The projected long-term biofuel prices are, on average, $\$ 1,157 / \mathrm{MT}$ for the maximized total biofuel scenario and $\$ 967 / \mathrm{MT}$ for the minimized price scenario, in contrast to a 2019 average MGO price of $\$ 700 / \mathrm{MT}$. However, these projected prices are weighted average prices from all evaluated technology groups. By utilizing all available feedstocks in the United States for the biofuel production capacity projection, certain expensive feedstocks and pathways were also included in the analysis, resulting in the overall higher fuel price. Still, there are individual pathways and technology groups that produce biofuels that are price competitive with fossil fuels.

Scaling up will require more biomass feedstock. The higher feedstock demand will introduce new logistical challenges that would need to be considered, including feedstock harvesting, delivery, and storage, resulting in higher feedstock cost (a key cost driver for biofuels). Therefore, the biofuel price will be higher at any given time when more of it is produced. However, over time, the overall feedstock cost will decrease, or more feedstock will be available 
at a similar cost and drive down the biofuel production cost. For example, for the scenario to maximize biofuel production, the annual biofuel capacity increases by $42 \%$ (due to the increased availability of biomass feedstocks) between 2022 and 2040, whereas the biofuel price decreases by $36 \%$ during the same period.

Both biofuel capacity and fuel types correlate well with biofuel price. At a price range up to $\$ 500 / \mathrm{MT}$, biodiesel is the main product, and the capacity (12 million MT) is limited to feedstock availability constraints. Both biodiesel and corn ethanol are the main biofuels at a price range up to $\$ 750 / \mathrm{MT}$. At a higher price point (above $\$ 750 / \mathrm{MT}$ ), both the biofuel types and annual capacity increase substantially (218 million MT/year). Biofuels include gasoline-, jet-, and diesel-range blendstocks, as well as bio-methanol, bio-propane, and biogas. Lowering the biofuel price to a more acceptable level holds the key for the maritime sector to tap into the projected biofuel capacity.

There are strategies to reduce biofuel production costs. Feedstock cost, a key cost contributor to biofuel production, can be lowered via the utilization of waste and low-quality feedstocks, adoption of integrated landscape management strategies, and feedstock logistic enhancements. Other strategies to achieve lower biofuel prices include co-processing biomass with fossil feedstock, developing atom-efficient biorefineries, intensifying process designs, utilizing existing infrastructure, and developing high-value coproducts.

Additionally, the potential for further price reductions coupled with economic incentives and policies would help enable biofuel adoption for the maritime industry. Initiative structures such as the "Clean Inland Shipping and Sustainable Logistics in Rotterdam," a temporary financial support incentive scheme, can accelerate the adoption of biofuels. The marine industry could also leverage or emulate existing incentive programs that are currently in place for other industries. 


\section{References}

Adeniyi, Oladapo Martins, Ulugbek Azimov, and Alexey Burluka. 2018. "Algae Biofuel: Current Status and Future Applications." Renewable and Sustainable Energy Reviews 90: 31635. https://doi.org/10.1016/j.rser.2018.03.067.

Apostolakou, A. A., I. K. Kookos, C. Marazioti, and K. C. Angelopoulos. 2009. "TechnoEconomic Analysis of a Biodiesel Production Process from Vegetable Oils." Fuel Processing Technology 90(7): 1023-31. https://doi.org/10.1016/j.fuproc.2009.04.017.

Argo, Andrew M, Eric CD Tan, Daniel Inman, Matt H Langholtz, Laurence M Eaton, Jacob J Jacobson, Christopher T Wright, et al. 2013. "Investigation of Biochemical Biorefinery Sizing and Environmental Sustainability Impacts for Conventional Bale System and Advanced Uniform Biomass Logistics Designs." Biofuels, Bioproducts and Biorefining 7(3): 282-302.

https://doi.org/10.1002/bbb.1391.

Argonne National Laboratory. 2016. Argonne National Laboratory Greenhouse Gases, Regulated Emissions, and Energy Use in Transportation (GREET) Computer Model (2016).

Argonne, IL: Argonne National Laboratory.

ARPA-E. 2017. "Macroalgae Research Inspiring Novel Energy Resources.” Release date September 19, 2017. https://arpa-e.energy.gov/technologies/programs/mariner.

ASTM International. 2018. ASTM D5797-18: Standard Specification for Methanol Fuel Blends (M51-M85) for Methanol-Capable Automotive Spark-Ignition Engines. West Conshohocken, PA: ASTM International. https://doi.org/10.1520/D5797-18.

Becqué, Renilde, Freda Fung, and Zhixi Zhu. 2018. Incentive Schemes for Promoting Green Shipping. Beijing, China: NRDC China Program.

https://assets.nrdc.org/sites/default/files/incentive-schemes-promoting-green-shipping-ip.pdf.

Bell, Allison. 2019. “Converting Waste, 'a Leftover Resource,' to Biofuels Reduces Emissions." UCLA Newsroom, August 1, 2019. https://newsroom.ucla.edu/releases/cutting-emissions-byconverting-waste-to-biofuel.

Bioenergy Technologies Office (BETO). 2020. Integrated Strategies to Enable Lower-Cost Biofuels. Washington, D.C.: BETO. DOE/EE-2079. https:/www.energy.gov/sites/ $\mathrm{prod} /$ files/2020/07/f76/beto-integrated-strategies-to-enable-low-cost-biofuels-july-2020.pdf.

Birch, Colin, Hedi Grati, Kurt Barrow, Sandeep Sayal, Elena Pravettoni, and Stephen Jew. 2017. "Refining and Shipping Industries Will Scramble to Meet the 2020 IMO Bunker Fuel Rules." IHS Markit. https://ihsmarkit.com/Info/0817/refining-and-shipping-imo.html.

Bothast, R. J. and M. A. Schlicher. 2005. "Biotechnological Processes for Conversion of Corn into Ethanol.” Applied Microbiology and Biotechnology 67(1): 19-25. https://doi.org/10.1007/s00253-004-1819-8. 
California Air Resources Board. 2020. Low Carbon Fuel Standard. Sacramento, CA: California Air Resources Board. https://ww2.arb.ca.gov/sites/default/files/2020-09/basics-notes.pdf.

_. 2021. "LCFS Pathway Certified Carbon Intensities.” Accessed January 8, 2021. https://ww2.arb.ca.gov/resources/documents/lcfs-pathway-certified-carbon-intensities.

Chong, Ting Yen, Siang Aun Cheah, Chin Tye Ong, Lee Yi Wong, Chern Rui Goh, Inn Shi Tan, Henry Chee Yew Foo, Man Kee Lam, and Steven Lim. 2020. “Techno-Economic Evaluation of Third-Generation Bioethanol Production Utilizing the Macroalgae Waste: A Case Study in Malaysia.” Energy 210: 118491. https://doi.org/10.1016/j.energy.2020.118491.

Chowdhury, Harun, Bavin Loganathan, Israt Mustary, Firoz Alam, and Saleh M. A. Mobin. 2019. "Chapter 12 - Algae for Biofuels: The Third Generation of Feedstock." In Second and Third Generation of Feedstocks, edited by Angelo Basile and Francesco Dalena, 323-44. Elsevier. https://doi.org/10.1016/B978-0-12-815162-4.00012-4.

Chu Van, Thuy, Jerome Ramirez, Thomas Rainey, Zoran Ristovski, and Richard J. Brown. 2019. "Global Impacts of Recent IMO Regulations on Marine Fuel Oil Refining Processes and Ship Emissions." Transportation Research Part D: Transport and Environment 70: 123-34. https://doi.org/10.1016/j.trd.2019.04.001.

Chynoweth, David P. 2002. Review of Biomethane from Marine Biomass. Gainesville, FL: University of Florida. https://arpa-e.energy.gov/sites/ default/files/Review\%20of $\% 20$ Biomethane $\% 20$ from $\% 20$ Marine $\% 20$ Biomass $\% 202002$.pdf.

Dave, Ashok, Ye Huang, Sina Rezvani, David McIlveen-Wright, Marcio Novaes, and Neil Hewitt. 2013. "Techno-Economic Assessment of Biofuel Development by Anaerobic Digestion of European Marine Cold-Water Seaweeds.” Bioresource Technology 135: 120-27. https://doi.org/10.1016/j.biortech.2013.01.005.

Davis, R., C. Kinchin, J. Markham, E.C.D. Tan, and L.M.L. Laurens. 2014. Process Design and Economics for the Conversion of Algal Biomass to Biofuels: Algal Biomass Fractionation to Lipid-and Carbohydrate-Derived Fuel Products. Golden, CO: National Renewable Energy Laboratory. NREL/TP-5100-62368. https://www.nrel.gov/docs/fy14osti/62368.pdf.

Davis, Ryan, Jennifer Markham, Christopher Kinchin, Nicholas Grundl, Eric C.D. Tan, and David Humbird. 2016. Process Design and Economics for the Production of Algal Biomass: Algal Biomass Production in Open Pond Systems and Processing Through Dewatering for Downstream Conversion. Golden, CO: National Renewable Energy Laboratory. NREL/TP5100-64772. https://doi.org/10.2172/1239893.

Davis, Ryan, Matthew Wiatrowski, Christopher Kinchin, and David Humbird. 2020. Conceptual Basis and Techno-Economic Modeling for Integrated Algal Biorefinery Conversion of Microalgae to Fuels and Products. 2019 NREL TEA Update: Highlighting Paths to Future Cost Goals via a New Pathway for Combined Algal Processing. Golden, CO: National Renewable Energy Laboratory. NREL/TP-5100-75168. https://doi.org/10.2172/1665822. 
Dutta, A., M. Talmadge, J. Hensley, M. Worley, D. Dudgeon, D. Barton, P. Groendijk, et al. 2011. Process Design and Economics for Conversion of Lignocellulosic Biomass to Ethanol: Thermochemical Pathway by Indirect Gasification and Mixed Alcohol Synthesis. Golden, CO: National Renewable Energy Laboratory. NREL/TP-5100-51400. https://doi.org/10.2172/1015885.

Dutta, Abhijit, Asad Sahir, and Eric Tan. 2015. Process Design and Economics for the Conversion of Lignocellulosic Biomass to Hydrocarbon Fuels: Thermochemical Research Pathways with In Situ and Ex Situ Upgrading of Fast Pyrolysis Vapors. Golden, CO: National Renewable Energy Laboratory. NREL/TP-5100-62455. https://www.nrel.gov/docs/fy15osti/62455.pdf.

European Bioplastics. 2020. "Bioplastics market data.” European Bioplastics e.V., accessed October 20, 2020. https://www.european-bioplastics.org/market/.

Evangelista, Roque L., Terry A. Isbell, and Steven C. Cermak. 2012. "Extraction of Pennycress (Thlaspi Arvense L.) Seed Oil by Full Pressing." Industrial Crops and Products 37(1): 76-81. https://doi.org/10.1016/j.indcrop.2011.12.003.

Ferdouse, Fatima, Susan Lovstad Holdt, Rohan Smith, Pedro Murua, and Zhengyong Yang. 2018. The Global Status of Seaweed Production, Trade and Utilization, Vol. 124. Rome: Food and Agriculture Organization of the United Nations.

NOAA Fisheries. 2020. "Seaweed Aquaculture.” Accessed September 28, 2020. https://www.fisheries.noaa.gov/national/aquaculture/seaweed-aquaculture.

Food and Agriculture Organization of the United Nations. 2014. The State of the World Fisheries and Aquaculture 2014: Opportunities and Challenges. Rome: Food and Agriculture Organization of the United Nations. http://www.fao.org/3/a-i3720e.pdf.

Geleynse, Scott, Kristin Brandt, Manuel Garcia-Perez, Michael Wolcott, and Xiao Zhang. 2018. "The Alcohol-to-Jet Conversion Pathway for Drop-In Biofuels: Techno-Economic Evaluation." ChemSusChem 11(21): 3728-41. https://doi.org/10.1002/cssc.201801690.

GoodFuels. 2019. "First Inland Vessel on 100\% Sustainable Biofuel for Heineken." GoodFuels, March 19, 2019. https://goodfuels.com/first-inland-vessel-on-100-sustainable-biofuel-forheineken/.

Humbird, D., R. Davis, L. Tao, C. Kinchin, D. Hsu, A. Aden, P. Schoen, et al. 2011. Process Design and Economics for Biochemical Conversion of Lignocellulosic Biomass to Ethanol: Dilute-Acid Pretreatment and Enzymatic Hydrolysis of Corn Stover. Golden, CO: National Renewable Energy Laboratory. NREL/TP-5100-47764. https://doi.org/10.2172/1013269.

IHS Markit. 2019. IMO 2020: What Every Shipper Needs to Know. London: IHS Markit. https://www.joc.com/sites/default/files/u45421/Whitepapers/GeminiSeaburyWP 24pages.pdf. 
Jones, Susanne B., Pimphan A. Meyer, Lesley J. Snowden-Swan, Asanga B. Padmaperuma, Eric Tan, Abhijit Dutta, Jacob Jacobson, and Kara Cafferty. 2013. Process Design and Economics for the Conversion of Lignocellulosic Biomass to Hydrocarbon Fuels: Fast Pyrolysis and Hydrotreating Bio-Oil Pathway. Richland, WA: Pacific Northwest National Laboratory. PNNL23053. https://doi.org/10.2172/1115839.

Kass, Michael D., Beth L. Armstrong, Brian C. Kaul, Raynella Maggie Connatser, Samuel Lewis, James R. Keiser, Jiheon Jun, Gavin Warrington, and Dino Sulejmanovic. 2020. "Stability, Combustion, and Compatibility of High-Viscosity Heavy Fuel Oil Blends with a Fast Pyrolysis Bio-Oil." Energy \& Fuels 34(7): 8403-13. https://doi.org/10.1021/acs.energyfuels.0c00721.

Kass, Michael D., Zia Abdullah, Mary J. Biddy, Corinne Drennan, Zia Haq, Troy Hawkins, Susanne Jones, et al. 2018. Understanding the Opportunities of Biofuels for Marine Shipping. Oak Ridge, TN: Oak Ridge National Laboratory. ORNL/TM-2018/1080. https://doi.org/10.2172/1490575.

Kennedy, Helena Tavares. 2019. "Marine Biofuel Refueling in Rotterdam a Success.” Biofuels Digest, March 31, 2019. https://www.biofuelsdigest.com/bdigest/2019/03/31/marine-biofuelrefueling-in-rotterdam-a-success/.

Konda, N. V. S. N. Murthy, Seema Singh, Blake A. Simmons, and Daniel Klein-Marcuschamer. 2015. "An Investigation on the Economic Feasibility of Macroalgae as a Potential Feedstock for Biorefineries." BioEnergy Research 8(3): 1046-56. https://doi.org/10.1007/s12155-015-9594-1.

Lamers, Patrick, Eric C. D. Tan, Erin M. Searcy, Christopher J. Scarlata, Kara G. Cafferty, and Jacob J. Jacobson. 2015. "Strategic Supply System Design - a Holistic Evaluation of Operational and Production Cost for a Biorefinery Supply Chain." Biofuels, Bioproducts and Biorefining 9(6): 648-60. https://doi.org/10.1002/bbb.1575.

Langholtz, M. H., B. J. Stokes, and L. M. Eaton. 2016. 2016 Billion-Ton Report: Advancing Domestic Resources for a Thriving Bioeconomy. Washington, D.C.: Bioenergy Technologies Office. DOE/EE-1440. https://doi.org/10.2172/1271651.

Lee, Roland Arthur and Jean-Michel Lavoie. 2013. "From First- to Third-Generation Biofuels: Challenges of Producing a Commodity from a Biomass of Increasing Complexity." Animal Frontiers 3(2): 6-11. https://doi.org/10.2527/af.2013-0010.

Leite, Gustavo B., Ahmed E. M. Abdelaziz, and Patrick C. Hallenbeck. 2013. "Algal Biofuels: Challenges and Opportunities." Bioresource Technology 145: 134-41. https://doi.org/10.1016/j.biortech.2013.02.007.

Marchetti, J. M., V. U. Miguel, and A. F. Errazu. 2008. "Techno-Economic Study of Different Alternatives for Biodiesel Production." Fuel Processing Technology 89(8): 740-48. https://doi.org/10.1016/j.fuproc.2008.01.007. 
Meister, Robin and Markus Wagner. 2018. Current Status and Environmental Incentives Policies of Seaports and Inland Ports in Europe. Beijing, China: Deutsche Gesellschaft für Internationale Zusammenarbeit (GIZ) GmbH. http://www.sustainabletransport.org/wpcontent/uploads/2018/10/Report-Port-Incentives-in-Europe EN_10102018.pdf.

Mohd Noor, C.W., M.M. Noor, and R. Mamat. 2018. "Biodiesel as Alternative Fuel for Marine Diesel Engine Applications: A Review." Renewable and Sustainable Energy Reviews 94: 12742. https://doi.org/10.1016/j.rser.2018.05.031.

Muth, David J., Matthew H. Langholtz, Eric C.D. Tan, Jacob J. Jacobson, Amy Schwab, May M. $\mathrm{Wu}$, Andrew Argo, et al. 2014. "Investigation of Thermochemical Biorefinery Sizing and Environmental Sustainability Impacts for Conventional Supply System and Distributed PreProcessing Supply System Designs.” Biofuels, Bioproducts and Biorefining 8(4): 545-67. https://doi.org/10.1002/bbb.1483.

Nebraska Department of Environment and Energy. 2020. "Ethanol Production Capacity by Plant." Accessed November 19, 2020. https://neo.ne.gov/programs/stats/inf/122.htm.

Nghiem, Nhuan P., Susanne Kleff, and Stefan Schwegmann. 2017. "Succinic Acid: Technology Development and Commercialization." Fermentation 3(2): 26.

https://doi.org/10.3390/fermentation3020026.

Olmer, Naya, Bryan Comer, Biswajoy Roy, Xiaoli Mao, and Dan Rutherford. 2017. Greenhouse Gas Emissions from Global Shipping, 2013-2015. Washington, D.C.: International Council on Clean Transportation. https://safety4sea.com/wp-content/uploads/2017/10/ICCT-Greenouse-gasemissions-from-global-shipping-2013-2015-2017 10-1.pdf.

Pearce, Fred. 2009. "How 16 Ships Create as Much Pollution as All the Cars in the World." Daily Mail, November 21, 2009. https://www.dailymail.co.uk/sciencetech/article-1229857/How16-ships-create-pollution-cars-world.html.

Phillips 66. 2020. "Phillips 66 Plans to Transform San Francisco Refinery into World's Largest Renewable Fuels Plant.” News release, August 12, 2020. https://investor.phillips66.com/ financial-information/news-releases/news-release-details/2020/Phillips-66-Plans-to-TransformSan-Francisco-Refinery-into-Worlds-Largest-Renewable-Fuels-Plant/default.aspx.

Phillips, S. D., J. K. Tarud, M. J. Biddy, and A. Dutta. 2011. Gasoline from Wood via Integrated Gasification, Synthesis, and Methanol-to-Gasoline Technologies. Golden, CO: National Renewable Energy Laboratory. NREL/TP-5100-47594. https://doi.org/10.2172/1004790.

Pimentel, David and Tad W. Patzek. 2005. "Ethanol Production Using Corn, Switchgrass, and Wood; Biodiesel Production Using Soybean and Sunflower." Natural Resources Research 14(1): 65-76. https://doi.org/10.1007/s11053-005-4679-8.

Rajendran, Karthik, Harshavardhan R. Kankanala, Rakel Martinsson, and Mohammad J. Taherzadeh. 2014. "Uncertainty over Techno-Economic Potentials of Biogas from Municipal Solid Waste (MSW): A Case Study on an Industrial Process.” Applied Energy 125: 84-92. https://doi.org/10.1016/j.apenergy.2014.03.041. 
Roesijadi, Guritno, Andre M. Coleman, Chaeli Judd, Frances B. Van Cleve, Ronald M. Thom, Kate E. Buenau, Jerry D. Tagestad, Mark S. Wigmosta, and Jeffrey A. Ward. 2011. Macroalgae Analysis: A National GIS-Based Analysis of Macroalgae Production Potential Summary Report and Project Plan." Richland, WA: Pacific Northwest National Laboratory. PNNL-21087. https://doi.org/10.2172/1039854.

Roesijadi, Guritno, Susanne B. Jones, Lesley J. Snowden-Swan, and Yunhua Zhu. 2010. Macroalgae as a Biomass Feedstock: A Preliminary Analysis. Richland, WA: Pacific Northwest National Laboratory. PNNL-19944. https://doi.org/10.2172/1006310.

Seiple, Timothy E., André M. Coleman, and Richard L. Skaggs. 2017. "Municipal Wastewater Sludge as a Sustainable Bioresource in the United States." Journal of Environmental Management 197: 673-80. https://doi.org/10.1016/j.jenvman.2017.04.032.

Shen, Li, Ernst Worrell, and Martin Patel. 2010. "Present and Future Development in Plastics from Biomass." Biofuels, Bioproducts and Biorefining 4(1): 25-40.

https://doi.org/10.1002/bbb.189.

Ship \& Bunker. 2020. “Average Bunker Prices.” Accessed November 26, 2020. https://shipandbunker.com/prices/av.

Snowden-Swan, Lesley J., Yunhua Zhu, Mark D. Bearden, Timothy E. Seiple, Susanne B. Jones, Andrew J. Schmidt, Justin M. Billing, et al. 2017. Conceptual Biorefinery Design and Research Targeted for 2022: Hydrothermal Liquefaction Processing of Wet Waste to Fuels. Richland, WA: Pacific Northwest National Laboratory. PNNL-27186. https://doi.org/10.2172/1415710.

Sofiev, Mikhail, James J. Winebrake, Lasse Johansson, Edward W. Carr, Marje Prank, Joana Soares, Julius Vira, Rostislav Kouznetsov, Jukka-Pekka Jalkanen, and James J. Corbett. 2018. "Cleaner Fuels for Ships Provide Public Health Benefits with Climate Tradeoffs." Nature Communications 9(1): 406. https://doi.org/10.1038/s41467-017-02774-9.

Soleymani, Mohsen and Kurt A. Rosentrater. 2017. "Techno-Economic Analysis of Biofuel Production from Macroalgae (Seaweed).” Bioengineering 4(4): 92. https://doi.org/10.3390/bioengineering4040092.

Squirrell, David. 2017. “A Multi-Fuel Future: The Impact of the IMO Sulphur Cap." Presented at: 6th Bunkernet Bunker Conference. 6 April 2017. Limassol, Cyprus. https://bunkernet.com.cy/wp-content/uploads/2017/04/05.-David-Squirrell .pdf.

SRI Consulting. 2011. "U.S. Producer Price Indexes - Total Index for Chemicals and Allied Products." In Chemical Economics Handbook: The Economic Environment of the Chemical Industry. Menlo Park, CA: SRI Consulting.

Supply Chain Movement. 2019. "New Initiatives to Speed up Sustainability in Shipping.” Supply Chain Movement, April 4, 2019. https://www.supplychainmovement.com/new-initiatives-tospeed-up-sustainability-in-shipping/. 
Tan, Eric C, and Ling Tao. 2019. Economic Analysis of Renewable Fuels for Marine Propulsion. Golden, CO: National Renewable Energy Laboratory. NREL/TP-5100-74678. https://doi.org/10.2172/1566063.

Tan, Eric C. D. 2019. “An Integrated Sustainability Evaluation of High-Octane Gasoline Production from Lignocellulosic Biomass." Biofuels, Bioproducts and Biorefining 13(6): 143953. https://doi.org/10.1002/bbb.2045.

Tan, Eric C. D., Lesley J. Snowden-Swan, Michael Talmadge, Abhijit Dutta, Susanne Jones, Karthikeyan K. Ramasamy, Michel Gray, et al. 2017. "Comparative Techno-Economic Analysis and Process Design for Indirect Liquefaction Pathways to Distillate-Range Fuels via BiomassDerived Oxygenated Intermediates Upgrading." Biofuels, Bioproducts and Biorefining 11(1): 41-66. https://doi.org/10.1002/bbb.1710.

Tan, Eric C. D., Michael Talmadge, Abhijit Dutta, Jesse Hensley, Lesley J. Snowden-Swan, David Humbird, Joshua Schaidle, and Mary Biddy. 2015. "Conceptual Process Design and Economics for the Production of High-Octane Gasoline Blendstock via Indirect Liquefaction of Biomass through Methanol/Dimethyl Ether Intermediates." Biofuels, Bioproducts and Biorefining 10(1): 17-35. https://doi.org/10.1002/bbb.1611.

Tan, Eric, Daniel Ruddy, Connor Nash, Dan Dupuis, Kylee Harris, Abhijit Dutta, Damon Hartley, and Hao Cai. 2020. High-Octane Gasoline from Lignocellulosic Biomass via Syngas and Methanol/Dimethyl Ether Intermediates: 2019 State of Technology. Golden, CO: National Renewable Energy Laboratory. NREL/TP-5100-76619. https://doi.org/10.2172/1659905.

Tanzer, Samantha Eleanor, John Posada, Sjors Geraedts, and Andrea Ramírez. 2019. "Lignocellulosic Marine Biofuel: Technoeconomic and Environmental Assessment for Production in Brazil and Sweden." Journal of Cleaner Production 239: 117845. https://doi.org/10.1016/j.jclepro.2019.117845.

Tao, Ling and Andy Aden. 2009. "The Economics of Current and Future Biofuels." In Vitro Cellular \& Developmental Biology - Plant 45(3): 199-217. https://doi.org/10.1007/s11627-0099216-8.

Tao, Ling, Anelia Milbrandt, Yanan Zhang, and Wei-Cheng Wang. 2017. "Techno-Economic and Resource Analysis of Hydroprocessed Renewable Jet Fuel." Biotechnology for Biofuels 10(1): 261. https://doi.org/10.1186/s13068-017-0945-3.

Tao, Ling, Eric C. D. Tan, Robert McCormick, Min Zhang, Andy Aden, Xin He, and Bradley T. Zigler. 2014. "Techno-Economic Analysis and Life-Cycle Assessment of Cellulosic Isobutanol and Comparison with Cellulosic Ethanol and n-Butanol." Biofuels, Bioproducts and Biorefining 8(1): 30-48. https://doi.org/10.1002/bbb.1431.

Tao, Ling, Jennifer N. Markham, Zia Haq, and Mary J. Biddy. 2017. "Techno-Economic Analysis for Upgrading the Biomass-Derived Ethanol-to-Jet Blendstocks." Green Chemistry 19(4): 1082-1101. https://doi.org/10.1039/C6GC02800D. 
Tao, Ling, Xin He, Eric C. D. Tan, Min Zhang, and Andy Aden. 2014. "Comparative TechnoEconomic Analysis and Reviews of n-Butanol Production from Corn Grain and Corn Stover." Biofuels, Bioproducts and Biorefining 8(3): 342-61. https://doi.org/10.1002/bbb.1462.

Toor, Saqib Sohail, Lasse Rosendahl, Mads Pagh Nielsen, Marianne Glasius, Andreas Rudolf, and Steen Brummerstedt Iversen. 2012. "Continuous Production of Bio-Oil by Catalytic Liquefaction from Wet Distiller's Grain with Solubles (WDGS) from Bio-Ethanol Production." Biomass and Bioenergy 36: 327-32. https://doi.org/10.1016/j.biombioe.2011.10.044.

UNCTAD. 2018. Review of Maritime Transport 2018. New York: United Nations Conference on Trade and Development. https://unctad.org/en/PublicationsLibrary/rmt2018 en.pdf.

U.S. EIA. 2020a. Annual Energy Outlook 2020 with Projections to 2050. Washington, D.C.: U.S. Energy Information Administration. https:/www.eia.gov/outlooks/aeo/pdf/aeo2020.pdf.

_. 2020b. "U.S. Fuel Ethanol Plant Production Capacity." September 25, 2020.

https://www.eia.gov/petroleum/ethanolcapacity/index.php.

- 2021a. Monthly Energy Review - Table 10.3: Fuel Ethanol Overview. Washington, D.C.: U.S. Energy Information Administration.

https://www.eia.gov/totalenergy/data/monthly/pdf/sec10 7.pdf.

- 2021b. Monthly Energy Review - Table 10.4: Biodiesel and Other Renewable Fuels Overview. Washington, D.C.: U.S. Energy Information Administration.

https://www.eia.gov/totalenergy/data/monthly/pdf/sec10_8.pdf.

U.S. EPA. 2015. “Clean Watersheds Needs Survey (CWNS) - 2012 Report and Data.” June 2, 2015. https://www.epa.gov/cwns/clean-watersheds-needs-survey-cwns-2012-report-and-data.

USDA Economic Research Service. 2020. "U.S. Bioenergy Statistics.” Accessed October 8, 2020. https://www.ers.usda.gov/data-products/us-bioenergy-statistics/us-bioenergystatistics/\#All\%20In\%20One.

Wan, Zheng, Abdel el Makhloufi, Yang Chen, and Jiayuan Tang. 2018. "Decarbonizing the International Shipping Industry: Solutions and Policy Recommendations." Marine Pollution Bulletin 126: 428-35. https://doi.org/10.1016/j.marpolbul.2017.11.064.

Yao, Guolin, Mark D. Staples, Robert Malina, and Wallace E. Tyner. 2017. "Stochastic TechnoEconomic Analysis of Alcohol-to-Jet Fuel Production." Biotechnology for Biofuels 10(1): 18. https://doi.org/10.1186/s13068-017-0702-7.

Ydersbond, Inga Margarete, Niels Buus Kristensen, and Harald Thune-Larsen. 2020. Nordic Sustainable Aviation. Copenhagen, Denmark: Nordic Council of Ministers. https://www.divaportal.org/smash/get/diva2:1512274/FULLTEXT01.pdf. 
Zhang, Yanan, Asad H. Sahir, Eric C. D. Tan, Michael S. Talmadge, Ryan Davis, Mary J. Biddy, and Ling Tao. 2018. "Economic and Environmental Potentials for Natural Gas to Enhance Biomass-to-Liquid Fuels Technologies." Green Chemistry 20(23): 5358-73.

https://doi.org/10.1039/C8GC01257A.

Zhu, Yunhua, Mary J. Biddy, Susanne B. Jones, Douglas C. Elliott, and Andrew J. Schmidt. 2014. "Techno-Economic Analysis of Liquid Fuel Production from Woody Biomass via Hydrothermal Liquefaction (HTL) and Upgrading." Applied Energy 129: 384-94.

https://doi.org/10.1016/i.apenergy.2014.03.053. 


\section{Appendix A. Biomass Feedstock Availability Supporting Information}

\section{A.1 Supplemental Logistics Costs and Assumptions}

Table A1. Herbaceous and Woody Biomass Dockage

Dockage Fees for Herbaceous and Woody Feedstocks

\begin{tabular}{|c|c|c|c|c|c|}
\hline & Corn Stover & Switchgrass & Miscanthus & Sorghum & Yard Trimmings \\
\hline Initial ash (\%) & $7 \%$ & $6 \%$ & $4 \%$ & $7 \%$ & $10 \%$ \\
\hline Ash dockage fee (\$/dry ton) & 2.71 & 2.33 & 1.55 & 2.71 & 3.88 \\
\hline Moisture at harvest (\%) & $20 \%$ & $15 \%$ & $15 \%$ & $40 \%$ & $20 \%$ \\
\hline \multirow[t]{2}{*}{ Moisture dockage fee (\$/dry ton) } & 3.36 & 3.36 & 3.36 & 6.72 & 3.36 \\
\hline & Whole Tree Chips & Logging Residues & Urban Wood Waste & Woody Energy Crops & C\&Da Waste \\
\hline Initial ash (\%) & $1 \%$ & $4 \%$ & $4 \%$ & $2 \%$ & $1 \%$ \\
\hline Ash dockage fee (\$/dry ton) & 0.23 & 1.55 & 1.55 & 0.78 & 0.39 \\
\hline
\end{tabular}

${ }^{a}$ Construction and demolition

Adopted from the 2016 Billion-Ton Report (BT16) Chapter 6, Tables 6.2 and 6.3 (Langholtz, Stokes, and Eaton 2016). Dockage fees, in the form of ash content, were used in the total recoverable biomass calculations for the high-cost scenarios. In the near-term (2022) scenarios, it was assumed that ash content was not recoverable biomass, and in the long-term (2040) scenarios, an ambitious assumption was made that there were no feedstock losses to ash content. 
Table A2. Herbaceous Resource Availability Breakdown

\begin{tabular}{|c|c|c|c|c|c|c|}
\hline \multirow{2}{*}{$\begin{array}{c}\text { Herbaceous } \\
\text { Resources }\end{array}$} & \multicolumn{3}{|c|}{ Near Term (2022) } & \multicolumn{3}{|c|}{ Long Term (2040) } \\
\hline & Farmgate Cost (\$60/Ton) & $\begin{array}{l}\text { Low Cost } \\
\text { (\$84/Ton) }\end{array}$ & $\begin{array}{l}\text { High Cost } \\
\text { (\$100/Ton) }\end{array}$ & Farmgate Cost (\$60/Ton) & Low Cost (\$84/Ton) & High Cost (\$100/Ton) \\
\hline \multicolumn{7}{|c|}{ Base Case Scenario (Million Tons of Resource Available) } \\
\hline Corn Stover & 106.0 & 30.0 & 58.3 & 154.0 & 61.7 & 114.4 \\
\hline Switchgrass & 46.0 & 13.0 & 25.3 & 161.0 & 64.5 & 119.6 \\
\hline Miscanthus & 28.0 & 7.9 & 15.4 & 160.0 & 64.1 & 118.9 \\
\hline Biomass Sorghum & - & - & - & 19.0 & 7.6 & 14.1 \\
\hline Subtotal & 180.0 & 51.0 & 99.0 & 494.0 & 198.0 & 367.0 \\
\hline Other Herbaceous & 17.0 & 4.8 & 9.4 & 23.0 & 9.2 & 17.1 \\
\hline Total & 197.0 & 55.8 & 108.4 & 517.0 & 207.2 & 384.1 \\
\hline \multicolumn{7}{|c|}{ High-Yield Scenario (Million Tons of Resource Available) } \\
\hline Corn Stover & - & - & - & 161.0 & 89.8 & 126.1 \\
\hline Switchgrass & - & - & - & 189.0 & 105.4 & 148.0 \\
\hline Miscanthus & - & - & - & 370.0 & 206.4 & 289.7 \\
\hline Biomass Sorghum & - & - & - & 31.0 & 17.3 & 24.3 \\
\hline Subtotal & - & - & - & 751.0 & 419.0 & 588.0 \\
\hline Other Herbaceous & - & - & - & 44.0 & 24.5 & 34.5 \\
\hline Total & - & - & - & 795.0 & 443.5 & 622.5 \\
\hline
\end{tabular}

Feedstock availability at a given cost, with supply chain losses, overcontracted material, and ash dockages. "Other Herbaceous" materials broken down in Table A3. 
Table A3. Million Tons of Unutilized Material in Each Case and Ratio of Utilized to Total Available Feedstock for Each Case

\begin{tabular}{llrrrrr}
\hline $\begin{array}{l}\text { Unused Base Case } \\
\text { Unused High Yield }\end{array}$ & 129.0 & 81.0 & & 296.0 & 127.0 \\
& & & & 332.0 & 163.0 \\
\hline & Ratio (Utilized/Total) & \multirow{2}{*}{0.28} & 0.55 & Ratio (Utilized/Total) & 0.40 & 0.74 \\
& & & & Ratio (Utilized/Total) & 0.56 & 0.78 \\
\hline
\end{tabular}

This calculated ratio was used to extrapolate calculations to "Other Herbaceous" feedstocks.

Table A4. Other Herbaceous Resource Availability Breakdown

\begin{tabular}{|c|c|c|c|c|c|c|}
\hline \multirow{2}{*}{$\begin{array}{l}\text { Other Herbaceous } \\
\text { Resources }\end{array}$} & \multicolumn{3}{|c|}{ Near Term (2022) } & \multicolumn{3}{|c|}{ Long Term (2040) } \\
\hline & $\begin{array}{l}\text { Farmgate Cost } \\
\text { (\$60/Ton) }\end{array}$ & $\begin{array}{l}\text { Low Cost } \\
\text { (\$84/Ton) }\end{array}$ & $\begin{array}{l}\text { High Cost } \\
\text { (\$100/Ton) }\end{array}$ & $\begin{array}{l}\text { Farmgate Cost } \\
\text { (\$60/Ton) }\end{array}$ & $\begin{array}{l}\text { Low Cost } \\
\text { (\$84/Ton) }\end{array}$ & $\begin{array}{l}\text { High Cost } \\
\text { (\$100/Ton) }\end{array}$ \\
\hline \multicolumn{7}{|c|}{ Base Case Scenario (Million Tons of Resource Available) } \\
\hline Wheat Straw & 16.0 & 4.5 & 8.8 & 21.0 & 8.4 & 15.6 \\
\hline Sorghum Residue & 1.0 & 0.3 & 0.6 & 1.0 & 0.4 & 0.7 \\
\hline Oat Residue & - & - & - & - & - & - \\
\hline Barley Residue & - & - & - & 1.0 & 0.4 & 0.7 \\
\hline Energy Cane & - & - & - & - & - & - \\
\hline Total & 17.0 & 4.8 & 9.4 & 23.0 & 9.2 & 17.1 \\
\hline \multicolumn{7}{|c|}{ High Yield Scenario (Million Tons of Resource Available) } \\
\hline Wheat Straw & - & - & - & 37.0 & 20.6 & 29.0 \\
\hline Sorghum Residue & - & - & - & 2.0 & 1.1 & 1.6 \\
\hline Oat Residue & - & - & - & - & - & - \\
\hline Barley Residue & - & - & - & - & - & - \\
\hline Energy Cane & - & - & - & 5.0 & 2.8 & 3.9 \\
\hline Total & - & - & - & 44.0 & 24.5 & 34.5 \\
\hline
\end{tabular}


Table A5. Breakdown of Unused Material for Each Herbaceous Case. High-Cost Case Recovers Material Recovered Due to Too Low Cost Assumptions (> \$/ton notation).

\begin{tabular}{|c|c|c|c|c|}
\hline Unused breakdown & 2022, Low & 2022, Median & 2040, Low & 2040, Median \\
\hline Unused Base Case (BC) & 141.2 & 88.7 & 309.8 & 132.9 \\
\hline $\begin{array}{l}\text { overcontracting buffer } \\
\text { supply chain }\end{array}$ & 49.25 & 49.25 & 0 & 0 \\
\hline Corn Stover & 7.42 & 7.42 & - & - \\
\hline Switchgrass & 2.76 & 2.76 & - & - \\
\hline Miscanthus & 1.12 & 1.12 & - & - \\
\hline Biomass Sorghum & - & - & - & - \\
\hline Other Herbaceous & 1.19 & 1.19 & - & - \\
\hline$>\$ /$ ton & 79.44 & 26.91 & 309.78 & 132.91 \\
\hline & & & $\begin{array}{c}\text { 2040, Low, } \\
\text { HY }\end{array}$ & $\begin{array}{c}\text { 2040, Median, } \\
\text { HY }\end{array}$ \\
\hline Unused High Yield (HY) & & & 351.5 & 172.5 \\
\hline $\begin{array}{l}\text { overcontracting buffer } \\
\text { supply chain }\end{array}$ & & & 0 & 0 \\
\hline Corn Stover & & & - & - \\
\hline Switchgrass & & & - & - \\
\hline Miscanthus & & & - & - \\
\hline Biomass Sorghum & & & - & - \\
\hline Other Herbaceous & & & - & \\
\hline$>\$ /$ ton & & & 351.45 & 172.55 \\
\hline
\end{tabular}




\section{A.2 Supplemental Woody Feedstock Tables}

Table A6. Woody Feedstock Availability at a Given Cost, with Supply Chain Losses, Overcontracted Material, and Ash Dockages

\begin{tabular}{|c|c|c|c|c|c|c|}
\hline \multirow[b]{2}{*}{ Woody Resources } & \multicolumn{3}{|c|}{ Near Term (2022) } & \multicolumn{3}{|c|}{ Long Term (2040) } \\
\hline & $\begin{array}{c}\text { Roadside Cost } \\
\text { (\$60/Ton) }\end{array}$ & $\begin{array}{l}\text { Low Cost } \\
\text { (\$84/Ton) }\end{array}$ & $\begin{array}{l}\text { High Cost } \\
\text { (\$100/Ton) }\end{array}$ & $\begin{array}{c}\text { Roadside Cost } \\
\text { (\$60/Ton) }\end{array}$ & $\begin{array}{l}\text { Low Cost } \\
\text { (\$84/Ton) } \\
\end{array}$ & $\begin{array}{l}\text { High Cost } \\
\text { (\$100/Ton) }\end{array}$ \\
\hline \multicolumn{7}{|c|}{ Base Case Scenario (Million Tons of Resource Available) } \\
\hline Whole-tree chips & 73.7 & 51.7 & 55.8 & 60.7 & 17.2 & 32.4 \\
\hline Logging residues & 19.4 & 13.6 & 14.7 & 20.7 & 5.9 & 11.0 \\
\hline Woody crops, coppice & 3.0 & 2.1 & 2.3 & 26.0 & 7.4 & 13.9 \\
\hline $\begin{array}{l}\text { Woody crops, non- } \\
\text { coppice }\end{array}$ & - & - & - & 45.0 & 12.7 & 24.0 \\
\hline Urban wood waste & 6.3 & 4.4 & 4.8 & 6.3 & 1.8 & 3.4 \\
\hline C\&D Waste & 23.0 & 16.1 & 17.4 & 25.0 & 7.1 & 13.3 \\
\hline Total & 125.4 & 88.0 & 95.0 & 183.7 & 52.0 & 98.0 \\
\hline \multicolumn{7}{|c|}{ High Yield Scenario (Million Tons of Resource Available) } \\
\hline Whole-tree chips & - & - & - & 40.7 & 19.0 & 26.8 \\
\hline Logging residues & - & - & - & 19.8 & 9.2 & 13.0 \\
\hline Woody crops, coppice & - & - & - & 67.0 & 31.2 & 44.1 \\
\hline $\begin{array}{l}\text { Woody crops, non- } \\
\text { coppice }\end{array}$ & - & - & - & 75.0 & 35.0 & 49.4 \\
\hline Urban wood waste & - & - & - & 6.3 & 2.9 & 4.1 \\
\hline C\&D Waste & - & - & - & 25.0 & 11.7 & 16.5 \\
\hline Total & - & - & - & 233.8 & 109.0 & 154.0 \\
\hline
\end{tabular}


Table A7. Million Tons of Unutilized Material in Each Case and Ratio of Utilized to Total Available Feedstock for Each Case

\begin{tabular}{llccrcc}
\hline $\begin{array}{l}\text { Unused BC } \\
\text { Unused HY }\end{array}$ & 37.4 & 30.4 & & 131.7 & 85.7 \\
& & & & & 124.8 & 79.8 \\
\hline & Ratio (Utilized/Total) & 0.70 & 0.76 & Ratio (Utilized/Total) & 0.28 & 0.53 \\
& & & & Ratio (Utilized/Total) & 0.47 & 0.66 \\
\cline { 2 - 6 } & & & & & & \\
\end{tabular}

Table A8. Breakdown of Unused Material for Each Woody Case. High-Cost Case Recovers Material Recovered Due to Too Low Cost Assumptions (>\$ton notation)

\begin{tabular}{|c|c|c|c|c|}
\hline Unused breakdown & Near, L & Near, $\mathrm{H}$ & Long, L & Long, $\mathrm{H}$ \\
\hline Unused BC & 37.4 & 30.4 & 131.7 & 85.7 \\
\hline overcontracting buffer & 12.54 & 12.54 & & \\
\hline \multicolumn{5}{|l|}{ supply chain } \\
\hline Whole-tree chips & 0.74 & 0.74 & & \\
\hline Logging residues & 0.78 & 0.78 & & \\
\hline Woody crops, coppice & 0.12 & 0.12 & & \\
\hline Woody crops, non-coppice & - & - & & \\
\hline Urban wood waste & 0.06 & 0.06 & & \\
\hline C\&D Waste & 0.23 & 0.23 & & \\
\hline \multirow[t]{2}{*}{$>\$ /$ ton } & 22.93 & 15.93 & 131.70 & 85.70 \\
\hline & & & Long, L, HY & Long, $\mathrm{H}, \mathrm{HY}$ \\
\hline Unused HY & & & 124.8 & 79.8 \\
\hline \multicolumn{5}{|l|}{ overcontracting buffer } \\
\hline \multicolumn{5}{|l|}{ supply chain } \\
\hline \multicolumn{5}{|l|}{ Whole-tree chips } \\
\hline \multicolumn{5}{|l|}{ Logging residues } \\
\hline \multicolumn{5}{|l|}{ Woody crops, coppice } \\
\hline \multicolumn{5}{|l|}{ Woody crops, non-coppice } \\
\hline \multicolumn{5}{|l|}{ Urban wood waste } \\
\hline \multicolumn{5}{|l|}{ C\&D Waste } \\
\hline$>\$ /$ ton & & & 124.80 & 79.80 \\
\hline
\end{tabular}




\section{A.3 Supplemental Waste Feedstock Tables}

Table A9. Waste Feedstock Availability at a Given Cost, with Supply Chain Losses, Overcontracted Material, and Ash Dockages

\begin{tabular}{|c|c|c|c|c|c|c|}
\hline \multirow[b]{2}{*}{ Other Waste Resources } & \multicolumn{3}{|c|}{ Near Term (2022) } & \multicolumn{3}{|c|}{ Long Term (2040) } \\
\hline & $\begin{array}{c}\text { Roadside Cost } \\
\text { (\$60/Ton) }\end{array}$ & $\begin{array}{c}\text { Low Cost } \\
\text { (\$84/Ton } \\
\text { ) }\end{array}$ & $\begin{array}{l}\text { High Cost } \\
\text { (\$100/Ton) }\end{array}$ & $\begin{array}{c}\text { Roadside Cost } \\
\text { (\$60/Ton) }\end{array}$ & $\begin{array}{l}\text { Low Cost } \\
\text { (\$84/Ton) }\end{array}$ & $\begin{array}{l}\text { High Cost } \\
\text { (\$100/Ton) }\end{array}$ \\
\hline \multicolumn{7}{|c|}{ Base Case Scenario (Million Tons of Resource Available) } \\
\hline Animal manures & 18.5 & 18.5 & 18.5 & 18.4 & 18.4 & 18.4 \\
\hline Other agricultural wastes ${ }^{a}$ & 17.3 & 4.9 & 9.5 & 19.6 & 7.9 & 14.6 \\
\hline Paper and paperboard & 17.1 & 17.1 & 17.1 & 17.1 & 17.1 & 17.1 \\
\hline $\begin{array}{l}\text { Other municipal solid } \\
\text { waste }\end{array}$ & 18.6 & 18.6 & 18.6 & 18.6 & 18.6 & 18.6 \\
\hline Forestry residues ${ }^{b}$ & 13.0 & 9.1 & 9.8 & 13.0 & 3.7 & 6.9 \\
\hline Other wood wastes ${ }^{b, c}$ & 7.3 & 5.1 & 5.5 & 7.3 & 2.1 & 3.9 \\
\hline Biosolids & 3.8 & 3.8 & 3.8 & 4.2 & 4.2 & 4.2 \\
\hline Trap grease & 1.1 & 1.1 & 1.1 & 1.2 & 1.2 & 1.2 \\
\hline Food processing wastes & 4.0 & 4.0 & 4.0 & 4.0 & 4.0 & 4.0 \\
\hline Utility tree trimmings & 0.5 & 0.5 & 0.5 & 0.5 & 0.5 & 0.5 \\
\hline Total & 101.2 & 82.7 & 88.5 & 103.9 & 77.6 & 89.4 \\
\hline
\end{tabular}

${ }^{a}$ Herbaceous feedstock utilization ratio used

${ }^{b}$ Woody feedstock utilization ratio used

c Excluding urban and C\&D wastes

Table A10. Ratio of Utilized to Total Available Feedstock for Woody and Herbaceous Materials. These Assumptions Were Applied to Similar Materials in this Waste Feedstock Analysis.

\begin{tabular}{|c|c|c|c|c|c|c|}
\hline & & \multicolumn{2}{|c|}{ Near Term (2022) } & & \multicolumn{2}{|c|}{ Long Term (2040) } \\
\hline & & $\begin{array}{l}\text { Low Cost } \\
\text { (\$84/Ton) }\end{array}$ & $\begin{array}{l}\text { High Cost } \\
\text { (\$100/Ton) }\end{array}$ & & $\begin{array}{l}\text { Low Cost } \\
\text { (\$84/Ton) }\end{array}$ & $\begin{array}{l}\text { High Cost } \\
\text { (\$100/Ton) }\end{array}$ \\
\hline $\begin{array}{l}\text { Woody feedstock } \\
\text { assumptions }\end{array}$ & $\begin{array}{l}\text { Ratio } \\
\text { (Utilized/Total) }\end{array}$ & 0.70 & 0.76 & $\begin{array}{l}\text { Ratio } \\
\text { (Utilized/Total) }\end{array}$ & 0.28 & 0.53 \\
\hline $\begin{array}{l}\text { Herbaceous feedstock } \\
\text { assumptions }^{\mathrm{b}}\end{array}$ & $\begin{array}{l}\text { Ratio } \\
\text { (Utilized/Total) }\end{array}$ & 0.28 & 0.55 & $\begin{array}{l}\text { Ratio } \\
\text { (Utilized/Total) }\end{array}$ & 0.40 & 0.74 \\
\hline
\end{tabular}

${ }^{a}$ Woody feedstock utilization ratio used

${ }^{\mathrm{b}}$ Herbaceous feedstock utilization ratio used 
Table A11. Breakdown of Unused Material for Each Waste Case. High-Cost Case Recovers Material Recovered Due to Too Low Cost Assumptions (>\$ton notation).

\begin{tabular}{ccccc}
\hline Unused breakdown & Near, L & Near, H & Long, L & Long, H \\
\hline Unused BC & $\mathbf{1 8 . 5}$ & $\mathbf{1 2 . 7}$ & $\mathbf{2 6 . 3}$ & $\mathbf{1 4 . 5}$ \\
overcontracting buffer & 6.36 & 6.36 & & \\
supply chain & & & & \\
Other agricultural wastes & 1.21 & 1.21 & & \\
Forestry residues & 0.13 & 0.13 & & \\
Other wood wastes* & 0.07 & 0.07 & & \\
$>$ \$/ton & 10.68 & 4.94 & 26.30 & 14.51 \\
\hline
\end{tabular}

\section{A.4 Supplemental Algae Feedstock Tables}

Table A12. Adopted from BT16 Appendix D, Table D-12. Summary of Algae Productivities Used for Minimum, Median, and Maximum Productivity Case.

\begin{tabular}{|c|c|c|c|c|c|}
\hline Scenario & Scenario (Culture medium) & Source of $\mathrm{CO}_{2}$ & Minimum & Median & Maximum \\
\hline \multirow{9}{*}{ Present Productivity } & \multirow{3}{*}{ Fresh water } & Coal & 15.87 & 11.63 & 3.21 \\
\hline & & Natural Gas & 16.77 & 13.63 & 7.17 \\
\hline & & Ethanol & 14.46 & 11.54 & 3.25 \\
\hline & \multirow{3}{*}{ Saline (minimally lined) } & Coal & 17.23 & 11.07 & 3.49 \\
\hline & & Natural Gas & 16.77 & 13.30 & 4.64 \\
\hline & & Ethanol & 14.46 & 11.31 & 3.23 \\
\hline & \multirow{3}{*}{ Saline (fully lined) } & Coal & 17.23 & 11.07 & 3.49 \\
\hline & & Natural Gas & 16.77 & 13.30 & 4.64 \\
\hline & & Ethanol & 14.46 & 11.31 & 3.23 \\
\hline \multirow{6}{*}{ Future Productivity } & \multirow{2}{*}{ Fresh water } & Coal & 29.81 & 27.66 & 6.88 \\
\hline & & Ethanol & 28.49 & 22.74 & 6.36 \\
\hline & \multirow{2}{*}{ Saline (minimally lined) } & Coal & 31.02 & 21.19 & 7.16 \\
\hline & & Ethanol & 29.31 & 28.67 & 5.30 \\
\hline & \multirow{2}{*}{ Saline (fully lined) } & Coal & 31.02 & 21.19 & 7.16 \\
\hline & & Ethanol & 29.31 & 28.67 & 5.30 \\
\hline
\end{tabular}




\section{A.5 Summary of Feedstock Availabilities}

For Tables A13-A14, feedstocks are grouped by conversion technology. Bold items are part of the "currently utilized feedstock" category. In some cases, for traditional first-generation feedstocks, the category was further broken down into subcategories (e.g., vegetable oils can more thoroughly be described by canola, corn, and soybean oils). These breakdowns are indicated by grey text. It should be noted that these do not add to the total feedstocks, but their sum should equal that of the feedstock to which they belong. 
Table A13. Near-Term (2022) Base Case Feedstock Availability

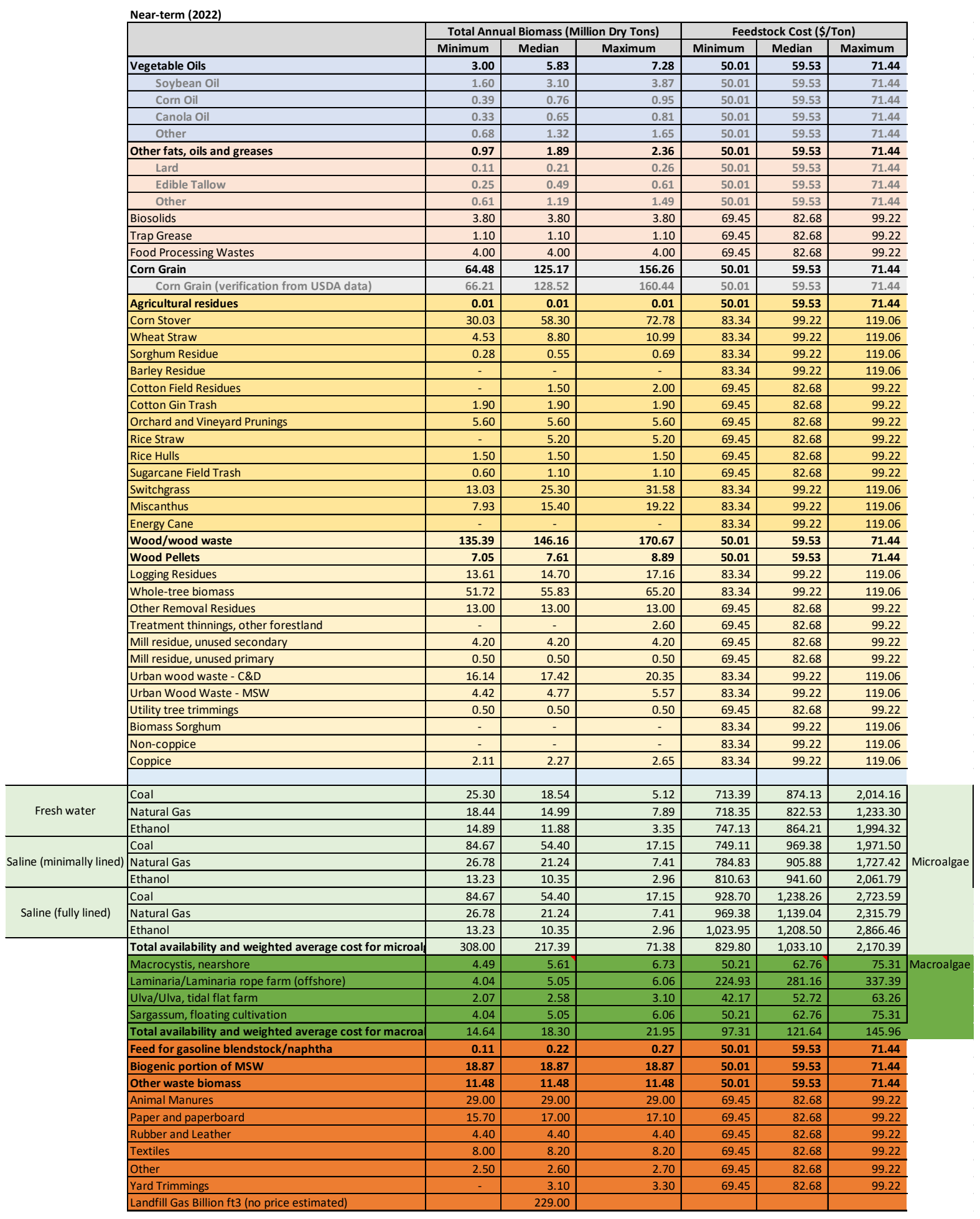


Table A14. Long-Term (2040) Base Case Feedstock Availability

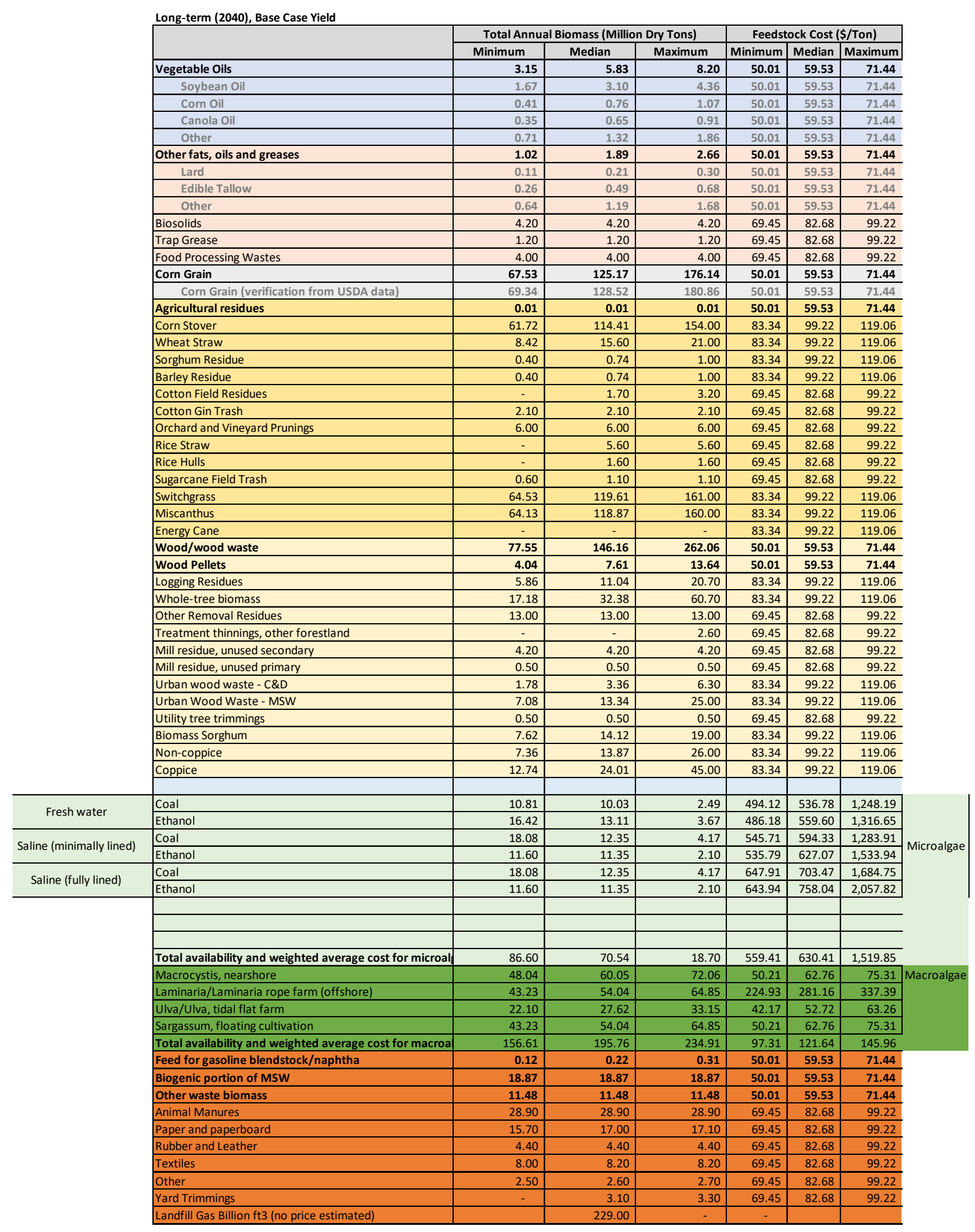


Table A15. Long-Term (2040) High-Yield Feedstock Availability

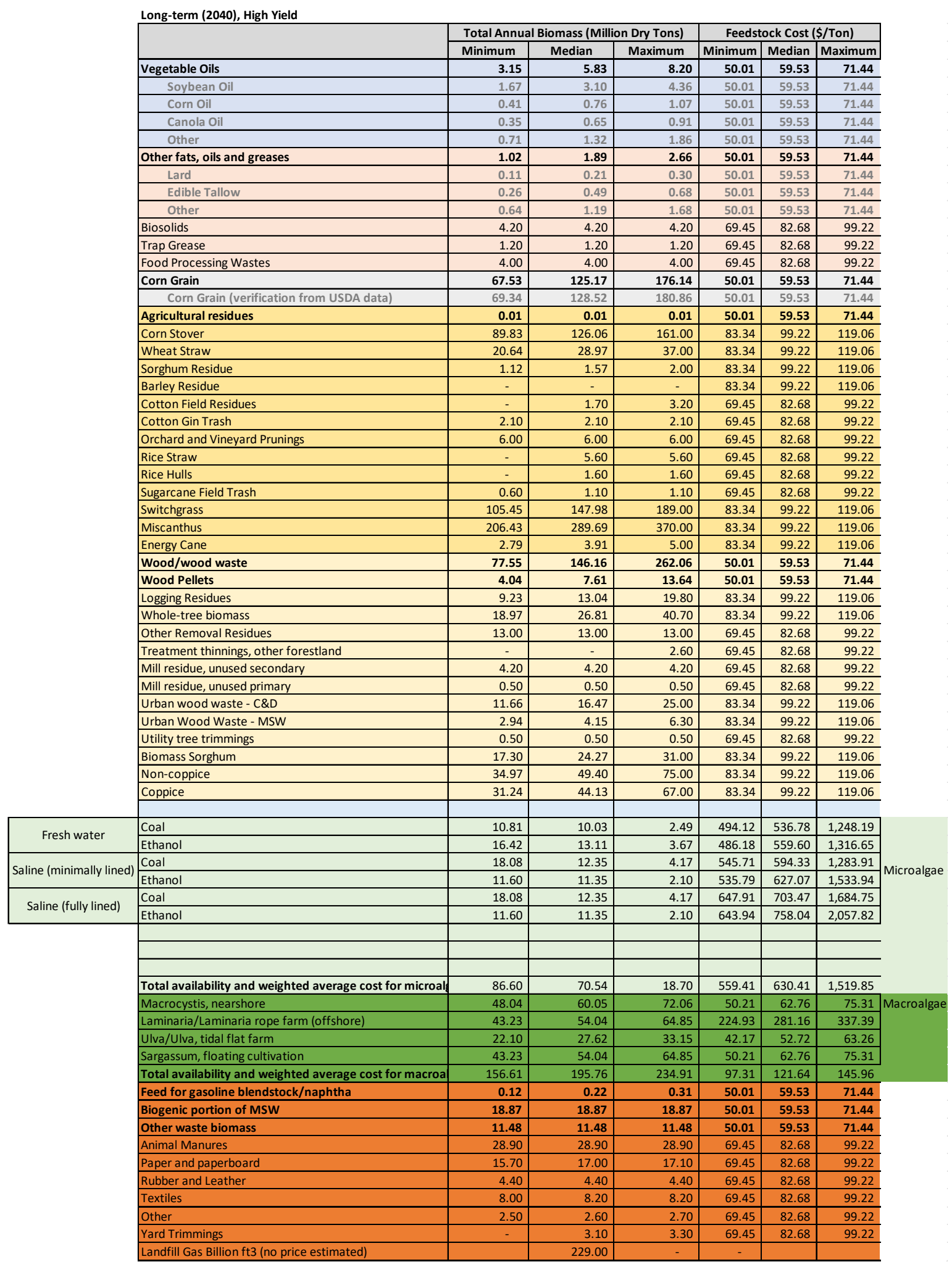




\section{Appendix B. Biomass Conversion Technology Assessment Pathway Details}

\section{B.1 N $\mathrm{N}^{\text {th }}$-Plant Economic Assumptions}

The conversion pathways described in Section 3 follow the assumptions used by the Bioenergy Technologies Office (BETO) for $\mathrm{n}^{\text {th }}$-plant economics. We define $\mathrm{n}^{\text {th }}$-plant economics for use throughout the pathways in this appendix. The key assumption of $\mathrm{n}^{\text {th }}$-plant economics is that several commercial plants using the same technology have been built. Additionally, they reflect a future scenario where there is a successful biomass collection, distribution, and conversion industry with many plants operating. This set of assumptions is useful for (1) studying new process technologies or (2) comparing integrated schemes to determine their relative economic impact. This approach allows us to ignore extraneous costs or artificial inflation of pioneer plants such as financing risk, longer start-ups, and equipment over design, among others. These costs can often overshadow the real economic impact of process engineering and conversion science improvements.

In the conversion technologies that follow the $\mathrm{n}^{\text {th }}$-plant economics in this study, the equipment costs are estimated explicitly; because of this, the $\mathrm{n}^{\text {th }}$-plant assumptions apply mainly to the factored cost models (e.g., discounted cash flow rate of return [DCFROR]) used to determine the total capital investment (TCI) from the purchased equipment costs and the assumptions for the plant's financing. The $\mathrm{n}^{\text {th }}$-plant economic assumptions apply to operating specifications such as on-stream time or start-up time. Table 13 lists the $\mathrm{n}^{\text {th }}$-plant economic assumptions.

The assumed design capacity was 2,000 dry metric tons (DMT) per day (2,205 dry U.S. tons per day). With an expected 7,884 operating hours per year ( $90 \%$ on-stream factor/availability), the annual feedstock requirement is approximately 657,000 DMT per year (724,000 dry U.S. tons per year). The assumed on-stream factor allows approximately 36 days of planned and unplanned downtime per year. The techno-economic analysis reported here uses $\mathrm{n}^{\text {th }}$-plant economic assumptions, the key aspect of which is that a successful industry has been established with many operating plants using similar process technologies.

\section{Conversion of Cost Years}

All conversion pathways in this study were published over many years and used a variety of cost years for their estimations. To better harmonize the comparison of the conversion pathways, cost years were converted from their initial year in the report to 2016 dollars using the Chemical Engineering Plant Cost Index and Equation B.1:

$$
\text { Corrected Cost }=\text { Base Cost }\left(\frac{2016 \text { Cost Index Value }}{\text { Base Year Cost Index Value }}\right)
$$

The indexes used for this study are shown in Figure B1. 


\begin{tabular}{|c|c|}
\hline Year & Index \\
\hline 1990 & 357.6 \\
\hline 1991 & 361.3 \\
\hline 1992 & 358.2 \\
\hline 1993 & 359.2 \\
\hline 1994 & 368.1 \\
\hline 1995 & 381.1 \\
\hline 1996 & 381.7 \\
\hline 1997 & 386.5 \\
\hline 1998 & 389.5 \\
\hline 1999 & 390.6 \\
\hline 2000 & 394.1 \\
\hline 2001 & 394.3 \\
\hline 2002 & 395.6 \\
\hline 2003 & 402.0 \\
\hline 2004 & 444.2 \\
\hline
\end{tabular}

\begin{tabular}{|l|l|}
\hline Year & Index \\
\hline 2005 & 468.2 \\
\hline 2006 & 499.6 \\
\hline 2007 & 525.4 \\
\hline 2008 & 575.4 \\
\hline 2009 & 521.9 \\
\hline 2010 & 549.5 \\
\hline 2011 & 585.7 \\
\hline 2012 & 584.6 \\
\hline 2013 & 567.3 \\
\hline 2014 & 576.1 \\
\hline 2015 & 556.8 \\
\hline 2016 & 541.7 \\
\hline 2017 & 567.5 \\
\hline 2018 & 587.8 \\
\hline
\end{tabular}

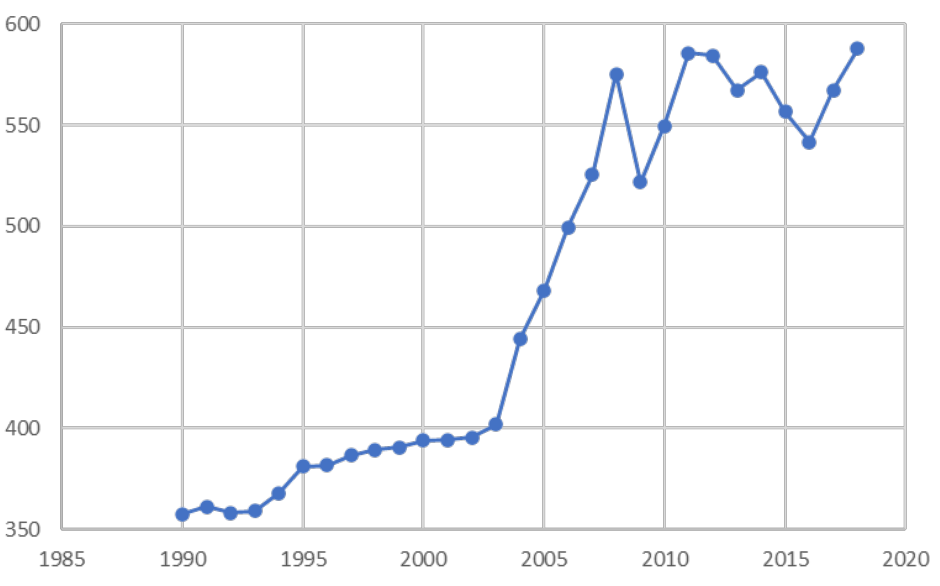

Figure B1. Chemical Engineering Plant Cost Index data

\section{B.2 Biofuel Production Technologies}

Pathway 1: Biodiesel Production from Rapeseed Oil via Alkali Catalysts

Feedstock: Rapeseed oil free of free fatty acids (FFAs)

Feedstock Processing Technology: N/A

Fuel Precursor: N/A

Fuel Processing Technology: Transesterification

Biofuel Product: $100 \%$ Diesel

Data Source: (Apostolakou et al. 2009)

\section{Process Summary}

The simplified block flow diagram is shown in Figure B2. 


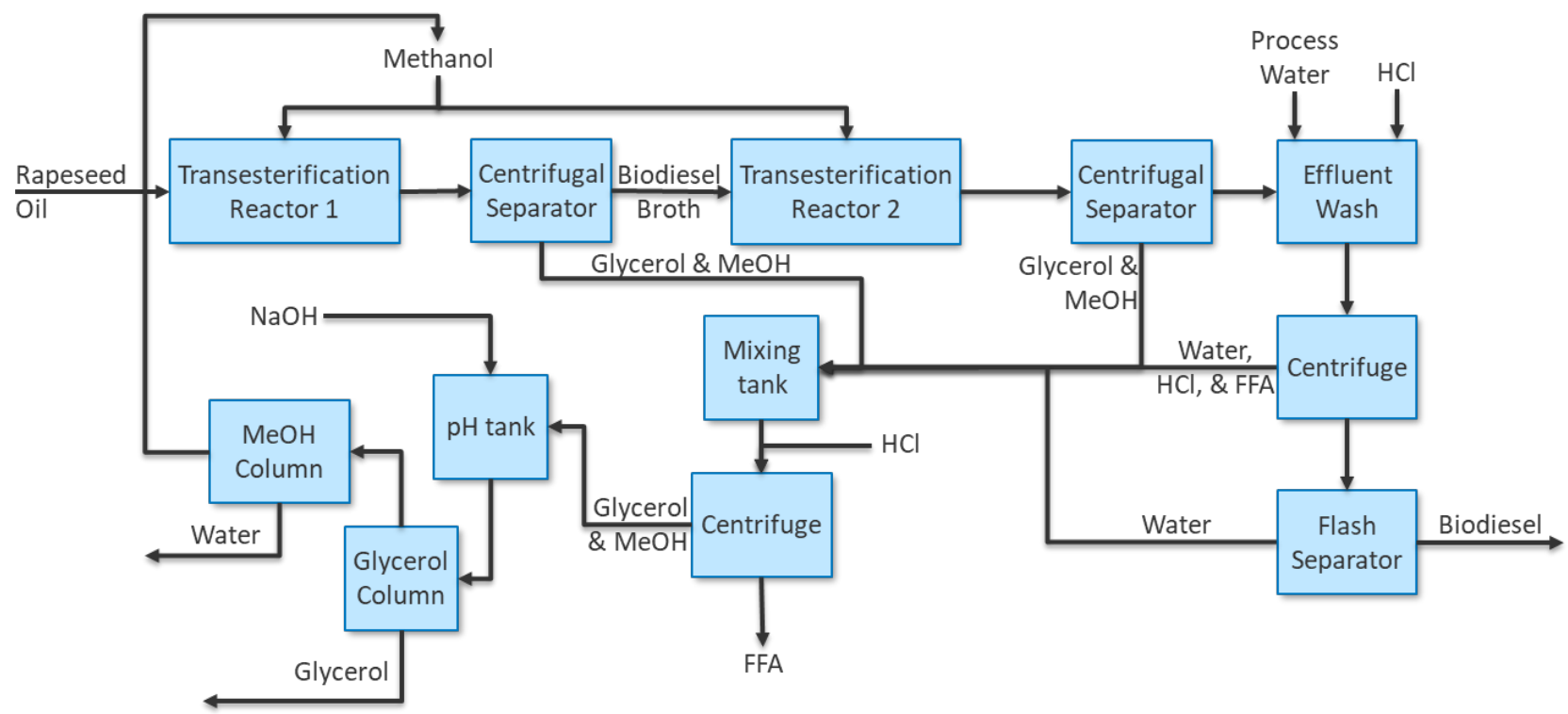

Figure B2. Simplified bock flow diagram for biodiesel production from rapeseed oil via alkali catalysts

\section{$\underline{\text { Process Design }}$}

This plant is designed to operate at $137 \mathrm{DMT} /$ day and utilizes rapeseed oil as the feedstock.

Rapeseed oil is delivered to the plant and mixed with methanol in a 6:1 molar ratio of methanol to rapeseed oil and catalyst. Catalysts used for transesterification are generally homogeneous alkali catalysts, and the one used in this study is sodium methoxide. The methanol-rapeseed oil mixture is mixed with the catalyst in a well-mixed tank reactor, where rapeseed oil is converted to biodiesel and glycerol. This reaction occurs at atmospheric pressure, $60^{\circ} \mathrm{C}$ with a 1 -hour residence time and achieves $90 \%$ yield of rapeseed oil to biodiesel.

The reactor effluent is then fed to a centrifugal separator that removes the biodiesel and unreacted oil from glycerol and methanol. The biodiesel-rapeseed oil mixture is then fed to a second well-mixed tank reactor with more methanol and catalyst. The second reactor operates at atmospheric pressure, $60^{\circ} \mathrm{C}$, has a 1 -hour residence time, and a $90 \%$ yield of rapeseed oil to biodiesel. Between both reactors, $99 \%$ of the incoming rapeseed oil is converted to biodiesel and glycerol. The second reactor effluent is fed to a similar centrifugal separator to remove glycerol and methanol from the biodiesel and any trace unreacted rapeseed oil.

The biodiesel is then sent to a mixing tank where process water and $\mathrm{HCl}$ are mixed to neutralize the catalyst and convert any soap produced during the reaction to FFAs. The solution has a residence time of 1 hour in the mixing tank before the mixture is fed to a centrifuge, where the FFA-HCl-water mixture is separated from the biodiesel, leaving the biodiesel with small amounts of water. The biodiesel is then fed to a flash drum that separates the water from the mixture, yielding fuel-grade biodiesel and water.

All of the waste streams produced so far - the glycerol and methanol streams from both postreactor centrifugal separators, FFA-HCl-water mixture from the centrifuge, and the water from the flash drum - are sent to a mixing tank, where it has a 1-hour residence time. The mixture is 
treated with $\mathrm{HCl}$ to convert any remaining soap to FFA before entering another centrifugal separator that removes the FFA from the remaining water, methanol, and glycerol. The watermethanol-glycerol mixture is fed to a $\mathrm{pH}$ adjustment tank, where $\mathrm{NaOH}$ is pumped in to neutralize the mixture to a $\mathrm{pH}$ of 7 for 1 hour. The effluent from the $\mathrm{pH}$ adjustment tank then enters the glycerol distillation column that operates just above atmospheric pressure. In the column, glycerol is separated from methanol and some water and leaves the bottom of the column in an 80 wt \% glycerol mixture with water. This mixture could be sold as a coproduct depending on the market price, but this study chose not to sell it as a coproduct. The watermethanol mixture that leaves the top of the glycerol column then enters a methanol distillation column that operates at 7.25 psia and yields near-pure (99.9 mol \%) methanol, which is recycled to the transesterification reactor, and water, which is recycled to the wash tanks.

\section{Process Economics}

This process does not follow the standard BETO assumptions listed at the beginning of this appendix. It varies in ways shown in Table B1.

Table B1. Economic Assumptions for Biodiesel Production from Rapeseed Oil via Alkali Catalysts

\begin{tabular}{|l|r|}
\hline Item & Assumption \\
\hline Maintenance & $10 \%$ of FCI \\
\hline Operating labor & Manning Estimates \\
\hline Lab costs & $20 \%$ of operating labor \\
\hline Supervision & $20 \%$ of operating labor \\
\hline Overhead & $50 \%$ of operating labor \\
\hline Capital charges & $15 \%$ of FCI \\
\hline Insurance, taxes, and royalties & $4 \%$ of FCI \\
\hline Plant life & 10 years \\
\hline
\end{tabular}

The capital expenses in this study were calculated using a variety of chemical engineering cost equations that utilized product material, flow rates, heat requirements, and more. More specific information on each equipment cost can be found in the source material. Using these equations, the fixed capital investment (FCI) was assumed to be $\$ 9.76$ million.

The operating costs were sourced from market prices for raw materials such as methanol, $\mathrm{HCl}$, and $\mathrm{NaOH}$ solutions. Rapeseed oil was assumed to be $\$ 1,160 / \mathrm{DMT}$, as that was a median price in Europe at the time of this study (2009). Costs for utilities were based on the requirements specified in the material and energy balances around the plant. It was estimated that 15 operators were required to run the plant at salaries of $\$ 41,500$ per year.

Producing 14.3 million gasoline gallon equivalents (GGE) per year and accounting for all capital and operating expenses, the minimum fuel selling price (MFSP) of the biodiesel was calculated to be $\$ 4.33 /$ GGE. The only sensitivity studied was plant size. It was determined that as plant size decreases, the MFSP increases in an exponential fashion. As the production rate decreases, the percentage that raw materials contribute to the MFSP decreases exponentially.

Table B2 summarizes the economic information about this conversion pathway. 
Table B2. Summary Results Table for Biodiesel Production from Rapeseed Oil via Alkali Catalysis

\begin{tabular}{|c|c|c|}
\hline Technology Pathway & $\begin{array}{l}\text { Biodiese } \\
\text { Rapesee }\end{array}$ & $\begin{array}{l}\text { Production from } \\
\text { oil via Alkali Catalysis }\end{array}$ \\
\hline Feedstock Type & Rapesee & Oil \\
\hline Hydrocarbon Product Slate, wt \% & $100 \%$ & Diesel \\
\hline Coproducts & & N/A \\
\hline Carbon Efficiency & $99 \%$ & \\
\hline Total Capital Investment, million \$ & $\$ 9.76$ & \\
\hline Total Operating Costs, million \$/yr & $\$ 68.4$ & \\
\hline Minimum Selling Price, \$/GGE & $\$ 4.33$ & \\
\hline \multicolumn{3}{|l|}{ Cost Contributions, \$/GGE } \\
\hline Capital Cost & $\$ 0.35$ & \\
\hline Feedstock Cost & $\$ 3.67$ & \\
\hline Operating Costs & $\$ 0.07$ & \\
\hline Operating Credits & $\$ 0.00$ & \\
\hline Taxes & $\$ 0.25$ & \\
\hline
\end{tabular}

Pathway 2-5: Hydroprocessed Jet Fuels

Feedstock: Jatropha Oil, Camelina Oil, Pennycress Oil, Castor Bean Oil

Feedstock Processing Technology: Hydroprocessed Esters and Fatty Acids

Fuel Precursor: Biocrude

Fuel Processing Technology: Catalytic Hydrotreating

Biofuel Product: $27.6 \%-34.5 \%$ Gasoline, $0.2 \%-13.7 \%$ Diesel, $57.8 \%-66.9 \%$ Jet

Data Source: (Tao et al. 2017)

\section{$\underline{\text { Process Summary }}$}

The simplified block flow diagram is shown in Figure B3.

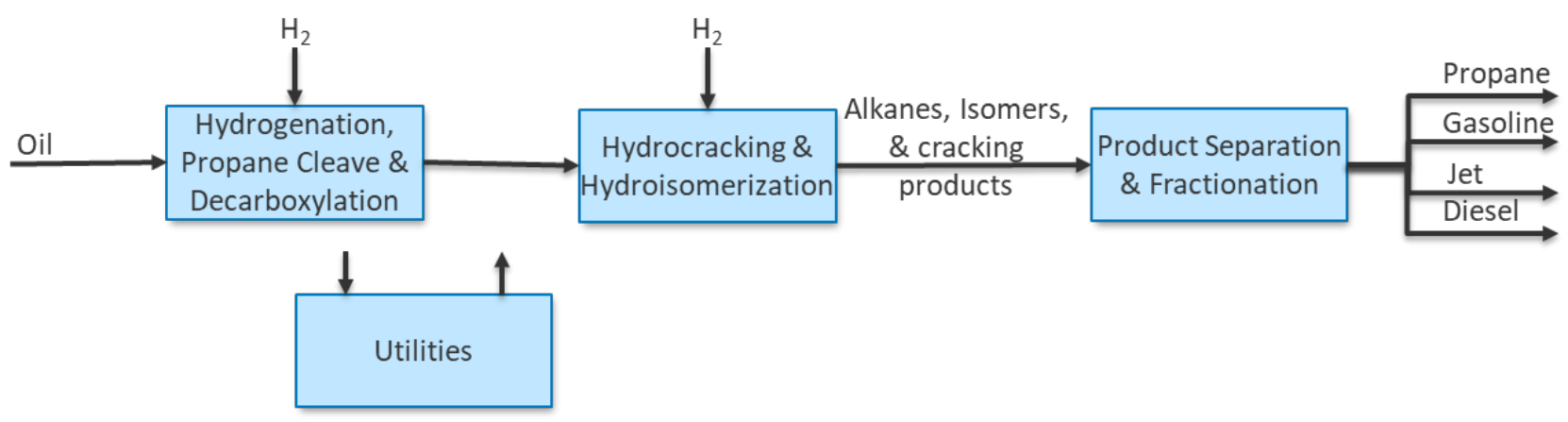

Figure B3. Simplified block flow diagram for hydroprocessed jet fuels

\section{Process Design}

In the hydroprocessing facility, bio-oils undergo three steps: hydrogenation, propane cleave, and decarboxylation: 
1. Converting liquid-phase unsaturated FFAs or glycerides into saturated with the addition of hydrogen, a hydrogenation step occurs to saturate the double bonds in the unsaturated triglycerides.

2. Cleaving the propane and producing three moles of FFAs per mole of triglycerides. The glycerol portion of the triglyceride molecule is converted into propane by adding $\mathrm{H}_{2}$. The propane cleave process removes the propane backbone from the molecule, turning glycerides into three fatty acids.

3. Removing the oxygen from the fatty acids through decarboxylation, in the form of carbon $\mathrm{CO}_{2}$. Alternately, oxygen can also be removed through decarbonylation, in the form of $\mathrm{CO}$, and hydrodeoxygenation, in the form of water.

All three reaction steps occur in a single reactor, which operates at $400^{\circ} \mathrm{C}$ and $9.2 \mathrm{MPa}$. The catalyst used in this process is $\mathrm{Pd} / \gamma-\mathrm{Al}_{2} \mathrm{O}_{3}$. Hydrogen gas is fed into the reactor for the hydrogenation and propane cleave. Hydrogen demand is calculated based on the amount required to saturate the double bonds of the unsaturated triglycerides and cleave the propane from the glycerol backbone. Removing the propane molecule from the triglycerides requires 3 mol of hydrogen per mole of triglycerides, whereas the requirement for saturating double bonds varies based on incoming oil saturation. The final products include liquid hydrocarbons and gas products, namely $\mathrm{CO}_{2}, \mathrm{H}_{2}$, and propane. The gas is purged and sent to a vapor-liquid separator to remove the gas-phase products. The liquid portion is routed to the hydrocracking and hydroisomerization area.

The produced sustainable aviation fuel or alternative jet fuel must have a high flash point and good cold flow properties to meet the jet fuel specifications. This can be accomplished by adding hydrocracking and hydroisomerization steps, which convert normal paraffins produced from deoxygenation to a synthetic paraffinic kerosene product. The isomerization process converts the straight-chain hydrocarbons to the branched structures, thus reducing the freeze point to meet the jet fuel standard. It is accompanied by a hydrocracking reaction, which results in minimum yield loss from the isomerized species. Sometimes the hydroisomerization will accompany cracking, which reduces the chain length and produces more molecules. The hydrocracking reactions are exothermic and result in the production of lighter liquids and gas products. They are relatively slow reactions; thus, most hydrocracking occurs in the last section of the reactor. The hydrocracking step primarily involves cracking and saturation of paraffins. Over-cracking will result in low yields of jet-fuel-range alkanes and high yields of light species ranging from $\mathrm{C} 1$ to $\mathrm{C} 4$ and naphtha ranging from $\mathrm{C} 5$ to $\mathrm{C} 8$.

For product separation, the hydrocarbon products from the hydroisomerization/cracking reactor are sent to the first distillation column to remove gaseous products. The gaseous products, which contain propane, $\mathrm{H}_{2}, \mathrm{CO}_{2}$, and trace amounts of liquid hydrocarbons, are subjected to further separation in the propane purification unit. In the propane purification unit, propane is dissolved in hexane and separated from $\mathrm{CO}_{2}$ and $\mathrm{H}_{2}$. Propane is conserved and can be sold as a coproduct. $\mathrm{CO}_{2}$ and $\mathrm{H}_{2}$ are vented or recycled. The liquid products containing all the hydrocarbons are sent to a second distillation column to separate the naphtha of the top of the column and heavier products of the bottom of the column. The naphtha product will be sold as a gasoline blendstock. The heavier species in the second column are further separated in a third distillation column. Heavier compounds like $\mathrm{C} 17$ and $\mathrm{C} 18$ hydrocarbons that stay at the bottom are considered diesel 
alternatives. The overhead stream with hydrocarbons ranging from $\mathrm{C} 8$ to $\mathrm{C} 16$ is considered a jetfuel-range blendstock. Residual unconverted oils are considered impurities, and a disposal fee is applied to dispose of the residue stream.

This pathway is also known as the hydroprocessed esters and fatty acids (HEFA) pathway.

\section{Process Economics}

This process follows standard BETO assumptions listed at the beginning of this appendix.

This study's capital expenses were calculated using the Aspen Plus Capital Cost Estimator, taken from literature, and generated using the study's in-house estimation methods. The operating costs were calculated by using material and energy balances from the process simulation and standard utility rates.

With all the capital and operating costs, the plant produces between 73 and 79 million GGE/year depending on the feedstock, and the MFSP varied from $\$ 3.57 / \mathrm{GGE}$ to $\$ 10.32 / \mathrm{GGE}$ depending on the feedstock. The cost breakdown for the area contributions to this is shown in Table B3. From this information, it can be seen that the feedstock cost contributes significantly more to the MFSP than any other area and contributes to some of the fuels having a much higher MFSP as compared to other pathways in this report. The operating expenses are the next-highest contributor, and that is mainly because of the continued need for supplied hydrogen, catalyst replacement costs, and the required heat and power for the facility. There were no sensitivity analyses produced for these pathways.

Table B3. Summary Results Table for Hydroprocessed Jet Fuels

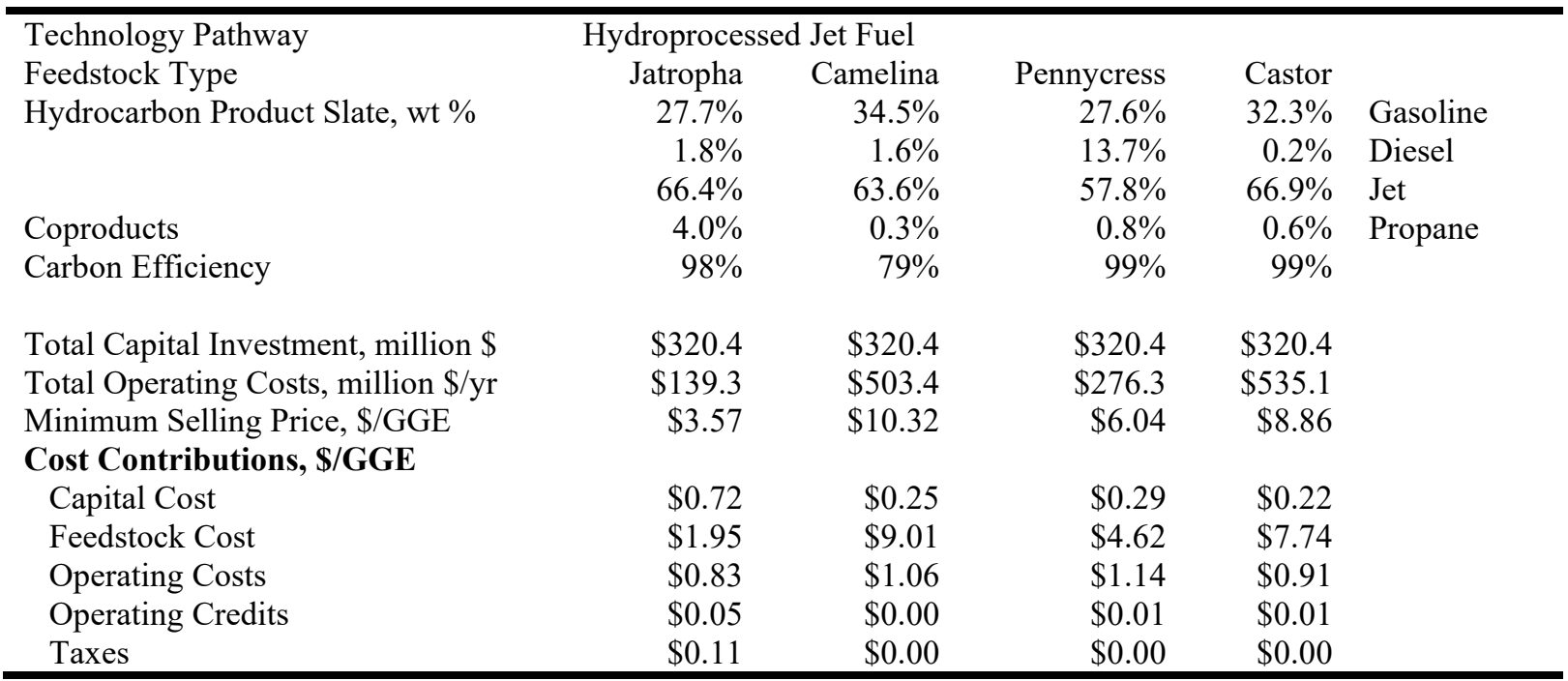

Pathway 6: Waste Oil Production of Biodiesel via Esterification

Feedstock: Waste Oil

Feedstock Processing Technology: Acid Pre-esterification

Fuel Precursor: Mixed oils 
Fuel Processing Technology: Transesterification

Biofuel Product: 100\% Diesel

Data Source: (Marchetti, Miguel, and Errazu 2008)

\section{Process Summary}

The simplified block flow diagram is shown in Figure B4.

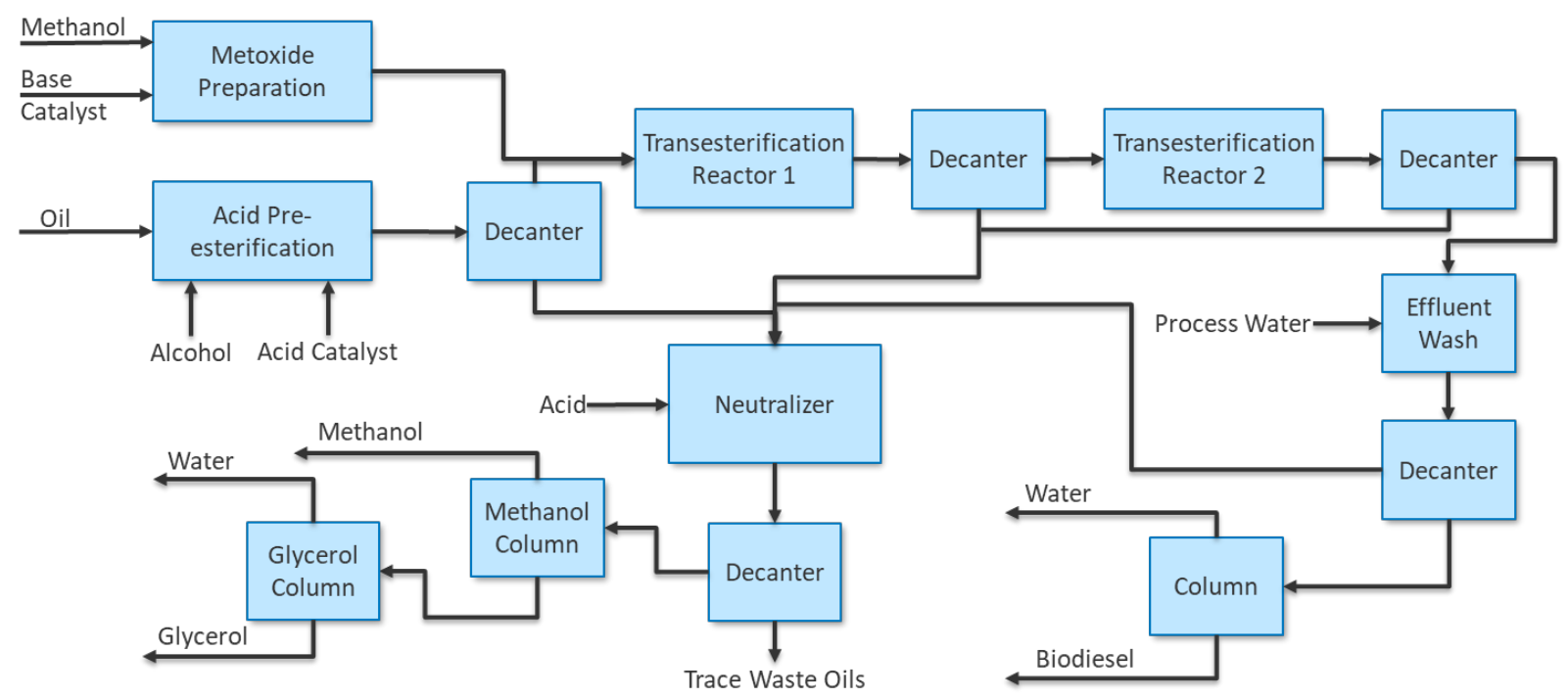

Figure B4. Simplified block flow diagram for waste oil production of biodiesel via esterification

\section{Process Design}

This plant is designed to operate at $99 \mathrm{DMT} /$ day and utilizes spent oil with 5\% FFA as the feedstock.

Oil first enters the plant and goes into an acid pre-esterification reactor. Here, it is mixed with sulfuric acid, which catalyzes the esterification of FFA. The reactor effluent then enters a decanter, where the oil and water phase separate. The oil phase then heads to the first of two transesterification reactors. The water is mixed with other streams, mentioned below, and fed to the neutralizer.

An alcoxy stream is produced in a methoxide preparation reactor, which mixes methanol and a base catalyst. More details on this stream can be found in the source material. The oil is mixed with the alcoxy stream as it enters the transesterification reactor. In the transesterification reactor, a homogeneous alkaline catalyst is used to convert the oil into biodiesel and glycerol. The reaction requires a source of alcohols, which the alcoxy stream provides. The reactor effluent then passes through a decanter, separating the glycerol from the oil phase containing the biodiesel and unreacted oil. The oil phase then heads to the second transesterification reactor, where a second alcoxy stream is mixed with it. The same homogeneous alkaline catalyst converts the unreacted oil to biodiesel and glycerol in the second transesterification reactor. The effluent goes to a similar decanter as before to remove the glycerol. 
The oil phase from the second decanter is then sent to be washed with water to remove any undesired compounds. The water-biodiesel mixture heads to another decanter where the aqueous phase and organic phase separate. The aqueous phase is sent to the neutralizer, and the organic phase is sent to a distillation column to remove any remaining water and methanol. The bottom of the distillation column yields $>99.5 \%$ pure biodiesel that can be sold as fuel.

As mentioned, the glycerol and water phases from all the decanters are fed to a neutralization reactor. An acid stream is also fed to the neutralization reactor to neutralize any remaining base catalyst. The effluent then enters a final decanter that separates any remaining oil from the remaining water, glycerol, and any trace methanol. The aqueous phase is then sent to a methanol column that removes the methanol from the glycerol and water. The methanol can then be recycled to the methoxide preparation reactor. The bottoms with water and glycerol then enter a glycerol column that separates most of the water from the glycerol, yielding $77 \%$ pure glycerol in water to be sold as a coproduct. The water that leaves the column in the distillate is recycled as process water. The overall conversion of oil to biodiesel is over $98 \%$.

\section{Process Economics}

This process does not follow the standard BETO assumptions listed at the beginning of this section and does not provide specific information on all the economic assumptions. Some assumptions specified are a plant life of 15 years, 100\% time on stream, private loan investment versus financing, and an internal rate of return (IRR) of $11.17 \%$. Wastewater treatment was also not included in the economic analysis.

The capital expenses in this study were calculated using SuperPro Designer. The most expensive pieces of equipment are the two transesterification reactors, followed closely by the preesterification reactor. The costs are shown in Table B4.

Table B4. Equipment Costs for Waste Oil Production of Biodiesel via Esterification

\begin{tabular}{lr}
\hline Equipment & Cost \\
\hline Pre-mixer of catalyst & $\$ 47,000$ \\
Pre-esterification reactor & $\$ 328,500$ \\
$1^{\text {st }}$ transesterification reactor & $\$ 329,500$ \\
$2^{\text {nd }}$ transesterification reactor & $\$ 329,500$ \\
Neutralization reactor & $\$ 13,000$ \\
All decanters & $\$ 109,000$ \\
Biodiesel distillation column & $\$ 56,000$ \\
Methanol distillation column & $\$ 38,000$ \\
Glycerol distillation column & $\$ 73,000$ \\
\hline
\end{tabular}

Other costs associated with the equipment were the piping, instrumentation, insulation, electrical facilities, buildings, yard improvements, auxiliary facilities, and equipment installation. These were all taken as a percentage of the purchase price and added to the total capital investment.

The operating costs were sourced from market prices for raw materials such as methanol and the catalysts used. Spent oil was assumed to be \$376/DMT, as reported by the Argentinean oil market. Costs for utilities were based on the requirements specified in the material and energy balances around the plant and market prices. 
The plant produces 10.3 million GGE/year, and accounting for all capital and operational expenses, the MFSP of the biodiesel was calculated to be $\$ 2.30 / \mathrm{GGE}$. There were no sensitivity analyses performed in this study.

Table B5 summarizes the economic information about this conversion pathway.

Table B5. Summary Results Table for Waste Oil Production of Biodiesel via Esterification

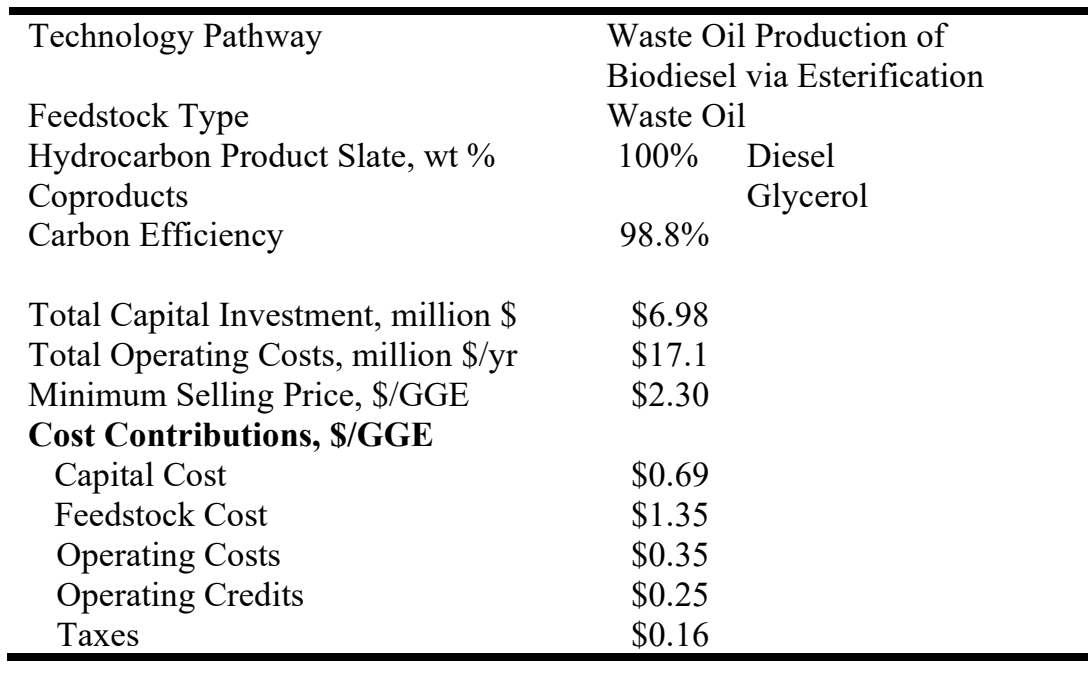

Pathway 7: Yellow Grease to Jet via HEFA Process

Feedstock: Yellow Grease

Feedstock Processing Technology: Acid Pre-esterification

Fuel Precursor: Mixed oils

Fuel Processing Technology: Transesterification

Biofuel Product: $100 \%$ Diesel

Data Source: (Tao et al. 2017)

\section{Process Summary}

The simplified block flow diagram is shown in Figure B5.

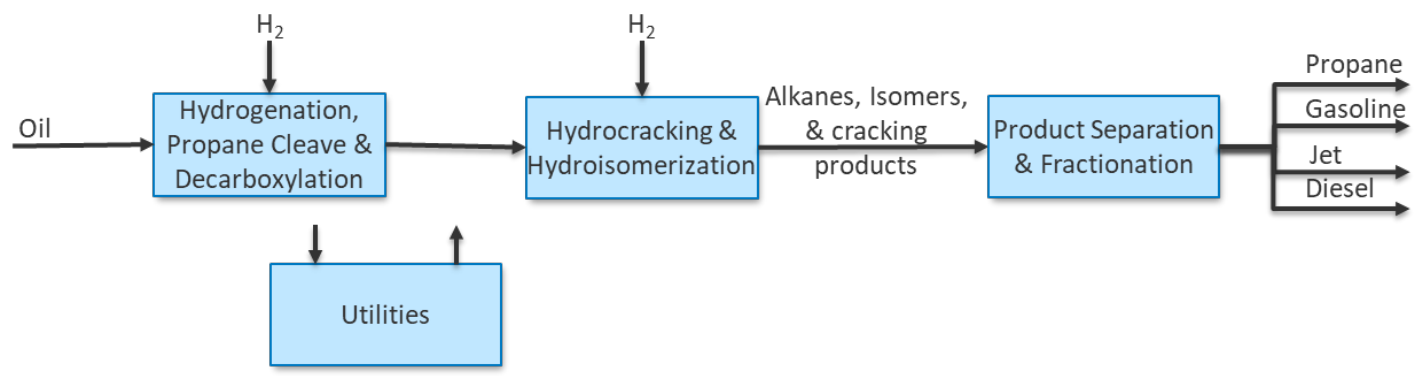

Figure B5. Simplified block flow diagram for yellow grease to jet via HEFA process 


\section{Process Design}

This plant is designed to operate at 715 DMT/day and utilizes yellow grease, which is mainly derived from used cooking oil generated by commercial and industrial cooking operations and may contain rendered animal fat as the feedstock.

Oils are delivered to the facility filtered and ready to enter the hydroprocessing unit. The processing of the waste oil is identical to the process unit operations and conditions as Pathways 2-5 and will not be repeated here.

\section{Process Economics}

This process follows standard BETO assumptions listed at the beginning of this appendix.

The capital expenses in this study were calculated using the Aspen Plus Capital Cost Estimator, taken from literature, and generated using the in-house estimation methods. The operating costs were calculated using material and energy balances from the process simulation and standard utility rates.

The plant produces 78.2 million GGE/year, and with all capital and operating expenses accounted for, the MFSP of the various hydrocarbon fuels was calculated to be $\$ 4.51 / \mathrm{GGE}$. The cost breakdown for the area contributions to this is shown in Table B6. From this information, it can be seen that the feedstock cost contributes significantly more to the MFSP than any other factor. The operating expenses are the next-highest contributor, mainly because of the continued need for supplied hydrogen, catalyst replacement costs, and the required heat and power for the facility. There were no sensitivity analyses produced for this pathway.

Table B6 summarizes the economic information about this conversion pathway.

Table B6. Summary Results Table for Yellow Grease to Jet via HEFA Process

\begin{tabular}{lcl}
\hline Technology Pathway & \multicolumn{2}{c}{ Yellow Grease to Jet via HEFA } \\
& Process & \\
Feedstock Type & Yellow Grease \\
Hydrocarbon Product Slate, wt \% & $32.2 \%$ & Gasoline \\
& $67.0 \%$ & Jet \\
& $0.3 \%$ & Diesel \\
& & Propane \\
Coproducts & $99.0 \%$ & \\
Carbon Efficiency & & \\
& $\$ 320$ & \\
Total Capital Investment, million \$ & $\$ 219$ & \\
Total Operating Costs, million \$/yr & $\$ 4.51$ & \\
Minimum Selling Price, \$/GGE & & \\
Cost Contributions, \$/GGE & $\$ 0.27$ & \\
Capital Cost & $\$ 3.30$ & \\
Feedstock Cost & $\$ 0.95$ & \\
Operating Costs & $\$ 0.01$ & \\
Operating Credits & Included & w/ Capital expenses \\
Taxes &
\end{tabular}


Pathway 8: Corn Ethanol via Fermentation Using Dry Grinding

Feedstock: Corn Grain

Feedstock Processing Technology: Enzymatic Hydrolysis

Fuel Precursor: Sugars (Glucose)

Fuel Processing Technology: Fermentation

Biofuel Product: Ethanol

Data Source: (Bothast and Schlicher 2005; Tao and Aden 2009)

Process Summary

The simplified block flow diagram is shown in Figure B6.

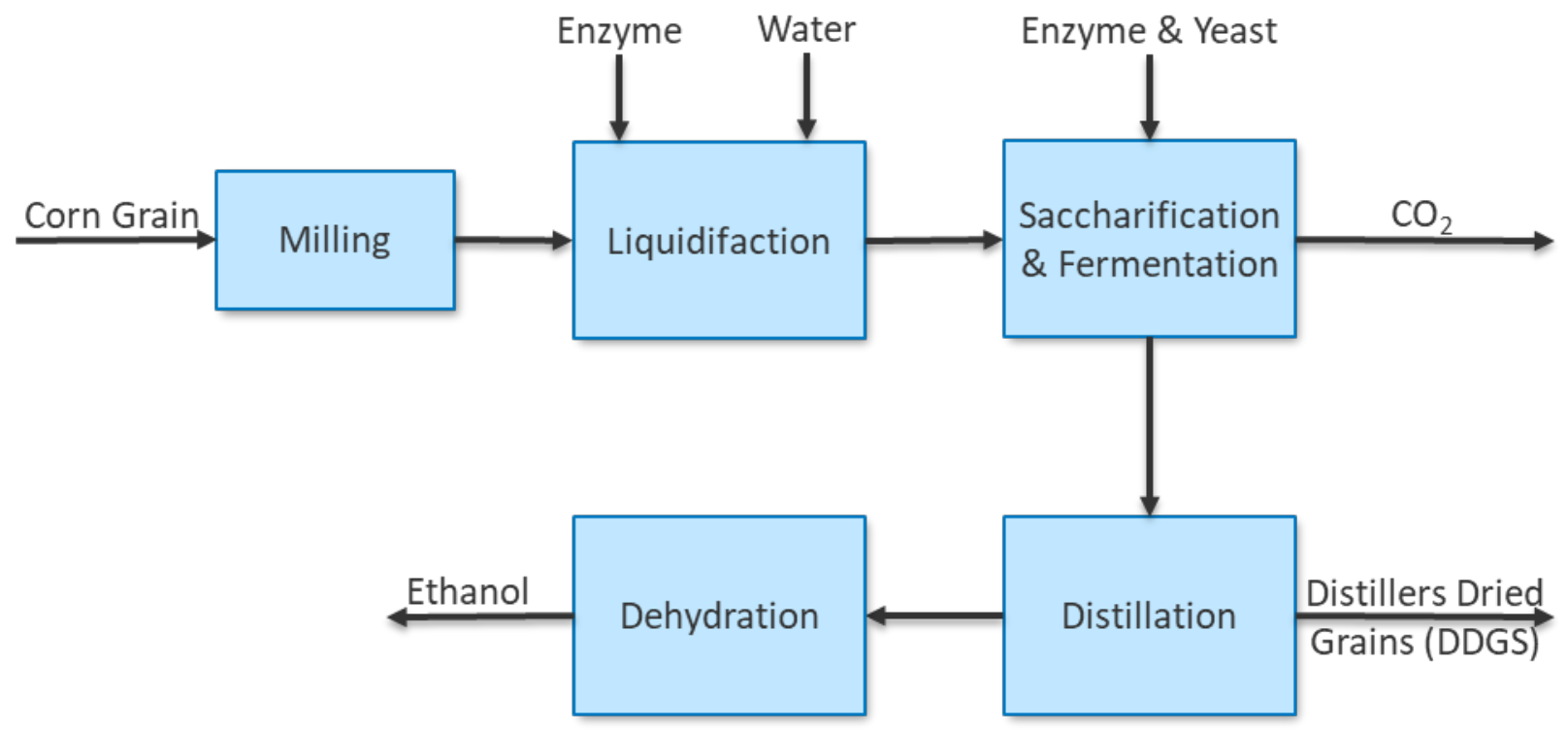

Figure B6. Simplified block flow diagram for corn ethanol via fermentation using dry grinding

\section{Process Design}

There are generally two processes to convert corn grain into ethanol for fuel use: dry grinding and wet milling. The wet milling produces ethanol with starch, high fructose corn syrup, corn gluten feed, and corn gluten meal as byproducts, whereas dry grinding only produces ethanol and distillers' dried grains with solubles (DDGS), which is used for animal feed. Because dry grinding has fewer byproducts, the yield to ethanol is higher for that process than the wet milling process. Additionally, dry grinding is less capital- and energy-intensive. For these various reasons, dry grinding is more prevalent in the United States and is estimated to be approximately $80 \%$ of all ethanol plants in the United States. The dry grinding method was chosen for evaluation and comparison in this study. 
In the dry grind process, the corn grain is milled and mixed with water and alpha-amylase (enzyme) to produce a slurry. The slurry is adjusted to a $\mathrm{pH}$ of 6.0 and $100^{\circ} \mathrm{C}$ before the alphaamylase is mixed. The slurry is allowed to liquefy for at least 30 minutes before the slurry is cooled, and the $\mathrm{pH}$ is adjusted to 4.5 . At this point, the glucoamylase enzyme is added such that the saccharification of the starch to glucose does not limit the fermentation of glucose to ethanol.

After the addition of glucoamylase, the mash is cooled further to $32^{\circ} \mathrm{C}$ and transferred to fermenters, where the yeast is added. The fermentation takes 48-72 hours and has a final ethanol concentration between $10 \%$ and $12 \%$ by volume. During fermentation, the $\mathrm{pH}$ decreases to about 4.5 , which is important to increase the glucoamylase activity while preventing the growth of contaminating bacteria. Some plants do simultaneous saccharification and fermentation that allows for $\sim 8 \%$ higher ethanol yields while also decreasing microbial contamination potential. The carbon dioxide produced during fermentation is captured and sold elsewhere for carbonating soft drinks, manufacturing dry ice, or other industrial processes.

From the fermenters, the broth is sent to a beer column, which separates the whole stillage (upgraded to DDGS to be sold as animal feed) and most water to yield 95\% ethanol. The distillation column not separating the last 5\% water is because of a naturally existing azeotrope between water and ethanol, making it impossible to yield only ethanol through traditional distillation only. However, the water must be removed for the ethanol to be used as fuel; this is achieved by using molecular sieves to produce $100 \%$ ethanol. The pure ethanol is then mixed with a denaturant (usually gasoline), rendering it undrinkable and not subject to alcohol beverage tax. After the mixing, it is sold to market for use as fuels.

\section{Process Economics}

This process differs from standard BETO economic assumptions in that the plant is online $96 \%$ of the time, as well as other metrics reflected in Table B7.

Table B7. Economic Assumptions for Corn Ethanol via Fermentation Using Dry Grinding

\begin{tabular}{|l|r|r|}
\hline Economic Parameter & \multicolumn{1}{|l|}{ Value } & \multicolumn{1}{l|}{ Unit } \\
\hline Installation factor & 3.0 & $\%$ of TPEC \\
\hline Depreciation Lifetime & 20 & Years \\
\hline Equipment Scaling Components & 0.6 & N/A \\
\hline On-Stream Time & $350(96 \%)$ & Days/year \\
\hline Corn Price & 3.45 & $\$ /$ bushel \\
\hline DDGS Price & 97.94 & $\$ /$ ton \\
\hline Enzyme Price & 1.06 & $\$ / l b$ \\
\hline Denaturant price & 2.06 & $\$ /$ gal \\
\hline Yeast Price & 0.87 & $\$ / l b$ \\
\hline
\end{tabular}

This plant was designed to produce 45 million gallons of ethanol per year, requiring over 1,000 DMT/day feedstock. With capital costs sourced from the Aspen Capital Cost Estimator, vendor quotes, and literature and operational expenses sourced from the Aspen Plus process simulation and standard assumptions for employee salaries, utilities costs, supplies, overheads, etc., an 
MFSP for the ethanol was calculated to be $\$ 2.41 /$ GGE. As with other pathways, the corn grain feedstock contributes the most to the MFSP, contributing $79 \%$ to the MFSP. The coproduct sales of the DDGS helps drop the price by $\$ 0.50 /$ GGE and offsets some of the more expensive operating costs such as natural gas.

There were no sensitivity analyses performed in the source material; however, as the feedstock has the highest impact on MFSP, it can easily be interpreted that if feedstock costs decreased, it would significantly reduce MFSP.

Table B8 gives a brief summary of the economic information about this conversion pathway.

Table B8. Summary Results Table for Corn Ethanol via Fermentation Using Dry Grinding

\begin{tabular}{|c|c|}
\hline Technology Pathway & $\begin{array}{l}\text { Corn Ethanol via Fermentation } \\
\text { using Dry Grinding }\end{array}$ \\
\hline Feedstock Type & Corn Grain \\
\hline Hydrocarbon Product Slate, wt \% & $100 \% \quad$ Ethanol \\
\hline Coproducts & DDGS \\
\hline Carbon Efficiency & $36.6 \%$ \\
\hline Total Capital Investment, million \$ & $\$ 67.8$ \\
\hline Total Operating Costs, million $\$ / y r$ & $\$ 76.3$ \\
\hline Minimum Selling Price, \$/GGE & $\$ 2.41$ \\
\hline \multicolumn{2}{|l|}{ Cost Contributions, \$/GGE } \\
\hline Capital Cost & $\$ 0.22$ \\
\hline Feedstock Cost & $\$ 1.91$ \\
\hline Operating Costs & $\$ 0.79$ \\
\hline Operating Credits & $\$ 0.50$ \\
\hline Taxes & Not specified \\
\hline
\end{tabular}

Pathway 9: Corn Stover to Acetone, n-Butanol, and Ethanol (ABE) via Fermentation

Feedstock: Corn Stover

Feedstock Processing Technology: Dilute-Acid Pretreatment/Enzymatic Hydrolysis

Fuel Precursor: Sugars

Fuel Processing Technology: Fermentation

Biofuel Product: 54\% n-Butanol (Main Product), 27\% Acetone (Byproduct), 4.5\% Ethanol (Byproduct)

Data Source: (Humbird et al. 2011; Tao, He, et al. 2014)

\section{Process Summary}

The simplified block flow diagram is shown in Figure B7. 


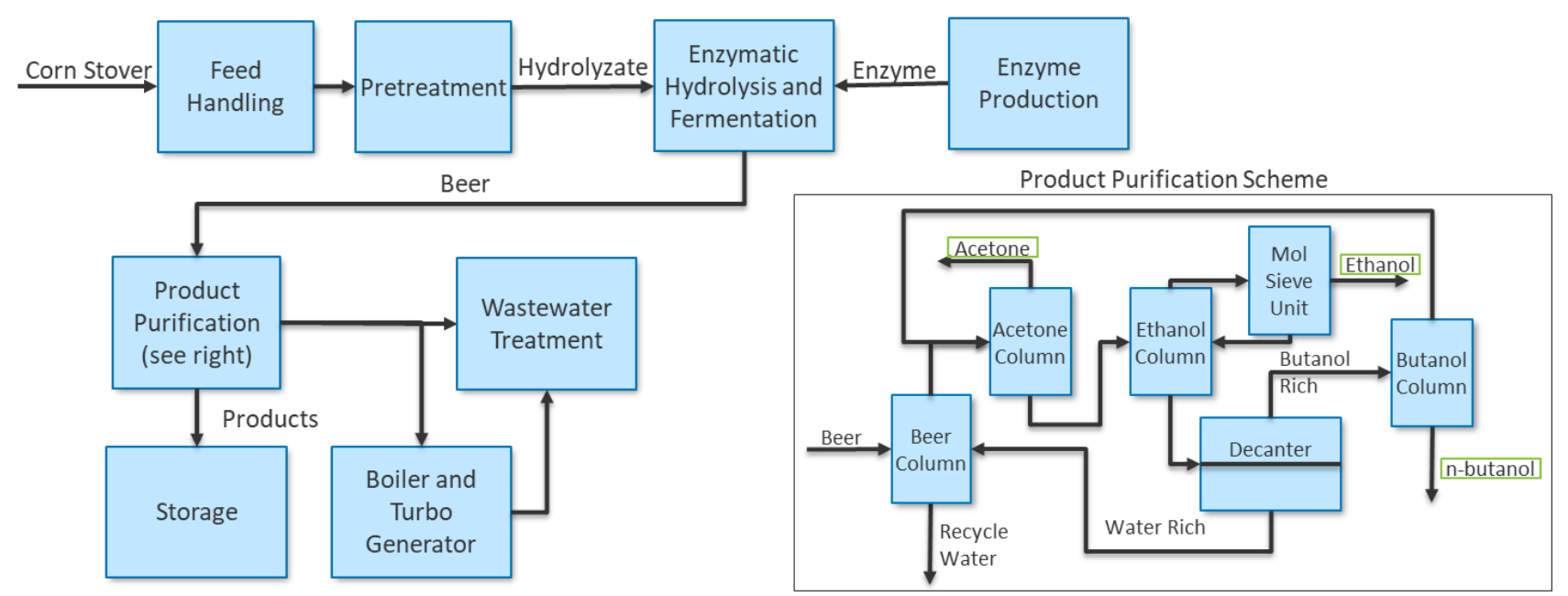

Figure B7. Simplified block flow diagram for corn stover to acetone, $n$-butanol, and ethanol via fermentation

\section{$\underline{\text { Process Design }}$}

The biochemical conversion pathway's processing steps include the breakdown of feedstocks to mixed sugars via dilute-acid pretreatment and enzymatic hydrolysis, conversion to beer via fermentation, and product purification via distillation, phase separation, and molecular size separation.

Corn stover, the feedstock, is pretreated via dilute-acid pretreatment, which encompasses a single horizontal reaction vessel where the biomass-sulfuric acid slurry is held at $158^{\circ} \mathrm{C}$ and a dilution of $18 \mathrm{mg}$ sulfuric acid per gram dry biomass for a time of 5 minutes. From the dilute-acid pretreatment, the hydrolysate slurry with $30 \mathrm{wt} \%$ total solids and $16.6 \mathrm{wt} \%$ insoluble solids is sent to a tank for dilution to just above $20 \mathrm{wt} \%$ total solids loading, ensuring miscibility with enzymatic hydrolysis. At this time, the slurry is also mixed with ammonia gas to raise the hydrolysate mixture's $\mathrm{pH}$ to 5 . This process is assumed to convert $90 \%$ of xylan to xylose and $5 \%$ of xylan to furfural. More detail about the pretreatment process is described elsewhere in the report (Humbird et al. 2011).

The hydrolysate mixture is then mixed with an enzyme slurry and pumped to a first-stage reactor, where the enzymatic hydrolysis breaks down the cellulose to glucose for 24 hours before being pumped to one of twelve vessels, and the process is allowed to continue for 60 more hours, all while being held at $48^{\circ} \mathrm{C}$. After 84 total hours of enzymatic hydrolysis, the slurry is cooled to $32^{\circ} \mathrm{C}$ for fermentation with $C$. acetobutylicum in a five-stage fermenter in two parallel trains. This results in a 24-hour residence time for fermentation, and it is assumed during fermentation that $92 \%$ of both glucose and xylose are fermented into solvent products consisting of n-butanol, acetone, ethanol, water, and other residual sugars. Henceforth, the mixture produced during fermentation is referred to as beer. The yield of the value-added products (n-butanol, acetone, and ethanol) is assumed to be $85 \%$, as this is the highest reported yield in literature for fermentation of 84 hours. A standard 3:6:1 molar ratio of acetone, n-butanol, and ethanol (ABE) is assumed for the value-added product distribution. After fermentation, the beer mixture is sent to the product separation scheme. 
The product separation scheme follows the subsection in the block flow diagram in Figure B7, with an addition of degassing of the beer stream (not shown), which is described in detail by (Humbird et al. 2011). In the separation scheme, the beer mixture is fed to a beer column where $\sim 90 \%$ of the water is removed, most of the high-boiling compounds (butyric acid, acetic acid, and other organic acids in low concentration) are removed, and solids are removed from the solvents. The remaining mixture is sent to the acetone column, which produces high-purity acetone in the distillate while diverting a mixture of ethanol, acetone, water, and n-butanol to the ethanol column. The mixture in the ethanol column is then separated to direct the ethanol-water mixture to the distillate, with the remaining mixture being sent to the decanter for liquid-liquid phase separation. The ethanol-water mixture is sent to the molecular sieve unit, where water is removed to obtain $99.5 \%$ ethanol. The organic phase from the decanter is sent to the n-butanol column, where n-butanol is recovered in high purity. Throughout this process, there are three recycle streams: the first is the water-rich stream from the decanter back to the beer column, allowing for more solvent recovery; the second is the distillate from the n-butanol column containing ethanol, acetone, and residuals, sent to the acetone column but could also be sent to the beer column; and the third is the unpurified stream from the molecular sieve unit back to the ethanol column to avoid ethanol loss.

This process's main product is n-butanol because its production rate is higher than ethanol or acetone and can be used directly as a blend into gasoline or further reacted to produce highercarbon-number fuels using technologies discussed by (Tan, Snowden-Swan, and Talmadge 2015).

Additionally, solids from the separation scheme and biogas produced during anaerobic digestion of the wastewater are combusted in a fluidized bed reactor, producing high-pressure steam for electricity generation and process heat. Enough steam is produced to cover the required process heat in the pretreatment and distillation process areas. The remaining steam is converted to electricity to power the biorefinery and sell back to the grid as a coproduct.

\section{Process Economics}

For this 2,000-DMT-per-day biomass federate plant, 25 million gallons of n-butanol, 10 million gallons of acetone, and 7 million gallons of ethanol are produced annually with $96 \%$ time on stream. The n-butanol energy production is equivalent to 21 million gallons of gasoline production. Both acetone and ethanol are sold as coproducts at a rate of $\$ 1.02 / \mathrm{kg}$ and $\$ 0.79 / \mathrm{kg}$, respectively. Between feedstock costs, operating costs, fixed costs, capital depreciation, and coproduct credits, an MFSP of \$3.99/GGE was calculated for n-butanol. The process area contributions by percentage are shown in Figure B8. As can be seen, the feedstock contributes to $25 \%$ of the overall costs. 


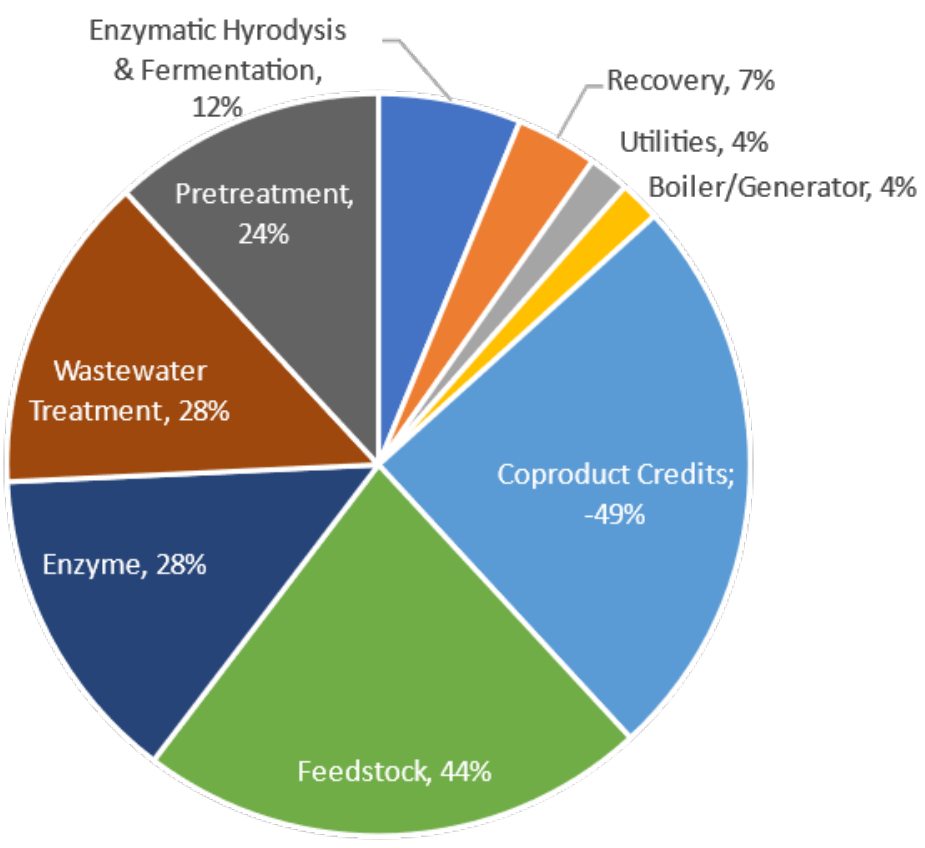

Figure B8. Process area contributions by percent for corn stover to ABE via fermentation

To understand areas for improvement, this study performed a point sensitivity analysis looking at two areas for improvement: sugar yield and product molar ratio. In this base case, sugar yield was assumed to convert $85 \%$ of glucose to either acetone, n-butanol, or ethanol. This yield has not been verified for corn stover utilizing C. acetobutylicum, nor has the $85 \%$ yield from xylose conversion been verified. Because these have yet to be verified, a simulation was run assuming sugar conversion of $60 \%$ for both glucose and xylose, which results in an increase of the MFSP from $\$ 3.99 / \mathrm{GGE}$ to $\$ 6.26 / \mathrm{GGE}$ - a $57 \%$ increase. Also, as stated previously, in this base case, a molar ratio of 3:6:1 for $\mathrm{ABE}$ was assumed, but with better-engineered strains of Clostridium, nbutanol yield can be increased significantly. Therefore, a simulation was run assuming an ABE ratio of 0.5:9:0.5, which resulted in an MFSP being lowered to \$3.69/GGE. This reduction in MFSP for $n$-butanol is promising; however, an optimal ABE ratio was found to be 1:8:1, resulting in an MFSP of $\$ 3.60 /$ GGE. This slightly higher ratio is because of the higher selling price of acetone compared to the MFSP for n-butanol, so higher acetone production reduces the MFSP through coproduct credits.

Though the MFSP of n-butanol in this conversion technology is highly dependent on feedstock, other areas of improvement are available such as verifying sugar conversion yield and engineering strains of Clostridium to produce more n-butanol. Metrics to compare this conversion pathway to others are shown in Table B9. 
Table B9. Summary Results Table for Corn Stover to Acetone, n-Butanol, and Ethanol via Fermentation

\begin{tabular}{|c|c|c|}
\hline Technology Pathway & $\begin{array}{l}\text { Corn Stc } \\
\text { Butanol, } \\
\text { Ferment }\end{array}$ & $\begin{array}{l}\text { ver to Acetone, n- } \\
\text { and Ethanol via } \\
\text { tion }\end{array}$ \\
\hline Feedstock Type & Corn Stc & \\
\hline Hydrocarbon Product Slate, wt \% & $100 \%$ & n-butanol \\
\hline Coproducts & 1007 & $\begin{array}{l}\text { Ethanol } \\
\text { Acetone } \\
\text { Electricity }\end{array}$ \\
\hline Carbon Efficiency & $15.0 \%$ & \\
\hline Total Capital Investment, million \$ & $\$ 457$ & \\
\hline Total Operating Costs, million $\$ / y r$ & $\$ 35.6$ & \\
\hline Minimum Selling Price, \$/GGE & $\$ 3.99$ & \\
\hline \multicolumn{3}{|l|}{ Cost Contributions, \$/GGE } \\
\hline Capital Cost & $\$ 2.40$ & \\
\hline Feedstock Cost & $\$ 2.16$ & \\
\hline Operating Costs & $\$ 1.81$ & \\
\hline Operating Credits & $\$ 2.75$ & \\
\hline Taxes & $\$ 0.37$ & \\
\hline
\end{tabular}

Pathway 10: Lignocellulosic Biomass to Ethanol via Dilute-Acid Pretreatment and Enzymatic Hydrolysis

Feedstock: Corn Stover

Feedstock Processing Technology: Dilute-Acid Pretreatment/Enzymatic Hydrolysis

Fuel Precursor: Sugars

Fuel Processing Technology: Fermentation

Biofuel Product: Ethanol

Data Source: (Humbird et al. 2011)

Process Summary

The simplified block flow diagram is shown in Figure B9. 


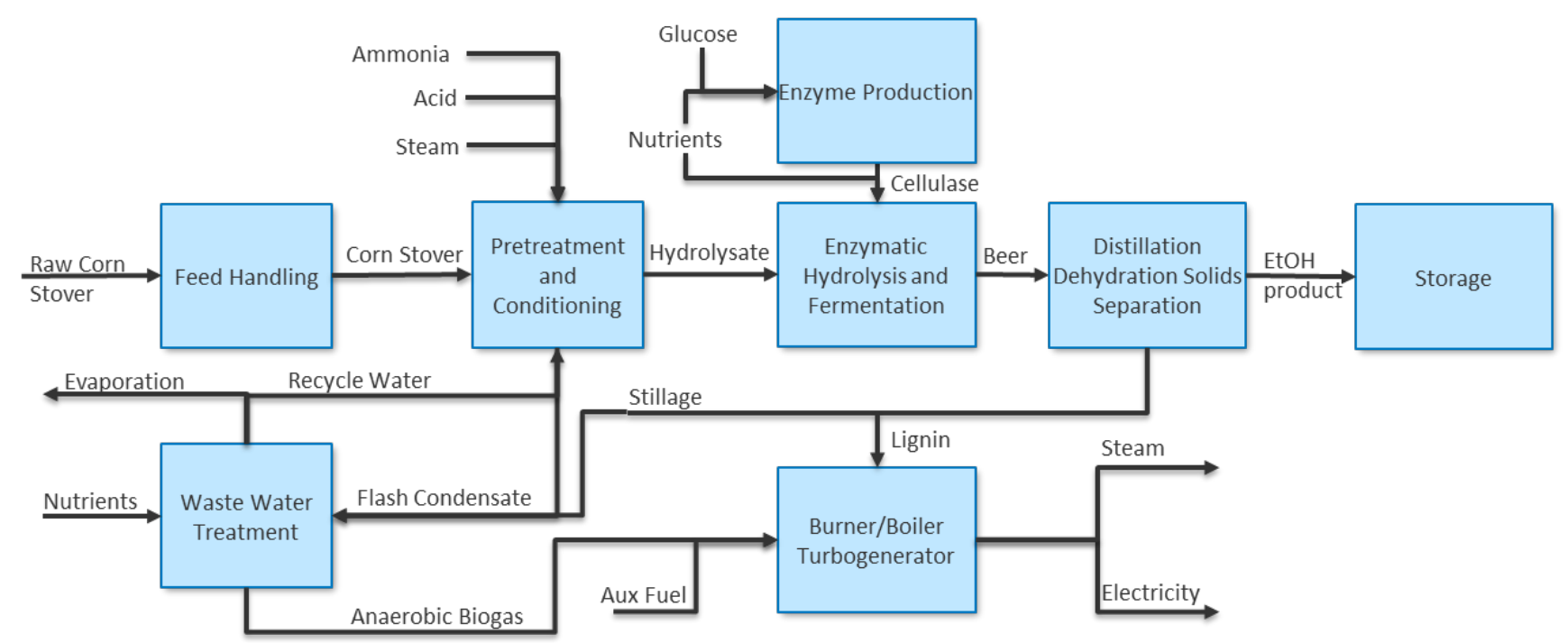

Figure B9. Simplified block flow diagram for lignocellulosic biomass to ethanol via dilute-acid pretreatment and enzymatic hydrolysis

\section{Process Design}

This ethanol production facility begins with the delivery of corn stover that is preprocessed and homogenized before delivery. The only required feed handling consists of weighing and unloading stations for biomass supply trucks, short-term storage in a concrete storage dome, and conveyance into the pretreatment reactor. In the pretreatment reactor, most of the hemicellulose carbohydrates are converted to soluble sugars via hydrolysis reactions catalyzed with dilute sulfuric acid (18 $\mathrm{mg}$ acid/dry gram biomass) and heat from steam (to operate the reactor at $158^{\circ} \mathrm{C}$ ). The sugars are composed of xylose, mannose, arabinose, and glucose, and the acetyl groups of the hemicellulose are converted to acetic acid. This initial hydrolysis helps with enzymatic hydrolysis, which disrupts cell wall structures, reducing the crystallinity of cellulose and releasing lignin into solution. Other side products formed, such as furfural, come from sugar degradation during the initial hydrolysis step. After the initial hydrolysis, which has a relatively short residence time of only 5-10 minutes, the slurry is drained into a second reactor with a lower temperature $\left(130^{\circ} \mathrm{C}\right)$ and longer residence time (20-30 minutes) where the majority of the xylose oligomers are broken down into xylose monomers. This slurry is then flashed, vaporizing much of the water, some acetic acid, and some furfural, all of which is sent to the on-site wastewater treatment area. The hydrolysate slurry is then cooled, $\mathrm{pH}$ raised from 1 to 5 with ammonia, and diluted to reduce the solids loading from $30 \mathrm{wt} \%$ total solids to just above $20 \mathrm{wt}$ $\%$ total solids.

From the dilute acid pretreatment area, the hydrolysate slurry is sent to the high-solids continuous hydrolysis reactor, where the cellulase enzyme mixture produced on site is mixed. The slurry has a residence time of 24 hours in the high-solids continuous hydrolysis reactor and afterward is pumped to a batch fermentation vessel, where it resides for 60 hours. In the $48^{\circ} \mathrm{C}$ reactor vessel, the enzymes are at a concentration of $20 \mathrm{mg}$ enzyme per gram cellulose, which achieves a $90 \%$ conversion to glucose. After the 60 hours in the batch fermentation reactor vessel, the saccharified slurry is cooled to $32^{\circ} \mathrm{C}$ for fermentation. Zymamonas mobilis is the ethanologen, as it can ferment glucose and xylose to ethanol simultaneously. The fermentation 
stage works in two trains with five fermenter stages and a fermenter volume of 200,000 gallons. The residence time in the reactor trains is 36 hours and the resulting fermentation beer is $5.4 \mathrm{wt}$ $\%$ ethanol.

The beer is pumped into the beer column containing 32 stages from the fermenter and operates at $48 \%$ efficiency, and the feed is entering on the fourth tray. The beer column removes $\mathrm{CO}_{2}$ and minimal ethanol to the distillate while removing $\sim 90 \%$ of water to the bottoms. The ethanol is removed as a vapor as a side draw fed to the rectification column. The rectification column consists of 45 stages with an efficiency of $76 \%$ and enriches the ethanol from $40 \mathrm{wt} \%$ up to 92.5 wt $\%$ in the distillate. The distillate then goes to a molecular sieve adsorption unit consisting of a system of packed columns with beds of the adsorbent. The adsorbent selectively adsorbs water, yielding $99.5 \%$ pure ethanol vapor that is cooled to a liquid after exiting the unit. There are other recycling streams not explained here, but the further explanation can be found in the source material.

Other areas not explained in detail in this report include the biorefinery wastewater treatment area that briefly anaerobically digests the wastewater, producing biogas burned on site for process heat and electricity generation. The other area not explained in detail here is the production of cellulosic enzymes. That information can be found in more detail in the source material.

\section{$\underline{\text { Process Economics }}$}

This process follows the same BETO assumptions listed at the beginning of this appendix. All equipment costs that contributed to the total capital investment came from the Aspen Capital Cost Estimator or vendor quotes with a cost year correction applied. The bulk electricity selling price was determined as the year's average determined by the North American Electric Reliability Corporation for a given year and was assumed to be $\$ 0.0589 / \mathrm{kWh}$. More detailed information about variable operating costs, fixed operating costs, land development for the site, and more can found in the source material. Specific economic information for this pathway can be found in Table B10.

Table B10. Summary Results Table for Lignocellulosic Biomass to Ethanol via Dilute-Acid Pretreatment and Enzymatic Hydrolysis

\begin{tabular}{ll}
\hline \multicolumn{1}{c}{ Technology Pathway } & $\begin{array}{l}\text { Lignocellulosic Biomass to } \\
\text { Ethanol via Dilute-Acid } \\
\text { Pretreatment and Enzymatic } \\
\text { Hydrolysis } \\
\text { Corn Stover } \\
100 \% \quad \text { Ethanol }\end{array}$ \\
$\begin{array}{l}\text { Feedstock Type } \\
\text { Hydrocarbon Product Slate, wt \% }\end{array}$ & $30.0 \%$ \\
Coproducts & Electricity \\
Carbon Efficiency & $\$ 436$ \\
Total Capital Investment, million \$ & $\$ 78.4$ \\
Total Operating Costs, million \$/yr & $\$ 3.39$ \\
Minimum Selling Price, \$/GGE & \\
Cost Contributions, $\mathbf{S G G E}$ & $\$ 1.24$ \\
$\quad$ Capital Cost & $\$ 1.17$ \\
\hline
\end{tabular}




\begin{tabular}{ll}
\hline Operating Costs & $\$ 0.96$ \\
Operating Credits & $\$ 0.17$ \\
Taxes & $\$ 0.19$ \\
\hline
\end{tabular}

Pathway 11: Corn Stover to Isobutanol via Fermentation

Feedstock: Corn Stover

Feedstock Processing Technology: Dilute-Acid Pretreatment/Enzymatic Hydrolysis

Fuel Precursor: Sugars

Fuel Processing Technology: Fermentation

Biofuel Product: 100\% Isobutanol

Data Source: (Tao, Tan, et al. 2014)

\section{Process Summary}

The simplified block flow diagram is shown in Figure B10.

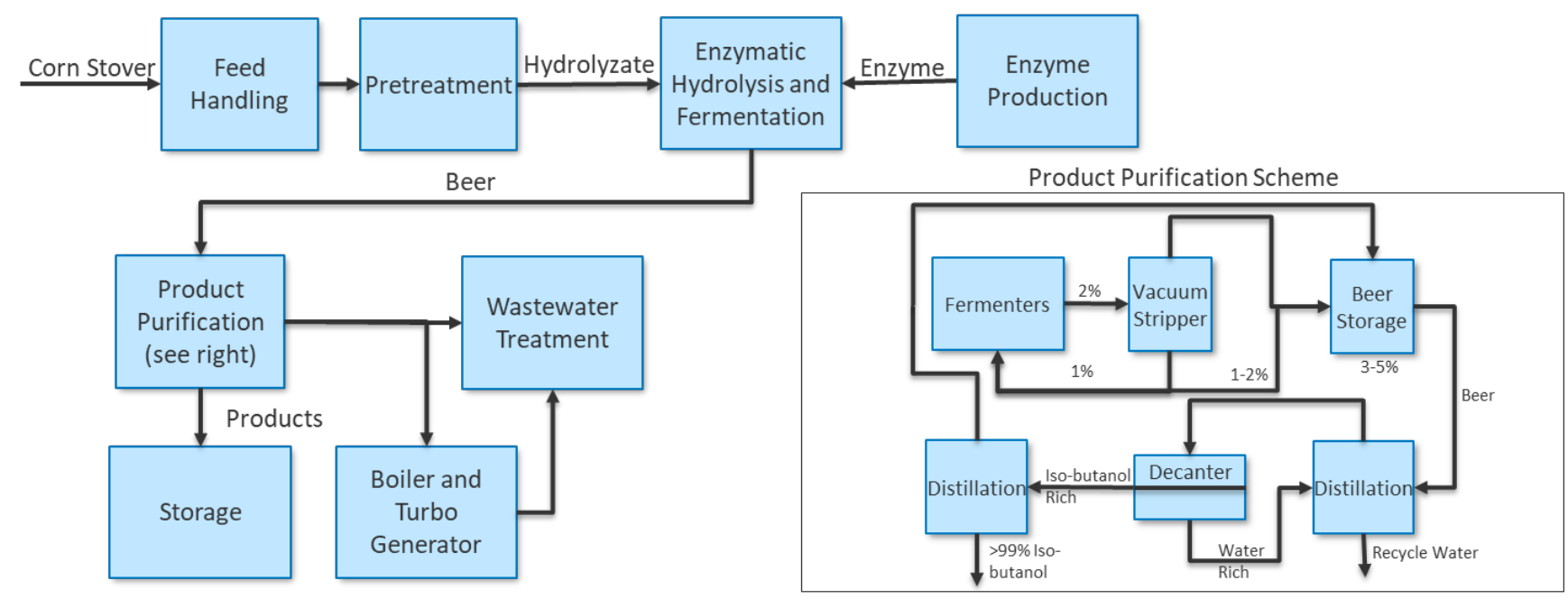

Figure B10. Simplified block flow diagram for corn stover to isobutanol via fermentation

\section{Process Design}

This process is very similar to the n-butanol case reported in Pathway 9, with the same capital equipment, flows, and process conditions up to the fermentation process. Starting with fermentation is where changes were made, with different fermentation strains being used and a different separation strategy. To be concise, the design will not be redescribed for the feed handling, pretreatment, or enzymatic hydrolysis; instead, the process design will be described starting with fermentation and detailed for process steps after that.

After 84 total hours of enzymatic hydrolysis, the slurry is cooled to $32^{\circ} \mathrm{C}$ for fermentation with an improved E. coli strain assumed to have the same production as Zymomonas mobilis used in 
Pathway 10. Again, the formation happens in a five-stage fermenter in two trains. The fermentation residence time is assumed to be 72 hours, and that in that time, microorganism growth and conversion of glucose and xylose to solvents is complete. The conversion is assumed to be $85 \%$ of sugars to isobutanol, with the remainder being converted to cell mass and byproducts. Henceforth, the effluent mixture from the fermentation pot is referred to as beer.

The product separation scheme follows the subsection in the block flow diagram in Figure B10. To begin with, there is no extra volume in the fermentation tanks for gases, which allows for vacuum stripping during operation. The beer from the vacuum stripper is then fed to beer storage, where it has a short residence time. From the beer storage, it is fed to the first column, which concentrates isobutanol in the distillate and provides a liquid-liquid split, removing $>90 \%$ of the water, some light products, most high-boiling-point components, and any solids. If there were no byproducts (ethanol or acetone), then the isobutanol-rich (distillate) stream from the first column could be sent directly to the second column. Because there are byproducts, the isobutanol-rich stream must be fed to a decanter, where the isobutanol is allowed to phase separate from the water and lighter products with a higher affinity for water. The rich isobutanol is then fed to the second distillation column, which takes off any light byproducts that are recycled to the beer storage and enriches the isobutanol to $>99 \%$ purity before sending it to storage.

The solids removed in the first column are sent to the wastewater treatment area, where they are anaerobically digested. The biogas is collected and burned in a fluidized bed combustor that produces high-pressure steam for electricity production and process heat. Enough steam is produced to cover the required process heat in the pretreatment and distillation process areas, and the remaining steam is converted to electricity to power the biorefinery and sell back to the grid as a coproduct.

\section{Process Economics}

For this 2,000-DMT-per-day biomass federate plant, 45 million gallons of isobutanol are produced annually with $96 \%$ time on stream. Between feedstock costs, operating costs, fixed costs, capital depreciation, and coproduct credits, an MFSP of \$3.56/GGE was calculated for isobutanol. The process area contributions by percentage are shown in Figure B11. As can be seen, the feedstock contributes to $32 \%$ of the overall costs. 


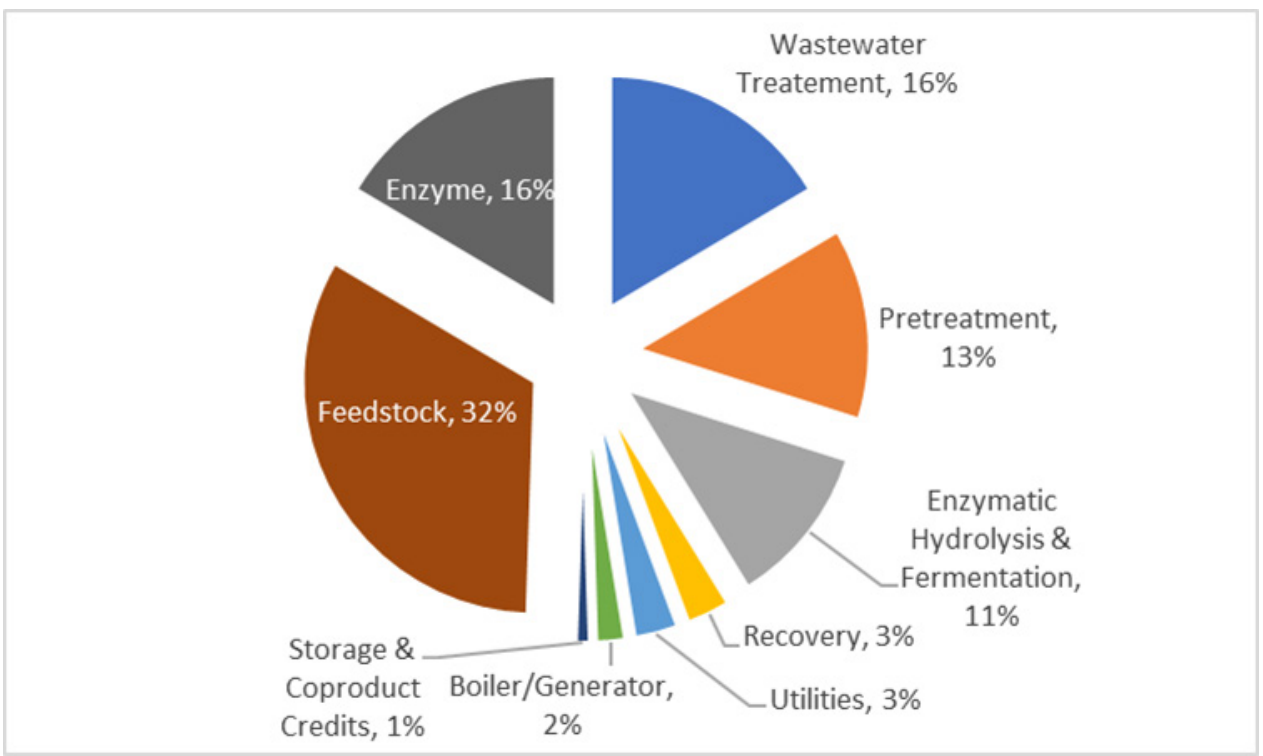

Figure B11. Cost contribution by area shown in percentages for corn stover to isobutanol via fermentation

To understand areas for improvement, this study performed a point sensitivity analysis looking at sugar yield. In this base case, sugar yield was assumed to convert $85 \%$ of glucose to isobutanol. This yield has not been verified for corn stover utilizing improved E. coli. Because these have yet to be verified, a simulation was run assuming sugar conversion at $45 \%$ for glucose and xylose. This resulted in an increase of the MFSP from $\$ 3.59 / \mathrm{GGE}$ to $\$ 6.67 / \mathrm{GGE}$, an $86 \%$ increase. This assumes that feedstock delivery is increased to produce the same amount of isobutanol. If the feedstock were to be held constant, it would decrease the isobutanol production from $45 \mathrm{million}$ gal/yr to 23 million gal/yr.

Though the MFSP of isobutanol in this conversion technology highly depends on feedstock, another area for improvement is verifying and improving sugar conversion yield. Metrics to compare this conversion pathway to others are shown in Table B11.

Table B11. Summary Results Table for Corn Stover to Isobutanol via Fermentation

\begin{tabular}{|c|c|}
\hline Technology Pathway & $\begin{array}{l}\text { Corn Stover to Isobutanol via } \\
\text { Fermentation }\end{array}$ \\
\hline Feedstock Type & Corn Stover \\
\hline Hydrocarbon Product Slate, wt \% & $100 \%$ isobutanol \\
\hline Coproducts & Electricity \\
\hline Carbon Efficiency & $26.7 \%$ \\
\hline Total Capital Investment, million \$ & $\$ 441$ \\
\hline Total Operating Costs, million $\$ / y r$ & $\$ 108$ \\
\hline Minimum Selling Price, $\$ / G G E$ & $\$ 3.56$ \\
\hline \multicolumn{2}{|l|}{ Cost Contributions, \$/GGE } \\
\hline Capital Cost & $\$ 1.30$ \\
\hline Feedstock Cost & $\$ 1.21$ \\
\hline Operating Costs & $\$ 1.00$ \\
\hline Operating Credits & $\$ 0.16$ \\
\hline Taxes & $\$ 0.20$ \\
\hline
\end{tabular}


Pathway 12: Woody Biomass to Liquid Hydrocarbons via Hydrothermal Liquefaction (HTL)

Feedstock: Blended Woody Biomass

Feedstock Processing Technology: Physical Grinding

Fuel Precursor: Biomass-Water slurry

Fuel Processing Technology: Hydrothermal Liquefaction

Biofuel Product: Liquid Fuels (42\% Gasoline, 40\% Diesel, 18\% Heavy Oil)

Data Source: (Zhu et al. 2014)

\section{Process Summary}

The simplified block flow diagram is shown in Figure B12.

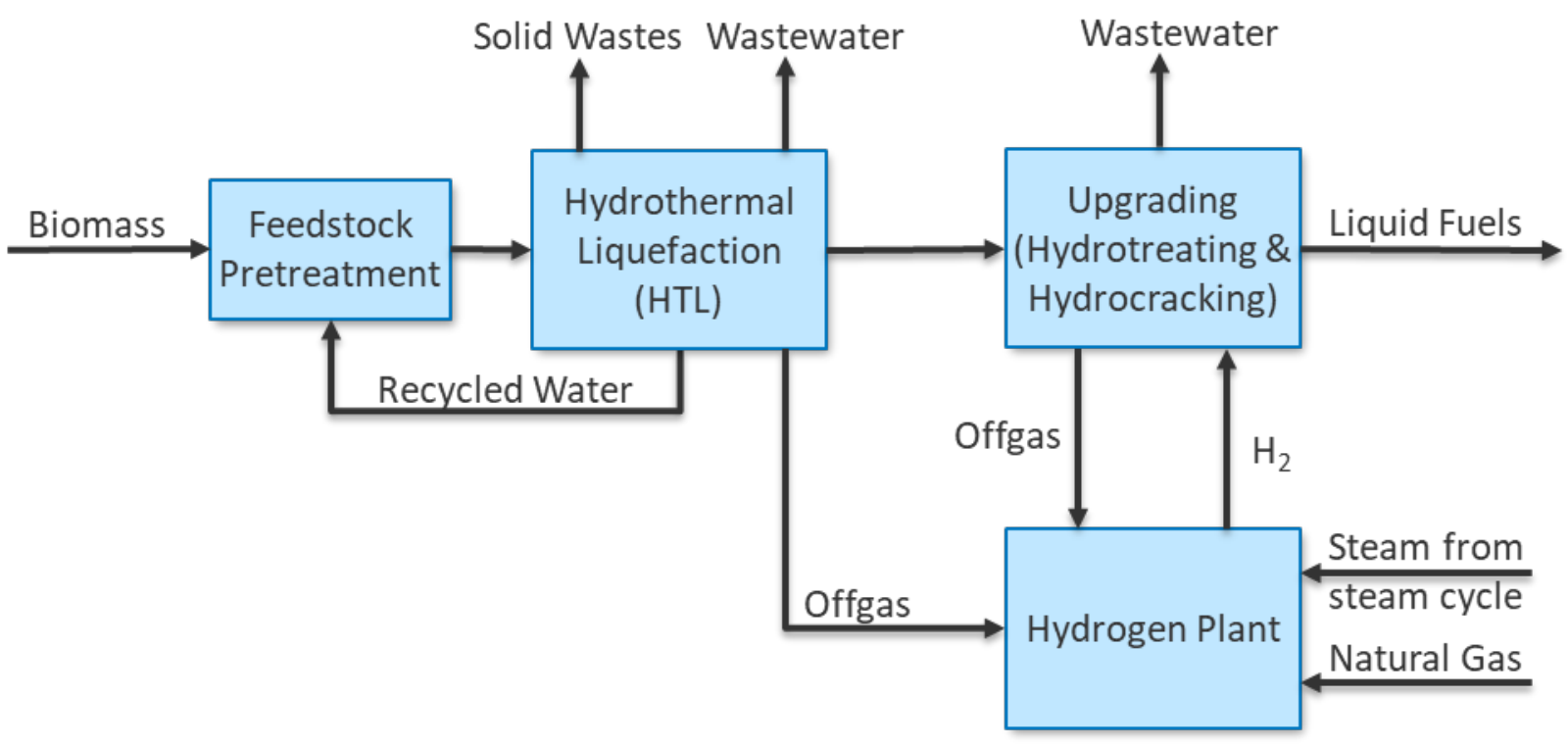

Figure B1. Simplified block flow diagram for woody biomass to liquid hydrocarbons via HTL

\section{Process Design}

Woody biomass is first mechanically ground into fine pieces at a rate of 2,000 DMT/day before it is mixed with recycled water from the HTL process. The biomass is mixed with water to a dilution of $15 \mathrm{wt} \%$ dry biomass and is pumped to $87 \mathrm{psia}$. The biomass-water slurry is pumped to the HTL reactor from the feedstock processing area.

Before entering the HTL reactor, the biomass-water slurry is preheated to $327^{\circ} \mathrm{C}$ and pumped to $2,420 \mathrm{psia}$. This is done using the hot effluent from the HTL reactor to recover heat in the system. The high-temperature, high-pressure biomass-water slurry then enters the HTL reactor that is operated at $336^{\circ} \mathrm{C}$ and 2,400 psia. The HTL reactor is a shell-and-tube plug-flow reactor because it is more economical than a continuously stirred tank reactor (CSTR) and allows for 
heat transfer between the slurry in the tube and the heat transfer hot fluid system on the shell side. The hot fluid system has its heat provided by a fired heater, and the system allows the fluid to maintain isothermal conditions in the reactor. In the reactor, the biomass is converted to oil, water, gas, and solid compounds with a yield distribution based on bench-scale results determined by gas chromatography-mass spectrometry and has a biomass conversion yield of $99.9 \%$.

Leaving the HTL reactor, the product stream is cooled by incoming biomass-water slurry to $148^{\circ} \mathrm{C}$ and depressurized to 29 psia, which separates the product stream into oil-, gas-, and aqueous-phase streams. The oil is sent directly for hydrotreating and hydrocracking to distillaterange fuels. The gas is composed mostly of $\mathrm{CO}_{2}(88.3 \mathrm{wt} \%), \mathrm{H}_{2}(0.9 \mathrm{wt} \%), \mathrm{CH}_{4}(1.8 \mathrm{wt} \%)$, and other hydrocarbons $(9.0 \mathrm{wt} \%)$ and is sent to the hydrogen plant for steam reforming to produce hydrogen used in the hydrotreating and hydrocracking reactor. The solid compounds separate into an aqueous phase with the unreacted water, and $20 \%$ is purged while the remainder is sent back to the feed area to be mixed with fresh biomass. The purged water is sent to wastewater treatment, where it is anaerobically digested to methane and carbon dioxide. A portion of that gas is sent to the hydrogen plant while the rest is burned to produce heat required for the system.

The oil is sent to a hydrotreating and hydrocracking reactor, both of which are used extensively in the petroleum industry. These reactors aim to remove remaining oxygen and saturate carbon chains to make saturated hydrocarbons suitable for diesel and gasoline applications. The hydrogen-rich off-gas from the hydrotreating reactor is recycled to the hydrocracking reactor. Some off-gas is purged from these reactor systems and sent back to the hydrogen plant for steam reforming to produce more hydrogen. The hydrocracking reactor, which precedes the hydrotreating reactor, is operated at $376^{\circ} \mathrm{C}, 1,520 \mathrm{psia}$, and a liquid hourly space velocity of $1^{\text {-h }}$. The hydrotreating reactor is a single-stage fixed-bed reactor that is operated at $165^{\circ} \mathrm{C}$ and 1,960 psia with a liquid hourly space velocity of $0.19 \mathrm{~h}^{-1}$. The resulting distillate-range fuels are separated in a fractional distillation column to create fuels that meet ASTM fuel specifications.

The hydrogen plant and steam cycle for heating of the HTL reactor are described in detail in the source material and will not be explained here.

\section{Process Economics}

The case presented here is the goal case from the original study and is based on $\mathrm{n}^{\text {th }}$-of-a-kind plant design, which assumes future improvements for commercialization. These assumed improvements are lower HTL reactor pressure as compared to the state of technology, fewer organics lost to the water phase, using the hydrocracker instead of just a hydrotreater (the state of technology assumes only hydrotreating), and only using a single reactor for the hydrotreating process (the state of technology assumes a two-stage hydrotreating reactor). These affect the economics of the plant and will be touched on in the comparison below.

For both cases, the capital costs for standard equipment (e.g., pumps, compressors, heat exchangers) were estimated using the Aspen Process Economic Analyzer. As mentioned before, the HTL reactor is a shell-and-tube reactor, and so a shell-and-tube heat exchanger was assumed 
for the reactor's capital costs. Other economic assumptions for both cases are shown in Table B12.

Table B12. Economic Assumptions for Goal and State-of-Technology Case

\begin{tabular}{|l|l|}
\hline Assumption & Value \\
\hline Missing Equipment Contingency Factor & $10 \%$ of Total Other Equipment Costs \\
\hline Installation Factor & 2.4 of Total Purchased Equipment Costs \\
\hline Indirect Cost Factor & $62 \%$ of TIC \\
\hline Equity Financing & $100 \%$ \\
\hline On-Stream Factor & $90 \%$ \\
\hline Cost Year Analysis & 2016 \\
\hline Internal Rate of Return & $10 \%$ \\
\hline Plant Life & 20 years \\
\hline Working Capital & $5 \%$ of FCI \\
\hline Maintenance and Overhead & $95 \%$ of Labor and Supervision \\
\hline Maintenance Materials & $2 \%$ of FCI \\
\hline Local Taxes and Insurance & $2 \%$ of FCI \\
\hline
\end{tabular}

a Total installed cost

Raw materials, chemicals, wastes, utilities, and other varying component costs contributing to the variable operating costs for both cases were calculated from process simulation results, vendor quotes on unit prices, and literature sources. The feedstock was assumed to be $\$ 72.19 / \mathrm{DMT}$ but does not include procurement costs or overhead costs included elsewhere in the variable operating costs.

These assumptions result in a $\$ 2.60 /$ GGE MFSP for the goal case and $\$ 4.58 /$ GGE for the stateof-technology case. This differing MFSP is the result of a few different assumptions. First, the goal case has an $8.6 \%$ lower total capital investment because of the one-stage hydrotreater, and the addition of the hydrocracker produces more sellable fuel. Also, the lower operating pressure and temperature in the goal case versus the state-of-technology case results in $10 \%$ lower installed costs for the HTL reactor. Additionally, the lower operating pressure is another factor that contributes to the lower loss of organics from the HTL reactor. These factors allow for a higher overall carbon efficiency, up from $43.7 \%$ to $56.4 \%$, which enables more carbon in the biomass to end up in sellable fuel. The lower organics loss also means less carbon in the wastewater that is anaerobically digested and therefore reduces costs for wastewater treatment and results in less off-gas, requiring more natural gas to retain the temperature of the isothermal HTL reactor. These few factors are the major players in the difference of MFSP in the goal versus state-of-technology case.

The target case presented here was used over the state-of-technology case for all linear modeling analyses because the technological advancements are assumed to be made in the short term. More information about this difference between the goal and state-of-technology case can be found in detail in the source material.

Table B13 gives a brief summary of the goal case's economic and performance metrics. 
Table B13. Summary Results Table for Woody Biomass to Liquid Hydrocarbons via Hydrothermal Liquefaction

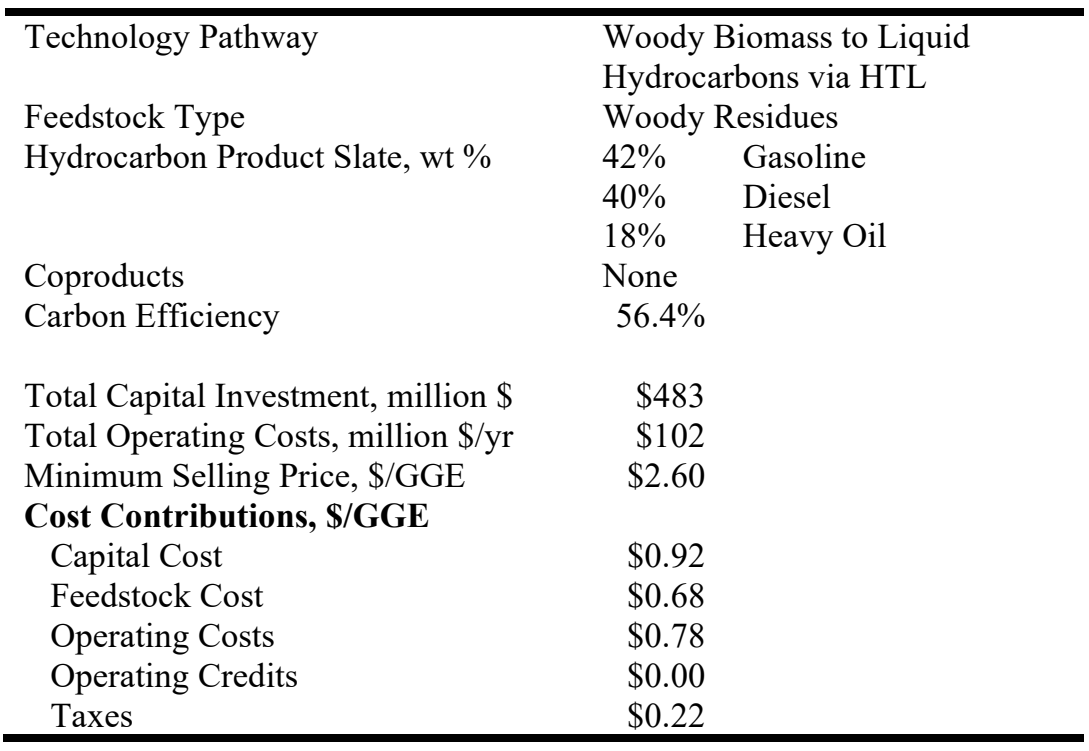

Pathway 13: Woody Biomass Fast Pyrolysis to Bio-Oil with Subsequent Hydrotreating

Feedstock: Woody Biomass

Feedstock Processing Technology: Fast Pyrolysis

Fuel Precursor: Bio-oil

Fuel Processing Technology: Hydrotreating

Biofuel Product: 48\% Gasoline, 52\% Diesel

Data Source: (Jones et al. 2013)

\section{Process Summary}

The simplified block flow diagram is shown in Figure B13. 


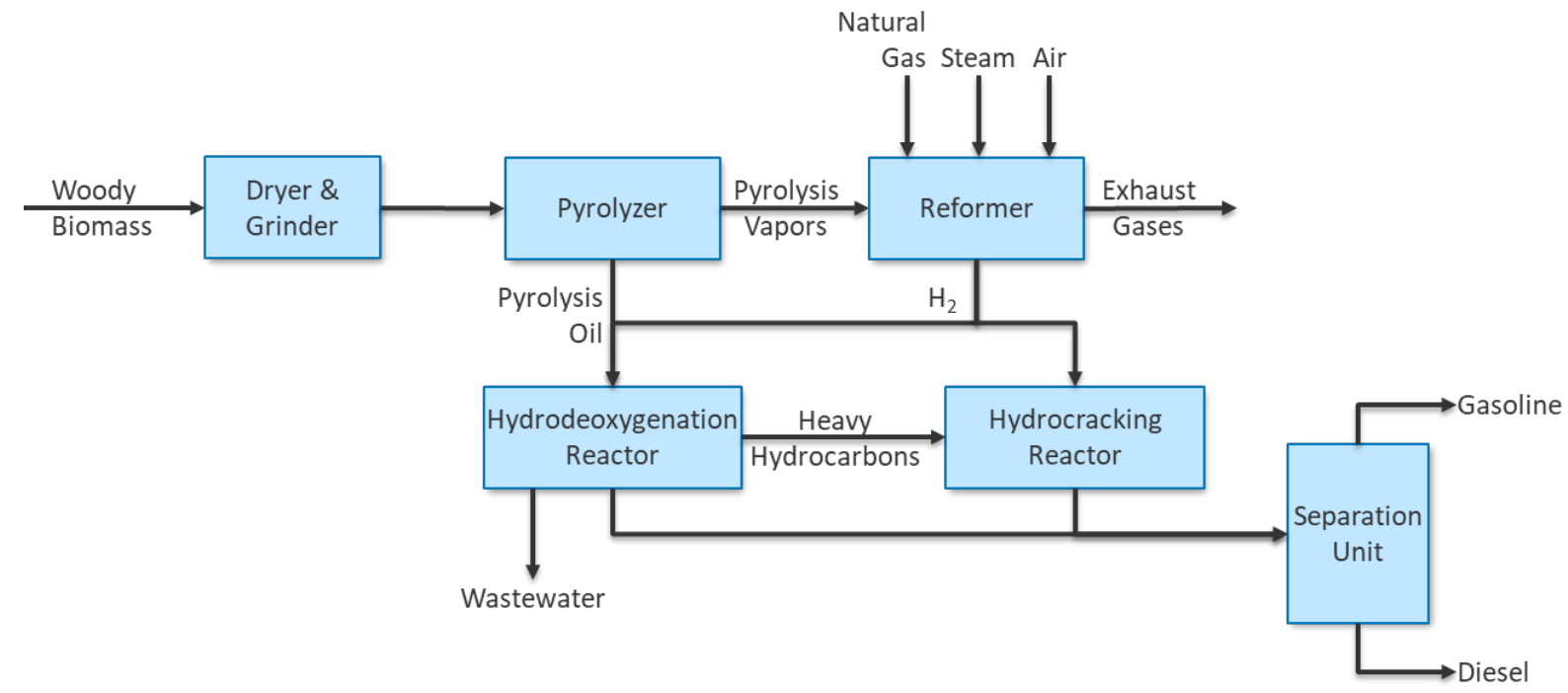

Figure B2. Simplified block flow diagram for woody biomass fast pyrolysis to bio-oil with subsequent hydrotreating

\section{Process Design}

This process is designed to accommodate 2,000 DMT/day and utilizes woody biomass as the feedstock.

The feedstock is delivered with $30 \mathrm{wt} \%$ moisture and enters a dryer that utilizes hot flue gas with 5-10 wt \% oxygen (to avoid biomass combustion) to dry the biomass to $10 \mathrm{wt} \%$ moisture. The dried biomass exits the dryer and is conveyed to a grinder. The grinder decreases the biomass particle size to $2-6 \mathrm{~mm}$, which is sufficiently small to react rapidly in the pyrolysis reactor (pyrolyzer).

The biomass is heated to $500^{\circ} \mathrm{C}$ before it enters one of two circulating fluidized bed pyrolyzers operating in parallel. The system circulates hot sand between the pyrolyzer and a separate sand reheater. In the pyrolyzer, the biomass is converted to solid char mixture of vapors in the absence of oxygen. The residence time of the biomass in the pyrolyzer is assumed to be less than 2 seconds, and after the reaction, the char and sand are separated from the vapors using a series of cyclones. The vapors are then rapidly cooled using previously condensed and cooled bio-oil, which separates the bio-oil from the non-condensable gases. A portion of the non-condensable gases are recycled to the pyrolyzer to help with fluidization and a second portion is mixed with the char and burned to produce heat for the sand re-heater. The remainder is sent to the hydrogen plant. The condensed bio-oil is filtered and sent to the hydrotreating area, explained in more detail below. The amount of solids and oils removed by the filter is dependent on the biomass, and instead of treating the filter retentate as waste, it is used for heat generation for the sand reheater.

The filtered bio-oil contains approximately $37 \mathrm{wt} \%$ oxygen, which cannot be utilized in final fuel products. Therefore, the oxygen must be removed by the fixed-bed hydrodeoxygenation reactor, which removes the oxygen by reacting the oil with gaseous hydrogen to form water and a hydrocarbon product. In the process, the bio-oil is pressurized, combined with gaseous 
hydrogen, and preheated before entering a three-stage hydrodeoxygenation reactor system. The first stage (stabilization bed) operates between $140^{\circ} \mathrm{C}$ and $180^{\circ} \mathrm{C}$ and 1,200 psia and converts the highly reactive oxygenated species. The second stage $\left(1^{\text {st }}\right.$ stage hydrotreater $)$ is more severe, with an operating temperature between $180^{\circ} \mathrm{C}$ and $250^{\circ} \mathrm{C}$ and 2,000 psia. The third stage (secondstage hydrotreater) operates under the most severe conditions at $350^{\circ} \mathrm{C}$ to $425^{\circ} \mathrm{C}$ while retaining the 2,000 psia. The reason for the three-stage system is to reduce tar formation and increase catalyst lifetime.

The products from the hydrotreating system are a gas stream and two liquid streams. The liquid streams are an aqueous-phase stream and a stable hydrocarbon oil-phase stream; these are phase separated when leaving the reactors. The gaseous product is composed of mostly light hydrocarbons (e.g., methane, ethane, propane), carbon dioxide, and hydrogen. The hydrogen is separated using a pressure swing adsorption unit and recycled to the hydrotreaters. The remaining gas is sent to the hydrogen production plant. The aqueous phase is considered wastewater and is sent for treatment. The hydrocarbon oil is sent to a fractionation column containing 40 stages and a tray efficiency of 0.75 to be separated into a gasoline/diesel blendstock (unseparated), sent to later fractionation columns, and heavies that are sent to a hydrocracking reactor.

The heavies sent to the hydrocracking reactor are heated to $750^{\circ} \mathrm{C}$ and pressurized to 1,300 psia and mixed with hydrogen gas and passed over an alumina-based catalyst in a fixed-bed configuration. This yield components in the diesel and gasoline range are sent for final product separation. The gasoline/diesel blendstock from the hydrotreater and the hydrocracker products require final product separation. This consists of two fractionation columns, both with 30 stages and a tray efficiency of 0.75 that operate at 25 and 15 psia. The gasoline and diesel fractions from these columns are then sold.

The hydrogen plant mentioned throughout the process will not be explained here but can be found explained in detail in the source material.

\section{Process Economics}

This process follows standard BETO assumptions listed at the beginning of this appendix.

The capital costs for equipment were sourced from the Aspen Capital Cost Estimator, vendor quotes, and literature. All capital costs were converted to the appropriate cost year using the U.S. Bureau of Labor Statistics Cost Indices. The capital costs of the different areas of the conversion plant are shown in Table B14.

Table B14. Capital Equipment Costs by Conversion Plant Area for Woody Biomass Fast Pyrolysis to Bio-Oil with Subsequent Hydrotreating

\begin{tabular}{lr}
\hline Process Area & $\begin{array}{l}\text { Fixed Capital } \\
\text { Investment (million \$) }\end{array}$ \\
\hline Feed Handling and Fast Pyrolysis & 258 \\
Heat Recovery and Filtration & 20 \\
Hydrotreating & 183 \\
Hydrocracking and Product Separation & 30 \\
Hydrogen Generation & 110 \\
Power, Process Water, and Wastewater & 15 \\
Total & $\mathbf{6 1 6}$ \\
\hline
\end{tabular}


The MFSP from the capital and operating expenses was calculated to be $\$ 3.14 / \mathrm{GGE}$, with cost breakdown shown more in Table B15. A sensitivity analysis was performed for the MFSP of this production pathway. It was found that plant size, expected IRR, and feedstock costs were the three major contributors that could change the MFSP. The plant size plays such a large factor because of the high TCI of $\$ 648$ million. If production were to decrease slightly, the initial investment cost must still be recovered by selling the fuel at a higher price. The high TCI also explains why the IRR has a significant impact, because the small percentage of the IRR significantly varies the gross amount needed to obtain that value, resulting in large fluctuations in price for a small percentage increase in return. Finally, the feedstock has a significant pathway, as do other lignocellulosic-based biomass conversion plants.

Table B15 summarizes the economic and performance information about this conversion pathway.

Table B15. Summary Results Table for Woody Biomass Fast Pyrolysis to Bio-Oil with Subsequent Hydrotreating

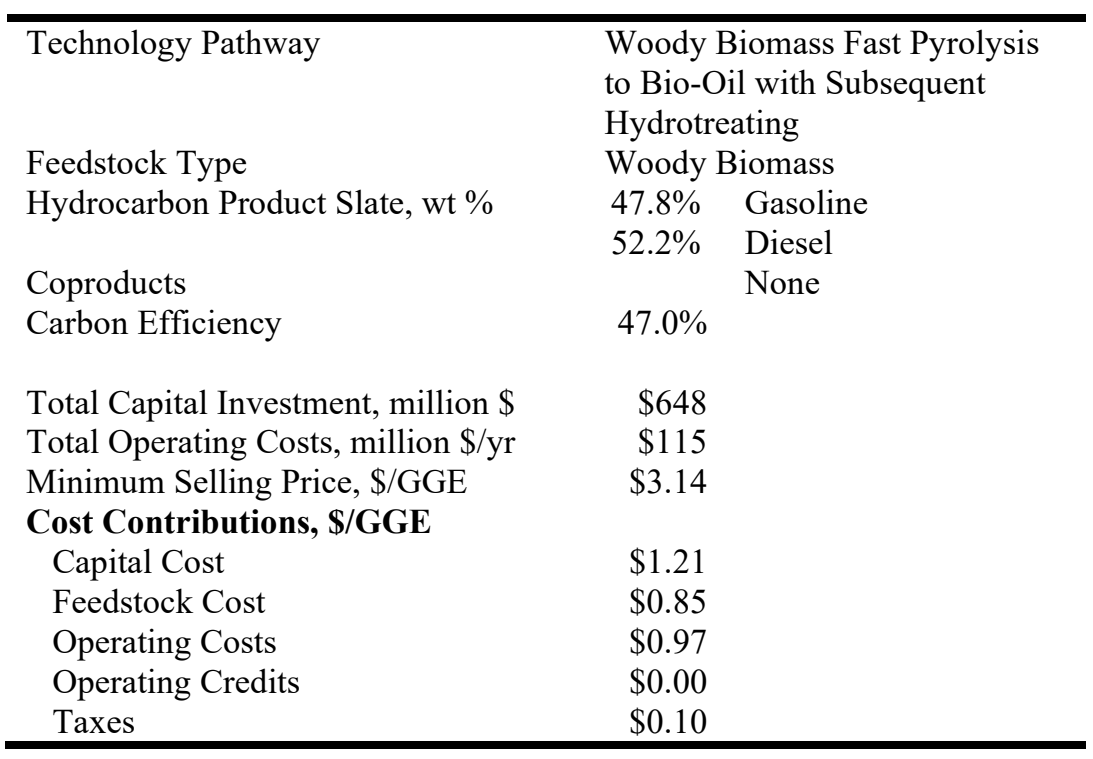

Pathway 14: Woody Biomass Catalytic Fast Pyrolysis with In Situ Vapor Upgrading

Feedstock: Woody Biomass

Feedstock Processing Technology: Catalytic Fast Pyrolysis

Fuel Precursor: Bio-Oil

Fuel Processing Technology: Hydrotreating

Biofuel Product: $72.9 \%$ Gasoline, 27.1\% Diesel

Data Source: (Dutta, Sahir, and Tan 2015)

Process Summary 
The simplified block flow diagram is shown in Figure B14.

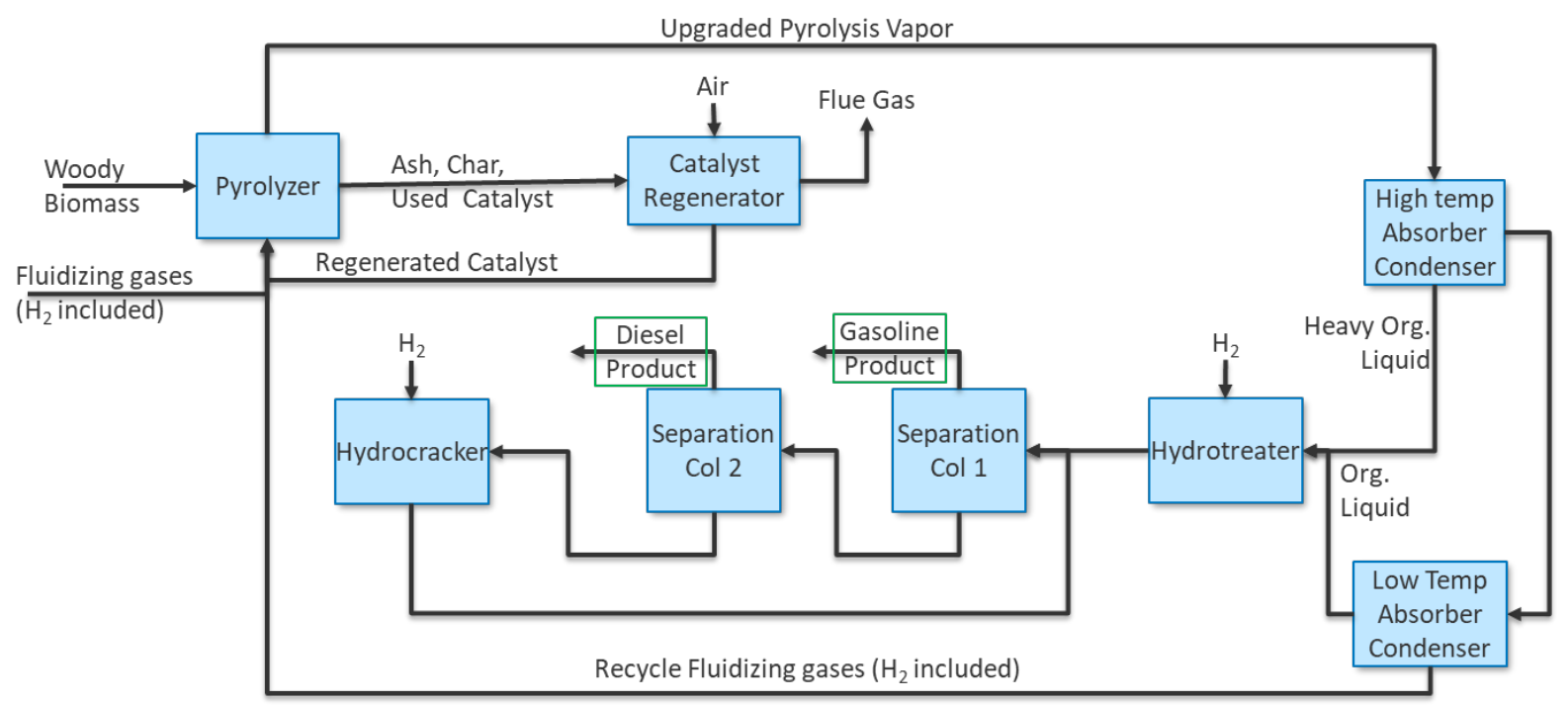

Figure B3. Simplified block flow diagram for woody biomass catalytic fast pyrolysis with in situ vapor upgrading

\section{$\underline{\text { Process Design }}$}

This process is designed to accommodate 2,000 DMT/day and utilizes woody biomass as the feedstock.

The feedstock is delivered with $10 \mathrm{wt} \%$ moisture and ground to $2-\mathrm{mm}$ particle size. The feedstock drying and grinding is included in the feedstock costs, which is different from other woody biomass conversion technologies. This technology consists of a blower that helps to warm the biomass before it enters the fast pyrolysis reactor (pyrolyzer). The blower also controls moisture levels in a humid environment, which is not assumed for this study.

The biomass is heated to $500^{\circ} \mathrm{C}$ before it enters one of two circulating fluidized bed pyrolyzers operating in parallel. The pyrolyzer circulates hot ZSM-5 catalyst (the fluidizing material) between the pyrolyzer and a separate catalyst regeneration reactor. In the pyrolyzer, the biomass is converted to solid char and mixture of vapors (both condensable and non-condensable) in the absence of oxygen at $500^{\circ} \mathrm{C}$ and 121 psia. Simultaneously, the condensable vapors are upgraded by the catalyst and hydrogen gas fed through the reactor to remove oxygen and produce hydrocarbons and water. The residence time of the biomass in the pyrolyzer is assumed to be less than 2 seconds. After the reaction, the char, catalyst, and ash are separated from the upgraded vapors using a series of two cyclones. The vapors are then sent to the condenser unit, explained in more detail below. The solids go to the catalyst regenerator, which operates at 117 psia and $650^{\circ} \mathrm{C}$, combusting the char and regenerating the catalyst. The ZSM-5 catalyst is replaced at 3.6 wt $\%$ per day because of catalyst degradation.

The upgraded vapors leaving the pyrolyzer are separated from the catalyst and other solids as mentioned. From here, they are condensed in a two-absorber condenser system that separates the condensable vapors from non-condensable vapors. The non-condensable vapors consist of $\mathrm{CO}$, $\mathrm{CO}_{2}$, and gases rich in hydrogen (e.g., methane, ethane, propane). The condensed gases consist 
of water and hydrocarbons that must be hydrotreated and hydrocracked to be used as fuels. The water and organic phases are separated in a decanter, with the aqueous phase being sent for wastewater treatment and the organic phase being sent to the hydrotreater. The non-condensable gases are divided for uses: $1 \%$ is purged to the reformer (part of the hydrogen plant not described here), $71 \%$ is sent back to the pyrolyzer for fluidization, and the rest is used in a sour water gas shift reactor that generates steam for process heat.

The organics sent to the hydrotreater are mixed with hydrogen gas and heated and pressurized to $375^{\circ} \mathrm{C}$ and $\sim 1,800$ psia to be further deoxygenated. In the three-bed packed reactor, the organics are converted to hydrocarbons and water utilizing a sulfided CoMo catalyst. When leaving the reactor, the products are flashed, condensing the hydrocarbons and water-which subsequently phase separate - and the remaining gases (mostly hydrogen) are recycled back to the reactor. The aqueous phase is sent for wastewater treatment and the hydrocarbons are sent for product purification.

The hydrocarbons from the hydrotreater and the products from the hydrocracking reactor (explained below) enter a first separation column (gasoline column) that has 26 stages, a tray efficiency of 0.75 , and operates at 35 psia, which separates light gases that are purged for on-site heat generation and a gasoline fraction that can then be sold. The bottoms from this column are sent to a second column (diesel column) that has 26 stages, a tray efficiency of 0.75 , and an operating pressure of $35 \mathrm{psia}$, where a diesel-boiling-point-range fraction is taken to be sold. The remaining hydrocarbons that boil above the diesel range are sent to a hydrocracking reactor to be broken down into gasoline- and diesel-range components.

The stream entering the hydrocracker is mixed with hydrogen gas, heated to $392^{\circ} \mathrm{C}$, and pressurized to $\sim 1,900$ psia before entering the fixed-bed reactor. The catalyst used is a crystalline silica-alumina-based catalyst doped with rare earth metals and other metals to increase hydrogenation activity; the specific metal loading was not specified. The products from this reaction are lower-boiling-point hydrocarbons that are sent back to the first separation column after being condensed and separated from the mostly hydrogen gas that is recycled into the hydrocracker.

This process assumes a production rate of $\sim 31,950 \mathrm{lb} / \mathrm{hr}$ of gasoline and $\sim 11,850 \mathrm{lb} / \mathrm{hr}$ of diesel fuel. Other areas in the processing plant include the hydrogen production plant, wastewater treatment area, and steam and power generation, which will not be explained here but can be found in detail in the source material.

\section{Process Economics}

This process follows standard BETO assumptions listed at the beginning of Appendix B.

As with other processing plants, the equipment's capital costs were sourced from the Aspen Capital Cost Estimator, vendor quotes, and literature. All capital costs were converted to the appropriate cost year using the U.S. Bureau of Labor Statistics Cost Indices. The capital costs, including TPEC and TIC of the different conversion plant areas, are shown in Table B16. 
Table B16. Capital Expenses Broken Down by Processing Area for Woody Biomass Catalytic Fast Pyrolysis with In Situ Vapor Upgrading

\begin{tabular}{lrr}
\hline Process Area & TPEC (million \$) & TIC (million \$) \\
\hline Feed Handling and Drying & 0.3 & 0.5 \\
Fast Pyrolysis and Vapor Upgrading & 28.8 & 85.6 \\
Pyrolysis Vapor Quench and Product Recovery & 11.3 & 20.7 \\
Hydroprocessing and Product Separation & 17.4 & 30.1 \\
Hydrogen Plant & 33.8 & 65.3 \\
Steam System and Power Generation & 27.1 & 48.5 \\
Cooling Water and Other Utilities & 4.4 & 8.7 \\
Wastewater Management and Recycle & 6.7 & 15.9 \\
Total & $\mathbf{1 2 9 . 5}$ & $\mathbf{2 7 5 . 3}$ \\
\hline
\end{tabular}

The variable operating costs for this process include some of the following pieces: catalyst for vapor phase upgrading, catalyst for hydrotreating and hydrocracking, steam methane reformer catalyst (used in hydrogen plant), solids disposal, natural gas (used in hydrogen plant), water makeup, wastewater treatment, and diesel fuel price (to be used on site). Some of the fixed operating costs in this process include employee salaries, benefits, overhead, maintenance, insurance, and taxes. The variable operating expenses and fixed operating expenses are assumed to be $\$ 28.67 \mathrm{million} / \mathrm{year}$ and $\$ 23.50 \mathrm{million} / \mathrm{year}$, respectively. These costs do not include the feedstock cost, another variable cost separated for a better understanding of the feedstock's role in the MFSP, which is $\$ 53.59$ million/year. This leads to total operating costs of $\$ 103.58$ million/year.

The MFSP from the capital expenses and operating expenses was determined to be $\$ 3.20 / \mathrm{GGE}$, with cost breakdown shown more in Table B17. A sensitivity analysis was performed for the MFSP of this production pathway. It was found that the total capital investment, feedstock costs, and expected IRR were the three major contributors that could significantly influence the MFSP. The TCI plays such a large factor that it is higher than other conversion technologies, specifically because it has multiple reactor systems before the biomass is converted to upgradable components. If fuel production were to decrease slightly, the initial investment cost must still be recovered by selling the fuel at a higher price. The feedstock has a significant contribution because its cost directly influences the process operating costs and because it is more than both the non-feedstock variable and fixed operating costs. If the feedstock cost increases slightly, the fuel price changes significantly. Finally, the expected IRR having the potential to change the MFSP significantly can be attributed to the high TCI.

Table B17 summarizes the economic and performance information about this conversion pathway.

Table B17. Summary Results Table for Woody Biomass Catalytic Fast Pyrolysis with In Situ Vapor Upgrading

\begin{tabular}{|c|c|}
\hline Technology Pathway & $\begin{array}{l}\text { Woody Biomass Catalytic Fast } \\
\text { Pyrolysis with In Situ Vapor } \\
\text { Upgrading }\end{array}$ \\
\hline Feedstock Type & Woody Biomass \\
\hline Hydrocarbon Product Slate, wt \% & $\begin{array}{ll}72.9 \% & \text { Gasoline } \\
27.1 \% & \text { Diesel }\end{array}$ \\
\hline Coproducts & Electricity \\
\hline Carbon Efficiency & $40.4 \%$ \\
\hline
\end{tabular}




\begin{tabular}{ll}
\hline Technology Pathway & $\begin{array}{l}\text { Woody Biomass Catalytic Fast } \\
\text { Pyrolysis with In Situ Vapor } \\
\text { Upgrading }\end{array}$ \\
Total Capital Investment, million \$ & $\$ 505$ \\
Total Operating Costs, million \$/yr & $\$ 104$ \\
Minimum Selling Price, \$/GGE & $\$ 3.20$ \\
Cost Contributions, \$/GGE & $\$ 1.11$ \\
Capital Cost & $\$ 0.99$ \\
Feedstock Cost & $\$ 0.96$ \\
Operating Costs & $\$ 0.04$ \\
Operating Credits & $\$ 0.18$ \\
Taxes & \\
\hline
\end{tabular}

Pathway 15: Woody Biomass Catalytic Fast Pyrolysis with Ex Situ Vapor Upgrading

Feedstock: Woody Biomass

Feedstock Processing Technology: Fast Pyrolysis

Fuel Precursor: Bio-Oil

Fuel Processing Technology: Hydrotreating

Biofuel Product: $45.2 \%$ Gasoline, $54.8 \%$ Diesel

Data Source: (Dutta, Sahir, and Tan 2015)

\section{Process Summary}

The simplified block flow diagram is shown in Figure B15.

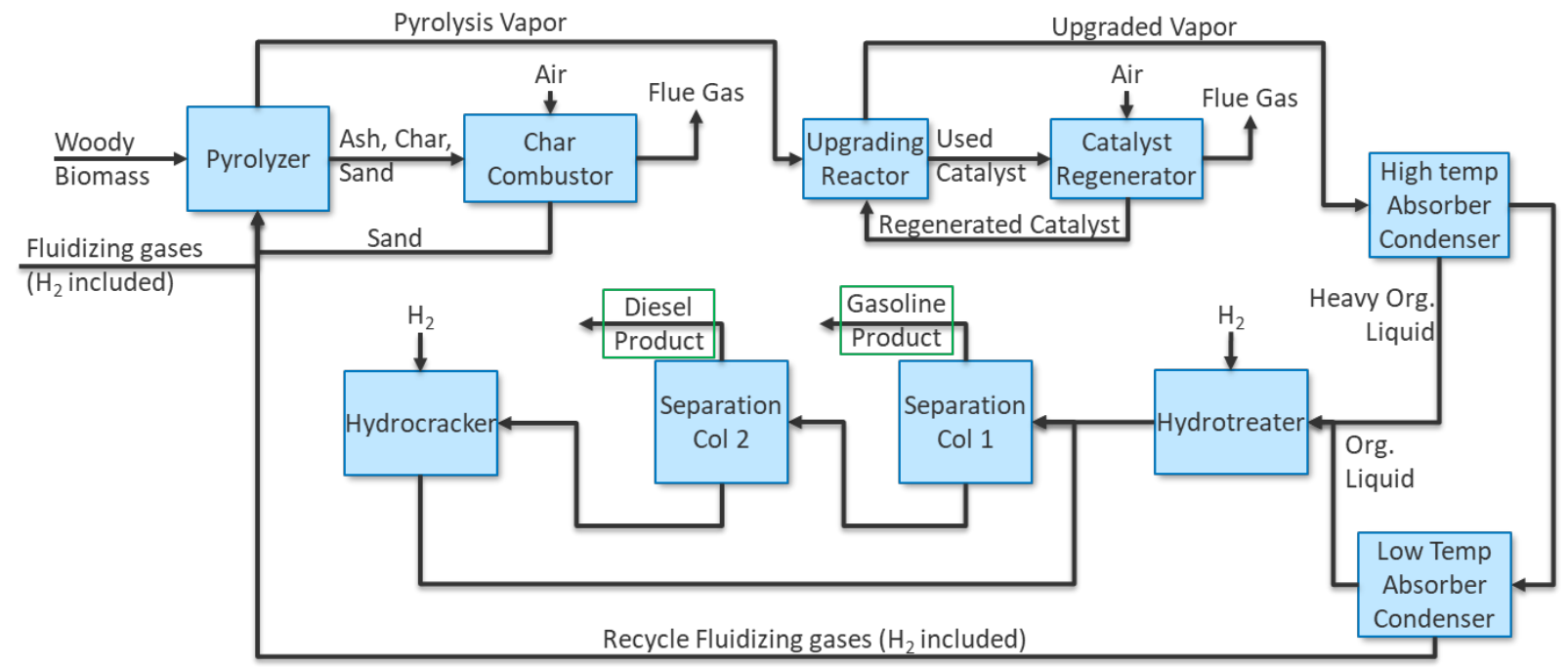

Figure B4. Simplified block flow diagram for woody biomass catalytic fast pyrolysis with ex situ vapor upgrading 


\section{Process Design}

This process is designed to accommodate 2,000 DMT/day and utilizes woody biomass as the feedstock.

The feedstock is delivered with $10 \mathrm{wt} \%$ moisture and ground to 2-mm particle size. The feedstock drying and grinding is included in the feedstock costs, which is different from other woody biomass conversion technologies. This technology does include a blower that helps to warm the biomass before it enters the fast pyrolysis reactor (pyrolyzer). The blower also controls moisture levels in a humid environment.

The biomass is heated to $500^{\circ} \mathrm{C}$ before it enters a circulating fluidized bed pyrolyzer, which circulates hot sand (the fluidizing material) between the pyrolyzer and a separate char combustor. In the pyrolyzer, the biomass is converted to solid char and a mixture of vapors (both condensable and non-condensable) in the absence of oxygen at $500^{\circ} \mathrm{C}$ and $121 \mathrm{psia}$. The residence time of the biomass in the pyrolyzer is assumed to be less than 2 seconds, and after the reaction, the char, sand, and ash are separated from the vapors using a series of two cyclones. The vapors are then sent to an ex situ upgrading reactor. The solids go to the char combustor, which operates at $117 \mathrm{psia}$ and $720^{\circ} \mathrm{C}$, and is supplied with $20 \%$ excess air to combust the char that reheats the sand before it is recirculated back to the pyrolyzer. The ash that is diverted to the char combustor and generated by the combustion of char is captured using a two-cyclone chain. The ash fines are disposed of, and the remaining flue gas is used for heat recovery before being vented. It should be noted that there are two of these systems that operate in parallel at 1,000 $\mathrm{DMT} /$ day

The vapors sent to the ex situ upgrading reactor enter the circulating fluidized bed reactor at $500^{\circ} \mathrm{C}$ and 120 psia with the HZSM-5 catalyst used as the fluidizing agent at a catalyst-to-drybiomass ratio (entering first reactor system) of 5. In the reactor, the condensable gases are converted from oxygenated species to hydrocarbons and water. The upgraded vapor is sent to a condenser unit after the reaction, explained in more detail below. The catalyst is separated from the upgraded vapors using a two-cyclone system. The catalyst is then sent to a catalyst regeneration reactor. The regeneration reactor operates at $650^{\circ} \mathrm{C}$ and afterward is cooled to $341^{\circ} \mathrm{C}$ before entering the upgrading reactor, as the reactions are exothermic, and this is required to maintain the operating temperature at $500^{\circ} \mathrm{C}$. The catalyst has $3.6 \%$ replaced per day due to attrition losses. This vapor upgrading reactor system is sized based on operational efficiency and volume of pyrolysis vapors from both pyrolyzer reactors.

The upgraded vapors leave the upgrading reactor and are separated from the catalyst as mentioned. From here, they have a similar separation and further upgrading (hydrotreating and hydrocracking) as the in situ case described in Pathway 14. For brevity, that information will not be repeated here.

\section{Process Economics}

This process follows standard BETO assumptions listed at the beginning of this appendix. As in Pathway 14, this pathway also does not account for any policy influence on selling price such as carbon credits, subsidies, or mandates. 
As with other processing plants, the capital costs for equipment were sourced from the Aspen Capital Cost Estimator, vendor quotes, and literature. All capital costs were converted to the appropriate cost year using the U.S. Bureau of Labor Statistics Cost Indices. The capital costs, including TPEC and TIC of the different areas of the conversion plant, are shown in Table B18.

Table B18. Capital Expenses Broken Down by Processing Area for Woody Biomass Catalytic Fast Pyrolysis with Ex Situ Vapor Upgrading

\begin{tabular}{lrr}
\hline Process Area & TPEC (million \$) & TIC (million \$) \\
\hline Feed Handling and Drying & 0.2 & 0.4 \\
Fast Pyrolysis and Vapor Upgrading & 37.6 & 117.4 \\
Pyrolysis Vapor Quench and Product Recovery & 12.2 & 22.4 \\
Hydroprocessing and Product Separation & 14.7 & 26.9 \\
Hydrogen Plan & 31.9 & 61.8 \\
Steam System and Power Generation & 24.7 & 44.3 \\
Cooling Water and Other Utilities & 4.3 & 8.6 \\
Wastewater Management and Recycle & 5.0 & 11.9 \\
Total & $\mathbf{1 3 0 . 6}$ & $\mathbf{2 9 3 . 7}$ \\
\hline
\end{tabular}

The variable and fixed operating costs for this process encompass the same materials and requirements as Pathway 14, but are slightly lower at \$20.69 million/year and \$24.93

million/year, respectively. Again, these costs do not include the feedstock cost, another variable cost separated for a better understanding of the feedstock's role in the MFSP, which is \$53.59 million/year. This leads to total operating costs of $\$ 97.83$ million/year.

The MFSP from the capital expenses and operating expenses was determined to be $\$ 3.06 / \mathrm{GGE}$, with cost breakdown shown more in Table B19. A sensitivity analysis was performed for the MFSP of this production pathway. It was found that the total capital investment, feedstock costs, and expected IRR were the three major contributors that could change the MFSP for the same reasons as Pathway 14.

Table B19 summarizes the economic information about this conversion pathway.

Table B19. Summary Results Table for Woody Biomass Catalytic Fast Pyrolysis with Ex Situ Vapor Upgrading

\begin{tabular}{|c|c|}
\hline Technology Pathway & $\begin{array}{l}\text { Woody Biomass Catalytic Fast } \\
\text { Pyrolysis with Ex Situ Vapor } \\
\text { Upgrading }\end{array}$ \\
\hline Feedstock Type & Woody Biomass \\
\hline Hydrocarbon Product Slate, wt \% & $\begin{array}{ll}45.2 \% & \text { Gasoline } \\
54.8 \% & \text { Diesel }\end{array}$ \\
\hline $\begin{array}{l}\text { Coproducts } \\
\text { Carbon Efficiency }\end{array}$ & $41.5 \% \quad$ Electricity \\
\hline $\begin{array}{l}\text { Total Capital Investment, million \$ } \\
\text { Total Operating Costs, million \$/yr } \\
\text { Minimum Selling Price, \$/GGE }\end{array}$ & $\begin{array}{l}\$ 545 \\
\$ 97.8 \\
\$ 3.06\end{array}$ \\
\hline $\begin{array}{l}\text { Cost Contributions, } \mathbf{\$ G G E} \\
\text { Capital Cost } \\
\text { Feedstock Cost } \\
\text { Operating Costs } \\
\text { Operating Credits } \\
\text { Taxes }\end{array}$ & $\begin{array}{l}\$ 1.15 \\
\$ 0.95 \\
\$ 0.81 \\
\$ 0.02 \\
\$ 0.18\end{array}$ \\
\hline
\end{tabular}


Pathways 16-18: High-Octane Gasoline via Indirect Gasification and Methanol Intermediate

Feedstock: Woody Residue

Feedstock Processing Technology: Gasification

Fuel Precursor: Syngas

Fuel Processing Technology: Methanol to Gasoline

Biofuel Product: High-Octane Gasoline Blendstock

Data Source: (Tan et al. 2020)

\section{Process Summary}

The simplified block flow diagram is shown in Figure B16.

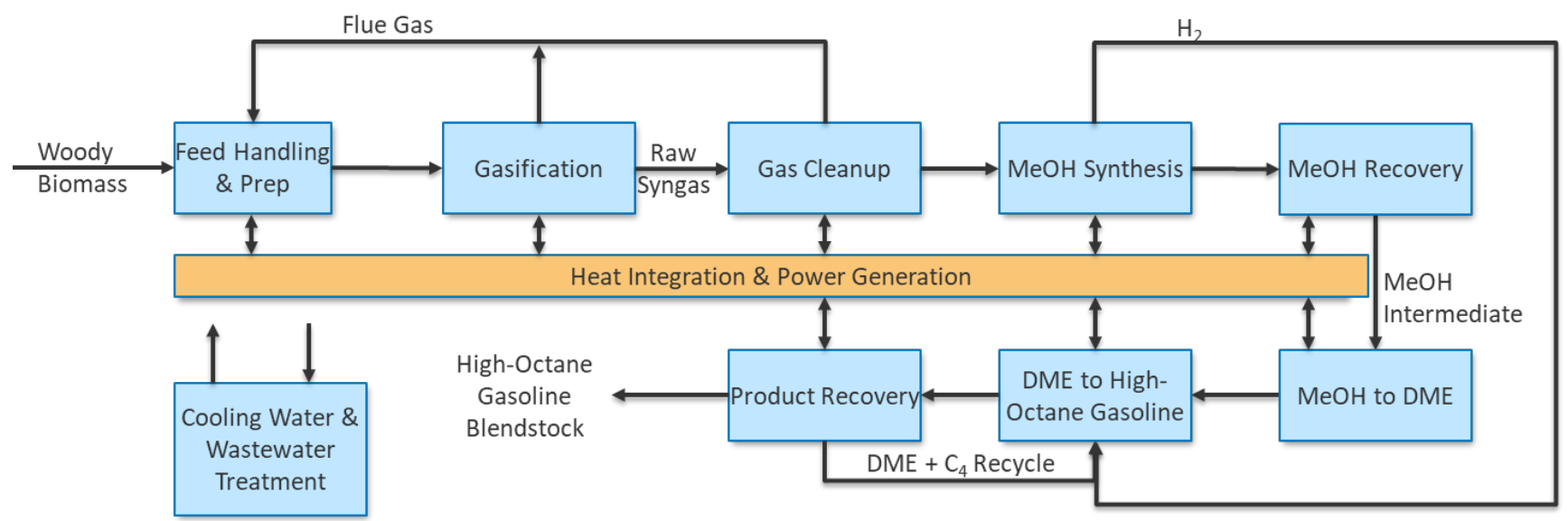

Figure B5. Simplified block flow diagram for high-octane gasoline via indirect gasification and methanol intermediate

\section{Process Design}

This process is designed to process 2,000 DMT/day and utilizes woody residue as the feedstock.

The incoming raw biomass's moisture content is $10 \mathrm{wt} \%$, with an ash content of $<1 \%$ and nominally sized to $2 \mathrm{~mm}$ for the gasifier. A crossflow dryer is included in the system to allow preheating of the feed prior to feeding into the reactor, using waste process heat. The dryer also plays an important role during wet weather, providing additional feed drying.

Biomass undergoes indirect gasification. Heat for the gasification reactions is supplied by circulating synthetic olivine sand preheated in a char combustor and fed to the gasifier. Conveyors and hoppers feed biomass to the low-pressure entrained flow gasifier. Steam is injected into the gasifier to stabilize the flow of biomass and olivine through the gasifier. Within the gasifier, biomass thermally deconstructs at $1,598^{\circ} \mathrm{F}\left(870^{\circ} \mathrm{C}\right)$ to a mixture of syngas components (such as $\mathrm{CO}, \mathrm{H}_{2}, \mathrm{CO}_{2}$, and $\mathrm{CH}_{4}$ ), tars, and solid char containing residual carbon 
from the biomass and coke deposited on olivine. Cyclones at the exit of the gasifier separate the char and olivine from the syngas. The solids flow to the char combustor, where the char is burned in a fluidized bed, resulting in olivine temperatures greater than $1,800^{\circ} \mathrm{F}\left(982^{\circ} \mathrm{C}\right)$. The hot olivine and residual ash are carried out of the combustor by the combustion gases and separated using a pair of cyclones. The first cyclone captures olivine, whereas the second cyclone captures ash and olivine fines. Hot olivine flows back into the gasifier, completing the gasification loop. The hot flue gas from the char combustor is utilized for heat recovery and feedstock preheating. Ash and olivine fines are cooled, moistened to minimize dust, and removed as waste.

The separated syngas is then cleaned up, which involves reforming of tars, methane, and other hydrocarbons followed by cooling, quenching, and scrubbing of the syngas for downstream operations. A water-gas shift reaction also occurs in the reformer. Tars, methane, and light hydrocarbons are reformed to syngas in a circulating, fluidized, solid catalyst system, complete with reforming and regeneration operations in separate beds. In the Aspen Plus simulation, the conversion of each compound is set to match targets that have been demonstrated at bench scale. Raw syngas is reacted with the tar reforming catalyst in an entrained flow reactor at $1,670^{\circ} \mathrm{F}$ $\left(910^{\circ} \mathrm{C}\right)$. The catalyst is then separated from the effluent syngas in a cyclone. From the cyclone, the spent catalyst flows to the catalyst regenerator vessel, where residual coke from the reforming reactions is removed from the catalyst by combustion. The hot catalyst is separated from the combustion flue gas in the regenerator cyclone and flows back to the tar reformer reactor to provide the energy necessary for the reforming reactions. Additional syngas and unreacted gases from the methanol synthesis reactor are also combusted in the regenerator to provide all the heat necessary for the endothermic reforming reactions. The hot reformed syngas is cooled through heat exchange with other process streams and scrubbed with water to remove persistent impurities like particulates, ammonia, halides, and recalcitrant tars. Scrubber water is purged and treated continuously at an on-site wastewater treatment facility. After heat recovery, the remaining low-quality heat in the flue gas from the catalyst regenerator is utilized for feedstock preheating. After quenching and removing any condensable material and solids, the low-pressure cooled scrubbed syngas is compressed using a three-stage centrifugal compressor with inter-stage cooling.

The compressed fresh syngas enters an amine-based acid gas enrichment unit and a Merichem LO-CAT sulfur recovery unit to remove the $\mathrm{CO}_{2}$ and $\mathrm{H}_{2} \mathrm{~S}$. The recovered $\mathrm{H}_{2} \mathrm{~S}$-rich acid gas stream is routed to the Merichem LO-CAT sulfur recovery unit, where $\mathrm{H}_{2} \mathrm{~S}$ is converted to elemental sulfur and stored for disposal. The remaining $\mathrm{CO}_{2}$ is vented to the atmosphere. After the acid gas removal step, the cleaned syngas is then split into two streams. The smaller stream of the cleaned syngas (about 6\%) is sent to a pressure swing adsorption system, where hydrogen is separated for hydrocarbon synthesis in the methanol to high-octane gasoline area. Most of the cleaned and conditioned syngas is further compressed to $735 \mathrm{psia}(5.07 \mathrm{MPa})$ for methanol synthesis; the syngas is converted to methanol in a tubular, fixed-bed reactor containing a copper, zinc oxide, and alumina catalyst. The vapor-phase product from the methanol synthesis reactor must be cooled to recover the methanol and to allow unconverted syngas and any inert gaseous species $\left(\mathrm{CO}_{2}, \mathrm{CH}_{4}\right)$ to be recycled or purged. This is accomplished with a series of heat exchangers, including air cooling and water cooling. The mixture of methanol and unconverted syngas is cooled through heat exchange with the steam cycle and other process streams. The methanol is separated by condensing it away from the unconverted syngas. Unconverted syngas is recycled back to the methanol synthesis reactor inlet. Heat must be removed from the 
methanol synthesis reactors because the synthesis reaction is exothermic. Temperature control and heat removal from the exothermic reactor is accomplished by steam production on the shell side of the tubular reactor. The steam temperature and pressure can be maintained and controlled by back-pressure control at the steam drum outlet.

The methanol leaving the reactor has been condensed at elevated pressure and has absorbed a sizeable quantity of gas (mostly $\mathrm{CO}_{2}$ ). Once the crude methanol stream is reduced to lower temperature and pressure, it is sent to a distillation column to de-gas the methanol. The methanol intermediate is sent to storage for upgrading to gasoline.

This is where Pathway 17 ends its conversion, and the remaining process area includes the conversion of methanol to dimethyl ether (DME), which is where Pathway 18 ends, and the subsequent conversion of DME to high-octane hydrocarbons (Pathway 16). Methanol dehydration to DME takes place in an adiabatic packed bed reactor with commercially available gamma-alumina $\left(\gamma\right.$-A12O3) catalyst at $482^{\circ} \mathrm{F}\left(250^{\circ} \mathrm{C}\right)$ and 140 psia $(0.965 \mathrm{MPa})$. The catalytic vapor-phase dehydration of methanol to DME is an exothermic reaction. The reactor heat is recovered with an intercooler for steam generation to allow for the adiabatic temperature rise with a targeted maximum reactor temperature of $482^{\circ} \mathrm{F}\left(250^{\circ} \mathrm{C}\right)$. DME is assumed to exit the methanol-to-DME reactor in equilibrium with methanol at the reactor exit temperature $(88.5 \%$ conversion of methanol).

Hydrocarbon formation from DME is accomplished in two four-stage packed bed reactors containing the National Renewable Energy Laboratory's (NREL's) in-house developed metal modified beta-zeolite (H-BEA) catalyst. The process's yields are heavily weighted toward branched C7 molecules with research octane numbers greater than 100. High-octane gasoline is subsequently produced by the combination of acid-catalyzed homologation of DME and methylation of olefins. DME is converted to gasoline-range hydrocarbons at a maximum temperature of $450^{\circ} \mathrm{F}\left(232^{\circ} \mathrm{C}\right)$. $\mathrm{C} 4$ products are recycled to the reactors for methylation of olefins to larger hydrocarbons. Unconverted DME is also recycled to the reactors for additional homologation. The single-pass conversion of DME is about $40 \%$, and the resulting overall DME conversion (including recycling) is $92.5 \%$. Hydrogen addition is considered for the current target process assessment and has the purpose of reducing aromatic byproducts. Temperature control and heat removal from the hydrocarbon synthesis reactors are accomplished using multiple adiabatic reactors in series with inter-stage cooling. The heat is recovered as low-pressure steam. It is assumed that although two reactors are in DME-to-hydrocarbons service, the other reactor is in coke-burn/catalyst regeneration. The catalyst regenerator burns carbon (coke) deposits off the catalyst particles, regenerating the catalyst activity and providing heat for steam generation.

Separation of the high-octane gasoline mixture is relatively simple compared to that used in refinery operations for gasoline recovery. This process area consists of just two distillation columns. The water-free crude hydrocarbon product is sent to the first distillation column, where liquid $\mathrm{C} 4+$ and gasoline-range hydrocarbons are separated from the light ends (C3-) and unconverted DME. DME is recycled to the hydrocarbon synthesis reactor, and the light gas stream (i.e., C3- or fuel gas) is sent to the fuel combustor in the synthesis gas cleanup area. The bottom product is subsequently sent to the second column, where $\mathrm{C} 4$ is separated from gasolinerange hydrocarbons. The overhead of the second column is then recycled to the hydrocarbon 
synthesis reactors. The bottoms of the second column are the high-octane hydrocarbons, which are cooled and then stored for sale as high-octane gasoline.

\section{Process Economics}

The economic evaluation for three design cases are presented in Table B20: woody biomass to methanol product, woody biomass to DME product, and woody biomass to hydrocarbon blendstock. All design cases are 2020 projections, not state-of-technology assessments. The summary of economic results presented in this section applies to the hydrocarbon blendstock end-product case.

The greatest cost contributor for the gasoline blendstock case is the feedstock cost, which accounts for about one-third of MFSP. Capital and operating cost contribute roughly $20 \%$ each, whereas production cost associated with the DME-to-high-octane-gasoline synthesis is about $14 \%$ of MFSP. Coproduct credits for electricity are taken from the methanol synthesis area for electricity from the syngas expansion and electricity from the steam system and power generation area. However, the process was adjusted so that the electricity generation balances the plant's electricity requirements, and no excess electricity is sold to the grid. A liquid petroleum gas coproduct credit is also included.

Table B20 summarizes results for high-octane-gasoline with methanol and dimethyl ether intermediates.

Table B20. Summary Results Table for High-Octane Gasoline via Indirect Gasification and Methanol Intermediate

\begin{tabular}{|c|c|c|c|}
\hline Technology Pathway & Methanol-to-Gas & line & \\
\hline Feedstock Type & Woody Residue & & \\
\hline Hydrocarbon Product Slate, wt \% & $100 \% \mathrm{MeOH}$ & $\begin{array}{r}85 \% \mathrm{DME} \\
15 \% \mathrm{MeOH}\end{array}$ & $100 \% \mathrm{HOG}^{\mathrm{a}}$ Blendstock \\
\hline Coproducts & None & None & Natural Gas \\
\hline Design Case & $\mathrm{MeOH}$ & DME & $\begin{array}{l}\text { HOG Blendstock } \\
2022 \text { Projection }\end{array}$ \\
\hline Carbon Efficiency & $33.5 \%$ & $35.5 \%$ & $28.0 \%$ \\
\hline Total Capital Investment, million \$ & $\$ 301$ & $\$ 345$ & $\$ 397$ \\
\hline Total Operating Costs, million $\$ / y r$ & $\$ 66.1$ & $\$ 68.2$ & $\$ 78.8$ \\
\hline Minimum Selling Price, $\$$ /GGE & $\$ 2.20$ & $\$ 2.16$ & $\$ 3.30$ \\
\hline \multicolumn{4}{|l|}{ Cost Contributions, \$/GGE } \\
\hline Capital Cost & $\$ 0.77$ & $\$ 0.81$ & $\$ 0.77$ \\
\hline Feedstock Cost & $\$ 0.92$ & $\$ 0.84$ & $\$ 1.11$ \\
\hline Operating Costs & $\$ 0.45$ & $\$ 0.44$ & $\$ 0.65$ \\
\hline Operating Credits & $\$ 0.00$ & $\$ 0.00$ & $\$ 0.00$ \\
\hline Taxes & $\$ 0.06$ & $\$ 0.06$ & $\$ 0.10$ \\
\hline
\end{tabular}

a High-octane gasoline

Pathway 19: Gasification and Fischer-Tropsch Synthesis of Woody Biomass

Feedstock: Woody Biomass

Feedstock Processing Technology: Gasification 
Fuel Precursor: Syngas

Fuel Processing Technology: Fischer-Tropsch

Biofuel Product: 36.3\% Gasoline, 43.6\% Jet, 20.1\% Diesel

Data Source: (Tan and Tao 2019)

\section{Process Summary}

The simplified block flow diagram is shown in Figure B17.

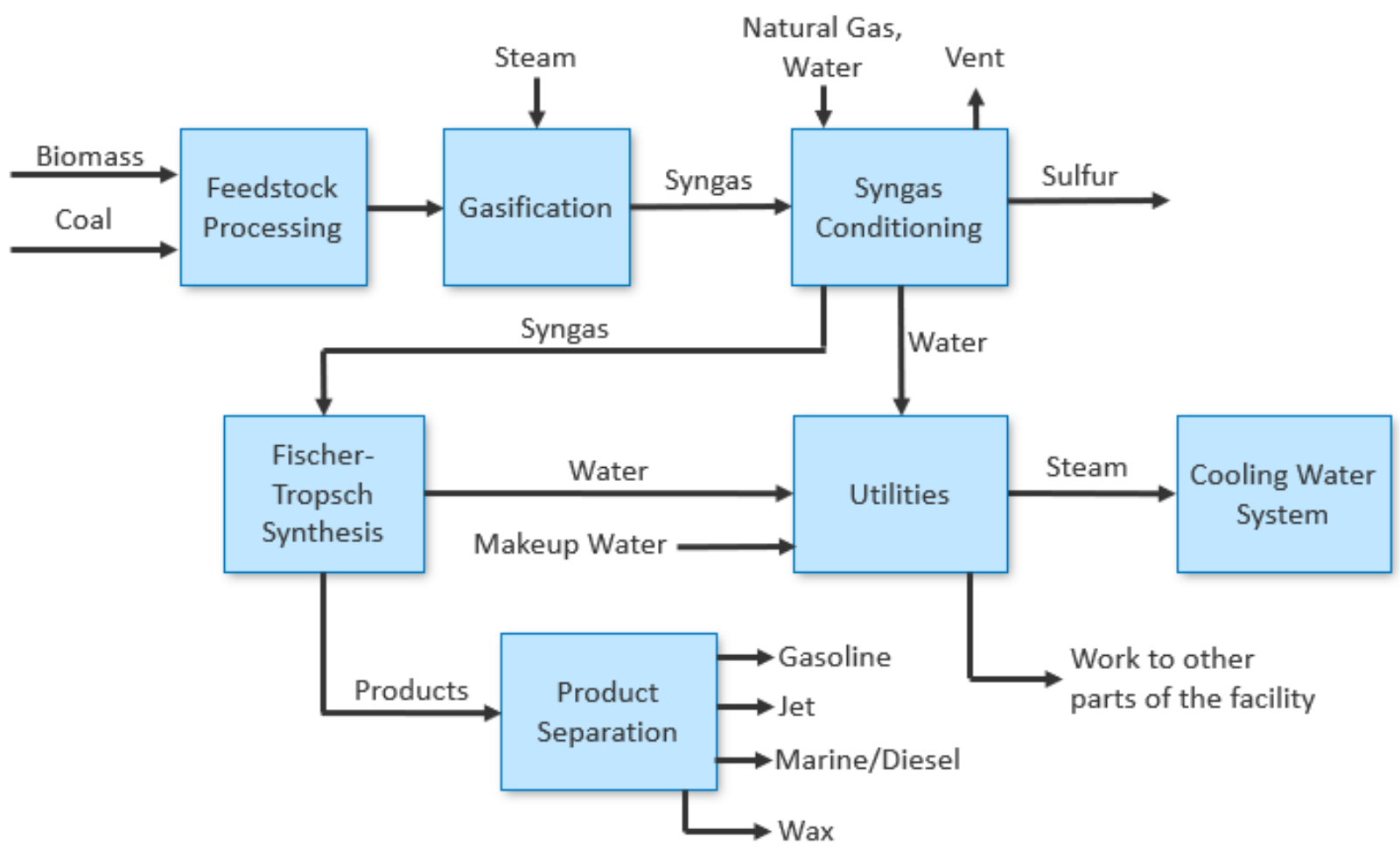

Figure B6. Simplified block flow diagram for gasification and Fischer-Tropsch synthesis of woody biomass

\section{Process Design}

The processing steps of the thermochemical conversion pathway include the conversion of feedstocks to syngas via gasification, gas cleanup via reforming of tars and other hydrocarbons, syngas conditioning (compression and acid gas removal), Fisher-Tropsch (FT) synthesis, hydrotreating, and product separation.

Woody biomass feedstock is dried from $30 \%$ moisture to $10 \%$ and sent to an entrained flow gasifier operating at $1,633^{\circ} \mathrm{F}\left(890^{\circ} \mathrm{C}\right)$ and 33 psia to make raw syngas (such as $\mathrm{CO}, \mathrm{H}_{2}, \mathrm{CO}_{2}$, and $\mathrm{CH}_{4}$ ), tars, and solid char. Cyclones at the exit of the gasifier separate the syngas from solidschar and olivine (sand used as a heat carrier). The solids flow to a fluidized bed char combustor where the char is burned in air, heating the olivine to $1,800^{\circ} \mathrm{F}\left(892^{\circ} \mathrm{C}\right)$. The hot olivine and residual ash are carried out of the char combustor by the combustion gases and separated using a 
pair of cyclones. The olivine is returned to the entrained flow gasifier to provide heat for gasification.

FT synthesis is considered a relatively mature conversion technology that involves the catalytic conversion of synthesis gas into a mixture of reaction products that could be refined into synthetic fuels, lubricants, and petrochemicals. One of the important advantages that the FT process offers is its capability of producing liquid hydrocarbon fuels from synthesis gas, which are nearly free from sulfur and relatively low in aromatic content. An important aspect of this process is the adjustment of the $\mathrm{H}_{2}$-to-CO ratio, which is usually determined by the upstream gasification and reforming technologies and operating conditions. The FT reactions involve catalytic $\mathrm{CO}$ polymerization and hydrogenation, where a carbon number distribution can describe the chain growth and termination of the reaction products.

The FT reactor products are condensed and separated through a typical hydrocarbon separation process in a multi-cut distillation column to recover the primary products (naphtha, jet, and diesel fractions) as individual streams. Each of the primary hydrocarbon cuts is further processed to yield fuel blendstocks for gasoline, jet fuel, and diesel. Wax produced from the synthesis reactor is sold as a coproduct. The jet and marine/diesel fractions undergo mild hydrotreating to remove any remaining heteroatom contaminants (sulfur, nitrogen, and oxygen) and improve blending properties.

\section{$\underline{\text { Process Economics }}$}

As with other lignocellulosic biomass conversion technologies, the feedstock contributes the most to the MFSP, at $50.8 \%$ of the cost. The TCI for this pathway is on the higher side, about $\$ 100$ million more than the pyrolysis technologies (Pathways 13, 14, and 15) and about double that of the high-octane gasoline via gasification technologies (Pathways 16, 17, and 18). The reason for this was not described in the source material.

This pathway has a lower relative MFSP than other technologies due to the relative maturity of FT technology. Table B21 summarizes the economic and performance information about this conversion pathway.

Table B21. Summary Results Table for Gasification Followed by Fischer-Tropsch Synthesis

\begin{tabular}{|c|c|}
\hline Technology Pathway & $\begin{array}{l}\text { Gasification followed by } \\
\text { Fischer-Tropsch Synthesis }\end{array}$ \\
\hline Feedstock Type & Woody Biomass Residue \\
\hline Hydrocarbon Product Slate, wt \% & $\begin{array}{ll}20.1 \% & \text { Diesel } \\
43.6 \% & \text { Jet } \\
36.3 \% & \text { Naphtha }\end{array}$ \\
\hline $\begin{array}{l}\text { Coproducts } \\
\text { Carbon Efficiency }\end{array}$ & $32.3 \%$ Wax \\
\hline $\begin{array}{l}\text { Total Capital Investment, million \$ } \\
\text { Total Operating Costs, million } \$ / y r \\
\text { Minimum Selling Price, } \$ / G G E\end{array}$ & $\begin{array}{l}\$ 633 \\
\$ 90.1 \\
\$ 2.99\end{array}$ \\
\hline $\begin{array}{l}\text { Cost Contributions, \$/GGE } \\
\text { Capital Cost } \\
\text { Feedstock Cost }\end{array}$ & $\begin{array}{l}\$ 1.52 \\
\$ 1.00\end{array}$ \\
\hline
\end{tabular}




\begin{tabular}{lc}
\hline Technology Pathway & $\begin{array}{l}\text { Gasification followed by } \\
\text { Fischer-Tropsch Synthesis }\end{array}$ \\
Operating Costs & $\$ 0.80$ \\
Operating Credits & $\$ 0.45$ \\
Taxes & $\$ 0.12$ \\
\hline
\end{tabular}

Pathway 20: Natural Gas to Enhance Biomass-to-Liquid Fuels

Feedstock: Wood Chips

Feedstock Processing Technology: Gasification

Fuel Precursor: Syngas

Fuel Processing Technology: Fischer-Tropsch

Biofuel Product: 36.3\% Gasoline, 43.6\% Jet, 20.1\% Diesel

Data Source: (Zhang et al. 2018)

\section{Process Summary}

The simplified block flow diagram is identical to Pathway 19, shown in Figure B17.

\section{Process Design}

The process design for this process is nearly identical to Pathway 19 , though it has the option to co-process with natural gas. The condition chosen in this study was a biomass-only scenario and differs from Pathway 19 in the woody biomass composition and feedstock capacity. The woody biomass is assumed to have a slightly decreased lower heating value than the woody biomass in Pathway 19, and the feedstock capacity assumed here is 2,427 DMT/day versus the 2,276 DMT/day in Pathway 19. The process train and conditions are nearly identical, with minimal differences in temperatures, pressures, and flow rates. For brevity, the process design will not be repeated here.

\section{Process Economics}

As this pathway is nearly identical to Pathway 19, the economic parameters are very similar as well. The MFSP is also low due to the relative maturity of FT, and the capital expenses are also high compared to other lignocellulosic biomass conversion technologies. This pathway has a slightly higher carbon efficiency attributed to higher assumed catalyst efficiencies. Overall, the economic parameters are very similar to Pathway 19. Table B22 summarizes the economic results.

Table B22. Summary Results Table for Natural Gas to Enhance Biomass-to-Liquid Fuels

\begin{tabular}{ll}
\hline Technology Pathway & Natural Gas to Enhance \\
& Biomass-to-Liquid Fuels \\
Feedstock Type & Woody biomass \\
Hydrocarbon Product Slate, wt \% & $20.1 \%$ Diesel \\
& $43.6 \%$ Jet \\
\hline
\end{tabular}




\begin{tabular}{|c|c|}
\hline Technology Pathway & $\begin{array}{l}\text { Natural Gas to Enhance } \\
\text { Biomass-to-Liquid Fuels }\end{array}$ \\
\hline & $36.3 \% \quad$ Gasoline \\
\hline Coproducts & Wax \\
\hline Carbon Efficiency & $40.3 \%$ \\
\hline Total Capital Investment, million \$ & $\$ 539$ \\
\hline Total Operating Costs, million $\$ / y r$ & $\$ 91.3$ \\
\hline Minimum Selling Price, \$/GGE & $\$ 2.75$ \\
\hline \multicolumn{2}{|l|}{ Cost Contributions, \$/GGE } \\
\hline Capital Cost & $\$ 1.20$ \\
\hline Feedstock Cost & $\$ 0.97$ \\
\hline Operating Costs & $\$ 0.90$ \\
\hline Operating Credits & $\$ 0.43$ \\
\hline Taxes & $\$ 0.10$ \\
\hline
\end{tabular}

Pathway 21: Woody Biomass to Hydrocarbon Fuels via Gasification followed by Fischer-Tropsch Synthesis

Feedstock: Woody Biomass

Feedstock Processing Technology: Gasification

Fuel Precursor: Syngas

Fuel Processing Technology: Fischer-Tropsch Synthesis

Biofuel Product: 35.8\% Gasoline, 25.9\% Diesel, 38.3\% Jet Fuel

Data Source: (Tan et al. 2017)

\section{Process Summary}

The simplified block flow diagram is shown in Figure B18.

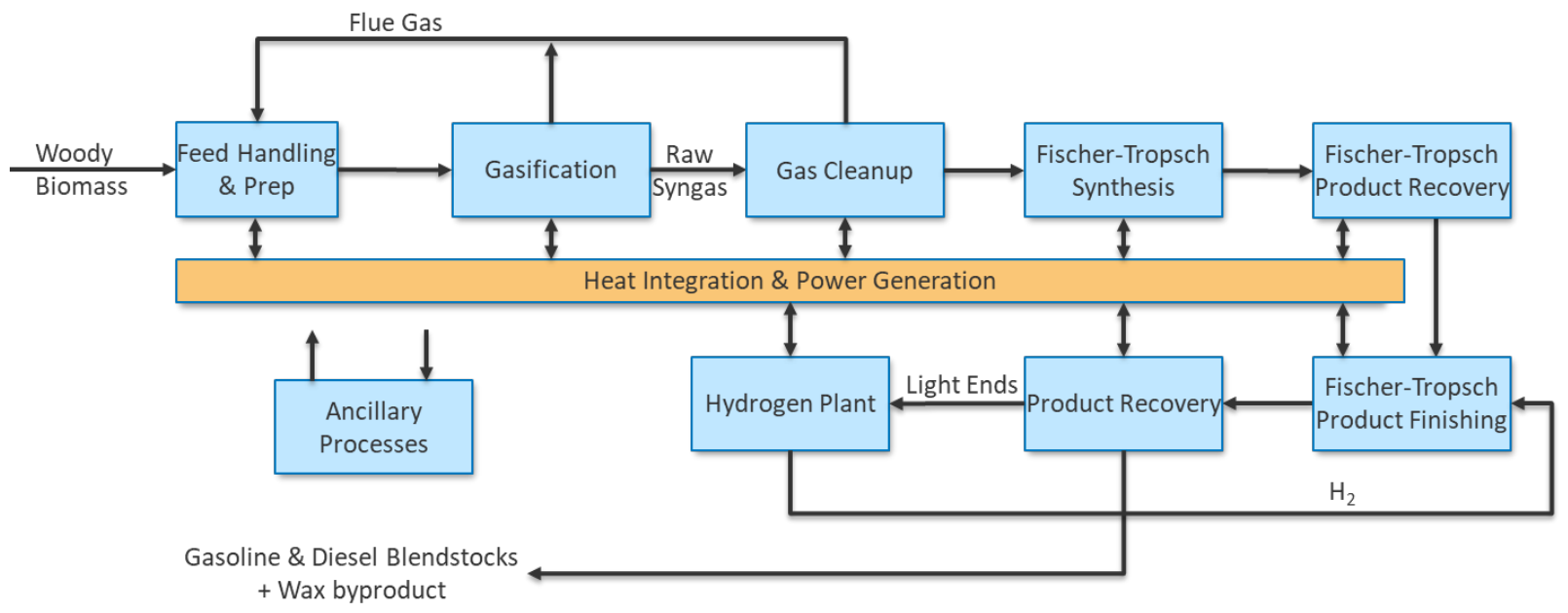

Figure B7. Simplified block flow diagram for woody biomass to hydrocarbon fuels via gasification followed by Fischer-Tropsch synthesis 


\section{Process Design}

This process is designed to accommodate 2,000 DMT/day and utilizes woody biomass as the feedstock.

The feedstock handling, preparation, gasification, and gas cleanup are the same as those reported in detail in Pathway 28 and will be described briefly here. For more details, please refer to Pathway 28.

The feedstock is delivered with $10 \mathrm{wt} \%$ moisture and ground to $2-\mathrm{mm}$ particle size. The feedstock drying and grinding is included in the feedstock costs, which is different from other woody biomass conversion technologies. This technology includes a crossflow dryer that helps warm the biomass utilizing process waste heat before the biomass enters the gasifier. The blower also controls moisture levels in a humid environment.

The biomass enters a low-pressure indirectly heated entrained flow gasifier that operates at $889^{\circ} \mathrm{C}$ and 33 psia. The gasifier converts the biomass into syngas components $\left(\mathrm{CO}, \mathrm{H}_{2}, \mathrm{CO}_{2}\right.$, and $\mathrm{CH}_{4}$ ), tars, solid char, and some unconverted biomass. The gasification products leave the gasifier and enter a cyclone unit that separates the char and olivine (heat carrier and fluidizing material) from the syngas. The olivine and char are sent to a separate fluidized bed reactor, where the char is combusted in air to heat the olivine to $982^{\circ} \mathrm{C}$. After char combustion, the olivine is separated from the combustion gases using another cyclone system and recycled back to the gasifier. The combustion gases are recycled back to the crossflow dryer to preheat the biomass feed.

The syngas and residual tars are sent for cleanup, where the tars pass through a steam tar reformer. The steam tar reformer consists of a two circulating solid-catalyst fluidized reactors that allow for tandem operation, where one reactor performs catalyst regeneration (burning off residual carbon deposits [coke] from the reactor) while the other is reforming the tars. The tar reformer converts the tars and other hydrocarbons to produce more $\mathrm{CO}$ and $\mathrm{H}_{2}$. After reforming, the syngas is quenched and scrubbed before further conversion.

The cleaned syngas then is sent to a slurry column reactor containing a cobalt-based catalyst as the slurrying material. The reactor operates as a low-temperature FT reactor with a temperature at $230^{\circ} \mathrm{C}$ and an $\mathrm{H}_{2} / \mathrm{CO}$ ratio of 1.7 . This ensures high conversion of $\mathrm{H}_{2}$ and $\mathrm{CO}$ to water and mixed organics found in crude oil. The carbon number of the organics range from 1 to over 100, with the majority in the range of 5 to 22 carbons. The organics produced in the FT reactor can be upgraded to synthetic fuels, lubricants, and petrochemicals.

The effluent from the FT reactor leaves the reactor as a mixture of gas- and liquid-phase products. The effluent is condensed and separated in a typical fractional distillation column used in the petroleum industry. The column recovers primary products like gasoline, jet, and diesel fuels as individual streams. The gasoline cut is further isomerized to increase chemical branching, which improves the octane rating (an anti-knock index) of the fuel. The diesel and jet cut require further hydrotreating to remove any sulfur, nitrogen, and oxygen. This hydrotreating allows for better blending with petroleum-based fuels. The product distribution is shown in Table B24. 
Additional process areas not described here include the steam plant, power production, and wastewater treatment. For more information on these areas, please see the source material.

\section{$\underline{\text { Process Economics }}$}

This process follows the standard BETO assumptions listed at the beginning of this section.

As with other processing plants, the capital costs for equipment were sourced from the Aspen Capital Cost Estimator, vendor quotes, and literature. The capital costs listed as TIC of the different areas of the conversion plant are shown in Table B23.

\section{Table B23. Capital Expenses Broken Down by Processing Area Woody Biomass to Hydrocarbon Fuels via Gasification Followed by Fischer-Tropsch Synthesis}

\begin{tabular}{lr}
\hline Process Area & TIC (million \$) \\
\hline Biomass to Clean Syngas & 105.4 \\
Hydrocarbon Production & 158.2 \\
Steam Plant, Power Plant, Wastewater Treatment & 33.0 \\
Balance of Plant & 9.8 \\
Total & 306.4 \\
\hline
\end{tabular}

This plant's operating costs are like other production routes, including labor costs, materials and feedstock costs, utility costs, and disposal costs. The costs were further split into variable and fixed operating costs. Variable operating costs were defined as costs incurred based on raw materials, waste handling charges, and coproduct credits that can change depending on operating production capacity. In contrast, fixed costs are assumed to be charges that are incurred during any operating capacity.

Between the capital expenses, variable and fixed operating costs, and taxes, the MFSP for the fuels produced is $\$ 3.31 / \mathrm{GGE}$. The further breakdown based on area, as well as other process metrics, is shown in Table B24. There was no sensitivity analysis performed for this production route.

Table B24. Summary Results Table for Woody Biomass to Hydrocarbon Fuels via Gasification Followed by Fischer-Tropsch Synthesis

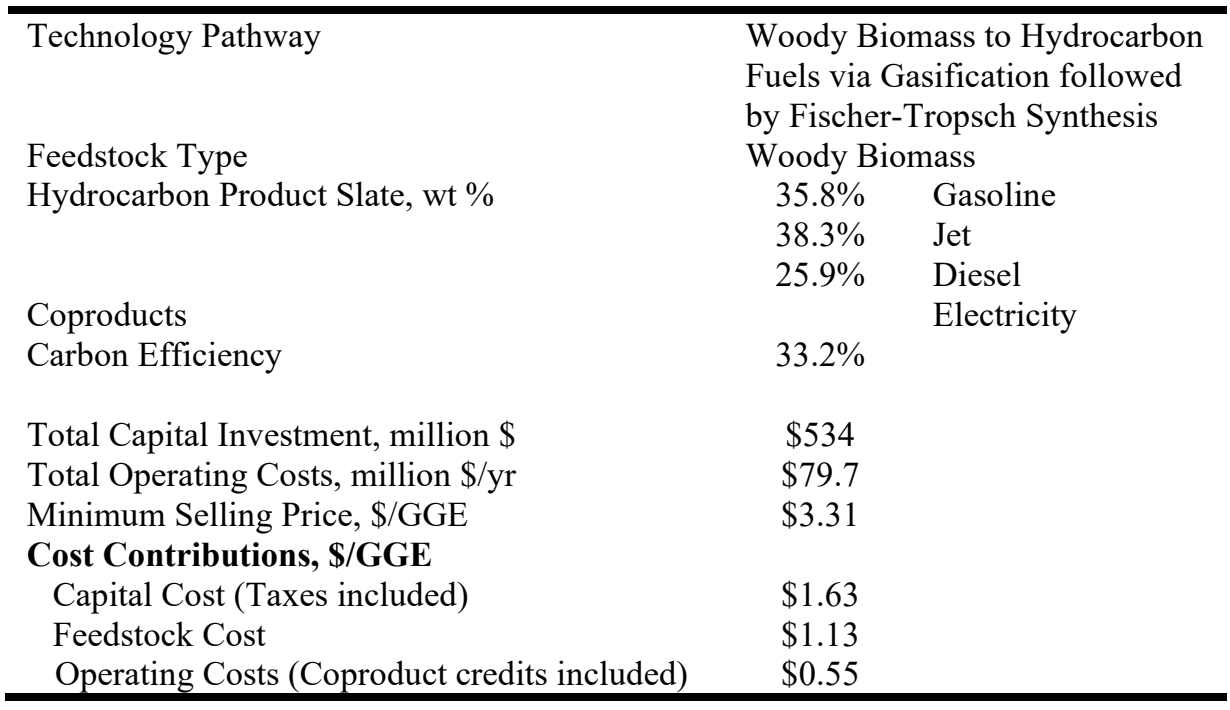


Pathway 22: Woody Biomass via Gasification to Methanol Upgraded to Olefins and then to Gasoline

Feedstock: Woody Biomass

Feedstock Processing Technology: Gasification

Fuel Precursor: Syngas

Fuel Processing Technology: Mobil Olefins to Gasoline and Distillates

Biofuel Product: 58.1\% Gasoline, 21.1\% Diesel, 20.8\% Jet Fuel

Data Source: (Tan et al. 2017)

\section{Process Summary}

The simplified block flow diagram is shown in Figure B19.

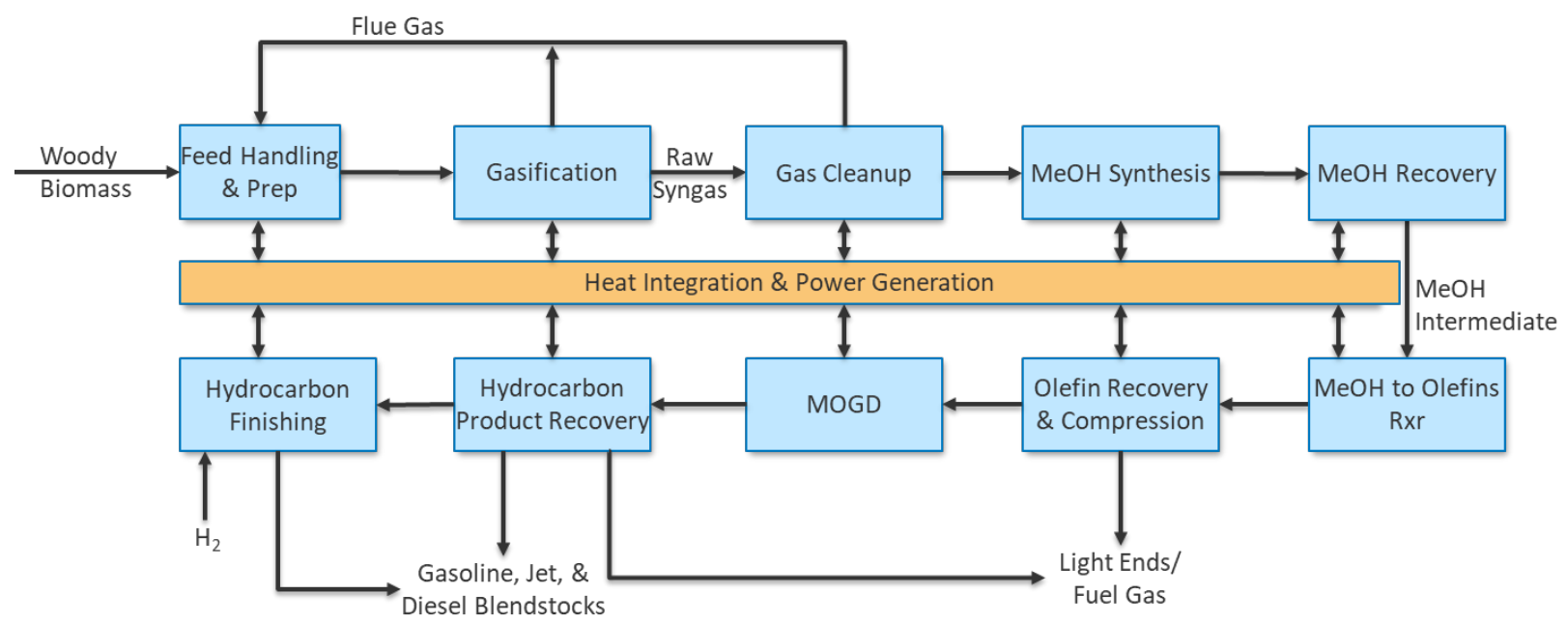

Figure B8. Simplified block flow diagram for woody biomass via gasification to methanol upgraded to olefins and then to gasoline

\section{Process Design}

Similar to Pathway 21, this process has the same feed handling, preparation, gasification, and syngas cleanup as Pathway 28. As a summary was given for Pathway 21 and specifics are given in Pathway 28, the description of these sections will be omitted here, and the process description will begin with the cleaned syngas.

The cooled and cleaned syngas is converted to methanol in a tubular, fixed-bed reactor that utilizes a copper-zinc-alumina catalyst. The methanol and unconverted syngas are cooled, condensing the methanol for recovery as a liquid while the unconverted syngas and light products stay in the gas phase and are recycled back into the methanol synthesis reactor. The methanol synthesis is an exothermic reaction, so the excess heat is removed by converting water to steam on the shell side of the heat exchanger. The steam is used elsewhere in the process. The 
reactor operates at $300^{\circ} \mathrm{C}, 735 \mathrm{psia}$, and has a space velocity of $8,000 \mathrm{~h}^{-1}$. The $\mathrm{CO}$ conversion to methanol in the reactor is assumed to be $41.8 \%$, which has been commercially proven and considered a conservative assumption.

The methanol after separation from the syngas is sent to the methanol-to-olefins unit, where it is converted to hydrocarbons and water. The hydrocarbons and water separate into an organic and aqueous phase, respectively. The water is sent for wastewater treatment, whereas the hydrocarbons are separated into an ethene-rich fuel gas, an aromatic gasoline stream (routed to final product blending), and a light-olefin feedstock for conversion to gasoline and diesel. The light olefins are fed to the gasoline and diesel conversion unit (which produces jet-range fuel, as it overlaps with gasoline and diesel fuels). The products from the gasoline and diesel conversion unit are separated using a fractional distillation column yielding a liquefied petroleum gas, fuel gas, gasoline, and raw distillate stream. The raw distillate stream is hydrotreated, producing a high-cetane-number product that can be further separated for jet and diesel applications. The fuel gas and liquified petroleum gas streams are used for on-site heat and electricity generation.

The gasoline-to-diesel ratio can be adjusted depending on the reaction conditions of the methanol-to-olefins reactor. It can be varied from $\sim 0: 1$ to about 1.5:1 while maintaining $>90 \%$ yield of hydrocarbons. When operated to maximize jet and diesel product, $18 \mathrm{wt} \%$ is gasoline and $79 \mathrm{wt} \%$ is jet and diesel, with the remainder being light hydrocarbon products. When operated to maximize gasoline, $84 \mathrm{wt} \%$ is gasoline and $7 \mathrm{wt} \%$ is diesel and jet with the remainder being light hydrocarbon products. Changing the product distribution has effects on the economics and MFSP of the main fuel. The product distribution used for the economic evaluation of this process is $58 \mathrm{wt} \%$ gasoline, $21 \mathrm{wt} \%$ diesel, and $21 \mathrm{wt} \%$ jet fuel.

\section{Process Economics}

This process follows all standard BETO economic assumptions. As mentioned, this process's fuel distribution is $58 \mathrm{wt} \%$ gasoline, $21 \mathrm{wt} \%$ diesel, and $21 \mathrm{wt} \%$ jet fuel and yields 42.7 million GGE per year using 2,000 DMT/day of woody biomass to produce the fuel. The overall carbon conversion efficiency for this process is $31.8 \%$, which is comparable to other thermochemical conversion routes of lignocellulosic biomass.

The capital costs of this process are high, with a total capital investment of \$531 million. This results in a higher cost contribution (31\%) to the MFSP for the capital expenses compared to other conversion routes. Other area costs are shown in Table B25.

Table B25. Summary of Area Contributions to MFSP for Woody Biomass via Gasification to Methanol Upgraded to Olefins and then to Gasoline

\begin{tabular}{|l|r|}
\hline Areas & Cost Contribution (\$/GGE) \\
\hline Feedstock & 1.20 \\
\hline Catalyst & 0.77 \\
\hline Olivine and $\mathrm{MgO}$ & 0.01 \\
\hline Hydrogen & 0.00 \\
\hline Other Raw Materials & 0.04 \\
\hline Waste Disposal & 0.01 \\
\hline
\end{tabular}




\begin{tabular}{|l|r|}
\hline Areas & Cost Contribution (\$/GGE) \\
\hline Fixed Costs & 0.53 \\
\hline Coproduct Credits & -0.09 \\
\hline Capital Depreciation & 0.38 \\
\hline Average Income Tax & 0.41 \\
\hline Average Return on Investment & 0.91 \\
\hline MFSP & 4.16 \\
\hline
\end{tabular}

As with other pathways, feedstock costs also have a significant impact on the MFSP. Though there was no sensitivity analysis performed for this pathway, if capital expenses and feedstock costs were decreased, the MFSP would decrease significantly.

Table B26 gives a brief summary of the economic and performance information about this conversion pathway.

Table B26. Summary Results Table for Woody Biomass via Gasification to Methanol Upgraded to Olefins and then to Gasoline

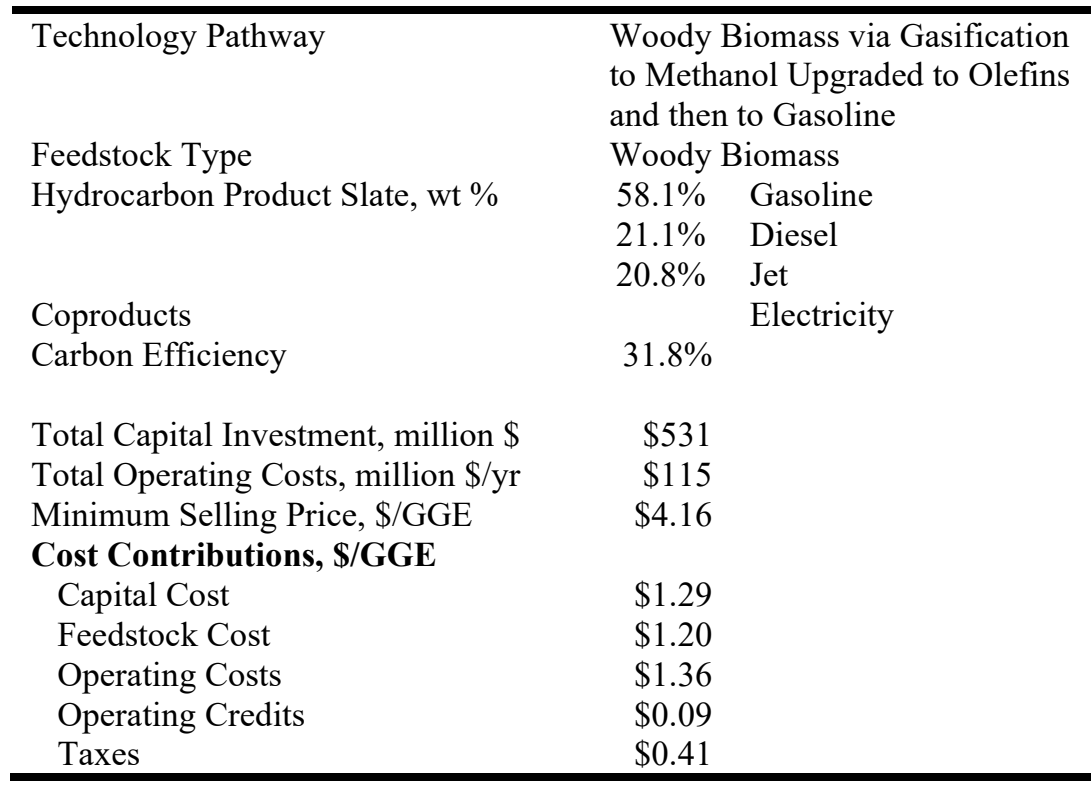

Pathway 23: Woody Biomass to Hydrocarbon Fuels via Gasification Upgraded via Alcohol Condensation and Oligomerization

Feedstock: Woody Biomass

Feedstock Processing Technology: Gasification

Fuel Precursor: Syngas

Fuel Processing Technology: Mixed Alcohol Synthesis and Alcohol Condensation

Biofuel Product: 52.5\% Diesel, 47.5\% Jet

Data Source: (Tan et al. 2017) 


\section{Process Summary}

The simplified block flow diagram is shown in Figure B20.

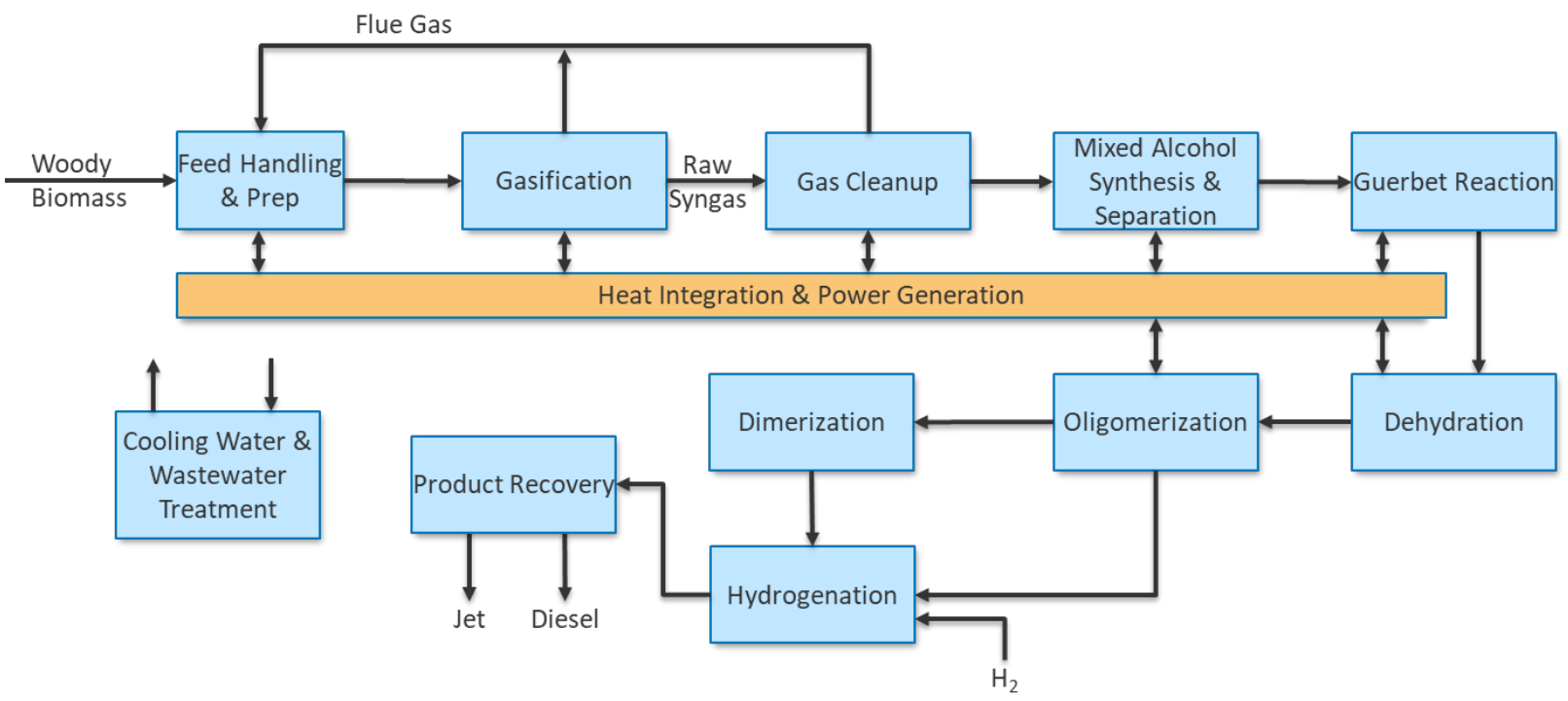

Figure B9. Simplified block flow diagram for woody biomass to hydrocarbon fuels via gasification upgraded via alcohol condensation and oligomerization

\section{Process Design}

Similar to Pathway 21, this process has the same feed handling, preparation, gasification, and syngas cleanup as Pathway 28. As a summary was given for Pathway 21 and specifics are given in Pathway 28, the description of these sections will be omitted here, and the process description will begin with the cleaned syngas.

The cleaned syngas is pressurized to 1,895 psia before being fed downward into one of two vertical shell-and-tube reactors that operate in parallel at a temperature of $300^{\circ} \mathrm{C}$ (mixed alcohol synthesis reactors). Within the reactor is a $\mathrm{MoS}_{2}$ catalyst that converts the syngas into a mixture of alcohols, mainly ethanol and longer-chained alcohols. The reaction is exothermic, and therefore the heat must be removed to maintain the $300^{\circ} \mathrm{C}$ reactor temperature. This is done by generating steam on the shell side of the reactor. The steam is used elsewhere in the plant for process heat. Upon leaving the reactor, the alcohols and unreacted gas are depressurized, flashing the system and condensing the alcohols and condensable gases. The non-condensable gases, consisting mainly of unconverted syngas, $\mathrm{CO}_{2}$, and $\mathrm{H}_{2} \mathrm{~S}$ (acid gases), are sent to an acid-gas removal system that utilizes dimethyl ether of polyethylene glycol as a physical solvent to remove the $\mathrm{CO}_{2}$ and $\mathrm{H}_{2} \mathrm{~S}$. The cleaned syngas is then recompressed and fed back to the mixed alcohol synthesis reactor. The removed $\mathrm{CO}_{2}$ and $\mathrm{H}_{2} \mathrm{~S}$ are further processed using a LO-CAT sulfur recovery unit that converts the $\mathrm{H}_{2} \mathrm{~S}$ into elemental sulfur that is then disposed. The $\mathrm{MoS}_{2}$ catalyst used in the mixed alcohol synthesis reactor requires a baseline level of sulfur to maintain activity, and to retain this, some $\mathrm{H}_{2} \mathrm{~S}$ is doped back into the reactor feed. More details on this doping can be found in the source material for Pathway 28. 
The condensed alcohol stream first has water removed by a molecular sieve system that leaves the solution with less than $0.5 \mathrm{wt} \%$ water. The dewatered alcohol stream is then fed to an alcohol distillation column that separates methanol from longer-chained alcohols. The methanol is recycled to the alcohol synthesis reactor for elongation, while ethanol and longer-chained alcohols are fed to the Guerbet reactor.

The Guerbet reactor utilizes a dual-function acid-base metal oxide catalyst. The catalyst selected for this configuration was an $\mathrm{MgO}-\mathrm{Al}_{2} \mathrm{O}_{3}$ catalyst with an $\mathrm{Mg}$-to-Al ratio of 3:1, which has been shown to selectively produce n-butanol. Other catalysts could be suitable for this reaction as well. The stream enters the reactor and is heated to $345^{\circ} \mathrm{C}$, held at a pressure of $35 \mathrm{psia}$, and has a weighted hourly space velocity of $1.0 \mathrm{~h}^{-1}$. While in the reactor, the catalyst couples alcoholsmainly ethanol - to make longer-chained alcohols, mainly n-butanol.

It should be noted that the catalyst cannot couple methanol with itself but can couple methanol with other, longer-chained alcohols. The single-pass conversion for ethanol in the reactor is $60 \%$; therefore, the reactor effluent is separated in a distillation column, and ethanol is recycled to the reactor to increase overall process conversion. It should be noted that $5 \%$ of the recycle stream is purged to a fuel combustor to prevent the buildup of longer-chained alcohols. The heavier products from the column containing about $90 \% \mathrm{n}$-butanol is sent to the alcohol dehydration reactor.

The stream containing primarily n-butanol enters the alcohol dehydration reactor that operates at $380^{\circ} \mathrm{C}$ and 35 psia. The reactor utilizes a modified $\Upsilon$-alumina catalyst that dehydrates the alcohols to their corresponding olefins. The reaction does not operate at $100 \%$ conversion of alcohols to olefins; therefore, the reactor effluent is separated using a distillation column to recycle unconverted alcohols, and the remaining olefins are sent for oligomerization.

The olefins, primarily consisting of 1-butene, are sent to the oligomerization reactor. This reactor is a packed bed reactor that utilizes a HZSM-23 zeolite catalyst and converts the short-chained olefins to longer-chained olefins in the carbon range from 8 to 20 carbons. The reaction takes place at $250^{\circ} \mathrm{C}, 435 \mathrm{psia}$, has a weight hourly space velocity of $0.21 \mathrm{~h}^{-1}$, and achieves a $95 \%$ single-pass n-butene conversion. The n-butene is converted with a selectivity to $\mathrm{C} 8, \mathrm{C} 12, \mathrm{C} 16$, and $\mathrm{C} 20+$ at $26.2 \%, 43.0 \%, 21.9 \%$, and $8.9 \%$, respectively. After exiting the reactor, the olefins are separated with a fractional distillation column, and the $\mathrm{C} 8$ olefins are sent to a dimerization reactor that is operated at $116^{\circ} \mathrm{C}$ and 54 psia and converts $100 \%$ of the $\mathrm{C} 8$ olefins to a $\mathrm{C} 16$ dimer. This dimer is then mixed back with the heavier olefin fraction and sent to the hydrogenation reactor.

The mixed olefin stream is sent to the hydrogenation reactor, similar to one developed by ABB Lummus Crest and IFP, which is expanded upon in the source material. The process operates at $45^{\circ} \mathrm{C}$ and 500 psia with excess hydrogen of 1.8 moles of $\mathrm{H}_{2}$ per mole of olefins and converts $100 \%$ of olefins to paraffins. This system requires external hydrogen to be supplied to the production facility versus the hydrogen being produced on site. The paraffin product is then separated into a jet and diesel stream fit for blending using a fractional distillation column like ones used in commercial petroleum refineries. Any unreacted hydrogen is recycled back into the hydrogenation reactor with any non-condensable gases. A small amount of hydrogen and noncondensable gas stream is purged to use as fuel gas on site. 
Additional process areas not described here include the steam plant, power production, and wastewater treatment. More information on these areas can be found in the source material.

\section{$\underline{\text { Process Economics }}$}

This process follows the standard BETO assumptions listed at the beginning of this section.

Aspen Capital Cost Estimator, vendor quotes, and literature were used to estimate capital costs for equipment throughout the facility. The capital costs listed as TIC of the different areas of the conversion plant are shown in Table B27.

Table B27. Capital Expenses Broken Down by Processing Area for Woody Biomass to Hydrocarbon Fuels via Gasification Upgraded via Alcohol Condensation and Oligomerization

\begin{tabular}{|l|r|}
\hline Process Area & TIC (million \$) \\
\hline Biomass to Clean Syngas & 70.1 \\
\hline Mixed Alcohol Production & 186.8 \\
\hline Fuel Production & 80.6 \\
\hline Steam Plant, Power Plant, Wastewater Treatment & 43.7 \\
\hline Balance of Plant & 9.5 \\
\hline Total & 390.7 \\
\hline
\end{tabular}

The operating costs of this plant are similar in nature to those in Pathway 22 but vary slightly in their actual values due to different flow rates and heat requirements within the plant.

Between the capital expenses, variable and fixed operating costs, and taxes, the MFSP for the fuels produced is $\$ 4.52 / \mathrm{GGE}$. A breakdown of cost contributions, as well as other process metrics, is shown in Table B28. There was no sensitivity analysis performed for this production route.

Table B28. Summary Results Table for Woody Biomass to Hydrocarbon Fuels via Gasification Upgraded via Alcohol Condensation and Oligomerization

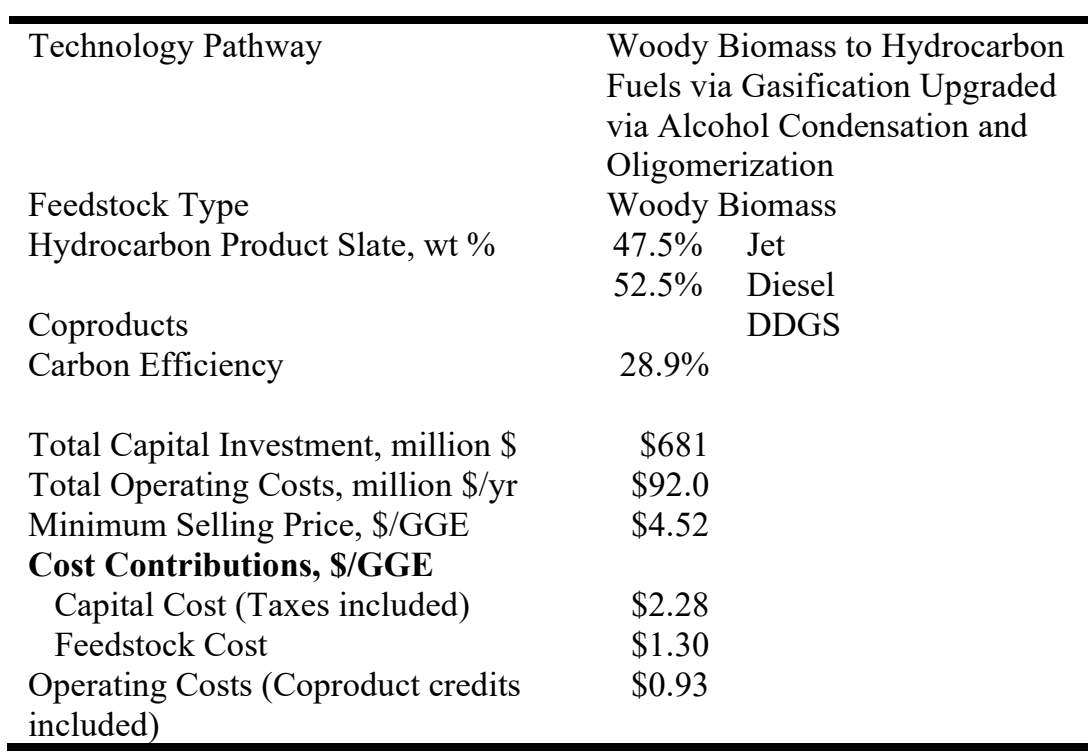


Pathway 24: Woody Biomass to Hydrocarbon Fuels via Gasification Upgraded by Syngas Fermentation and Alcohol Condensation plus Oligomerization

Feedstock: Woody Biomass

Feedstock Processing Technology: Gasification

Fuel Precursor: Syngas

Fuel Processing Technology: Syngas Fermentation and Alcohol Condensation

Biofuel Product: 24.0\% Gasoline, 10.1\% Diesel, 65.9\% Jet

Data Source: (Tan et al. 2017)

\section{Process Summary}

The simplified block flow diagram is shown in Figure B21.

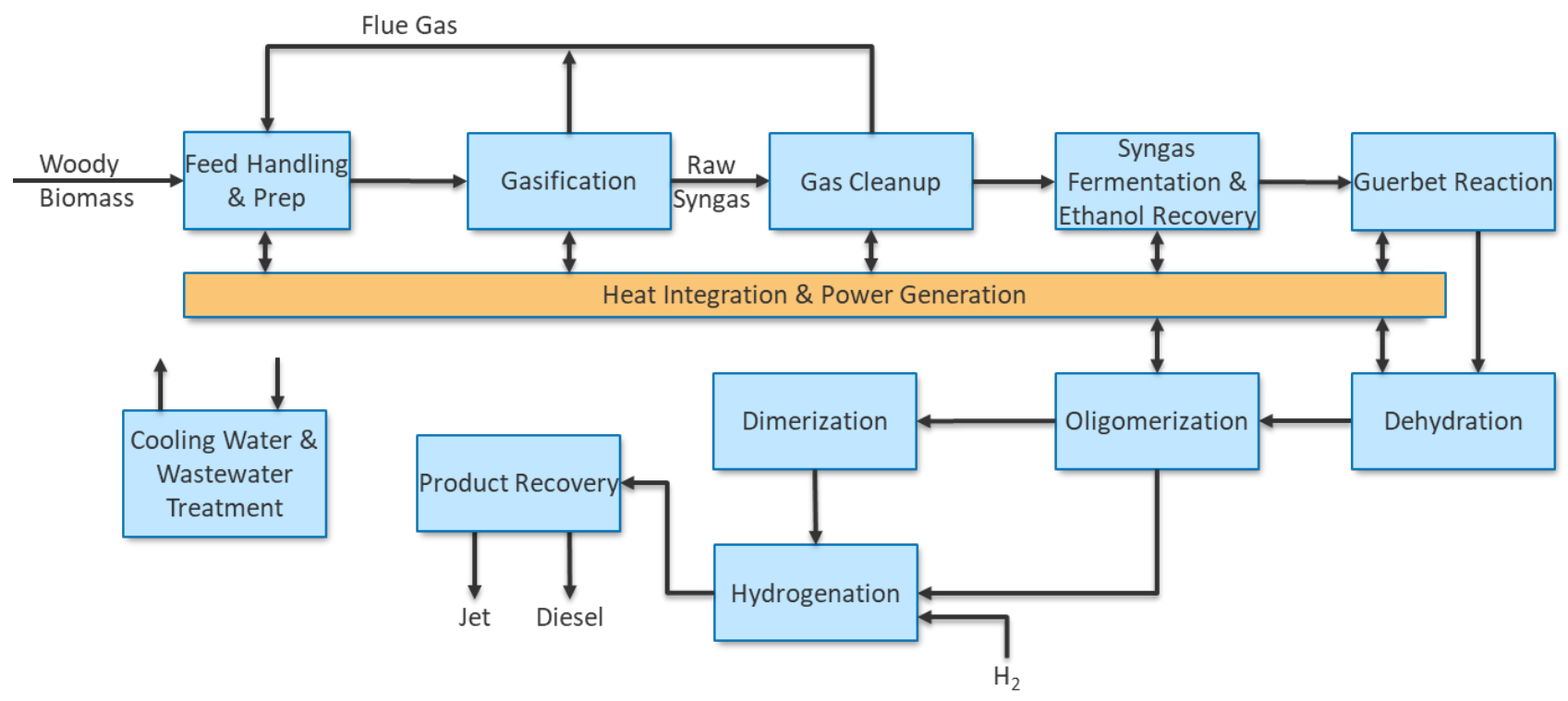

Figure B10. Simplified block flow diagram for woody biomass to hydrocarbon fuels via gasification upgraded by syngas fermentation and alcohol condensation plus oligomerization

\section{Process Design}

Similar to Pathway 21, this process has the same feed handling, preparation, gasification, and syngas cleanup as Pathway 28. As a summary was given for Pathway 21 and specifics are given in Pathway 28, the description of these sections will be omitted here, and the process description begins with the cleaned syngas.

The syngas after cleanup is cooled to $37.8^{\circ} \mathrm{C}$ and compressed to $30 \mathrm{psia}$. It is then sent to one of the multiple fermentation vessels that operate in parallel, allowing for continuous operation within the plant. The syngas enters the CSTR fermentation vessels through nozzles that will enable vapor distribution, optimizing mass transfer into the aqueous phase. The aqueous phase is 
circulated throughout the CSTR to maximize mass transfer as well. The organism used in the CSTR is an anaerobic bacterium from the Clostridium genus that converts $\mathrm{CO}$ and water to ethanol and $\mathrm{CO}_{2}$, as well as converting $\mathrm{CO}_{2}$ and $\mathrm{H}_{2}$ to ethanol and water. The syngas can limit these reactions based on the amount of $\mathrm{H}_{2}$ available. If insufficient $\mathrm{H}_{2}$ is present, the bacterium will convert the $\mathrm{CO}$ to $\mathrm{H}_{2}$ utilizing the internal water gas shift reaction $\left(\mathrm{CO}+\mathrm{H}_{2} \mathrm{O} \rightarrow \mathrm{H}_{2}+\mathrm{CO}_{2}\right)$. After the syngas is converted to ethanol and water, the resulting fermentation broth has an ethanol concentration of $\sim 50 \mathrm{~g} / \mathrm{L}$. Side products from the fermentation process include acetic acid and 2,3-butanediol.

The fermentation broth is separated using a distillation system as described in Pathway 28. This process separates water from the ethanol to the maximum allowed by the existing ethanol-water azeotrope. The azeotropic mixture is then dried using vapor-phase molecular sieves. This purifies the ethanol to $99.5 \%$, which is suitable for fuel use or further upgrading via Guerbet reaction followed by further upgrading to diesel-, jet-, and gasoline-range fuels. The water separated from the broth is either recycled to the fermenters or sent for wastewater treatment.

The oxygenate stream consisting of majority ethanol and minor contributions from other side products is sent to a Guerbet reactor, identical to the one described in Pathway 23. The upgrading stages after the Guerbet reactor are also identical to those described in Pathway 23. For brevity, these will not be repeated here. Because of the different distribution of alcohols entering the Guerbet reactor, the final product distribution differs, but all operating conditions, reactors, and operating conditions are the same. For more information on the product distribution, see Table B30.

Additional process areas not described here include the steam plant, power production, and wastewater treatment. Please see the source material for further descriptions of these areas.

\section{$\underline{\text { Process Economics }}$}

This process follows the standard BETO assumptions listed at the beginning of this section.

Aspen Capital Cost Estimator, vendor quotes, and literature were used to estimate capital costs for equipment throughout the facility. The capital costs listed as TIC of the different areas of the conversion plant are shown in Table B29.

\section{Table B29. Capital Expenses Broken Down by Processing Area Woody Biomass to Hydrocarbon Fuels via Gasification Upgraded by Syngas Fermentation and Alcohol Condensation Plus Oligomerization}

\begin{tabular}{lr}
\hline Process Area & TIC (million \$) \\
\hline Biomass to Clean Syngas & 70.0 \\
Mixed Oxygenate Production & 80.6 \\
Fuel Production & 67.0 \\
Steam Plant, Power Plant, Wastewater Treatment & 26.1 \\
Balance of Plant & 10.5 \\
Total & 254.1 \\
\hline
\end{tabular}

The operating costs of this plant are similar in nature to those described in Pathway 22 but vary slightly in their values due to different flow rates and heat requirements within the plant. 
Between the capital expenses, variable and fixed operating costs, and taxes, the MFSP for the fuels produced is $\$ 3.14 / \mathrm{GGE}$. A breakdown of cost contributions, as well as other process metrics, is shown in Table B30. There was no sensitivity analysis performed for this production route.

Table B30. Summary Results Table for Woody Biomass to Hydrocarbon Fuels via Gasification Upgraded by Syngas Fermentation and Alcohol Condensation plus Oligomerization

\begin{tabular}{ll}
\hline Technology Pathway & $\begin{array}{l}\text { Woody Biomass to Hydrocarbon } \\
\text { Fuels via Gasification Upgraded } \\
\text { by Syngas Fermentation and } \\
\text { Alcohol Condensation plus }\end{array}$ \\
& $\begin{array}{l}\text { Oligomerization } \\
\text { Woody Biomass }\end{array}$ \\
$\begin{array}{l}48.5 \% \quad \text { Jet } \\
\text { Feedstock Type }\end{array}$ & $51.5 \% \quad$ Diesel \\
Hydrocarbon Product Slate, wt \% & \multicolumn{1}{c}{ Electricity } \\
Coproducts & $33.8 \%$ \\
Carbon Efficiency & $\$ 443$ \\
Total Capital Investment, million \$ & $\$ 78.8$ \\
Total Operating Costs, million \$/yr & $\$ 3.14$ \\
Minimum Selling Price, \$/GGE & \\
Cost Contributions, \$/GGE & $\$ 1.39$ \\
$\quad$ Capital Cost (Taxes included) & $\$ 1.19$ \\
$\quad \begin{array}{l}\text { Feedstock Cost } \\
\text { Operating Costs (Coproduct credits } \\
\text { included) }\end{array}$ & $\$ 0.56$ \\
\hline
\end{tabular}

Pathway 25: Woody Biomass to Hydrocarbon Fuels via Gasification and Upgraded via Carbon Coupling and Oligomerization

Feedstock: Woody Biomass

Feedstock Processing Technology: Gasification

Fuel Precursor: Syngas

Fuel Processing Technology: Syngas Fermentation and Alcohol Condensation Mixed Oxygenate Synthesis and Carbon Coupling

Biofuel Product: $24.0 \%$ Gasoline, 10.1\% Diesel, 65.9\% Jet fuel

Data Source: (Tan et al. 2017)

\section{Process Summary}

The simplified block flow diagram is shown in Figure B22. 


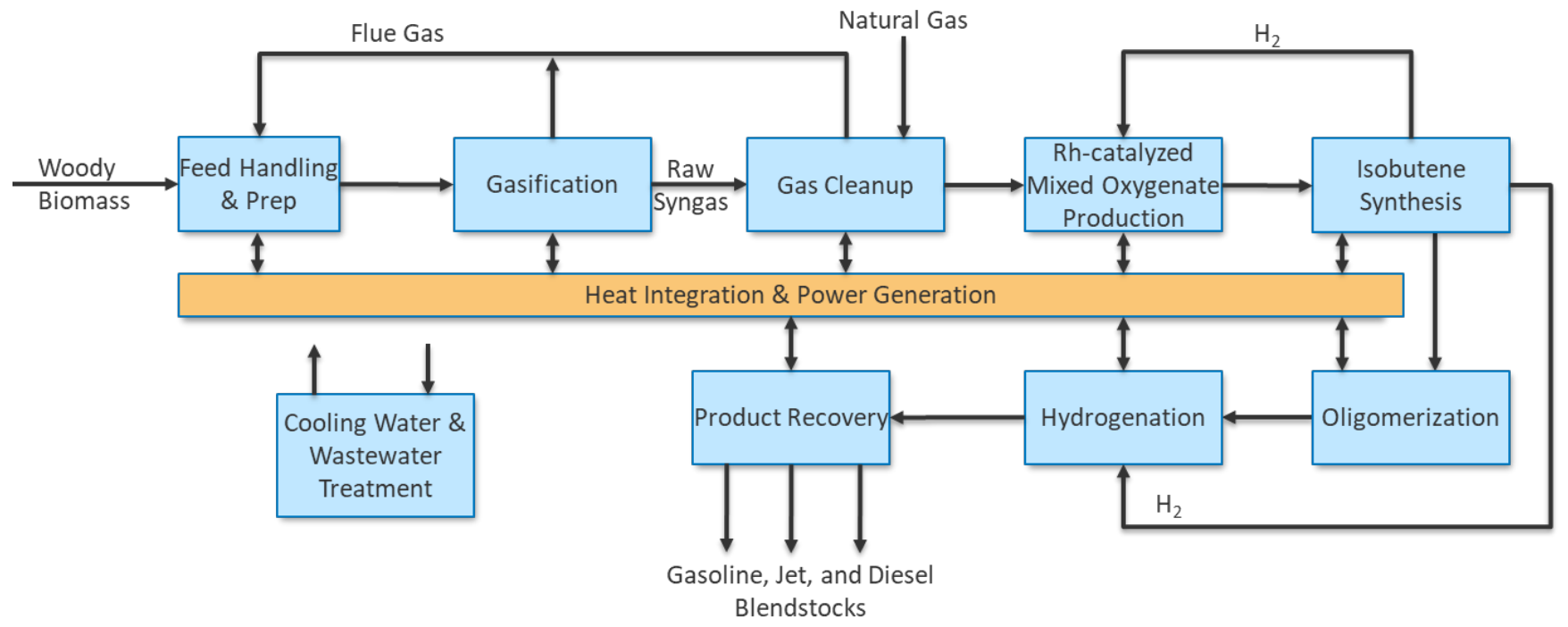

Figure B11. Simplified block flow diagram for woody biomass to hydrocarbon fuels via
gasification upgraded via carbon coupling and oligomerization

\section{Process Design}

Similar to Pathway 21, this process has the same feed handling, preparation, gasification, and syngas cleanup as Pathway 28. As a summary was given for Pathway 21 and specifics are given in Pathway 28, the description of these sections will be omitted here, and the process description will begin with the cleaned syngas.

The cleaned syngas is mixed with downstream hydrogen from the isobutene reactor (described below) to obtain an $\mathrm{H}_{2}: \mathrm{CO}$ ratio of 1.3. The hydrogen-enriched stream is compressed further in a two-stage compressor to 1,220 psia (the operating pressure for the mixed oxygenates reactor), heated to $260^{\circ} \mathrm{C}$, and fed to a vertical tube-and-shell reactor, where the gas flows downward over an Rh-based catalyst packed within the tube. The catalyst, supported on a carbon base, contains $\mathrm{Rh}, \mathrm{Mn}$, and Ir as promotors. It converts the syngas to oxygenates and hydrocarbons, maintaining a high carbon selectivity. The reaction has a gas hourly space velocity of $3,247 \mathrm{~h}^{-1}$ and has a $35 \%$ single-pass conversion. Because of the low single-pass conversion, unreacted syngas is separated from the target products by cooling, resulting in condensation of the target products. The unreacted syngas is then recycled back to the reactor inlet. The condensed reaction products are composed mainly of ethanol, acetaldehyde, ethyl acetate, and acetic acid, all of which are well suited for isobutene synthesis downstream. The mixed oxygenate reaction is exothermic, requiring heat to be transferred away by flowing other process streams through the shell side of the reactor.

The condensed product stream is then depressurized to 215 psia and reheated to $500^{\circ} \mathrm{C}$ before being fed to a second shell-and-tube reactor. In the reactor, the mixed oxygenates are passed through a $\mathrm{Zn}_{\mathrm{x}} \mathrm{Zr}_{\mathrm{y}} \mathrm{O}_{\mathrm{z}}$ catalyst filled tube at $449^{\circ} \mathrm{C}, 215 \mathrm{psia}$, for a gas hourly space velocity of $2000 \mathrm{~h}^{-1}$. This catalyst converts the oxygenates to isobutene, propylene, and additional side products. This reaction is endothermic, requiring heat from the shell side of the reactor. Natural gas is supplied to heat the heat transfer fluid; this is used instead of flue gas to increase product fuel yields. 
After conversion, the products are cooled to $54.4^{\circ} \mathrm{C}$, transferring the heat to the reactor inlet stream. After cooling, it is sent through a vapor-liquid separator that reduces the water to $1.3 \mathrm{~mol}$ $\%$, allowing for an increase in activity of the oligomerization catalyst. The stream-now containing $36 \mathrm{wt} \%$ olefins diluted with $\mathrm{CO}_{2}$ and $\mathrm{H}_{2}$ and lesser amounts of $\mathrm{CO}$, methane, water, and other light components - is compressed to 270 psia and fed to a gas absorption unit that removes $\mathrm{CO}_{2}, \mathrm{H}_{2}$, and light gases to enrich the olefins to $95 \mathrm{wt} \%$. The $\mathrm{H}_{2}$ removed is used downstream for hydrogenation or recycled to the mixed oxygenates synthesis reactor at the front end of the syngas upgrading train.

The enriched olefin stream at 261 psia is oligomerized in a packed bed reactor with an Amberlyst 36 catalyst that converts the shorter olefins to longer-chained olefins with high selectivity to compounds in the 7 to 16 carbon range. The reactor is a five-stage reactor with air cooling to remove the heat generated by the exothermic reaction. The inlet to the reactor is held at $110^{\circ} \mathrm{C}$ and the temperature within the reactor bed is allowed to reach $152^{\circ} \mathrm{C}$, the maximum temperature allowed due to the high-temperature instabilities of the Amberlyst 36 catalyst. The weight hourly space velocity within the reactor is $0.756 \mathrm{~h}^{-1}$ with $100 \%$ single-pass conversion.

The mixed $\mathrm{C} 7$ to $\mathrm{C} 16$ olefins are then hydrogenated, yielding distillate-range fuels. The hydrogenation reactor and following process separation steps are similar to those described in Pathway 23 and will not be repeated here.

Additional process areas not described here include the steam plant, power production, and wastewater treatment. For more information on these areas, please see the source material.

\section{Process Economics}

This process follows the standard BETO assumptions listed at the beginning of this section.

Aspen Capital Cost Estimator, vendor quotes, and literature were used to estimate capital costs for equipment throughout the facility. The capital costs listed as TIC of the different areas of the conversion plant are shown in Table B31.

Table B31. Capital Expenses Broken Down by Processing Area for Woody Biomass to Hydrocarbon Fuels via Gasification Upgraded via Carbon Coupling and Oligomerization

\begin{tabular}{lr}
\hline Process Area & TIC (million \$) \\
\hline Biomass to Clean Syngas & 71.9 \\
Mixed Oxygenate Production & 83.5 \\
Fuel Production & 32.4 \\
Steam Plant, Power Plant, Wastewater Treatment & 32.8 \\
Balance of Plant & 8.1 \\
Total & 228.7 \\
\hline
\end{tabular}

The operating costs of this plant are similar in nature to those described in Pathway 22 but vary slightly in their values due to different flow rates and heat requirements within the plant.

Between the capital expenses, variable and fixed operating costs, and taxes, the MFSP for the fuels produced is $\$ 3.41 / \mathrm{GGE}$. A breakdown of cost contributions, as well as other process metrics, is shown in Table B32. There was no sensitivity analysis performed for this production route. 
Table B32. Summary Results Table for Woody Biomass to Hydrocarbon Fuels via Gasification Upgraded via Carbon Coupling and Oligomerization

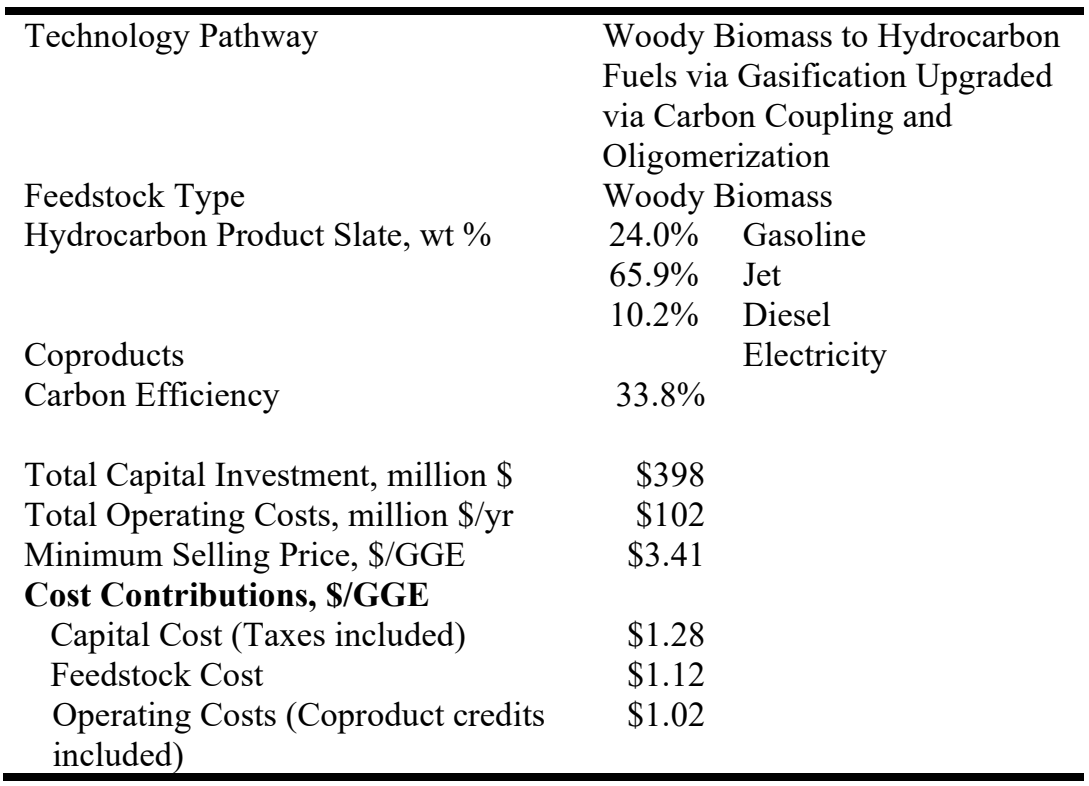

Pathway 26: Woody Biomass to Hydrocarbon Fuels via Gasification Upgraded via Syngas Fermentation and Carbon Coupling plus Oligomerization

Feedstock: Woody Biomass

Feedstock Processing Technology: Gasification

Fuel Precursor: Syngas

Fuel Processing Technology: Syngas Fermentation and Carbon Coupling

Biofuel Product: 24.0\% Gasoline, 10.1\% Diesel, 65.9\% Jet

Data Source: (Tan et al. 2017)

\section{Process Summary}

The simplified block flow diagram is shown in Figure B23. 


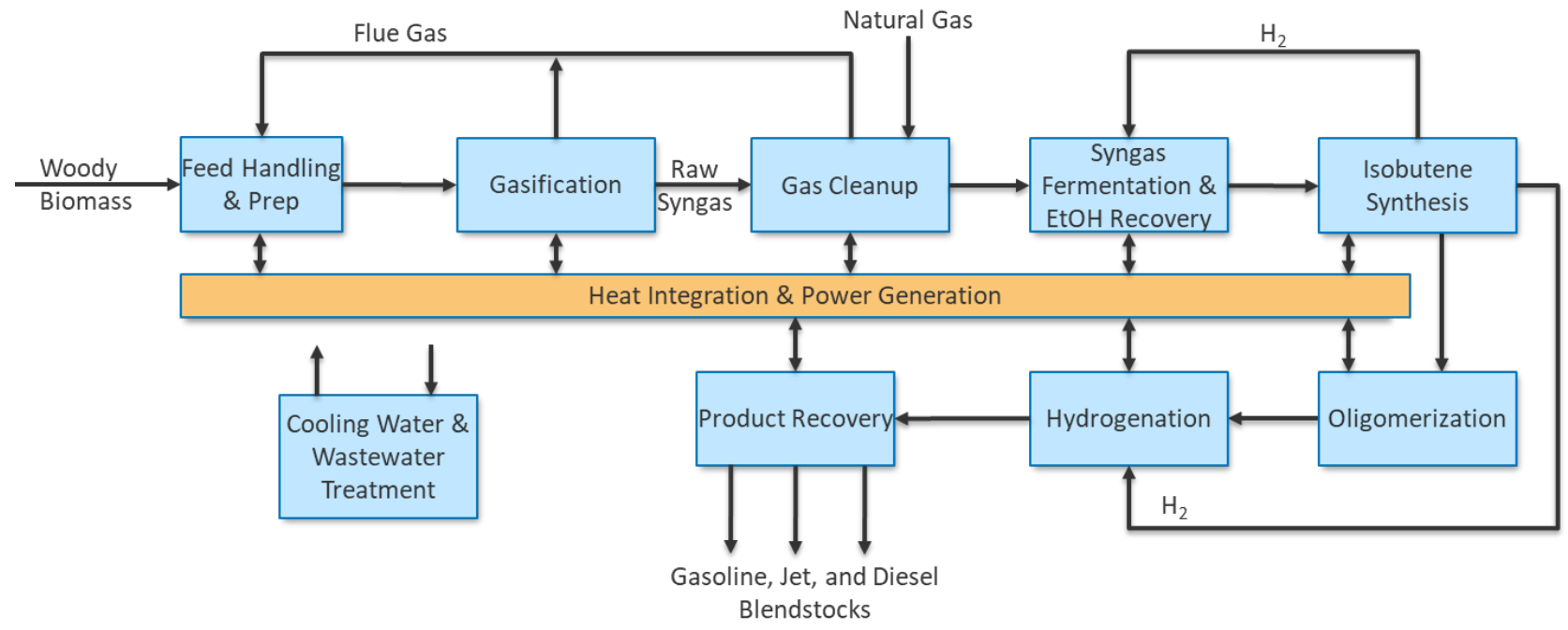

Figure B12. Simplified block flow diagram for woody biomass to hydrocarbon fuels via gasification upgraded via syngas fermentation and carbon coupling plus oligomerization

\section{Process Design}

Similar to Pathway 21, this process has the same feed handling, preparation, gasification, and syngas cleanup as Pathway 28. As a summary was given for Pathway 21 and specifics are given in Pathway 28, the description of these sections will be omitted here, and the process description will begin syngas after syngas cleanup.

The purified ethanol from the syngas fermentation phase is pressurized to $215 \mathrm{psia}$ and heated to $500^{\circ} \mathrm{C}$ before being fed to a shell-and-tube reactor for isobutene synthesis. The isobutene synthesis and downstream upgrading are identical to the process described in Pathway 25 and will not be repeated here. Because the syngas fermentation stream is different from the mixed oxygenates in Pathway 25, the final product distribution is slightly different. For information on the varying product distribution, please see Table B34.

Additional process areas not described here include the steam plant, power production, and wastewater treatment. For more information on these areas, please see the source material.

\section{Process Economics}

This process follows standard BETO assumptions listed at the beginning of this appendix.

Aspen Capital Cost Estimator, vendor quotes, and literature were used to estimate capital costs for equipment throughout the facility. The capital costs listed as TIC of the different areas of the conversion plant are shown in Table B33. 
Table B33. Capital Expenses Broken Down by Processing Area for Woody Biomass to Hydrocarbon Fuels via Gasification Upgraded via Syngas Fermentation and Carbon Coupling plus Oligomerization

\begin{tabular}{lr}
\hline Process Area & TIC (million \$) \\
\hline Biomass to Clean Syngas & 85.3 \\
Ethanol Production & 87.5 \\
Fuel Production & 32.4 \\
Steam Plant, Power Plant, Wastewater Treatment & 23.8 \\
Balance of Plant & 36.9 \\
Total & 265.9 \\
\hline
\end{tabular}

The operating costs of this plant are similar in nature to those described in Pathway 22 but vary slightly in their values due to different flow rates and heat requirements within the plant.

Between the capital expenses, variable and fixed operating costs, and taxes, the MFSP for the fuels produced is $\$ 4.66 / \mathrm{GGE}$. A breakdown of cost contributions, along with other process metrics, is shown in Table B34. There was no sensitivity analysis performed for this production route.

Table B34. Summary Results Table for Woody Biomass to Hydrocarbon Fuels via Gasification Upgraded via Syngas Fermentation and Carbon Coupling plus Oligomerization

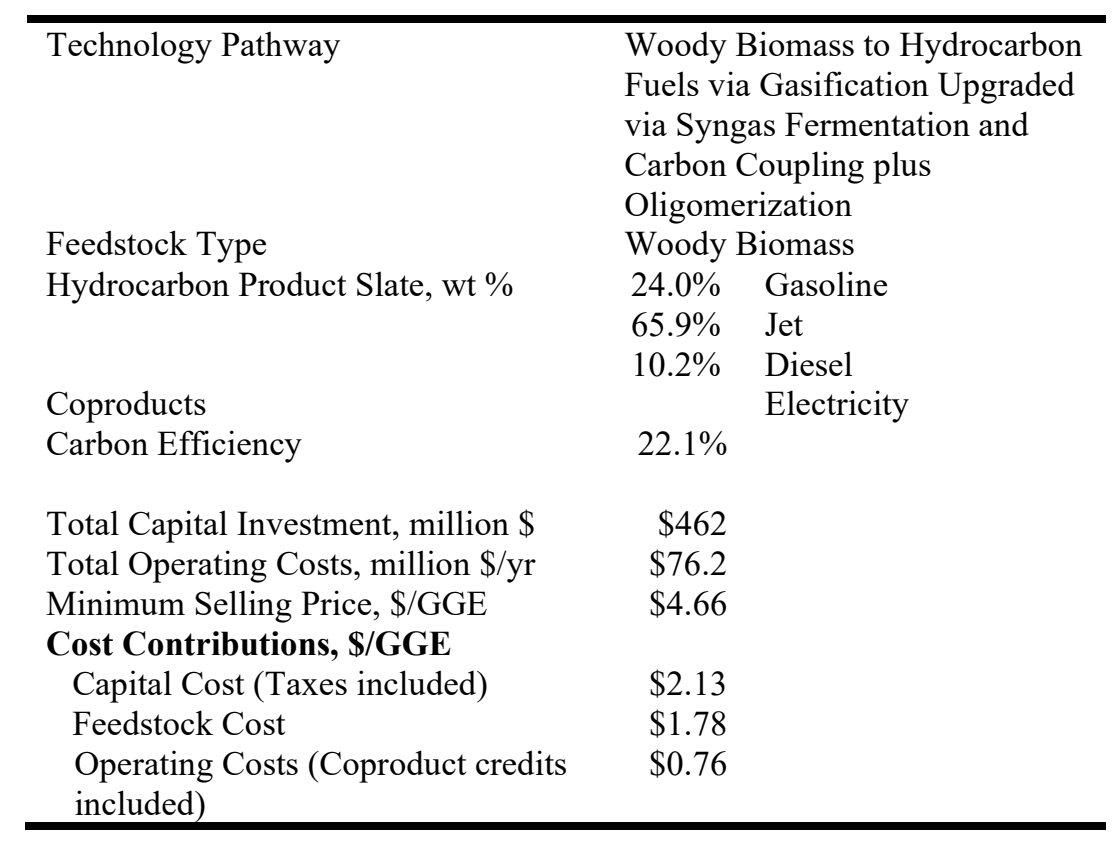

Pathway 27: Woody Biomass to Hydrocarbon Fuels via Gasification and Methanol-to-Gasoline Technologies

Feedstock: Hybrid Poplar

Feedstock Processing Technology: Gasification

Fuel Precursor: Syngas

Fuel Processing Technology: Syngas Fermentation and Alcohol Condensation 
Biofuel Product: 100\% Gasoline

Data Source: (Phillips et al. 2011)

\section{Process Summary}

The simplified block flow diagram is shown in Figure B24.

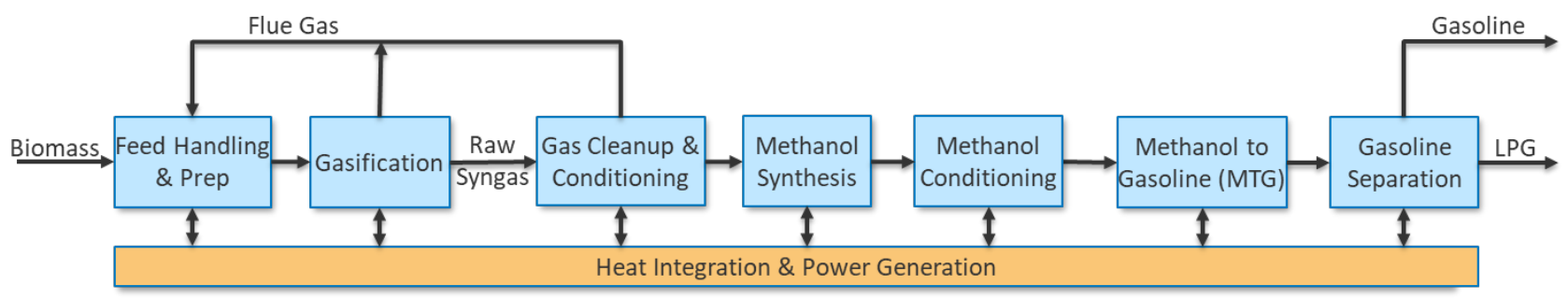

Figure B13. Simplified block flow diagram for woody biomass to hydrocarbon fuels via gasification and methanol-to-gasoline technologies

\section{Process Design}

This process is designed to accommodate 2,000 DMT/day and utilizes hybrid poplar as the feedstock.

The hybrid poplar wood chip feedstock is delivered to the plant using trucks, which dump the feedstock into temporary storage. After spending a short time in storage, the chips are conveyed through a magnetic separator and screened to separate particles larger and smaller than 2 inches. Particles larger than 2 inches are sent through a hammer mill for size reduction. The prepped chips are then loaded into a dryer feed bin, where the biomass is dried using hot flue gas from the gasification and gas cleanup units. The biomass is dried to $10 \mathrm{wt} \%$ moisture before being conveyed to the gasifier.

There are two gasifiers operating in parallel to obtain the required 2,000-DMT/day throughput (1,000 DMT/day each). The gasifiers are low-pressure, indirectly heated circulating fluidized bed gasifiers. The biomass enters the gasifier being fluidized by synthetic olivine circulating at a rate of $27 \mathrm{lb}$ of olivine per pound biomass. The synthetic olivine provides heat from the char combustor for the endothermic gasification process. The gasifier operates at $23 \mathrm{psia}$ and $883^{\circ} \mathrm{C}$. Within the gasifier, the biomass is converted into syngas, tars, and char. The gasifier's effluent is separated using a two-stage cyclone system that separates the gaseous material and tars from the char and olivine. The char and olivine are sent to the char combustor, where the char is burned in excess air, heating the olivine to $991^{\circ} \mathrm{C}$ before it is separated from the residual char fines using a two-cyclone system and being recycled back to the gasifier.

The syngas and tars are sent to the catalytic tar reformer, also a fluidized bed reactor. The tar reformer converts tars and unconverted hydrocarbons to $\mathrm{CO}$ and $\mathrm{H}_{2}$ and $\mathrm{NH}_{3}$ to $\mathrm{N}_{2}$ and $\mathrm{H}_{2}$. The reactor operates at $883^{\circ} \mathrm{C}$. The hot syngas leaving the tar reformer is then cooled with a steam cycle and cooling water via scrubbing, consisting of a venturi scrubber and a quench chamber. The scrubber removes any residual particulate matter, tars, and ammonia. After scrubbing, the 
syngas goes through a water-gas shift steam reformer allowing the $\mathrm{H}_{2}$ : $\mathrm{CO}$ ratio within the syngas to be altered to a ratio of $4: 1$.

From here, the syngas is cooled further to $60^{\circ} \mathrm{C}$ before being compressed in a five-stage centrifugal compressor to 765 psia. The compressed syngas enters another low-temperature shift process that alters the syngas $\mathrm{H}_{2}$ : $\mathrm{CO}$ ratio to $6.38: 1$ using a copper-based catalyst containing reactive zinc oxide. This is different than syngas cleanup phases in other conversion processes reported in this study. The syngas leaving the low-temperature shift process has a $\mathrm{CO}_{2}$ composition of $23.3 \mathrm{wt} \%$, which is too high for the methanol synthesis reactor. Therefore, it is removed using an acid-gas removal system utilizes monoethanolamine as a physical extraction sorbent. The $\mathrm{CO}_{2}$ removed is vented to the atmosphere. More detail on the acid-gas removal process can be found elsewhere in the source material.

The cleaned and conditioned syngas is then sent to the fixed-bed methanol synthesis reactor that operates at 735 psia, much lower than mixed-alcohol synthesis reactors described in other pathways in this study. The reactor contains a copper/zinc oxide catalyst on an alumina support. Within the reactor, syngas is converted to methanol exothermically and quickly reaches equilibrium. The heat generated within the reactor is removed by steam generation, allowing the reactor to stay isothermal at $300^{\circ} \mathrm{C}$. The syngas-methanol mixture is then cooled to $32^{\circ} \mathrm{C}$, which separates the methanol from unreacted syngas by phase change. The condensed methanol, still at high pressure, has dissolved gases within it. To remove these, the pressure is lowered, releasing the gases. These gases are mixed with the separated syngas and then recycled to the methanol synthesis reactor. It should be noted that $4 \%$ of the recycled syngas is purged to the fuel gas stream to prevent the buildup of inert gases. The methanol is then sent to a storage tank, which serves as a surge buffer between the methanol synthesis reactor and the methanol-to-gasoline section.

From the storage tank, the methanol is pressurized to 200 psia on its way to the methanol-togasoline reactor. The reactor is a fluidized bed reactor that uses a ZSM-5 zeolite catalyst. Due to catalyst deactivation, it must be continuously circulated and regenerated by burning off any coke formed. This is done in a combustor-type reactor. Within the reactor, methanol is converted to various hydrocarbons varying from light gases to higher-carbon-number, gasoline-range molecules; $79 \mathrm{wt} \%$ of the product from the reactor is within the gasoline range, with the remaining being lighter products. The reactor operates a $400^{\circ} \mathrm{C}$ and approximately 200 psia.

The reactor effluent is then separated into a gasoline blendstock, liquid petroleum gas, and fuel gas. The gasoline blendstock is the main product, and liquid petroleum gas is sold as a coproduct along with excess electricity generated on site by the fuel gas. The gasoline blendstock is within the bounds of gasoline requirements, having $28 \mathrm{wt} \%, 6.6 \mathrm{wt} \%, 11.2 \mathrm{wt} \%$, and $52.2 \mathrm{wt} \% \mathrm{of}$ aromatics, cycloparaffins, olefins, and paraffins, respectively. The liquid petroleum gas has a composition of $28.6 \mathrm{~mol} \%, 4.2 \mathrm{~mol} \mathrm{\% ,} 42.8 \mathrm{~mol} \%$, and $24.4 \mathrm{~mol} \mathrm{\%}$ of propane, propene, isobutane, and n-butane, respectively. This type of fuel has market value and can be sold as-is.

Other plant areas not described here include steam system, power generation, cooling water, and utilities. These are described in detail elsewhere in the source material. 


\section{Process Economics}

This process follows the standard BETO assumptions listed at the beginning of this section.

The capital costs for this process were calculated using a variety of sources, including Aspen IPE software, previous studies, and engineering consultants. Appropriate installation factors from the literature were used to determine the total installed cost for the equipment. The most expensive equipment area within this process was the catalytic tar reformer and quench system at $\$ 28.3$ million.

Variable costs for this production pathway included feedstock, catalyst costs, and make-up olivine costs, as well as utilities and taxes. Using a discounted cash flow analysis for the life of the plant, accounting for depreciation and other fixed costs, it was found that the MFSP for this pathway is $\$ 1.43 / \mathrm{GGE}$. As with other lignocellulosic biomass conversion technologies, the feedstock contributed the most to the fuel price, contributing $41.7 \%$. It should be noted that this conversion pathway has a significantly lower MFSP than other pathways because of the lower operating pressure for the methanol synthesis and overall lower capital costs.

A sensitivity analysis was performed for this production pathway, and it was found that feedstock cost, expected IRR, total project investment, and plant size all had significant potential to affect the MFSP. This is similar to other lignocellulosic biomass conversion technologies.

Table B35 summarizes the economic information about this conversion pathway.

Table B35. Summary Results Table for Woody Biomass to Hydrocarbon Fuels via Gasification and Methanol-to-Gasoline Technologies

\begin{tabular}{|c|c|c|}
\hline Technology Pathway & \multicolumn{2}{|c|}{$\begin{array}{l}\text { Woody Biomass to Hydrocarbon } \\
\text { Fuels via Gasification and Methanol- } \\
\text { to-Gasoline Technologies }\end{array}$} \\
\hline Feedstock Type & \multicolumn{2}{|c|}{ Hybrid Poplar Wood Chips } \\
\hline Hydrocarbon Product Slate, wt \% & \multirow[t]{2}{*}{$100 \%$} & Gasoline \\
\hline Coproducts & & $\begin{array}{l}\text { Electricity and Liquified } \\
\text { Petroleum Gas }\end{array}$ \\
\hline Carbon Efficiency & \multicolumn{2}{|l|}{$31.0 \%$} \\
\hline Total Capital Investment, million \$ & \multicolumn{2}{|l|}{$\$ 206$} \\
\hline Total Operating Costs, million $\$ / y r$ & \multicolumn{2}{|l|}{$\$ 56.5$} \\
\hline Minimum Selling Price, $\$ / G G E$ & \multicolumn{2}{|l|}{$\$ 1.43$} \\
\hline \multicolumn{3}{|l|}{ Cost Contributions, \$/GGE } \\
\hline Capital Cost & \multicolumn{2}{|l|}{$\$ 0.34$} \\
\hline Feedstock Cost & \multicolumn{2}{|l|}{$\$ 0.87$} \\
\hline Operating Costs & \multicolumn{2}{|l|}{$\$ 0.05$} \\
\hline Operating Credits & \multirow{2}{*}{\multicolumn{2}{|c|}{ with Operating costs }} \\
\hline Taxes & & \\
\hline
\end{tabular}

Pathway 28: Lignocellulosic Biomass to Ethanol via Gasification and MixedAlcohol Synthesis

Feedstock: Forest Residues

Feedstock Processing Technology: Gasification 
Fuel Precursor: Syngas

Fuel Processing Technology: Mixed-Alcohol Synthesis

Biofuel Product: Ethanol 100\%

Data Source: (Dutta et al. 2011)

\section{Process Summary}

The simplified block flow diagram is shown in Figure B25.

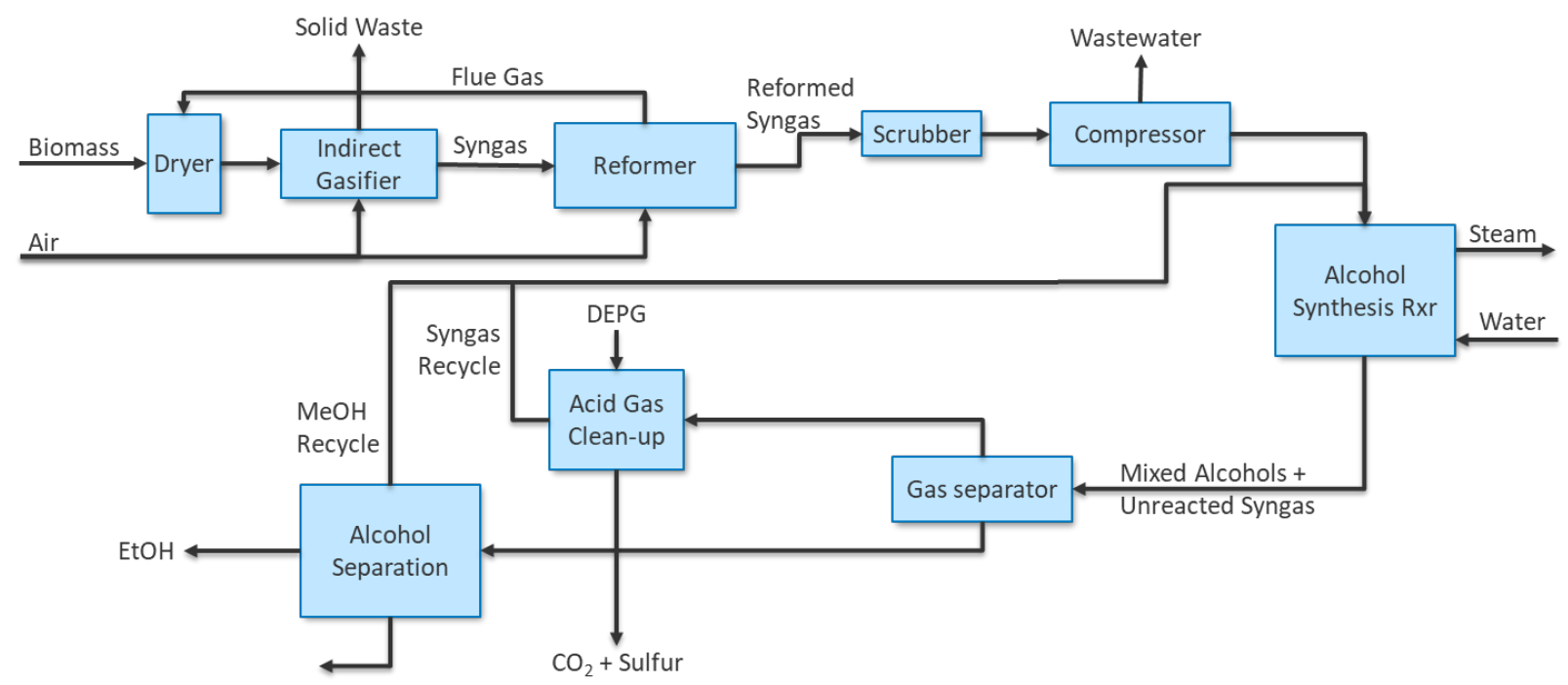

Figure B14. Simplified block flow diagram for lignocellulosic biomass to ethanol via gasification and mixed-alcohol synthesis

\section{Process Design}

This plant was designed to process biomass at 2,000 DMT/day, producing 64.7 million gal/year of ethanol. Biomass is fed from temporary storage on site to a waste heat dryer that utilizes flue gas from downstream processing steps to dry the biomass to $10 \%$ moisture. The dried biomass is then fed to the gasifier. The gasifier is heated through circulating synthetic olivine (27 lb olivine per pound biomass) heated by the combustion of char in a separate combustion reactor. The gasifier is fluidized by injecting steam, which also acts as a reactant at high temperatures. Two gasifiers run in parallel and operate at $1,000 \mathrm{DMT} / \mathrm{day}, 33 \mathrm{psia}$, and $869^{\circ} \mathrm{C}$. In both gasifiers, the steam-to-biomass feed ratio is held at $0.4 \mathrm{lb}$ steam per pound of biomass. The gasification-char combustor system runs similarly to a fluid catalytic cracker often found at oil refineries. The heat produced from combusting the char is enough to continually run the gasifier without requiring supplemental heat. The char combustor operates at $987^{\circ} \mathrm{C}$ with $20 \%$ excess air to ensure complete oxidation of the char. The synthetic olivine and char from the gasifier are recovered from the syngas and tars using a two-cyclone separator. A similar two-cyclone separator is used to recover the olivine and flue gas from the char fines after char combustion. The resulting flue gas from the cyclone separator is used to dry the biomass before entering the gasification unit. 
The syngas that comes out of the gasifier cyclone separator system is then fed to the catalytic tar reformer; the reformer is an entrained-flow, fluidized catalytic reactor. The reactor converts methane, tars, and other hydrocarbons to $\mathrm{CO}$ and $\mathrm{H}_{2}$, while also converting $\mathrm{NH}_{3}$ to $\mathrm{N}_{2}$ and $\mathrm{H}_{2}$. When leaving the reformer, the syngas is in water-gas-shift equilibrium. More information on the catalyst used in the tar reformer can be found in the source material. The hot syngas from the tar reformer is cooled to $60^{\circ} \mathrm{C}$ via heat exchangers and then sent through a scrubbing system that removes particulates, ammonia, halides, and residual tars. The scrubbing system encompasses a venturi scrubber, cyclone separator, and a quench water system. The quench water system is a closed-loop system and therefore does not require makeup water. The syngas leaving the quench system is at $54^{\circ} \mathrm{C}$ and is sent to a compressor system before entering the alcohol synthesis reactor.

The syngas is sent to a six-stage centrifugal compressor with inter-stage cooling, where it is compressed to 3,000 psia. The fresh compressed syngas is mixed with recycled syngas and methanol and preheated to $313^{\circ} \mathrm{C}$ before entering the alcohol synthesis reactor. The reactor contains a patented metal-sulfide catalyst, and therefore details could not be shared about it. Generally, the reactor converts $\mathrm{CO}$ and $\mathrm{H}_{2}$ to varying length alcohols and water. Methyl esters, light hydrocarbons, and aldehydes are produced as well, but in much smaller quantities. The reaction to make the mixed alcohols is exothermic, and therefore the reactor must be cooled by generating steam in a shell around the reactor. The steam is used as process heat elsewhere in the biorefinery. The effluent from the reactor is cooled and flashed to create a liquid stream rich in alcohols to be separated in the alcohol purification area. The remaining unreacted syngas is cleaned to remove $\mathrm{CO}_{2}$ and $\mathrm{H}_{2} \mathrm{~S}$ (acid gases) before being recycled back into the reactor. The acid gas removal system is not explained in detail here, but more information can be found in the source material.

The liquid alcohol stream from the gas-liquid separator enters the separation area and is directly degassed from any remaining gases that may be present by reducing the pressure from 2,937 psia to $60 \mathrm{psia}$, flashing the stream. The remaining vapor stream is recycled to the tar reformer while the liquid stream is sent through one of two molecular sieve columns; the one not in use is regenerating the sieves with recycled methanol. The molecular sieves remove any water left in the alcohol stream. The dried stream is then sent to one of two distillation columns. The first, called the crude alcohol column, is a typical trayed column with an overhead condenser and reboiler. The column removes all the methanol and $99 \%$ of the ethanol entering the column in the distillate, and the heavier alcohols leave the bottom of the column to storage before being sold as a byproduct. The methanol-ethanol stream is sent to the second column, which is also a typical trayed column with an overhead condenser and reboiler. In this second column, the ethanol is collected in the bottoms and contains $99 \%$ of the feed ethanol, and the methanol is removed in the distillate stream for recycling to the alcohol synthesis reactor for elongation or other areas of the biorefinery requiring methanol. The ethanol stream from this column contains less than $0.5 \mathrm{wt} \%$ methanol, ensuring it meets ASTM product specifications for fuel ethanol. This ethanol stream is cooled out of the column and sent to storage before being sold.

There is much more detail about recycling streams, reactor specifications, and steam and power generation on site in the source material. Please refer to the source material if more information is desired. 


\section{Process Economics}

This process follows the standard BETO economic assumptions mentioned in the beginning of this section.

All data for the equipment costs throughout this process were obtained from various sources including technology licensors, industry equipment suppliers, published literature, and the Aspen Icarus Process Evaluator. Capital costs for the different processing areas of the plant are shown in Table B36.

Table B36. Summary of Capital Costs by Area for Lignocellulosic Biomass to Ethanol via Gasification and Mixed-Alcohol Synthesis

\begin{tabular}{|l|r|l|}
\hline Process Area & TPEC (million \$) & TIC (million \$) \\
\hline Feed Handling and Drying & $\begin{array}{r}\text { Included in } \\
\text { Feedstock \$ }\end{array}$ & Included in \\
& Feedstock \$ \\
\hline Gasification & 19.3 & 44.6 \\
\hline Gas Cleanup & 13.0 & 27.7 \\
\hline Alcohol Synthesis & 77.0 & 155.2 \\
\hline Alcohol Separation & 13.6 & 20.9 \\
\hline Steam Plant and Power & 26.6 & 47.2 \\
\hline Cooling Water and Other Utilities & 4.7 & 9.9 \\
\hline Total & 154.2 & 305.5 \\
\hline
\end{tabular}

Conversion from TPEC to TIC was done using installation factors determined through various criteria explained in more detail in the source material.

Variable costs for the plant included gasifier bed material (synthetic olivine), the tar reformer catalyst that was replaced at $0.1 \mathrm{wt} \%$ per day, alcohol synthesis catalyst that is replaced once every 2 years during the plant lifetime, solids disposal, diesel fuel price needed for operations at the plant, water makeup, chemicals, and wastewater. The fixed operating costs for the plant included salaries and benefits for 62 employees; maintenance costs, which were assumed to be $3 \%$ of FCI; and insurance and taxes, which were assumed to be $0.7 \%$ of FCI. The total variable operating costs were $\$ 539.5$ million/year when including feedstock costs and $\$ 7.5$ million/year excluding feedstock costs. The total fixed operating costs were $\$ 24.0$ million/year, for a total operating cost of $\$ 563.3$ million/year when including feedstock costs. Based on this information, it is clear that the MFSP of the fuel will depend greatly on feedstock costs; the lower the feedstock cost, the lower the MFSP will be.

Further sensitivity analyses were done for this process and will be touched on briefly here. Besides feedstock, other areas that significantly affect the MFSP include the plant size, assumed return on investment, and the assumed average installation factor. The plant size has the most significant potential savings in the MFSP due to economies of scale. One of the limitations of increased plant size is increased feedstock transportation costs, which can significantly increase MFSP. The assumed ROI is also a major factor because if the expected ROI increases, then the fuel must compensate for that because the coproducts are set at a fixed price in this analysis. For more information on these sensitivity analyses, please see the source material. 
Table B37 summarizes the performance and economic metrics on this conversion pathway.

Table B37. Summary Results Table for Lignocellulosic Biomass to Ethanol via Gasification and Mixed-Alcohol Synthesis

\begin{tabular}{|c|c|}
\hline Technology Pathway & $\begin{array}{l}\text { Lignocellulosic Biomass to } \\
\text { Ethanol via Gasification and } \\
\text { Mixed-Alcohol Synthesis }\end{array}$ \\
\hline Feedstock Type & Woody Residues \\
\hline Hydrocarbon Product Slate, wt \% & $100 \% \quad$ Ethanol \\
\hline Coproducts & Mixed Alcohols \\
\hline Carbon Efficiency & $28.2 \%$ \\
\hline Total Capital Investment, million $\$$ & $\$ 532$ \\
\hline Total Operating Costs, million $\$ / y r$ & $\$ 64.7$ \\
\hline Minimum Selling Price, \$/GGE & $\$ 3.22$ \\
\hline \multicolumn{2}{|l|}{ Cost Contributions, \$/GGE } \\
\hline Capital Cost & $\$ 1.50$ \\
\hline Feedstock Cost & $\$ 1.16$ \\
\hline Operating Costs & $\$ 0.76$ \\
\hline Operating Credits & $\$ 0.37$ \\
\hline Taxes & $\$ 0.18$ \\
\hline
\end{tabular}

Pathway 29: Combined Algal Processing to Renewable Diesel Blendstock

Feedstock: Microalgae

Feedstock Processing Technology: Fermentation

Fuel Precursor: Lipids

Fuel Processing Technology: Catalytic Hydrotreating

Biofuel Product: $76.3 \%$ Diesel, 23.6\% Gasoline

Data Source: (Davis et al. 2014, 2016, 2020)

\section{Process Summary}

The simplified block flow diagram is shown in Figure B26. 


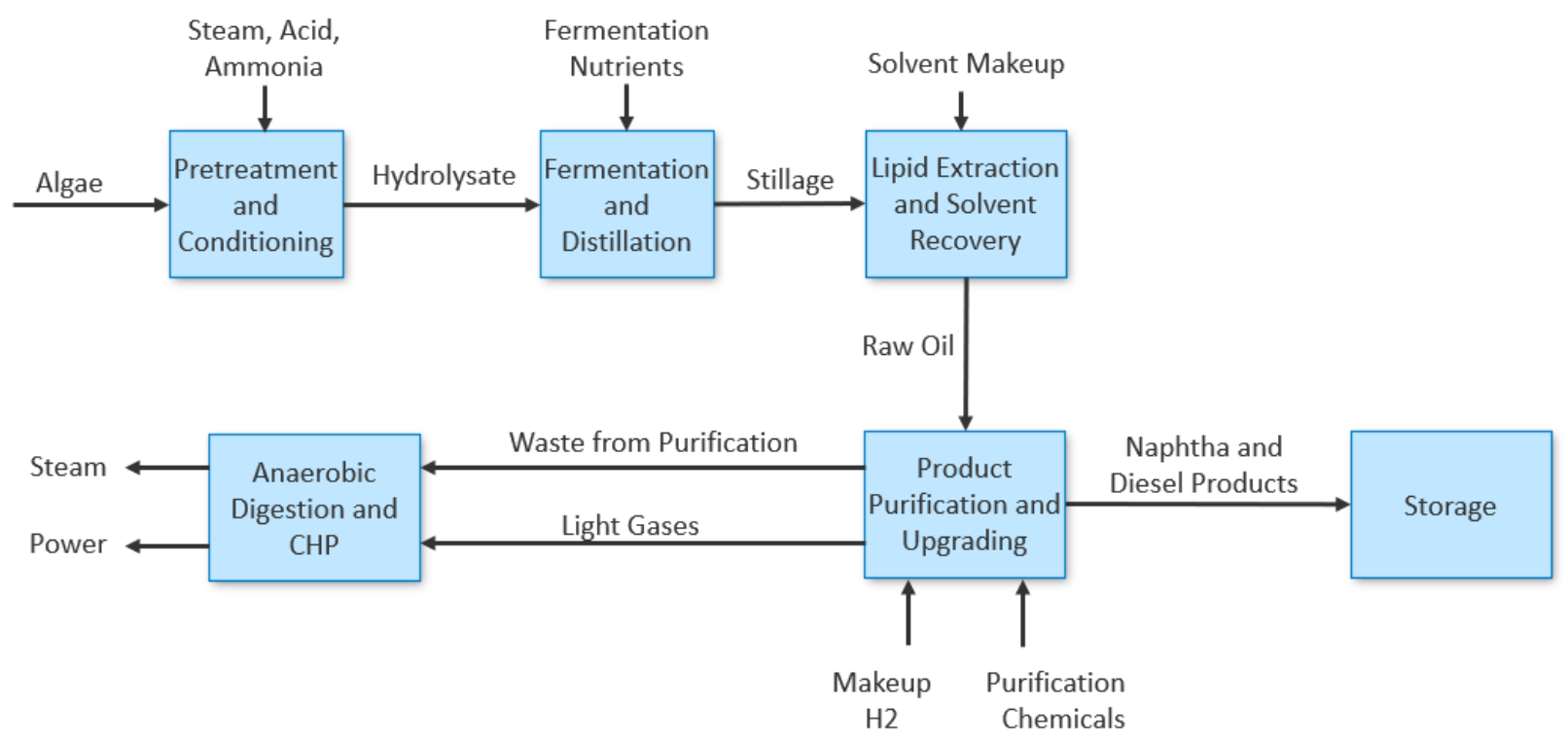

Figure B26. Simplified block flow diagram for combined algal processing to renewable diesel blendstock

The exact process conditions and combined production of naphtha and diesel products and succinic acid coproducts were not published in an NREL technical report or literature. The case producing succinic acid was an internal NREL study based on the case reported in the 2014 NREL report (Davis et al. 2014) The succinic acid case utilizes a different microorganism for fermentation than the 2014 technical report; the microorganism produces succinic acid instead of ethanol. This option was explored because succinic acid has a much higher market value than ethanol, and therefore reduces the MFSP of the hydrocarbon fuels. Additionally, the feedstock flow rate for the succinic acid case used in this study was lower than reported in the 2014 technical report, as information in the NREL 2016 report suggested a smaller production rate of microalgae could improve the MFSP (Davis et al. 2016). A technical report or journal article was not published because there was a pivot to researching co-upgrading of proteins and lipids instead of processing them separately. This research was recently published in a 2020 NREL technical report (Davis et al. 2020). Here we will present the case reported in the 2014 technical report, but note that the metrics for the case used in this study are different due to the production of succinic acid in place of ethanol and a different feedstock flow rate.

\section{Process Design}

The algal biomass delivered to the biorefinery contains $20 \mathrm{wt} \%$ solids upon processing through upstream dewatering. The seasonal variation in the raw feed rate to conversion were addressed in the design. Briefly, $35 \%$ of the total summertime feed rate (2,229-ton/day ash-free dry weight basis) is diverted away to drying in a natural-gas-fired dryer and stored for use in the winter. The remainder is sent on to the pretreatment fractionation step. Subsequently, during the fall, winter, and spring seasons, all delivered material is sent straight to the fractionation step at a flow rate of $1,264,416$, and 1,449 tons/day (ash-free dry weight basis), respectively. The winter season also adds the additional 780 tons/day from the storage (from summer) to constitute a total winter flow to fractionation of 1,196 tons/day. 
The biomass pretreatment is a fractionation step, which enables successful recovery and conversion of both the carbohydrate and lipid components. Pretreatment fractionation takes place at a temperature of $130^{\circ} \mathrm{C}-180^{\circ} \mathrm{C}$ and corresponding bubble-point pressures, with a residence time ranging from 1 to 10 minutes. The resulting hydrolysate slurry is subsequently flash-cooled, vaporizing a fraction of water, which is condensed and routed to the water recycle pool. This is followed by the ammonium hydroxide conditioning step at $\mathrm{pH} 5$.

The batch fermentation step converts sugars (primarily glucose and mannose) to ethanol using Saccharomyces cerevisiae D5A (yeast). At the end of the batch fermentation (i.e., 1.5 days), the fermentation broth is sent to ethanol purification consisting of beer and rectification distillation columns and vapor-phase molecular sieve adsorption, which ultimately concentrates the ethanol product up to $99.5 \%$.

For the lipid process, the lipid extraction and recovery area targets the extraction of the algal lipid fraction for subsequent cleanup and upgrading to renewable diesel blendstock, the main product to overall GGE fuel yield. The beer column's stillage product is routed to a liquid-liquid extraction system. Hexane is the solvent for the extortion, in which it extracts the lipids at high solvent loading in a multistage countercurrent extraction column. The extracted light oil phase contains a solvent, lipids (both fatty acid lipids and polar lipid impurities), and a small amount of water. The solvent is recovered using a stripping column. The lipid stream has high $(\sim 99.7 \%)$ total lipids. The aqueous product is sent to anaerobic digestion, generating biogas as the fuel for heat and power generation.

The recovered purified neutral lipid material after lignin purification undergoes upgrading in a hydrotreater for deoxygenation and saturation, primarily yielding a diesel-range product with a small yield of gasoline product and off-gas, which is combusted in the biogas turbine.

\section{Process Economics}

Because this pathway with succinic acid coproduct was not published, no sensitivity analyses were performed or further economic evaluation beyond calculating an MFSP and segmenting it by area. These results are shown in Table B38, along with other pathway metrics.

Table B38. Summary Results Table for Combined Algal Processing

\begin{tabular}{lcl}
\hline Technology Pathway & Combined Algal Processing \\
Feedstock Type & Algae (20 wt \% solids) \\
Hydrocarbon Product Slate, wt \% & $76.3 \%$ & $\begin{array}{l}\text { Diesel } \\
\text { Naphtha } \\
\text { Succinic Acid }\end{array}$ \\
Coproducts & $23.6 \%$ & \\
Carbon Efficiency & $36 \%$ & \\
& & \\
Total Capital Investment, million $\$$ & $\$ 333.9$ \\
Total Operating Costs, million \$/yr & $\$ 144.5$ \\
Minimum Selling Price, \$/GGE & $\$ 3.11$ \\
Cost Contributions, \$/GGE & \\
Capital Cost & $\$ 2.87$ \\
Feedstock Cost & $\$ 6.65$ \\
Operating Costs & $\$ 3.82$ \\
Operating Credits & $\$ 10.68$ \\
Taxes & $\$ 0.44$ \\
\hline
\end{tabular}


Pathway 30: Diesel from Wastewater Sludge Converted to Bio-Oil and Catalytically Upgraded

Feedstock: Wastewater Sludge

Feedstock Processing Technology: Hydrothermal Liquefaction

Fuel Precursor: Biocrude

Fuel Processing Technology: Catalytic Hydrotreating

Biofuel Product: $23.5 \%$ Gasoline, $76.5 \%$ Diesel

Data Source: (Seiple, Coleman, and Skaggs 2017)

\section{Process Summary}

The simplified block flow diagram is shown in Figure B27.

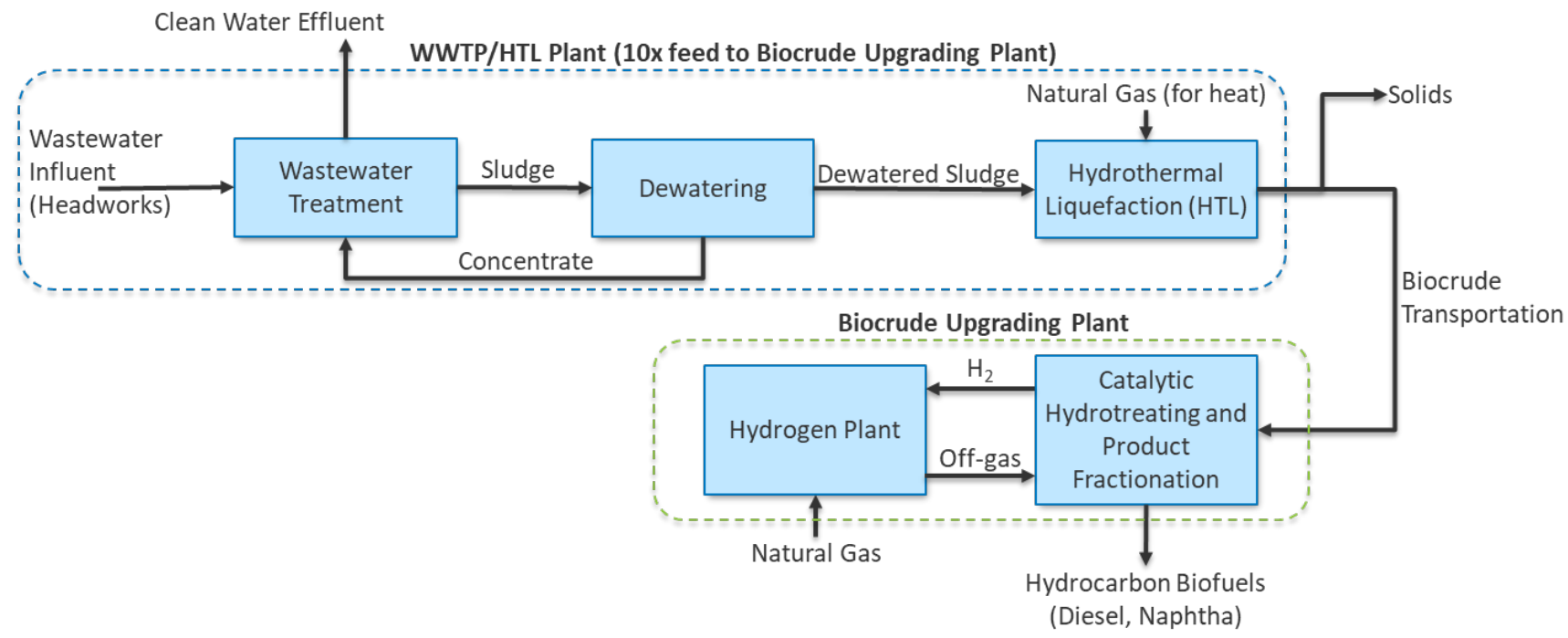

Figure B27. Simplified block flow diagram for diesel from wastewater sludge converted to bio-oil and catalytically upgraded

\section{Process Design}

Multiple HTL facilities are assumed to be co-located with wastewater treatment plants to avoid sludge transportation costs. The rationale is that collection of sludge within a reasonable radius and within densely populated areas could be more economic feasible, especially for a larger HTL facility. The HTL process produces various products, namely an oil phase (biocrude), a solids stream containing mostly ash and some char, and an aqueous stream containing $1 \%-3 \%$ carbon. Details can be found in the literature (Seiple, Coleman, and Skaggs 2017).

The study's scale is 110 dry tons/day of sludge (including ash), which is the approximate minimum size that is economically feasible (due to economies of scale) for the HTL facilities, corresponding to a wastewater treatment plant that processes about 110 million gallons per day 
of incoming wastewater and serves approximately 1.3 million people (U.S. EPA 2015). The biocrude upgrading plant is assumed to receive biocrude from 10 HTL plants within a 100-mile radius and produces 2,700 barrels per stream day of fuel blendstocks. Further analysis is needed to determine the optimum radius for individual regions in the country.

A wastewater treatment plant generates sludges from its primary and secondary treatment steps, at $3 \%$ and $0.8 \%$ solids content, respectively. The feed is a $25 \%$ solids ground slurry that is pumped to 2,900-3,000 psia. Subsequently, using heat from the reactor liquid product (biocrude/aqueous mixture), the feed is preheated to $550^{\circ} \mathrm{F}\left(288^{\circ} \mathrm{C}\right)$ in two double-pipe heat exchangers in series. The HTL reactor temperature of $656^{\circ} \mathrm{F}\left(347^{\circ} \mathrm{C}\right)$ was achieved with a fired heater with a hot oil system. The HTL products include an organic biocrude phase, an aqueous phase, solids, and a small amount of gases. The general HTL reaction pathways are: (1) depolymerization of the biomass components; (2) decomposition of biomass monomers by cleavage, dehydration, decarboxylation, and deamination; and (3) recombination of reactive fragments (Toor et al. 2012). The biocrude from sludge is comparable to biocrude from algae HTL, comprising a mixture of fatty acids, amides, ketones, hydrocarbons, phenols, alcohols, and other components. The HTL reactor effluent is fed to a hot filter for the removal of solids, consisting of $60 \%-70 \%$ water, ash, char, and low levels of organics from the aqueous phase and biocrude phase. Detailed description of biocrude upgrading and product recovery can be found in the report (Seiple, Coleman, and Skaggs 2017). The final hydrocarbon product contains $76.5 \%$ diesel and $23.5 \%$ gasoline.

\section{Process Economics}

This process follows the standard BETO assumptions listed at the beginning of this appendix. The economic analysis was performed by determining TCI for the HTL plants and the biocrude upgrading plant, as well as the variable and fixed operating costs.

The TCI for one HTL plant is assumed to be $\$ 34.0$ million, whereas the biocrude upgrading plant has a TCI of $\$ 141.4$ million. This results in a total TCI for the 10 HTL plants and one upgrading facility of $\$ 481.8$ million. The variable operating costs for the HTL plant included polymers for sludge dewatering, natural gas for heating, electricity for pumps, and quicklime for aqueousphase ammonia stripping. The most significant variable cost was quicklime. The fixed operating costs consisted of employees to run the plant, overhead, maintenance, insurance, and taxes. The fixed operating costs were more than the variable operating costs. The variable operating costs for the upgrading facility included the hydrotreating and hydrocracking catalysts, hydrogen production, cooling tower chemical makeup, boiler chemical makeup, water makeup, and wastewater fees. The upgrading facility has the same categories for fixed operating costs. Between the 10 HTL plants and the upgrading plant, the total operating costs are $\$ 55.3$ million. It should be noted that the cost for the wastewater feedstock is assumed to be zero because the wastewater needs to be treated regardless. Between the 10 HTL plants and biocrude upgrading plant capital costs and operating costs, an MFSP of $\$ 3.25 / \mathrm{GGE}$ was calculated. The cost contributions and other pathway metrics are shown in Table B39.

A sensitivity analysis on the plant scale, biocrude yield, and avoided disposal cost of the wastewater sludge was performed for the overall HTL and upgrading plant. The HTL plant scale was varied from 25 dry tons per day up to 950 dry tons per day (the largest assumed in the 
United States), and a smaller scale increased the MFSP by almost $\$ 2.00 / \mathrm{GGE}$, whereas the increased scale has the potential to decrease the MFSP about $\$ 1.00 / \mathrm{GGE}$ due to economies of scale. The biocrude yield was assumed at $48 \%$ for the base case and in all the material presented thus far. The yield was varied up to $60 \%$ and down to $30 \%$, which resulted in a decreased MFSP of $\sim \$ 0.50 / \mathrm{GGE}$ and an increased MFSP of $\sim \$ 1.30 / \mathrm{GGE}$, respectively. The avoided disposal cost of the wastewater sludge was assumed to be zero for the base case and was varied from a \$200per-dry-ton credit to a cost of $\$ 25$ per dry ton. The credit for disposal resulted in a decreased MFSP of $\sim \$ 1.80 / \mathrm{GGE}$, whereas the cost for disposal increased the MFSP by approximately $\$ 0.30 /$ GGE. From this information, future research should focus on increased biocrude yield and increased HTL scale, whereas policy should focus on providing credit for avoided disposal cost of wastewater sludge.

\section{Table B39. Summary Results Table for Diesel from Wastewater Sludge Converted to Bio-Oil and} Catalytically Upgraded

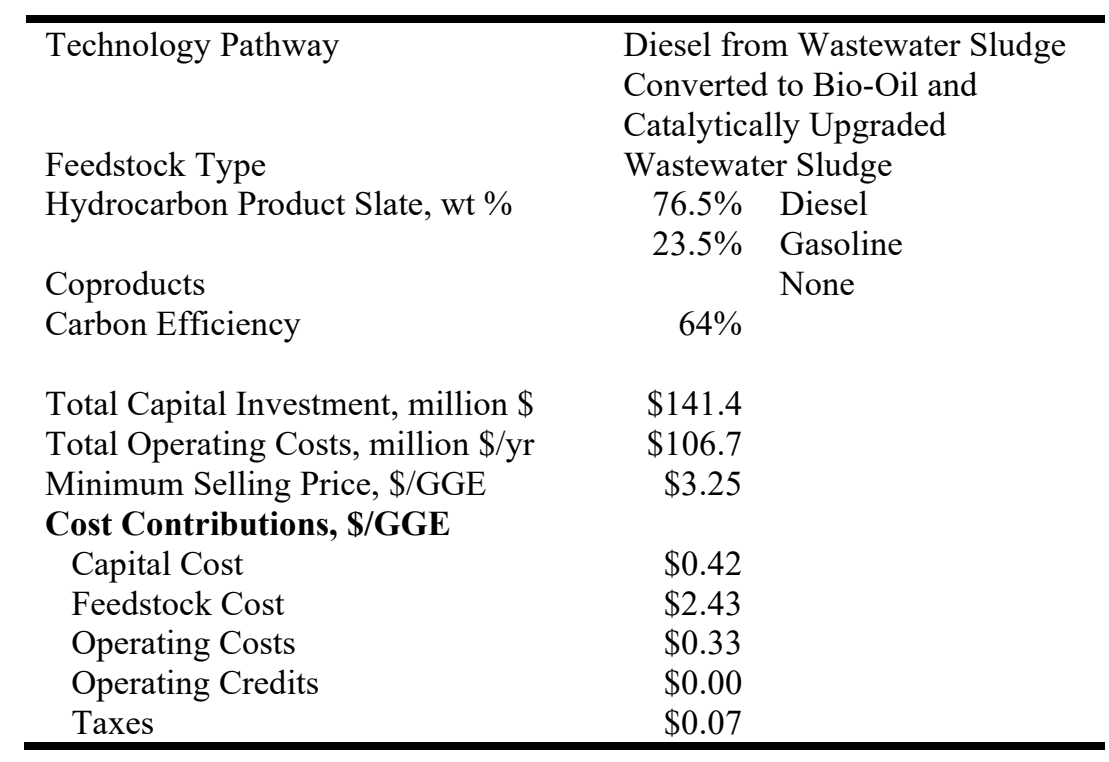

Pathway 31: Municipal Solid Waste Upgraded to Biogas via Anaerobic Digestion for Use in Natural Gas Vehicles

Feedstock: Organic Fraction of Municipal Solid Waste

Feedstock Processing Technology: Anaerobic Digestion

Fuel Precursor: Biogas

Fuel Processing Technology: $\mathrm{CO}_{2}$ Absorption by Amine

Biofuel Product: Compressed Biogas (99\% Methane)

Data Source: (Rajendran et al. 2014)

\section{Process Summary}

The simplified block flow diagram is shown in Figure B28. 


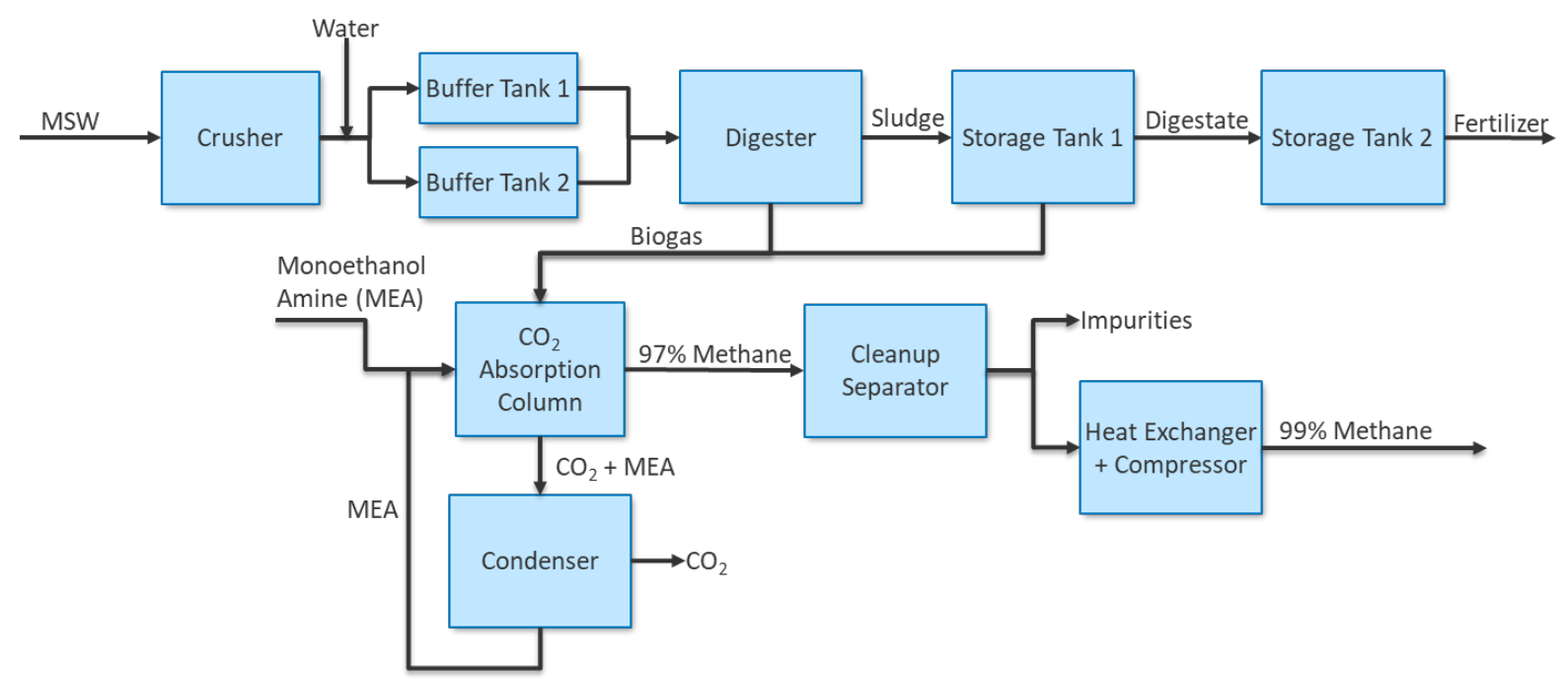

Figure B28. Simplified block flow diagram for municipal solid waste upgraded to biogas via anaerobic digestion for use in natural gas vehicles

\section{Process Design}

The processing steps for anaerobic digestion of the organics of municipal solid waste (MSW) include crushing the material using a hammer mill to reduce the particle size to less than $5 \mathrm{~mm}$. Once crushed, water is added to the MSW to reduce the total solids loading from $33 \%$ to $15 \%$. The MSW-water slurry is then pumped into one of two storage tanks, where the solution sits for 72 hours. The slurry is then pumped into the anaerobic digester, where the slurry is held at $55^{\circ} \mathrm{C}$ by internal heating and the organic loading rate is maintained at $3.3 \mathrm{~kg} / \mathrm{m}^{3} /$ day with a hydraulic retention time of 19 days. During this time, the biogas produced is collected and sent for biogas cleanup.

After digestion, the digestate is pumped into a storage tank (Storage Tank 1), where it is retained for 53 hours. The biogas released in Storage Tank 1 is collected and fed to the biogas cleanup with the biogas produced during anaerobic digestion. The combined biogas is compressed and cooled to 8 bar and $5^{\circ} \mathrm{C}$ before being fed through a carbon dioxide absorption by amine column (COOAB), which utilizes monoethanolamine as the absorption amine. This biogas cleanup method removes both $\mathrm{CO}_{2}$ and $\mathrm{H}_{2} \mathrm{~S}$ and is operated at 5 bar. The monoethanolamine is recycled after releasing the $\mathrm{CO}_{2}$ and $\mathrm{H}_{2} \mathrm{~S}$ at a ratio of 0.95 . The COOAB system enriches the biogas to a methane concentration of $\sim 97 \%$, where it is then sent through another separator to remove any remaining impurities. The enriched methane is then cooled and compressed to $5^{\circ} \mathrm{C}$ and 300 bar for use as a transportation fuel. It should be noted that this compressed methane is only usable in engines designed specifically for natural gas use.

\section{Process Economics}

This process was based on a throughput of 55,000 $\mathrm{m}^{3} /$ year (196 DMT/day) of MSW with an annual operating time of 8,000 hours $(91 \%$ time on stream) and a plant lifetime of 20 years. The economic calculations were done with the following assumptions: a straight-line depreciation method, working capital being 5\% of total capital investment ( $\$ 1.61$ million), a 10\% interest rate on financed capital, a $33 \%$ tax rate, and a salvage value of $5 \%$ of the total capital investment at the end of the plant life ( $\$ 1.61$ million). Specific resource prices are shown in Table B40. It 
should be noted that the taxes for this pathway are considerably higher than other pathways in this study, but there was no rationale given. Additionally, digestate is produced as a coproduct, but the credit from this was not reported.

Table B40. Summary of Resource Prices Assumed for Municipal Solid Waste Upgraded to Biogas via Anaerobic Digestion for Use in Natural Gas Vehicles

\begin{tabular}{|c|c|c|}
\hline Resource & Cost & Unit \\
\hline Electricity & 0.0718 & $\$ / \mathrm{kWh}$ \\
\hline Water & 0.0009 & $\$ / \mathrm{kg}$ \\
\hline Steam & 0.0093 & $\$ / \mathrm{kg}$ \\
\hline Wastewater & 0.0001 & $\$ / \mathrm{m}^{3}$ \\
\hline Monoethanolamine & 1.3899 & $\$ / \mathrm{kg}$ \\
\hline MSW & 0 & $\$ / \mathrm{kg}$ \\
\hline
\end{tabular}

A few sensitivity analyses were performed for this conversion technology. The first sensitivity analysis was performed on the feedstock cost of the MSW. There are two reason for varying the price of the MSW. First, citizens may pay a tipping fee to get rid of their waste, creating a negative price for the MSW. Second, if there is not a tipping fee, then there is the cost of collection and transportation, which may increase the MSW to have a positive price. Because of this, the price of MSW was varied at $-\$ 200,-\$ 100, \$ 0, \$ 100$, and $\$ 200$ per ton, with $\$ 0 /$ ton being the base case reported above. Instead of the change in MFSP being varied as the dependent variable, the net present value was reported as the dependent variable for this sensitivity analysis. For this conversion pathway, when the tipping fee was imposed at $\$ 200 /$ ton (a credit to operations of $-\$ 200 /$ ton), the net present value increased to $\sim \$ 50$ million and decreased linearly to $\$ 0$ at an operation cost of $\$ 200 /$ ton, inferring that collection and transportation costs of the MSW can severely impact the profitability of the plant.

Table B41 summarizes of the pathway's metrics.

Table B41. Summary Results Table for Municipal Solid Waste Upgraded to Biogas via Anaerobic Digestion for Use in Natural Gas Vehicles

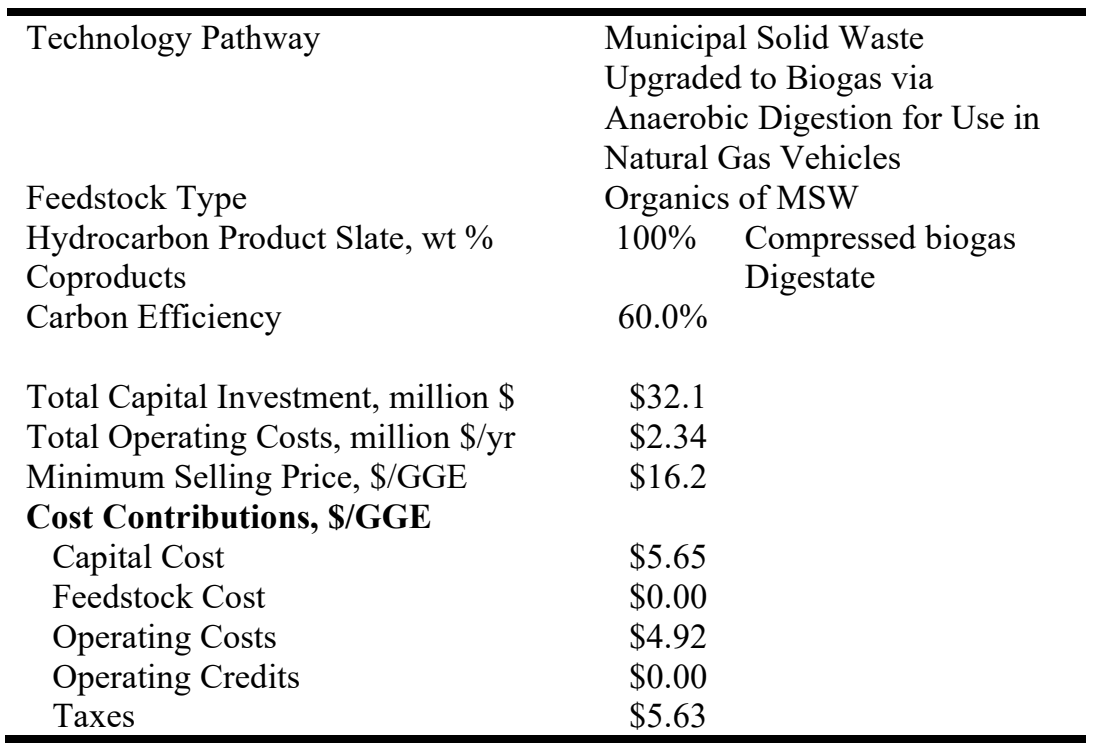




\section{Pathway 32: Ethanol Production from Fermentation of Macroalgae}

Feedstock: Seaweed

Feedstock Processing Technology: Dilute-Acid Pretreatment

Fuel Precursor: Sugars

Fuel Processing Technology: Fermentation

Biofuel Product: $100 \%$ Ethanol

Data Source: (Konda et al. 2015)

\section{Process Summary}

The simplified block flow diagram is shown in Figure B29.

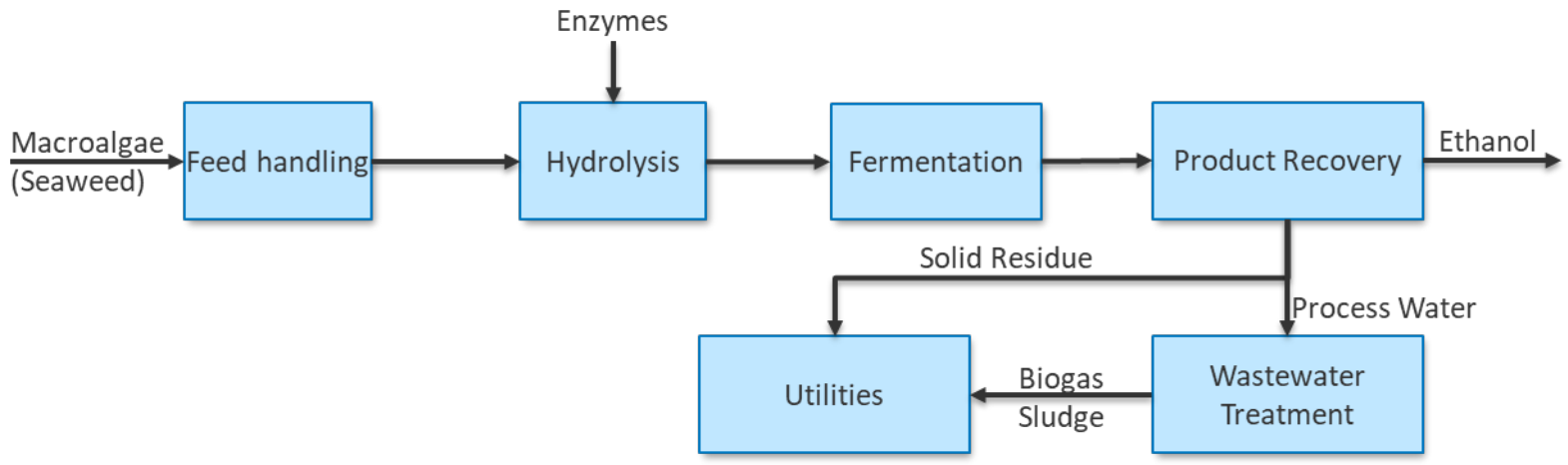

Figure B29. Simplified block flow diagram for ethanol production from fermentation of macroalgae

\section{Process Design}

This process is designed to accommodate 2,000 DMT/day and utilizes Laminaria saccharina brown seaweeds as the feedstock.

In this study, the seaweed is ambiently dried from $85 \mathrm{wt} \%$ moisture to $25 \mathrm{wt} \%$ moisture before it is delivered to the conversion facility. The study largely followed the process steps and operations of Pathway 10, with the omission of the pretreatment stage because there is no lignin in seaweed.

The biomass enters the facility and is milled to less than $1 / 4$ inch in diameter before being conveyed to the hydrolysis reactor. On its way to the continuous high-solids hydrolysis reactor, the biomass is mixed with $20 \mathrm{mg}$ of cellulase enzymes per gram of biomass and diluted to 5\% solids loading. Once in the reactor, cellulase enzyme works to breakdown the cellulose fibers into fermentable sugars, mainly glucose. The hydrolysis reactor operates at $48^{\circ} \mathrm{C}$ and has an 84 hour residence time. Within the hydrolysis reactor, it is assumed that $67 \%$ of the polysaccharides in the biomass are converted to monomeric, fermentable sugars. 
Upon leaving the hydrolysis reactor, the slurry is cooled to $32^{\circ} \mathrm{C}$ and then pumped to the fermenters. There are two trains of fermenters to allow for continuous processing. The fermenters are 950,000-gallon vessels and in them, Zymomonas mobilis, produced elsewhere, converts the sugars to ethanol and carbon dioxide. It is assumed that within the reactor, $67 \%$ of fermentable sugars are converted to ethanol, bringing the broth to $\sim 5 \mathrm{wt} \%$ ethanol. Between the hydrolysis and fermentation, the process has a $50 \%$ yield of polysaccharides to ethanol. Studies have shown that brown algae can be converted at yields up to $80 \%$ but also as low as $28 \%$, depending on enzyme loading, fermentation microorganisms, and operating conditions.

After leaving the fermenter, the fermentation broth containing only liquids, henceforth known as beer, is sent to a beer column where $\sim 90 \%$ of the water is separated and recycled. The enriched ethanol stream then enters a second rectification column that enriches ethanol to near its azeotropic limit; again, the removed water is recycled. The beer and rectification columns have 32 and 45 stages and $48 \%$ and $76 \%$ efficiency, respectively. The distillate from the rectification column is a near-azeotropic ethanol-water mixture in the vapor phase and is fed to a molecular sieve adsorption column that enriches the ethanol to $99.5 \mathrm{wt} \%$ suitable for fuel use.

The solids left in the fermenter are sent to the on-site wastewater treatment center, where they are anaerobically digested. The biogas and digestate produced from this process are then burned on site for electricity and heat use throughout the facility.

Other areas not fully described here include the performance metrics of the wastewater treatment area, the cellulase enzyme production, and the Zymomonas mobilis production. Information on these areas can be found in the source material for Pathway 10.

\section{Process Economics}

This process follows standard BETO assumptions listed at the beginning of this appendix.

Utilizing the capital and operating costs from a combination of Pathway 10 and other literature sources, the MFSP was found to be $\$ 12.03 /$ GGE. This is significantly higher than other biomass conversion routes for a few reasons. The feedstock cost contributes significantly to the MFSP, consisting of $24 \%$ of the annual operating expenses. The high feedstock cost of $\$ 92.66 / \mathrm{DMT}$ is due to high production expenses and a limited market for macroalgae production. Other major cost contributors to the high MFSP include the hydrolysis enzymes, natural gas, and capital costs. As an exercise, solids loading, yield, and enzyme loading were varied, and their effects on MFSP were studied. It was found that the solids loading affected the capital costs because with low solids loading, equipment must be larger, increasing costs. Additionally, these larger pieces of equipment require more utilities to move, mix, heat, and cool process streams. A higher yield was found to affect all cost contributions because at low yields, higher production costs are incurred for lower revenues. Overall, increased yields, higher solids loading, and decreased enzyme cost would improve the MFSP.

A sensitivity analysis was performed for this conversion pathway, and it was found that the main cost drivers that could make the greatest influence with little change were feedstock costs, yield, and solids loading. There was little more expansion on the sensitivity analysis.

Table B42 summarizes the performance and economic metrics for this pathway. 
Table B42. Summary Results Table for Ethanol Production from Fermentation of Macroalgae

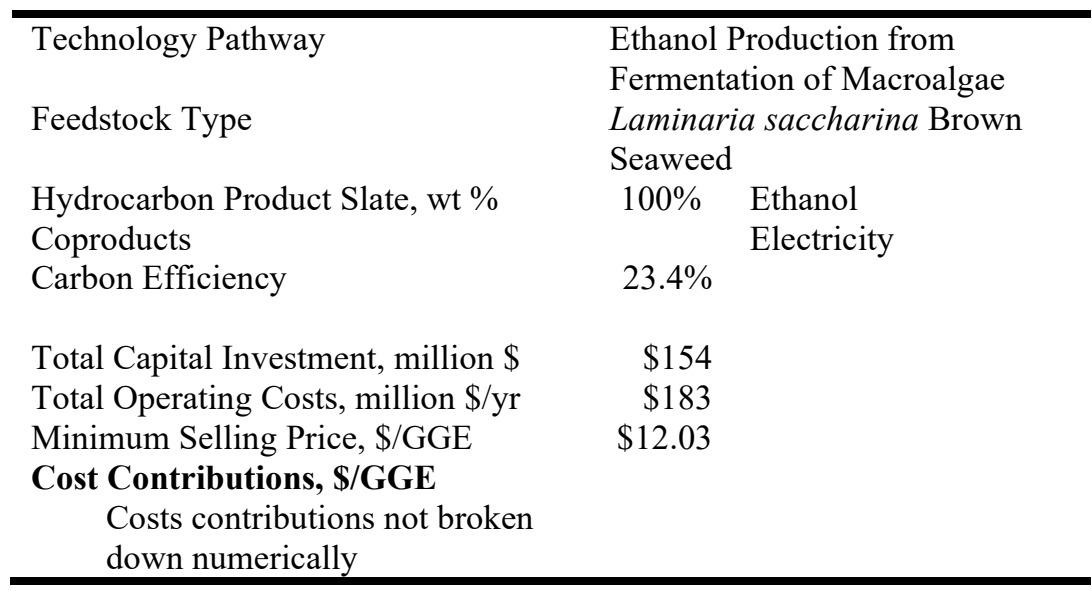

Pathway 33: Ethanol and Electricity Production from Fermentation of Macroalgae Feedstock: Seaweed

Feedstock Processing Technology: Dilute-Acid Pretreatment

Fuel Precursor: N/A

Fuel Processing Technology: Fermentation

Biofuel Product: $100 \%$ Ethanol

Data Source: (Soleymani and Rosentrater 2017)

\section{Process Summary}

The simplified block flow diagram is shown in Figure B30.

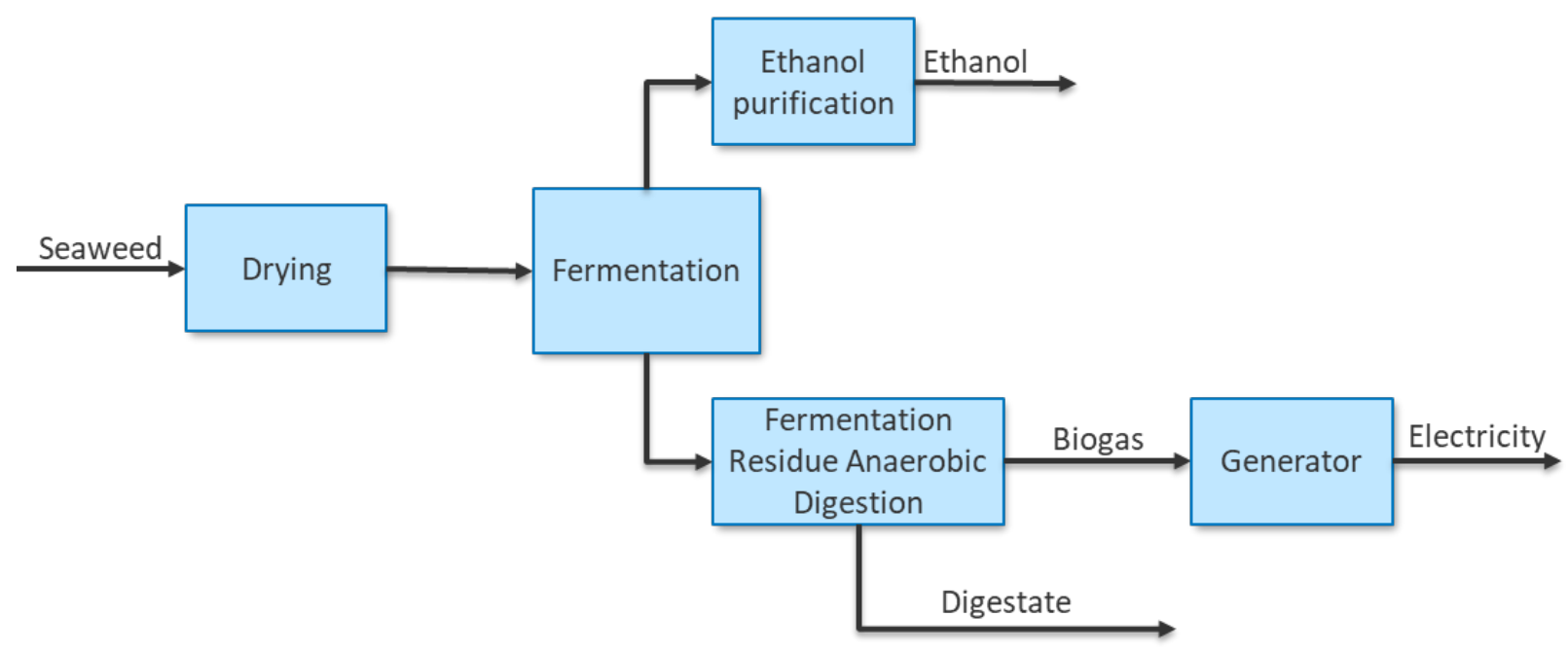

Figure B30. Simplified block flow diagram for ethanol and electricity production from fermentation of macroalgae 


\section{Process Design}

This process is designed to accommodate 2,600 DMT/day and utilizes a variety of brown seaweeds as the feedstock, producing 90.25 million liters of ethanol per year (15.6 million GGE/yr).

The biomass in this study is assumed to be cultivated specifically for the conversion plant. After cultivation, the feedstock cost is assigned based on the costs of production. This study made these assumptions because different cultivation methods were compared. The cultivation method that was found to be the lowest cost was a longline cultivation method. The longline cultivation method involves first collecting and settling zoospores on seed strings, producing seedlings, transplanting and outgrowing the seedlings, and finally harvesting the seedlings.

Once the biomass is cultivated and harvested, its moisture content is approximately $85 \mathrm{wt} \%$. The high-moisture biomass is sent directly to the drying facility, where it is dried using a three-layer dryer. The dryer lowers the moisture content to $22 \mathrm{wt} \%$, and the biomass then goes into storage. This process is not continuous because of growing seasons that are particularly short in cold regions. When the biomass is ready to be used at the conversion facility, assumed to be 25 miles away, it is trucked there to be mixed with water and fed to a saccharification tank, where it sits for 6 hours. In the saccharification tank, glucoamylase and sulfuric acid are added to break down the biomass into fermentable sugars.

From the saccharification tanks, it is fed to a continuous four-cascade fermentation system, where it is retained at a temperature below $34^{\circ} \mathrm{C}$ and has a residence time of 46 hours. The fermentation microorganisms used were Saccharomyces cerevisiae, Zymomonas mobilis, glucanases, mannitol dehydrogenize, laminarinase, and cellulase, as they are all commonly used in industrial fermenters. As there have been no more than bench-scale studies for the conversion of brown seaweed to ethanol via fermentation, performance metrics of corn ethanol conversion were assumed. It was assumed that 25 gallons of ethanol were produced per dry ton of biomass. It should be noted that this is higher than proven for seaweed and therefore artificially lowers the cost of the ethanol.

After fermentation, the ethanol in water is approximately $9 \mathrm{wt} \%$. The ethanol-water mixture is pumped to an ethanol purification system that consists of a beer distillation column, enriching the ethanol to $91 \mathrm{wt} \%$ and recycling the water to be mixed with new incoming biomass. The 91 wt \% ethanol stream is then superheated and passed through a molecular sieve bed that enriches the ethanol to $99 \mathrm{wt} \%$, suitable for fuel use.

The fermentation broth solids are transferred to an anaerobic digester that converts the solid sludge to biogas and digestate. The biogas is burned on site for electricity that is either used on site or sold. The digestate is also sold as animal feed.

\section{Process Economics}

This process does not follow the standard BETO assumptions listed at the beginning of this appendix, but limited information was given on such factors as financing, labor rates, and taxes. It was noted that all capital costs were sourced from literature, and the plant life is 10 years. The 
MFSP was calculated by summing all costs, subtracting all revenues from coproducts, and dividing by the quantity of ethanol produced.

With these performance metrics and the capital costs from literature, an MFSP was calculated to be $\$ 8.56 /$ GGE. A cost breakdown by area was given, and the areas that contributed most to the cost of the fuel were the feedstock and operating expenses. The high feedstock cost was attributed to the unproven nature of cultivating and harvesting such large quantities of seaweed in a longline cultivation method, the costs of fuel for transportation of the moist biomass from the cultivation site to the drying facility, and costs of fuel for transportation of the dried biomass from the drying facility to the conversion facility. The high operating expenses were attributed to high labor costs in the United States compared to other regions around the world.

There were no sensitivity analyses performed for this study. Table B43 summarizes the economic and performance metrics associated with this pathway.

\section{Table B43. Summary Results Table for Ethanol and Electricity Production from Fermentation of Macroalgae}

\begin{tabular}{|c|c|c|}
\hline Technology Pathway & \multicolumn{2}{|c|}{$\begin{array}{l}\text { Ethanol and Electricity Production from } \\
\text { Fermentation of Macroalgae }\end{array}$} \\
\hline Feedstock Type & \multicolumn{2}{|c|}{ Brown Seaweed } \\
\hline Hydrocarbon Product Slate, wt \% & $100 \%$ & Ethanol \\
\hline Coproducts & & $\begin{array}{l}\text { Electricity } \\
\text { Digestate (Fertilizer) }\end{array}$ \\
\hline Carbon Efficiency & $12.2 \%$ & \\
\hline Total Capital Investment, million \$ & $\$ 456$ & \\
\hline Total Operating Costs, million $\$ / y r$ & $\$ 159$ & \\
\hline Minimum Selling Price, \$/GGE & $\$ 8.56$ & \\
\hline \multicolumn{3}{|l|}{ Cost Contributions, \$/GGE } \\
\hline Capital Cost & $\$ 0.91$ & \\
\hline Feedstock Cost & $\$ 5.69$ & \\
\hline Operating Costs & $\$ 3.78$ & \\
\hline Operating Credits & $\$ 1.83$ & \\
\hline Taxes & $\$ 0.00$ & (included in Capital expenses) \\
\hline
\end{tabular}

Pathway 34: Ethanol Production from Fermentation of Seaweed

Feedstock: Brown Seaweed

Feedstock Processing Technology: Enzymatic Hydrolysis

Fuel Precursor: Sugars

Fuel Processing Technology: Fermentation

Biofuel Product: 100\% Ethanol

Data Source: (Roesijadi et al. 2010) 


\section{Process Summary}

The simplified block flow diagram is shown in Figure B31.

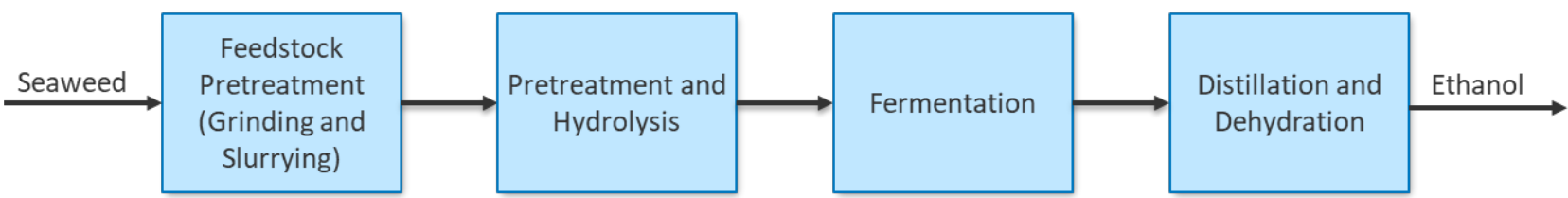

Figure B15. Simplified block flow diagram for ethanol production from fermentation of seaweed

\section{Process Design}

This process is designed to accommodate 1,522 DMT/day and utilizes Laminaria brown seaweed as the feedstock.

The seaweed is assumed to be cultivated, harvested, and dried off-site. The biomass is then delivered to the ethanol production facility. The costs of all these processes are included in the feedstock price. Once delivered, the seaweed is ground into small pieces and mixed with fresh water to create a slurry. The water-to-biomass ratio was not specified. The biomass-water slurry is then pretreated using enzymatic hydrolysis, similar to Pathway 10. After hydrolysis, the resulting sugars are concentrated by evaporating the water from the slurry.

The concentrated solution then enters the fermenters, which are modeled as large CSTRs, and multiple operate in parallel to allow the process to run continuously. Within the fermenters, the biomass is converted to ethanol by using one of a few different organisms that were not specified within the source material. It was assumed that $50 \%$ of the dry seaweed could be converted to ethanol. This conversion yield has yet to be shown at the bench scale but is assumed to be reached within a few years.

The fermentation residues are collected after the broth leaves the CSTR and used in an on-site combustor to generate electricity. The fermentation broth is then sent to a distillation column similar to the ethanol-water separation system in Pathway 10 that concentrates the ethanol up to the azeotropic limit. The water from the columns is either recycled to be used with fresh biomass or is sent for wastewater treatment. The ethanol is then dried using a molecular sieve unit that dries the ethanol to $99.9 \%$ purity, suitable for fuel use.

It should be noted that the yields assumed for this process have not been shown with seaweed; the yields are assumed to be comparable to those expected for cellulosic ethanol from corn stover.

\section{$\underline{\text { Process Economics }}$}

This process does not follow standard BETO assumptions listed at the beginning of this appendix but does follow a few, such as plant life and financing assumptions. Other assumptions are not explicitly stated.

The TCI for this ethanol plant is assumed to be \$229 million, with operating expenses assumed to be $\$ 27.6 \mathrm{million} / \mathrm{year}$, which does not include the feedstock cost. This study also fixed the 
MFSP at \$3.16/GGE and varied the feedstock cost to understand the feedstock cost required for the conversion pathway to be viable. It was found that a feedstock cost of \$0.08/DMT was required - significantly lower than any seaweed can be produced for. Because the feedstock cost requirement is assumed to be much lower than the market price, this pathway has many uncertainties and the MFSP would be significantly higher if a more realistic price of $\sim \$ 105 / D M T$ were used.

Another assumption to note for this pathway that affects the economics is the ethanol yield. The assumption is that $50 \%$ of the seaweed by dry weight is fermentable. This has yet to be shown on the bench scale and will need more research to achieve. The conversion pathway also assumes a discounted enzyme cost for enzymatic hydrolysis, further improving the economics but which may not be a valid assumption.

With these yield assumptions and the 1,522 DMT/day, it is assumed that 27.5 million GGE/yr of ethanol are produced, resulting in a carbon efficiency of $38.3 \%$. There were no sensitivity analyses performed for this conversion pathway. Table B44 summarizes the economic and performance metrics for this conversion pathway.

Table B44. Summary Results Table for Ethanol Production from Fermentation of Seaweed

\begin{tabular}{|c|c|c|}
\hline Technology Pathway & $\begin{array}{l}\text { Ethanol } \\
\text { Ferment }\end{array}$ & $\begin{array}{l}\text { Production from } \\
\text { ation of Seaweed }\end{array}$ \\
\hline Feedstock Type & Laminar & ia Brown Seaweed \\
\hline Hydrocarbon Product Slate, wt \% & $100 \%$ & Ethanol \\
\hline Coproducts & & Electricity \\
\hline Carbon Efficiency & $38.3 \%$ & \\
\hline Total Capital Investment, million \$ & $\$ 229$ & \\
\hline Total Operating Costs, million $\$ / y r$ & $\$ 27.6$ & \\
\hline Minimum Selling Price, $\$ / G G E$ & $\$ 3.16$ & \\
\hline \multirow{2}{*}{\multicolumn{3}{|c|}{ Cost Contributions, \$/GGE }} \\
\hline & & \\
\hline
\end{tabular}

Pathway 35: Macroalgae to Biogas via Anaerobic Digestion

Feedstock: Brown Seaweed

Feedstock Processing Technology: Physical Cutting and Slurrying

Fuel Precursor: N/A

Fuel Processing Technology: Anaerobic Digestion

Biofuel Product: 100\% Biogas

Data Source: (Dave et al. 2013)

Process Summary

The simplified block flow diagram is shown in Figure B32. 


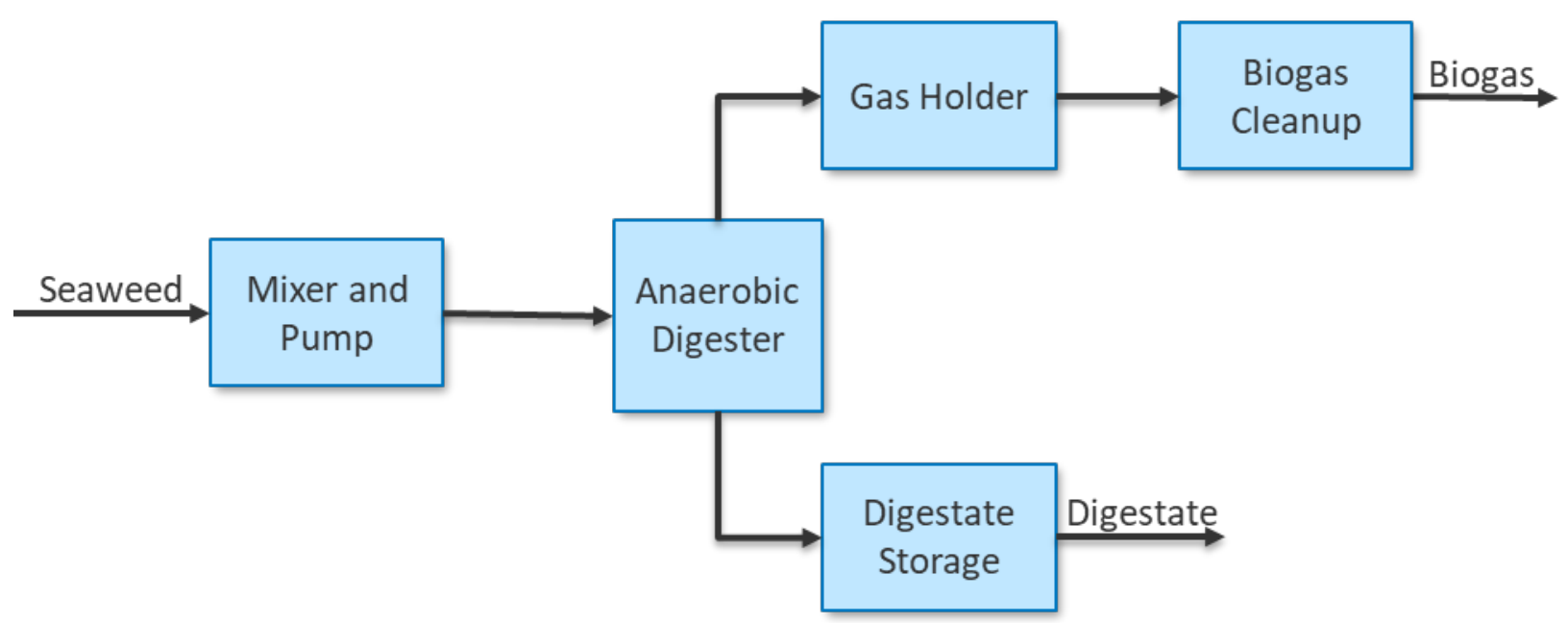

Figure B16. Simplified block flow diagram for macroalgae to biogas via anaerobic digestion

\section{Process Design}

This process is designed to accommodate 8.64 DMT/day and utilizes Laminaria digitata brown seaweed as the feedstock. It should be noted that this production pathway has a meager biomass feed rate as compared to other production pathways.

The biomass is assumed to be cultivated near the shore using a line breeding method. The cultivation site will be near the biofuel production plant to decrease transportation costs. The purchase price of the feedstock considers the cultivation costs and transportation costs to the facility.

Once at the production facility, the biomass is chopped and mixed with fresh water to create a biomass slurry. The slurry uses freshwater because saltwater can decrease the anaerobic digestion process performance. The slurry is made to obtain approximately $10 \%$ total solids loading. The biomass slurry is then pumped to a $1,300-\mathrm{m}^{3}$ digester, where unspecified organisms convert the biomass into a mixture of methane and $\mathrm{CO}_{2}$, with a side product being digestate that can be used as fertilizer. This process occurs over 15 days at a temperature of $37^{\circ} \mathrm{C}$. It is assumed that $64 \%$ of all material entering the digester, excluding ash content, is converted to methane and $\mathrm{CO}_{2}$. The biogas leaving the digester is then collected and burned in an internal combustion engine for electricity and heat usage. In this study, we assumed the biogas was cleaned and sold as a low-grade fuel. It should be noted that the biogas could be further separated than what was modeled here to produce pure methane for energy generation or upgraded to standard commercial fuels. The composition of the biogas is shown in Table B45.

Table B45. Biogas Composition by Weight and Volume for Major Components

\begin{tabular}{lrr}
\hline Component & Wt \% & \multicolumn{1}{c}{ Vol \% } \\
\hline Methane & $28.6 \%$ & $51.5 \%$ \\
Carbon Dioxide & $67.7 \%$ & $44.4 \%$ \\
Hydrogen & $0.01 \%$ & $0.5 \%$ \\
Hydrogen Disulfide & $1.3 \%$ & $1.1 \%$ \\
Nitrogen & $2.4 \%$ & $2.4 \%$ \\
\hline
\end{tabular}


After fermentation, the digestate is removed and $80 \%$ goes to digestate storage, where water evaporates before the digestate is sold as fertilizer, providing a credit to decrease the MFSP of the biogas. The remaining $20 \%$ of the digestate is recycled to be a part of the freshwater biomass slurry. This has been proven to increase macroalgae conversion rate to combustible gases.

With these performance metrics, the plant can produce $\sim 340 \mathrm{GGE} /$ day from an 8.64-DMT/day input. This comes to a production yield of $39.5 \mathrm{GGE} / \mathrm{MT}$, comparable to other conversion technologies. As noted, this is for a much lower production rate than other technologies used in this study. It has yet to be proven if this technology could be scaled linearly to the production rates of other technologies in this study. It should also be noted that if scaled, feedstock costs could increase due to a larger cultivation area needed and therefore increase feedstock transportation costs. Other concerns for scaling this process are the availability of freshwater, low methane yields, and further operational challenges of large-scale seaweed production.

\section{$\underline{\text { Process Economics }}$}

This process does not follow standard BETO assumptions listed at the beginning of this appendix. Instead, the working capital and capital fees were fixed at $25 \%$ of the TCI and the insurance, operating, and maintenance costs were set to $0.5 \%, 2.5 \%$, and $1.5 \%$ of TCI, respectively. Additionally, the plant life was fixed at 20 years, with 1 year for construction and commissioning. A payback period of 17 years was assumed for the calculation of the MFSP.

With these performance and economic metrics, the MFSP was calculated to be $\$ 2.94 / \mathrm{GGE}$. The major cost contributor was the feedstock price, followed by the capital costs. The feedstock contributed to $48.5 \%$ of the MFSP and the capital costs contributed $37.5 \%$.

Sensitivity analyses were performed for this production pathway, and it was found that the feedstock price had the greatest ability to change the MFSP. Other components that played a minor role were the ability to produce power on site versus purchasing it, as well as the capital investment. There was little more expanded on during the sensitivity analysis.

Table B46 summarizes the economic and performance metrics for this pathway.

Table B46. Summary Results Table for Macroalgae to Biogas via Anaerobic Digestion

\begin{tabular}{|c|c|c|}
\hline Technology Pathway & \multicolumn{2}{|c|}{$\begin{array}{l}\text { Macro Algae to Biogas via Anaerobic } \\
\text { Digestion }\end{array}$} \\
\hline Feedstock Type & \multicolumn{2}{|c|}{ Laminaria digitata Brown Seaweed } \\
\hline Hydrocarbon Product Slate, wt \% & $100 \%$ & Biogas \\
\hline Coproducts & & Digestate (Fertilizer) \\
\hline Carbon Efficiency & $25.8 \%$ & \\
\hline Total Capital Investment, million \$ & $\$ 1.14$ & \\
\hline Total Operating Costs, million $\$ / y r$ & $\$ 0.20$ & \\
\hline Minimum Selling Price, \$/GGE & $\$ 2.94$ & \\
\hline \multicolumn{3}{|l|}{ Cost Contributions, \$/GGE } \\
\hline Capital Cost & $\$ 1.44$ & \\
\hline Feedstock Cost & $\$ 1.86$ & \\
\hline Operating Costs & $\$ 0.54$ & \\
\hline Operating Credits & $\$ 0.91$ & \\
\hline Taxes & $\$ 0.00$ & (included in Capital expenses) \\
\hline
\end{tabular}


Pathway 36: Macroalgae waste to Ethanol via Fermentation

Feedstock: Macroalgae Cellulosic Residue

Feedstock Processing Technology: Anaerobic Digestion

Fuel Precursor: Biogas

Fuel Processing Technology: $\mathrm{CO}_{2}$ Absorption by Amine

Biofuel Product: Compressed Biogas (99\% methane)

Data Source: (Chong et al. 2020)

Process Summary

The simplified block flow diagram is shown in Figure B33.

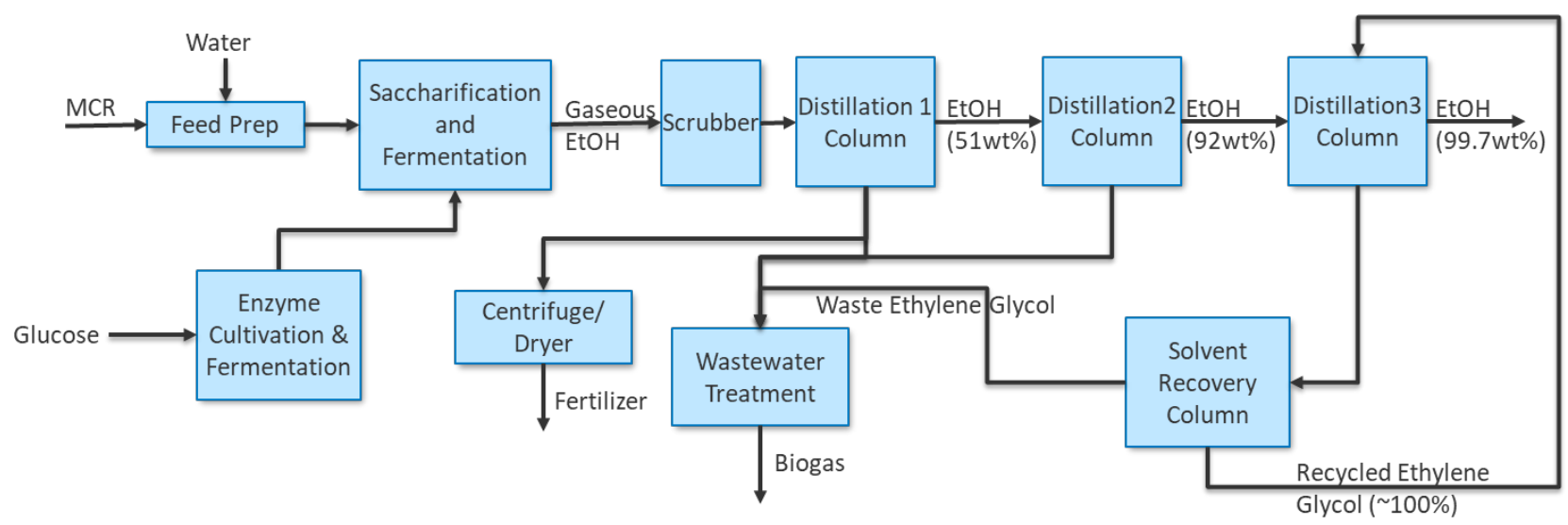

Figure B17. Simplified block flow diagram for macroalgae waste to ethanol via fermentation

\section{Process Design}

The plant was designed with four major areas: the bioreactor, on-site cellulase cultivation, ethanol purification, and wastewater treatment, all depicted in Figure B33, with more detail shown for the ethanol purification.

To start, the cellulase enzyme, Trichoderma reesei, is cultivated on site first in seed inoculum, which increases the cell density. This initial step has a batch time of 36 hours, including cleaning. The size of the seed train reactors increases by a factor of 10 within the sequence. After the seed train, the inoculum is passed into cellulase fermenters, which secrete the enzyme required for hydrolysis of the biomass. The fermentation time to produce the necessary enzymes is 7 days, including cleaning. The fermentation broth is maintained at $28^{\circ} \mathrm{C}, \mathrm{pH} 5$, and is fed with glucose as the carbon source for aerobic digestion. The enzymes are then used in the fermentation of the biomass in the bioreactor.

The prepped macroalgae cellulosic residue is loaded directly into the saccharification and fermentation reactor (bioreactor) with the aforementioned cellulase enzyme at $50^{\circ} \mathrm{C}$ to allow for 
pre-hydrolyzing. Following the reactor loading and pre-hydrolyzing, the yeast (Saccharomyces cerevisiae) is added to undergo fermentation at $43^{\circ} \mathrm{C}$ and $\mathrm{pH} 4.8$. The macroalgae cellulosic residue is assumed to be $99.8 \mathrm{wt} \%$ cellulose, and the total solids loading in the bioreactor is 20 wt $\%$, with cellulase enzyme loading of $20 \mathrm{mg} / \mathrm{g}$ cellulose and a yeast loading of $17.5 \mathrm{mg} / \mathrm{mL}$. The assumed yield is $85.5 \%$ of fermentable sugars being converted to ethanol. The assumed reaction time was set to 1 hour to prevent ethanol evaporation.

After fermentation, the broth is $8-12 \mathrm{wt} \%$ ethanol. Because of ethanol's high volatility, some will be retained in the $\mathrm{CO}_{2}$ gaseous stream. To recover this ethanol, a scrubber is used, and water is added to achieve an ethanol absorption factor of 1.5. Meanwhile, the liquid stream is sent to a centrifuge to separate the solids that are dried and used for fertilizer. The recovered ethanol broth stream is sent to the first of three distillation columns. The first column concentrates the ethanol to $\sim 51 \mathrm{wt} \%$ in the distillate, with the bottoms containing mostly water. This water is either recycled or sent to the wastewater treatment area. The $51 \mathrm{wt} \%$ ethanol distillate is sent to the second column, which purifies the ethanol to $\sim 92 \mathrm{wt} \%$ ethanol. Again, the bottoms contain mostly water to be recycled or sent to the wastewater treatment area. The $92 \mathrm{wt} \%$ ethanol stream is sent to a third column, which is an extractive distillation column utilizing ethylene glycol as the extractant to pull the remaining water out of solution. This purifies the ethanol to $>99.7 \mathrm{wt} \%$, suitable for fuel use. The ethylene glycol is recycled around the extraction column, as shown in Figure B33.

The wastewater treatment area utilizes an aerobic digester to convert any solids or wastes into biogas, which is collected and burned for electricity and heat generation to be used on site.

\section{Process Economics}

The designed plant can process $400 \mathrm{DMT} /$ day of macroalgae cellulosic residue, producing 18 million metric tons of ethanol per year at $90 \%$ time on stream. The plant life is 20 years with 2 years for design and construction. Though there is no published price for macroalgae cellulosic residue, it was assumed to be $30 \%$ of Eucheuma cottonii, which has a selling price of $\$ 66.91 / \mathrm{DMT}$. The selling price for the fertilizer produced during fermentation was assumed to be $\$ 0.18 / \mathrm{kg}$, which is about $30 \%$ of the ethanol selling price.

The capital costs for all the equipment manufactured and installed was \$29.18 million, with $\$ 3.69$ million of that being for land acquisition. Operating expenses totaled $\$ 19.75$ million/year, which includes feedstock costs. The MFSP for the ethanol was calculated at $\$ 1.21 / \mathrm{GGE}$ and resulted in a return on investment of $16.6 \%$. A further breakdown of the cost contributions is shown in Table B47. Further information on economic details are reported in the source material and will not be touched on here. 
Table B47. Summary Results Table for Macroalgae Waste to Ethanol via Fermentation

\begin{tabular}{|c|c|c|}
\hline Technology Pathway & \multicolumn{2}{|c|}{$\begin{array}{l}\text { Macroalgae waste to ethanol via } \\
\text { Fermentation }\end{array}$} \\
\hline Feedstock Type & \multicolumn{2}{|c|}{ Macroalgae Cellulosic Residue } \\
\hline Hydrocarbon Product Slate, wt \% & $100 \%$ & Bioethanol \\
\hline Coproducts & & Fertilizer \\
\hline Carbon Efficiency & $62.8 \%$ & \\
\hline Total Capital Investment, million \$ & $\$ 54.0$ & \\
\hline Total Operating Costs, million $\$ / y r$ & $\$ 19.8$ & \\
\hline Minimum Selling Price, \$/GGE & $\$ 1.21$ & \\
\hline \multicolumn{3}{|l|}{ Cost Contributions, \$/GGE } \\
\hline Capital Cost & $\$ 0.16$ & \\
\hline Feedstock Cost & $\$ 0.10$ & \\
\hline Operating Costs & $\$ 1.09$ & \\
\hline Operating Credits & $\$ 0.18$ & \\
\hline Taxes & $\$ 0.03$ & \\
\hline
\end{tabular}




\section{Appendix C. Annual Biofuel Production Capacity and Cost}

Table C1. Detailed Description of Feedstock Group Used for Production Capacity and Cost Projection Modeling

\begin{tabular}{|c|c|c|}
\hline Feedstock Group & General Description & Detailed List \\
\hline \multirow[t]{4}{*}{ a } & Vegetable Oils & Soybean Oil \\
\hline & & Corn Oil \\
\hline & & Canola Oil \\
\hline & & Other \\
\hline \multirow[t]{6}{*}{ b } & Fats, Oils, and Greases & Lard \\
\hline & & Edible Tallow \\
\hline & & Other Fats, Oils, Greases \\
\hline & & Biosolids \\
\hline & & Trap Grease \\
\hline & & Food Processing Wastes \\
\hline C & Corn Grain & Corn Grain \\
\hline \multirow[t]{13}{*}{$d$} & Agricultural Residues & Corn Stover \\
\hline & & Wheat Straw \\
\hline & & Sorghum Residue \\
\hline & & Barley Residue \\
\hline & & Cotton Field Residues \\
\hline & & Cotton Gin Trash \\
\hline & & Orchard and Vineyard Prunings \\
\hline & & Rice Straw \\
\hline & & Rice Hulls \\
\hline & & Sugarcane Field Trash \\
\hline & & Switchgrass \\
\hline & & Miscanthus \\
\hline & & Energy Cane \\
\hline \multirow[t]{14}{*}{ e } & Forestry Residues & Wood/wood waste \\
\hline & & Feed for gasoline blendstock/naphtha \\
\hline & & Logging Residues \\
\hline & & Whole-tree biomass \\
\hline & & Other Removal Residues \\
\hline & & Treatment thinnings, other forestland \\
\hline & & Mill residue, unused secondary \\
\hline & & Mill residue, unused primary \\
\hline & & Urban wood waste - C\&D \\
\hline & & Urban Wood Waste - MSW \\
\hline & & Utility tree trimmings \\
\hline & & Biomass Sorghum \\
\hline & & Non-coppice \\
\hline & & Coppice \\
\hline
\end{tabular}




\begin{tabular}{|c|c|c|}
\hline Feedstock Group & General Description & Detailed List \\
\hline$f$ & Municipal Solid Waste (MSW) & $\begin{array}{l}\text { Biogenic portion of MSW } \\
\text { Other waste biomass } \\
\text { Animal Manures } \\
\text { Paper and paperboard } \\
\text { Rubber and Leather } \\
\text { Textiles } \\
\text { Other MSW } \\
\text { Yard Trimmings } \\
\text { Landfill Gas Billion } \mathrm{ft}^{3} \text { (no price estimated) }\end{array}$ \\
\hline g & Microalgae & $\begin{array}{l}\text { Fresh Water Coal } \mathrm{CO}_{2} \\
\text { Fresh Water Natural Gas } \mathrm{CO}_{2} \\
\text { Fresh Water Ethanol } \mathrm{CO}_{2} \\
\text { Saline (minimally lined) } \mathrm{Coal} \mathrm{CO}_{2} \\
\text { Saline (minimally lined) Natural Gas } \mathrm{CO}_{2} \\
\text { Saline (minimally lined) Ethanol } \mathrm{CO}_{2} \\
\text { Saline (fully lined) Coal } \mathrm{CO}_{2} \\
\text { Saline (fully lined) Natural Gas } \mathrm{CO}_{2} \\
\text { Saline (fully lined) Ethanol } \mathrm{CO}_{2} \\
\end{array}$ \\
\hline h & Macroalgae & $\begin{array}{l}\text { Macrocystis, nearshore } \\
\text { Laminaria/Laminaria rope farm (offshore) } \\
\text { Ulva/Ulva, tidal flat farm } \\
\text { Sarqassum, floating cultivation }\end{array}$ \\
\hline
\end{tabular}

\section{Linear Model Operation}

The model is set up by first selecting the biomass feedstocks, the feedstock supply curve (minimum, median, or maximum availability), and the analysis timeframe, either near term (2022) or long term (2040). These values determine the total availability (in million dry U.S. tons per year) and the price (in $\$$ /dry U.S. ton) for each selected biomass feedstock. The pathways that will be evaluated in the optimization are selected in another database. This database serves as a lookup table for the yield values, baseline capital and operating costs, and the linear equation parameters needed to calculate the cost of fuel output for each combination of conversion pathway and biomass feedstock. Once the feedstocks and pathways have been specified, the user then sets the sensitivity multipliers for capital cost, feedstock cost, and operating costs. The yield sensitivity values are set by selecting the yield case, which in turn determines which set of linear equations will be used to calculate the plant-gate price $(\$ / G G E)$ for each pathway as well as the corresponding yield value for the pathway. Figure $\mathrm{C} 1$ depicts the basic structure of the optimization model. To run a single iteration of the optimization solver, the user selects the optimization strategy and clicks "Run Solver" (A). The solver fills in the changing value matrix with guesses for the amount of biomass routed to each pathway (B). The amount of fuel (GGE) produced at what cost is tabulated for each combination $(\mathrm{C})$ and compared to the constraints and optimization objective. The solver adjusts values in the matrix until the objective is met within the constraints. Clicking "Run Sensitivity Cases" runs the optimization solver for each of the 
three optimization strategies for the low, median, and high values for each of the sensitivity variables - a total of 81 cases - and tabulates the results on a separate sheet.

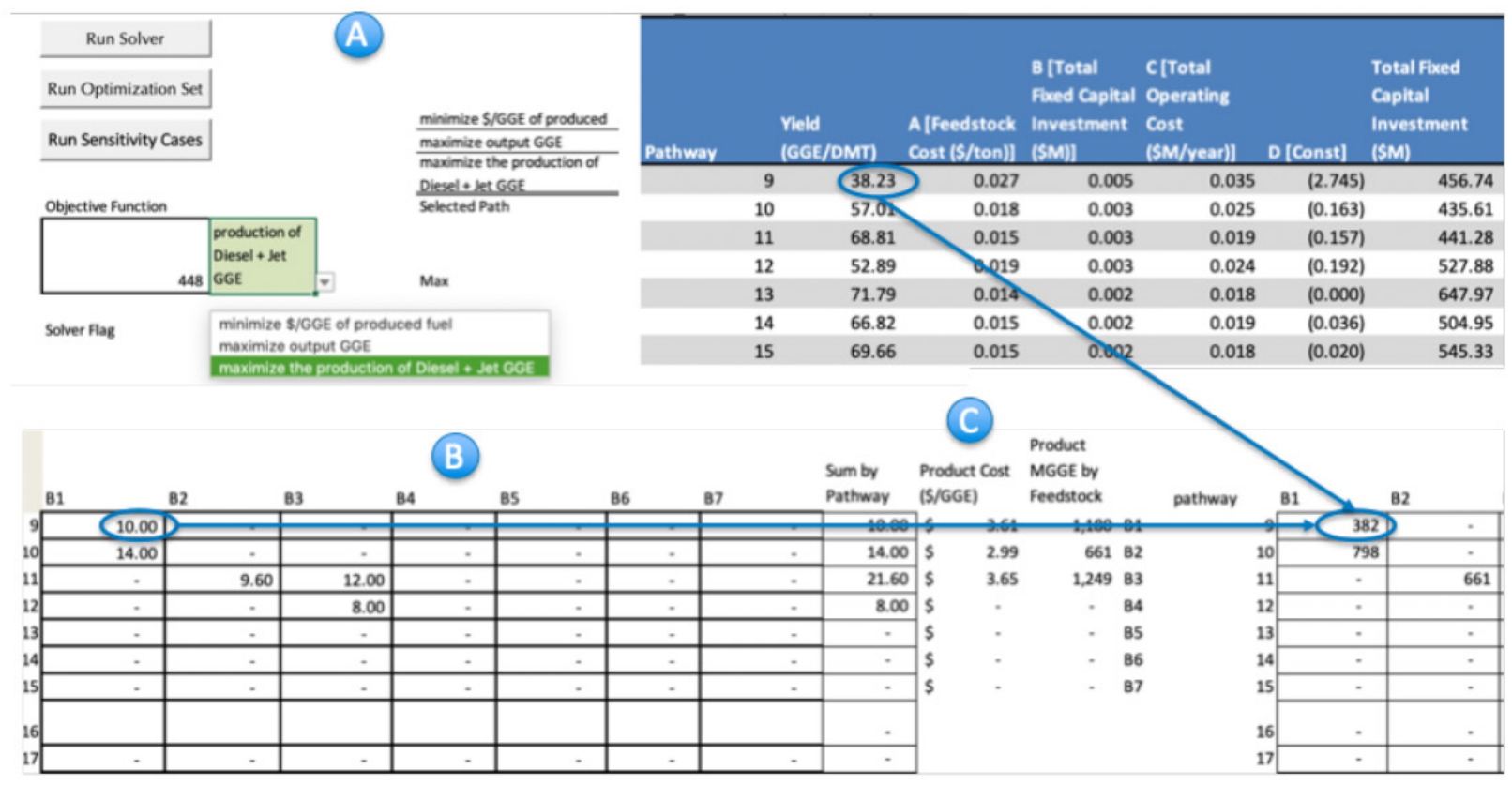

Figure C1. Optimization calculations 
Group A - Projected Annual Overall Biofuel Capacity (Million Tonnes)

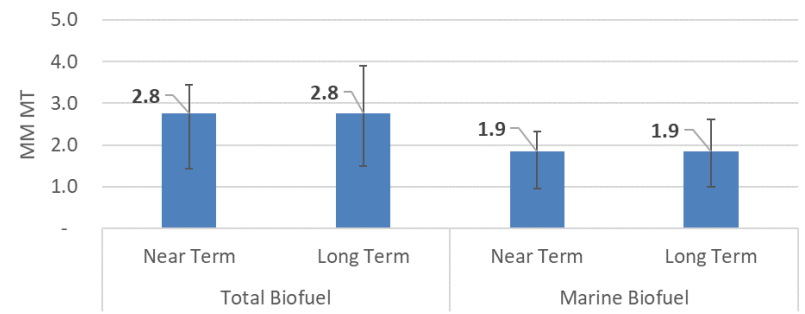

Group C - Projected Annual Overall Biofuel Capacity (Million Tonnes)

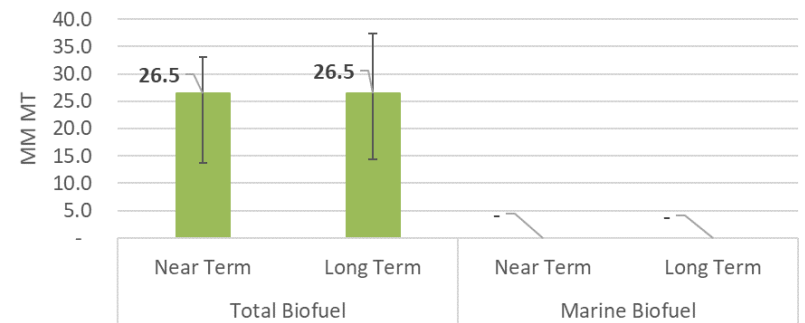

Group E - Projected Annual Overall Biofuel Capacity (Million Tonnes)

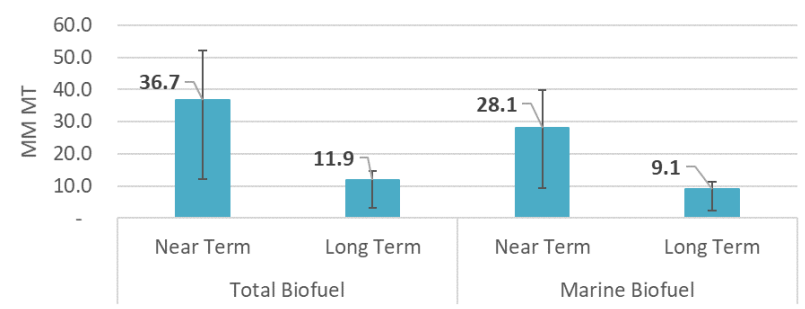

Group H - Projected Annual Overall Biofuel Capacity (Million Tonnes)

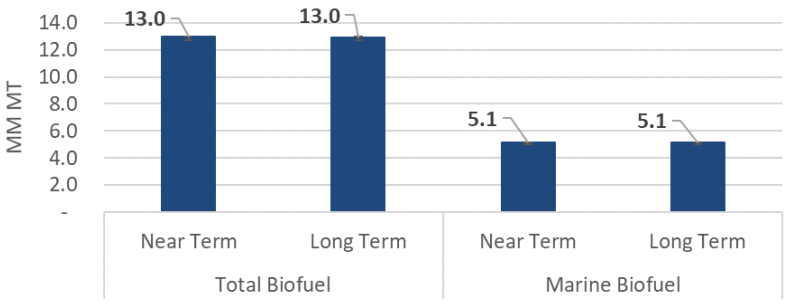

Group B - Projected Annual Overall Biofuel Capacity (Million Tonnes)

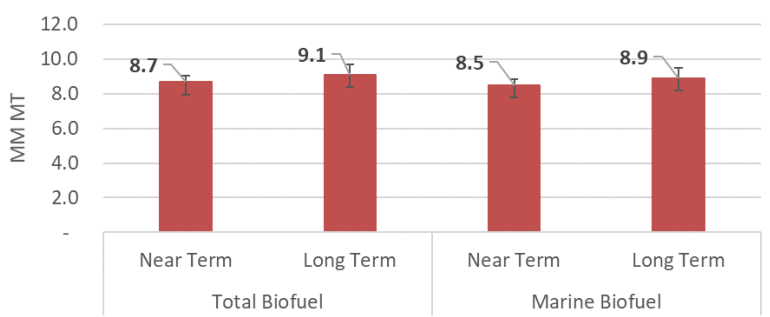

Group D - Projected Annual Overall Biofuel Capacity (Million Tonnes)

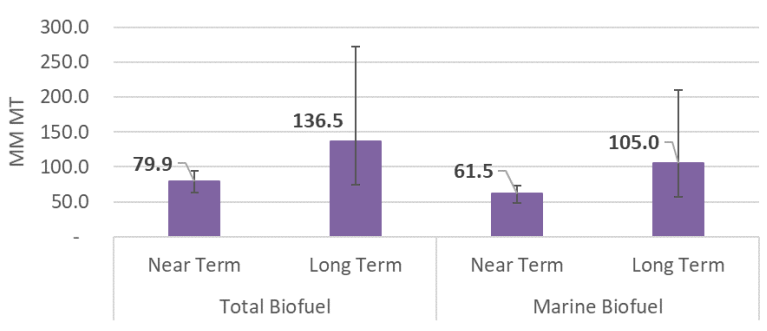

Group F - Projected Annual Overall Biofuel Capacity (Million Tonnes)

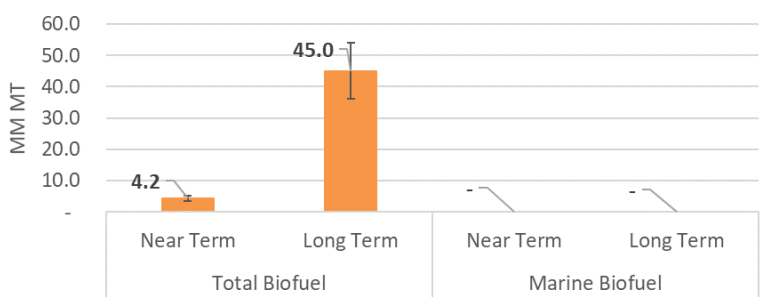

Group K - Projected Annual Overall Biofuel Capacity (Million Tonnes)

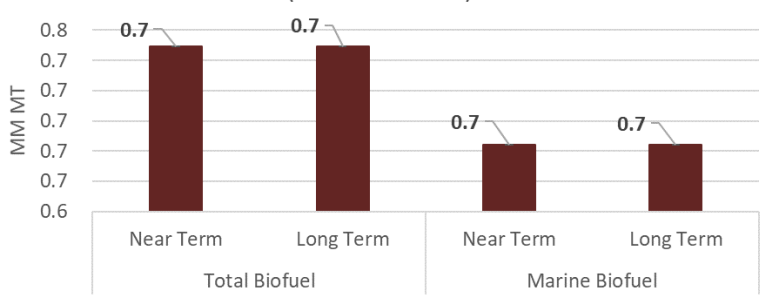

Figure C2. Projected annual biofuel and marine biofuel capacity by technology group in million metric tons 
Group A - Projected Annual Overall Biofuel Capacity (Billion HFO-Gallon-Equivalent)

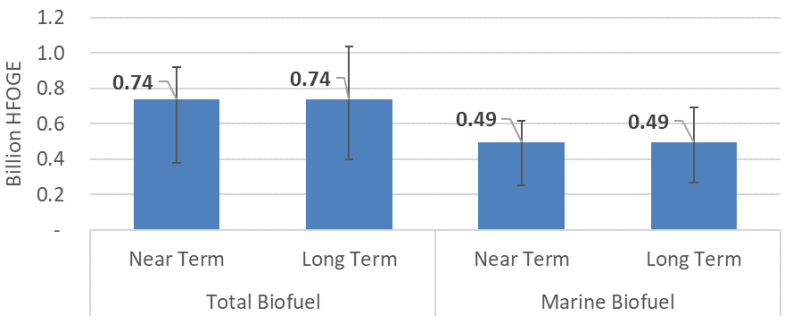

Group C - Projected Annual Overall Biofuel Capacity (Billion HFO-Gallon-Equivalent)

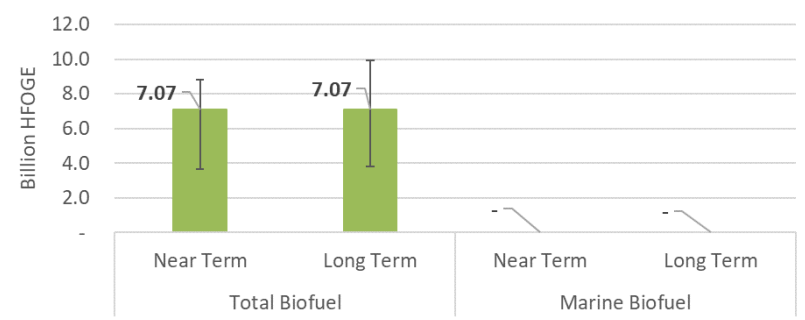

Group E - Projected Annual Overall Biofuel Capacity (Billion HFO-Gallon-Equivalent)

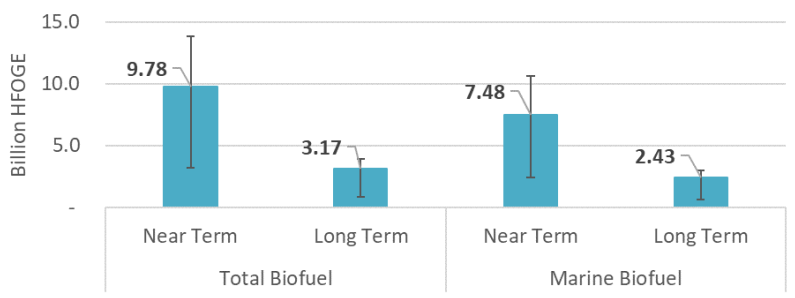

Group H - Projected Annual Overall Biofuel Capacity (Billion HFO-Gallon-Equivalent)

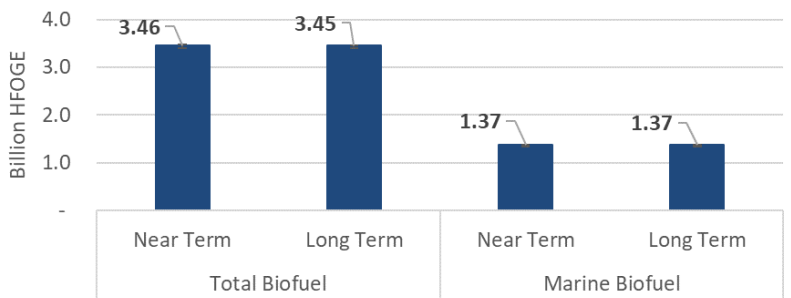

Group B - Projected Annual Overall Biofuel Capacity (Billion HFO-Gallon-Equivalent)

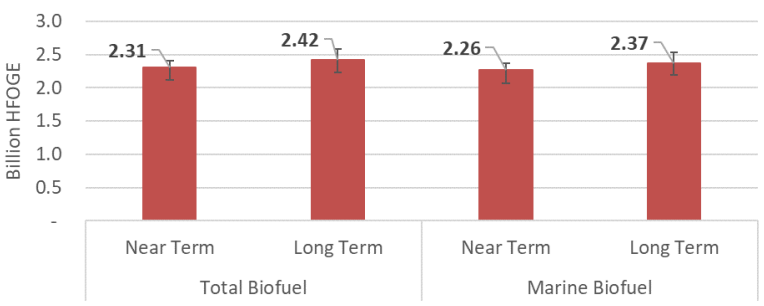

Group D - Projected Annual Overall Biofuel Capacity (Billion HFO-Gallon-Equivalent)

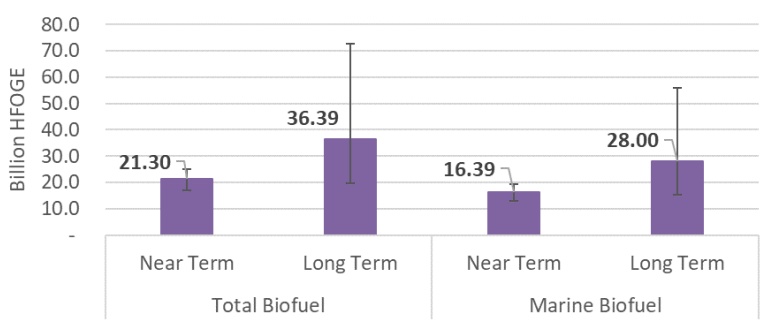

Group F - Projected Annual Overall Biofuel Capacity (Billion HFO-Gallon-Equivalent)

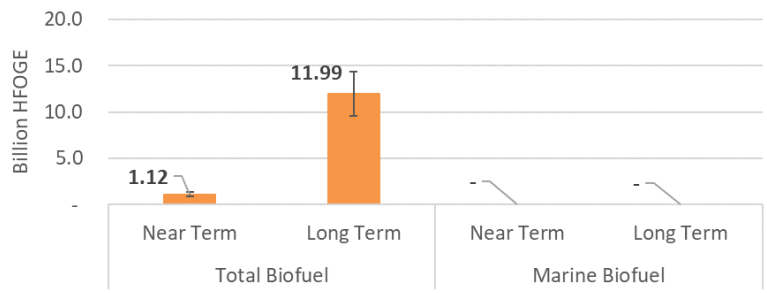

Group K - Projected Annual Overall Biofuel Capacity (Billion HFO-Gallon-Equivalent)

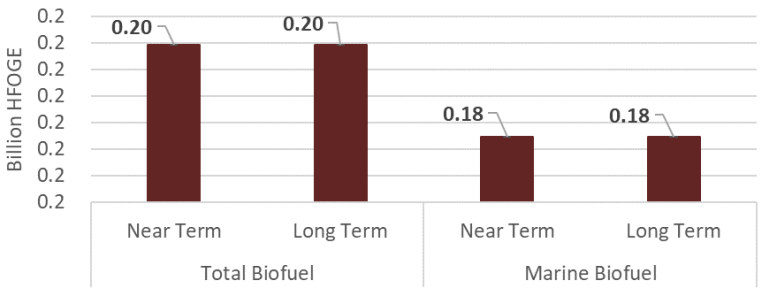

Figure C3. Projected annual biofuel and marine biofuel capacity by technology group in billion heavy fuel oil gallon equivalents (HFOGE) 


\section{Combined - Projected Annual Overall Biofuel Capacity}

(Billion HFO-Gallon-Equivalent)

80.0

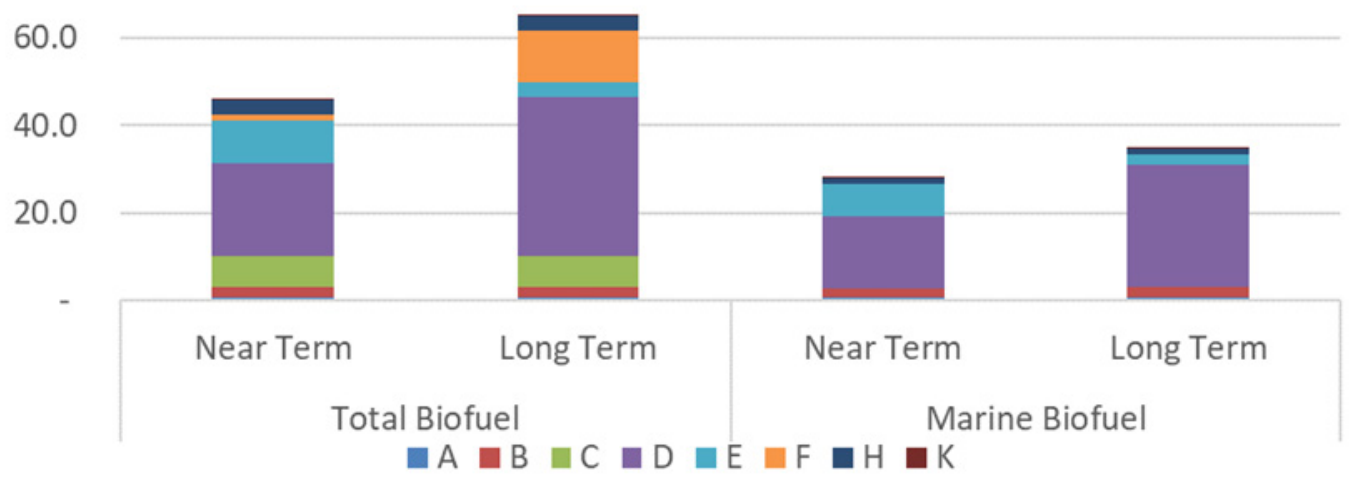

Figure C4. Projected biofuel capacity broken down by feedstock group contributions on an HFOGE basis for maximum total biofuel and maximum marine biofuel scenarios 
All Feedstock Groups - Projected Annual Biofuel Capacity

(Billion HFO-Gallon-Equivalent)

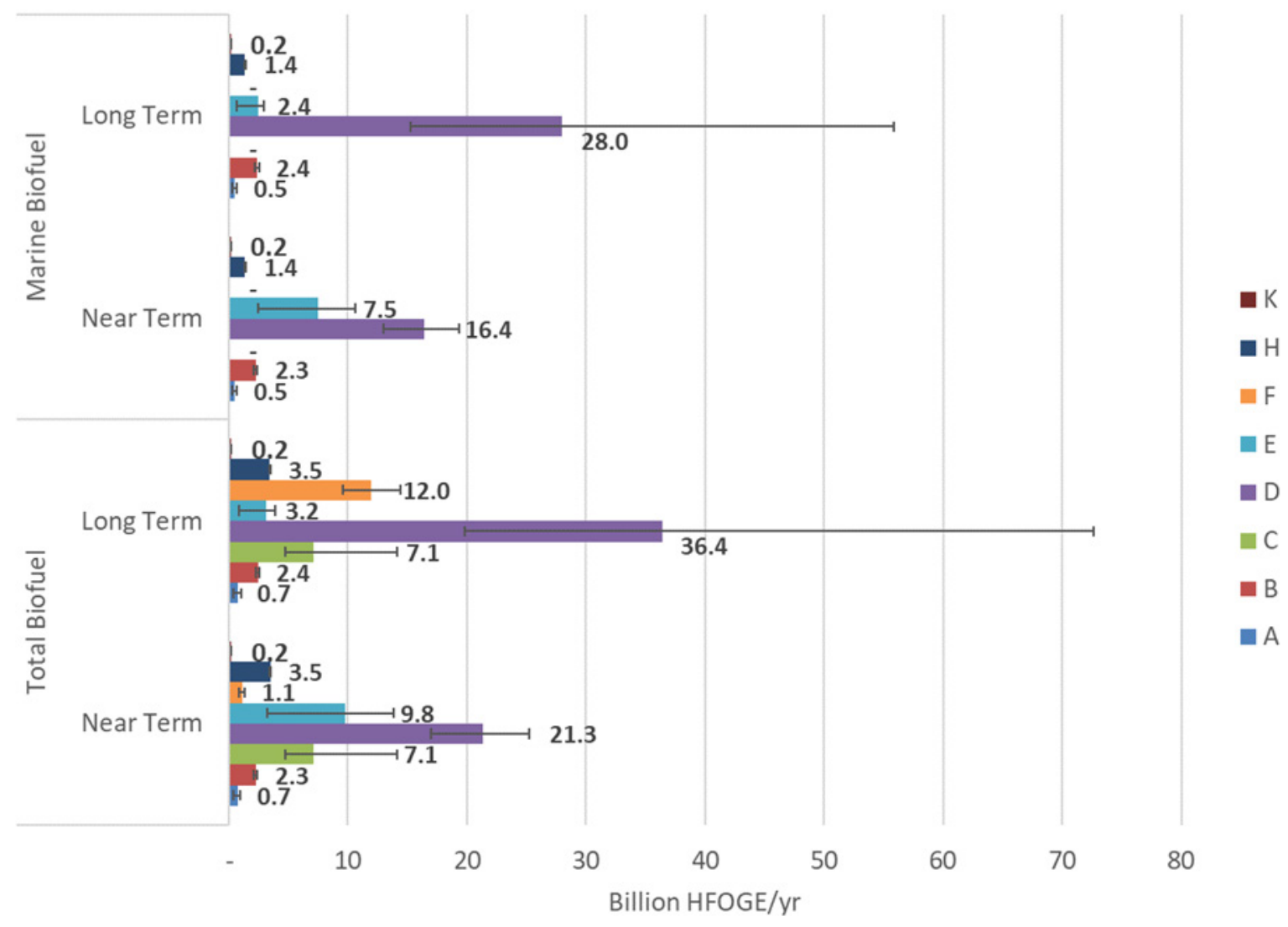

Figure C5. Feedstock group fuel contributions on an HFOGE basis for maximum total biofuel and maximum marine biofuel scenarios. Error bars indicate maximum and minimum feedstock availability for each group. 
All Feedstock Groups - Projected Cost at Annual Biofuel Capacity

(Dollars per HFO-Gallon-Equivalent)

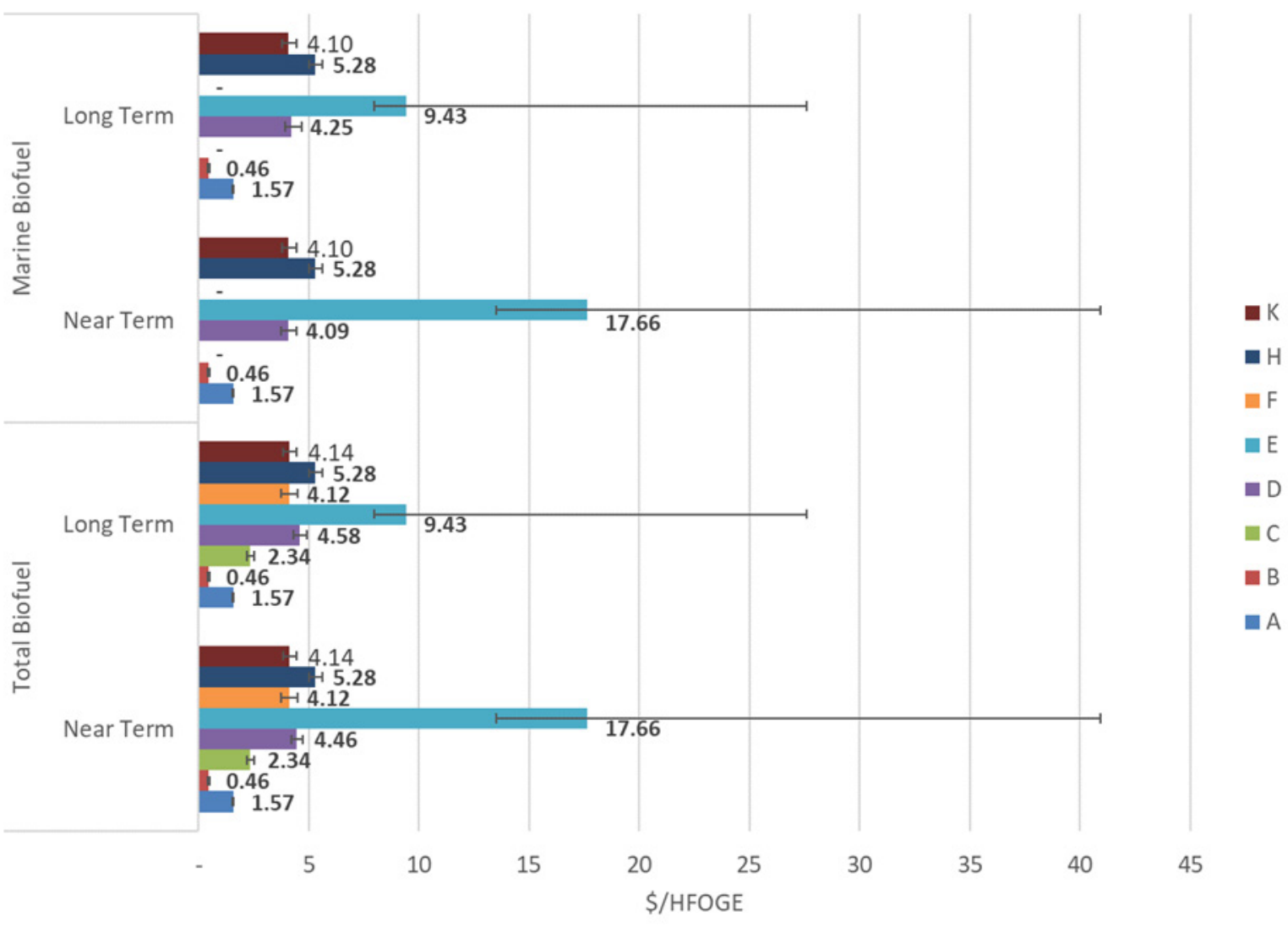

Figure C6. Price of produced fuel per feedstock group on an HFOGE basis for maximum total biofuel and maximum marine biofuel scenarios. Error bars indicate maximum and minimum feedstock cost for each group. 
Table C2. Solver Results (C2.1-C2.9) for Optimization Constraint: Minimize Biofuel Cost. All Results in \$/MT Biofuel.

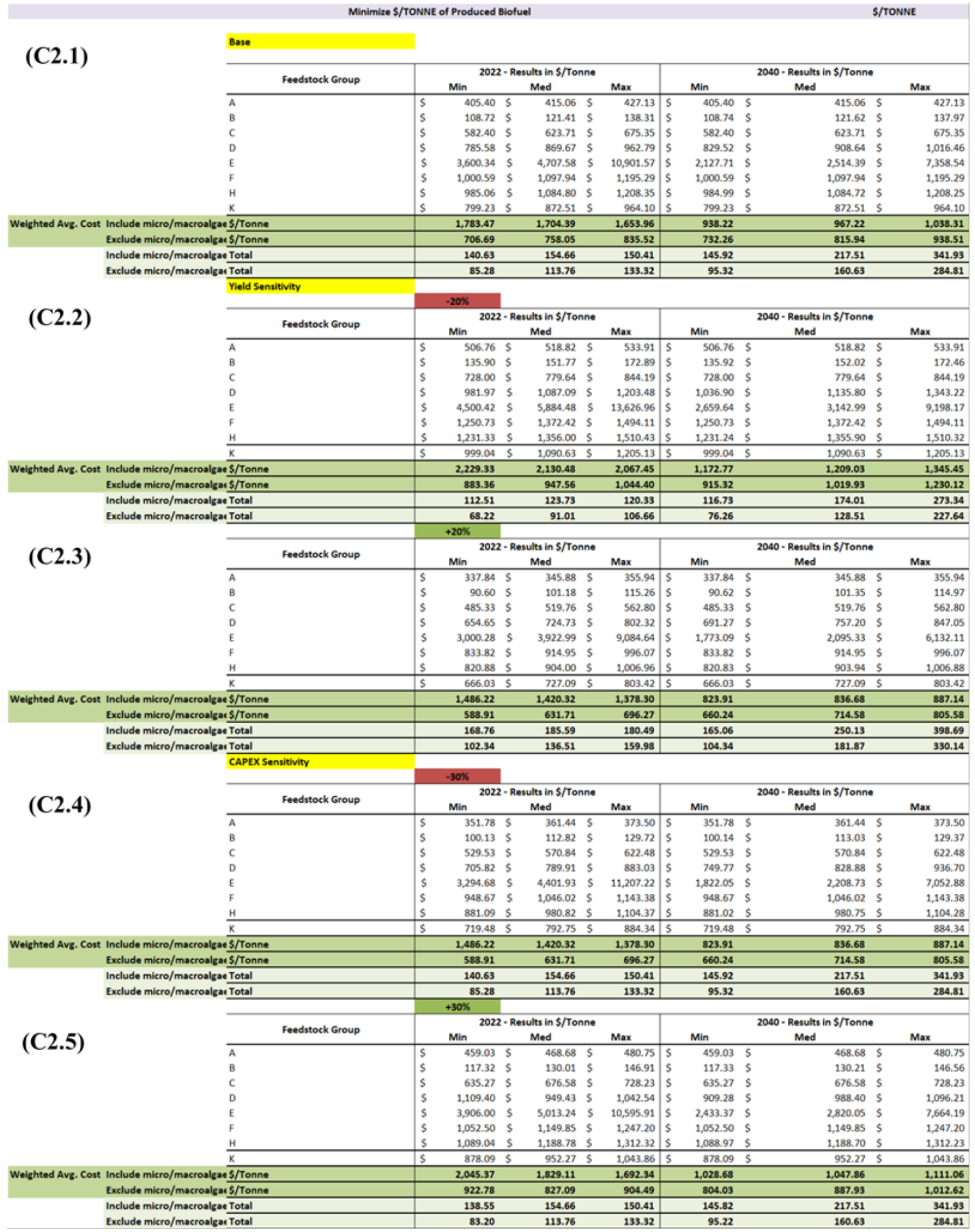




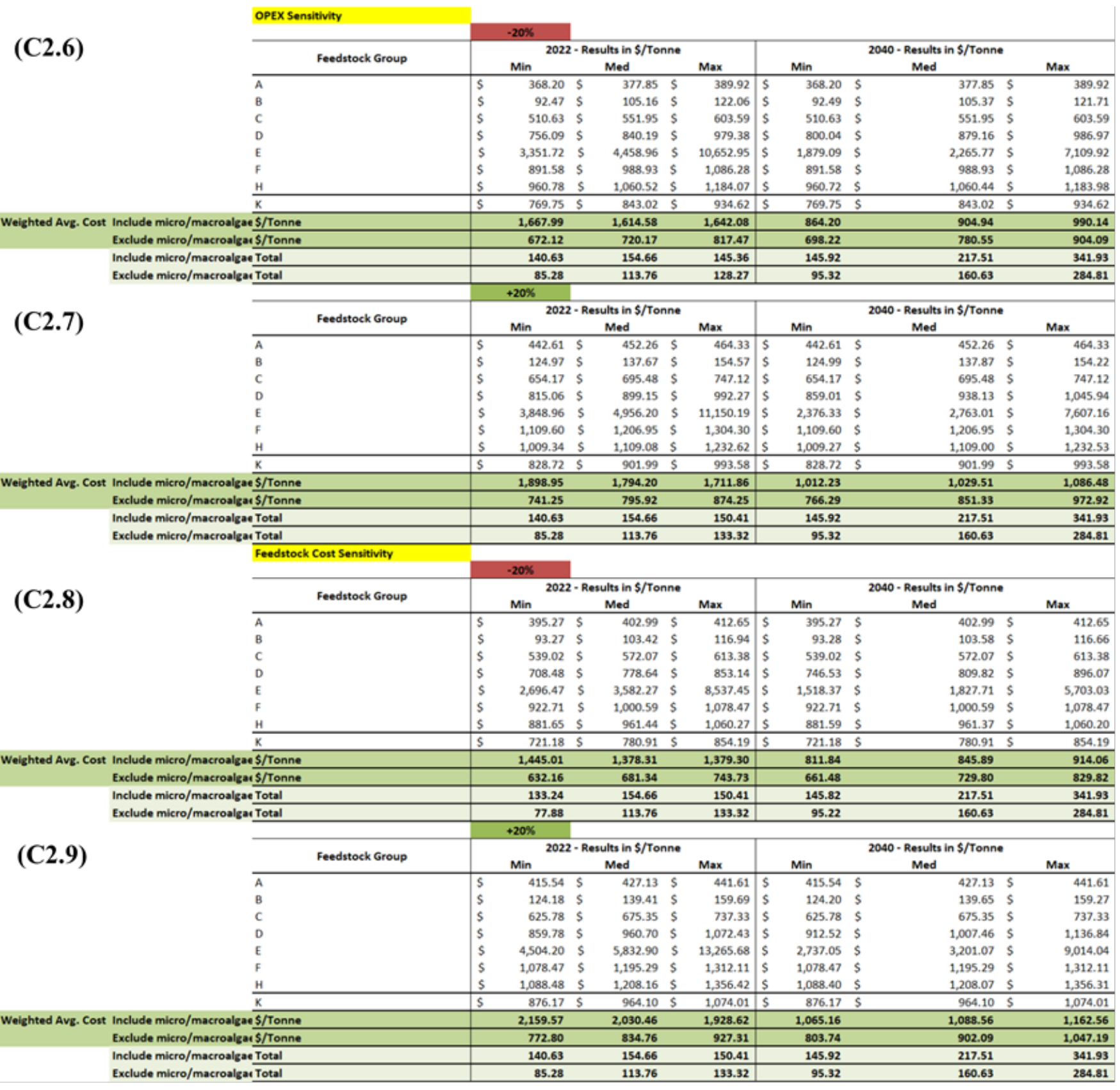


Table C3. Solver Results (C3.10-C3.18) for Optimization Constraint: Maximize Total Biofuel. All Results in Million Metric Tons Biofuel.

\begin{tabular}{|c|c|c|c|c|c|c|c|c|}
\hline \multicolumn{9}{|c|}{ Maximize Total Output - Results in MM Tonne } \\
\hline \multicolumn{9}{|c|}{ Base } \\
\hline 3.10$)$ & & \multirow{2}{*}{ Feedstock Group } & \multicolumn{3}{|c|}{2022 - Million Tonnes Biofuel/yr } & \multicolumn{3}{|c|}{2040 - Million Tonnes Biofuel/yr } \\
\hline & & & Min & Med & $\operatorname{Max}$ & Min & Med & $\operatorname{Max}$ \\
\hline & & A & 1.42 & 2.76 & 3.45 & 1.49 & 2.76 & 3.89 \\
\hline & & B & 7.93 & 8.67 & 9.05 & 8.37 & 9.07 & 9.69 \\
\hline & & c & 13.67 & 26.53 & 33.12 & 14.31 & 26.53 & 37.34 \\
\hline & & D & 63.50 & 79.93 & 94.48 & 74.34 & 136.52 & 272.56 \\
\hline & & E & $\$ 1.99$ & 36.70 & 12.05 & 14.62 & 11.91 & 3.16 \\
\hline & & $\mathbf{F}$ & 3.36 & 4.20 & 5.04 & 35.98 & 44.97 & 53.97 \\
\hline & & H & 12.74 & 12.98 & 13.01 & 12.72 & 12.96 & 12.99 \\
\hline & & k & 0.75 & 0.75 & 0.75 & 0.75 & 0.75 & 0.75 \\
\hline & \multicolumn{2}{|c|}{ Include micro/macroalgae Total } & 155.36 & 172.52 & 170.94 & 162.59 & 245.48 & 394.34 \\
\hline & Exclude miero/macroalgat & $\overline{\text { Total }}$ & 100.01 & 131.62 & 153.85 & 111.99 & 188.60 & 337.21 \\
\hline Weighted Avg. Cost & Include micro/macroalgae & s/Tonne & $1,859.09$ & $1,798.45$ & $1,769.38$ & $1,111.08$ & $1,156.54$ & $1,250.94$ \\
\hline & Exclude micro/macroalgat & \$ \$/Tonne & 982.76 & $1,009.72$ & $1,072.98$ & $1,013.88$ & $1,084.78$ & $1,202.66$ \\
\hline & & Vield Sensitivity & & & & & & \\
\hline & & & $-20 \%$ & & & & & \\
\hline & & Feedstock Group & $2022-N$ & Tonnes Biof & & & lion Tonnes Biofue & \\
\hline & & Feedatock Group & Min & Med & Max & Min & Med & Max \\
\hline & & A & 1.14 & 2.21 & 2.76 & 1.19 & 2.21 & 3.11 \\
\hline & & B & 6.35 & 6.94 & 7.24 & 6.70 & 7.26 & 7.75 \\
\hline & & c & 10.93 & 21.22 & 26.50 & 11.45 & 21.22 & 29.87 \\
\hline & & D & 50.80 & 63.94 & 75.58 & 59.48 & 109.22 & 218.04 \\
\hline & & E & 41.59 & 29.36 & 9.64 & 11.69 & 9.53 & 2.53 \\
\hline & & $\mathbf{F}$ & 2.69 & 3.36 & 4.03 & 28.78 & 35.98 & 43.17 \\
\hline & & H & 10.19 & 10.38 & 10.41 & 10.18 & 10.37 & 10.39 \\
\hline & & k & 0.60 & 0.60 & 0.60 & 0.60 & 0.60 & 0.60 \\
\hline & Include micro/macroalgae & Total & 124.29 & 138.01 & 136.75 & 130.07 & 196.39 & 315.47 \\
\hline & Exclude micro/macroalgat & Total & 80.01 & 105.29 & 123.08 & 89.60 & 150.88 & 269.77 \\
\hline Weighted Avz. Cost & Include micro/macroalgae & $\$$ /Tonne & $2,323.86$ & $2,248.06$ & $2,211.72$ & $1,388.85$ & $1,445.67$ & $1,563.67$ \\
\hline & Exclude micro/macroalgat & S/Tonne & $1,228.45$ & $1,262.15$ & $1,341.23$ & $1,267.35$ & $1,355.98$ & $1,503.32$ \\
\hline & & & $+20 \%$ & & & & & \\
\hline & & Feedetock Grour & $2022-N$ & Tonnes Biof & & & Ion Tonnes Biofue & \\
\hline 3.12$)$ & & 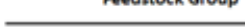 & Min & Med & Max & Min & Med & $\operatorname{Max}$ \\
\hline & & A & 1.71 & 3.32 & 4.14 & 1.79 & $\mathbf{3 . 3 2}$ & 4.67 \\
\hline & & B & 9.52 & 10.40 & 10.86 & 10.05 & 10.88 & 11.63 \\
\hline & & c & 16.40 & 31.84 & 39.74 & 17.18 & 31.84 & 44.80 \\
\hline & & D & 76.20 & 95.91 & 113.37 & 89.21 & 163.83 & 327.07 \\
\hline & & E & 62.39 & 44.03 & 14.46 & 17.54 & 14.29 & 3.79 \\
\hline & & $\mathbf{F}$ & 4.03 & 5.04 & 6.05 & 43.17 & 53.97 & 64.76 \\
\hline & & H & 15.29 & 15.57 & 15.61 & 15.27 & 15.55 & 15.59 \\
\hline & & $k$ & 0.90 & 0.90 & 0.90 & 0.90 & 0.90 & 0.90 \\
\hline & Include micro/macroalgae & Total & 186.44 & 207.02 & 205.13 & $\mathbf{1 9 5 . 1 1}$ & 294.58 & 473.20 \\
\hline & Exclude miero/macroalgat & 4 Total & 120.01 & 157.94 & 184.62 & 134.39 & 226.32 & 404.65 \\
\hline Weighted Avz. Cost & Include micro/macroalgae & \$/Tonne & $1,549.24$ & 1.498 .71 & $1,474.48$ & 925.90 & 963.78 & $1,042.45$ \\
\hline & Exclude micro/macroalgat & s/Tonne & 818.97 & 841.44 & 894.15 & 844.90 & 903.99 & $1,002.21$ \\
\hline & & CAPEXX Sensitivity & & & & & & \\
\hline & & & $-30 \%$ & & & & & \\
\hline & & Feedstock Group & $2022 \cdot N$ & Tonnes Biof & & & lion Tonnes Biofue & \\
\hline$(3.13)$ & & 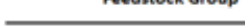 & Min & Med & Max & Min & Med & Max \\
\hline & & A & 1.42 & 2.76 & 3.45 & 1.49 & 2.76 & 3.89 \\
\hline & & B & 7.93 & 8.67 & 9.05 & 8.37 & 9.07 & 9.69 \\
\hline & & c & 13.67 & 26.53 & 33.12 & 14.31 & 26.53 & 37.34 \\
\hline & & D & 63.50 & 79.93 & 94.48 & 74.34 & 136.52 & 272.56 \\
\hline & & E & 51.99 & 36.70 & 12.05 & 14.62 & 11.91 & 3.16 \\
\hline & & $\mathrm{F}$ & 3.36 & 4.20 & 5.04 & 35.98 & 44.97 & 53.97 \\
\hline & & H & 12.74 & 12.98 & 13.01 & 12.72 & 12.96 & 12.99 \\
\hline & & $k$ & 0.75 & 0.75 & 0.75 & 0.75 & 0.75 & 0.75 \\
\hline & Include micro/macroalgae & Total & 155.36 & 172.52 & 170.94 & 162.59 & 245.48 & 394.34 \\
\hline & Exclude micro/macroalgat & Total & 100.01 & 131.62 & 153.85 & 111.99 & 188.60 & 337.21 \\
\hline Weighted Avg. Cost & Include micro/macroalgat & S/Tonne & $1,679.00$ & $1,645.10$ & $1,687.24$ & 989.20 & $1,038.53$ & $1,132.85$ \\
\hline & Exclude miero/macroalgat & \$ $\$ /$ Tonne & 863.64 & 895.60 & 959.48 & 893.51 & 962.86 & $1,075.74$ \\
\hline & & & $+30 \%$ & & & & & \\
\hline & & Feedstock Group & $2022-N$ & Tonnes Biof & & & lion Tonnes Biofue & \\
\hline (C3.14) & & Feedstock Group & Min & Med & Max & Min & Med & Max \\
\hline & & A & 1.42 & 2.76 & 3.45 & 1.49 & 2.76 & 3.89 \\
\hline & & B & 7.93 & 8.67 & 9.05 & 8.37 & 9.07 & 9.69 \\
\hline & & c & 13.67 & 26.53 & 33.12 & 14.31 & 26.53 & 37.34 \\
\hline & & D & 63.50 & 79.93 & 94.48 & 74.34 & 136.52 & 272.56 \\
\hline & & E & 51.99 & 36.70 & 12.05 & 14.62 & 11.91 & 3.16 \\
\hline & & $\mathrm{F}$ & 3.36 & 4.20 & 5.04 & 35.98 & 44.97 & 53.97 \\
\hline & & H & 12.74 & 12.98 & 13.01 & 12.72 & 12.96 & 12.99 \\
\hline & & $k$ & 0.75 & 0.75 & 0.75 & 0.75 & 0.75 & 0.75 \\
\hline & Include micro/macroalgae & Total & 155.36 & 172.52 & 170.94 & 162.59 & 245.48 & 394.34 \\
\hline & Exclude micro/macroalgat & 4 Total & 100.01 & 131.62 & 153.85 & 111.99 & 188.60 & 337.21 \\
\hline Weighted Avg. Cost & Include mikro/macroalgae & e $5 /$ Tonne & $2,039.18$ & $1,951.79$ & $1,851.52$ & $1,232.96$ & $1,274.55$ & $1,369.02$ \\
\hline & Exelude miero/macroalgat & $4 /$ Tonne & $1,101.88$ & $1,123.84$ & $1,186.48$ & $1,134.25$ & $1,206.71$ & $1,329.58$ \\
\hline
\end{tabular}




\begin{tabular}{|c|c|c|c|c|c|c|c|c|}
\hline & OPEX Sens: & tivity & & & & & & \\
\hline & & & $-20 \%$ & & & & & \\
\hline & & & $2022-N$ & Tonnes Bio & & & ion Tonnes Biofuel & \\
\hline (C).15) & & Feedstock Group & Min & Med & Max & Min & Med & Max \\
\hline & A & & 1.42 & 2.76 & 3.45 & 1.49 & 2.76 & 3.89 \\
\hline & B & & 7.93 & 8.67 & 9.05 & 8.37 & 9.07 & 9.69 \\
\hline & c & & 13.67 & 26.53 & 33.12 & 14.31 & 26.53 & 37.34 \\
\hline & D & & 63.50 & 79.93 & 94.48 & 74.34 & 136.52 & 272.56 \\
\hline & E & & 51.99 & 36.70 & 12.05 & 14.62 & 11.91 & 3.16 \\
\hline & $\mathrm{F}$ & & 3.36 & 4.20 & 5.04 & 35.98 & 44.97 & 53.97 \\
\hline & H & & 12.74 & 12.98 & 13.01 & 12.72 & 12.96 & 12.99 \\
\hline & $\mathrm{k}$ & & 0.75 & 0.75 & 0.75 & 0.75 & 0.75 & 0.75 \\
\hline & Include micro/macroalgae Total & & 155.36 & 172.52 & 170.94 & 162.59 & 245.48 & 394.34 \\
\hline & Exclude micro/macroalgar Total & & 100.01 & 131.62 & 153.85 & 111.99 & 188.60 & 337.21 \\
\hline Weighted Avg. Cost & Include micro/macroalgae $\$ /$ Tonne & & $1,729.51$ & $1,690.83$ & $1,687.22$ & $1,017.59$ & $1,071.95$ & $1,175.35$ \\
\hline & Exclude micro/macroalzar $5 /$ Tonne & & 914.38 & 941.46 & $1,004.74$ & 945.63 & $1,016.37$ & $1,134.04$ \\
\hline & & & $+20 \%$ & & & & & \\
\hline & & Fendetock Groun & $2022-N$ & Tonnes Bio & & & lion Tonnes Biofuel & \\
\hline & & Feedstock Group & $\operatorname{Min}$ & Med & $\operatorname{Max}$ & Min & Med & $\operatorname{Max}$ \\
\hline & A & & 1.42 & 2.76 & 3.45 & 1.49 & 2.76 & 3.89 \\
\hline & B & & 7.93 & 8.67 & 9.05 & 8.37 & 9.07 & 9.69 \\
\hline & c & & 13.67 & 26.53 & 33.12 & 14.31 & 26.53 & 37.34 \\
\hline & D & & 63.50 & 79.93 & 94.48 & 74.34 & 136.52 & 272.56 \\
\hline & E & & 51.99 & 36.70 & 12.05 & 14.62 & 11.91 & 3.16 \\
\hline & $\mathbf{F}$ & & 3.36 & 4.20 & 5.04 & 35.98 & 44.97 & 53.97 \\
\hline & H & & 12.74 & 12.98 & 13.01 & 12.72 & 12.96 & 12.99 \\
\hline & $\underline{K}$ & & 0.75 & 0.75 & 0.75 & 0.75 & 0.75 & 0.75 \\
\hline & Include micro/macroalgae Total & & 155.36 & 172.52 & 170.94 & 162.59 & 245.48 & 394.34 \\
\hline & Exclude micro/macroalgar Total & & 100.01 & 131.62 & 153.85 & 111.99 & 188.60 & 337.21 \\
\hline Weighted Avg. Cost & Include micro/macroalgae $\$ /$ Tonne & & $1,988.66$ & $1,906.07$ & $1,851.54$ & $1,204.57$ & $1,241.13$ & $1,326.52$ \\
\hline & Exclude micro/macroalgar $\$ /$ Tonne & & $1,051.15$ & $1,077.99$ & $1,141.22$ & $1,082.13$ & $1,153.20$ & $1,271.27$ \\
\hline & $\begin{array}{lll}\text { Feedstock } \\
\end{array}$ & Cost Sensitivity & & & & & & \\
\hline & & & $-20 \%$ & & & & & \\
\hline & & Feedstock Group & $2022-N$ & Tonnes Bio & & & lion Tonnes Biofuel & \\
\hline & & (e) & Min & Med & $\operatorname{Max}$ & Min & Med & $\operatorname{Max}$ \\
\hline & A & & 1.42 & 2.76 & 3.45 & 1.49 & 2.76 & 3.89 \\
\hline & B & & 7.93 & 8.67 & 9.05 & 8.37 & 9.07 & 9.69 \\
\hline & c & & 13.67 & 26.53 & 33.12 & 14.31 & 26.53 & 37.34 \\
\hline & D & & 63.50 & 79.93 & 94.48 & 74.34 & 136.52 & 272.56 \\
\hline & E & & 51.99 & 36.70 & 12.05 & 14.62 & 11.91 & 3.16 \\
\hline & $\mathrm{F}$ & & 3.36 & 4.20 & 5.04 & 35.98 & 44.97 & 53.97 \\
\hline & $\mathrm{H}$ & & 12.74 & 12.98 & 13.01 & 12.72 & 12.96 & 12.99 \\
\hline & $\underline{k}$ & & 0.75 & 0.75 & 0.75 & 0.75 & 0.75 & 0.75 \\
\hline & Include micro/macroalgae Total & & 155.36 & 172.52 & 170.94 & 162.59 & 245.48 & 394.34 \\
\hline & Exclude micro/macroalgar Total & & 100.01 & 131.62 & 153.85 & 111.99 & 188.60 & 337.21 \\
\hline Weighted Avg. Cost & Include micro/macroalgae $\mathrm{S} /$ Tonne & & $1,518.64$ & $1,505.72$ & $1,527.22$ & 996.80 & $1,048.75$ & $1,142.99$ \\
\hline & Exclude micro/macroalgar $\$ /$ Tonne & & 926.38 & 942.90 & 992.90 & 952.53 & $1,011.05$ & $1,110.62$ \\
\hline & & & $+20 \%$ & & & & & \\
\hline & & Feedstock Group & $2022-N$ & Tonnes Bio & & & lion Tonnes Biofuel & \\
\hline (C3.18) & & 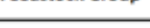 & Min & Med & Max & Min & Med & Max \\
\hline & A & & 1.42 & 2.76 & 3.45 & 1.49 & 2.76 & 3.89 \\
\hline & B & & 7.93 & 8.67 & 9.05 & 8.37 & 9.07 & 9.69 \\
\hline & c & & 13.67 & 26.53 & 33.12 & 14.31 & 26.53 & 37.34 \\
\hline & D & & 63.50 & 79.93 & 94.48 & 74.34 & 136.52 & 272.56 \\
\hline & E & & 51.99 & 36.70 & 12.05 & 14.62 & 11.91 & 3.16 \\
\hline & $\mathrm{F}$ & & 3.36 & 4.20 & 5.04 & 35.98 & 44.97 & 53.97 \\
\hline & H & & 12.74 & 12.98 & 13.01 & 12.72 & 12.96 & 12.99 \\
\hline & $K$ & & 0.75 & 0.75 & 0.75 & 0.75 & 0.75 & 0.75 \\
\hline & Include micro/macroalgae Total & & 155.36 & 172.52 & 170.94 & 162.59 & 245.48 & 394.34 \\
\hline & Exclude micro/macroalgar Total & & 100.01 & 131.62 & 153.85 & 111.99 & 188.60 & 337.21 \\
\hline Weighted Avg. Cost & Include micro/macroalgae $\$$ /Tonne & & $2,199.54$ & $2,091.17$ & $2,011.54$ & $1,225.36$ & $1,264.33$ & $1,358.88$ \\
\hline & Exclude micro/macroalgar \$/Tonne & & $1,039.15$ & $1,076.55$ & $1,153.06$ & $1,075.23$ & $1,158.52$ & $1,294.70$ \\
\hline
\end{tabular}


Table C4. Solver Results (C4.19-C4.27) for Optimization Constraint: Maximize Total Marine Biofuel. All Results in Million Metric Tons Biofuel.

Maximize the Production of Marine Biofuels - Results in MM Tonne

Results in MM MT

(C4.19)

\begin{tabular}{|c|c|c|c|c|c|c|}
\hline \multirow{2}{*}{ Feedstock Group } & \multicolumn{3}{|c|}{2022 - Million Tonnes Biofuel/yr } & \multicolumn{3}{|c|}{2040 - Million Tonnes Biofuel/yr } \\
\hline & Min & Med & Max & Min & Med & $\operatorname{Max}$ \\
\hline $\bar{A}$ & 0.95 & 1.85 & 2.31 & 1.00 & 1.85 & 2.61 \\
\hline B & 7.77 & 8.50 & 8.87 & 8.20 & 8.89 & 9.50 \\
\hline c & - & - & - & - & - & - \\
\hline D & 48.85 & 61.49 & 72.69 & 57.20 & 105.04 & 209.70 \\
\hline $\mathrm{E}$ & 39.78 & 28.07 & 9.22 & 11.18 & 9.11 & 2.42 \\
\hline $\mathrm{F}$ & - & - & - & - & - & - \\
\hline H & 5.04 & 5.14 & 5.15 & 5.04 & 5.13 & 5.14 \\
\hline $\mathrm{k}$ & 0.68 & 0.68 & 0.68 & 0.68 & 0.68 & 0.68 \\
\hline Total & 103.09 & 105.74 & 98.92 & 83.31 & 130.71 & 230.05 \\
\hline Total & 63.31 & 77.66 & 89.70 & 72.13 & 121.60 & 227.63 \\
\hline le $\overline{\$} /$ Tonne & $1,947.18$ & $1,976.39$ & $1,998.73$ & $1,109.18$ & $1,159.81$ & $1,261.30$ \\
\hline$\overline{\$} /$ Tonne & 908.56 & 989.09 & $1,083.79$ & 951.25 & $1,058.32$ & $1,196.60$ \\
\hline
\end{tabular}

(C4.20)

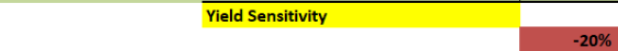

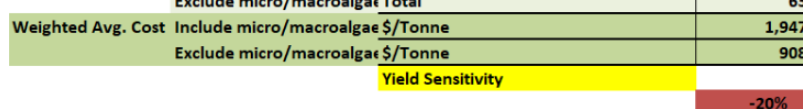

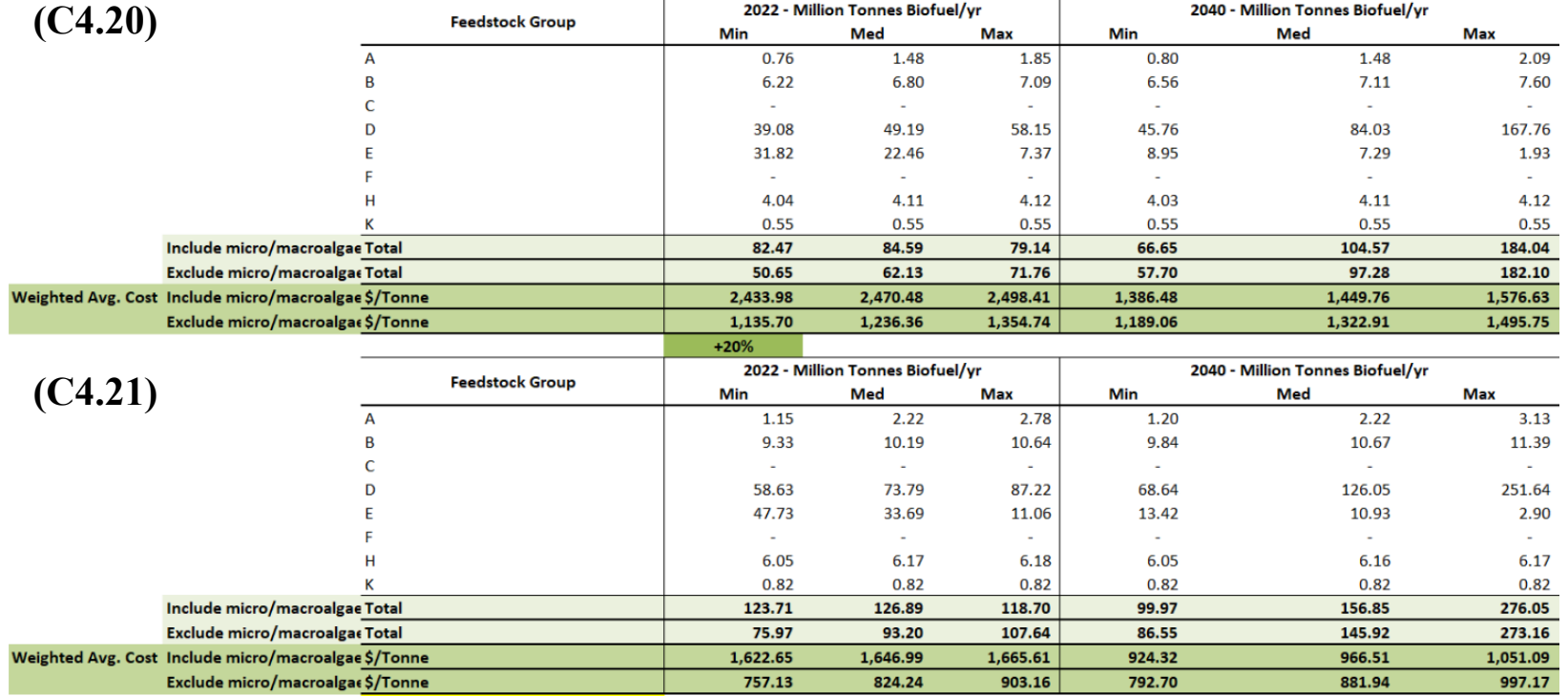

(C4.22)

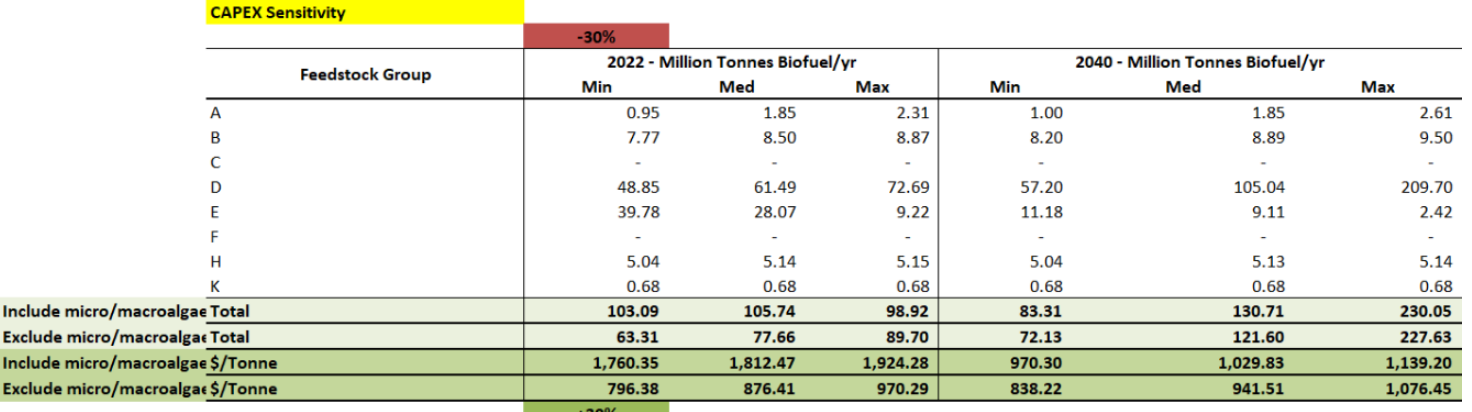

Weighted Avg. Cost Include micro/macroalgae \$/Tonne

(C4.23)

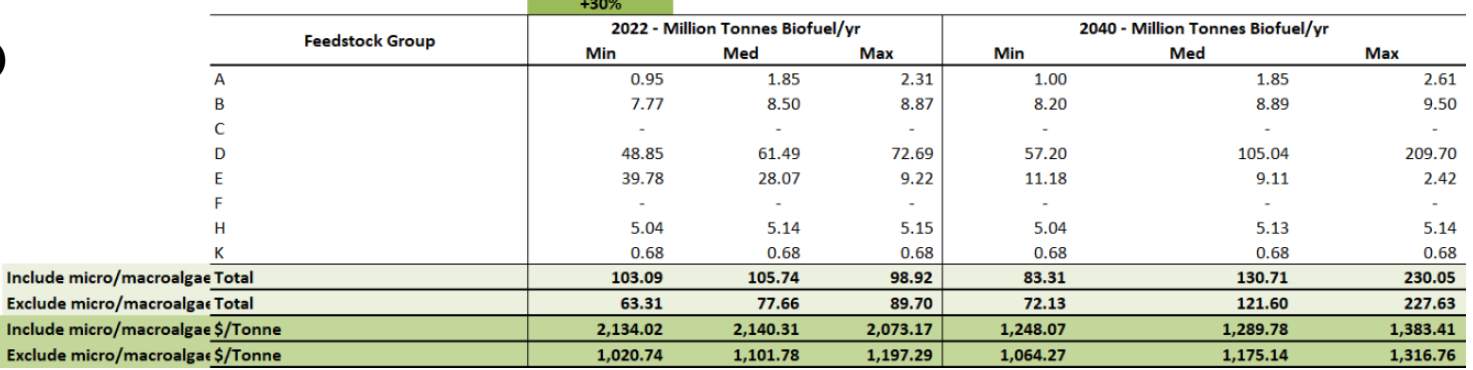




\begin{tabular}{|c|c|c|c|c|c|c|c|c|}
\hline \multicolumn{9}{|c|}{ OPEX Sensitivity } \\
\hline ( C4 14$)$ & & \multirow[b]{2}{*}{ Feedstock Group } & \multicolumn{3}{|c|}{2022 - Million Tonnes Biofuel/yr } & \multicolumn{3}{|c|}{2040 - Million Tonnes Biofuel/yr } \\
\hline$(C 4.24)$ & & & Min & Med & Max & Min & Med & Max \\
\hline & A & & 0.95 & 1.85 & 2.31 & 1.00 & 1.85 & 2.61 \\
\hline & B & & 7.77 & 8.50 & 8.87 & 8.20 & 8.89 & 9.50 \\
\hline & c & & - & - & - & - & - & - \\
\hline & D & & 48.85 & 61.49 & 72.69 & 57.20 & 105.04 & 209.70 \\
\hline & $\mathrm{E}$ & & 39.78 & 28.07 & 9.22 & 11.18 & 9.11 & 2.42 \\
\hline & $\mathrm{F}$ & & - & - & - & - & - & - \\
\hline & $\mathrm{H}$ & & 5.04 & 5.14 & 5.15 & 5.04 & 5.13 & 5.14 \\
\hline & $\mathrm{k}$ & & 0.68 & 0.68 & 0.68 & 0.68 & 0.68 & 0.68 \\
\hline & \multicolumn{2}{|l|}{ Include micro/macroalgae Total } & 103.09 & 105.74 & 98.92 & 83.31 & 130.71 & 230.05 \\
\hline & \multicolumn{2}{|l|}{ Exclude micro/macroalgat Total } & 63.31 & 77.66 & 89.70 & 72.13 & 121.60 & 227.63 \\
\hline \multirow{15}{*}{ Weighted Avg. Cost } & \multicolumn{2}{|l|}{ Include micro/macroalgae $\$ /$ Tonne } & $1,824.30$ & $1,878.46$ & $1,936.35$ & $1,038.07$ & $1,102.36$ & $1,216.25$ \\
\hline & \multicolumn{2}{|l|}{ Exclude micro/macroalgat $\$ /$ Tonne } & 864.68 & 945.64 & $1,040.55$ & 907.66 & $1,015.19$ & $1,153.71$ \\
\hline & & & \multirow{2}{*}{\multicolumn{3}{|c|}{$\begin{array}{l}+20 \% \\
2022 \text { - Million Tonnes Biofuel/yr }\end{array}$}} & & & \\
\hline & & & & & & \multicolumn{3}{|c|}{2040 - Million Tonnes Biofuel/yr } \\
\hline & & Feedstock Group & Min & Med & Max & Min & Med & Max \\
\hline & A & & 0.95 & 1.85 & 2.31 & 1.00 & 1.85 & 2.61 \\
\hline & B & & 7.77 & 8.50 & 8.87 & 8.20 & 8.89 & 9.50 \\
\hline & c & & - & - & - & - & - & - \\
\hline & D & & 48.85 & 61.49 & 72.69 & 57.20 & 105.04 & 209.70 \\
\hline & $\mathrm{E}$ & & 39.78 & 28.07 & 9.22 & 11.18 & 9.11 & 2.42 \\
\hline & $\mathrm{F}$ & & - & - & - & - & - & - \\
\hline & H & & 5.04 & 5.14 & 5.15 & 5.04 & 5.13 & 5.14 \\
\hline & $\mathrm{k}$ & & 0.68 & 0.68 & 0.68 & 0.68 & 0.68 & 0.68 \\
\hline & \multicolumn{2}{|l|}{ Include micro/macroalgae Total } & 103.09 & 105.74 & 98.92 & 83.31 & 130.71 & 230.05 \\
\hline & \multicolumn{2}{|l|}{ Exclude micro/macroalgat Total } & 63.31 & 77.66 & 89.70 & 72.13 & 121.60 & 227.63 \\
\hline \multirow{16}{*}{ Weighted Avg. Cost } & Include micro/macroalgae $\$ /$ Tonne & & $2,070.06$ & $2,074.31$ & $2,061.10$ & $1,180.29$ & $1,217.26$ & $1,306.36$ \\
\hline & Exclude micro/macroalgat $\$ /$ Tonne & & 952.44 & $1,032.54$ & $1,127.03$ & 994.83 & $1,101.45$ & $1,239.50$ \\
\hline & $\begin{array}{ll}\text { Feedstock } \\
\end{array}$ & Cost Sensitivity & & & & & & \\
\hline & & & $-20 \%$ & & & & & \\
\hline & & & $2022-M$ & Tonnes Bio & & & ion Tonnes Biofue & \\
\hline & & Feedstock Group & Min & Med & $\operatorname{Max}$ & Min & Med & Max \\
\hline & A & & 0.95 & 1.85 & 2.31 & 1.00 & 1.85 & 2.61 \\
\hline & B & & 7.77 & 8.50 & 8.87 & 8.20 & 8.89 & 9.50 \\
\hline & c & & - & - & - & - & - & - \\
\hline & D & & 48.85 & 61.49 & 72.69 & 57.20 & 105.04 & 209.70 \\
\hline & E & & 39.78 & 28.07 & 9.22 & 11.18 & 9.11 & 2.42 \\
\hline & $\mathrm{F}$ & & - & - & - & - & - & - \\
\hline & $\mathrm{H}$ & & 5.04 & 5.14 & 5.15 & 5.04 & 5.13 & 5.14 \\
\hline & $\mathrm{k}$ & & 0.68 & 0.68 & 0.68 & 0.68 & 0.68 & 0.68 \\
\hline & Include micro/macroalgae Total & & 103.09 & 105.74 & 98.92 & 83.31 & 130.71 & 230.05 \\
\hline & Exclude micro/macroalgat Total & & 63.31 & 77.66 & 89.70 & 72.13 & 121.60 & 227.63 \\
\hline Weighted Avg. Cost & Include micro/macroalgae $\$$ /Tonne & & $1,555.31$ & $1,614.34$ & $1,683.60$ & 959.57 & $1,021.66$ & $1,122.93$ \\
\hline & Exclude micro/macroalga $\$ /$ Tonne & & 838.35 & 902.96 & 979.23 & 872.92 & 961.27 & $1,074.33$ \\
\hline & & & $+20 \%$ & & & & & \\
\hline & & Feedstock Groun & $2022-M$ & Tonnes Bio & & & ion Tonnes Biofue & \\
\hline( & & Feedstock Group & Min & Med & Max & Min & Med & Max \\
\hline & A & & 0.95 & 1.85 & 2.31 & 1.00 & 1.85 & 2.61 \\
\hline & B & & 7.77 & 8.50 & 8.87 & 8.20 & 8.89 & 9.50 \\
\hline & c & & - & - & - & - & - & - \\
\hline & D & & 48.85 & 61.49 & 72.69 & 57.20 & 105.04 & 209.70 \\
\hline & $\mathrm{E}$ & & 39.78 & 28.07 & 9.22 & 11.18 & 9.11 & 2.42 \\
\hline & $\mathrm{F}$ & & - & - & - & - & - & - \\
\hline & H & & 5.04 & 5.14 & 5.15 & 5.04 & 5.13 & 5.14 \\
\hline & $\underline{K}$ & & 0.68 & 0.68 & 0.68 & 0.68 & 0.68 & 0.68 \\
\hline & Include micro/macroalgae Total & & 103.09 & 105.74 & 98.92 & 83.31 & 130.71 & 230.05 \\
\hline & Exclude micro/macroalga $\mathrm{Total}$ & & 63.31 & 77.66 & 89.70 & 72.13 & 121.60 & 227.63 \\
\hline Weighted Avg. Cost & Include micro/macroalgae $\$$ /Tonne & & $2,339.06$ & $2,338.43$ & $2,313.86$ & $1,258.79$ & $1,297.95$ & $1,399.68$ \\
\hline & Exclude micro/macroalgat $\$$ /Tonne & & 978.77 & $1,075.22$ & $1,188.35$ & $1,029.57$ & $1,155.37$ & $1,318.88$ \\
\hline
\end{tabular}


Table C5. Solver Results (C5.28-C5.36) for Optimization Constraint: Minimize Biofuel Cost. Data Are the Complementary Results to the Optimization Function (i.e., the Production Capacity Values at Optimized Cost). All Results in Million Metric Tons Biofuel.

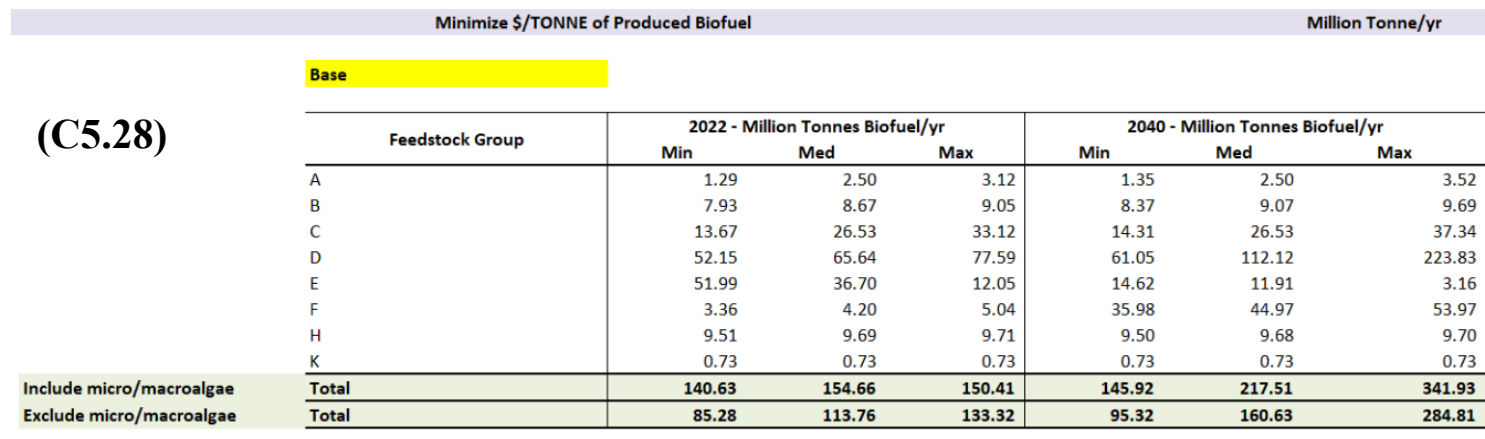

(C5.29)

\begin{tabular}{|c|c|c|c|c|c|c|}
\hline \multicolumn{7}{|l|}{ Yield Sensitivity } \\
\hline & $-20 \%$ & & & & & \\
\hline \multirow{2}{*}{ Feedstock Group } & \multicolumn{3}{|c|}{2022 - Million Tonnes Biofuel/yr } & \multicolumn{3}{|c|}{2040 - Million Tonnes Biofuel/yr } \\
\hline & Min & Med & Max & Min & Med & $\operatorname{Max}$ \\
\hline A & 1.03 & 2.00 & 2.50 & 1.08 & 2.00 & 2.81 \\
\hline B & 6.35 & 6.94 & 7.24 & 6.70 & 7.26 & 7.75 \\
\hline c & 10.93 & 21.22 & 26.50 & 11.45 & 21.22 & 29.87 \\
\hline D & 41.72 & 52.51 & 62.07 & 48.84 & 89.70 & 178.86 \\
\hline E & 41.59 & 29.36 & 9.64 & 11.69 & 9.53 & 2.53 \\
\hline $\mathrm{F}$ & 2.69 & 3.36 & 4.03 & 28.78 & 35.98 & 43.17 \\
\hline H & 7.61 & 7.75 & 7.77 & 7.60 & 7.75 & 7.76 \\
\hline$k$ & 0.58 & 0.58 & 0.58 & 0.58 & 0.58 & 0.58 \\
\hline Total & 112.51 & 123.73 & 120.33 & 116.73 & 174.01 & 273.34 \\
\hline Total & 68.22 & 91.01 & 106.66 & 76.26 & 128.51 & 227.64 \\
\hline
\end{tabular}

(C5.30)

Include micro/macroalgae

\begin{tabular}{|c|c|c|c|c|c|c|}
\hline \multirow{3}{*}{ Feedstock Group } & $+20 \%$ & & & & & \\
\hline & \multicolumn{3}{|c|}{2022 - Million Tonnes Biofuel/yr } & \multicolumn{3}{|c|}{2040 - Million Tonnes Biofuel/yr } \\
\hline & Min & Med & $\operatorname{Max}$ & Min & Med & $\operatorname{Max}$ \\
\hline A & 1.55 & 3.00 & 3.74 & 1.62 & 3.00 & 4.22 \\
\hline B & 9.52 & 10.40 & 10.86 & 0.00 & 0.00 & 0.00 \\
\hline c & 16.40 & 31.84 & 39.74 & 17.18 & 31.84 & 44.80 \\
\hline D & 62.58 & 78.77 & 93.10 & 73.27 & 134.54 & 268.60 \\
\hline $\mathrm{E}$ & 62.39 & 44.03 & 14.46 & 17.54 & 14.29 & 3.79 \\
\hline $\mathrm{F}$ & 4.03 & 5.04 & 6.05 & 43.17 & 53.97 & 64.76 \\
\hline H & 11.42 & 11.63 & 11.66 & 11.40 & 11.62 & 11.64 \\
\hline $\mathrm{k}$ & 0.88 & 0.88 & 0.88 & 0.88 & 0.88 & 0.88 \\
\hline Total & 168.76 & 185.59 & 180.49 & 165.06 & 250.13 & 398.69 \\
\hline Total & 102.34 & 136.51 & 159.98 & 104.34 & 181.87 & 330.14 \\
\hline
\end{tabular}

Exclude micro/macroalgae

CAPEX Sensitivity

(C5.31)

\begin{tabular}{|c|c|c|c|c|c|c|}
\hline \multirow{2}{*}{ Feedstock Group } & \multicolumn{3}{|c|}{2022 - Million Tonnes Biofuel/yr } & \multicolumn{3}{|c|}{2040 - Million Tonnes Biofuel/yr } \\
\hline & Min & Med & Max & Min & Med & Max \\
\hline A & 1.29 & 2.50 & 3.12 & 1.35 & 2.50 & 3.52 \\
\hline B & 7.93 & 8.67 & 9.05 & 8.37 & 9.07 & 9.69 \\
\hline c & 13.67 & 26.53 & 33.12 & 14.31 & 26.53 & 37.34 \\
\hline D & 52.15 & 65.64 & 77.59 & 61.05 & 112.12 & 223.83 \\
\hline E & 51.99 & 36.70 & 12.05 & 14.62 & 11.91 & 3.16 \\
\hline $\mathrm{F}$ & 3.36 & 4.20 & 5.04 & 35.98 & 44.97 & 53.97 \\
\hline H & 9.51 & 9.69 & 9.71 & 9.50 & 9.68 & 9.70 \\
\hline $\mathrm{k}$ & 0.73 & 0.73 & 0.73 & 0.73 & 0.73 & 0.73 \\
\hline Total & 140.63 & 154.66 & 150.41 & 145.92 & 217.51 & 341.93 \\
\hline Total & 85.28 & 113.76 & 133.32 & 95.32 & 160.63 & 284.81 \\
\hline
\end{tabular}

(C5.32)

Include micro/macroalgae Exclude micro/macroalgae

\begin{tabular}{|c|c|c|c|c|c|c|}
\hline \multirow{3}{*}{ Feedstock Group } & $+30 \%$ & & & & & \\
\hline & \multicolumn{3}{|c|}{2022 - Million Tonnes Biofuel/yr } & \multicolumn{3}{|c|}{2040 - Million Tonnes Biofuel/yr } \\
\hline & Min & Med & Max & Min & Med & Max \\
\hline A & 1.29 & 2.50 & 3.12 & 1.35 & 2.50 & 3.52 \\
\hline B & 7.93 & 8.67 & 9.05 & 8.37 & 9.07 & 9.69 \\
\hline c & 13.67 & 26.53 & 33.12 & 14.31 & 26.53 & 37.34 \\
\hline D & 50.17 & 65.64 & 77.59 & 61.05 & 112.12 & 223.83 \\
\hline E & 51.99 & 36.70 & 12.05 & 14.62 & 11.91 & 3.16 \\
\hline $\mathrm{F}$ & 3.36 & 4.20 & 5.04 & 35.98 & 44.97 & 53.97 \\
\hline H & 9.51 & 9.69 & 9.71 & 9.50 & 9.68 & 9.70 \\
\hline K & 0.63 & 0.73 & 0.73 & 0.63 & 0.73 & 0.73 \\
\hline Total & 138.55 & 154.66 & 150.41 & 145.82 & 217.51 & 341.93 \\
\hline Total & 83.20 & 113.76 & 133.32 & 95.22 & 160.63 & 284.81 \\
\hline
\end{tabular}


(C5.33)

\begin{tabular}{|c|c|c|c|c|c|c|}
\hline \multicolumn{7}{|l|}{ OPEX Sensitivity } \\
\hline & $-20 \%$ & & & & & \\
\hline \multirow{2}{*}{ Feedstock Group } & \multicolumn{3}{|c|}{2022 - Million Tonnes Biofuel/yr } & \multicolumn{3}{|c|}{2040 - Million Tonnes Biofuel/yr } \\
\hline & Min & Med & Max & Min & Med & Max \\
\hline A & 1.29 & 2.50 & 3.12 & 1.35 & 2.50 & 3.52 \\
\hline B & 7.93 & 8.67 & 9.05 & 8.37 & 9.07 & 9.69 \\
\hline c & 13.67 & 26.53 & 33.12 & 14.31 & 26.53 & 37.34 \\
\hline D & 52.15 & 65.64 & 72.54 & 61.05 & 112.12 & 223.83 \\
\hline$E$ & 51.99 & 36.70 & 12.05 & 14.62 & 11.91 & 3.16 \\
\hline $\mathrm{F}$ & 3.36 & 4.20 & 5.04 & 35.98 & 44.97 & 53.97 \\
\hline $\mathrm{H}$ & 9.51 & 9.69 & 9.71 & 9.50 & 9.68 & 9.70 \\
\hline K & 0.73 & 0.73 & 0.73 & 0.73 & 0.73 & 0.73 \\
\hline Total & 140.63 & 154.66 & 145.36 & 145.92 & 217.51 & 341.93 \\
\hline Total & 85.28 & 113.76 & 128.27 & 95.32 & 160.63 & 284.81 \\
\hline
\end{tabular}

(C5.34)

Include micro/macroalgae

\begin{tabular}{|c|c|c|c|c|c|c|}
\hline \multirow{3}{*}{ Feedstock Group } & $+20 \%$ & & & & & \\
\hline & \multicolumn{3}{|c|}{2022 - Million Tonnes Biofuel/yr } & \multicolumn{3}{|c|}{2040 - Million Tonnes Biofuel/yr } \\
\hline & Min & Med & Max & Min & Med & Max \\
\hline A & 1.29 & 2.50 & 3.12 & 1.35 & 2.50 & 3.52 \\
\hline B & 7.93 & 8.67 & 9.05 & 8.37 & 9.07 & 9.69 \\
\hline C & 13.67 & 26.53 & 33.12 & 14.31 & 26.53 & 37.34 \\
\hline D & 52.15 & 65.64 & 77.59 & 61.05 & 112.12 & 223.83 \\
\hline$E$ & 51.99 & 36.70 & 12.05 & 14.62 & 11.91 & 3.16 \\
\hline $\mathrm{F}$ & 3.36 & 4.20 & 5.04 & 35.98 & 44.97 & 53.97 \\
\hline $\mathrm{H}$ & 9.51 & 9.69 & 9.71 & 9.50 & 9.68 & 9.70 \\
\hline K & 0.73 & 0.73 & 0.73 & 0.73 & 0.73 & 0.73 \\
\hline Total & 140.63 & 154.66 & 150.41 & 145.92 & 217.51 & 341.93 \\
\hline Total & 85.28 & 113.76 & 133.32 & 95.32 & 160.63 & 284.81 \\
\hline
\end{tabular}

Exclude micro/macroalgae

Feedstock Cost Sensitivity

(C5.35)

\begin{tabular}{|c|c|c|c|c|c|c|}
\hline \multirow{3}{*}{ Feedstock Group } & \multicolumn{6}{|l|}{$-20 \%$} \\
\hline & \multicolumn{3}{|c|}{2022 - Million Tonnes Biofuel/yr } & \multicolumn{3}{|c|}{2040 - Million Tonnes Biofuel/yr } \\
\hline & Min & Med & Max & Min & Med & Max \\
\hline A & 1.29 & 2.50 & 3.12 & 1.35 & 2.50 & 3.52 \\
\hline B & 7.93 & 8.67 & 9.05 & 8.37 & 9.07 & 9.69 \\
\hline c & 13.67 & 26.53 & 33.12 & 14.31 & 26.53 & 37.34 \\
\hline D & 44.85 & 65.64 & 77.59 & 61.05 & 112.12 & 223.83 \\
\hline E & 51.99 & 36.70 & 12.05 & 14.62 & 11.91 & 3.16 \\
\hline $\mathrm{F}$ & 3.36 & 4.20 & 5.04 & 35.98 & 44.97 & 53.97 \\
\hline H & 9.51 & 9.69 & 9.72 & 9.50 & 9.68 & 9.70 \\
\hline $\mathrm{K}$ & 0.63 & 0.73 & 0.73 & 0.63 & 0.73 & 0.73 \\
\hline Total & 133.24 & 154.66 & 150.41 & 145.82 & 217.51 & 341.93 \\
\hline Total & 77.88 & 113.76 & 133.32 & 95.22 & 160.63 & 284.81 \\
\hline
\end{tabular}

(C5.36)

Include micro/macroalgae

$++20 \%$

\begin{tabular}{|c|c|c|c|c|c|c|}
\hline \multirow{2}{*}{ Feedstock Group } & \multicolumn{3}{|c|}{2022 - Million Tonnes Biofuel/yr } & \multicolumn{3}{|c|}{2040 - Million Tonnes Biofuel/yr } \\
\hline & Min & Med & Max & Min & Med & Max \\
\hline A & 1.29 & 2.50 & 3.12 & 1.35 & 2.50 & 3.52 \\
\hline B & 7.93 & 8.67 & 9.05 & 8.37 & 9.07 & 9.69 \\
\hline c & 13.67 & 26.53 & 33.12 & 14.31 & 26.53 & 37.34 \\
\hline D & 52.15 & 65.64 & 77.59 & 61.05 & 112.12 & 223.83 \\
\hline E & 51.99 & 36.70 & 12.05 & 14.62 & 11.91 & 3.16 \\
\hline $\mathrm{F}$ & 3.36 & 4.20 & 5.04 & 35.98 & 44.97 & 53.97 \\
\hline H & 9.51 & 9.69 & 9.72 & 9.50 & 9.68 & 9.70 \\
\hline K & 0.73 & 0.73 & 0.73 & 0.73 & 0.73 & 0.73 \\
\hline Total & 140.63 & 154.66 & 150.41 & 145.92 & 217.51 & 341.93 \\
\hline Total & 85.28 & 113.76 & 133.32 & 95.32 & 160.63 & 284.81 \\
\hline
\end{tabular}

This report is available at no cost from the National Renewable Energy Laboratory at www.nrel.gov/publications. 
Table C6. Solver Results (C6.37-C6.45) for Optimization Constraint: Maximize Total Biofuel. Data Compiled are the Complementary Results to the Optimization Function (i.e., Biofuel Cost at the Optimized Production Capacity). All Results in \$/MT Biofuel.

\begin{tabular}{|c|c|c|c|c|c|c|c|c|c|c|c|c|}
\hline \multicolumn{13}{|c|}{ Maximize Total Output - Results in $\$ /$ Tonne } \\
\hline \multicolumn{13}{|l|}{ Base } \\
\hline \multirow{2}{*}{ Feedstock Group } & \multicolumn{6}{|c|}{2022 - Results in \$/Tonne } & \multicolumn{6}{|c|}{2040 - Results in \$/Tonne } \\
\hline & & Min & & Med & & Max & & Min & & Med & & Max \\
\hline A & $\$$ & 410.47 & $\$$ & 419.72 & $\$$ & 431.29 & $\$$ & 410.47 & $\$$ & 419.72 & $\$$ & 431.29 \\
\hline B & $\$$ & 108.72 & $\$$ & 121.41 & $\$$ & 138.31 & $\$$ & 108.74 & $\$$ & 121.62 & $\$$ & 137.97 \\
\hline C & $\$$ & 582.40 & $\$$ & 623.71 & $\$$ & 675.35 & $\$$ & 582.40 & $\$$ & 623.71 & $\$$ & 675.35 \\
\hline D & $\$$ & $1,119.97$ & $\$$ & $1,189.03$ & $\$$ & $1,265.50$ & $\$$ & $1,156.06$ & $\$$ & $1,221.04$ & $\$$ & $1,309.58$ \\
\hline E & $\$$ & $3,600.34$ & $\$$ & $4,707.58$ & $\$$ & $10,901.57$ & $\$$ & $2,127.71$ & $\$$ & $2,514.39$ & $\$$ & $7,358.54$ \\
\hline $\mathrm{F}$ & $\$$ & $1,000.59$ & $\$$ & $1,097.94$ & $\$$ & $1,195.29$ & $\$$ & $1,000.59$ & $\$$ & $1,097.94$ & $\$$ & $1,195.29$ \\
\hline H & $\$$ & $1,333.77$ & $\$$ & $1,408.27$ & $\$$ & $1,500.54$ & $\$$ & $1,333.72$ & $\$$ & $1,408.21$ & $\$$ & $1,500.48$ \\
\hline K & $\$$ & $1,031.18$ & $\$$ & $1,102.62$ & $\$$ & 1,191.91 & $\$$ & $1,031.18$ & $\$$ & $1,102.62$ & $\$$ & $1,191.91$ \\
\hline
\end{tabular}

\begin{tabular}{|c|c|c|c|c|c|c|c|c|c|c|c|c|}
\hline \multicolumn{13}{|l|}{ Yield Sensitivity } \\
\hline \multirow{3}{*}{ Feedstock Group } & & $-20 \%$ & & & & & & & & & & \\
\hline & \multicolumn{6}{|c|}{2022 - Results in \$/Tonne } & \multicolumn{6}{|c|}{2040 - Results in \$/Tonne } \\
\hline & & Min & & Med & & $\operatorname{Max}$ & & Min & & Med & & Max \\
\hline A & $\$$ & 513.09 & $\$$ & 524.65 & $\$$ & 539.12 & $\$$ & 513.09 & $\$$ & 524.65 & $\$$ & 539.12 \\
\hline B & $\$$ & 135.90 & $\$$ & 151.77 & $\$$ & 172.89 & $\$$ & 135.92 & $\$$ & 152.02 & $\$$ & 172.46 \\
\hline C & $\$$ & 728.00 & $\$$ & 779.64 & $\$$ & 844.19 & $\$$ & 728.00 & $\$$ & 779.64 & $\$$ & 844.19 \\
\hline D & $\$$ & $1,399.97$ & $\$$ & $1,486.29$ & $\$$ & $1,581.88$ & $\$$ & $1,445.08$ & $\$$ & $1,526.30$ & $\$$ & $1,636.98$ \\
\hline$E$ & $\$$ & $4,500.42$ & $\$$ & $5,884.48$ & $\$$ & $13,626.96$ & $\$$ & $2,659.64$ & $\$$ & $3,142.99$ & $\$$ & $9,198.17$ \\
\hline $\mathrm{F}$ & $\$$ & $1,250.73$ & $\$$ & $1,372.42$ & $\$$ & $1,494.11$ & $\$$ & $1,250.73$ & $\$$ & $1,372.42$ & $\$$ & $1,494.11$ \\
\hline H & $\$$ & $1,667.21$ & $\$$ & $1,760.33$ & $\$$ & $1,875.68$ & $\$$ & $1,667.15$ & $\$$ & $1,760.26$ & $\$$ & $1,875.59$ \\
\hline $\mathrm{K}$ & $\$$ & $1,288.98$ & $\$$ & $1,378.27$ & $\$$ & $1,489.89$ & $\$$ & $1,288.98$ & $\$$ & $1,378.27$ & $\$$ & $1,489.89$ \\
\hline
\end{tabular}

(C6.39)

\begin{tabular}{|c|c|c|c|c|c|c|c|c|c|c|c|c|}
\hline \multirow{3}{*}{ Feedstock Group } & & $+20 \%$ & & & & & & & & & & \\
\hline & \multicolumn{6}{|c|}{2022 - Results in \$/Tonne } & \multicolumn{6}{|c|}{2040 - Results in $\$ /$ Tonne } \\
\hline & & Min & & Med & & Max & & Min & & Med & & Max \\
\hline A & $\$$ & 342.06 & $\$$ & 349.77 & $\$$ & 359.41 & $\$$ & 342.06 & $\$$ & 349.77 & $\$$ & 359.41 \\
\hline B & $\$$ & 90.60 & $\$$ & 101.18 & $\$$ & 115.26 & $\$$ & 90.62 & $\$$ & 101.35 & $\$$ & 114.97 \\
\hline C & $\$$ & 485.33 & $\$$ & 519.76 & $\$$ & 562.80 & $\$$ & 485.33 & $\$$ & 519.76 & $\$$ & 562.80 \\
\hline D & $\$$ & 933.31 & $\$$ & 990.86 & $\$$ & $1,054.59$ & $\$$ & 963.39 & $\$$ & $1,017.53$ & $\$$ & $1,091.32$ \\
\hline E & $\$$ & $3,000.28$ & $\$$ & $3,922.99$ & $\$$ & $9,084.64$ & $\$$ & $1,773.09$ & $\$$ & $2,095.33$ & $\$$ & $6,132.11$ \\
\hline $\mathrm{F}$ & $\$$ & 833.82 & $\$$ & 914.95 & $\$$ & 996.07 & $\$$ & 833.82 & $\$$ & 914.95 & $\$$ & 996.07 \\
\hline H & $\$$ & $1,111.47$ & $\$$ & $1,173.55$ & $\$$ & $1,250.45$ & $\$$ & $1,111.43$ & $\$$ & $1,173.51$ & $\$$ & $1,250.40$ \\
\hline K & $\$$ & 859.32 & $\$$ & 918.85 & $\$$ & 993.26 & $\$$ & 859.32 & $\$$ & 918.85 & $\$$ & 993.26 \\
\hline
\end{tabular}

(C6.40)

\begin{tabular}{|c|c|c|c|c|c|c|c|c|c|c|c|c|}
\hline \multicolumn{13}{|l|}{ CAPEX Sensitivity } \\
\hline \multirow{3}{*}{ Feedstock Group } & & $-30 \%$ & & & & & & & & & & \\
\hline & \multicolumn{6}{|c|}{2022 - Results in \$/Tonne } & \multicolumn{6}{|c|}{2040 - Results in \$/Tonne } \\
\hline & & Min & & Med & & Max & & Min & & Med & & Max \\
\hline A & $\$$ & 359.06 & $\$$ & 368.32 & $\$$ & 379.88 & $\$$ & 359.06 & $\$$ & 368.32 & $\$$ & 379.88 \\
\hline B & $\$$ & 100.13 & $\$$ & 112.82 & $\$$ & 129.72 & $\$$ & 100.14 & $\$$ & 113.03 & $\$$ & 129.37 \\
\hline C & $\$$ & 529.53 & $\$$ & 570.84 & $\$$ & 622.48 & $\$$ & 529.53 & $\$$ & 570.84 & $\$$ & 622.48 \\
\hline D & $\$$ & 979.09 & $\$$ & $1,048.15$ & $\$$ & $1,124.62$ & $\$$ & $1,015.18$ & $\$$ & $1,080.16$ & $\$$ & $1,168.70$ \\
\hline $\mathrm{E}$ & $\$$ & $3,294.68$ & $\$$ & $4,401.93$ & $\$$ & $11,207.22$ & $\$$ & $1,822.05$ & $\$$ & $2,208.73$ & $\$$ & $7,052.88$ \\
\hline $\mathrm{F}$ & $\$$ & 948.67 & $\$$ & $1,046.02$ & $\$$ & $1,143.38$ & $\$$ & 948.67 & $\$$ & $1,046.02$ & $\$$ & $1,143.38$ \\
\hline H & $\$$ & $1,177.98$ & $\$$ & $1,252.48$ & $\$$ & $1,344.76$ & $\$$ & $1,177.94$ & $\$$ & $1,252.42$ & $\$$ & $1,344.69$ \\
\hline $\mathrm{K}$ & $\$$ & 872.21 & $\$$ & 943.65 & $\$$ & $1,032.94$ & $\$$ & 872.21 & $\$$ & 943.65 & $\$$ & $1,032.94$ \\
\hline
\end{tabular}

(C6.41)

\begin{tabular}{|c|c|c|c|c|c|c|c|c|c|c|c|c|}
\hline & & $+30 \%$ & & & & & & & & & & \\
\hline \multirow{2}{*}{ Feedstock Group } & \multicolumn{6}{|c|}{2022 - Results in \$/Tonne } & \multicolumn{6}{|c|}{2040 - Results in \$/Tonne } \\
\hline & \multicolumn{2}{|r|}{ Min } & \multicolumn{2}{|c|}{ Med } & \multicolumn{2}{|c|}{ Max } & \multicolumn{2}{|r|}{ Min } & \multicolumn{2}{|c|}{ Med } & \multicolumn{2}{|c|}{ Max } \\
\hline $\bar{A}$ & $\$$ & 461.88 & $\$$ & 471.13 & $\$$ & 482.70 & $\$$ & 461.88 & $\$$ & 471.13 & $\$$ & 482.70 \\
\hline B & $\$$ & 117.32 & $\$$ & 130.01 & $\$$ & 146.91 & $\$$ & 117.33 & $\$$ & 130.21 & $\$$ & 146.56 \\
\hline c & $\$$ & 635.27 & $\$$ & 676.58 & $\$$ & 728.23 & $\$$ & 635.27 & $\$$ & 676.58 & $\$$ & 728.23 \\
\hline D & $\$$ & $1,260.86$ & $\$$ & $1,329.92$ & $\$$ & $1,406.39$ & $\$$ & $1,296.95$ & $\$$ & $1,361.92$ & $\$$ & $1,450.46$ \\
\hline E & $\$$ & $3,906.00$ & $\$$ & $5,013.24$ & $\$$ & $10,595.91$ & $\$$ & $2,433.37$ & $\$$ & $2,820.05$ & $\$$ & $7,664.19$ \\
\hline $\mathrm{F}$ & $\$$ & $1,052.50$ & $\$$ & $1,149.85$ & $\$$ & $1,247.20$ & $\$$ & $1,052.50$ & $\$$ & $1,149.85$ & $\$$ & $1,247.20$ \\
\hline H & $\$$ & $1,489.55$ & $\$$ & $1,564.05$ & $\$$ & $1,656.33$ & $\$$ & $1,489.50$ & $\$$ & $1,563.99$ & $\$$ & $1,656.26$ \\
\hline K & $\$$ & $1,190.15$ & $\$$ & $1,261.58$ & $\$$ & $1,350.88$ & $\$$ & $1,190.15$ & $\$$ & $1,261.58$ & $\$$ & $1,350.88$ \\
\hline
\end{tabular}


(C6.42)

\begin{tabular}{|c|c|c|c|c|c|c|c|c|c|c|c|c|}
\hline \multicolumn{13}{|l|}{ OPEX Sensitivity } \\
\hline \multirow{3}{*}{ Feedstock Group } & \multicolumn{2}{|r|}{$-20 \%$} & & & & & & & & & & \\
\hline & \multicolumn{6}{|c|}{2022 - Results in \$/Tonne } & \multicolumn{6}{|c|}{2040 - Results in \$/Tonne } \\
\hline & \multicolumn{2}{|r|}{ Min } & \multicolumn{2}{|c|}{ Med } & \multicolumn{2}{|c|}{ Max } & \multicolumn{2}{|r|}{ Min } & \multicolumn{2}{|r|}{ Med } & \multicolumn{2}{|r|}{ Max } \\
\hline A & $\$$ & 372.22 & $\$$ & 381.48 & $\$$ & 393.05 & $\$$ & 372.22 & $\$$ & 381.48 & $\$$ & 393.05 \\
\hline B & $\$$ & 92.47 & $\$$ & 105.16 & $\$$ & 122.06 & $\$$ & 92.49 & $\$$ & 105.37 & $\$$ & 121.71 \\
\hline C & $\$$ & 510.63 & $\$$ & 551.95 & $\$$ & 603.59 & $\$$ & 510.63 & $\$$ & 551.95 & $\$$ & 603.59 \\
\hline D & $\$$ & $1,050.84$ & $\$$ & $1,119.90$ & $\$$ & $1,196.37$ & $\$$ & $1,086.93$ & $\$$ & $1,151.91$ & $\$$ & $1,240.45$ \\
\hline $\mathrm{E}$ & $\$$ & $3,351.72$ & $\$$ & $4,458.96$ & $\$$ & $10,652.95$ & $\$$ & $1,879.09$ & $\$$ & $2,265.77$ & $\$$ & $7,109.92$ \\
\hline $\mathrm{F}$ & $\$$ & 891.58 & $\$$ & 988.93 & $\$$ & $1,086.28$ & $\$$ & 891.58 & $\$$ & 988.93 & $\$$ & $1,086.28$ \\
\hline $\mathrm{H}$ & $\$$ & $1,235.77$ & $\$$ & $1,310.27$ & $\$$ & $1,402.54$ & $\$$ & $1,235.72$ & $\$$ & $1,310.21$ & $\$$ & $1,402.48$ \\
\hline K & $\$$ & 982.17 & $\$$ & $1,053.61$ & $\$$ & $1,142.90$ & $\$$ & 982.17 & $\$$ & $1,053.61$ & $\$$ & $1,142.90$ \\
\hline
\end{tabular}

(C6.43)

\begin{tabular}{|c|c|c|c|c|c|c|c|c|c|c|c|c|}
\hline \multirow{3}{*}{ Feedstock Group } & & $+\mathbf{2 0} \%$ & & & & & & & & & & \\
\hline & \multicolumn{6}{|c|}{2022 - Results in \$/Tonne } & \multicolumn{6}{|c|}{2040 - Results in \$/Tonne } \\
\hline & \multicolumn{2}{|r|}{ Min } & \multicolumn{2}{|c|}{ Med } & \multicolumn{2}{|r|}{ Max } & \multicolumn{2}{|r|}{ Min } & \multicolumn{2}{|r|}{ Med } & \multicolumn{2}{|r|}{ Max } \\
\hline A & $\$$ & 448.71 & $\$$ & 457.97 & $\$$ & 469.54 & $\$$ & 448.71 & $\$$ & 457.97 & $\$$ & 469.54 \\
\hline B & $\$$ & 124.97 & $\$$ & 137.67 & $\$$ & 154.57 & $\$$ & 124.99 & $\$$ & 137.87 & $\$$ & 154.22 \\
\hline C & $\$$ & 654.17 & $\$$ & 695.48 & $\$$ & 747.12 & $\$$ & 654.17 & $\$$ & 695.48 & $\$$ & 747.12 \\
\hline D & $\$$ & $1,189.11$ & $\$$ & $1,258.17$ & $\$$ & $1,334.64$ & $\$$ & $1,225.20$ & $\$$ & $1,290.17$ & $\$$ & $1,378.71$ \\
\hline $\mathrm{E}$ & $\$$ & $3,848.96$ & $\$$ & $4,956.20$ & $\$$ & $11,150.19$ & $\$$ & $2,376.33$ & $\$$ & $2,763.01$ & $\$$ & $7,607.16$ \\
\hline $\mathrm{F}$ & $\$$ & $1,109.60$ & $\$$ & $1,206.95$ & $\$$ & $1,304.30$ & $\$$ & $1,109.60$ & $\$$ & $1,206.95$ & $\$$ & $1,304.30$ \\
\hline $\mathrm{H}$ & $\$$ & $1,431.77$ & $\$$ & $1,506.26$ & $\$$ & $1,598.54$ & $\$$ & $1,431.72$ & $\$$ & $1,506.21$ & $\$$ & $1,598.47$ \\
\hline K & $\$$ & $1,080.19$ & $\$$ & $1,151.62$ & $\$$ & $1,240.92$ & $\$$ & $1,080.19$ & $\$$ & $1,151.62$ & $\$$ & $1,240.92$ \\
\hline
\end{tabular}

(C6.44)

\section{Feedstock Cost Sensitivity}

\begin{tabular}{|c|c|c|c|c|c|c|c|c|c|c|c|c|}
\hline \multirow{2}{*}{ Feedstock Group } & \multicolumn{6}{|c|}{2022 - Results in \$/Tonne } & \multicolumn{6}{|c|}{2040 - Results in \$/Tonne } \\
\hline & & Min & & Med & & Max & & Min & & Med & & Max \\
\hline$A$ & $\$$ & 400.75 & $\$$ & 408.16 & $\$$ & 417.41 & $\$$ & 400.75 & $\$$ & 408.16 & $\$$ & 417.41 \\
\hline B & $\$$ & 93.27 & $\$$ & 103.42 & $\$$ & 116.94 & $\$$ & 93.28 & $\$$ & 103.58 & $\$$ & 116.66 \\
\hline C & $\$$ & 539.02 & $\$$ & 572.07 & $\$$ & 613.38 & $\$$ & 539.02 & $\$$ & 572.07 & $\$$ & 613.38 \\
\hline D & $\$$ & $1,059.03$ & $\$$ & $1,114.28$ & $\$$ & $1,175.46$ & $\$$ & $1,087.91$ & $\$$ & $1,139.89$ & $\$$ & $1,210.72$ \\
\hline$E$ & $\$$ & $2,696.47$ & $\$$ & $3,582.27$ & $\$$ & $8,537.45$ & $\$$ & $1,518.37$ & $\$$ & $1,827.71$ & $\$$ & $5,703.03$ \\
\hline $\mathrm{F}$ & $\$$ & 922.71 & $\$$ & $1,000.59$ & $\$$ & $1,078.47$ & $\$$ & 922.71 & $\$$ & $1,000.59$ & $\$$ & $1,078.47$ \\
\hline $\mathrm{H}$ & $\$$ & $1,256.53$ & $\$$ & $1,316.12$ & $\$$ & $1,389.95$ & $\$$ & $1,256.49$ & $\$$ & $1,316.08$ & $\$$ & $1,389.89$ \\
\hline K & $\$$ & 956.17 & $\$$ & $1,013.32$ & $\$$ & $1,084.76$ & $\$$ & 956.17 & $\$$ & $1,013.32$ & $\$$ & $1,084.76$ \\
\hline
\end{tabular}

(C6.45)

\begin{tabular}{|c|c|c|c|c|c|c|c|c|c|c|c|c|}
\hline \multirow{3}{*}{ Feedstock Group } & & $+20 \%$ & & & & & & & & & & \\
\hline & \multicolumn{6}{|c|}{2022 - Results in \$/Tonne } & \multicolumn{6}{|c|}{2040 - Results in \$/Tonne } \\
\hline & \multicolumn{2}{|r|}{ Min } & \multicolumn{2}{|c|}{ Med } & \multicolumn{2}{|c|}{ Max } & \multicolumn{2}{|r|}{ Min } & \multicolumn{2}{|r|}{ Med } & \multicolumn{2}{|r|}{ Max } \\
\hline $\bar{A}$ & $\$$ & 420.19 & $\$$ & 431.29 & $\$$ & 445.18 & $\$$ & 420.19 & $\$$ & 431.29 & $\$$ & 445.18 \\
\hline B & $\$$ & 124.18 & $\$$ & 139.41 & $\$$ & 159.69 & $\$$ & 124.20 & $\$$ & 139.65 & $\$$ & 159.27 \\
\hline C & $\$$ & 625.78 & $\$$ & 675.35 & $\$$ & 737.33 & $\$$ & 625.78 & $\$$ & 675.35 & $\$$ & 737.33 \\
\hline D & $\$$ & $1,180.92$ & $\$$ & $1,263.79$ & $\$$ & $1,355.55$ & $\$$ & $1,224.22$ & $\$$ & $1,302.19$ & $\$$ & $1,408.44$ \\
\hline E & $\$$ & $4,504.20$ & $\$$ & $5,832.90$ & $\$$ & $13,265.68$ & $\$$ & $2,737.05$ & $\$$ & $3,201.07$ & $\$$ & $9,014.04$ \\
\hline $\mathrm{F}$ & $\$$ & $1,078.47$ & $\$$ & $1,195.29$ & $\$$ & $1,312.11$ & $\$$ & $1,078.47$ & $\$$ & $1,195.29$ & $\$$ & $1,312.11$ \\
\hline $\mathrm{H}$ & $\$$ & $1,411.01$ & $\$$ & $1,500.41$ & $\$$ & $1,611.14$ & $\$$ & $1,410.95$ & $\$$ & $1,500.34$ & $\$$ & $1,611.06$ \\
\hline K & $\$$ & $1,106.19$ & $\$$ & $1,191.91$ & $\$$ & $1,299.06$ & $\$$ & $1,106.19$ & $\$$ & $1,191.91$ & $\$$ & $1,299.06$ \\
\hline
\end{tabular}


Table C7. Solver Results (C7.46-C7.54) for Optimization Constraint: Maximize Total Marine Biofuel. Data are the Complementary Results to the Optimization Function (i.e., Biofuel Cost at the Optimized Production Capacity). All Results in \$/MT Biofuel.

Maximize the Production of Marine Biofuels - Results in $\$ /$ Tonne

Base

(C7.46)

\begin{tabular}{|c|c|c|c|c|c|c|c|c|c|c|c|c|}
\hline \multirow{2}{*}{ Feedstock Group } & \multicolumn{6}{|c|}{2022 - Results in \$/Tonne } & \multicolumn{6}{|c|}{2040 - Results in \$/Tonne } \\
\hline & & Min & & Med & & Max & & Min & & Med & & Max \\
\hline A & $\$$ & 410.47 & $\$$ & 419.72 & $\$$ & 431.29 & $\$$ & 410.47 & $\$$ & 419.72 & $\$$ & 431.29 \\
\hline B & $\$$ & 108.72 & $\$$ & 121.41 & $\$$ & 138.31 & $\$$ & 108.74 & $\$$ & 121.62 & $\$$ & 137.97 \\
\hline C & $\$$ & - & $\$$ & - & $\$$ & - & $\$$ & - & $\$$ & - & $\$$ & - \\
\hline D & $\$$ & $1,000.18$ & $\$$ & $1,089.94$ & $\$$ & $1,189.33$ & $\$$ & $1,047.09$ & $\$$ & $1,131.54$ & $\$$ & $1,246.62$ \\
\hline $\mathrm{E}$ & $\$$ & $3,600.34$ & $\$$ & $4,707.58$ & $\$$ & $10,901.57$ & $\$$ & $2,127.71$ & $\$$ & $2,514.39$ & $\$$ & $7,358.54$ \\
\hline $\mathrm{F}$ & $\$$ & - & $\$$ & - & $\$$ & - & $\$$ & - & $\$$ & - & $\$$ & - \\
\hline H & $\$$ & $1,333.77$ & $\$$ & $1,408.27$ & $\$$ & $1,500.54$ & $\$$ & $1,333.72$ & $\$$ & $1,408.21$ & $\$$ & $1,500.48$ \\
\hline K & $\$$ & $1,014.76$ & $\$$ & $1,092.97$ & $\$$ & $1,190.74$ & $\$$ & $1,014.76$ & $\$$ & $1,092.97$ & $\$$ & $1,190.74$ \\
\hline
\end{tabular}

(C7.47)

\begin{tabular}{|c|c|c|c|c|c|c|c|c|c|c|c|c|}
\hline \multicolumn{13}{|l|}{ Yield Sensitivity } \\
\hline & & $-20 \%$ & & & & & & & & & & \\
\hline \multirow{2}{*}{ Feedstock Group } & \multicolumn{6}{|c|}{2022 - Results in \$/Tonne } & \multicolumn{6}{|c|}{2040 - Results in \$/Tonne } \\
\hline & & Min & & Med & & Max & & Min & & Med & & Max \\
\hline A & $\$$ & 513.09 & $\$$ & 524.65 & $\$$ & 539.12 & $\$$ & 513.09 & $\$$ & 524.65 & $\$$ & 539.12 \\
\hline B & $\$$ & 135.90 & $\$$ & 151.77 & $\$$ & 172.89 & $\$$ & 135.92 & $\$$ & 152.02 & $\$$ & 172.46 \\
\hline C & $\$$ & - & $\$$ & - & $\$$ & - & $\$$ & - & $\$$ & - & $\$$ & - \\
\hline D & $\$$ & $1,250.23$ & $\$$ & $1,362.43$ & $\$$ & $1,486.67$ & $\$$ & $1,308.86$ & $\$$ & $1,414.43$ & $\$$ & $1,558.28$ \\
\hline $\mathrm{E}$ & $\$$ & $4,500.42$ & $\$$ & $5,884.48$ & $\$$ & $13,626.96$ & $\$$ & $2,659.64$ & $\$$ & $3,142.99$ & $\$$ & $9,198.17$ \\
\hline $\mathrm{F}$ & $\$$ & - & $\$$ & - & $\$$ & - & $\$$ & - & $\$$ & - & $\$$ & - \\
\hline H & $\$$ & $1,667.21$ & $\$$ & $1,760.33$ & $\$$ & $1,875.68$ & $\$$ & $1,667.15$ & $\$$ & $1,760.26$ & $\$$ & $1,875.59$ \\
\hline $\mathrm{K}$ & $\$$ & $1,268.45$ & $\$$ & $1,366.21$ & $\$$ & $1,488.42$ & $\$$ & $1,268.45$ & $\$$ & $1,366.21$ & $\$$ & $1,488.42$ \\
\hline
\end{tabular}

(C7.48)

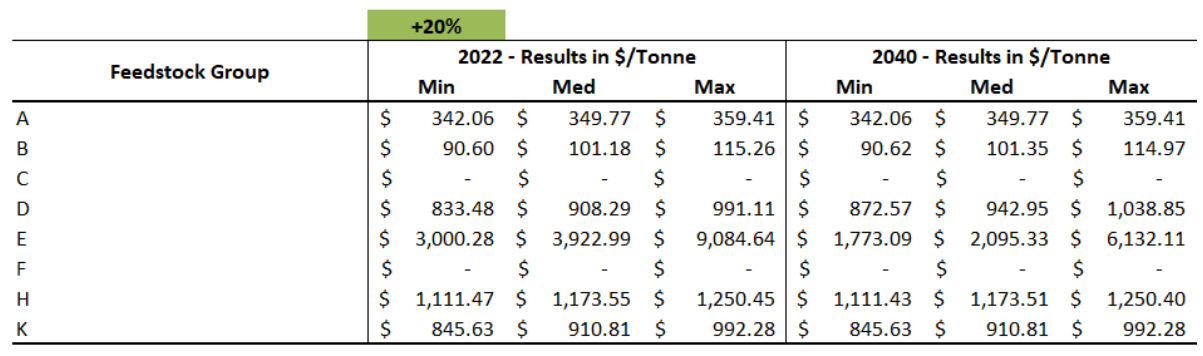

(C7.49)

\begin{tabular}{|c|c|c|c|c|c|c|c|c|c|c|c|c|}
\hline \multicolumn{13}{|l|}{ CAPEX Sensitivity } \\
\hline \multirow{3}{*}{ Feedstock Group } & & $-30 \%$ & & & & & & & & & & \\
\hline & \multicolumn{6}{|c|}{2022 - Results in $\$ /$ Tonne } & \multicolumn{6}{|c|}{2040 - Results in \$/Tonne } \\
\hline & & Min & & Med & & Max & & Min & & Med & & Max \\
\hline A & $\$$ & 359.06 & $\$$ & 368.32 & $\$$ & 379.88 & $\$$ & 359.06 & $\$$ & 368.32 & $\$$ & 379.88 \\
\hline B & $\$$ & 100.13 & $\$$ & 112.82 & $\$$ & 129.72 & $\$$ & 100.14 & $\$$ & 113.03 & $\$$ & 129.37 \\
\hline C & $\$$ & - & $\$$ & - & $\$$ & - & $\$$ & - & $\$$ & - & $\$$ & - \\
\hline D & $\$$ & 875.01 & $\$$ & 964.77 & $\$$ & $1,064.16$ & $\$$ & 921.92 & $\$$ & $1,006.37$ & $\$$ & $1,121.45$ \\
\hline $\mathrm{E}$ & $\$$ & $3,294.68$ & $\$$ & $4,401.93$ & $\$$ & $11,207.22$ & $\$$ & $1,822.05$ & $\$$ & $2,208.73$ & $\$$ & $7,052.88$ \\
\hline $\mathrm{F}$ & $\$$ & - & $\$$ & - & $\$$ & - & $\$$ & - & $\$$ & - & $\$$ & - \\
\hline $\mathrm{H}$ & $\$$ & $1,177.98$ & $\$$ & $1,252.48$ & $\$$ & $1,344.76$ & $\$$ & $1,177.94$ & $\$$ & $1,252.42$ & $\$$ & $1,344.69$ \\
\hline K & $\$$ & 889.59 & $\$$ & 967.80 & $\$$ & $1,065.57$ & $\$$ & 889.59 & $\$$ & 967.80 & $\$$ & $1,065.57$ \\
\hline
\end{tabular}

(C7.50)

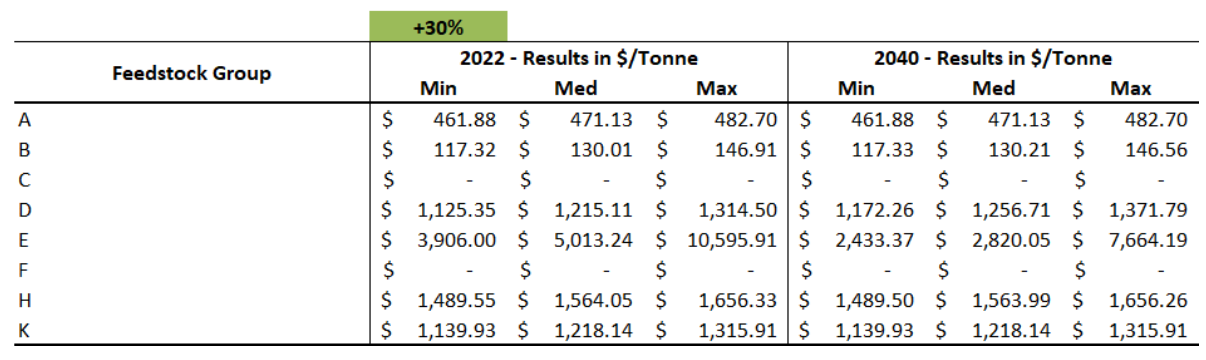




\begin{tabular}{|c|c|c|c|c|c|c|c|c|c|c|c|c|c|}
\hline \multirow{4}{*}{ (C7.51) } & \multicolumn{13}{|l|}{ OPEX Sensitivity } \\
\hline & & \multicolumn{12}{|c|}{$-20 \%$} \\
\hline & \multirow{2}{*}{ Feedstock Group } & \multicolumn{6}{|c|}{2022 - Results in \$/Tonne } & \multicolumn{6}{|c|}{2040 - Results in \$/Tonne } \\
\hline & & & Min & & Med & & $\operatorname{Max}$ & & Min & & Med & & $\operatorname{Max}$ \\
\hline & A & $\$$ & 372.22 & $\$$ & 381.48 & $\$$ & 393.05 & $\$$ & 372.22 & $\$$ & 381.48 & $\$$ & 393.05 \\
\hline & B & $\$$ & 92.47 & $\$$ & 105.16 & $\$$ & 122.06 & $\$$ & 92.49 & $\$$ & 105.37 & $\$$ & 121.71 \\
\hline & c & $\$$ & - & $\$$ & - & $\$$ & - & $\$$ & - & $\$$ & - & $\$$ & - \\
\hline & D & $\$$ & 957.37 & $\$$ & $1,047.13$ & $\$$ & $1,146.52$ & $\$$ & $1,004.28$ & $\$$ & $1,088.73$ & $\$$ & $1,203.81$ \\
\hline & $\mathrm{E}$ & $\$$ & $3,351.72$ & $\$$ & $4,458.96$ & $\$$ & $10,652.95$ & $\$$ & $1,879.09$ & $\$$ & $2,265.77$ & $\$$ & $7,109.92$ \\
\hline & $\mathrm{F}$ & $\$$ & - & $\$$ & - & $\$$ & - & $\$$ & - & $\$$ & - & $\$$ & - \\
\hline & H & $\$$ & $1,235.77$ & $\$$ & $1,310.27$ & $\$$ & $1,402.54$ & $\$$ & $1,235.72$ & $\$$ & $1,310.21$ & $\$$ & $1,402.48$ \\
\hline & $\mathrm{k}$ & $\$$ & 971.95 & $\$$ & $1,050.16$ & $\$$ & $1,147.93$ & $\$$ & 971.95 & $\$$ & $1,050.16$ & $\$$ & $1,147.93$ \\
\hline
\end{tabular}

\begin{tabular}{|c|c|c|c|c|c|c|c|c|c|c|c|c|c|}
\hline \multirow{4}{*}{ (C7.52) } & \multirow{3}{*}{ Feedstock Group } & \multicolumn{12}{|c|}{$+20 \%$} \\
\hline & & \multicolumn{6}{|c|}{2022 - Results in $\$ /$ Tonne } & \multicolumn{6}{|c|}{2040 - Results in $\$ /$ Tonne } \\
\hline & & & Min & & Med & & Max & & Min & & Med & & Max \\
\hline & A & $\$$ & 448.71 & $\$$ & 457.97 & $\$$ & 469.54 & $\$$ & 448.71 & $\$$ & 457.97 & $\$$ & 469.54 \\
\hline & B & $\$$ & 124.97 & $\$$ & 137.67 & $\$$ & 154.57 & $\$$ & 124.99 & $\$$ & 137.87 & $\$$ & 154.22 \\
\hline & c & $\$$ & - & $\$$ & - & $\$$ & - & $\$$ & - & $\$$ & - & $\$$ & - \\
\hline & D & $\$$ & $1,042.99$ & $\$$ & $1,132.75$ & $\$$ & $1,232.14$ & $\$$ & $1,089.90$ & $\$$ & $1,174.35$ & $\$$ & $1,289.43$ \\
\hline & $\mathrm{E}$ & $\$$ & $3,848.96$ & $\$$ & $4,956.20$ & $\$$ & $11,150.19$ & $\$$ & 2,376.33 & $\$$ & $2,763.01$ & $\$$ & $7,607.16$ \\
\hline & $\mathrm{F}$ & $\$$ & - & $\$$ & - & $\$$ & - & $\$$ & - & $\$$ & - & $\$$ & - \\
\hline & $\mathrm{H}$ & $\$$ & $1,431.77$ & $\$$ & $1,506.26$ & $\$$ & $1,598.54$ & $\$$ & $1,431.72$ & $\$$ & $1,506.21$ & $\$$ & $1,598.47$ \\
\hline & $\mathrm{k}$ & $\$$ & $1,057.57$ & $\$$ & $1,135.78$ & $\$$ & $1,233.55$ & $\$$ & $1,057.57$ & $\$$ & $1,135.78$ & $\$$ & $1,233.55$ \\
\hline
\end{tabular}

\begin{tabular}{|c|c|c|c|c|c|c|c|c|c|c|c|c|c|}
\hline \multirow{5}{*}{ (C7.53) } & \multicolumn{13}{|l|}{ Feedstock Cost Sensitivity } \\
\hline & & \multicolumn{12}{|c|}{$-20 \%$} \\
\hline & \multirow{2}{*}{ Feedstock Group } & \multicolumn{6}{|c|}{2022 - Results in $\$ /$ Tonne } & \multicolumn{6}{|c|}{2040 - Results in \$/Tonne } \\
\hline & & & Min & & Med & & $\operatorname{Max}$ & & Min & & Med & & Max \\
\hline & A & $\$$ & 400.75 & $\$$ & 408.16 & $\$$ & 417.41 & $\$$ & 400.75 & $\$$ & 408.16 & $\$$ & 417.41 \\
\hline & B & $\$$ & 93.27 & $\$$ & 103.42 & $\$$ & 116.94 & $\$$ & 93.28 & $\$$ & 103.58 & $\$$ & 116.66 \\
\hline & C & $\$$ & - & $\$$ & - & $\$$ & - & $\$$ & - & $\$$ & - & $\$$ & - \\
\hline & D & $\$$ & 920.97 & $\$$ & 992.78 & $\$$ & $1,072.29$ & $\$$ & 958.50 & $\$$ & $1,026.06$ & $\$$ & $1,118.12$ \\
\hline & E & $\$$ & $2,696.47$ & $\$$ & $3,582.27$ & $\$$ & $8,537.45$ & $\$$ & $1,518.37$ & $\$$ & $1,827.71$ & $\$$ & $5,703.03$ \\
\hline & $\mathrm{F}$ & $\$$ & - & $\$$ & - & $\$$ & - & $\$$ & - & $\$$ & - & $\$$ & - \\
\hline & H & $\$$ & $1,256.53$ & $\$$ & $1,316.12$ & $\$$ & $1,389.95$ & $\$$ & $1,256.49$ & $\$$ & $1,316.08$ & $\$$ & $1,389.89$ \\
\hline & $\mathrm{k}$ & $\$$ & 932.63 & $\$$ & 995.20 & $\$$ & $1,073.42$ & $\$$ & 932.63 & $\$$ & 995.20 & $\$$ & $1,073.42$ \\
\hline
\end{tabular}

\begin{tabular}{|c|c|c|c|c|c|c|c|c|c|c|c|c|c|}
\hline \multirow{4}{*}{ (C7.54) } & \multirow{3}{*}{ Feedstock Group } & \multirow{2}{*}{\multicolumn{6}{|c|}{$\begin{array}{l}+20 \% \\
2022-\text { Results in } \$ / \text { Tonne }\end{array}$}} & \multirow{2}{*}{\multicolumn{6}{|c|}{2040 - Results in \$/Tonne }} \\
\hline & & & & & & & & & & & & & \\
\hline & & \multicolumn{3}{|c|}{ Min } & Med & \multicolumn{2}{|c|}{ Max } & \multicolumn{2}{|r|}{ Min } & \multicolumn{2}{|r|}{ Med } & \multicolumn{2}{|c|}{ Max } \\
\hline & A & $\$$ & 420.19 & $\$$ & 431.29 & $\$$ & 445.18 & $\$$ & 420.19 & $\$$ & 431.29 & $\$$ & 445.18 \\
\hline & B & $\$$ & 124.18 & $\$$ & 139.41 & $\$$ & 159.69 & $\$$ & 124.20 & $\$$ & 139.65 & $\$$ & 159.27 \\
\hline & c & $\$$ & - & $\$$ & - & $\$$ & - & $\$$ & - & $\$$ & - & $\$$ & - \\
\hline & D & $\$$ & $1,079.39$ & $\$$ & $1,187.10$ & $\$$ & $1,306.37$ & $\$$ & $1,135.68$ & $\$$ & $1,237.02$ & $\$$ & $1,375.12$ \\
\hline & E & $\$$ & $4,504.20$ & $\$$ & $5,832.90$ & $\$$ & $13,265.68$ & $\$$ & $2,737.05$ & $\$$ & $3,201.07$ & $\$$ & $9,014.04$ \\
\hline & $\mathrm{F}$ & $\$$ & - & $\$$ & - & $\$$ & - & $\$$ & - & $\$$ & - & $\$$ & - \\
\hline & $\mathrm{H}$ & $\$$ & $1,411.01$ & $\$$ & $1,500.41$ & $\$$ & $1,611.14$ & $\$$ & $1,410.95$ & $\$$ & $1,500.34$ & $\$$ & $1,611.06$ \\
\hline & $\mathrm{K}$ & $\$$ & $1,096.88$ & $\$$ & $1,190.74$ & $\$$ & $1,308.06$ & $\$$ & $1,096.88$ & $\$$ & $1,190.74$ & $\$$ & $1,308.06$ \\
\hline
\end{tabular}




\section{Appendix D. Marine Biofuel Adoption Supporting Information}

Table D1. Exajoule Unit Conversion Chart

\begin{tabular}{lll}
\multicolumn{3}{l}{ One EJ (Exajoule) is equivalent to 8,164 MM gallon gasoline equivalent (GGE) or } \\
\hline Fuels & MM Gal & MM Metric Tonnes \\
\hline Crude oil & 7,309 & 23.43 \\
Synthetic crude oil (SCO) & 7,016 & 22.92 \\
Gasoline blendstock & 8,164 & 23.02 \\
Petroleum naphtha & 8,107 & 22.25 \\
Bunker fuel for ocean & 6,753 & 25.34 \\
tanker & 6,753 & 25.34 \\
Residual oil & 11,157 & 21.46 \\
Liquefied petroleum gas & & 23.37 \\
(LPG) & 7,379 & \\
U.S. conventional diesel & & $\mathrm{J}$ \\
\hline Unit Conversion Factors & $1 \mathrm{E}+18$ & $\mathrm{Btu}$ \\
\hline 1 EJ $=$ & 116,090 & $\mathrm{~J}$ \\
1 gal gasoline blendstock $=$ & $1,055.06$ & \\
1 BTU = &
\end{tabular}

The conversion factors used for this study are that $1 \mathrm{HFOGE}$ is equal to $140,353 \mathrm{Btu}$ and 1 metric ton of heavy fuel oil is equal to 267 HFOGE. 
Table D2. Biofuel Availability by Technology Group in Exajoules

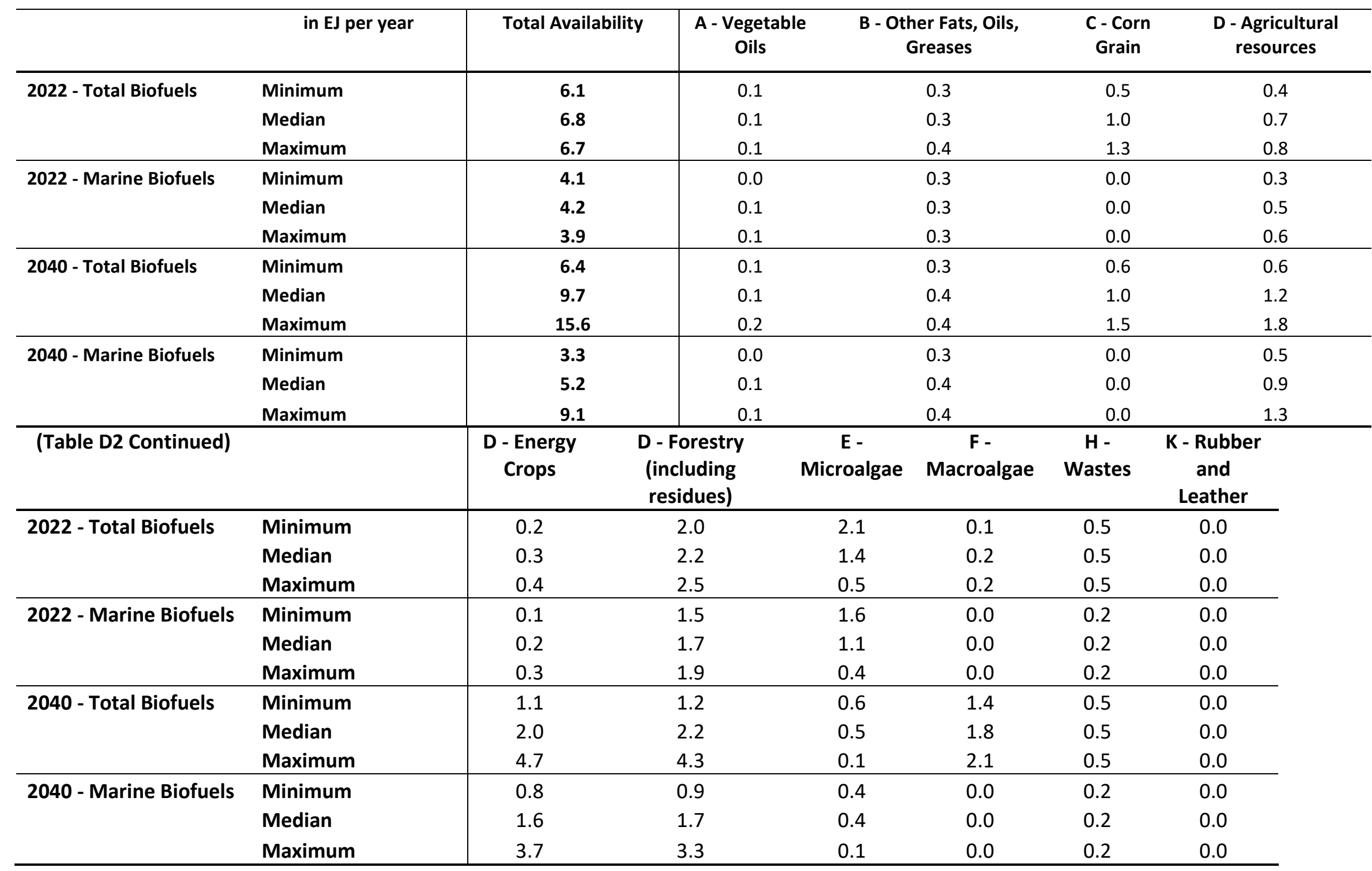


Table D3. Data from U.S. Energy Information Administration's Annual Energy Outlook 2020 (Table 17 - "Renewable Energy Consumption by Sector and Source") (U.S. EIA 2020a)

\begin{tabular}{lrr}
\hline Renewable Energy Consumption by Sector and Source & (quadrillion Btu) \\
Sector and Source & $\mathbf{2 0 2 2}$ & $\mathbf{2 0 4 0}$ \\
\hline Residential (wood)* & $\mathbf{0 . 4 6}$ & $\mathbf{0 . 3 4}$ \\
Commercial (biomass)* & $\mathbf{0 . 1 3}$ & $\mathbf{0 . 1 3}$ \\
Industrial & $\mathbf{2 . 5 0}$ & $\mathbf{2 . 9 0}$ \\
Conventional Hydroelectric Power & 0.00 & 0.00 \\
Municipal Waste* & 0.17 & 0.20 \\
Biomass* & 1.47 & 1.82 \\
Biofuels Heat and Coproducts* & 0.87 & 0.88 \\
Transportation & $\mathbf{1 . 7 0}$ & $\mathbf{1 . 7 6}$ \\
Ethanol used in E85* & 0.02 & 0.01 \\
Ethanol used in Gasoline Blending* & 1.17 & 1.06 \\
Biodiesel used in Distillate Blending* & 0.40 & 0.41 \\
Biobutanol* & 0.00 & 0.02 \\
Liquids from Biomass* & 0.00 & 0.00 \\
Renewable Diesel and Gasoline* & 0.11 & 0.26 \\
Electric Power & $\mathbf{8 . 4 9}$ & $\mathbf{1 2 . 1 9}$ \\
Conventional Hydroelectric Power & 2.56 & 2.31 \\
Geothermal & 0.15 & 0.34 \\
Biogenic Municipal Waste* & 0.37 & 0.52 \\
Biomass* & 0.21 & 0.22 \\
Solar Thermal & 0.03 & 0.03 \\
Solar Photovoltaic & 1.41 & 3.89 \\
Wind & 3.75 & 4.88 \\
\hline Total Marketed Renewable Energy & $\mathbf{1 3 . 2 8}$ & $\mathbf{1 7 . 3 3}$ \\
Total Biomass Only* & $\mathbf{5 . 3 8}$ & $\mathbf{5 . 8 8}$ \\
\hline
\end{tabular}

Table D4. Data from U.S. Energy Information Administration's Annual Energy Outlook 2020 (Table 7 - "Transportation Sector Key Indicators and Delivered Energy Consumption") (U.S. EIA 2020a)

\begin{tabular}{lcr}
\hline \multicolumn{1}{c}{$\begin{array}{c}\text { Transportation Sector Key Indicators and } \\
\text { Delivered Energy Consumption }\end{array}$} & (quadrillion Btu) & \\
\hline Ground Transportation & $\mathbf{2 0 2 2}$ & $\mathbf{2 0 4 0}$ \\
Air & 21.93 & 18.82 \\
Shipping, Domestic & 2.71 & 3.21 \\
Shipping, International & 0.08 & 0.05 \\
Recreational Boats & 0.84 & 0.85 \\
Rail & 0.25 & 0.24 \\
Other & 0.52 & 0.51 \\
\hline Total & 1.32 & 1.35 \\
\hline
\end{tabular}

